\title{
Human development and autonomy in project aid : experiences from four bilateral projects in Nicaragua and El Salvador
}

Citation for published version (APA):

Muñiz Castillo, M. R. (2009). Human development and autonomy in project aid : experiences from four bilateral projects in Nicaragua and El Salvador. [Doctoral Thesis, Maastricht University]. Boekenplan. https://doi.org/10.26481/dis.20090923mm

Document status and date:

Published: 01/01/2009

DOI:

10.26481/dis.20090923mm

Document Version:

Publisher's PDF, also known as Version of record

\section{Please check the document version of this publication:}

- A submitted manuscript is the version of the article upon submission and before peer-review. There can be important differences between the submitted version and the official published version of record. People interested in the research are advised to contact the author for the final version of the publication, or visit the DOI to the publisher's website.

- The final author version and the galley proof are versions of the publication after peer review.

- The final published version features the final layout of the paper including the volume, issue and page numbers.

Link to publication

\footnotetext{
General rights rights.

- You may freely distribute the URL identifying the publication in the public portal. please follow below link for the End User Agreement:

www.umlib.nl/taverne-license

Take down policy

If you believe that this document breaches copyright please contact us at:

repository@maastrichtuniversity.nl

providing details and we will investigate your claim.
}

Copyright and moral rights for the publications made accessible in the public portal are retained by the authors and/or other copyright owners and it is a condition of accessing publications that users recognise and abide by the legal requirements associated with these

- Users may download and print one copy of any publication from the public portal for the purpose of private study or research.

- You may not further distribute the material or use it for any profit-making activity or commercial gain

If the publication is distributed under the terms of Article 25fa of the Dutch Copyright Act, indicated by the "Taverne" license above, 


\section{Human Development and Autonomy in Project Aid}

Experiences from four bilateral projects in Nicaragua and El Salvador 
All rights reserved. No part of this publication may be reproduced, stored in a retrieval system, or transmitted in any form, or by any means, electronic, mechanical, photocopying, recording or otherwise, without the prior permission in writing, from the author.

ISBN 9789086661091

Cover picture by Mirtha R. Muñiz Castillo (San Agustín, El Salvador)

Published by Boekenplan, Maastricht, The Netherlands 


\section{Human Develo pment and Autonomy in Project Aid: Experiences from four bilateral projects in N icaragua and El Salvador}

\section{DISSERTATION}

to obtain the degree of Doctor at the Maastricht University, on the authority of the Rector Magnificus, Prof. dr. G.P.M.F. Mols, in accordance with the decision of the Board of Deans, to be defended in public on Wednesday 23 September 2009, at 14.00 hours

by

Mirtha Rosaura Muñiz Castillo 
Supervisor:

Co-supervisors:

Assessment Committee:
Prof. Dr. C.R.J. de Neubourg

Prof. Dr. D.R. Gasper, Institute of Social Studies, The Hague Prof. Dr. J.M. Billson, George Washington University, USA

Prof. Dr. L. de la Rive Box, Rector of the Institute of Social Studies (chairman)

Prof. Dr. Ir. W.E. Bijker

Prof. Dr. S. Vanhoonacker

Dr. K. Križ, Malcolm Wiener Center for Social Policy, Harvard /Emmanuel College, USA

Dr. R. Wagener, IGSS Ministry of Social Security, Luxembourg

The work presented in this dissertation has been carried out at the Maastricht Graduate School of Governance.

Financial support has been received from the following institutions in Luxembourg:

- The Ministry of Culture, Higher Education and Research;

- The Fonds National de la Recherche (FNR); and

- The Ministry of Foreign Affairs.

This publication was co-financed by the FNR Luxembourg and the Maastricht University. 


\section{Dedication}

To all the persons who opened their homes and shared their lives with me in Nicaragua and El Salvador.

To my parents for their immense love, understanding, support, enthusiasm and faith; they are the best partners on all my adventures.

In memory to my grandparents, María Mena and Leonidas, who taught me an important lesson: that our journey on Earth is too short to worry about the future and that this journey requires enthusiasm, love, strength and, above all, courage. 


\section{Preface and acknowledgements}

The pages that you are about to read are the result of a research work that has taken a little more than four years. Looking retrospectively at my experience, I can say that my worldview has changed a great deal. Definitely, the intellectual motivation, the living experiences in different countries and the time shared with friends and colleagues have enriched my life, fostered my critical autonomy and made this process enjoyable and interesting. I keep my optimism in the goodness of human beings. There were 'angels' along my way; even the poorest people had gestures of generosity and kindness for me. I am grateful to all.

It is true, as some people say, that preparing a $\mathrm{PhD}$ dissertation requires perseverance in addition to high scientific standards and that the final writing up can be a lonely process. But, overall, I can say that it needs authenticity. How satisfactory it is to take a project on by which one is inspired! I thank God for so many opportunities that he has offered me in life, for the desire to better myself and the curiosity with which he has permeated me, and for the joy that writing this dissertation has brought me. I felt that I was doing by choice what He had planned for me.

I cannot imagine writing my dissertation on a topic different than this one. I am pleased for being able to share with you some of my ideas and others' ideas about how people aspire and take action to live more worthy, inspiring and truly human lives and about how projects financed by international cooperation can help them in their efforts. I hope that this dissertation can contribute to the design, management and evaluation of projects so that these can explicitly contribute to the enhancement of individual autonomy and human development.

As you will read throughout the coming pages, it is important not only what you achieve but also how you achieve it. This research project could have lingered in being just an idea, but thanks to many people it is a reality now. As much as I would like to thank all these people by name, I am afraid I will be able to name only a few.

First, as this is an achievement of intellectual nature, I would like to thank my supervisors.

Thank you very much to Chris de Neubourg. His broad support, faith in my work and the agreeable work environment during the time I spent in Maastricht gave me the perfect conditions to develop my ideas with freedom.

To Des Gasper, I am immensely grateful. He helped me to discover new paths in my research. Being always there, with analytical rigour and respecting my own research process, he challenged me intellectually and, at the same time, supported my self-confidence.

I am very thankful to Janet Mancini Billson. Her kind and expert advice during my fieldwork in Nicaragua and El Salvador was invaluable. Always, her objectivity, precise comments and encouraging feedback motivated me.

Second, I am deeply indebted to Raymond Wagener. Without his optimism and mentoring, I would not have thought of pursuing a PhD. He introduced me to the capability approach, helped me to realise my research interests and facilitated the means to carry out my project. 
Third, I would like to thank the more than 300 people who voluntary participated in the different fieldwork activities in Nicaragua and El Salvador. The names of some of them are in Appendix 2-A. I may have forgotten some names unintentionally. Special consideration goes to Petrona in Santa María, Mirna and Damaris in San Fernando, Víctor Manuel and Manuela in Agua Fría, and Antonio, José Mario and Numas in San Agustín.

Fourth, I would like to thank some people in different countries:

In Maastricht, I thank my teachers in the Faculty of Economics and the teachers of the International Labour Office (master courses), especially to Michael Cichon for his precise comments about my dissertation in the seminar (2006) and later in Geneva (2007) and for his support to my professional career. My gratitude goes also to Denis de Crombrugghe for his kind advice when I had some doubts about quantitative analysis. I thank my classmates at the beginning of my $\mathrm{PhD}$, especially to my friend Adriana with whom I have kept close contact and to Fifi for long and relaxed talks when we felt under pressure.

Within the Maastricht Graduate School of Governance, I enjoyed the calm and friendly work environment, thanks to Céline, Mieke and Susan who kindly helped me since my master studies. I would also like to thank to Geranda for her friendship and to Annemarie, Franziska and Renée for the encouraging talks and comments. I thank Mindel for her encouragement and practical help during the last stages of my submission. The School is growing and several researchers are engaged in multiple activities. I thank Hao, Robert, Zina, Pascal, Denisa, David, Paty, Melissa, Britta, Keetie, Bianca, Henry, Nicola, Florian, Maha, and Treena. Please, feel all named here. I appreciate their inputs during my presentation in the seminar series and in the tutorial meetings, and overall their solidarity. I met some of them in between trips; I wished I could have spent more time with them.

My special thanks go out to my two dear friends, Lina and Jessica. Thank you very much for your unconditional support, encouragement, enthusiasm, understanding and every detail that make each of you special. You were the nearest thing to a family that I had in Maastricht and indeed, I have felt part of your families. Thanks to Alex and Paola, of course.

I extend my special thanks to Rally for proof-reading and editing my chapters. More than that, she has been there encouraging me along the writing up process and keeping my optimism high with every email. Thanks for offering your friendship since the beginning.

In Luxembourg, I would like to express my gratitude to the Ministry of Culture, Superior Education and Research of Luxembourg that granted me the research scholarship (BFR03 068) and to the Ministry of Foreign Affairs, Direction of Development and Humanitarian Aid that financed a large part of my fieldwork expenses and gave access to the projects managed by Lux-Development S.A. In the Ministry of Culture, I thank Josiane Entringer. In the Ministry of Foreign Affairs, I especially thank Ambassador Jean Feyder and René Lauer. In Lux-Development S.A., I thank its former director, Raymond Weber, and the kindness of Nathalie Davila-Levy who facilitated me the project information. Thanks also to Alice Risch, and Pascal Rossignol. I am very thankful to the Fonds National de la Recherche that awarded me a grant at the last stage of my PhD.

I am grateful to CEPS/NSTEAD and especially to its scientific director, Pierre Hausman, who supported my scholarship application. I thank the General Inspection of Social Security 
and its director, Georges Schroeder, for hosting the seminar on September 2006. I am very grateful to the participants of that seminar who commented on my work.

In Nicaragua, I would like to thank the general vice-rector, Jesús Manuel Sariego, and the former dean of the Faculty of Humanities, Donald Méndez, of the Central American University (UCA). My special consideration is for Prof. José Inocente Rodríguez, at the 'National Observatory of the Poverty and Human Development' of the UCA, whose practical advice during my fieldwork was crucial. Thanks also to the personnel of Lux-Development S.A. in the regional office of Managua, to Marc Riel, Sara Briones, Liliana Aragón, María Nieves Aramburú, Eduardo Acuña and Jean-Louis Augeras. I am indebted to Chiara Trombetta for her help in finding me accommodation (close to hers) and transportation. Diego Osorio was the perfect driver in Nueva Segovia, respectful and trustworthy.

My stay in Nicaragua was more enjoyable thanks to the kind welcome of the families Noguera Villagra, Caldera Villagra, and Rocha Noguera. They were the first example of the warmth of the Nicaraguan people in Managua.

My immense appreciation goes to Yamileth Escobar, sociologist, who was my assistant during the fieldwork activities in Nicaragua and El Salvador. Thank you for sharing your experience with me and showing a commitment and solidarity that exceeded all my expectations. It was a pleasure to work with you and to share exciting, enjoyable and sometimes uncertain times.

In El Salvador, I would like to thank many people. I am especially grateful to Prof. Lilian Vega, chief of the Economics department of the 'José Simeón Cañas' Central American University (UCA). Her help during my fieldwork and numerous emails exchanged after that have been priceless. I appreciate the support of my friends Claudia Riasco and Christyane Quan who helped me to find the right contacts in their country.

Thanks also to María Vilar, Sandra Romero and her husband Danilo Fernández, and Salvador Alvarado and his wife, for helping me to find accommodation and transportation in San Miguel and San Salvador. I am very grateful to Georges Burri, for facilitating the contacts in San Agustín and San Alejo and for his warm welcome to the Eastern region of El Salvador.

In Bath, I appreciate my time as visiting researcher (2006) at the ESCR research group on Well-being in Developing Countries (University of Bath) during which I could participate in periodic meetings as one of their team and had access to all university facilities. Thanks to the staff of $\mathrm{WeD}$ and Theo Papadopoulos for propitiating this visit. My special appreciation goes to Allister McGregor, Ian Gough, Laura Camfield, and Séverine Deneulin for their detailed comments on a first draft of Chapter 2. Thanks also to Mónica, Jackeline, Peter, Becky, Claudia, Fara, Virginia, James, Mateo and other colleagues for contributing to make my stay more pleasant.

I would like to thank several people whom I met during conferences, external courses or through other colleagues. I thank Véronique Mottier and Max Bergman for their advice at the summer school in Essex (August 2006). I extend my special thanks to Kees Biekart at the Institute of Social Studies for his kind advice, comments on preliminary versions of chapters 3 and 4 , and for introducing me to his research work. I also thank several members of the Human Development and Capabilities Association whom I met during the 2004 and 2006 conferences and who had punctual comments about my work in informal talks, walks, din- 
ners or during the 2006 summer school. My thanks also goes to the participants of the PhD seminar on research in Latin America (October 2006) sponsored by CEDLA (Amsterdam). I am also thankful to those who commented on my work during the 2nd Latin American and Caribbean Conference on Human Development and the Human Capabilities Approach in Montevideo, Uruguay (October 2008).

In Lima, thanks to María Polo Puelles for entering and organising the data of the screening and survey questionnaires, to Lenin Abad Torres for transcribing the focus group discussions and individual interviews, and to Luz Angélica Pérez Vásquez for preparing the structured transcripts. Thanks also to Teresa Fernández for an introduction to her qualitative work in Peru and to Daniel Urday who helped Luz Angélica.

I especially thank my friends and relatives in Lima for their understanding and support during my PhD research, for the time that we could not share and the talks that we could not have and, at the same time, for their closeness despite the geographical distance. To all of them: 'It is done!'

I thank my younger sister, Graciela, for understanding my commitment to this academic project even though we could not share many important things while she was growing up to become the admirable young woman she is now.

I want to thank especially my mama, Mirtha Sonia, for her precise and cautious comments about my investigation, her company during my first study visit, her support in every step of my life and also during this time. I thank my papa, Estuardo, for his confidence in my capacities and constant encouragement in any circumstance. Both have been always present throughout this journey of intellectual challenge and personal self-discovery.

I invite you all to follow me on this exploration done with a great deal of affection, respect and care. 


\section{Contents}

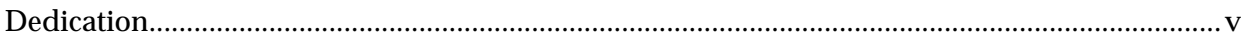

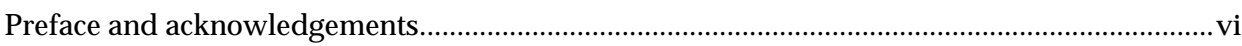

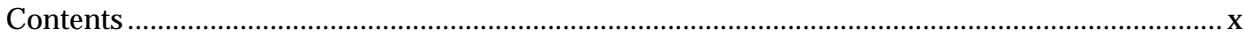

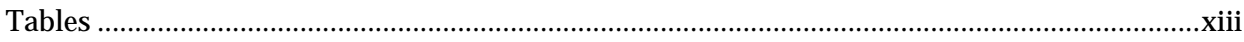

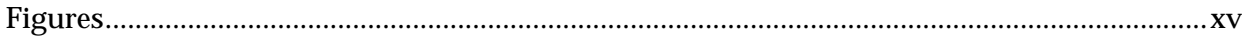

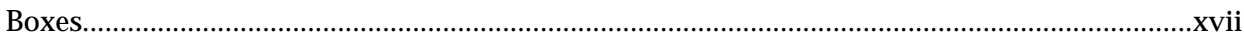

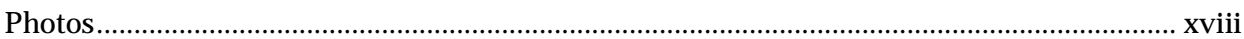

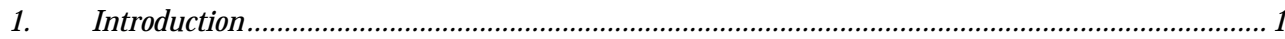

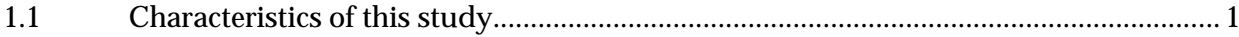

$1.2 \quad$ The research questions and overall approach ...................................................... 3

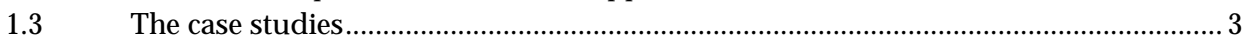

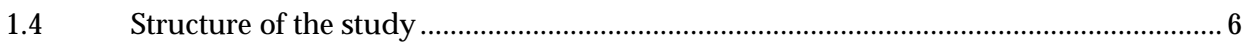

\section{Part I: The conceptual model and research approach}

2. A conceptual model of human development and autonomy ........................................................ 11

$2.1 \quad$ Human development: means and ends................................................................. 12

$2.2 \quad$ Autonomy: the concept and the details.................................................................... 24

2.3 Individual autonomy: the conceptual model ............................................................. 35

2.4 Empowerment: the means to promote human development...................................... 46

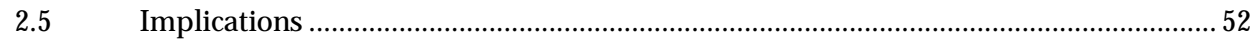

3. The practices and the effects of international aid: from macro to micro-level analysis ......................54

3.1 The macro-level context of international aid: what has changed? .................................55

3.2 The micro-level context of international aid: what can projects tell? ........................... 65

3.3 Autonomy and project assessments: what would be the linkages?.............................. 71

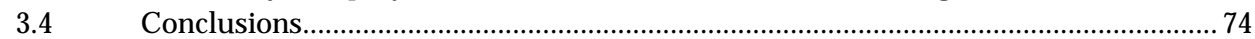

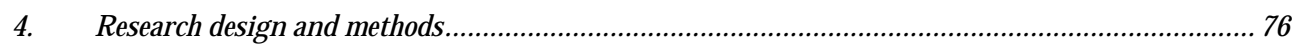

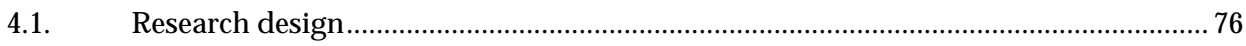

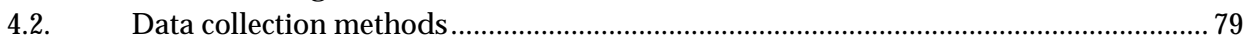

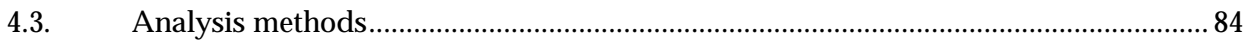

4.4. Character and limitations of the study ...................................................................... 91

\section{Part II: The empirical study}

5. Four case studies and their multilevel contexts: an introduction .................................................95

5.1. Description of the projects and localities studied ….................................................... 95

5.2. The country contexts and their linkages with local contexts.......................................98

5.3. The donor cooperation policy and general practices.................................................. 105

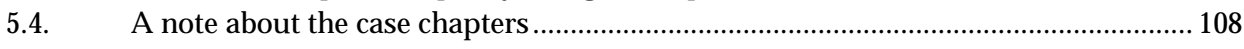

6. The struggle for a livelihood in Santa María: The scars from the volcano ................................... 109

6.1. The communities and the landslide that transformed life forever ............................ 110

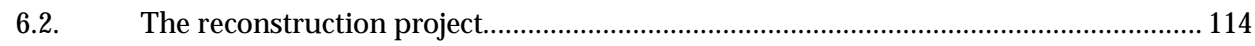




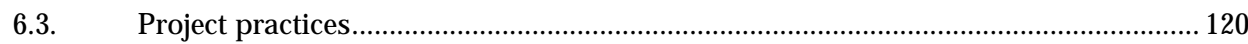

6.4. Understanding individual autonomy in Santa María ........................................... 127

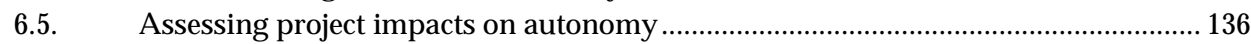

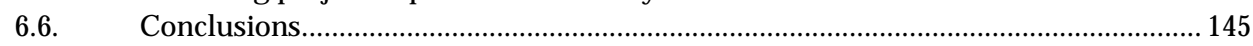

7. The encounter of two worlds in Agua Fría: The role of local governance in a water project.......... 147

7.1. Agua Fría before the project and the issue of water ......................................... 148

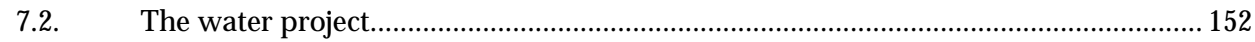

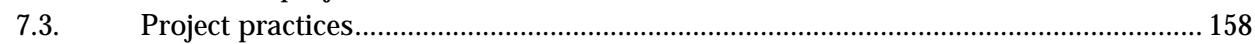

7.4. Understanding individual autonomy in Agua Fría................................................. 164

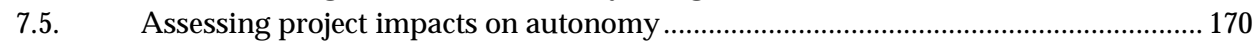

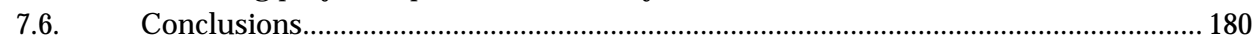

8. Women building up community in San Fernando: A water project that fuelled hope .................. 183

8.1. San Fernando before the project............................................................................ 184

8.2. The water project in San Fernando ......................................................................... 187

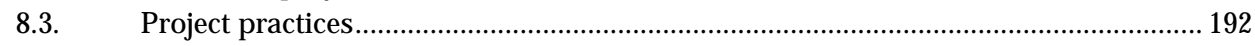

8.4. Understanding individual autonomy in San Fernando ....................................... 199

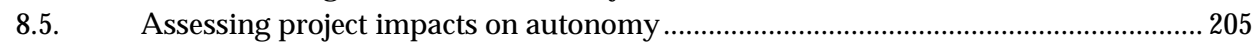

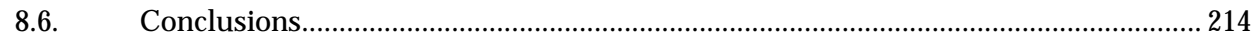

9. Reconstruction after the earthquakes in San Agustin: The awakening of a community ............... 216

9.1 San Agustín and the earthquakes that reactivated 'energy' .................................. 217

9.2 The reconstruction project in San Agustín......................................................... 221

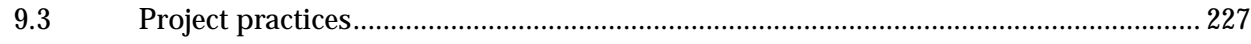

9.4 Understanding individual autonomy in San Agustín........................................... 236

9.5 Assessing project impacts on autonomy .............................................................. 241

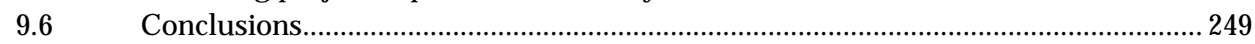

\section{Part III: Discussion}

10. An autonomy-focused assessment of four aid projects: A comparative study and a proposal ......... 253

$10.1 \quad$ Antecedents of the communities....................................................................... 253

10.2 An analytical framework of project effects on individual autonomy...................... 257

$10.3 \quad$ Understanding values, relations and practices in structural contexts......................260

10.4 Participation and the exercise of individual autonomy ..........................................266

10.5 Sectoral features: different impacts on autonomy?............................................2275

10.6 Summing up project effects on individual autonomy ...............................................28 284

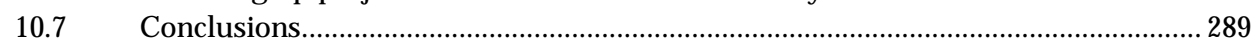

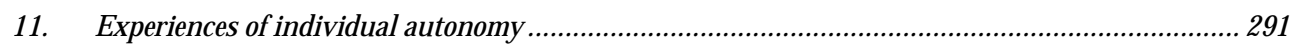

11.1 The foundations of autonomy: entitlements and agency ..................................... 291

11.2 The exercise of autonomy in micro-level contexts ............................................... 301

11.3 Self-confidence and conditions for individual empowerment..................................314

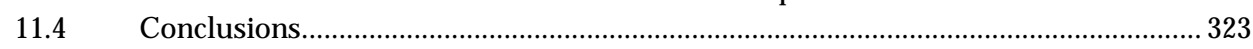

12. The development path: reducing vulnerability and enhancing critical autonomy ........................ 326

12.1 Two sides of the coin: vulnerability and individual autonomy .............................327

12.2 Critical autonomy to promote significant improvement in well-being ......................338

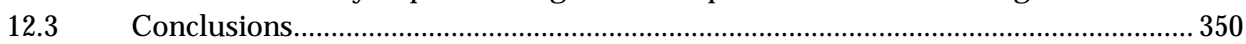




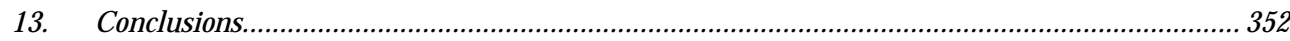

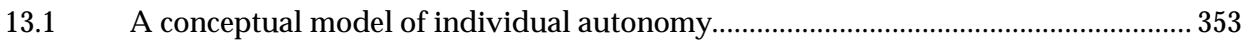

13.2 Aid projects and the expansion of individual autonomy............................................ 354

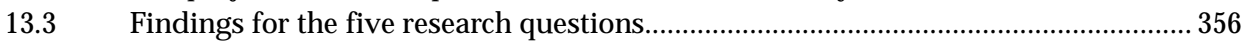

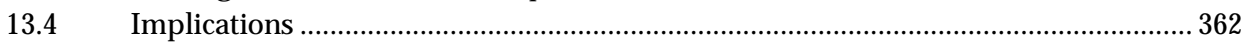

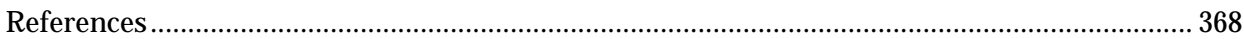

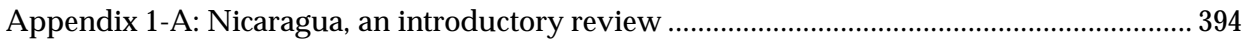

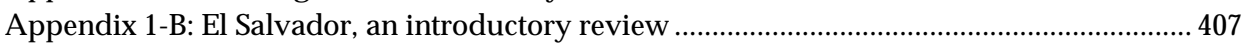

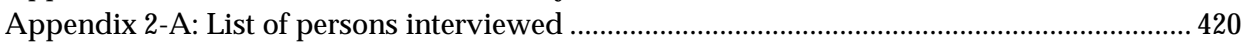

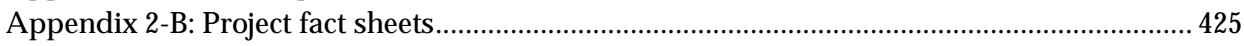

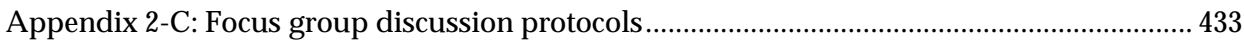

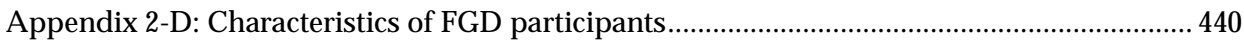

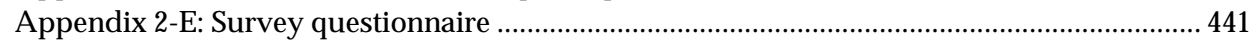

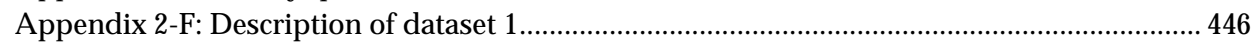

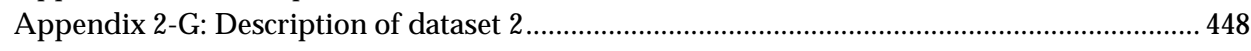

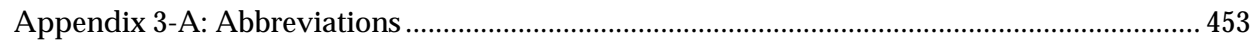

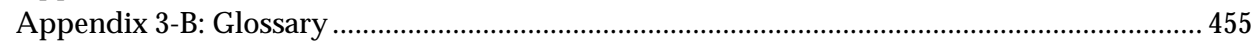

Summary

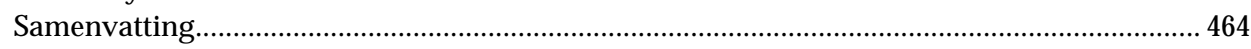

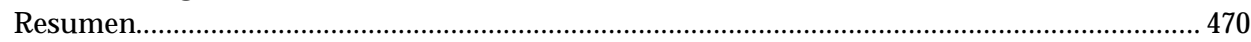

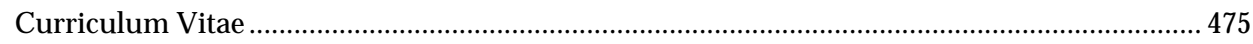




\section{Tables}

Table 1-1: Case studies

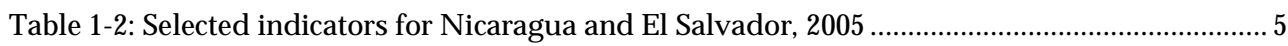

Table 2-1: Relation between well-being and human development ................................................... 12

Table 2-2: Nussbaum's central human functional capabilities ........................................................ 18

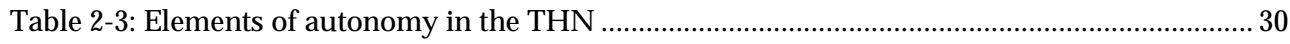

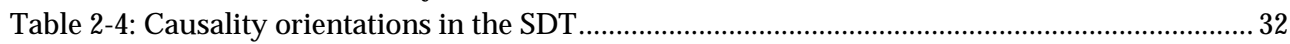

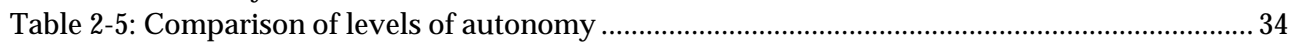

Table 2-6: Relationship between well-being, human development and autonomy........................... 49

Table 3-1: Millennium development goals and capabilities.............................................................57

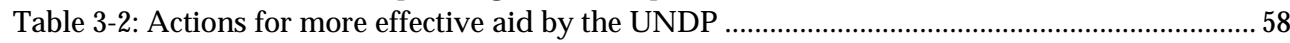

Table 3-3: Identifying four types of structured practices at the macro-level ......................................60

Table 3-4: Ellerman's approach for autonomy-respecting assistance …….......................................... 70

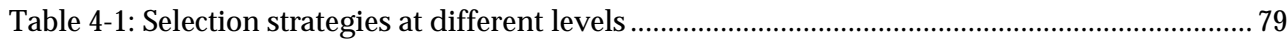

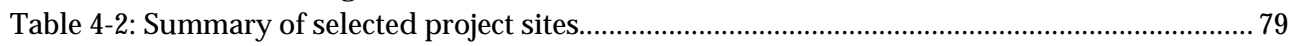

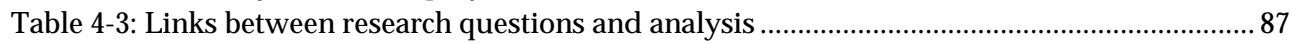

Table 4-4: Assessment matrix of project effects on the determinants of autonomy ........................... 88

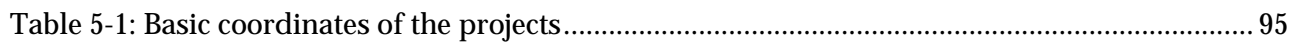

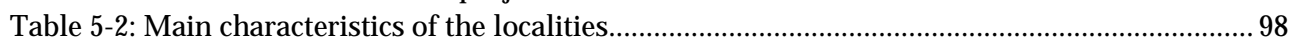

Table 5-3: Comparative country analysis (selected characteristics) ................................................99

Table 5-4: Bilateral aid of Luxembourg to Nicaragua and El Salvador, 2000 and 2005 .................. 106

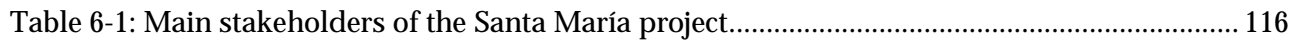

Table 6-2: Comparison of relevant reconstruction projects in Posoltega ......................................... 117

Table 6-3: Main practices during the Santa María project.............................................................. 120

Table 6-4: Individual perception about the quality of the houses in Santa María............................ 126

Table 6-5: Expected and actual benefits of the Santa María project ................................................. 137

Table 6-6: Levels of information self-reported by non-leaders in Santa María.................................. 143

Table 6-7: The intensity of change in variables associated to autonomy by FGD in Santa María. 144

Table 7-1: Short-term evidence of migration in Agua Fría (2001-2003) ............................................ 151

Table 7-2: Access to water per site before the project ..................................................................... 151

Table 7-3: Main stakeholders of the Agua Fría project ...................................................................... 155

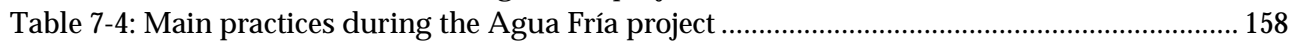

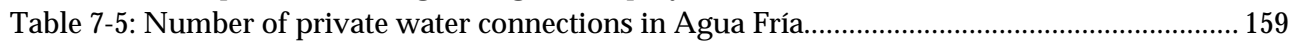

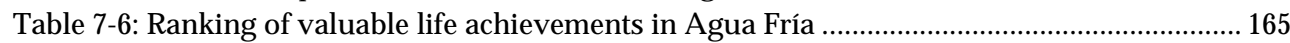

Table 7-7: Communal participation and perceived opportunities in Agua Fría ............................... 170

Table 7-8: Expected and actual benefits of the Agua Fría project..................................................... 171

Table 7-9: The awareness of personal skills by gender in Agua Fría ................................................. 178

Table 7-10: The intensity of change in variables associated to autonomy by FGD in Agua Fría .. 179

Table 8-1: Selected indicators of the San Fernando municipality $(2000 / 2001)$................................. 185

Table 8-2: Neighbourhoods in San Fernando's municipality centre (2005) ..................................... 186 


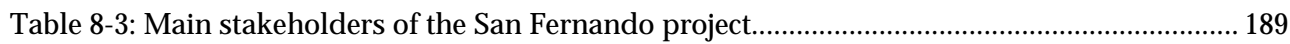

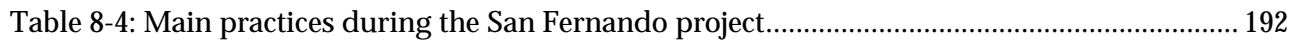

Table 8-5: Planned and actual number of latrines allocated in San Fernando................................... 196

Table 8-6: Ranking of valuable life achievements in San Fernando ................................................. 200

Table 8-7: Communal participation by gender in San Fernando .................................................... 204

Table 8-8: Expected and actual benefits of the San Fernando project ............................................. 206

Table 8-9: Overall participation in the project by gender in San Fernando ...................................... 213

Table 8-10: Levels of information self-reported by women in San Fernando ................................... 214

Table 9-1: Comparison of municipalities with severe extreme poverty in El Salvador (2004) ...... 218

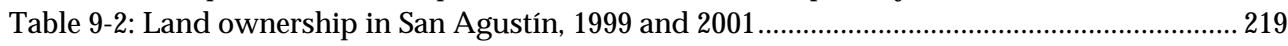

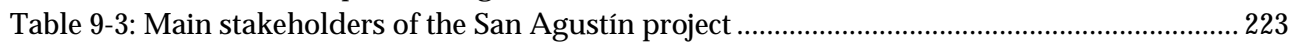

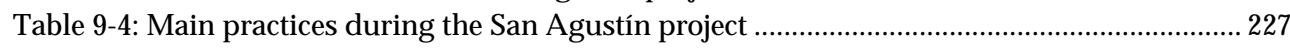

Table 9-5: Organisational structure of CRDM (San Agustín) ........................................................... 232

Table 9-6: Characteristics of the NGOs involved in the San Agustín project ................................... 234

Table 9-7: The extent of control on decisions by gender and social domain in San Agustín......... 239

Table 9-8: Expected and actual benefits of the San Agustín project................................................ 242

Table 9-9: The awareness of personal skills by gender in San Agustín .......................................... 249

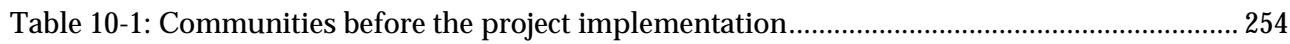

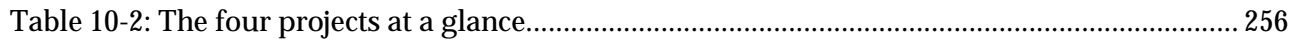

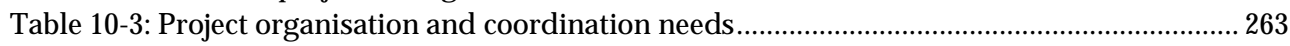

Table 10-4: Decision-making by leadership status and project (at different project stages) .......... 268

Table 10-5: The level of involvement of non-leaders by project......................................................... 269

Table 10-6: Comparing levels of participation in the projects (rankings by sector) ......................... 270

Table 10-7: Comparison of project activities in San Fernando (SF) and Agua Fría (AF) ................ 282

Table 10-8: Elements of the analytical framework of project effects on autonomy.......................... 283

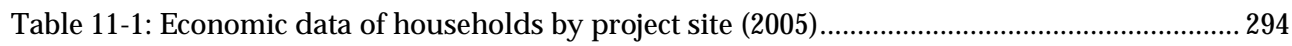

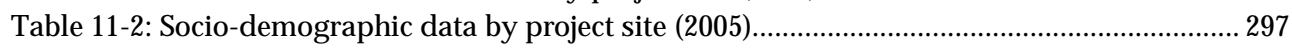

Table 11-3: Levels of information about community by project....................................................... 307

Table 11-4: Valuable aspects of life and relative achievements (selected elements) ......................... 308

Table 11-5: Possible effects of the projects on intra-community attitudes and relationships ......... 311

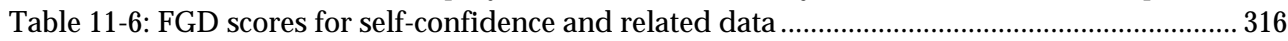

Table 11-7: Some factors relevant to perceived agency in micro-level contexts ................................ 317

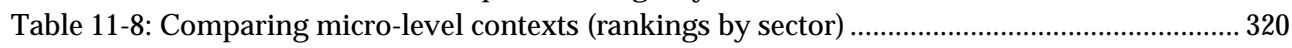

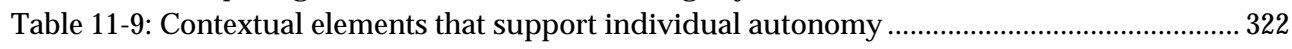

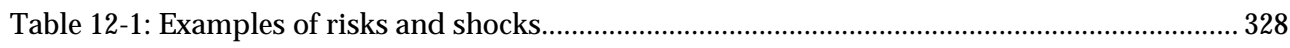

Table 12-2: Relationship between concepts of autonomy and vulnerability ................................... 329

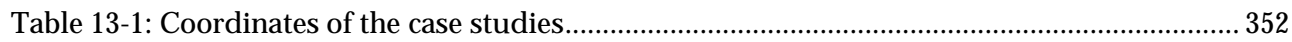

Table 13-2: Looking at values and goals to assess empowerment (possible cases).......................... 356 


\section{Figures}

Figure 1-1: Structure of the study

Figure 2-1: Formation of capabilities and functionings .................................................................. 15

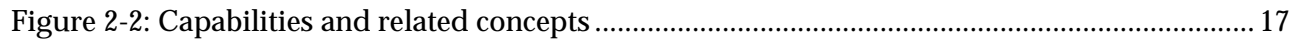

Figure 2-3: The (valuable) capabilities, functionings and resources of Isabel .................................17

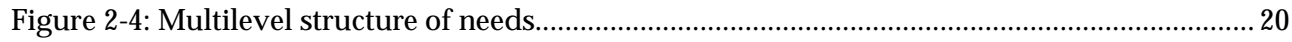

Figure 2-5: The determinants of relative autonomy in the SDT ....................................................... 32

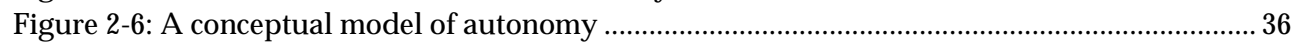

Figure 2-7: Autonomy as combined capability and the layers of autonomy …................................. 45

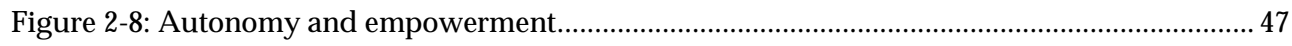

Figure 3-1: Evolution of net ODA from DAC countries 1997-2005 .................................................55

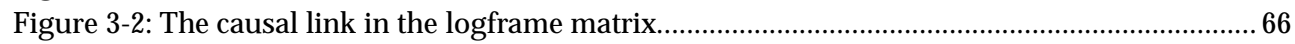

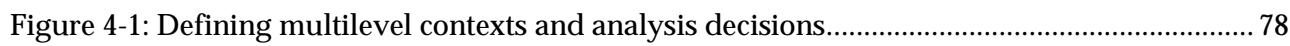

Figure 4-2: Data collection strategy with non-leader participants ................................................... 81

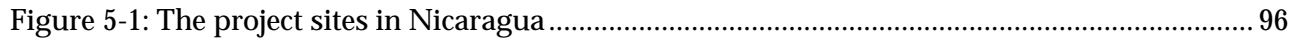

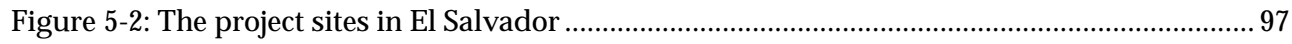

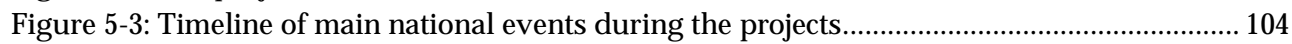

Figure 5-4: Basic relationships in the management of bilateral projects ....................................... 107

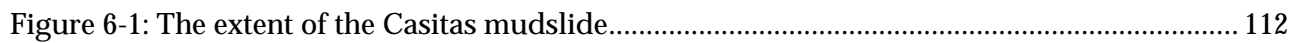

Figure 6-2: The organisational structure of the Santa María project............................................... 115

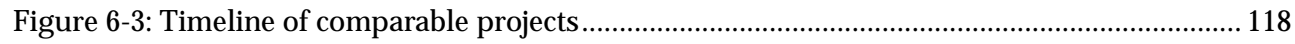

Figure 6-4: Perceptions about community in Santa María .......................................................... 132

Figure 6-5: Average changes in variables associated to autonomy by gender in Santa María...... 143

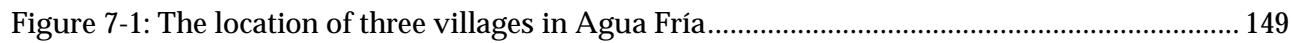

Figure 7-2: The organisational structure of the Agua Fría project ................................................... 154

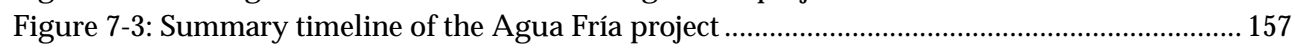

Figure 7-4: Local diagnosis of causes of the unreliability of the water service (Agua Fría)............ 163

Figure 7-5: Household expenditures and remittances in Agua Fría ............................................... 166

Figure 7-6: Distribution of self-perceived achievements in Agua Fría .............................................167

Figure 7-7: Perceptions about community in Agua Fría.................................................................. 168

Figure 7-8: Number of reported cases of acute diarrhoeal disease (ADD) in Agua Fría................. 174

Figure 7-9: Distribution of self-confidence scores reported by women in Agua Fría ....................... 180

Figure 8-1: Map of San Fernando in the department of Nueva Segovia ............................................ 186

Figure 8-2: The organisational structure of the San Fernando project............................................. 189

Figure 8-3: Summary timeline of the San Fernando project............................................................ 191

Figure 8-4: Distribution of self-perceived achievements in San Fernando...................................... 201

Figure 8-5: Perceptions about community in San Fernando........................................................... 203

Figure 8-6: Average changes in variables associated to autonomy by gender in San Fernando... 213 


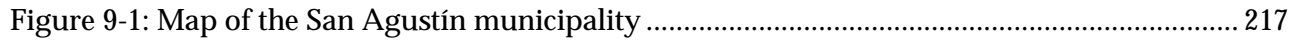

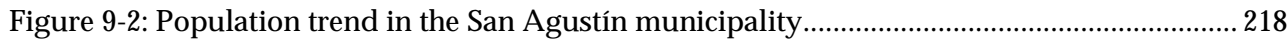

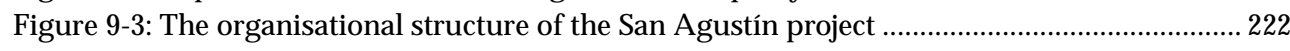

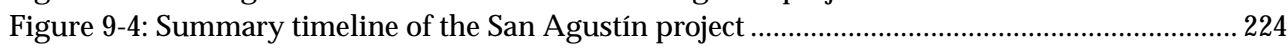

Figure 9-5: Houses reconstructed in the San Agustín municipality ................................................ 225

Figure 9-6: Socio-demographic characterisation of project beneficiaries (2005)............................. 237

Figure 9-7: The role of community as enabler of opportunities in San Agustín............................. 239

Figure 9-8: Average changes in variables associated to autonomy by gender in San Agustín ..... 248

Figure 10-1: Cases compared by relative affluence and disaster impact........................................ 255

Figure 10-2: An analytical framework of project effects on individual autonomy ......................... 258

Figure 10-3: Expected logic chain from participation to individual empowerment ....................... 270

Figure 10-4: Comparing Index 1 and Index 2, the cases with the highest overall involvement.... 271

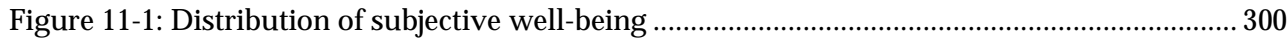

Figure 11-2: Relationship between community organisations and projects .....................................304

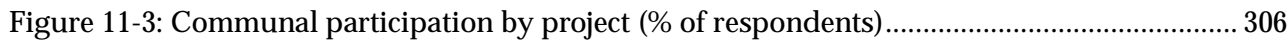

Figure 11-4: Communities and perceived opportunities by project site............................................ 312

Figure 11-5: Possible factors explaining communal participation..................................................... 313

Figure 11-6: Perceived agency and micro-level contexts by project site.......................................... 320

Figure 12-1: Vulnerability and individual motivations for collective action (conceptual link)..... 334

Figure 13-1: Working hypotheses related to the exercise of autonomy ............................................ 361 


\section{Boxes}

Box 2-1: Elements of minimum personal competence

Box 4-1: The case study database

Box 4-2: The index of individual involvement in the project.

Box 4-3: Scoring exercise during the focus group discussions with non-leader participants .......... 82

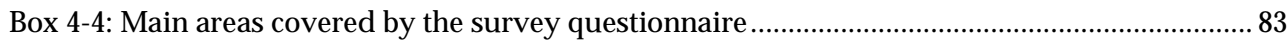

Box 4-5: 'Basic capabilities survey' and multidimensional well-being .............................................90

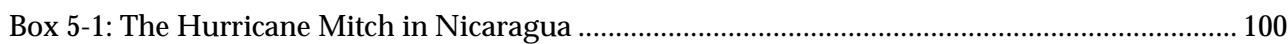

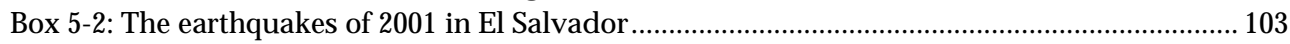

Box 6-1: Committee of communal development (CDC) and the community council .................... 132

Box 6-2: A controlling climate that said more than a thousand words in Santa María ................... 133

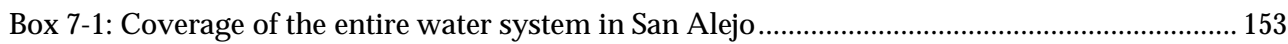

Box 7-2: The impasse with the municipal mayor from the perspective of Agua Fría residents.... 155

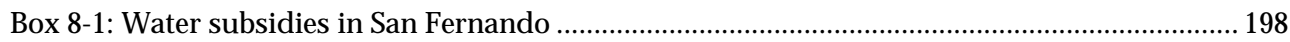

Box 8-2: The formation of the new communal development committee ........................................ 210

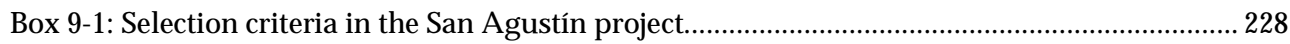

Box 9-2: FUNDAMUNI's strategy to support processes of local development .............................. 229

Box 10-1: Two indexes of individual involvement (quantitative cross-case analysis) ..................... 270

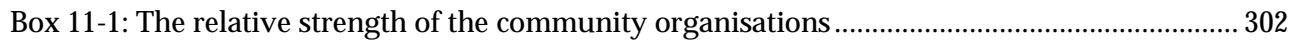

Box 11-2: The dynamics of micro-level contexts............................................................................... 309

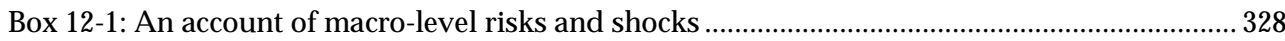




\section{Photos}

Photo 6-1: Women in classes of dressmaking at the community centre...................................... 109

Photo 6-2: Houses in Santa María................................................................................................... 125

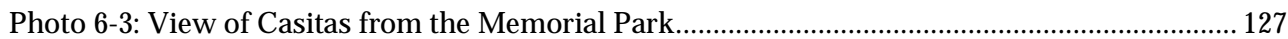

Photo 6-4: A focus group discussion with women................................................................. 145

Photo 7-1: Doña Estela taking part in a focus group discussion at the communal house............. 147

Photo 7-2: Some houses at foot of the road in Trinchera .............................................................. 148

Photo 7-3: A woman preparing clotted cream in Agua Fría ......................................................... 150

Photo 7-4: A man with his daughter working the stone in Piedra Gorda ................................... 150

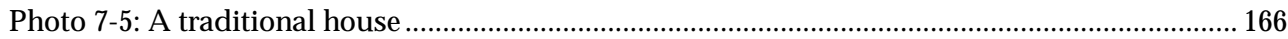

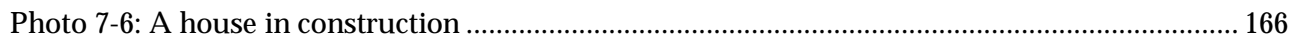

Photo 8-1: Detail of the central park of San Fernando, the patron saint...................................... 183

Photo 8-2: Panoramic view of San Fernando's urban centre .................................................... 186

Photo 8-3: Women taking part in reforestation activities ............................................................... 195

Photo 8-4: Leaders showing a sanitation system (reedbed) in a backyard ................................. 197

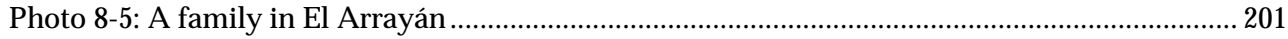

Photo 9-1: Assembly at the multi-purpose communal centre...................................................216

Photo 9-2: Houses affected by earthquakes in San Agustín's urban centre ..................................220

Photo 9-3: People in a canton meeting in San Agustín ................................................................. 230

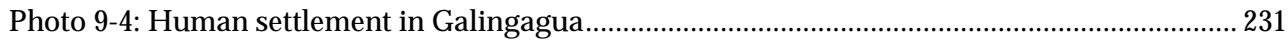

Photo 9-5: Human settlement in Buenos Aires ............................................................................. 231 


\section{Introduction}

This study is grounded in the human development paradigm that places human beings in the centre of development. The objective of development is not economic or material progress, determined by high GDP growth or wealth accumulation, but the improvement of human well-being. This improvement takes place through several means, which include resources, rights, or instrumental freedoms. Material progress is only one of these means. Human development has a different nature.

Well-being is a multidimensional concept, usually contrasted to poverty or ill-being. It has a meaning broader than income poverty (e.g., 'Voices of the Poor', Narayan et al., 2000). Wellbeing is about what people are, what they do, what they can become, what they feel, in which relationships they engage, and so on. In this context, the approaches of human needs and capabilities are related to discussions on human development because these approaches try to capture those 'things' that make possible a worthy life.

The human development paradigm acknowledges the role of human beings as agents of their own development, not as passive recipients of the help from others. In this sense, the term 'human development' refers to the opportunities of people to help themselves (cf., Ellerman, 2006). The logical question would be: 'help to do what?' Sen (1987a; 1987b; 1999) would respond: 'to lead the lives that they have reason to value'. This response implicitly assumes that people have certain capacity to reflect about and to choose among alternative lifestyles. This might not be true because of personal characteristics such as intellectual or physical capacities or because of contextual constraints such as an insecure environment, low access to social infrastructure or unequal power structures. Moreover, values are not intrinsically 'good' for everyone.

The capacity to choose and to achieve is defined here as autonomy. It has an instrumental value to enhance human development. Autonomy is considered an effective capability that requires certain conditions for its realisation (see Chapter 2). Institutional features and relationships between social actors in multilevel contexts are primordial.

The experiences of the inhabitants of four project sites in Nicaragua and El Salvador form the basis for understanding how people exercise individual autonomy in situations of change and how external actors can promote or constrain positive changes in well-being and human development. The study period is from 1998 to 2005, which covers the lifespan of the four projects and the year of the fieldwork (2005).

\subsection{Characteristics of this study}

This research study investigates how foreign aid projects can support the individual autonomy of final aid recipients (individuals in communities). The study focuses on official bilateral cooperation financed by Luxembourg that heavily relies on project aid to promote the access of individuals to social infrastructure and services in poor countries.

The starting point is to consider that processes as well as outputs are important to enhance human development. Projects providing basic infrastructure are instrumental to human 
development, as they provide means for being healthy, well educated or feeling safe. This study puts forward that these kinds of projects are also intrinsically important to enhance individual autonomy.

On the one hand, one can state that, if it is possible to find the mechanisms how these projects promoted or could have promoted individual autonomy, new projects could be designed with more attention to practices and relationships and less emphasis on only activities and operational outputs. On the other hand, projects directly focused on enhancing intellectual or organisational capacities such as work insertion training, agricultural or microfinance projects could reorient their project activities so that they do not merely transmit knowledge but promote human creativity and inventiveness (Carmen, 1996), without harming other formal project goals.

Examining foreign aid projects confirms that country and local institutional features are crucial. Effective aid to achieve operational outputs and have longer term positive impacts on human development requires local ownership and the respectful support from external actors, without imposing tasks or conditioning help. Certainly, contextual factors and interpersonal relationships are very different in each case.

\subsubsection{General objectives}

These pages describe a practically-oriented, fundamental research study. This study has a basic theoretical component and a practical-oriented component:

1. It develops a conceptual model of autonomy, informed by approaches in the human development paradigm and multidisciplinary studies, and enriched by the experiences of individuals in the four localities.

2. It proposes an analytical framework to evaluate the effects of projects on individual autonomy, which explicitly looks at practices, goals, motivations, and values of intended beneficiaries, project staff and other stakeholders. In this way, it aims at contributing to the design, implementation and evaluation of aid projects that promote human autonomy.

3. It uses and tests that framework in examination of the four projects.

Local contexts are crucial in determining individual options. Donor community has increased their awareness about the importance of contexts (as stated in copious project reports) but this awareness has hardly explained a change in behaviours or project practices. The proposed framework highlights the interactions of stakeholders in specific projects; hence, it helps to examine effects that may not be reflected in the logical frameworks or traditional evaluation reports.

\subsubsection{Relevance}

Exploring the links between autonomy and aid projects is important for several reasons. First, it is necessary to reflect about which objectives are defined, by whom, with whom they are shared, and how they are pursued. The objective of all these projects was to enhance people's well-being via the provision of means. However, would it be possible not only providing means but also enhancing autonomy so that people themselves might fuel sustained increases in their well-being? 
Second, processes also have impacts which may expand or shrink autonomy. If the autonomy of the final aid recipients was enhanced, how did it happen? (The opposite question is also pertinent) Is it possible to push autonomy from outside? Or, did individuals somehow become aware that they had a certain level of autonomy? Are there conditions that support this awareness? What happens later to the groups and individuals receiving help?

Third, is it really possible to enhance autonomy in the case of infrastructure projects and when recipients most likely lack the skills to actively participate, not to only be mobilised? This concern parallels discussions on empowerment and participation in projects. Indeed, several studies explore methods to assess empowerment (see especially, Alsop, Bertelsen \& Holland, 2006), while efforts are developed to trace individual changes based on subjective indicators (see Alkire, 2005). This study proposes that questions about processes of change are better assessed with a combination of methods.

\subsection{The research questions and overall approach}

The specific research questions can be grouped in two main themes:

\section{A. Conceptual model of individual autonomy}

1. How important is individual autonomy for promoting human development?

2. How do individuals in communities experience autonomy in their lives?

3. How can communities shape opportunities for autonomy and human development?

\section{B. Impacts of aid projects on individual autonomy}

4. How might projects have affected the autonomy of non-leaders and leaders?

5. In which communities are individuals more likely to experience an expansion of autonomy? And why?

Chapter 2 conceptually responds to the first research question. A sub-question is: how important do inhabitants of the four localities think individual autonomy is for development? This question is answered in the case chapters (6 to 9) and in Chapter 11. Chapter 4 presents the methods to approach the other research questions. The analysis is interpretive and relies on qualitative and quantitative data. These data were collected or produced jointly with project participants (through participatory tools) during two study visits in year 2005.

The cases were purposively selected. Each of them is object of an independent enquiry, reported in an individual case chapter. The cases are the communities composed by individuals living in a locality, not the projects. They are not a small sample of cases from which to draw conclusions for individuals benefited by Luxembourg aided projects in Nicaragua and El Salvador. Conclusions are valid to a specific time and place, and to specific circumstances. Theory is generated from each case, based on data. The comparative cross-case analysis is made at an abstract level. This analysis consists of identifying themes, contrasting explanations and comparing results (see Chapter 4).

\subsection{The case studies}

The empirical part of the study is based on four projects assisted by Luxembourg in Nicaragua and El Salvador. The four projects provided basic infrastructure: houses and social in- 
frastructure (i.e., reconstruction projects), or water and sanitation systems (i.e., water projects). Table 1-1 presents the cases studied.

Table 1-1: Case studies

\begin{tabular}{|c|c|c|c|}
\hline & \multicolumn{2}{|c|}{ Country } \\
\hline & & Nicaragua & El Salvador \\
\hline Sector & $\begin{array}{c}\text { Water } \\
\text { Reconstruction }\end{array}$ & $\begin{array}{c}\text { San Fernando } \\
\text { (deficit caused by Hurricane Mitch) } \\
\text { Santa María } \\
\text { (tragedy caused by a mudslide) }\end{array}$ & $\begin{array}{c}\text { Agua Fría } \\
\text { (structural deficit) } \\
\text { San Agustín } \\
\text { (disaster caused by earthquakes) }\end{array}$ \\
\hline
\end{tabular}

Note: The cases have the names of the localities, not of the projects (some projects covered several localities). Reasons for the need of aid appear between parentheses.

A common feature is that, in each case, every household worked in the construction activities and communal organisations participated in several tasks, varying from supervision of construction works and organisation of workdays to strategic planning. This means that project planners valued the participation of final aid recipients during the project cycle, although to different extents. However, the projects were not community-based or purely participatory projects. The projects had an independent management led by staff external to the localities, with the support of a formal public counterpart.

These projects are not the usual 'development' projects that promote income-generating activities and are not the usual 'emergency' projects that provide short-term relief in extreme cases when survival is at risk. Although three of the projects responded to emergencies, triggered by Hurricane Mitch in Nicaragua and earthquakes in El Salvador, the projects were envisaged with a long-term lens. Indeed, the project apparatuses stayed in the localities for longer periods, between two and four years, than usual emergency projects do.

It must be noticed that this study does not evaluate the performance of Luxembourg bilateral aid. Bilateral practices and organisation have changed over time. These changes are considered external events for the purposes of this study, that is, they are not influenced by the actions of particular project stakeholders, but are important to understand the contexts in which the projects were carried out.

Furthermore, the kind of lessons based on ex-post evaluations would be qualitatively different from the findings in this study because the goal here is to analyse the effects of the projects on the autonomy of final aid recipients or participants, not necessarily the effects in terms of stated project objectives. The aim of describing the specific practices during the projects (in case chapters) is to understand the nature of the project effects, their causes and contextual influences, not to evaluate the performance of the aid agency or the effectiveness of the aid policies.

It is worth noticing that, as an aid agency officer pointed out, individual autonomy was not centrally important for the formulation, implementation and evaluation of the projects analysed in this study. Hence, conclusions about effects on individual autonomy are not considered evaluation findings. As Chapter 3 explains, this has to change: enhancing individual autonomy should be an explicit objective of international aid; both donors and recipient governments should be accountable for it.

Some aspects relevant to analyse the country and local contexts are presented below. These aspects are deepened in the coming chapters. 


\subsubsection{National contexts}

Nicaragua is the largest country of Central America, with an area of 130,374 $\mathrm{km}^{2}$, and coast lines on both the Pacific Ocean and the Caribbean Sea. It has 5.1 million inhabitants. In contrast, El Salvador covers an area of only $21,041 \mathrm{~km}^{2}$ but hosts 5.8 million inhabitants; it is the most densely populated country in Latin America. About $56 \%$ of Nicaraguans and $60 \%$ Salvadorians live in urban areas. International emigration has increasing importance in both countries so that remittances account for more than $12 \%$ of the GDP. However, this phenomenon is more extended in El Salvador; more than 2 million Salvadorians could be living abroad (UNDP, 2005b).

El Salvador is relatively richer than Nicaragua. In 2005, its real GDP per capita was 1.4 times that of Nicaragua, but still less than two-thirds the average of Latin America. This difference translates into much lower poverty rates in El Salvador than in Nicaragua (see Table 1-2). Human development indicators are also better for El Salvador, but income inequality is higher there, in line to long-lasting social exclusion (see Chapter 5). Concomitantly with a weaker economic situation, Nicaragua is more dependent on aid flows than El Salvador. Annual foreign aid flows to Nicaragua exceed $10 \%$ of its national GDP. Nicaragua, considered a low income country and highly indebted, has benefited from debt relief initiatives during the last years.

Table 1-2: Selected indicators for Nicaragua and El Salvador, 2005

\begin{tabular}{|lccc|}
\hline & Nicaragua & El Salvador & Latin America \\
\hline Income indicators & & & \\
\hline GDP per capita (PPP, US\$) & 3,674 & 5,255 & 8,417 \\
\$1-a-day poverty rate, \% population & 45.1 & 19.0 & \\
\$2-a-day poverty rate, \% population & 79.9 & 40.6 & \\
GINI Coefficient (between 0 and 1) & 0.431 & 0.524 & \\
Income of richest 20\% to poorest 20\% (times) & 8.8 & 20.9 & \\
\hline Human development indicators & & & \\
\hline Human Development Index (HDI) ranking & 110 & 103 & \\
HDI Value & 0.710 & 0.735 & 0.803 \\
Infant mortality rate (per 1,000 live births) & 30 & 23 & 26 \\
Access to an improved water source (\% of population) & 79 & 84 & 91 \\
Literacy (\% of population aged 15+) & 76.7 & 80.6 & 90.3 \\
\hline
\end{tabular}

$\mathrm{PPP}=$ Purchasing power parity

Source: UNDP (2007b).

The inhabitants of Nicaragua and El Salvador faced particular circumstances: intense armed conflicts during the 1980s and part of the 1990s, and natural disasters. These events had important effects on human development such as human right violations and forced emigration but also social mobility, destruction of social and economic infrastructure but also changes in land property structure via the agrarian reforms, and so on. The mark of these events in the lives of inhabitants of the four localities studied is still visible, either as vulnerability in different areas such as economic or environment, or as potential to develop collective action, based on previous organisational experiences. This will be clarified in the specific case chapters, which show that those aspects can also be concurrent.

In both countries, there were liberal governments during the 1990s and early-2000s that applied market-oriented policy reforms and export-led economic strategies, with different 
results. First, economic growth was not impressive. During the study period (1998-2005), the average annual growth rate of real GDP per capita was $0.5 \%$ in El Salvador and $2.4 \%$ in Nicaragua. ${ }^{1}$ Second, there was no significant reduction of poverty and inequality. Only in the case of El Salvador was there a decrease in (official) rural poverty, from $58.7 \%$ to $42.5 \%$ of households between 1998 and 2005 (DIGESTYC, 2007). In Nicaragua, rural poverty slightly increased to reach $70.3 \%$ of individuals in 2005 (INIDE, 2007).

Moreover, differences in the access to social services and economic infrastructure between rural and urban areas, and the capital city and other departments, persist. The inhabitants of the four localities studied are small farmers or merchants not fully integrated to the modern economy so that the benefits of economic growth take time to reach them.

\subsubsection{Local contexts}

The longer the aid chain the more complex the context in which the project takes place. In this study, contexts are considered at several levels: macro or international level (e.g., donor and recipient country), meso or national level (e.g., public water company and line ministries) and micro or local level (e.g., project staff, community leaders and local government). Hence, social actors interact in multilevel structural contexts.

The focus of this work is on the micro-level of analysis. The project has an organisation, staff, predefined objectives, incentives and an underlying theory of how things must be done to achieve the goals, explicit in a logical framework. Aid recipients have their own worldviews and expectations about the project as well. How these expectations match or do not match the reality has varied impacts on people's lives. Hence, next to investigating objective changes, this study identifies perceptions of change or, more properly, perceptions of change in autonomy. Relationships between individuals in communities are crucial. Gender relations are also subject of inquiry as may influence the meanings and the exercise of autonomy.

\subsection{Structure of the study}

The study is composed of three parts, as shown in Figure 1-1. Part I contains three chapters that develop the conceptual model, various macro and micro elements to analyse international aid and the research approach. Part II presents the case studies. Each case contains a detailed description, data-grounded interpretation and analysis. Part III presents three chapters that compare the case studies from different perspectives. Some conclusions are summarised in the final chapter of this study.

Part I. Chapter 2 develops the conceptual model that guides this study. It establishes the linkages between individual autonomy and human development and discusses how projects could expand individual autonomy and promote empowerment. Chapter 3 explores the practices and goals of international aid, fundamental for analysing the functioning of specific projects. It develops a method to identify the full project logic, and summarises some working hypotheses on the effects of the projects on individual autonomy. Chapter 4 explains the design of the empirical work and its data collection and analysis methods.

${ }^{1}$ Own calculations based on statistics published by central banks of both countries (BCN, 2007; BCR, 2006). 
Figure 1-1: Structure of the study

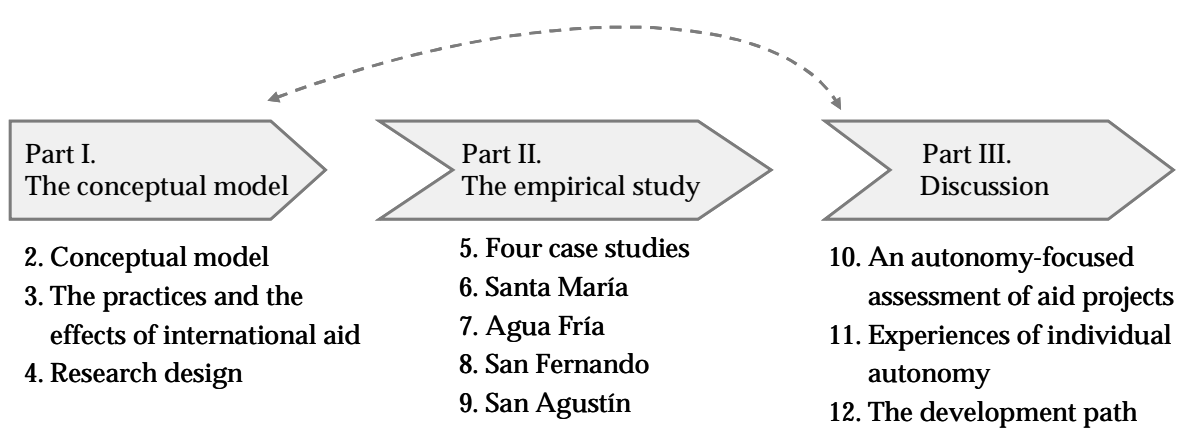

Part II. Chapter 5 introduces the analysis of the case studies. It briefly describes the localities and projects, discusses special features of the countries that influence the local contexts, and presents general policies and practices of Luxembourg bilateral aid. Chapters 6 to 9 analyse each case independently in light of the conceptual model. The objective is to explore the understandings and experiences of autonomy of the residents of the four localities and whether the projects had effects on their autonomy, based on the project practices.

Part III. Chapter 10 presents a comparative analysis of the four projects. It presents an analysis of the project features that can influence individual autonomy and proposes an analytical framework to assess project effects on individual autonomy. Chapter 11 explores the factors that characterise the experiences of individual autonomy in dynamic terms (during a process of change) and investigates how communities can shape opportunities for autonomy and human development. Chapter 12 returns to two fundamental topics in promotion of human development: the reduction of vulnerability and the enhancement of critical autonomy, which makes possible critical participation. 



\section{Part I:}

The conceptual model and research approach 



\section{A conceptual model of human development and autonomy}

The idea of autonomy is not merely an evaluative or reflective notion, but includes as well some ability both to alter one's preferences and to make them effective in one's actions and, indeed, to make them effective because one has reflected upon them and adopted them as one's own (Dworkin, 1988, p. 17).

This chapter presents the conceptual model that guides the empirical study on four projects in Nicaragua and El Salvador. The purpose is twofold: (i) to explain the relation between human development and autonomy and (ii) to develop a conceptual model of autonomy, feasible to be used in evaluating aid projects. In this way, the expansion of autonomy could be an explicit goal of international aid.

The model here developed is based on:

(i) The notion of human development by the UNDP (1990). People are agents that should be free to make choices. Both expanding their valuable options and improving their actual well-being are development goals; and

(ii) The recognition of the social nature of human beings. People have objectives beyond their own well-being based on shared understandings that explain their behaviour and their lives. They are 'embedded within social institutions which both enable and constrain action' (Gore, 1997, p. 245).

The study of autonomy has been pursued in different fields such as political philosophy, education, health, psychology and development studies. In some cases, the individual character of autonomy has been emphasised, leading to conceptual confusion. Some practitioners have understood autonomy as independence, attached to specific personality traits. In contrast, autonomy is also related to connectedness (Deci \& Ryan, 2000) and both aspects are related to psychological well-being. Indeed, individuals care about others and their commitments with others are evidence of autonomy, not of dependence (Christman, 1998)

Aid projects usually focus on expanding access to basic services and productive assets or on promoting market-related activities. In these cases, the channel to foster development is the access to resources. However, the process also matters: how projects are formulated, implemented or evaluated influences the lives of real people who value to help themselves. Unfortunately, some projects fail to take into account what people truly need or value (Alkire, 2002). Sometimes, high-quality participation is limited because participants have (or project designers think that they have) a limited capacity to make choices and achieve valuable outcomes. This chapter explains why this capacity has to be explicitly promoted, in order to fuel human development.

The chapter is divided into five sections. Section 2.1 reviews some approaches of human capabilities and human needs to define human development. Section 2.2 explores the concept of autonomy, its philosophical foundations and related notions in the approaches reviewed. Section 2.3 contains the conceptual model of autonomy, differentiating agency from structural contexts and autonomy. Section 2.4 distinguishes between an expansion of individual autonomy and empowerment. Section 2.5 summarises the main conclusions. 


\subsection{H uman development: means and ends}

From an evaluative point of view, human development refers to an improvement in people's lives and the opportunities to achieve such an improvement (Gasper, 2004). Table 2-1 presents a first overview of the concepts of well-being and human development. Well-being refers to the quality of the actual lives of people or their states of being at a particular time: what they are, what they do, what they can become, what they feel, in which relations they engage and so on.

Table 2-1: Relation between well-being and human development

\begin{tabular}{|l|l|}
\hline Level element & $\begin{array}{l}\text { Well-being: } \\
\text {-Evaluation of actual lives that people lead (outcomes). } \\
\\
\text {-Evaluation of the opportunities to have a good life. }\end{array}$ \\
\hline Change element & $\begin{array}{l}\text { Human development: } \\
\text {-Improvement in well-being (positive change in outcomes). } \\
\text {-Expansion of valuable human potentials (opportunities). }\end{array}$ \\
\hline
\end{tabular}

Human development occurs when people experience a positive change in their well-being or when they have more opportunities to exercise their potentials. Human development is a process, not a fixed destination with a pre-determined path. Human beings are in continuous pursuit of exercising their potentials and they do this in different ways taking into account the contexts in which they interact.

Next, it is necessary to decide (i) the approach to evaluate well-being and whether there has been an improvement, and (ii) who defines the criteria for such an assessment.

\subsubsection{Approaches and criteria to assess well-being}

Concerning the first issue, the approach to evaluate well-being can come from either hedonism or eudaimonism. The second is the philosophical foundation of this study.

Hedonism argues that all and only pleasure has value, while pain intrinsically has disvalue (Moore, 2004). In this account, pleasure can be regarded as a distinctive life experience or as an intentional state (belief or desire) toward one aspect of oneself or the world. Utility would be the variable in focus.

Traditionally, utility was related to happiness as pleasure or fulfilment of desires but, in both senses, it failed to assess well-being. ${ }^{2}$ Happiness is a mental state that can have different causes. For example, a poor woman might experience more happiness enjoying a sunny day in the park with her children than a corporate lawyer receiving a Christmas bonus (or vice versa). Desires are related to people's particular circumstances; people may adjust their preferences and expectations to what they consider feasible or are used to. Moreover, after fulfilling a desire, people would not necessarily feel or be better off.

The current view of utility is related to choice, the result of a person's revealed preference: If I choose $X$ over $Y$, it is because I prefer $X$ more than $Y$, that is, I have more satisfaction from consuming $X$ than $Y$. Choices are observable, but the formation of preferences and choices is not. These processes may be different in each person's case so that it is considered not possi-

\footnotetext{
2 The explanations that follow are mainly based on Nussbaum (2000) and Sen (1999).
} 
ble to compare the utilities of different persons or conclude whether a change of personal preferences (choices) reflects a change of well-being.

On the other hand, people can make choices having different motivations, deriving from desires, emotions or truly valued goals. Desires are not necessarily objects of value (Sen, 1985a, p. 190); they come over unexpectedly and can fuel action without reflection. ${ }^{3}$ Emotions contain intention toward an object outside the self, deemed important by the individual (Nussbaum, 1995b). Human beings are not always rational thinkers; their beliefs about an object and corresponding actions need not have a rational foundation. As Christman (2003) explains, 'we value ourselves and others as passionate reasoners not merely reasoners per se' (ibid, 'Autonomy in moral philosophy' section, II 7).

Values and commitments can explain choices. People may have concerns beyond their own well-being, including the well-being of significant others and political or religious causes. In addition, although they had a reflection-based preference for a lifestyle that they value, they might not choose what they value ('valuation neglect' in Sen, 1985a).

Consequently, assessing well-being by only looking at the choices made would fail to reflect what people desire, need or value. In contrast, eudaimonism refers to human excellence and the actualisation of good human potentials. In this account, human flourishing (eudaimonia) is related not only to feelings but also to living well and doing well; a good life is related to a fully human functioning (Ryan \& Deci, 2001).

The second point, the criteria to assess well-being, is in the core notion of autonomy. If all human beings are capable to think and act by themselves, they should make their own decisions. In the context of this discussion, it means that everyone should have the opportunity to evaluate his or her own life based on meaningful criteria (assuming certain minimum capacities). In the context of aid projects, it is linked to the principle of subsidiarity: decisions should be made as low down as possible depending on local capacities (Chambers, 1995; Alkire, 2002; Friedmann, 1992).

It is difficult to reach an agreement on the criteria for a good life. Individuals may value different things depending on their personal characteristics, their own biographies and their particular social, economic or political contexts. 'Voices of the Poor' (Narayan et al., 2000) is the most ambitious study to capture the local conceptions of well-being of over 20,000 people in 23 countries. Participatory methods used in poverty studies and project assessments, can 'contribute to the understanding of well-being because it draws out of culture, location and social group-specific understandings' (White \& Pettit, 2004, p. 8). Basic necessities surveys produce accounts of poverty based on local definitions (Davies \& Smith, 1998; Pantazis et al., 2000) and can be adapted to characterise well-being (e.g., Box 4-5). Camfield and Ruta (2007) develop an index of subjective well-being, tested in three developing countries. Clark (2005) supports an 'empirical philosophy' that, based on theoretical accounts of well-being and development, explores human values by asking (poor) people themselves what a good form of life is (ibid, p. 833).

In contrast, other scholars propose 'objective' theories to identify elements (usually in a list) valuable for all human beings, so that the well-being of a person is evaluated independently of this person's subjectivity. Scanlon (1993) describes them as 'substantive good theories'

${ }^{3}$ However, philosophers distinguish between orders of desires (see section 2.2.1). 
because they are 'based on substantive claims about what goods, conditions, and opportunities make life better' (p. 189). Scanlon argues that it is possible to identify a set of principles to evaluate actions that all individuals, even those with different values could accept. ${ }^{4}$ The importance of each principle can vary across societies. Moreover, the derived lists can include different inputs as people have different ways to satisfy or achieve common valuable goals.

Several lists intend to capture the most valuable elements of human life. Alkire (2002) presents 39 lists, discusses some of them and elaborates her own (adapted from Finnis' list) to assess the impact of three development projects. Those lists show major commonalities, for instance, they include concepts similar to the topic of discussion here: practical reason, understanding, freedom of choice and action, self-direction, self-determination, and so forth.

An appealing debate is whether lists are group-specific or universal. In principle, human beings have basic common features so there must be aspects of our life that require to be promoted for all. These aspects can be called 'basic human needs' or 'central capabilities' (see sections 2.1.2 \& 2.1.3). However, the details of such lists (modes and standards) will evolve over time and across societies because culture is also dynamic, 'constantly recreated as people question, adapt and redefine their values and practices to changing realities and exchanges of ideas' (UNDP, 2004, p. 4).

Individuals in groups may have particular preferences and ideas about what makes a good life, based on their shared experiences and cultural context. However, the conventions rooted in those preferences may not be fair or desirable for all inside and outside the groups. Cross-cultural learning (Gough, 2004), scrutiny of underlying local values and public reasoned deliberation (Drèze \& Sen, 2002) could enrich the identification of relevant elements.

If an ideal list of ingredients for a good life were attainable, what would the nature of these items be? Candidates are resources, entitlements, functionings, capabilities and needs. Next sections present a review of approaches in terms of human capabilities and of human needs.

\subsubsection{Approaches in terms of human capabilities}

Amartya Sen and Martha Nussbaum pioneered the work on human capabilities, but their approaches have clear differences (see Crocker, 1995; Gasper, 2003) influenced by their different backgrounds: Sen, an economist who won the Nobel prize (1998) for his work on welfare economics and Nussbaum, a philosopher with special interest in law and ethics. Their audiences are also different: Sen oriented more to economists and analytic philosophers and Nussbaum more to humanities scholars (Gasper, 2000a, p. 997).

Sen defends democratic participation as the tool for applying his approach (Sen, 2004) so that it 'may be filled in by reasoned public debate, itself a valuable process' (Alkire, 2002, p. 29). In contrast, Nussbaum aims to develop a normative philosophical theory so that all human beings have the access to central capabilities guaranteed; her approach would be then directly applicable.

\footnotetext{
${ }^{4}$ Scalon relies on a contractualistic moral theory so that people could reach agreement on basic principles for a good life by means of mutual justification (Scalon, 1993, p. 196).
} 
Capabilities and functionings are the core concepts, further developed over time. This section is based on Sen's work (unless otherwise noted) and his capability approach (CA). Some special features of Nussbaum's approach are discussed later.

Functionings are 'the various things a person may value doing or being' (Sen, 1999, p. 75). These are activities, such as taking part in community activities, or parts of the state of being, such as being well-educated or being healthy. From an action-based view, functionings can be seen as either realised or potential functionings. Realised functionings describe what people have achieved, while potential functionings are the capabilities. Sen (1993) defines that 'the capability of a person reflects the alternative combinations of functionings the person can achieve, and from which he or she can choose one collection' (p. 31).

Capabilities are what people can do or be, that is, their opportunities to have the life they have 'reason to value' (Sen, 1999, p. 56). Human beings have reasons because they hold values and have reflection capacities. In this approach, life is a matter of reflected choices, but, as seen earlier, there are other motivations that explain actions not only values.

\section{- Formation of capabilities in the CA}

Figure 2-1 shows theoretically how the capabilities are formed and an achieved functioning is produced based on a resource (cf., Robeyns, 2005). It describes a process in which the inputs are the entitlements and individual-specific conversion factors.

Figure 2-1: Formation of capabilities and functionings

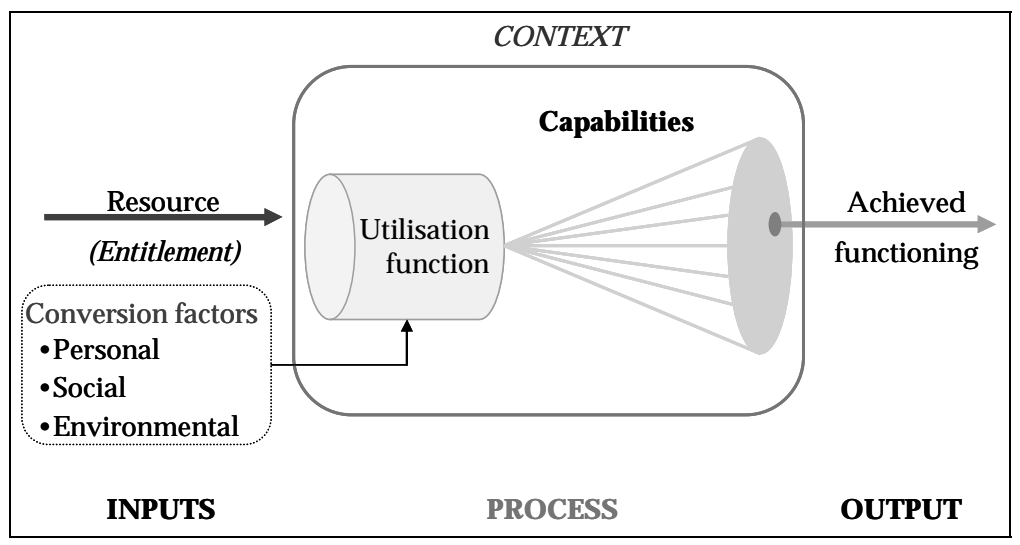

Entitlements are resources accessible to the individual, that is, resources that he or she owns or can use directly (e.g., available to everyone such as free public education) or by exchanging other entitlements (e.g., working for a wage to buy resources). Types of resources include market products, non-market products, monetary income, public goods, stateprovided goods or social transfers. At first, Sen (1982) defined entitlements primarily based on legal ownership or rights, but later he extended the concept to include 'socially legitimated' entitlements not conferred by legal mechanisms (Devereux, 2001, p. 250-253).

The use of these entitlements depends on conversion factors: personal characteristics, such as physical condition, metabolism, age, sex or individual skills; social characteristics, such as conventions and customs, gender roles, intra-family resource allocation or societal hierarchies; and environmental characteristics, such as climatic conditions, endemic diseases or pollution incidences. The mix of these factors determines each person's situation. 
The utilisation function (Sen, 1985a) transforms the characteristics of the resources into particular ways of how each individual can use them, depending on his or her conversion factors, so defining a capability set or a set of opportunities to function.

The final combination of functionings achieved based on the capability set depends on the contexts and the reasons people have. For instance, the existence of a public school (resource) in a village would not assure that a boy is well-educated if he had to work in the plot everyday for long hours because his parents did not value formal education as much as practical life duties that have direct effect on physical survival. The different groups to which people belong during their lifetime (family, friends, schoolmates, neighbours, work colleagues, etc.) have an impact on their identities and choices. These groups could enlarge the set of 'favourable' options (capability set) or restrict it.

However, a functioning is not always the result of choice. For example, the existence of an efficient health system provided by the state, with its positive externalities, gives the individual the capability to enjoy a malaria-free life 'thanks largely to others' (Sen, 1993, p. 45). Consequently, the individual, being healthy, is able to pursue valuable goals. In fact, well-being depends on 'instrumental freedoms' (Sen, 1999) facilitated by the context. These freedoms include political freedoms, economic facilities, social opportunities, transparency guarantees and protective security, which are interrelated. For instance, having the right to vote is not the same as being able to vote if a person cannot commute to the voting centre because there are no safe transport means.

On the other hand, as Muellbauer (1987) points out, some functionings could be individual habits or customs, explained by the search costs associated with non-habitual behaviour or the accumulation of specific human and cultural capital. For instance, farmers' relation with land can be so intimate that they define themselves in these terms: 'We are not birds that live in the air. We are not fish that live in the sea. We are men who live from the land.' (Bernardino Díaz Ochoa, Nicaraguan, 1964)

\section{- Resources and capabilities}

An approach centred on functionings and capabilities is clearly different from another centred on resources (opulence) ${ }^{5}$. The CA recognises that resources, or more specifically entitlements, are necessary to achieve valuable things, but their role is instrumental.

Figure 2-2 clarifies that specific difference. Individuals want to access resources because of the things that they can do with them (based on their characteristics), that is, because of the functionings that they can achieve. Different resources can have similar characteristics, like a well-balanced diet could be based on different ingredients. Moreover, individuals are different so that we are not able to do the same with a given resource, e.g. to be well-nourished with the same food basket, or with a given set of characteristics. The possible uses depend on individual conversion factors and utilisation functions, which define the capabilities.

Finally, reaching a certain state of being or well-being (in terms of functionings) can bring a level of utility, which (as seen earlier) could also depend on several heterogeneous factors, such as concerns for others or ephemeral events.

\footnotetext{
5 The notion of resources used for this analysis is the most restricted, as used by Sen. It is not, for instance, the one used in the Resource Profiles Framework or RPF from researchers at the University of Bath (see McGregor, 2000; Gough \& McGregor, eds., 2007).
} 
Figure 2-2: Capabilities and related concepts

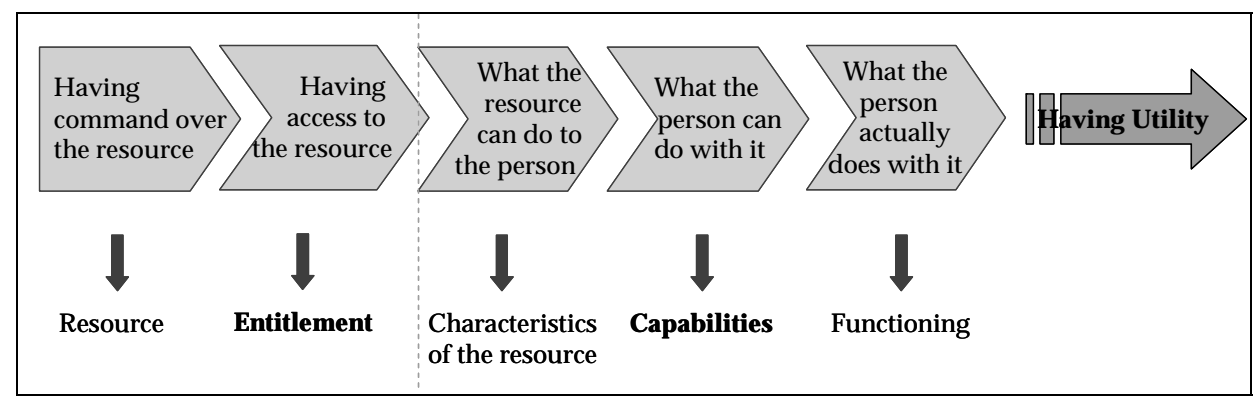

Note: The distinction between what the resource can do to the person and what the person can do with it was deeply explored by Cohen (1993). The other elements have been discussed everywhere by different authors.

The example of Isabel helps to clarify the distinction between resources and functionings and to reinforce the idea that it is inadequate to assess well-being only on the basis of utility. Figure 2-3 shows two dimensions of life that she values and that have influence on her wellbeing: social relations and self-esteem. She values to entertain friends (a functioning) and can do it by inviting her friends either to watch TV or to play cards (for simplicity only two options). These are means to reach the objective of entertaining friends but they have the common characteristic that can be shared with several people (to name just one feature).

Figure 2-3: The (valuable) capabilities, functionings and resources of Isabel

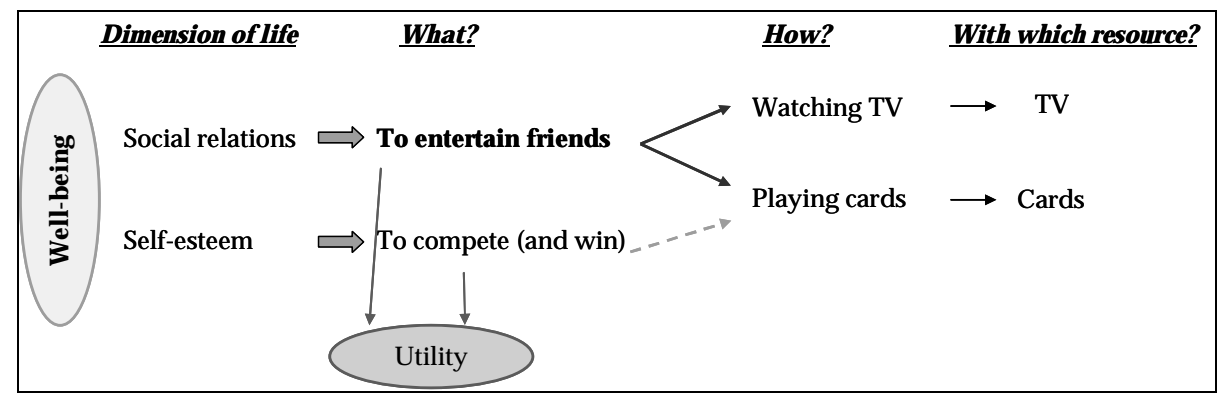

These two options require her access to two different resources (a TV and cards). Playing cards also gives her a kind of pleasure or excitement (utility) because she likes to compete and win when playing cards. Hence, this last option promotes two functionings, related to two dimensions of life valuable for her. It is not straightforward what Isabel would do.

Although Isabel could value more to grow into her self-esteem thus by playing cards, she could choose to invite her friends to watch TV because she thinks they will enjoy it more than 'watching her win'. In this reasoning, she does not make her choice because she likes to watch TV, but because she cares about her friends. An observer cannot know these reasons.

Does her choice mean that she has more utility entertaining friends than competing? If so, do social relations have more value to her than self-esteem? No one except Isabel can answer the first question. About the second question, it can be said that 'Isabel values building social relations', but it cannot be said 'to what extent and how much' she does, in comparison to self-esteem. As the rankings of valuable states of affairs are intrinsically incomplete, Isa- 
bel herself may not be able to rank all her goals. Moreover, she may not choose what she values most either (Sen, 1985a).

On the other hand, Isabel may desire to offer a splendid dinner to her friends instead of watching TV or playing cards, but she could not be able to afford it. With three different actions she can achieve the functioning of entertaining her friends (the primary reason). At last, if she decided to offer the dinner, thus fulfilling her desire, this could affect her wellbeing (e.g., putting at risk her household budget and food security). Then, a choice view of utility to assess well-being would not be accurate.

The following remarks by Sen (1987a) help to compare the notions just discussed:

You could be well off, without being well. You could be well, without being able to lead the life you wanted. You could have got the life you wanted, without being happy. You could be happy, without having much freedom. You could have a good deal of freedom, without achieving much. (p. 1, [italics in original])

An open fundamental issue in this approach is how values are formed and compared. Sen (1988, p. 21) identifies at least two problems: (i) 'value-heterogeneity' because the values differ from person to person, and (ii) 'value-endogeneity', which means that the process of development itself may alter the values of the people involved. This last problem is relevant when the exercise is to evaluate the impact of projects or to assess processes of change.

\section{- Special features of the capabilities in Nussbaum's approach}

The purpose of this section is to discuss some features of Nussbaum's approach that are different from Sen's approach and relevant for the conceptual model proposed in this study. Nussbaum (2000) defines human capabilities as 'what people are actually able to do and to be -in a way informed by an intuitive idea of a life that is worthy of the dignity of the human being' (p. 5). She considers three kinds of capabilities:

(i) Basic capabilities, which are innate yet undeveloped capacities that must be nurtured so that people can reach their true potential;

(ii) Internal capabilities, or the matured basic capabilities ready to be used; and

(iii) Combined capabilities, which are the internal capabilities supported by external and social conditions that allow their exercise.

Nussbaum has built a list of combined capabilities (Table 2-2) that she defends should be the foundation for basic political principles to be constitutionally guaranteed in all nations.

Table 2-2: Nussbaum's central human functional capabilities

\begin{tabular}{|c|c|}
\hline 1 Life & 6 Practical reason \\
\hline 2 Bodily health & 7 Affiliation \\
\hline 3 Bodily integrity & 8 Other species \\
\hline 4 Senses, imagination, and thought & 9 Play \\
\hline 5 Emotions & 10 Control over one's environment \\
\hline
\end{tabular}

Source: Nussbaum (2000, pp. 78-80).

While for Sen, a capability refers to a combination of functionings, for Nussbaum, a combined capability refers to the opportunity to reach a single valued functioning. On the other hand, the conception of Nussbaum is closer to the meaning commonly associated to 'capability'. An internal capability 'can be nurtured, acquired, developed, maintained, exercised, im- 
peded, diminished, lost and (sometimes) restored' (Crocker, 1995, p. 161). UNDP (1990) uses this meaning when affirms that capabilities such as improved health or knowledge are 'formed' and 'used' for work or leisure (p. 10-11).

People develop internal capabilities over time, but only when they find the adequate material and social conditions that support these capabilities in maturing. It is then that people are free to choose to realise a combined capability or not, according to their values and external circumstances.

Nussbaum's list reflects a substantive good theory (section 2.1.1). She affirms that it is result of overlapping consensus (Nussbaum, 2000, p. 76), is open-ended and subject to ongoing revision and, to some extent, independent of preferences that may be shaped under unjust background conditions (Nussbaum, 2003a). Her list, she argues, has universal political justification, committed to what a human life with dignity is. However, its implementation and more precise specification are left to the people in question (Nussbaum, 1995a; 2003a).

These central capabilities 'are not to be an exhaustive account of what is worthwhile in life' (Nussbaum, 2000, p. 95) but people should have the real possibility to pursue them. Nussbaum is concerned for a threshold level of each capability that should be available 'for each and every person', in line with 'the principle of each person's capability' (ibid, p. 74).

\subsubsection{Approaches of human needs}

Scholars from different fields (e.g., psychology, economics and health sciences) have focused on human needs. First, it is necessary to introduce briefly the basic need approach (BNA) and clarify what is meant by 'needs'. Then, the notions of needs and satisfiers are explained in order to distinguish universal and local conceptions of good life.

Streeten et al. (1981) emphasise that the BNA focuses on providing all human beings with the 'opportunities for the full physical, mental, and social development of the human personality' (p. 33). These include material dimensions such as education, health, water, and sanitation, and nonmaterial dimensions such as:

needs for self-determination, self-reliance, and security, needs for the participation of workers and citizens in the decision-making that affects them, needs for national and cultural identity, and needs for a sense of purpose in life and work (Streeten et al, 1981, p. 34).

Unfortunately, some misunderstood this approach based on the fact that, operationally, it focused on a minimal decent life, defined in material terms (Deneulin, 2004, p. 4). For instance, UNDP (1990) indicates:

[The BNA] usually concentrates on the bundle of goods and services that deprived population groups need: food, shelter, clothing, health care and water [and] it focuses on the provision of these goods rather than on the issue of human choices (p. 11).

On the contrary, Streeten (1984) asserts that focusing on a specified bundle of goods is 'incompatible with respect for human autonomy' (p. 974). Later, the label has been marginalised, product of the prominence of neo-liberalism during the 1980s 'which accuses needs analyses of being rigid, asocial and authoritarian' (Gasper, 2004, p. 133) and new versions have arisen with more conceptual clarity and a more appealing political and technical language (Gasper, 2007). 
What does 'need' means? Gasper $(2004 ; 2007)$ considers three uses for this word: (a) in descriptive analysis: as wants, desires or behaviours; (b) in instrumental analysis: as requisites for meeting a given end; and (c) in normative analysis: as justified or priority requisites. Then, current approaches have to be analysed in terms of where they stand. Typically, people consider that needs are wants that motivate an action, and are requirements for wellbeing, and have ethical priority. Nonetheless, there are cases in which people feel desires without objective or function, or feel desires with a function but without normative priority. Moreover, there are also needs with functional value and normative priority but without a drive - which means that their fulfilment would promote objective well-being but not necessarily subjective well-being. These cases also deserve attention.

Normative accounts of needs are complex and may include several hierarchical levels. A three-level structure is presented in Figure 2-4.

Figure 2-4: Multilevel structure of needs

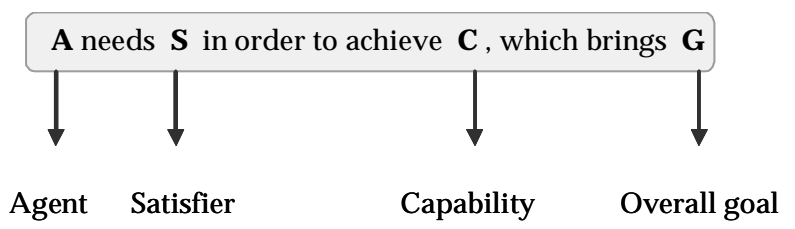

In this case, the agent $\mathbf{A}$ may value to achieve $\mathbf{C}$ (a capability or a basic human need) but he or she requires certain things to do that. These things are the 'satisfiers' or ways how to satisfy needs, not necessarily resources (cf., Reader, 2006). Satisfiers are instrumental and relative (across cultures and societies). The same person might even use different satisfiers depending on the situation because of his or her different social roles or identities. Overall there is a deep reason, $\mathbf{G}$, for which the agent value to achieve $\mathbf{C}$.

Returning to the case of Isabel (Figure 2-3), she has two levels of needs. At a higher level, she has (i) social relations and (ii) self-esteem; at a lower level, she has (i) to entertain friends and (ii) to compete. To fulfil these lower-level needs, there are two satisfiers: watching TV and playing cards. Of course, Isabel cannot claim that her need structure is universal; for instance, there are reasons to doubt the priority value of 'to compete (and win)'.

In the same way, it is possible to analyse Nussbaum's approach. Her central capabilities are C, while the overall goal G is leading a fully human life (Nussbaum, 2000, p. 74). Then, her capabilities may be understood as needs with at least the instrumental and normative uses. She acknowledges local specification of her list, which is related to the notion of satisfiers.

The need structure becomes more complex the more thresholds are distinguished or the more variants are used of the overall goal G. In the context of capabilities, Williams (1987) defined 'basic capability' (not to be confused with Nussbaum's notion of innate capacity) to the underlying or fundamental capability that remains invariable in relation to their satisfiers. For instance, the 'capability to command the materials of self-respect' is deeper than the 'capability to appear without shame in public', which does not always depend on having a linen shirt (Adam Smith's famous example). The different substantive good theories and the resulting lists intend to identify a set of these fundamental capabilities. For instance, the elements of Alkire's lists are 'basic reasons for action' (Alkire, 2002, p. 44). 
Two approaches provide important elements for the conceptual model and can be considered as deeper reformulations of the BNA: the theory of human need (THN) and the theory of human scale development (THSD). These are complemented with a glance at the selfdetermination theory (SDT), which is further explored in section 2.2.

\section{- A comparison of two theories of human needs}

The THN by Doyal and Gough (1991) and the THDS by Max-Neef et al. (1991) assert that the quality of life depends on the possibilities that people have to satisfy their human needs, which are universal and finite. However, these theories differ in regard to their objectives, the nature of needs, the set of basic needs (the lists), the features of satisfiers, and the different levels of needs.

\section{The objectives}

Doyal and Gough (1991) aim to build a substantive and procedural theory to assess quality of life according to the degree to which a series of needs - derived from a criterion of need has been satisfied (p. 4). Max-Neef et al. (1991) build an approach to development based on human needs, which is directly applicable so that local actors are able to evaluate their own current situation, and to design and carry out development strategies (p. 14-15).

The nature of needs

The THN associates human needs to lacks or 'what persons must achieve if they are to avoid sustained and serious harm' (Doyal \& Gough, 1991, p. 50) that would result in dramatically impaired participation in a form of life. Needs are a negative notion; the lack of fulfillment of every basic need to certain optimum causes harm. However, there is one need with a positive sense: critical autonomy (see later).

In contrast, the THSD considers that human needs do not imply only deprivation and cause poverties or pathologies when they are not fulfilled. Max-Neef et al. (1991) explain that 'to the degree that needs engage, motivate and mobilize people, they are potential and may become resources' (p. 24). Therefore, needs are not only satisfied or fulfilled: needs are realised, experienced or actualised through time and space (ibid).

The set of basic needs

The THN distinguishes two universal goals: (i) the avoidance of serious harm or minimally disabled social participation and (ii) critical participation in a chosen form of life. Participation is essential because human beings learn from others and build their self-conceptions through their interactions with others. Derived from these two goals, the universal basic needs are:

1. a) Physical health and b) autonomy of agency, in order to achieve full participation in any society, so that people can choose socially meaningful activities in which they will take part within their culture; and

2. Critical autonomy, to achieve in addition intellectual independence with respect to the goals of society, so that people can question and agree or change the rules of a culture (see section 2.2.4).

Universal goal (i) implies the first basic need. Universal goal (ii) requires both the first and the second. 
Max-Neef et al. (1991) identify nine types of fundamental human needs: subsistence, protection, affection, understanding, participation, idleness, creation, identity and freedom. They are interrelated and interactive.

The features of satisfiers

For the THN, satisfiers are objects, activities or relationships that can be used by people to satisfy their human needs. There are two types of satisfiers:

(i) Universal satisfiers, also called intermediate needs, are those universal characteristics of the satisfiers which allow the fulfilment of basic needs; and

(ii) Specific (relative) satisfiers are the specific characteristics that vary across cultures and can be seen as means to meet intermediate needs.

The universal satisfiers are: nutritional food and clean water, protective housing, a nonhazardous work environment, a non-hazardous physical environment, appropriate health care, security in childhood, significant primary relationships, physical security, economic security, appropriate education, and safe birth control and child-bearing.

For the THSD, the satisfiers are the way in which a need is expressed. They represent forms of being (related to personal or collective attributes), having (related to institutions, mechanisms, laws), doing (related to actions) and interacting (in spaces and environment). For instance, the need of subsistence can be in part satisfied in the 'being' category with physical health and in the 'having' category with food and shelter; Max-Neef et al. (1991, p. 32). The satisfiers depend in addition on the culture, circumstances, limitations or aspirations of specific individuals and require economic goods for their materialisation.

Max-Neef et al. propose a matrix with the nine basic needs and four kinds of satisfiers to be built by local people as a participatory exercise to diagnose their current situation, their lacks and potentials, and envisage which synergic satisfiers would support the simultaneous realisation of several needs. ${ }^{6}$ The focus is on the process of development itself: how people mobilise their resources, generate synergic processes and carry out development strategies.

\section{Identifying different levels of needs}

Doyal and Gough develop a complete hierarchical framework with needs, satisfiers and societal preconditions for the adequate fulfilment or needs. In contrast, with the exception of the need of subsistence, Max-Neef et al. do not propose a hierarchy for their basic needs.

Identifying basic needs and their interrelations is a complex exercise. Therefore, the search for synergic satisfiers to fuel the realisation of potentials and pursue development makes complete sense.

\footnotetext{
${ }^{6}$ There are five types of satisfiers: (i) violators or destroyers, which inhibit the satisfaction of the need they were supposed to satisfy and of other needs; (ii) pseudo-satisfiers, which stimulate a false feeling of satisfaction, (iii) inhibiting satisfiers, which may over-satisfy and inhibit the satisfaction of other needs, (iv) singular satisfiers, which are exclusively focused toward one need and are neutral to the others, and (v) synergic satisfiers, which do not only satisfy a need but also stimulate and contribute to the simultaneous satisfaction of other needs.
} 


\section{- $\quad$ The self-determination theory (SDT)}

The SDT complements the previous theories. In contrast to Nussbaum's approach and the THN that follow a normative logic and the THSD that essays existential ontology, the SDT is a theory of human motivation.

The SDT studies the development and functioning of personality within social contexts. It is focused on psychological well-being, but it is concerned on the engagement of individuals in social contexts which explains personal development. This theory is based on three basic assumptions:

1. Humans are active (rather than passive), inclined to act in inner and outer environments, and engage in activities that interest them.

2. They are naturally inclined toward the integration of their psychic elements into a unified sense of self (personal coherence: autonomy) and the integration of themselves into larger social structures (interpersonal coherence: homonomy).

3. They thus have a set of basic psychological needs: competence, relatedness and autonomy.

These basic psychological needs are 'universal, innate, and essential for health and wellbeing' (SDT, n.d., II 3). However, people express these needs differently within cultures with different values (Ryan \& Deci, 2000). This idea is similar to the one about satisfiers that are context-dependent.

Once these needs are satisfied to some extent, true interests and values drive behaviour, that is, people behave not specifically to satisfy those needs but they do what is interesting and important (Deci \& Ryan, 2000, p. 230). In contrast, when needs are threatened people do not function properly and show evidence of ill-being in behavioural, interpersonal and mental health outcomes (Ryan \& Deci, 2006). These ideas are close to the one of Nussbaum about a minimum threshold, the one of the THN about the satisfaction of needs to avoid serious harm, and the one of the THSD about poverties and pathologies resulting from the no satisfaction of needs.

The SDT emphasises that people need supportive social contexts to reach their potentials. However, what matters is the person's perception of events or contexts, its psychological meaning (Deci \& Ryan, 1987), which is 'influenced by both contextual and personal factors and may in turn actually affect how the social context responds to the person' (ibid, p. 1033).

This theory complements the concepts previously presented because, in order to experience well-being, individuals have to feel that they can realise their needs (i.e., they are competent) in the context in which they interact because they value to be integrated into social structures (i.e., they value relationships). This also means that the capability set depends on the meanings of contexts that influence how each person can use the resources.

\subsubsection{A definition of human development}

After reviewing different approaches to assess well-being, it can be concluded that human needs and capabilities are similar terms if understood as valuable aspects of life that (i) require to be fulfilled at an appropriate level (negative notion) and (ii) demand to be actualised so that individuals can achieve a worthwhile life (positive notion). Then, the second part of the definition of human development introduced in Table 2-1, 'the expansion of valuable human potentials', can refer to both terms, for which there are well-thought ap- 
proaches. Although there is no full consensus about which are the priority potentials to be promoted, there is considerable overlap between the particular elements.

In addition, the definition of human development has to include other elements. First, as Nussbaum (2003a) asserts, dignity of many types has to be respected. Healthy adults, children and adults with intellectual disabilities, elderly people with senility or dementia, babies, all of them need to have their potentials promoted. Second, there is a concern for actual lives because as Alkire (2002, p. 19) affirms 'the fundamental objective... is not to produce opportunities, but to create meaningful and fulfilled lives'. These lives could be not only worthwhile but also enjoyable, which depends on how people perceive themselves and the relationships in which they engage. Third, improvements in well-being have to be sustainable (economically, socially, institutionally, and environmentally) for all so that future generations can profit from them. Therefore:

Human development refers to (i) a sustainable improvement in well-being or a positive change in the actual lives that people lead - that include objective and subjective aspects, and (ii) the expansion of valuable human potentials (capabilities) that secure a life with dignity for everyone in interaction with others.

\subsection{Autonomy: the concept and the details}

This section explores conceptions of autonomy and their link with human development. First, it presents some philosophical concepts. Then, it focuses on the approaches of human capabilities and of human needs. The SDT is discussed more extensively because it can be understood as a study of degrees of autonomy.

\subsubsection{A glance at philosophical concepts}

Autonomy (from the Greek auto = self or own, and nomos = rule or law) is related to selfdetermination. In ancient Greece, 'a city had autonomia when its citizens made their own laws, as opposed to being under control of some conquering power' (Dworkin, 1988, pp. 1213).

Individuals exercise autonomy when they rely on their own judgement about how to act, considering the contexts in which they engage. They need a capacity to reflect upon their motivations and accept or change them so that their actions are fuelled by authentic motivations. Individual autonomy can be analysed with respect to desires, preferences or actions.

\section{a) Autonomous desires}

Autonomous desires are those that individuals volitionally endorse at the highest order of reflection. ${ }^{7}$ This means that they consciously identify with their desires (Taylor, 1999) and these are effective in moving them to act. The reasons for this might be that:

\footnotetext{
7 The 'hierarchical models of autonomy' have been criticised by the issues of manipulation (i.e., a third party can inculcate desires into a person), regress-cum-incompleteness (i.e., what is the limit for levels of reflection?), and authority and $a b$ initio problem (i.e., why second-order desires are more indicative than first-order desires?). The conditions presented in this section are features that theorists included to these models trying to overcome those problems. See Taylor $(1999 ; 2005)$ for discussions on these and other issues.
} 
(i) Individuals are satisfied with those desires (Frankfurt, 1992; Bratman, 1996), that is, the desires belong to their motivational set or are compatible with their identities or long-term plans; or

(ii) The process through which they reflect upon their desires is independent (Dworkin, 1988), in the sense that those have not been produced by 'manipulation, deception, the withholding of relevant information, and so on' (Dworkin, 1976, cited in Taylor, 2005, p. 4); and

(iii) Individuals are aware of their personal history and accept that the process of desire formation depends on it (Christman, 1991) - because people form their desires in function to their previous experiences and circumstances.

For instance, Juanita who works as a volunteer in a day-care communal centre may suddenly desire to stay at home and not to go to work - her first-order desire is 'not to work'. However, she might then reflect that her work is important and that she would not feel well if she did not go so that she rejects that desire - her second-order desire is 'not to want not to work'. If she is really committed to her work and usually collaborates with her community (personal history), she will recognise this second-order desire as hers and will act accordingly. It does not mean that she will always do that (higher order reflection may not occur), but that this specific second-order desire is autonomous.

\section{b) Authorised preferences}

Ekstrom (1993) distinguishes between 'the self' and 'the true self' in order to define an authorised preference. The self is an evaluative entity that decides which preferences to accept. The self has beliefs that mark and distinguish the individual and has the power for fashioning and refashioning itself. The true self is a sub-set of the self in which preferences are coherent to each other.

An authorised preference, sanctioned as one's own, is one that coheres with the true self. Hence, the act is autonomous or authentic when there is an authorised preference regarding the desire moving the person to act. This notion is similar to the SDT's that assumes that individuals pursue personal coherence: a unified self. For those authentic acts people take responsibility (Ryan \& Deci, 2006, p. 1561).

In the case of Juanita, her desire 'not to work' was not an authorised preference because it was not coherent with her true self that values to collaborate with her community (i.e., this is good for her and coherent with her other preferences).

Other example is the one of Julio. He is a young father who cannot provide for his family because the harvest has been bad for the last years. He loves his family but he desires to work abroad as a manual worker to send money to his family and build up some capital for fertilisers and tools. First, this desire is originated by a subsistence need. Second, this desire is endorsed at a high-order level of reflection because it is good (to provide for his family) so that it belongs to his self. However, there is a conflict with other preferences that he has such as keeping the couple united, raising their children together, supporting them emotionally, and so on. Third, he realises deeply that he first needs to assure their physical survival so that 'to work abroad' is coherent with the love he has for his family and part of his true self. He is willing to face the risks to achieve this goal and feels responsible for his decision. 


\section{c) Autonomous actions}

For Taylor (1999), an autonomous action is motivated by an autonomous desire, for which the agent had an independent reason, provided by his or her motivational set.

In the case of Julio, his autonomous desire 'to work abroad' was based on his need to provide for his family and on the fact of not having other choices at home. His decision was restricted, not with an independent reason. If the harvest had been good, he would not leave his family. This is not an autonomous action. The more the work alternatives in his home country, the more autonomously he could act when deciding how and where to work. In this study, the focus is on autonomous actions which require authentic motivations. Then, enlarging Julio's work options, among others factors, is necessary to expand his autonomy.

With respect to reasons, there are two basic approaches: responsiveness to reasons and responsiveness to reasoning (Buss, 2002). The first approach considers a person autonomous if he or she can appreciate the reason he or she has (as Juanita who considers important the life in community). The second approach goes beyond; an autonomous agent has to have the capacity to evaluate the motives in what he or she believes and to adjust these motives in response to his or her evaluations. For instance, Juanita could consider that 'the government is going to cut the funds anyway so that voluntary work is not an effort worth making' and this evaluation could result in a change in her motives of 'not to want not to work'.

\subsubsection{What autonomy is not?}

This section clarifies the meanings of two concepts sometimes confused with autonomy: freedom and independence.

\section{- Autonomy is a special type of freedom}

Is freedom 'to do whatever one wants to do'? Frankfurt (1989) defines two types of freedom: 'freedom of action' and 'freedom of the will'. Freedom of action is equivalent to acting in response to wants or alien desires. In contrast, freedom of the will is related to autonomous desires, with higher-order endorsement. It means that the person is free to have the will he or she wants. For this, the person has to have reflective self-evaluation. Autonomy is closer to freedom of the will.

Frankfurt's definition is strong because, he argues, if a person wanted that will (that moves him or her to action) to be his or hers, it is not necessary to analyse whether the person had options to act otherwise (ibid, p. 73). The idea of freedom without alternatives is however hard to digest (Sen, 1996). It suffices to note that autonomy is more than acting on a wish.

Berlin (1969) distinguishes freedom into negative and positive. Negative freedom is 'freedom from' or the absence of interference to significant action (Berlin, 1969/1999, p. 39). This is an opportunity-concept or formal freedom. Positive freedom means being one's own master (ibid, p. 44) or exercising control over one's life. This is an exercise-concept or effective freedom that 'can be promoted... by putting [people] in a position to do things they would not otherwise be able to do' (Swift, 2004, p. 56)

However, Taylor (1979) deems this distinction misleading. He explains that a negative freedom requires the removal of external and internal barriers. The importance of the internal barriers depends on the significance of their purposes and whether they reflect authentic 
preferences. If these barriers are not authentic, individuals can remove them and expand their negative freedom. But this would require them to exercise self-understanding and to evaluate their own preferences, which is a positive notion of freedom linked to selfrealisation. Negative freedom in this case requires positive freedom (Taylor, 1979/1999, p. 162).

MacCallum (1967/1999) goes further and affirms that freedom is 'always of something (an agent or agents), from something, to do, not do, become, or not become something' (p. 102). Then, freedom is 'always one and the same triadic relation' (p. 100): $X$ is (is not) free from constraint $Y$ to do (become) $Z$. Scholars all have the same concept of freedom but they differ in what they identify as $X, Y$, and $Z$.

Sometimes a certain positive freedom is restricted in order to protect a negative freedom. For instance, a family can put bars on the door and windows of its house, restricting their freedom to enjoy the view to the street, to protect them from robberies. Likewise, transit rules restrict everyone to cross the street at certain times but are endorsed by citizens to live in society - here institutions impose rules that open up possibilities (Hodgson, 2006). However, the lack of these negative freedoms is not a serious problem.

At this point, two aspects are relevant to differentiate autonomy from freedom:

First, autonomy is a positive notion. People can restrain their negative freedom when they are committed to certain causes, while pursuing their own conception of the good:

What is valuable about autonomy is that the commitments and promises a person makes be the ones he views as his, as part of the person he wants to be, so that he defines himself via those commitments (Dworkin, 1988, p. 26).

Second, autonomy refers to significant aspects of life. Autonomy is not exercised in every matter but only on those aspects that have special significance (Taylor, 1979/1999; Doyal \& Gough, 1991). Kabeer (1999) refers to 'strategic life choices' that are critical for people such as the choice of livelihood, where to live, whether to marry and who, whether to have children, and so on (ibid, p. 3).

\section{- Autonomy does not imply independence}

The SDT (section 2.1.3) differentiates autonomy from independence. Dependence is 'reliance on others for guidance, support, or needed supplies' (Chirkov et al., 2003, p. 98). One can be dependent on another person because one decided to do so. Deci \& Ryan (2000) clarify:

Autonomy involves being volitional, acting from one's integrated sense of the self, and endorsing one's actions. It does not entail being separate from, not relying upon, or being independent of others (p. 242).

Christman (1998) further clarifies the distinction between autonomy and independence. First, a person is independent of 'something', so the factors from which he or she is independent must be stated. Second, no person is simply independent because people engage in dependent interactions, which partially defines one's identity and perspective (cf., Devine, Camfield \& Gough, 2006). For instance, a person can depend on his or her spouse to take meaningful decisions together, a religious person may willingly follow a priest's advice, a student can rely on a professor to analyse career options, and so on. Autonomy is in no way coherent with a view of human beings unattached and isolated who only rely on their self- 
conceptions, which are indeed related to others' perceptions (Christman, 2003), and their inner capacities to reflect and choose among alternatives. In fact, autonomy and dependence do not conflict with each other, except when certain 'factors and influences... disrupt or destroy one's ability to function as a unique person' (Christman, 1998, p. 386).

This links to the relational conception of autonomy, which explicitly recognises that autonomy is 'both defined and pursued in a social context [which] significantly influences the opportunities an agent has to develop or express autonomy skills' (McLeod \& Sherwin, 2000, p. 259). The authentic self is constructed throughout the process of exercising one's autonomy (Barclay, 2000), for which one requires 'socially supportive conditions' in conjunction with the internal sense of being autonomous (Anderson \& Honneth, 2005, p. 129-130).

Christman (1998) criticises that independence is quite often considered an attainable goal, in social policy analysis: It is said that welfare benefits should be cut off to make people 'independent from welfare states'. But the effects on autonomy could be quite negative as people could lack the conditions to achieve even a basic level of autonomy (without physical harm). Welfare benefits have indeed a role to avoid material deprivation and its negative effects on cognitive capabilities, self-reflection, emotions, motivation, work options and income distribution, opportunities of stable lifestyles and, fundamentally, on well-being.

On the other hand, autonomy is not equal to individualism. Autonomy requires inner endorsement and can exist in individualistic or collectivist cultures. Chirkov et al. (2003) explain that people who identify with a group may adopt values or behaviours 'that lend priority to that group, and, in doing so, they can be acting autonomously' (p. 107). Moreover, cultures are not divided in two fixed stable types; they are the result of persons coordinating their lives who interact exhibiting several lifestyles based on their positions in the social organisation (Douglas, 2004).

\subsubsection{Autonomy in approaches of human capabilities}

How do the approaches previously reviewed address the issue of autonomy?

\section{- Sen: freedom to choose}

Autonomy has a primordial role in the CA. There are three different terms that Sen uses to refer to autonomy, although not explicitly: ability to choose, agency and freedom.

First, Sen often stresses that people have reasons to value that define why they behave in a certain way. This suggests that he assumes that people can reflect and have certain 'ability to choose' (Carmen, 2000; Gasper, 2000a) so that they can select a particular functioning out of the capability set. If people had not this ability to choose they would not have a capability set at all; they would be functioning in the only possible way, defined by external factors. Having a capability implies having options, that is, having freedom.

For instance, Ignacia centres her life on her family and feels self-realised for raising her children; this is what she values. She had the economic means to get a university degree and pursue a professional career. She had a capability set with several options. In contrast, Soledad works in a city far from her home as a housemaid to provide for her children because her husband left to work abroad and never came back. She cannot choose to stay at home with her children; she is doing what she can to survive. She did not have a capability set. 
Second, the CA defines agency as 'the ability of people to help themselves and to influence the world' (Sen, 1999, p. 18). Sen considers two dimensions in which a life can be evaluated: well-being and agency. Well-being evaluation concerns objectives related to one's welfare, which could be affected by the well-being of significant others (sympathy). Agency evaluation concerns all objectives the person can pursue. It requires understanding the 'aims, objectives, allegiances, obligations, and - in a broad sense - the person's conception of the good' (Sen, 1985b, p. 203). In agency terms, the person is seen as a doer and a judge; while, in well-being terms, the person is seen as a beneficiary whose interests and advantages have to be considered (ibid, p. 208). The first perspective is agreeable to autonomy-respectful projects (see section 3.3).

Third, Sen (1985b; 1996; 2002/2003) distinguishes two types of freedom: process freedom or (procedural) control and opportunity freedom or (effective) power. Process freedom is the control that a person has over the process of choice. The person has relevant options and takes decisions, although he or she might not achieve his or her goals. The questions to identify this kind of freedom are: How are the choices executed? Who exercises the control? Opportunity freedom is the power that a person has to achieve his or her goals because either the person makes successful choices or the outcomes are caused by others. The relevant question is: Can the outcomes be achieved?

For Sen, individuals can make choices considering whatever objectives they have; functionings are valuable partly because they are result of choice. Moreover, 'both negative and positive freedom' (Sen, 1996, p. 112, [italics in original]) are relevant, as reflected by his analysis of process and opportunity freedom, respectively. However, it seems that autonomy would be a positive notion (cf., Peter, 2003; Quizilbash, 1996), including more than formal freedom and meaning more than being in control. It has intrinsic and instrumental value to promote human development.

\section{- Nussbaum: practical reason}

Like Sen, Nussbaum considers that the capability reflects choice, the opportunity to function in a certain way. In contrast, she considers that some freedoms (capabilities), which could be accommodated in Sen's approach, are not 'good'. Hence, only a set of priority freedoms are agreeable with human flourishing (Nussbaum, 2003a; 2003b). Her list of central capabilities reflects a possible set (section 2.1.2).

Nussbaum refers to autonomy in two senses. First, Nussbaum (2000; 2003b) affirms that a certain threshold of each capability has to be reached for every person. Before this happens, no capability is negotiable. After this happens, individuals can extend the capabilities more important to them by exercising their choice. Moreover, governments enhance choice by making opportunities available (Nussbaum, 1995a, p. 95).

For some people, realising their humanity (Crocker, 1995) might mean to live a religious life while others can form a family or pursue a good job. For example, María has a family and a professional career that requires her to be abroad for some weeks a year. Her achievement in both spheres of life depends on the support that her husband gives to her (e.g., whether he looks after their children when she is gone) and the relationships at work (e.g., whether her employer allows flexible work hours when she needs them and also offers her the option for promotions based on her merits). If she had these supportive conditions, she would be able 
to choose both valuable dimensions of life and to realise her potentials. Autonomy is then a combined capability - as all central capabilities in Nussbaum's list.

Second, Nussbaum (2000) includes 'practical reason' in her list of central capabilities. Practical reason is defined as 'being able to form a conception of the good and to engage in critical reflection about the planning of one's life' (ibid, p. 79). In an earlier version of her approach, she defined a lower threshold related to being able to choose and to evaluate and to function accordingly (Nussbaum, 1995a, p. 78).

Moreover, Nussbaum (2000) considers that practical reason and affiliation are the two most important capabilities (p. 82), in line with her conception of human being:

The core idea is that of the human being as a dignified free being who shapes his or her own life in cooperation and reciprocity with others... A life that is really human is one that is shaped throughout by these human powers of practical reason and sociability (ibid, p. 72).

Autonomy (re-interpreted from practical reason) has a social component because her exercise is possible in relation to others. Autonomy, even at a lower threshold, could be constrained by external contexts, not only by internal powers. This implies that changing the contexts in which people interact could effectively foster their individual autonomy (Burchardt, 2004).

Nussbaum does not consider it necessary to distinguish between agency and well-being for evaluative purposes, as Sen does. Crocker (1995) explains that for her, 'human well-being... consists only of those functionings that are both chosen and valuable, [and therefore] choosing, rather than a separate functioning, is integral to all valuable functioning' (p. 166).

\subsubsection{Autonomy in approaches of human needs}

What are the notions of autonomy in the three leading need approaches earlier reviewed? The emphasis is on the THN and the SDT because these explicitly regard autonomy as a priority basic human need.

\section{- $\quad$ The theory of human need: freedom of agency}

The THN gives a central role to autonomy, needed for successful participation in society (section 2.1.3). Autonomy has degrees and its improvement occurs over time. Elements of each level of autonomy are presented in Table 2-3.

Table 2-3: Elements of autonomy in the THN

\begin{tabular}{|l|l|}
\hline Level of autonomy & Elements \\
\hline $\begin{array}{l}\text { 1) Autonomy as freedom } \\
\text { of agency }\end{array}$ & $\begin{array}{l}\text { Level of understanding a person has about herself, her culture and what is } \\
\text { expected of her as an individual within it. } \\
-\end{array}$ \\
\hline $\begin{array}{l}\text { The psychological capacity she has to formulate options for herself. } \\
\text { The objective opportunities enabling her to act accordingly. }\end{array}$ \\
\hline $\begin{array}{l}\text { The capacity to compare cultural rules, to reflect upon the rules of one's } \\
\text { own culture and to work with others to change them. }\end{array}$ \\
The capacity to move to another culture if all else fails (in extremis).
\end{tabular}

Source: Doyal and Gough, 1991 (p. 60, 67, 187-188).

Autonomy as freedom of agency is the first level. Here, agency has a more specific meaning than for Sen; it refers to the ability to deliberate, choose and act purposively. The success of future actions depends on the actual achievement in physical health and freedom of agency when the action is made (Doyal \& Gough, 1991, p. 55). Autonomy requires the fulfilment of 
intermediate needs to some extent, while its expansion depends on its continuous exercise, which is possible by minimising the social constraints for socially meaningful activities.

Critical autonomy is the second level. It requires that individuals exercise freedom of agency with higher levels of reflection and that they enjoy political freedom. At this level:

[Individuals] can... adopt personal projects, develop relationships, and accept commitments to causes, through which their personal integrity and sense of dignity and self-respect are made concrete (Raz, 1986, cited in Doyal \& Gough, 1991, pp. 67-68).

Moreover, individuals with critical autonomy can promote significant social change in cooperation with others.

The THN includes four societal preconditions to ensure the survival and flourishing of human beings (Doyal \& Gough, 1991, p. 80): (i) the production of need-satisfiers; (ii) an adequate biological reproduction and child socialisation, to guarantee the survival of the culture; (iii) the transmission of skills and values, to promote cultural understanding; and (iv) a political authority that assures the learning and enforcement of rules.

Without these external conditions, autonomy toward successful social participation would not exist. Then, autonomy refers to positive freedom not only to the elimination of restrictions. The interdependence between individual capacities and external conditions renders this notion similar to Nussbaum's of combined capability. In addition, the THN acknowledges the importance of cultural awareness (Gough, 2003), which is partially captured in Christman's notion of awareness of personal history (section 2.2.1).

\section{- The theory of human scale development: self-reliance}

Max-Neef et al. (1991) asserts that self-reliance is not independence but horizontal interdependence without authoritarian relationships. Individuals having confidence on their potentials and capacities can pursue their own development in solidarity with others thus promoting participation and creativity and reinforcing cultural identity. Self-reliance is a 'metasatisfier' (Cruz Barreiro, 2006, p. 84) because it fosters development by supporting both individual and collective projects and promotes the actualisation of several human needs.

This notion of self-reliance is close to previous conceptions of autonomy (Nussbaum and THN) and the fact that autonomy is exercised in interdependent relationships.

\section{- The self-determination theory: degrees of autonomy}

The SDT analyses the degree to which behaviours are self-determined or 'people endorse their actions at the highest level of reflection and engage in the actions with a full sense of choice' (SDT, n.d., II 1). Every person develops degrees of more or less self-determined behaviours (Deci \& Ryan, 2000, p. 237).

Next, the following topics are discussed: self-perception of reasons to act, the determinants of relative autonomy, and the motivations to act.

a) Self-perception of reasons to act

The SDT differentiates between 'locus of control' and 'locus of causality'. In the first case, individuals have expectations about how controllable the outcomes are, whether (i) they can control the outcomes so that their actions prove and reinforce their self-efficacy, or (ii) the outcomes are explained by external circumstances (e.g., luck). Locus of causality concerns 
not only who controls the outcomes but also who causes the behaviour and why (Deci \& Ryan, 1985). Each perceived locus of causality (PLOC) corresponds with a causality orientation (Table 2-4). These orientations are relatively enduring aspects of personality; each one exists within each person to some degree, but one may prevail in different life domains.

Table 2-4: Causality orientations in the SDT

\begin{tabular}{|c|c|c|}
\hline PLOC & Causality orientation & Explanation \\
\hline Internal & Autonomy & $\begin{array}{l}\text { People experience a large extent of choice with respect to } \\
\text { the initiation and regulation of their behaviour, acting on } \\
\text { basis of interests and self-endorsed values. }\end{array}$ \\
\hline External & Control & $\begin{array}{l}\text { People experience events as controlling; they behave ac- } \\
\text { cording to external influences or how they should. }\end{array}$ \\
\hline Impersonal & Impersonal & $\begin{array}{l}\text { People experience their behaviour as being beyond their } \\
\text { intentional control (they cannot affect outcomes). }\end{array}$ \\
\hline
\end{tabular}

PLOC means perceived locus of causality.

Source: Deci and Ryan $(1985,2000)$.

\section{b) Determinants of relative autonomy}

Figure 2-5 shows the elements that determine relative autonomy. These elements can be autonomy-supportive if they encourage the process of choice, or controlling if they pressure toward specific outcomes. Contextual factors include external events and interpersonal contexts. External events are specifiable occurrences and are classified into three groups: informational, controlling, and amotivating. Informational events promote competence and autonomy, such as those that offer choice to agents and positive feedback. Controlling events exert pressure or condition behaviour such as rewards, deadlines, and evaluations. Amotivating events promote perceived incompetence.

Figure 2-5: The determinants of relative autonomy in the SDT

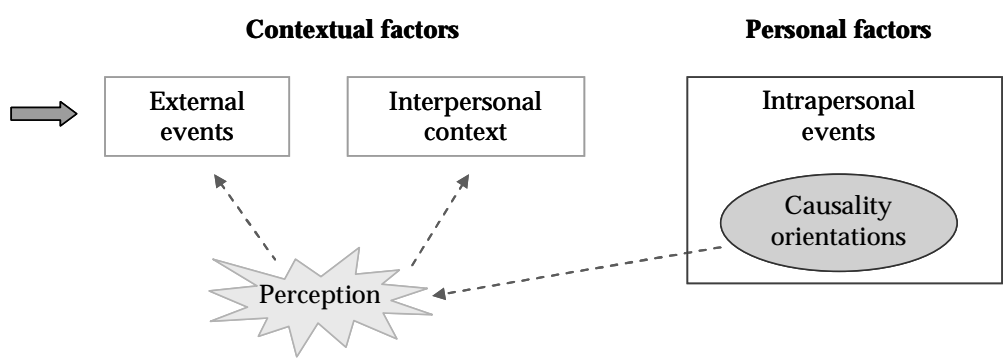

Based on Deci and Ryan (1987).

Interpersonal or social contexts are the environments in which events occur and action is performed. Positive feedback that could support competence and intrinsic motivation may be perceived as controlling if the context prompts an external PLOC (Deci, Koestner \& Ryan, 2001); the opposite case is also possible. For instance, in a reconstruction project, a person may face a controlling event such as working in a construction team to get a house (i.e., a performance-contingent reward) but the interpersonal context can be autonomy-supportive if the relationship with project staff is respectful and there are possibilities for learning new 
skills. ${ }^{8}$ The actions associated to such context can have different individual interpretations (e.g., some people could reject workshops) so that the effects on motivation and autonomy will vary among people.

Personal factors include intrapersonal or internal events and causality orientations. Intrapersonal events refer to actions originated within the person and can be caused by internal constraints of the personality (e.g., a person who forces him or herself to do something without any external obligation), thus depending on personal processes such as ego development. The perception of contexts is affected by the causality orientation of the person.

c) Motivations and internalisation of reasons to act

Actions can be externally or internally driven. Motivations in turn are of two kinds. Extrinsic motivation refers to goals of action that extend beyond the activity itself and are separable from this, such as pursuing rewards or avoiding punishments. Intrinsic motivation refers to doing the activity for its inherent value, that is, it refers to 'the inherent tendency to seek out novelty and challenges, to extend and exercise one's capacities, to explore, and to learn' (Ryan \& Deci, 2000, p. 70). Ellerman (2006) expands the notion of intrinsic motivation to include 'activities undertaken due to one's identification with a larger social group and one's own judgment about what is best for that community' (p. 37). ${ }^{9}$

Not all externally driven action is controlling per se. People can internalise reasons for behaving in certain ways so that they consider such behaviours as important and originated by them (i.e., autonomy causality orientation). The degree of internalisation depends on contextual and personal factors, and is fuelled by a process of integration. However, 'autonomy must emanate from oneself and can therefore only be facilitated by contextual events' (Deci \& Ryan, 1987, p. 1027).

\subsubsection{Comparing and integrating approaches}

Table 2-5 compares the conceptions of autonomy earlier reviewed. It does not include Sen's approach because it spells out neither a list nor a hierarchy of capabilities or the THSD because it does not further elaborate on self-reliance. Nussbaum and Doyal and Gough (THN) share a two-level structure for autonomy, but autonomy receives higher importance in the THN. In contrast, the SDT does not present two levels but several degrees of autonomy.

Contexts and external events have the potential to promote autonomous behaviour by supporting intrinsic motivation or the internalisation of extrinsic motivation, while people engage in project activities. For Ellerman (2006) the internalisation of conditioned changes or reforms in development aid would occur in exceptional cases (p. 47).

\footnotetext{
${ }^{8}$ Ryan and Sapp (2007, p. 76) extend the classification of social contexts. Because there are two other basic needs, competence and relatedness, contexts can also be classified as: effectance supporting (versus overchallenging, inconsistent or otherwise discouraging) or relationally supportive (versus impersonal or rejecting).

${ }^{9}$ In terms of the SDT, this motivation would be extrinsic but internalised through identification or through integration. In the first case, people would value the group goals and would accept them as personally important. In the second case, people would fully assimilate those values and consider them as congruent with their selves (Ryan \& Deci, 2000, p. 72-73). The SDT identifies a continuum of self-determined behaviours with different types of motivation, regulatory styles and locus of causality.
} 


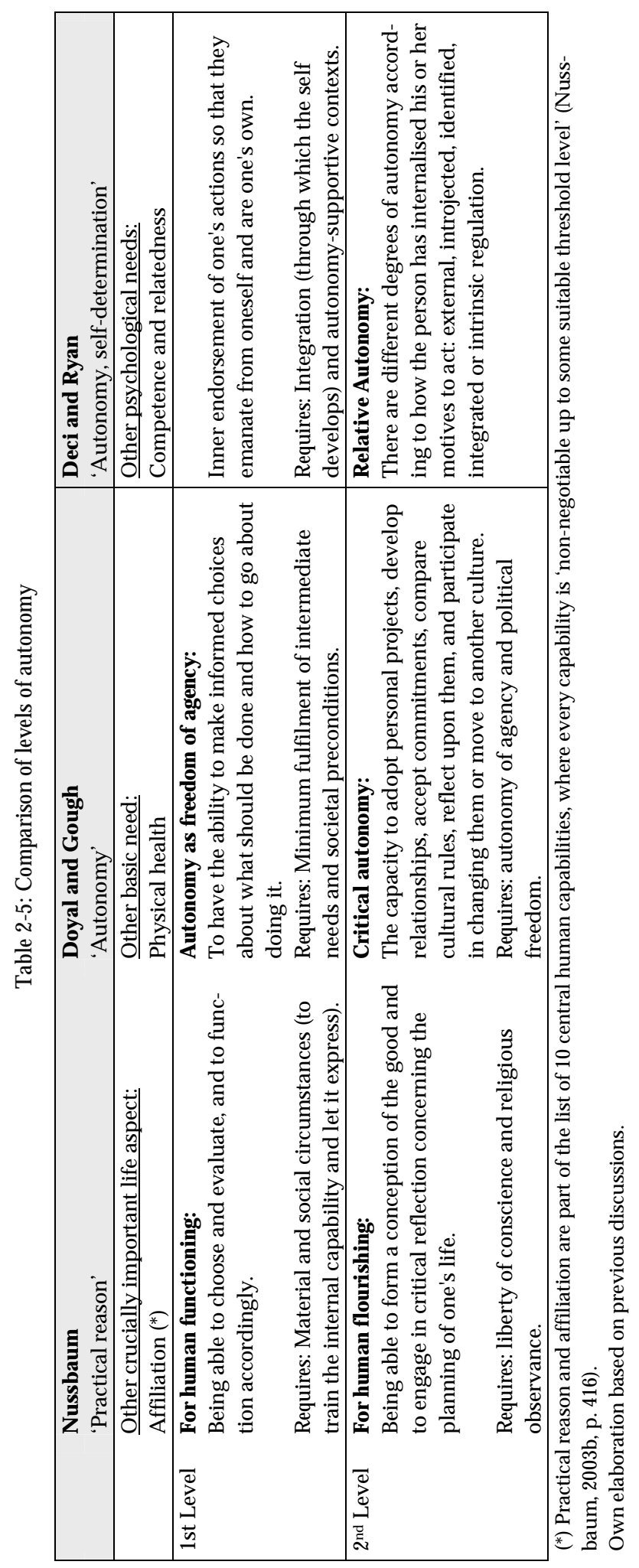


Ellerman (2006) uses a foreground / background model to explain motivation and autonomy. Autonomy means, he explains, that internal motivation is in the foreground although there could be extrinsic motivation in the background. For instance, people could work in self-construction activities for the welfare of their community (in the foreground) but also be receiving a minimum payment (in the background). If the subsistence need was threatened because the tough work conditions made it impossible for people to carry out other activities, the extrinsic motivation would pass to the foreground because it would be what helps to satisfy that need. It is then possible to introduce extrinsic motivation as long as it does not change the locus of causality.

Autonomy is a positive notion because people could willingly commit themselves to certain causes and reduce their negative freedom (section 2.2.2). The reasoning is that their future actions are tied to previous decisions (commitment) so that their set of options is reduced. This would not mean that the person was forced by external causes to follow a given path.

Nonetheless, personal commitments under certain circumstances could become obligations if there is a change in the locus of causality. In these cases, commitments would become controlling and reduce self-determination, in a process opposite to the internalisation of external events. For instance, communal leaders in a small rural village who enthusiastically started an organisation (i.e., committed with intrinsic motivation) could realise, years later, that their neighbours do not support them, that political authorities do not finance projects in the village and that their physical strengths are not enough for working in the plot and organising social activities. Under these conditions, they could perceive that their formal role of leader is a burden or unpleasant constraint that restricts their opportunities for pursuing other valuable goals.

In conclusion, based on this review, autonomy is promoted when the individuals perceive that they have or had options - if they freely committed to a cause in the past. It is necessary that they have covered their basic needs (i.e., to feel socially competent), developed social networks, experienced choice in previous occasions (so that they became aware of their own skills), and interacted in autonomy-supporting contexts. Autonomy is more than being in control, it is to be leading one's life. Thus, people may explore their potentials and pursue goals coherent with their true self, even pushing toward the change of current cultural rules.

\subsection{Individual autonomy: the conceptual model}

There is a long debate about agency and structure and which aspect has priority (e.g., Alexander, 1992; Archer, 2002; Booth, 1994; King, 2004; Long, 1992b, 2001; Long \& van der Ploeg, 1994). The conception put forward here is that both agency and structure are important and that autonomy depends on both.

This section proposes a conceptual model of autonomy, which focuses on three determining factors: agency, entitlements and structural contexts. Agency is an internal capability and autonomy is a combined capability (in Nussbaum's sense) because autonomy is exercised in external contexts. Figure 2-6 plots the conceptual model. 


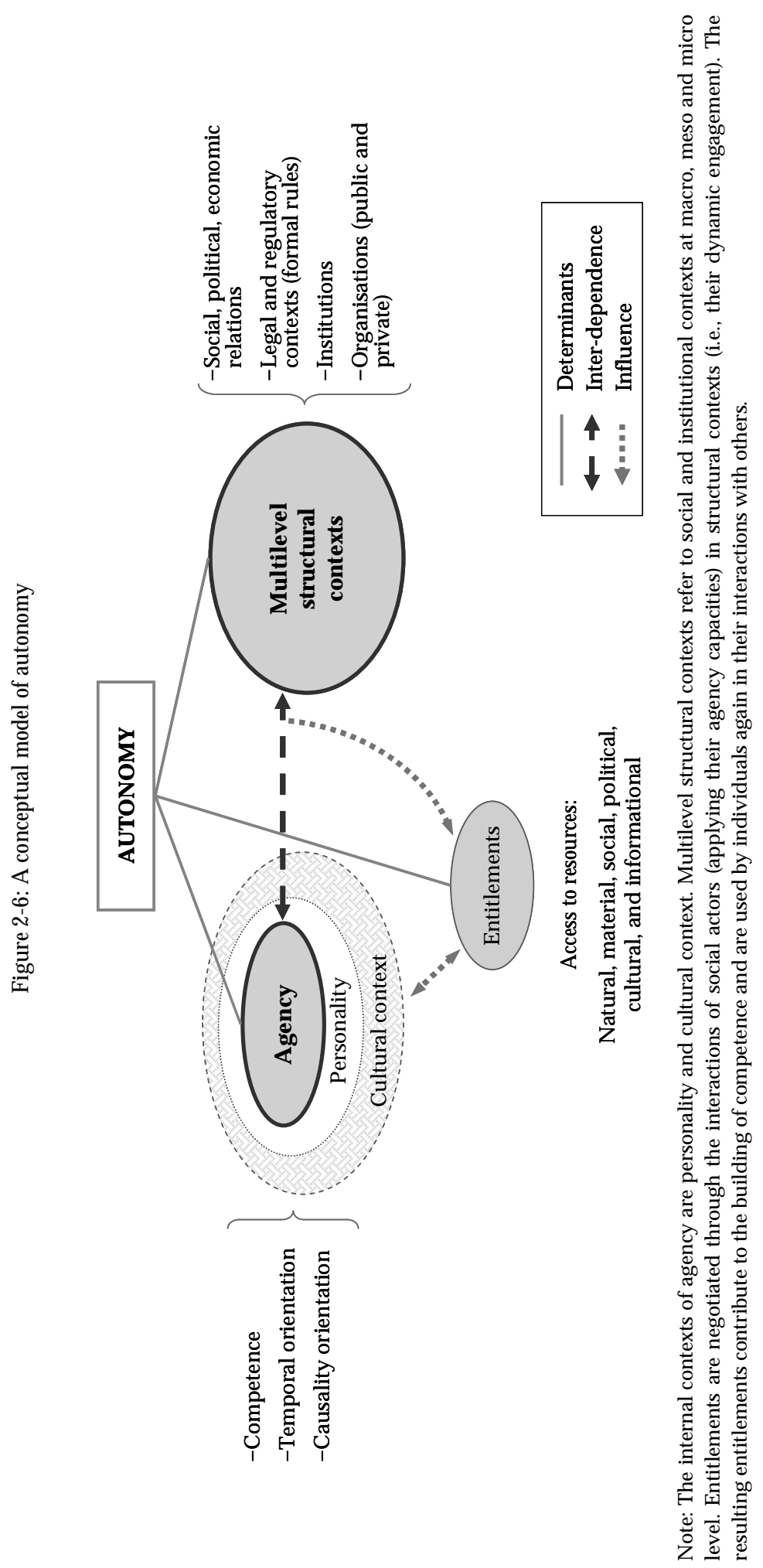




\subsubsection{Agency is a human capability}

Agency has been defined as the ability to act purposively. People can 'process social experience and to devise ways of coping with life, even under the most extreme forms of coercion' (Giddens, 1984, cited in Long, 1992b, p. 23). They attempt to solve their problems, consider contingent circumstances, act and monitor their actions and observe the reactions of others to their behaviour. They can redefine and organise their relations with others and be able to make a difference in the pre-existing state of affairs (Long \& van der Ploeg, 1994, p. 75).

In this study, agency is the internal capability of social actors to make reasoned choices and act accordingly. Agency is determined by personal competence, internal (or intra-personal) contexts that influence the nature and range of possible actions, and internal processes of agency that enable and explain the initiation of action. These determinants and the individual entitlements (negotiated in structural contexts) are the inputs to any possible action.

It is worth noticing that agency is a human capacity, inherent to social actors. Long (1992b) explains that social actors are not only individuals but also enterprises, political parties, community associations, religious organisations, and so on, if they 'have means of reaching and formulating decisions and of acting on at least some of them' (Hindess, 1986, cited in Long, 1992b, p. 23). Collectivities, agglomerates or social categories based on ethnicity, gender or economic situation are not social actors and do not have agency. This distinction is important for the discussion on 'community empowerment' at the end of this chapter. A community association and individuals living in a locality can become more or less empowered, but a 'community' understood as an entity independent of its members cannot.

\section{- Personal competence as a foundation of agency}

Competence is the capacity to perform well, to use one's personal capacities and reach goals. These personal capacities are physical, intellectual and emotional. Physical capacities include bodily health and strength and the absence of lasting disabilities. These capacities require the provision of universal satisfiers (THN) such as food, protective shelter, basic services, and health care services. Intellectual capacities include abstract thought, self-reflection, selfknowledge, literacy skills, and so on. The distinct intellectual capacities reinforce each other.

Emotional capacities influence intentional action significantly. Positive emotions support the sense of self-efficacy (Cleaver, 2007) and the capacity to aspire (Appudarai, 2004) or imagine positive future scenarios that expand the range of feasible options, while negative emotions could harm the decision-making by blocking other capacities. Ryan and Deci (2001) argue, based on research by Sheldon et al. (1996) and Ries et al. (2000), that fluctuations in experiences of fulfilment of autonomy and competence explain fluctuations in positive affects (p. 151). Emotions could trigger non-reflected actions with regard to objects important to the individual, although some people could manage and express their emotions in different situations more intelligently and empathetically than others. ${ }^{10}$ However, both conscious and unconscious emotions characterise a person's subjectivity and promote connectedness with others (Mumby \& Putnam, 1992).

\footnotetext{
10 'Emotional intelligence', in: Oxford English Dictionary Online, Draft entry, March 2003. Retrieved March 10, 2008 from http://dictionary.oed.com
} 


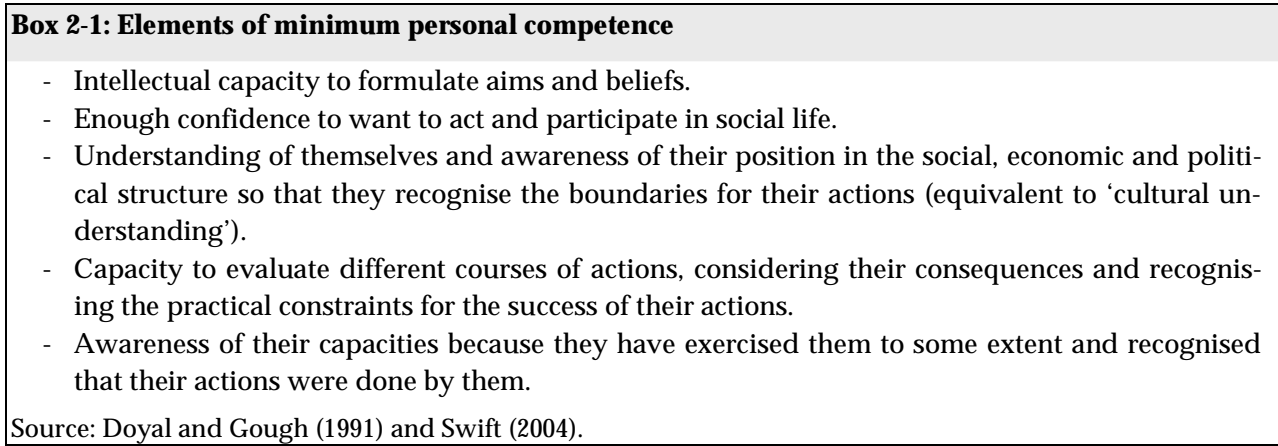

Every adult human being is endowed with minimum competence to make choices (Doyal \& Gough, 1991, p. 52; Nussbaum, 1995a, p. 78). Box 2-1 presents some elements of this competence. Feinberg (1989) explains:

Some competent persons are no doubt more richly endowed with intelligence, judgement, and other relevant capabilities than others, but above the appropriate threshold they are deemed no more competent (qualified) than the others at the 'task' of living their own lives according to their own values as they choose (ibid, p. 29).

Two qualities latent in all human beings require to be especially supported in order to fuel autonomy: self-confidence and the capacity to aspire.

First, self-confidence is essential for autonomy because people's perceptions of themselves and their efficacy influence their objectives, aspirations and perceptions about the opportunities and risks in the external environment (Bandura, 2000). Self-confident people trust their capacity to make appropriate choices, to act on these decisions and generate outcomes (McLeod and Sherwin, 2000). They are more likely to pursue their goals and to be happy (Diener \& Biswas-Diener, 2005). Their perceived agency (section 2.3.2) is higher.

Moreover, self-confidence is associated to relatedness and intrinsic motivation. Doyal and Gough (1991) relate self-confidence to pro-social attitudes, altruism and generosity (p. 65). However, solidarity cannot be taken for granted in collective action. Not all kinds of collective action promote individual autonomy, only the one that supports human learning and cooperation does (Carmen, 2000). This kind of collective action also fuels a sense of collective influence on the social conditions of one's life (Cleaver, 2007).

Second, the capacity to aspire is a 'cultural-meta capacity' (Appudarai, 2004, p. 82) because it results from social interactions of individuals over time and place, and it fuels the building of other capacities by individuals themselves. In addition, this capacity is reinforced when autonomy is enhanced as authentically motivated people devise plans to realise their aspirations in the world. In this way, 'the boundaries for their actions' can expand.

\section{- Internal contexts give character to agency}

Alexander $(1992,1993)$ identifies two internal contexts of action: the cultural context and the socio-psychological context (i.e., the personality). Figure 2-6 shows them as concentric circles around agency to indicate that they influence agency and that the cultural context (larger circle) is filtered by the personality that gives it meaning. 
Culture integrates the historical experiences of a specific human collective in symbols, values, norms, artefacts, and ways of living together. It is acquired, learnt, transmitted, and reinvented by actors in society. Culture is 'a set of distinctive spiritual, material, intellectual and emotional features' (UNESCO, 2002, II 5), which inform subjectivities and is then part of what social actors are or their identities.

Hence, authorised preferences that cohere with one's true self (section 2.2.1) are influenced by the cultural context. This context shapes the individual motivations and the strategies used by people to reproduce and transform meanings and resources in order to pursue their goals in society (Cleaver, 2007). Since values are informed by culture, autonomous actions (value-laden decisions) also depend on culture (Kabeer, 2000), but diverse individuals can endorse the same values to different extents because they have unique histories and personalities. They are 'persons-in-relations' (Nelson, 1996, cited in Kabeer, 2000, p. 327).

The socio-psychological context results from individual mental and emotional processes that go beyond the objective intellectual capacities of the actors and depend on their unique character, their specific life experiences and their cultural contexts. In terms of the SDT, this context explains the intrapersonal events. In plain language, it reflects the personality.

Individuals belong to several groups in their lifetime and perform different social roles so that they have several identities that arise in specific situations. Then, labelling individuals in categories such as 'women', 'farmers', 'the poor' or 'non-leaders' (i.e., assuming uniformity) can hide and misinterpret the particular meanings of contexts and motivations (cf., White \& Pettit, 2004). This point must be taken into account for the empirical study.

\section{- The internal processes of agency can tell about motivations}

Two internal processes are relevant for autonomous action: temporal orientation (Emirbayer \& Mische, 1995) and causality orientation (Deci \& Ryan, 1985; 2000).

Temporal orientation is relevant because action occurs through time. People understand their own relation with the time differently and show varying degrees of creativity and reflection when engaging in contexts. Their insights change over time so that behaviours may adjust. On the other hand, human beings interact with others in different situations at the same time - a capacity called 'sociality' by Mead (1932, cited in Emirbayer \& Mische, 1995, p. 968). They may make decisions in each situation taking into account different perspectives about their competence to affect outcomes in the future. In some cases, people would behave as usual (looking at similar past experiences), while in others they would rely on their inventiveness to explore future options.

Temporal orientation is the tendency of individuals to focus on the past, future or present when they analyse the possible course of an action. Accordingly, agency has three elements in relation to which temporal orientation is dominant in explaining action. First, the iterational element gives stability and order to internal contexts. Second, the projective element fuels imagination and creativity in relation to the individual's hopes, fears, and desires for the future. It feeds the capacity to aspire that, when expressed in voice and participation, 
fuels development. Third, the practical-evaluative element supports practical and normative judgements based on emerging conditions. ${ }^{11}$

People's temporal orientations may vary according to the area of life in which the action occurs. For instance, in the societal domain, people can make family decisions with iterational agency (e.g., endorsing norms and not deviating), while they can make business decisions with projective agency (e.g., envisaging alternative trade scenarios in which a new agricultural project could fit).

Causality orientation, a concept taken from the SDT (section 2.2.4), refers to what the person understands are the reasons for performing an action, either external reasons (control orientation), internal reasons (autonomy orientation) or no reasons (impersonal orientation). Although this orientation is more or less stable, it is based on previous life experiences and new events that bring significant consequences to individual well-being. An improvement of the autonomy causality orientation has a meaning similar to subjective or psychological empowerment (see section 2.4.1).

Looking at causality orientation in a study of autonomy is crucial because, for instance, people can make reasoned choices and act accordingly (i.e., exhibit agency) even when their choices are based on rewards or punishments. It is necessary to understand the reasons why people make certain decisions, especially in the contexts of aid projects that require a multiplicity of activities from local people. For instance, a person who collaborates in the maintenance of communal social infrastructure because people from abroad would visit (control causality orientation) is much likely to stop this behaviour if he or she perceived that visitors would not arrive anymore. This brings consequences to the sustainability of that infrastructure, in addition to reflect a lack of group identification.

\subsubsection{The relationship between agency and structural contexts}

Agency is not the same as action as not all actions are reflected. There is no action independent from its context or an action fully determined by this. In fact, individuals have variable capacities to engage in significant actions with others within contexts and to affect them. They also relate to contexts in different ways and exercise different degrees of autonomy. This section explains the concept of multilevel structural contexts, underlines the role of entitlements and introduces the notion of perceived agency.

\section{- Multilevel structural contexts: complex and crucial to support autonomy}

The multilevel structural contexts are the external contexts or the social structures in which individuals negotiate their roles, meaning systems and entitlements (Alexander, 1993). These contexts can be analysed at household, group, community, local, national or international level. Individuals interact at the same time in different contexts which are interrelated and on which they have influence. In fact, these (socio) structural contexts comprise all sets of social relations (economic, political and associational) coordinated with stable or sporadic, formal or informal rules. Institutions and organisations are elements of these contexts.

\footnotetext{
${ }^{11}$ Each element is oriented simultaneously to several temporal dimensions but one prevails. The iterational element is basically oriented toward the past. However, individuals with this primary orientation constrast their previous experiences to current contingencies in order to produce stable expectations, in coherence with their long-lasting identities.
} 
Institutions are 'systems of established and prevalent social rules that structure social interactions' (Hodgson, 2006, p. 2). These rules include laws, regulations, norms and customs that influence the outcome of social actors' actions or what they can achieve (Holland \& Brook, 2004; Bastiaensen et al., 2005). Organisations are a particular type of institution that have certain embedded rules of communication, membership and sovereignty (Hodgson, 2006). Organisations at several levels include public and private associations, civil society, NGOs and so on. In the localities studied, the functioning and inclusiveness of each community organisation and the within-group interactions (Siegel, 2005) are defined in contexts by formal and informal rules.

These contexts are autonomy-supportive when there is no coercion (i.e., people do not act due to external demands), when understandable and timely relevant information is shared, and when there are meaningful and attainable options so that social actors can act based on authentic motivations. In these situations, if individuals have agency (as internal capability) they can take responsibility for their actions because these would be their own.

\section{- Entitlements: their meaning is defined by their possible uses}

In contrast to empowerment frameworks (e.g., Alsop \& Heinsohn, 2005; Holland \& Brook, 2004) and livelihood approaches (e.g., Moser, 1998, Carney et al., 1999) that directly refer to assets or capitals, this conceptual model makes explicit that individuals require entitlements to resources for exercising autonomy and reaching goals.

Entitlements support the development of competence. However, individuals may need to negotiate them with other individuals within socio-structural contexts. As people engage in interdependent but unequal relations, their access to resources is also unequal, depending on their personal characteristics and circumstances that define conditions of negotiation and constraints - 'entitlement relations' (Sen, 1982) and 'terms of recognition' (Appudarai, 2004). Hence, the opportunities to enhance agency and autonomy also differ for individuals in different settings.

The definition of entitlement used in this study is broader than the legal one, which guarantees the right for certain people to benefit from resources (e.g., ownership rights, social welfare benefits). For instance, a person could be entitled to use the community centre just because he or she is resident of a village not due to legal ownership. The addition over Sen's extended notion (section 2.1.2), which already includes social aspects, is the treatment of resources. Entitlements are not only to commodity bundles but also to intangible resources. Moreover, resources have meaning by the purpose assigned to them (White \& Ellison, 2007).

Resources are classified as natural (e.g., land, forests, basins), material (e.g., credit, savings, equipment, infrastructure, labour wage), social (families, relations and networks), cultural (e.g., race, ethnicity, language), political (e.g., authority, voice, citizenship), and informational (knowledge).

All aspects related to human skills that allow the exchange of entitlements are part of personal competence in this model (other approaches introduce human capital and psychological assets to the portfolio of resources). In contrast to natural resources, material resources result from the action of human beings so that these include physically-transformed resources based on natural resources, human skills and technology. 
Social resources are the relations in which individuals engage to facilitate their access to other resources (Gough et al., 2007). Some people rely on others who are more experienced or powerful, to act in their interests. Bandura (2000) calls this 'proxy agency' (p. 75). However, relations are not always permissive (based on solidarity and cooperation) but abusive. Individuals invest in relations by applying their entitlements (Copestake, 2007); although they might compromise other valuable ends in order to secure their access to priority resources. Once entitlements are negotiated, they are used by individuals thus determining their chances to participate successfully in structural contexts. In fact, social relations are reinterpreted and re-enacted through interactions (De Herdt, 2006).

Cultural resources are symbols or personal features indicative of meanings that 'can be deployed in negotiations over the value of endowments' (Gough et al., 2007, p. 20). Culture plays a double role; it is a resource and is part of the internal context that influences the definition of entitlements and the feasible actions (White \& Ellison, 2007, p. 167). Cultural resources include personal characteristics such as age (e.g., older people could have more authority than others in some settings), physical appearance, origin, and religious and political affiliation, that influence status. In turn, it is based on several factors such as social roles, interpersonal relations in the locality and in upper-level contexts, relative wealth or behaviours that produce respect, esteem and deference (Uphoff, 2005, p. 225).

Social status has influence on what people can do (Holland \& Brook, 2004). For instance, a member of a family with good reputation might be better informed and more involved in actions promoted by external actors such as aid projects. Moreover, maintaining social status and prestige requires effort to feed interpersonal relations. For instance, there may be things that a well-raised young woman cannot do in a rural village, such as interacting in recreational spaces, without her husband.

Political resources are those rights and resources that individuals can activate in order to have access to decision-making in the political process (Rakodi, 1999). They are used to promote goals that are likely to face resistance from others (Baumann, 2000, p. 22) because they may transform power relations or the structure of rights. Political resources are based on social resources because individuals need others to enact their political action - to mobilise common resources and energies.

Political resources may include relations with public officials and donors, associational membership, authority roles or public employment. People endowed with resources such as status or wealth can influence government policies. Political resources facilitate the exercise of critical autonomy because the initiation of significant social change, in most cases, requires addressing authorities at local and national levels. When trying to influence government policies, social actors take advantage of resources broadly available to all, such as state fiscal capacity and state internal organisation, and specific situations, such as competition between local and central governments and political pacts (Birner \& Wittmer, 2000).

Informational resources basically refer to knowledge about relevant matters, acquired and built through different channels. It includes, for instance, scientific knowledge acquired through reading and study, strategic knowledge about the functioning of a particular community acquired through experience as leader in a communal organisation, and practical inter-cultural knowledge learned through contact with foreigners or trips abroad. These resources could become political resources as they could have implications on voice and 
authority. However, they are considered a particular resource-category because a requisite to make meaningful decisions is to be reasonably informed. Likewise, Narayan (2002, p. vi) points out that the access to information in areas such as state and private sector performance, financial services and markets, and rules and rights regarding basic services, are almost always present in successful experiences of expansion of autonomy supported by structural contexts.

There are interrelations between entitlements. For example, 'groups that lack assets tend also to lack voice, security, and a stake in the larger society' (World Bank, 2002, cited in Siegel, 2005, p. 10). In these conditions, they would negotiate entitlements in structural contexts with low chances of success in front of power-holders. Even capable actors (with optimum intellectual and emotional capacities) could fail to improve their access to resources if they lack material, social and political resources. This in turn affects how the institutional context is able to respond to their needs.

\section{- Perceived agency influences individual behaviour}

Agency has been defined as the internal capability of social actors to make reasoned choices and act accordingly (section 2.3.1). Given that agency is an inherent feature of human beings, a person who do not exercise it, frequently, might feel not capable or do not trust his or her competence to make choices.

Therefore, it is perceived agency what most influences individual behaviour. Although it has a concrete foundation in personal competence, the contexts in which people interact affect their self-perception, the negotiation of entitlements, and internal processes of agency. As seen earlier, causality orientation also influences the perception of contexts (SDT). Consequently, objective and subjective factors behind certain attitudes and behaviours must be taken into account as they, together, explain social participation. Supporting self-confidence and aspirations makes complete sense as they allow the awareness of personal capacities and promote the initiation of change. Chapter 11 explores these issues.

\subsubsection{Autonomy is a combined capability}

To develop a deeper characterisation of individual autonomy, it is necessary to underline two main features (section 2.2). First, autonomy is not detached from relatedness. Social networks, as both resources and players in structural contexts, can support individual actions. Moreover, when relatedness (and competence) is a result of autonomous behaviours, people will display optimal engagement and psychological well-being (Deci \& Ryan, 2000, p. 243).

Second, although structural contexts shape values and opportunities, autonomy is an individual feature of unique human beings with their own biographies, emotions, aspirations and commitments. As Christman (1998) affirms, 'the autonomous person is one who acts, chooses, and judges for herself (however complex, embedded and interconnected with others that self turns out to be)' (p. 387).

In line with these findings, the conceptual model proposed distinguishes three determinants of autonomy: entitlements, agency and structural contexts, which are interrelated. It acknowledges that perceived agency primarily influences individual behaviour. Then, how different is autonomy from agency? 


\section{- Autonomy as qualified effective agency}

Autonomy is the combined capability of social actors to make choices in significant matters and act authentically motivated, in coherence with their values and personality, by applying their agency in structural contexts that may promote or restrict purposive action.

This definition contains new elements with respect to the definition of agency previously proposed. In fact, autonomy can be considered as qualified effective agency.

First, autonomy is an effective agency because individuals can exercise decision-making after taking into account the structural contexts, if they so decide. It means that the nature of relations in the social contexts and their effects on agency and entitlements are important.

Second, autonomy is a qualified effective agency because autonomy refers to actions that (i) concerns significant aspects of life (valuable for the individual) and (ii) cohere with values and personality and for which individuals are authentically motivated (not controlled or pseudo-motivated). No person exercises autonomy in every decision that is made.

Regrettably and most likely, individual free choice in significant aspects of life could face opposition from powerful actors. Therefore, assessing individual autonomy requires to look beyond perceived agency as an overall self-evaluation of decision-making capacities and to focus on opportunities for significant decision-making taking into account the multilevel structural contexts in which people live. As Dworkin (1988) puts forward, autonomy is more than a reflection capacity and an authenticity of goals; it is about being able to enact those goals and change one's circumstances, if one so chooses (Dworkin, 1988).

People exercising their autonomy develop different strategies to pursue their goals and to enrol others in their personal projects (Long, 1992b). They use their entitlements and relations. Moreover, entitlements are renegotiated and different social practices emerge. It is then necessary to understand these practices, which might differ even for individuals in the same geographical community.

Those practices might change as result of a new situation that leads to a rearrangement of power. For instance, a foreign aided project with the participation of external social actors (e.g., project staff, NGO, public agencies) might not include the activities and processes originally planned in the 'logical framework' (see section 3.2.2) precisely because local actors would find ways to reshape the project, if they find it valuable. Even the most deprived people can create 'room for manoeuvre' (Long, 1992b, p. 36) so that an expansion of autonomy can be evaluated in function to the change in room for manoeuvre or the reduction in barriers (Drydyk, 2006) for authentically motivated action.

\section{- Basic and critical autonomy}

Following Nussbaum (2000) and Doyal and Gough (1991), this model propose to differentiate two layers of autonomy (see Figure 2-7). 
Figure 2-7: Autonomy as combined capability and the layers of autonomy

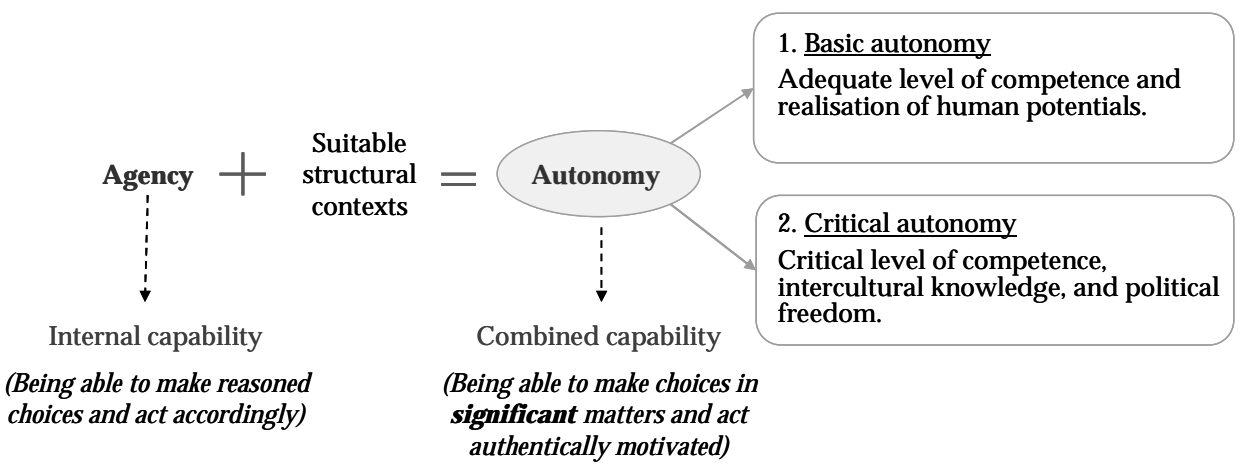

Basic autonomy requires a certain level of competence (section 2.3.1) and achievement in human capabilities (negative freedom) so that people can search for what is really important to them. The level of competence that is necessary for people to effectively participate in social life depends on the particular cultural setting.

Critical autonomy requires a higher level of competence, intercultural knowledge, and political freedom so that individuals can realise the capabilities that they choose, in structural contexts that may support or restrict an authentically significant change.

How do these two layers related to those proposed by Doyal and Gough? Critical autonomy has the same meaning in this conceptual model than in the THN. Basic autonomy here corresponds to autonomy as freedom of agency. The main difference is that agency in this conceptual model is an internal capability, while agency in the THN is a combined capability because it requires certain societal preconditions.

\section{- Autonomy and human development}

There are two main channels to denote how autonomy is related to human development. First, human development promotes autonomy because it expands human potentials and people's opportunities to participate in social life. People are more competent and have more options to choose. Second, autonomy supports human development because it makes possible for people to be their own masters. If necessary, they can enact significant social change in coordination with others to pursue common goals, improving their present and future wellbeing.

These observations imply that the promotion of autonomy and human development can go in parallel and that autonomy actually improves the quality of human development because people feel development as their own. Nevertheless, the poorest and most excluded people in many occasions cannot choose and access to certain crucial resources. Then, promoting a truly human development requires helping them to exercise their voice and changing the terms in which development as merely material progress has been pursued (cf., Carmen, 2000; Max-Neef et al., 1991). 


\subsection{Empowerment: the means to promote human development}

Having defined autonomy, the next step is to think in ways to expand it. Facilitating the access to resources, improving personal competence and opening up opportunities in the structural contexts can help people to exercise autonomy to pursue their goals.

Empowerment is a popular concept related to this process. It has been broadly discussed (e.g., Narayan, 2002; Alsop, ed., 2004; Narayan, ed., 2005; Alsop, Bertelsen \& Holland, 2006) although sometimes overused given its relatively imprecise meaning. This section clarifies the links between autonomy and empowerment in light of this conceptual model. Then, the issue of community empowerment, especially of poor people, is taken up.

\subsubsection{A definition of empowerment}

For the World Bank, 'empowerment is the process of increasing the capacity of individuals and groups to make choices and to transform these into desired actions and outcomes' (WB, n.d.). It is assessed in terms of three degrees (Alsop et al., 2006):

(i) Whether a person has the opportunity to make a choice;

(ii) Whether a person actually uses the opportunity to choose; and

(iii) Once the choice is made, whether it brings the desired outcome.

In this study, autonomy stands on the first degree or the existence of options and in the second degree or the exercise of choice. Empowerment refers also to the third degree so that empowerment can be understood as the expansion of autonomy evidenced in the degree of effectiveness of authentically motivated actions. ${ }^{12}$

Nonetheless, assessing whether people have choice (first degree) might be more relevant than observing actual actions and concluding about their effectiveness. Behaviours are not always product of authentic motivation, that is, people do not necessarily have autonomy causality orientation and endorse their actions and their possible consequences, feeling responsible for them. Let's take the example of the inhabitants of a small village invited to attend a general assembly in which important investment decisions would be made with the presence of potential donors. Some people could willingly not attend the meeting to signal their discontent toward the community organisation (like an expression of protest), while others could attend because they did not feel that could oppose leaders in any way. In the first case, staying away was a reasoned choice; while, in the second case, attending was a conditioned action - probably led by unequal power. However, this second case could be wrongly interpreted as free choice driven by an important reason related to community development.

On the other hand, not all options are valuable and not all matters are important. With respect to the valuable matters, it is relevant to analyse whether people are able to bring their goals about. Three questions (based on Sen, section 2.2.3) help to analyse this:

\footnotetext{
${ }^{12}$ Alkire (2005) considers that empowerment 'is related to, although not synonymous with, an increase in human agency' (p. 220). Here, the expansion is in autonomy not in agency because empowerment requires an enhancement of internal capacities and more supportive structural contexts that open up valuable opportunities to improve well-being.
} 
(i) Do people act in pursuing their objectives? This is related to process freedom or control over how the decisions are made. The focus is on how people live their lives, whether they exercise autonomy or not.

(ii) Do external influences produce the expected results? Outcomes may be caused by factors other than an autonomous action. Actors could have opportunity freedom because the outcomes of actions made by others are favourable to them (similar to their goals).

(iii) Does the action produce the expected results? A positive answer would tell that the person had control over the process of choice and achieved the intended outcomes. The focus is on both process and outcomes.

The analysis of empowerment focuses on the third question, but the other questions are also relevant. For example, a housing project would be importance if it provides physical security. This is the case even if the project beneficiaries did not elaborate the project proposal, did not choose the house design or did not work in the construction activities. It is desirable that people enjoy positive outcomes or results even if they do not participate in the process to achieve them. Their well-being and agency will be enhanced.

For this reason, an instrumental goal of development is 'the expansion of autonomy' and not only 'empowerment'. However, empowerment should be of priority because it supports the capacity of people to effect change in their own lives. If people consider that their actions have real positive outcomes, their self-confidence to initiate actions will improve. In the context of aid projects, the degree of this positive effect on autonomy depends on the role that participants had and their motivations to participate. Chapter 10 explores these issues.

Figure 2-8 shows the links between autonomy and empowerment. First, people exercise autonomy in significant aspects of their life with a given objective, to reach certain outcomes. Second, their actions can have varied effects on entitlements, agency and structural contexts. Third, the outcomes of such actions might not be in line with the initial goals and expected outcomes (based on what is feasible given the resources at reach and competence). The degree of effectiveness may vary across individuals and domains and people will try to find reasons for success or failure.

Figure 2-8: Autonomy and empowerment

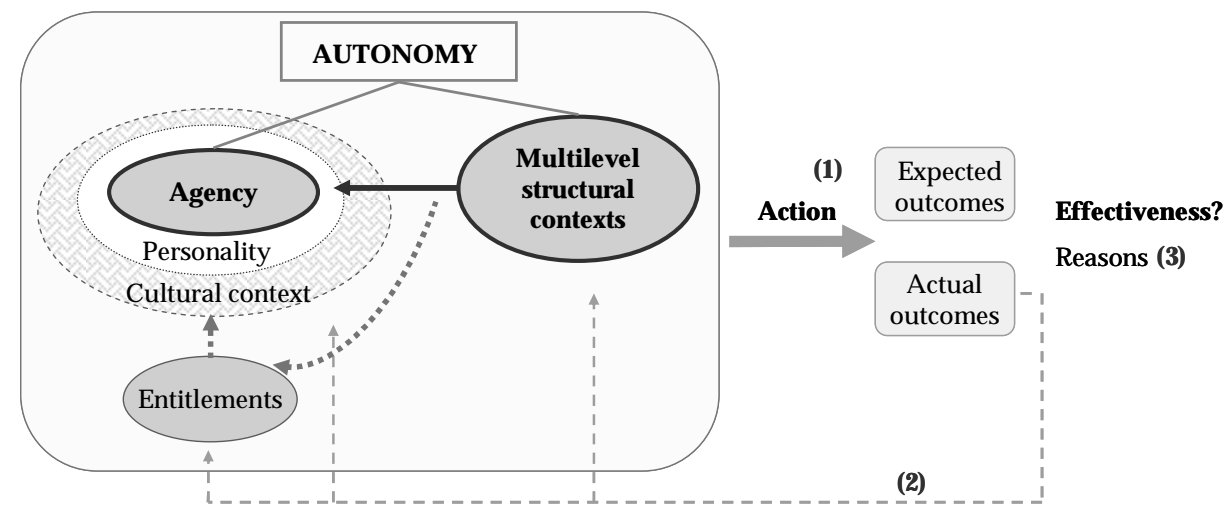


Therefore, thinking in terms of empowerment and outcomes of valuable decisions brings the distinction ex-ante and ex-post to the conceptual model of autonomy. This temporal distinction is also necessary to assess changes in autonomy related to aid projects.

Given that autonomy can be expanded by several sources, it is necessary to clarify that:

- Empowerment can be promoted by expanding the access to resources, although whether and how people will use these resources depends on the dynamics of structural contexts, that is, how entitlements are negotiated.

- Empowerment is promoted when individuals improve their self-confidence, become aware of and/or increase their personal skills, so that they can better exercise their autonomy.

- Empowerment is seen when individuals exercise decision-making in valuable aspects of their life, they feel responsible for the consequences of such decisions because they were authentically motivated, and (i) they are able to defend these decisions in the face of opposition (cf., Drydyk, 2006) or (ii) they are able to make reinforcements, so that positive outcomes are sustained.

Given that many factors can explain outcomes and people make decisions based on the information at their reach (which is not complete), autonomous actions might not be effective. However, people could still feel empowered if they recognised that the causes for the gap between expected and actual outcomes were beyond their efforts. Nonetheless, recurrent failures could harm autonomy causality orientation and aspirations. At this respect, Cleaver (2005) indicates:

Of course poor people are not incapable of exercising agency, nor do they have any less potential capacity than others for self-consciousness and reflection, for constructing purpose and meaning in social relationships or for originating acts. However, I suggest that these potential capacities are constantly, routinely, and indeed systematically frustrated by the workings of inequitable social and economic structures and the institutions through which social norms and values are channelled (Cleaver, 2005, p. 895, [italics in original]).

This frustrated exercise of autonomy has negative long-term consequences for well-being because people could search for 'compensatory activities or substitute fulfilments' (pseudosatisfiers in Max-Neef's terms) and 'step up their efforts' to exercise autonomy (Deci \& Ryan, 2000, p. 231).

Narayan (2002) proposes an alternative definition of empowerment as the expansion of assets and capabilities of poor people to participate in, negotiate with, influence, control, and hold accountable institutions that affect their lives' (p. vi). Narayan adds that empowerment has four key elements that act in synergy: access to timely and understandable information, inclusion and participation, accountability, and investment in local organisation capacity. It seems that the focus is on a specific domain: the state and the relations of poor citizens within its formal structure. Information and relations are considered resources to exercise decision-making. The definition proposed in this chapter is broader; it can accommodate different purposes that people could have and look at several resources that they could use to reach their goals.

It is necessary to notice that empowerment is related to power and that a neutral definition is not possible (cf., Drydyk, 2006; Chambers, 2004; Lyons et al., 2001). Eyben (2004) identifies six types of power: 'power to' is close to the definition of agency as a positive notion; 'power 
over' is relational and refers to acting upon others and things; 'power with' refers to collective action and organisation; 'power within' is about self-confidence; 'power everywhere' is the broadest notion that covers everyday practices; and 'power/knowledge' recognises that knowledge is contingent to the relations of power and expressed through discourses that affect individual meanings of the world (cf., Long, 1992b).

In those terms, the definition of empowerment proposed here has roots in the notion of 'power to' or positive freedom to pursue goals, but also includes the idea of 'power over'. Actions could have effects on structural contexts thus affecting power relations and informal social arrangements. These could in turn make available new options thus expanding effective agency of previously deprived groups. For instance, a water project could be initially perceived as result of the effort of leaders, regarded as powerful. However, if everyone gets access to safe drinking water, in contrast to the previous situation in which only some had (because they lived close to a river or they could afford bottled water), power relations could change. Everyone would have the same opportunities to use their time and money and could feel more capable (e.g., healthier) and interested in solving other kind of issues.

However, empowerment of some is not always at the expense of others. Power is not a zerosum model (Long, 1992b). It is not possessed, accumulated or depleted. In contrast, power emerges out of processes of social interaction. In the example above, villagers who after the project are more interested in their community development could have a positive effect on everyone's welfare because more ideas would be discussed and collective action could be more effective ('power with'). Furthermore, in this new situation, leaders could have to renegotiate roles (e.g., who sits to discuss what) and entitlements (e.g., who benefits from new projects and how much in relation to others). During the process, if leaders helped others to participate more actively and significantly in the community by opening spaces for discussion, making relevant information available, and so on, the power of leaders would not be lower than before but of a different nature. It would turn from 'power over' to 'power to empower' (Chambers, 2004, p. 27).

Empowerment, as defined in this study, is a special case of expansion of autonomy. In parallel, development is understood as a change of well-being (section 2.1). Table 2-6 presents a comparison between the main concepts of this chapter. Autonomy appears in the same row as well-being and can indeed be considered an aspect of it (i.e., intrinsic value). In contrast, empowerment is a qualified change in autonomy that can promote human development by improving well-being and/or expanding opportunities (i.e., instrumental value).

Table 2-6: Relationship between well-being, human development and autonomy

\begin{tabular}{|l|l|l|}
\hline Level element & $\begin{array}{l}\text { Well-being: } \\
\text {-Evaluation of actual lives that people } \\
\text { lead (outcomes). } \\
\text {-Evaluation of the opportunities to have } \\
\text { a good life. }\end{array}$ & $\begin{array}{l}\text { Autonomy: } \\
\text { Combined capability to make choices in } \\
\text { significant matters and act authentically } \\
\text { motivated. }\end{array}$ \\
\hline Change element & $\begin{array}{l}\text { Human development: } \\
\text {-Improvement in well-being (positive } \\
\text { change in outcomes) } \\
\text {-Expansion of valuable human potentials } \\
\text { (opportunities). }\end{array}$ & $\begin{array}{l}\text { - Expansion of autonomy } \\
\text { - Empowerment: } \\
\text { Expansion of autonomy, considering the } \\
\text { effectiveness of authentically motivated } \\
\text { actions (outcomes). }\end{array}$ \\
\hline
\end{tabular}


Action is made at different levels. In the empirical study, if the purpose is to analyse the empowerment of individuals in municipalities or cantons, the analysis can be at individual, household, group, community and municipality levels (Uphoff, 2005). Empowerment in one level is not necessarily associated to empowerment in another. For example, individuals who are empowered at group level, because of their experience with an NGO work, can be disempowered at community level if elites concentrate all relevant information, control pivotal decisions and block their efforts (Mosse, 2004; Holland \& Brook, 2004; and others).

\subsubsection{Community empowerment}

In this work, community refers to individuals that live in the same territory or those who, having emigrated, still keep strong family ties in their locality. Members of a community 'at least form part of a network of interaction' (Gasper, 2004, p. 206). They may share some values and have others that are conflicting; they do not necessarily share emotional ties (Johnston et al., eds., 2000). They may belong to several groups such as direct or extended family, school group, development committee, church committee, gangs or landowners.

In short, community is not a homogenous group. Even when a community is regarded as poor, people within the community have different entitlements, life experiences and interests. Furthermore, they may interact in different formal or informal networks and, for this reason, have different perceptions of their community.

Community empowerment concerns effectiveness regarding (i) the achievement of common objectives of the community members, and (ii) the success in facing the opposed interests of outsiders and the wider society (Ashley \& Hussein, 2000, p. 26). The first point assumes that it is possible to identify common goals that unify distinct people. Most likely the projects in this study responded to needs of everyone in the specific localities. Then, it is possible to analyse in a societal domain - other domains would be the state and the market - how the individual autonomy of community members expanded or not and how their combined efforts had or did not have an effect on entitlements, individual agency and multilevel structural contexts. Communal organisations and local governments are crucial institutions in these contexts, whose organisation capacities and control of resources influence what people can individually achieve.

Because for poor people, individual effectiveness is difficult (as they lack entitlements, relatively speaking), collective action fuelled by cooperation and social connectedness is often the major way to exercise claims and pursue goals. Actions such as maintaining local sanitation system, cleaning common roads, denouncing thieves, solidary work in communal plots, and so on, can result in expanded capabilities for individuals (Comin \& Carey, 2001; Evans, 2002), ${ }^{13}$ and intrinsically enhance individual self-respect (Stewart, 2005) by promoting perceived agency, which is required for autonomous actions.

It is important that opportunities for collective action are attainable, that is, that the costs of pursuing goals are low in comparison to the expected benefits. Social capital can work here by reducing costs and increasing the probability of success (ex-ante). Aid projects can have the same effect while project implementation takes place.

\footnotetext{
${ }^{13}$ Evans (2002) goes further and argues that the capability of choosing itself may be, in essence, a collective rather than an individual capability' (p. 56).
} 
Social capital is defined by Putnam (1993) as 'features of social organization, such as networks, norms, and trust that facilitate coordination and cooperation for mutual benefit'. Woolcock (2001) discusses that trust as well as tolerance and cooperation are consequences of social capital so that a definition should focus on the causes. This is the approach used here: 'social capital refers to the norms and networks that facilitate collective action' (ibid, p. 9). Social capital enhances individual perceived agency and through this channel, promotes collective action.

Nevertheless, social capital could have negative consequences such as rent-seeking activities carried out by small groups to the detriment of other groups and strongly bonded inner groups that exclude large parts of the wider community (Birner \& Wittmer, 2000) or that are excluded, depending on how the networks function. In such cases, unequal power structures would be strengthened and the position of a community (of which smaller heterogeneous groups are part) in front of the macro-level environment would be weakened (OECD, 2001; Mayoux, 2001).

The ideal empowerment could be viewed as affecting both individuals and the whole community. A situation in which only the elite derive benefits from an organisation empowerment is not desirable development.

Collective action will have effects (expected or not) in the distribution of resources and decision making (Eklund, 1999). In some cases, collective action is related to productive initiatives (Hirschman, 1984) that generate individual and collective resources, over which new entitlements are negotiated. The kind of individual participation will have different effects on self-confidence and perceptions of community strength or the assessment of how supportive is the community to personal needs and goals. Positive outcomes will improve a sense of community and thus reinforce social capital. ${ }^{14}$

A chief issue is whether the actual empowerment (degree of effectiveness of actions) differs from that one perceived by individuals. Especially for people recently empowered, to some extent, their perceptions could be highly optimistic in contrast to their realities because subjective well-being is high at the moment of successful achievements (cf., Diener \& BiswasDiener, 2005). If other members of the community also perceived them as empowered, they would be in a better position to negotiate entitlements (a transformative effect). So, subjective empowerment could actually have broader real effects than actual empowerment in some contexts, but only temporarily, because it requires an objective foundation to last.

From the above discussion, community empowerment is the expansion of the capacity of an organised group of people, living in a common geographical location, to take effective collective action that allows significant positive change in the lives of its members. It requires and supports the expansion of individuals' autonomy and thus it is fuelled by democratic participation.

Members of an empowered community (as defined above) feel that they own their development process; they are involved in decisions that affect their lives and feel responsible for the results of those decisions, whether expected or not. In this view, community empower-

\footnotetext{
${ }^{14}$ McMillan and Chavis (1986, cited in Eklund, 1999, p. 52) explain that 'sense of community' includes membership (feeling of belonging), influence (a sense of mattering among members and group), reinforcement (integration and feeling that needs will be fulfilled by action of the group), and shared emotional connection (commitment).
} 
ment nurtures autonomy. At a higher level, significant positive change refers to 'choices with the potential for challenging and destabilizing social inequalities' (Kabeer, 1999, p. 10). This links the discussion to critical autonomy, deeply explored in Chapter 12.

\subsection{Implications}

This chapter presented a conceptual model to analyse human development and autonomy. The elements identified in this chapter will be explored in the lives of the inhabitants of the four project sites studied. The following points deserve special attention.

1. This dissertation does not discuss whether autonomy is the ultimate value. It states that autonomy is intrinsically valuable because it is part of well-being and is also instrumental to promote human development (section 2.3.3 and 2.4.1).

2. Individuals can form their own conception of the good or their inner self based on their reflection capacities and own subjectivities, informed by cultural contexts. When actions in significant aspects of life cohere with this inner self, individuals are acting autonomously or authentically, not merely as they wish in terms of doing whatever they want (section 2.2.2).

3. It is necessary to identify clearly which actions are authentically motivated. Extrinsic motivations can be internalised as long as the individual maintains an autonomy causality orientation in regard to the actions promoted. This distinction is important for the analysis of practices to be done in the coming chapters.

4. Because human lives and individual perceptions about the world are shaped in society, autonomy is different from independence. Furthermore, entitlements, inputs to the exercise of autonomy, are negotiated in multilevel structural contexts. Moreover, their meaning is given by the use that individuals make of resources, which is culturally influenced (sections 2.3.1 and 2.3.2).

5. Autonomy is promoted when individuals acquire meaningful and attainable options to reach alternative lifestyles, when their intermediate needs are covered (THN), when they interact in horizontal social networks with relevant information sharing, when they trust themselves and their competence because they exercised autonomy in the past, and when they face structural contexts that promote choice instead of coercion or controls.

6. Individuals themselves are the ones who actualise their potentials when they take opportunities by making use of their autonomy. Therefore, it is necessary to promote the opening up of opportunities by influencing multilevel structural contexts, supporting self-confidence and the capacity to aspire, and enhancing the personal but learned skills or reasoning and acting' (Gasper, 2000a, p. 998) that are foundations for autonomy.

7. Moreover, if individuals reach a high level of competence (cognitive skills), have access to intercultural knowledge and enjoy political freedom, they can develop critical autonomy. Through this, they could promote their (chosen) valuable potentials for a 'good' human life and even push toward cultural change. 
8. The importance of empowerment is clear. If people make significant decisions that are effective, their self-confidence and autonomy causality orientation will be enhanced. This means that advances in empowerment can go in parallel with the promotion of human development because empowerment actually improves the quality of human development when people live the development process as their own.

9. Aid projects can - ideally - provide the supporting elements and opportunities to exercise autonomy according to actors' capacities and current situations so that they are better prepared to take initiatives and to face challenges (i.e., power imbalances have to be assessed). Consequently, actors would be the owners of their development process in their own particular way, and at a higher critical level, would be able to promote and defend significant change in their lives. 


\section{The practices and the effects of international aid: from macro to micro-level analysis}

External development assistance -'to do no harm', not to mention to be effective - must be autonomy respecting (Ellerman, 2006, p. 104).

Efficiency is indispensable to those who would humanize our anti-developed world. Efficiency, however, like development strategies themselves, must be redefined so as to serve human values (Goulet, 1983, p. 621).

This chapter focuses on international aid because the cases studied correspond to projects financed by a foreign donor. The objective of this study is to raise awareness of the fact that aid has a role to promote autonomy, as a means to enhance human development. Therefore, it is necessary to strengthen, at a conceptual level, the linkages between the structural practices of international aid and the functioning of specific projects.

The macro-level structural practices or the ways how the actors of the aid industry (financiers and recipients of aid flows) interact and define strategies have influence on the goals, the design, the practices and the effects of specific projects. Their influence varies depending on the specific characteristics of the countries and the project context. The detailed analysis of the four cases is presented in part II. This chapter explores the macro-level fundamentals for such analyses, develops a three-step method to identify the project logic, and summarises some working hypotheses on the impacts of projects on individual autonomy, based on the conceptual model in Chapter 2.

At the macro level, section 3.1 characterises the context of international aid. It describes its main goals, the trends in aid flows and the changes in the relationships between donors and recipients. The focus is on grants and concessional loans, not on loans at market rates that correspond to middle or high-income countries. Subsequently, this section discusses the challenges of the aid industry to effectively reduce poverty in low-income and lower-middle income countries such as Nicaragua and El Salvador. Special attention is put into the principles stated in the Paris Declaration (2005) and their related practices of selection and design, conditionality, coordination, and accountability.

At the micro level, section 3.2 introduces some concepts related to project management and evaluation. It discusses the notions of explicit and implicit logic of projects, which are used in the specific case chapters, by looking at the project documents and project practices. This section also examines several project evaluation criteria and presents Ellerman's approach of autonomy-respecting assistance, which is similar to the analytical framework proposed in this study (see chapter 10).

Section 3.3 elaborates on effectiveness and efficiency as evaluation criteria for projects that aim to promote individual autonomy. It also proposes three steps to understand the project logic and presents the working hypotheses to be tested in the specific case chapters, regarding the project effects. Section 3.4 summarises the main conclusions of the chapter. 


\subsection{The macro-level context of international aid: what has changed?}

The international aid industry has faced important changes in the last fifteen years. The amounts of aid and the number of donors have increased significantly. The goals have also broadened to explicitly include the alleviation of human poverty. The role of national governance and politics has been emphasised and, consequently, the relationships between funders and recipients of aid flows have become more complex than earlier.

Total aid funds have steadily grown in the last decade as Figure 3-1 depicts. In 2005, net official development assistance (ODA) reached USD 107 billion, almost twice in nominal terms and about $145 \%$ in real terms the amount of 2002 (OECD, 2008b).

Figure 3-1: Evolution of net ODA from DAC countries 1997-2005*

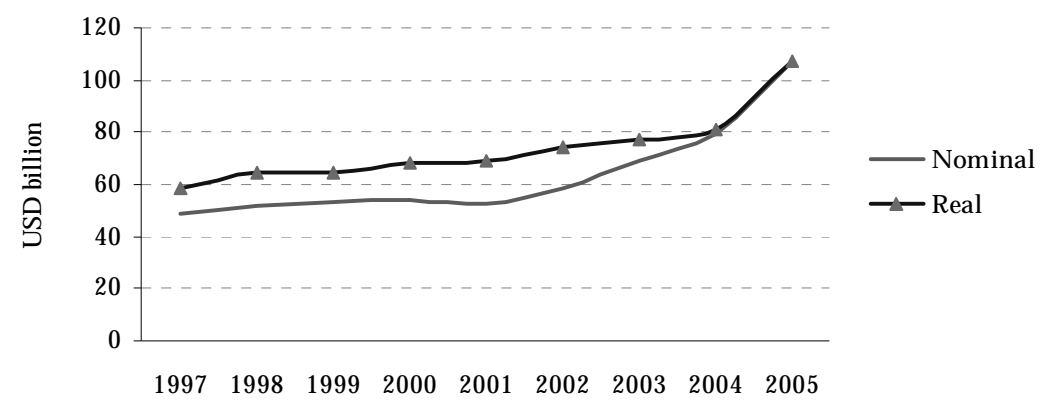

*For the 23 major bilateral donors and members of the Development Assistance Committee (DAC). Nominal figures in USD million of each period and real figures at 2005 prices and exchange rates.

Source: OECD (2008b).

Aid funds are channelled through multilateral channels (IMF, WB, regional development banks and the United Nations' specialised agencies) and bilateral channels (basically, government development agencies and non-governmental development organisations). However, there have been changes. On the one hand, there are new actors. Increasingly, aid funds have been transferred through private foundations, NGOs and corporations; while some developing countries are also donating - bilateral grants by NGOs and aid flows from non-DAC countries were equivalent to around 19\% of ODA from DAC countries in 20022005 (OECD, 2008b).

On the other hand, there are new aid modalities. There is a growing trend to allocate aid through a sector-wide approach (SWAp) instead of stand alone projects. Global aid funds focused on specific objectives have gained relevance such as the Global Alliance for Vaccines and Immunization and the Global Fund to Fight AIDS, Tuberculosis and Malaria.

The proliferation of donors with their own aid channels, procedures and practices has troubled the recipient governments. Their interactions with donors have increased the transaction costs of aid. OECD (2007) reports that, in 2005, 37 recipient countries had 24 donors or more, and 24 countries had problems of fragmentation (i.e., more than 15 donors representing together up to $10 \%$ of total programmable aid in the country). In Nicaragua and El Salvador, their 14 smallest donors added up to $10 \%$ of total received aid (ibid, p. 22-23). 
In this context, countries are considered dependent on external aid when they 'cannot perform many of the core functions of government, such as operations and maintenance, or the delivery of basic public services, without foreign aid funding and expertise' (Braütigam, 2000, p. 2). 'Aid dependence' is different from 'aid intensity' that can be temporary; for instance, when external aid arrives immediately after conflicts to rebuild social and economic infrastructure. In the case of Nicaragua and El Salvador, both countries had high aid intensity during the armed conflicts in the 1980s and after the Sandinista government, in Nicaragua. However, the weaker economic performance of Nicaragua (see Appendix 1-A) led to aid dependence. In year 2005, according to OECD (2008a), ODA represented 15.4\% of GNI for Nicaragua and 1.2\% of GNI for El Salvador. Furthermore, $71 \%$ of public investments were financed by foreign loans or grants in Nicaragua (GON, 2006a).

\subsubsection{The goals of international aid}

International aid has different goals related to (i) economic development, including the promotion of productive activities, (ii) social development, via the provision of basic infrastructure and services such as education and health, (iii) emergency relief, aiming to remediate sudden falls in people's well-being caused by events such as natural shocks or international trade crises, (iv) democratisation in post-conflict or dictatorship societies, by supporting activities such as truth commissions, and (v) institutional capacity building of governments and civil society organisations.

The two first objectives are related, although not explicitly, to the broad objective of poverty reduction. A positive link is expected between economic growth and poverty reduction; while the enhancement of human capacities has direct effects on well-being and also indirect effects via the expansion of work opportunities, which improve the prospects of material well-being.

Emergency relief aims to protect human lives and to avoid deprivation so that food or other commodities are delivered. Aid relief reaches its intended beneficiaries quicker than other interventions because the situations are extreme and much attention is put into delivery methods. However, centralised large-scale interventions, sometimes used for speediness, may undermine longer-term development efforts (Raffer \& Singer, 1996; Hoddinott, 1999). Aid interventions targeting post-conflict societies must be designed with an understanding of those societies (which is challenging even with the participation of local people). However, their outcomes may be still vulnerable to the re-emergence of conflict.

The last goal (institutional capacity building) is usually integrated into programmes aiming at poverty reduction because there is agreement that certain policy reforms and institutions are required to enhance the effectiveness of aid (see section 3.1.3).

Deducting the debt relief (for which Iraq was the main beneficiary) and humanitarian aid, the growth of aid funds is less impressive than what first appeared. In real terms, these 'adjusted' aid flows grew by $3.8 \%$ per year, lower than the $9.5 \%$ rate of total aid. Besides debt relief, social infrastructure is the sector that has showed the most steady and significant growth of inflows. This sector together with economic infrastructure is the main destination of aid, adding up to around $40 \%$ of total aid funds. In contrast, flows directed to productive sectors (agriculture and industry) have shown an erratic performance. 
In the case of social infrastructure projects, the weak fiscal situation of the recipient countries may lead to a situation in which the donor-funded infrastructures are not adequately maintained and later on abandoned. This is not unusual for water projects and is a disincentive for donors. Especially in the case of rural areas where the required investments are high because the population is more dispersed than in urban areas, governments do not have a long-run interest to provide services funded from abroad in small areas that are beyond their support capacity (Cassen et al., 1994).

\subsubsection{More focused goals and new principles}

A major step forward to improve people's well-being all over the world has been the agreement, reached by world leaders, with respect to the priority of the so called Millennium Development Goals (MDGs) and the commitment to reach specific targets for 2015. The MDGs cover different dimensions of well-being and are related to specific central capabilities (see Table 3-1).

Table 3-1: Millennium development goals and capabilities

\begin{tabular}{|ll|}
\hline Key capabilities for human development & Corresponding MDGs \\
\hline Living a long and healthy life. & Goals 4, 5 and 6: Reducing child mortality, improving \\
Being educated. & $\begin{array}{l}\text { maternal health and combating major diseases. } \\
\text { Goals 2 and 3: Achieving universal primary education, } \\
\text { promoting gender equality (especially in education) } \\
\text { and empowering women. }\end{array}$ \\
Having a decent standard of living . & Goal 1: Reducing poverty and hunger. \\
Enjoying political and civil freedoms to partici- & Not a goal but an important global objective included in the \\
pate in the life of one's community. & Millennium Declaration. \\
\hline Essential conditions for human development & Corresponding MDGs \\
\hline Environmental sustainability. & Goal 7: Ensuring environmental sustainability. \\
Equity-especially gender equity. & Goal 3: Promoting gender equality and empowering \\
Enabling global economic environment. & women. \\
& Goal 8: Strengthening partnership between rich and \\
\hline
\end{tabular}

Source: UNDP (2003a, p. 28).

The UN (2007) estimates that Southern Asia and sub-Saharan Africa are off of track to meet most of the specific targets for those goals. The reasons would be related to weak governance in institutional and policy environments and poverty traps, which mean that some countries are too poor to make progress (UN Millennium project, 2005). On the other hand, the gains in economic growth have not been equally shared, both within and among countries in the world. Income inequality is especially high in Latin America and sub-Saharan Africa. This means that the traditional approach that international aid has to promote economic growth is not enough. Aid flows have to support the poorest countries in their efforts to achieve the MDGs and these flows have to be effectively used.

The agreed strategy has been to increase aid flows so to make a 'big push' of basic investments in key infrastructure, human capital, and public administration (UN Millennium Project, 2005, p. 39). Many rich countries have committed to contribute with funds equivalent to $0.7 \%$ of their GNI by 2015 and to $0.5 \%$ of their GNI by 2010 (UN, 2002; 2005). Given that net ODA disbursements achieved only $0.33 \%$ GNI in 2005, it is expected that aid funds 
would increase significantly in the coming years. In this context, the question is what donor and recipient countries can do to assure that these funds will produce the expected results.

\section{- Improving the quality of aid through partnership}

The Paris Declaration on Aid Effectiveness (2005) defines commitments for donors and recipient countries ${ }^{15}$ focused on five main principles:

- Ownership, for which the recipient countries exercise effective leadership over their development policies and strategies and coordinate development actions;

- Alignment of development strategies to the priorities, systems and procedures of recipients; while conditions, if applicable, are derived from a common framework;

- Harmonisation of actions among donors that implies the division of labour according to each donor's competitive advantage so that donors establish common arrangements, simplify their procedures, and share information;

- Management for results, which requires the improvement of statistical, monitoring and evaluation systems of the recipient countries to improve decision making; and

- Mutual accountability that promotes joint assessments of progress and the transparent reporting to parliaments and citizens of donor and recipient countries.

These principles aim for more effective aid that reduces poverty and inequality, promotes growth, builds capacity and accelerates the achievement of the MDGs. Moreover, there are specific targets for 11 indicators to be achieved by 2010, whose monitoring is the responsibility of a working group at OECD-DAC. In line with these principles, UNDP (2005a) proposes the actions shown in Table 3-2.

Table 3-2: Actions for more effective aid by the UNDP

\begin{tabular}{|c|c|c|}
\hline Actions & Implications for donor & Implications for recipient \\
\hline $\begin{array}{l}\text { Making aid more predict- } \\
\text { able. }\end{array}$ & Fulfil aid commitments. & $\begin{array}{l}\text { Better planning of investments given } \\
\text { the increased reliability of funds. }\end{array}$ \\
\hline $\begin{array}{l}\text { Reducing excessive condi- } \\
\text { tionality. }\end{array}$ & $\begin{array}{l}\text { Keep macro conditions, based on } \\
\text { PRSPs or national development } \\
\text { strategies but do not mix them with } \\
\text { micro management conditions. } \\
\text { Strengthen local capacity. }\end{array}$ & $\begin{array}{l}\text { Governments define local strategies } \\
\text { and targets (related to MDGs) and } \\
\text { rely on their improved delivery and } \\
\text { monitoring systems. }\end{array}$ \\
\hline $\begin{array}{l}\text { Increasing donor harmoni- } \\
\text { sation. }\end{array}$ & $\begin{array}{l}\text { Donors tend to specialise in some } \\
\text { sectors, which implies sharing the } \\
\text { control of resources and accepting } \\
\text { that reporting systems managed by } \\
\text { others. }\end{array}$ & $\begin{array}{l}\text { Governments ideally deal with one } \\
\text { donor per sector, reducing transac- } \\
\text { tion costs and avoiding the duplica- } \\
\text { tion of functions in line ministries. }\end{array}$ \\
\hline Ending tied aid. & $\begin{array}{l}\text { Loans or grants not conditioned to } \\
\text { the purchase of services or goods } \\
\text { from the donor countries (e.g., in } \\
\text { technical assistance). }\end{array}$ & $\begin{array}{l}\text { Aid flows have higher value; local } \\
\text { ownership increases. }\end{array}$ \\
\hline $\begin{array}{l}\text { Providing more aid as } \\
\text { programme support } \\
\text { through government } \\
\text { budgets. }\end{array}$ & $\begin{array}{l}\text { Donors plan in advance and fulfil } \\
\text { commitments in priority areas iden- } \\
\text { tified in partnership with recipient. }\end{array}$ & $\begin{array}{l}\text { Governments are less vulnerable to } \\
\text { sudden aid shocks. National strate- } \\
\text { gies count with multiyear donor } \\
\text { commitment. }\end{array}$ \\
\hline
\end{tabular}

Based on UNDP (2005a).

${ }^{15}$ Product of the high-level forum 'Joint Progress toward Enhanced Aid Effectiveness' with the participation of 96 ministries of state, and representatives of 26 international organisations and 14 civil society organisations. 
Some actions are more feasible to implement than others. For instance, ending tied aid whose costs represent a tax of about $8 \%$ (UNDP, 2005a, p. 76) - depends on the will of donors to give up certain commercial interests. The chances for alignment and real ownership depend on the quality of the recipient's national systems of procurement and financial management. If donors do not trust these systems, they will tend to use their own systems and even to create parallel management structures (as earlier). Indeed, these principles and actions require that donor community supports the capacities of recipient countries.

\section{- $\quad$ Projects and the sector-wide approach}

The two basic modalities to deliver aid are discrete projects and programmes. Programme aid consists of food aid and financial aid. The latter includes three main types: balance of payment support (i.e., debt relief and import support), budget support and interventions framed in the sector-wide approach (SWAp). ${ }^{16}$ Some concepts overlap; for instance, sector budget support is also considered a SWAp. Other modalities of SWAp include pooled or basked funds provided by several donors but under the management of an independent aid agency (outside of national treasury) and coordinated projects, grouped into a multiyear sector programme signed by the recipient government with bilateral or multilateral donors (part of a country programme).

Projects have clearly specified objectives with tangible outputs within a defined period and with a defined budget (EC, 2004). However, there is a fungibility risk: if recipient governments would have invested in such projects even without foreign aid, the donors might end up indirectly financing marginal non-developmental activities (Collier, 2002). Fungibility is overcome by the SWAp because recipient and donor governments have to agree on overall objectives and strategies for the sectors to be funded. In stand alone projects, most likely recipients are accountable to the donors; while in the SWAp, recipients and donors can be mutually accountable.

The Paris Declaration sets as a target for 2010 that ' $66 \%$ of aid flows are provided in the context of programme-based approaches' (indicator of progress 9). A monitoring survey found that $42 \%$ of aid is provided in that way (WB, 2007). However, local ownership is challenged by donor practices such as channelling aid outside the government systems (e.g., through NGOs) or earmarking funds for specific purposes, which do not include capacity building or recurrent operative costs, especially in the health and education sectors. Aid is not effective if ministries cannot operate, although they have equipments or drugs. This observation signals the complex array of factors in the aid industry.

\subsubsection{From the Paris principles to macro-level structural practices}

The Paris principles represent a will to do things better, in partnership, that however might not be reflected in actual practices. This section identifies four kinds of structured practices (forms of interaction and practical strategies) that characterise the relations between donors and low-income aid recipients, which are later applied to the micro-level analysis of specific projects. The four practices are related to the Paris principles as shown in Table 3-3.

Selection and design practices refer to which criteria are used for allocating aid flows and which and whose objectives are pursued. They reflect the negotiation rules and norms and

${ }^{16}$ See: White \& Dijkstra (2003), UNDP (2005d) and Riddell (2007). 
the power relations among countries, which determine whether ownership is real or presumed and whether donor countries align to recipient countries' priorities or the opposite occurs.

Table 3-3: Identifying four types of structured practices at the macro-level

\begin{tabular}{|c|c|c|}
\hline Paris principles & Structured practices ${ }^{*}$ & Situation \\
\hline 1. Ownership & $\begin{array}{l}\text { Selection and design decisions } \\
(1,2) \\
\text { Conditionality }(1)\end{array}$ & $\begin{array}{l}\text { Poverty focus; it requires enhanc- } \\
\text { ing the capacities of recipients } \\
\text { - General conditions: policy re- } \\
\text { forms and quality of governance }\end{array}$ \\
\hline $\begin{array}{l}\text { 2. Alignment } \\
\text { 3. Harmonisation } \\
\text { 4. Managing for results } \\
\text { 5. Mutual accountability }\end{array}$ & $\begin{array}{l}\text { Coordination }(2,3) \\
\text { Accountability }(4,5)\end{array}$ & $\begin{array}{l}\text { - Weak but improving } \\
\text { - Upward }\end{array}$ \\
\hline
\end{tabular}

* The numbers between parentheses indicate which Paris principle is related to the specific structured practice.

Conditionality is generally accepted - money is hardly given without conditions - but ownership can be downgraded if conditions are so restrictive that they affect the definition of national policies in the recipient country. Coordination practices refer to the relationships between the donor and recipient governments and between donors. Accountability is analysed from the perspective of processes (between donor and recipient governments) and of outcomes (focused on final beneficiaries).

\section{- The selection of aid recipients and the design of development strategies}

Based on studies that indicate that aid is more effective in promoting growth when the recipient country has good economic institutions and policies (e.g., Collier \& Dollar, 2002), most donors are selective and allocate aid to poor countries with positive governance conditions. However, this conclusion is contestable (Easterly, 2006a); while other factors such as geopolitics, commercial interests and history are frequently prioritised (Easterly, 2002; Riddell, 2007, Part II). Furthermore, two of the largest donors, USA and France, are not necessary selective (Dollar \& Levin, 2004); although this situation has improved recently (e.g., the Millennium Challenge Account).

Collier (2002) asserts that the modality of aid would vary according to the quality of the policy environment so that:

(i) If the policy environment supports reasonable policies and institutions, almost all projects can work.

(ii) If the policy environment is poor but there is potential for institutional reform, (a) local capacities should be strengthened so that broad interests are represented and local ownership is fuelled, (b) the focus should be on a limited agenda for reform, and (c) some demonstration projects with visible effects on current government practices can be developed.

(iii) If the policy environment is hostile and unpromising and the economy is weak, it is advisable that one service authority delivers basic services, with independence from the government and accountable to donors.

Variables such as socio-economic structures, political regimes, governance conditions and geography are included in models to explain the effects of aid across countries (e.g., McGillivray, 2003; Dalgaard et al., 2004). Although the findings are not conclusive, the need is clear to explore which aid channels (and not only how much aid) are better suited to particular contexts. Based on such studies, UNDP (2005a) and OECD (2005a) recommend that: 
- Well-governed poverty trap countries are fast tracked with a significant increase in ODA, paying attention to their absorptive capacity and avoiding an over-dependence on aid,:17

- Poorly-governed poverty trap countries with lack of political volition receive only smallscale humanitarian aid, while those with volition but weak public administration receive flows for building public sector capacity;

- Particular approaches are applicable to countries in conflict or with geopolitical importance, but this aid should not divert attention and financial resources from poor countries;

- Countries with special needs such as small island states, landlocked states, mountain states, and states vulnerable to natural disasters have access to special funds; and

- Middle-income countries, which already have access to non-ODA funds, step up their donor efforts toward low-income countries.

How are flows of aid used? The design of development strategies should respond to the priorities of the recipient country. A Poverty Reduction Strategy Paper (PRSP) or a national development plan is expected to be country-driven and as such to involve the main social actors in the country, that is, not only the government but also civil society, corporations and financial institutions, political organisations and social movements (Friedmann, 1992). The socio-historical experience, the existing economic and social institutions, and the political culture of the countries determine whether there is such a broad-based participation. Quite frequently, instead of country ownership, there is only government ownership of the national policies and strategies, which imply 'strong and effective leadership at sector ministry level, commitment to the process at senior political level, and the active involvement of the Ministry of Finance' (OECD, 2005b, p. 35). Truly, government ownership is necessary to negotiate the aid terms and modalities suitable to the national plans, but it is not sufficient to promote sustainable human development for all in recipient countries.

\section{- Conditionality and its effects on ownership}

During the 1980s and 1990s, structural adjustment loans were commonplace but controversial because they failed to improve people's quality of life, despite their positive macroeconomic results in some countries. International financial institutions (IFIs) realised that countries did not or could not fulfil agreed-upon conditions. Their distrust about the capacity and the willingness of countries to comply with conditions explained the shift from ex-ante to ex-post conditionality (Sogge, 2002). Currently, poor countries have to behave, not only to promise to behave, in a certain way always, if they want to be eligible for international aid.

Undergoing policies are taken as indicative of future policies and assessments are made periodically to decide on aid funds. For example, the Country Policy Institutional Assessment (CPIA) index is a scorecard elaborated by the International Development Association (IDA), part of the WB that finances low-income countries. It focuses on issues such as sound economic management, transparency, clean government, social inclusion, and adequate public sector management, among others (IDA, 2004a; 2004b). However, CPIA can lead to high conditionality and be more influential than a PRSP (Alexander, 2004). Governments may keep certain behaviours to assure funds, under pressure (e.g., external debt obligations, huge fiscal deficits, and widespread poverty), not necessarily because their policies maintain or had broad national support in the first place. In any case, linking the disbursement of aid

\footnotetext{
${ }^{17}$ Absorptive capacity refers to the macro and micro-level constraints faced by recipient countries to use external aid effectively (de Renzio, 2007). For instance, poor procurement systems could lead to under-spending of grant-funded investments.
} 
funds to visible conditions, especially policy 'improvements', externalise the motivation and represents a step backward on the alignment principle (cf., Booth \& Fritz, 2008).

The drafting of a PRSP could also be externally driven. For instance, in Nicaragua, government officials elaborated the PRSP according to donor directives without involvement of the civil society (Dijkstra, 2005; Gosparini et al., 2006) and political parties, which later caused difficulties for the approval of reforms by the Parliament (Núñez Almerón, 2006) and the disbursement of some tranches of budget support. When reforms are not the result of local participation, reforms are poorly implemented, not sustainable and even reversible, depending on the country's aid dependency. Some governments could threaten the IFIs with reversing reforms if new funds are not delivered or exaggerate the reform costs abroad in order to provide the least possible reform per unit of funds (Collier, 2002, p. 8).

In this respect, OECD (2005a, p. 25) recommends that donors limit the number of conditions to those that are essential, derived from national plans such as the PRSP, and that these conditions are presented transparently (without sudden changes during an ongoing programme), in close dialogue and collaboration with the government. However, their interpretation should be flexible in certain contexts (Booth \& Fritz, 2008, p. 16). These recommendations can work if the PRSP truly represents the country priorities, that is, if the conditions do not distort the intrinsic motivation of social actors (Ellerman, 2006).

In the case of discrete projects, conditions may include local co-financing as government contribution or community work, complementary investments such as electricity systems or roads, the provision of budgetary resources for operation and maintenance of the project infrastructure, or the local financing of project management and monitoring and evaluation activities. These practices have changed. On the one hand, the fulfilment of conditions does not assure the operational success of projects, as failures may be explained by poor design, inadequate customisation (one-size-fits-all proposals), political intrusion, administrative deficiencies, and so on (Hirschman, 1967/1995). On the other hand, project performance may depend more on general institutional capacity than on the characteristics of the projects (Raffer \& Singer, 1996). Hence, nowadays, conditions refer to general policy environments.

\section{- Coordination and its challenges}

With higher expected aid flows (section 3.1.2), the coordination between donor and recipient countries has to improve in order to carry out sectoral programmes that are result-oriented and accountable to final aid beneficiaries. The recipient government should have strong leadership and control over the process of defining priorities, development strategies and aid modalities. The Paris agreement is optimistic: 'Donors commit to base their overall support - country strategies, policy dialogues and development co-operation programmeson partners' national development strategies and periodic reviews of progress in implementing these strategies' (Paris Declaration, 2005, II 16).

However, the recipient-donor and donor-donor coordination maybe complex because of: (i) the weakness of financial management systems; (ii) underdeveloped local leadership; (iii) a relatively passive, corrupt or incompetent government when it comes to designing integrated sectoral strategies; (iv) the lack of interest on the part of a donor, because it helps several countries so that the specifics of a particular country are treated as relatively irrelevant in its portfolio, or because it tends to emphasise short-term success rather than longterm impacts; (v) unwillingness of a donor to share information with other funders; (vi) 
conflicting objectives; or (vii) donor proliferation. As a result, donors could mimic their 'good practices' without regard for the recipient's long-term planning, duplicating management systems, and increasing the transaction costs for recipient governments.

Weak absorptive capacity continues to be a problem for poor countries. Hence, the targets for 2010 in Paris Declaration for the use of national systems vary according to the initial quality level of such systems. Technical cooperation for institutional strengthening is important, especially led by experts with experience in contexts with characteristics similar to those of the recipient country, in order to foster the horizontal exchange of experiences and common learning (Ellerman, 2006).

Nonetheless, there are two negative cases to be avoided. First, donors highly-concentrated in a particular country may put at risk local ownership of sectoral programmes, if they invest in their preferred sectors - in which they have expertise - and overcrowd them, without supporting local capacity building. Second, given the rapid turnover of foreign experts, some donors lack the institutional memory (IDS, 2005) to develop in-depth understandings of sectoral needs and options with government representatives. However, at least to avoid being blamed for failures in a given country, donors might favour coordination and become 'a cartel of good intentions' (Easterly, 2002).

\section{- Accountability and its motivational drive}

Accountability can be seen from two perspectives: processes and outcomes. Accountability with respect to processes is the mutual accountability, between donor and recipient governments, referred to the fulfilment of responsibilities, roles and expected monitoring and evaluation practices, including the prudent use of resources (OECD, 2002a). Mutual accountability is stressed in the Paris Declaration, which sets targets regarding mutual assessment reviews and performance assessment frameworks.

Accountability with respect to outcomes is the accountability to the populations of donor and recipient countries, and especially to the latter whose needs are addressed. This type of accountability has received little attention. Accountability should include 'the obligation to bear the consequences for failure to perform as expected'. ${ }^{18}$ The problem is that increases in aid commitments and even the MDGs could become for donors just promises to do their best to remediate poverty if 'nobody is individually responsible for doing anything for any one result' (Easterly, 2006b, n.p.). Easterly asserts that the problem is rooted in the lack of right incentives. He develops a logic chain called CIAO:

Customer feedback $\rightarrow$ Incentives $\rightarrow$ Accountability $\rightarrow$ Outcome

Poor people lack voice to express their needs and to show their dissatisfaction when things go wrong so that there is no customer feedback (Easterly, 2006a; 2006b). Consequently, project staff do not have the incentives to perform well (and deliver outputs) because it would not suffer a sanction, as the aid funders are not informed of the existing gaps. Only if project staff knew that the final recipients would complain and be listened to, would they be accountable and outcomes would be more likely achieved. The problem is that the poorest do not have clear agencies to which to complain, while populations in donor countries only

\footnotetext{
18 'Accountability', in: Porter, N. (Ed.) (1993). Webster's Revised Unabridged Dictionary. Retrieved June 2, 2006, from http://www.answers.com/topic/accountability
} 
hear about a few successful or touching stories. Independent evaluations can promote accountability for outcomes (Easterly, 2006b).

Sogge (2002) explains that as the aid chain grows, accountability runs upwards (to the donor) and outwards, which leads to the externalisation of governance. This is the case of some aid dependent countries, in which 'development choices and initiatives are in the hands of foreigners or local actors who "do their thing" but are not accountable to public authority' (ibid, p. 100). Donors end up involved with local elites and bureaucratic government institutions (that may not be particularly accountable) in order to target aid into 'their' priority sectors. Often facing high-risk environments, some donors prefer to define tangible outputs, easy to communicate, and more likely to be achieved (Easterly, 2002) so that they can justify the resources spent. This behaviour reflects the fact that goals are defined in terms of volume (this has to change), which discourages accountability for outcomes on people's lives. The involvement of grassroots organisations in aid interventions can improve accountability given certain conditions, in which democratic practices are fostered. This involvement would promote empowerment, which requires process freedom in significant matters, depending on the specific cultural features. It is important then to analyse aid at the microlevel, which is where processes and values are better assessed (see section 3.2).

\subsubsection{A glance at aid effectiveness}

Effectiveness refers to the extent to which objectives are achieved, taking into account their relative importance (OECD, 2002a, p. 20). However, several objectives of aid are difficult to quantify, causality assumptions do not always hold, and several external and countryspecific structural factors affect outcomes. Hence, aid generally influences the processes of change only at the margin.

The relevant question is: Aid should be effective, for what? (Collier, 2002) The issue is not growth-oriented but MDG-oriented aid. In line with the Paris principles of alignment and ownership, donors must change their behaviour and pass from 'aid in return for reform', which is not incentive-compatible, to 'aid in return for improved health and education' and other MDGs (White, 2005). Given that there are multiple intervening factors and possible interactions (see section 3.2.3) that explain changes in a particular goal, the best approach could be to identify channels how aid could contribute to specific purposes.

Another issue is whether the emphasis on short-term outcomes with direct impact on wellbeing is at the expense of long-term institutional capacity (de Renzio, 2007) or productive activities for wealth creation (Riddell, 2007, p. 377-8). Only strong national institutions assure the sustainability of development outcomes. Hence, donor countries should also be accountable for outcomes in institutions; at least, they should not harm local institutions or create incentives for money wasting. This implies, among other things, that current practices of earmarked funds should be more flexible. For instance, basket funds targeting health and education programmes should support the capacities of ministries and not bypass national systems by managing parallel delivery structures.

On the other hand, governance assessments made by donors determine the aid funds to poor countries. But, what about the poor countries who are poorly governed? When will they develop capacity if their governments are always bypassed? Foreign aid cannot convert bad governments into good governments (Easterly, 2006a) but donors can support the local 
efforts to improve capacities while they provide aid funds; this requires a close engagement with the socio-historical processes and the political culture of recipient countries (cf., Booth \& Fritz, 2008; Riddell, 2007).

However, there are no blueprints about how donors should engage with recipient governments and grassroots movements. It seems that being closer to them and investing time in understanding their local realities and needs is a necessary step (Ellerman, 2006). Experimentation and mutual learning would enrich the donor-recipient relationship and, most importantly, they would sustain the benefits brought about by the own agents of development (aid recipients) with the support of donors.

\subsection{The micro-level context of international aid: what can projects tell?}

This section presents some traditional project evaluation criteria, guidelines to shed light on the explicit and implicit logic of projects, and Ellerman's approach of autonomy respecting assistance, as introduction to the three-step method developed in section 3.3.

\subsubsection{The rationality of projects}

Projects comprise, at least on paper, a series of activities with defined objectives. Mirroring the goals of international aid, projects may promote economic or social development, provide emergency relief or support institutional capacity building. In general, their role is to fill the gaps that poor countries face in terms of resources, skills and systems (Riddell, 2007, p. 180).

As seen earlier, donors will gradually reduce their funding through stand alone projects and increase the use of other aid modalities within the SWAp. This means that most projects (coordinated within a sectoral programme) would be under the responsibility of the recipient countries; while, some projects would remain under the direct support of donors in specific cases such as short-term emergency relief, post-conflict situations, technical assistance or institutional building pilot projects.

Some bilateral donors might keep the control of discrete projects depending on their perception of the recipient country. In fact, the main reason for the far-reaching existence of project implementation units (PIUs) is the lack of trust in local ownership, management capacities, transparency or responsiveness of recipient governments. Moreover, in countries with weak governance, most donors would prefer, rather than supporting local institutions, directly addressing beneficiaries or contracting local NGOs, regarded as more efficient to deliver services (Riddell, 2007, p. 307). Some donors prefer to directly manage large infrastructure projects or even small projects for which they would receive public attention (Easterly, 2006b), so that their constituencies at home would regard their job as effective. These practices are hard to change in the short-term. In 2004-2005, projects represented around 13\% and $9 \%$ of bilateral grants from all donors and OECD-DAC donors, respectively (OECD, 2008b).

\subsubsection{The explicit and implicit logic of projects}

Project formulation reports include detailed descriptions with main activities and sometimes technical evaluations (depending on the sector). Project documents and logical frameworks reflect the prevailing project theory (Rossi, Lipsey \& Freeman, 2004) and express the explicit 
logic of a project. However, a project is not only about what is written and expected, but also about what is done and how that is done. Practices reflect the implicit logic of a project.

\section{- The logical framework and its causal links}

The most used tool in project design is the logical framework approach, which is made operational through the logframe matrix (see Eggers, 1998), the 'logframe'. It defines a series of causal links between a project and its objectives, establishing an explicit hierarchy, as shown in Figure 3-2 (from left to right). The outputs are quantifiable and intended results of the activities of the project carried out with its respective inputs. The arrow in the figure represents the most contestable part of the matrix because it reflects the expected causal link between the operational results and their effects on people's lives.

Figure 3-2: The causal link in the logframe matrix

\begin{tabular}{|c|c|c|}
\hline \multicolumn{3}{|c|}{ Implementation of the project } \\
\hline Inputs & Activities & Outputs \\
\hline $\begin{array}{c}\text { Resources, staff, } \\
\text { technical features }\end{array}$ & Process & $\begin{array}{c}\text { Operational } \\
\text { results }\end{array}$ \\
\hline
\end{tabular}

\begin{tabular}{|c|c|}
\hline \multicolumn{2}{|c|}{ Effects of the project } \\
\hline Outcomes & Impacts \\
\hline $\begin{array}{c}\text { Purposes or near- } \\
\text { term impacts }\end{array}$ & $\begin{array}{c}\text { Overall goals or } \\
\text { long-term impacts }\end{array}$ \\
\hline
\end{tabular}

\begin{tabular}{c}
$\begin{array}{c}\text { Sphere of control: } \\
\text { Project staff }\end{array}$ \\
\hline
\end{tabular}

\begin{tabular}{|c|c|}
\hline Sphere of influence: & Sphere of concern: \\
Boundary partners & Final beneficiaries \\
\hline
\end{tabular}

Based on Hofmann et al. (2004) and Crawford et al. (2005).

Project staff can secure outputs, to a certain extent, but the realisation of intended effects depends on other people's behaviours. For instance, in water projects, an output is 'a drinking water network is created and put into operation', which can be reasonably secured by technical staff. However, an outcome or specific purpose 'to provide a stable access to drinking water service' depends on other social actors such as the public water company or the community organisation. Reaching an overall goal, 'to contribute to the improvement of the health and living conditions of inhabitants' is complex. ${ }^{19}$ To pass from having access to safe drinking water at home to enjoying good health requires affordable water bills, good hygiene habits, adequate sanitation systems and solid waste collection, good maintenance of water systems, and much more. These sorts of requirements (for each level of result) are supposed to be included as assumptions or risk factors in the logframe, related to aspects external to the project. The validity of such assumptions is rarely reviewed over time.

In fact, change can be influenced by non-project factors, unintended interactions of a project with other factors, unintended routes or unforeseen effects (Conway \& Maxwell, 1999; Gasper, 1999). As Hirschman (1967/1995) reflects 'each project turns out to represent a unique constellation of experiences and consequences, of direct and indirect effects' (p. 186). This array of possible influences, pathways and effects is not captured by a logframe.

Gasper (2000b) warns about the misuses of the logframe derived from:

(i) Logic-less frame, when the matrix is created after the project is designed, so that it is forced by external funders and not discussed with the social actors in the recipient country;

(ii) Jamming, when it attempts too much in one small format, so that it includes supra-goals that are not directly related to the project because such goals are affected by several factors;

\footnotetext{
${ }^{19}$ These expected results come from the logical framework of one of the water projects studied. The project fact sheets in Appendix 2-B contain the logframe of each project.
} 
(iii) Lack-frame, when it is too simple thus leaving out important factors; and

(iv) Lock-frame, when it keeps rigid without changes through the project life.

Nevertheless, the logframe is potentially useful to make the project logic explicit and to make project design and implementation transparent conceptually. In addition, the logframe can be used as a participatory tool to deepen the understandings of projects (Bell, 2000), and to recognise multiple views and differences in priorities (Gasper, 1999).

The logframe includes for each intended result an objectively verifiable indicator and a means of verification, to be used for monitoring purposes. However, for this end, the logframe should be updated, considering the evolving goals and actions of project stakeholders over time. An 'interpretivist perspective' (Crawford et al., 2005) that puts at the centre of the analysis the experiences of social actors during the change process supported by the project is more useful for assessing effects - considering that projects that support ongoing or authentically motivated change (Ellerman, 2006) have more sustainable impacts.

Returning to Figure 3-2, project staff is under the sphere of control of 'the project logic' because personnel work together to reach explicit outputs. 'Boundary partners' (Earl et al., 2002, cited by Crawford et al., 2005) such as the communal leaders or local politicians can only be influenced to support the project; however, their actions determine whether the outcomes will be achieved. Negotiations could take place, even leading to the redefinition or inclusion of new objectives. Finally, the ultimate beneficiaries (e.g., villagers whose needs are addressed) are the ones whose actions should influence the change process and the aid project in the first place. Nonetheless, it is not always the case that projects are truly responsive to their needs emerging beyond what is framed in the matrix.

\section{- The project cycle and the project practices}

The project cycle describes the main stages of a project from when it is conceived (i.e., a need is identified) until its impacts are evaluated. The main stages are identification (prefeasibility study), formulation (feasibility study), implementation, and evaluation and audit (EC, 2004). The idea behind this concept of cycle is that lessons from evaluation and audit can be incorporated into the design of new projects so that there is an iterative process of learning and improvement (Crawford et al., 2005). There is an initial stage of programming that corresponds to the elaboration of the indicative cooperation programme that defines the core sectors and goals to which the specific projects will contribute - following the national priorities defined in the PRSP or a similar document.

The duration of each stage depends on the type of project. For instance, the identification and formulation stages will probably last longer in the case of water projects than reconstruction projects. Technical issues might cause delays in the feasibility studies for water systems. In contrast, in reconstruction projects, the nature of the emergency might lead to a prompt financing decision and implementation, sometimes without accurate baseline data which could hinder an ulterior evaluation (Hofmann et al., 2004). In the case of discrete projects, the financing decision takes place after the formulation; while, in the case of projects that are part of a programme, the financing decision is made after the identification (EC, 2004) carried out by the recipient country. During the formulation, the project design is completed, with a detailed logframe matrix. This stage includes the definition of management, coordination, financing, monitoring, evaluation, and audit arrangements. 
The four macro-level practices (selection and design decisions, conditionality, coordination and accountability) are, to some extent, replicated at the project level. However, the emergence of certain practices is not determined by the stage of the project.

Selection and design decisions are made over the project cycle. The initial selection criteria could change over time, with diverse individual effects on individual entitlements and agency. Relevant questions are: Did stakeholders participate in the design of the project? Was there a needs assessment to explore the relevance of the project or alternative projects? Who led the process? What was the role of political authorities and donors? Did experts show respect by taking into account or even being led by the ideas of individuals in the community? If the project is a learning organisation, the possibilities would be enormous for adapting knowledge, inventing, and transmitting experiences to others because people would feel ownership in the project (Ellerman, 2006).

Conditionality to the recipient government might be transferred to the final aid beneficiaries as a wrong way to assure project ownership. For instance, communal work in infrastructure projects can be tied to the granting of the aid (resulting from agreed contributions in the cooperation programmes). Project participants could feel their self-confidence or opportunities to make significant decisions affected, if they neither internalised that condition nor considered it necessary to reach a more important goal (section 2.2.4). Indeed, local ownership cannot be created, only enhanced and facilitated (de Valk, Apthorpe \& Guimarães, 2005; Ellerman, 2006). Looking at the roles of different groups during the project, the implicit or explicit commitments, the extent and degree of participation (whether forced or voluntary), the existence of co-payments and how these were defined, and so on, helps to judge whether practices are controlling or autonomy-supportive.

Coordination practices at the micro-level may resemble those at the macro-level, especially in the case of high-profile projects, in large localities or hosting important population groups (e.g., migrants, former guerrilla fighters, etc.) that attract large numbers of donors. Some practices might be revealed from common discourses expressed by project staff, beneficiaries and other stakeholders. In such cases, it is relevant to distinguish whether they are result of knowledge delivered by the project (with top-down logic) or jointly searched and generated by project participants (Ellerman, 2006).

Accountability with respect to outcomes is better assessed at the micro than at the macro level. Existing local political and institutional arrangements determine whether, once the project is completed, the project outcomes will be sustained. The quality of the project outputs depends on the capacity of individuals to exercise voice and influence the behaviour of project staff and aid agencies, so that the latter have the incentives to offer what people really need and to provide what they offer. Furthermore, empowered local actors are the most motivated to sustain positive change.

\subsubsection{The project evaluation criteria and their limitations}

Relevance, effectiveness, efficiency, impact and sustainability are the customary criteria to evaluate projects (EC, 2004). Relevance responds to the question whether the objectives and design of the project are appropriate to beneficiaries' needs and priorities.

Insofar as the objectives are achieved (i.e., the project is effective), the criterion of efficiency responds to the question whether there are better ways of achieving the results or better 
ways of using the resources. The cost-benefit analysis (CBA) is widely used to assess efficiency. It determines if a project brings a net welfare gain (with welfare conceived according to ability and willingness to pay) and how that gain compares with the ones from alternative projects. It includes assumptions about what is valuable (monetised benefits and costs and monetary equivalents) and for whom, and the role of the market as the distributor of resources and the determinant of economic values. CBA privileges wants, those revealed in 'willingness to pay', over needs. Hence, it is 'appropriate for projects whose benefits are measurable in monetary terms and whose output has a market price that is relatively easy to assess' (Belli et al., 1997, p. 47). However, Oka (2003) points out that, even from a monetarybased perspective, CBA is only 'relatively efficient' because there is no actual compensation for people who suffer losses, the ex-post distribution of benefits and costs may lead to inequality, and fluctuations in the availability of certain goods (which depend on institutional factors) makes difficult the comparison of two states of benefits.

Impact is defined by OECD (2002a) as a 'positive and negative, primary and secondary longterm effect produced by a development intervention, directly or indirectly, intended or unintended' (p. 24). In this study, impact has a comprehensive meaning. Similarly, as proposed by Roche (1999/2004), impacts are 'lasting or significant changes - positive or negative, intended or not - in people's lives brought about by a given action or series of actions' (p. 21). This definition implies that:

- The relevant effects are on people's lives, what really matters (Hofmann et al., 2004) and whose richness cannot be captured only by quantitative indicators.

- The effects are not necessarily lasting, because of the interaction of several post-project factorscan. This problem is especially important in emergency cases, in which relief aid can save lives in the short time, which is a significant effect per se, but does not assure a sustainable livelihood.

- Deciding which change is significant involves judgements (which involve choices of: for whom and by whom?).

In contrast, project evaluations tend to focus on immediate outputs so that what is assessed is operational effectiveness. Riddell (2007) reports that, under this criterion, recorded success rates have improved over time and ranged from $70 \%$ to about $85 \%$ (ibid, p. 180), although these rates are likely to be exaggerated and, further, the sustainability of those successes would be much lower.

Impact studies are the most challenging type of post-hoc evaluations. They intend to test the causal relationships between achievement of formal project objectives at different levels and the project inputs and activities (i.e., attribution of achievements, to the project or to other factors). The methods used include cost-benefit analysis, econometric impact analysis, qualitative case studies, participatory studies, and so on. However, these evaluations, typically, only focus on intended effects.

Once project effects are identified, the next criterion is sustainability: How can the positive outcomes persist in the long run? White (2005) proposes to deepen a theory-based evaluation to assess sustainability and risk, clarifying key assumptions and identifying nonquantifiable risk-variables such as 'government commitment'. Fundamentally, sustainability depends on the existence of local social actors who have ownership of projects or reforms. However, sustainability results from combining local capacities, external advice and sound public relations within multilevel structural contexts. 
It is worth mentioning that because of the short-term horizon in which aid projects usually take place, a pseudo-motivated (behavioural) change could be wrongly considered the evidence of sustainable change (Ellerman, 2006, p. 111) in ongoing and ex-post evaluations. Aid recipients could behave as project staff expects and play as 'good beneficiaries' in order to secure what they perceive the project can offer. This observation once again underlines the need to identify and find the authentic motivation of local people that would fuel sustainable change to improve their lives as they value.

This study looks for impact or longer-term effect on a much wider objective: the expansion on human autonomy. There are projects to foster democracy, good governance or empowerment but: (i) these have not focused on individual lives, and (ii) human autonomy has not been explicitly considered a goal of traditional infrastructure projects. Below, a particular approach that does focus on autonomy, at several levels of analysis, is presented.

\subsubsection{The autonomy-respecting assistance approach}

Ellerman (2001; 2004; 2006; 2007) develops an indirect approach for 'helping people help themselves'. Its basic aspects are presented here. The proposal developed throughout this study (see section 10.2) agrees with it in many aspects. Table 3-4 presents the five principles proposed by Ellerman, adapted to the micro-level reality of projects.

Table 3-4: Ellerman's approach for autonomy-respecting assistance

\begin{tabular}{|c|c|c|}
\hline & Principle & Explanation \\
\hline First Do & Starting from present institutions. & $\begin{array}{l}\text { Project participants have their own change proc- } \\
\text { ess. The helpers cannot come to change every- } \\
\text { thing to create 'ideal' institutions; such change } \\
\text { would not be sustainable. }\end{array}$ \\
\hline Second Do & $\begin{array}{l}\text { Seeing the world through the eyes of } \\
\text { project participants. }\end{array}$ & $\begin{array}{l}\text { The helpers have to understand and enter the } \\
\text { internal frame of reference of project participants, } \\
\text { to help them generate and appropriate their own } \\
\text { knowledge. This process enables social change. }\end{array}$ \\
\hline First Don't & $\begin{array}{l}\text { Transformation and help cannot be } \\
\text { externally imposed. }\end{array}$ & $\begin{array}{l}\text { Transformation implies a change of beliefs. Beliefs } \\
\text { cannot be imposed; they are the result of reflec- } \\
\text { tion. }\end{array}$ \\
\hline Second Don't & $\begin{array}{l}\text { Help should not be given purely as a } \\
\text { benevolent gift from helpers to } \\
\text { project participants, displacing their } \\
\text { efforts and choices. }\end{array}$ & $\begin{array}{l}\text { In order to foster the self-respect of the poor, they } \\
\text { need to work to improve their own lives and have } \\
\text { the opportunity to be involved in projects. }\end{array}$ \\
\hline Third Do & $\begin{array}{l}\text { Project participants must be 'in the } \\
\text { driver's seat'. }\end{array}$ & $\begin{array}{l}\text { There is project ownership when the outcomes are } \\
\text { the fruits of the activities of the participants, when } \\
\text { their institutions are strengthened and their de- } \\
\text { velopment strategies are supported by projects. }\end{array}$ \\
\hline
\end{tabular}

Source: Ellerman (2006 and others).

It is an indirect approach because it focuses on the conditions and the contexts in which aid is provided so that people can make decisions autonomously. Ellerman proposes that aid agencies or 'the helpers' must respect, foster and sustain the autonomy of project participants because aid agencies do not do development (Ellerman, 2007, p. 6-7).

This approach is applicable to both the macro and the micro-level contexts of international aid. At the macro-level, Ellerman argues that conditionality by large aid agencies or multi- 
lateral organisations has often undercut the initiative and local capacities of poor recipient countries to help themselves. At the micro-level, he focuses on the relations between project experts and intended beneficiaries - 'doers' in contraposition to passive aid recipients - and how the latter should use their existing capacities to address their problems with the help of experts, not blindingly follow experts' advice.

\subsection{Autonomy and project assessments: what would be the linkages?}

This section discusses the meaning of effectiveness and efficiency for the case of projects that respect and promote individual autonomy. It also presents a three-step method to understand the project logic, and the diverse effects on autonomy. Finally, it summarises the working hypotheses to be explored in the empirical part of this study.

\subsubsection{Redefining the evaluation criteria for autonomy-focused projects}

The MDGs underlines some aspects of well-being to be enhanced (achievements in capabilities) so that international aid aims to provide the satisfiers for these ends. However, the best way to make these gains in well-being sustainable and, more importantly, to promote further enhancements in human development and to promote further enhancements once aid flows are withdrawn is to increase the capacity of people to help themselves.

This means that, for every project, effectiveness should be assessed in relation to the degree to which individual autonomy has been expanded - in addition to other formal project goals. This criterion is named as human autonomy effectiveness, to differentiate it from operational effectiveness that refers to the achievement of operational results under the sphere of control of project staff (section 3.2.2) and from economic effectiveness focused on objectives expressible in monetary terms. Because the concept of effectiveness includes a judgement on the relative importance of goals (OECD, 2002a), human autonomy effectiveness does not imply that every value held by people in society is included in the assessment but that individual autonomy, which is instrumental to human development, is considered a priority goal.

Concerning the difference between expansion in autonomy and empowerment (section 2.4.1), it is worth noticing that the criterion of human autonomy effectiveness for project evaluation examines whether individual autonomy has expanded and how. It is not about how individuals or groups are more or less empowered given that, at an aggregate level, it is hard to conclude about the definition of personal priority goals and their achievement.

As the case chapters will show, project outputs, practices and the dynamic contexts over a project lifespan have effects on individual autonomy, whether these effects are intended or not. Then, a first step toward fostering autonomy-supportive practices in international aid is to raise awareness on the intended and unintended effects and their mechanisms: what works for whom and in what circumstances (Pawson \& Tilley, 2000).

An impact assessment exercise focused on individual autonomy is challenging given that the target is complex and not easily quantifiable. A way to address this goal is to analyse how individual autonomy can be promoted, by distinguishing between its separate determining factors (entitlements, agency, and multilevel structural contexts). A project might have different effects on each one. Moreover, projects might affect the access to resources, individual skills, and power relationships, but each in a different way. Perhaps, it would be 
more accurate to analyse project influences than project effects, as many factors will explain human development outcomes.

Another important evaluation criterion is efficiency. 'Efficiency concerns the relationship between valuable results and the valuable means that have been used to achieve them' (Gasper, 2004, p. 57) and, therefore, judgements on the degree of efficiency depend on the objectives and values included and their relative weights. Under this criterion, the expansion of autonomy can be seen as a valuable benefit and the costs of different project practices (in addition to inputs) would need to be included. For instance, the costs of conditioning project participants to work in self-construction could be expressed in terms of time, cultural resources or economic opportunity cost. However, the analysis should extend beyond a business concern for only monetary costs and benefits. For instance, workload is not only a cost to be minimised; it could be a benefit in terms of self-respect resulting from such work, depending on the project context.

The traditional cost-benefit analysis is not suited to include these factors. Identifying a single unit that replaces money to measure and compare benefits and costs requires further research (see Clements, 1995). Most likely, the scoring resulting from participatory exercises would work better. Another difficulty would be the definition of relative weights to aggregate costs, but this is a standard type of issue in multi-criteria evaluation, and weights need only to be refined to the extent needed to make the current decision. Non-aggregating forms of multi-criteria evaluation are also possible, with final judgements made through introspection or voting.

This study proposes that projects should be evaluated in terms of human autonomy effectiveness, not in terms of narrowly conceived economic efficiency. This means that the objective is to examine the impacts of the projects on individual autonomy with special emphasis on how those impacts took place in function to the processes and the outcomes of the projects.

\subsubsection{A proposal for understanding the logic of a project}

This section proposes that the full project logic can be elicited by:

1. Knowing the project theory explicit in the logical framework and other project documents;

2. Identifying the specific activities carried out during the project cycle, who decided about changes to the original design, why and under which circumstances; and

3. Investigating the practices that evolved over time, as result of the interaction of individuals with project staff and other actors in the multilevel structural contexts.

These proposed steps acknowledge that processes as well as results are important. Practices are 'emergent forms of interaction, procedures, practical strategies, and types of discourse and cultural categories present in specific contexts' (Long \& van der Ploeg, 1994, p. 78). They delineate the implicit project logic so that a project's full de facto logic is jointly constructed - by project participants, project staff, formulators and other stakeholders. As such:

- The project logic has to be discovered and reviewed through several channels during the project cycle so that changes in interpersonal relations and entitlements are traced over time. Hence, opportunities as well as challenges for project operational effectiveness, such as punctual interferences or high administrative workload (cf., Hirschman, 1967), could be identified and opportunely addressed. 
- It has to be re-examined at the project completion when doing an ex-post evaluation in order to analyse changes that could have resulted from a redefinition of goals.

- Understanding the project logic helps to understand how a project works, how different it is from others (even in the same sector or with similar institutional contexts), and what makes it to work in a given way (Pawson \& Tilley, 2000).

Project practices reflect the power relations in specific communities and between stakeholders and project staffs. For example, excessive conditionality during the execution of a project could signal that beneficiaries could not give feedback to the aid agency or donor about how to improve their conditions, or that the project staff was unable to incorporate changes when necessary (i.e., lock-frame).

Project practices determine whether the intended effects are achieved and explain the emergence of unintended or unexpected effects (see Table 4-4 in section 4.3.1). Practices are dynamic, not rigidly linked to particular events or even formal project activities. The same activity can have different meanings for individuals in the same locality and can estimulate different (and sometimes opposite) responses, depending on each person' specific capacities, social standing and internal contexts of agency (personality and cultural context).

Practices and relations, not only logframes and planned activities, should be the focus of any project assessment because a change process is not caused merely by a design. Change is pursued, lived and felt by individuals who negotiate goals, experience conflicts or reach agreements while exercising their autonomy in their specific circumstances.

\subsubsection{Working hypotheses about project effects on individual autonomy}

Any project means a change, at least temporary, in the lives of participants. A project brings its own organisational culture and functional structure. Project staff (not necessarily from only one organisation) may hold values and promote social practices different from the local ones, with different effects on aid recipients. Contextual factors in interaction with project factors can explain change. Hence, the challenge is to examine whether changes in the determinants of individual autonomy were primarily driven by the project or other factors, by analysing thoroughly the full project logic.

More properly, project could have influences on participants' autonomy. In conceptual terms:

1. A project could change the entitlements at individual and community level;

2. A project could support agency, primarily individual competence capacities, through an improvement in health conditions, intellectual skills, and so on;

3. Self-confidence (at the individual level) and organisational capacity (at the community level) could also be fostered or undermined depending on the quality of the participation and cooperation of individuals within community organisations; and

4. The structural contexts could change, for instance, if power relations are affected as a result of a redistribution of resources and decision-making.

An expected effect of infrastructure projects (as the ones here studied) is the expansion of entitlements on material resources provided by the project. However, actual entitlements to resources might even decrease if, for instance, elites concentrate resources, undermining trust, with even deeper impact on the causality orientation of other community members. To a large extent, how the project is designed, implemented, monitored and evaluated (i.e., activities and practices during the project cycle) will affect behaviours. Building partner- 
ships with local people in the presence of power imbalances is a sensitive issue. In some cases, project staff could facilitate the participation of otherwise excluded people who already possess a motivation to improve their lives. Project staff's role would be to identify intrinsic motivation and support local efforts.

There might be reinforcing and opposite effects because some practices might support one element of autonomy while constraining another. For instance, when projects include selfconstruction activities, long work hours could assure a prompt delivery of outputs but undermine the self-confidence of project participants or their entitlements to other resources, if project participants are mistreated or hindered from working in their own affairs. Therefore, it is important to identify the synergic satisfiers (Max-Neef et al., 1991) that support more than one relevant factor contributing to individual autonomy, without restricting others. First, it is necessary that project staff understands the livelihoods of project participants that will also help to explain their motivations to participate (Ashley \& Hussein, 2000, p. 55). Project staff has to cultivate special abilities and to have the right incentives so that they can channel local expectations and initiatives successfully during the project cycle, making the necessary design adjustments.

In practical terms, a project could help people to achieve:

a) The realisation of current individual capacities or awareness that they can make things to happen, which already implies an expansion of capabilities that endure only when exercised;

b) A change in the sharing of information and other entitlements within the community;

c) An opening of spaces for discussion on community issues (i.e., opportunity for socially significant activities in the terms of THN);

d) A change in individual participation in community decisions, related to contexts that either promote trust and self-confidence (autonomy-supportive) or restrict the exchange of ideas (controlling contexts); or

e) The actual exercise of decision-making (process freedom).

Because the effects are of diverse nature, a combination of methods would be most suitable to assess the impacts on autonomy. Causality has to be explored via qualitative methods in order to capture what really matters to beneficiaries and the meanings and interpretations that they form. The issues discussed here about practices and potential impacts will be taken up in the empirical part of this study. Chapter 4 elucidates the choice of research methods.

\subsection{Conclusions}

This chapter underlines the view that autonomy is a capability that has to be supported by international aid. The objective has been to present the fundamentals for the analyses carried out in the coming chapters. The main conclusions are below:

1. Four types of practices were identified at the macro-level context of aid, which can be applied to micro-level contexts: selection and design decisions, conditionality, coordination, and accountability (section 3.1.3). At the macro level, conditions related to country governance are more relevant than specific conditions related to sectoral management, credits or projects, which externalise motivation.

2. Economic growth is not enough to secure well-being for the poorest. Effectiveness to reach the MDGs is more relevant. However, there is concern whether the emphasis on 
short-term outcomes with direct impact on well-being is at the expense of long-term institutional capacity or productive activities for wealth creation (section 3.1.4).

3. The complexity of current aid relationships calls for flexible approaches with several aid modalities. In the case of countries with poor capacity and poor governance, the risks are high but experience shows that aid should not be used as a tool to impose (pseudomotivated) change, for this fails to create cooperation, motivation and sustained impact. The long-term engagement of donors, on the ground, to understand socio-historical processes, political cultures and values of aid recipients helps to identify how aid can contribute to specific goals and which aid channels are better suited to particular contexts.

4. At the micro level, practices should be observed during the project cycle and compared with the project logic as stated in the logframe. Activities can be tracked to detect deviations from the plan, who decided about these, why and under which circumstances.

5. The logical framework should be regarded as a design tool that can help to clarify the intended effects of a project but is not sufficient as a monitoring or evaluation tool (section 3.3.2). It offers a simple linear causal link that leaves out significant, indirect and unintended, positive and negative effects that a project could have on human beings. Moreover, assessments of effectiveness based on the logframe do not consider human values and immaterial effects without monetary value.

6. This chapter proposes that, when evaluating projects, it is necessary to identify the full project logic (section 3.3.2): the logic explicit in logframes and project documents, and the logic implicit in practices and crucial processes. This methodology acknowledges the goal-oriented nature and relatedness needs of human beings. During the multiple interactions that take place during a project, participants and others stakeholders make decisions, negotiate goals, experience conflicts or reach agreements.

7. A change process is not caused by a design. Change is pursued, lived and felt by individuals. In this study, impacts are significant changes in people's lives. When project goals correspond to what participants need and value, they interact with others in certain ways (practices) so that the change is sustainable. The support of project staff to the voice of participants and their efforts to help themselves contributes to accountability.

8. This study evaluates the projects in terms of human autonomy effectiveness, not in terms of narrowly conceived economic efficiency (section 3.3.1). The objective is to examine the impacts of the projects on individual autonomy with special emphasis on how those impacts took place. Looking for synergic satisfiers that would support more than one factor contributing to individual autonomy, without restricting others, is important.

9. Human beings are at the centre of this analysis. Their experiences explain many unintended effects and can shed light on new routes to provide aid by promoting their human potentials, without patronising them as mere recipients. As will be seen in the case chapters, the macro-level aid practices and country contexts have influence on what happens in particular project contexts. To different extents and with different degrees of success, project stakeholders try to use and change these influences. 


\section{Research design and methods}

We move from one case to another, not because they are descriptively similar, but because we have ideas that can encompass them both... What are transferable between cases are not lumps of data but sets of ideas. (Pawson \& Tilley, 2000, p. 119-20)

Accelerating the rate at which empirical findings are translated into 'theoretical' formulations is important... because it is only at theoretical level that research findings achieve a sufficient level of generality to be of interest to... wider audiences. (Booth, 1994, p. 15)

This chapter establishes the links between the conceptual model and the empirical part of this study, based on four cases in Nicaragua and El Salvador. The analysis will answer the question: How do (and can) foreign aid projects support the autonomy of final aid recipients?

In addition to understand the experiences of autonomy of the residents of the localities studied, this study aims to conclude about how these experiences have or have not changed because of a specific event in the micro-level context: the aid project. The five research questions, introduced in Chapter 1, are:

\section{A. Conceptual model of individual autonomy}

1. How important is individual autonomy for promoting human development: a) conceptually, and b) from the view of the inhabitants of the four localities?

2. How do individuals in communities experience autonomy in their lives?

3. How can communities shape opportunities for autonomy and human development?

\section{B. Impacts of aid projects on individual autonomy}

4. How might projects affect the autonomy of non-leaders and leaders?

5. In which communities are individuals more likely to experience an expansion of autonomy? Why?

As discussed earlier, autonomy does not imply independence. On contrary, autonomy is exercised by individuals in society so that the relations between individuals in communities deserve special attention in this study. The focus is not on their political participation, understood as a vertical relationship between citizens and the state, although some findings highlight links between social and political domains.

The chapter presents the research design (section 4.1), the data collection methods (section 4.2) and the methods for the within-case and cross-case analysis (section 4.3), discussing the different perspective of analysis. ${ }^{20}$

\subsection{Research design}

For this research, the individual is the main unit of analysis, specifically adults who participated in the project. I contacted heads of households or their spouses, although in some

\footnotetext{
${ }^{20}$ This chapter contains statements written in first person to clearly show that I made crucial research decisions, which will influence the findings of this study.
} 
cases the oldest son or another adult relative was approached. The goal was to contact adults with decision-making power within the household. ${ }^{21}$

Individuals are nested in a larger group: community, which refers to individuals living in the same geographical location (section 2.4.2). The individual is the unit of data source and the unit of measurement. However, the analysis also includes the communities; they are crucial to understand autonomy because individuals require autonomy-supportive contexts in order to participate successfully in social life. Since I analyse each community with emphasis on individuals, each project is instrumental to understand individual and group processes. Moreover, the purpose of this study is not to evaluate specific projects, but to investigate their effects on individual autonomy.

The research is designed as a collective case study, in which the communities themselves are the cases of study with an embedded unit of analysis: individuals who took part in the project. Yin (1981) explains:

As a research strategy, the distinguishing characteristic of the case study is that it attempts to examine: (a) a contemporary phenomenon in its real-life context, especially when (b) the boundaries between phenomenon and context are not clearly evident. (p. 59, [emphasis in original])

To examine the case studies in their real-life context, I carried out a fieldwork study in the year 2005, which included two study visits to the project sites of a total of four months. At that time, project operations were concluding or had concluded. The fieldwork study consisted primarily of engaging respondents in retrospective analysis about their experiences during the projects and their assessment of the current role of community. These analyses were complemented by my observations of their social practices (ways of doing things) and attitudes (predispositions to act) during the fieldwork.

\subsubsection{Defining the scope of the analysis}

The interactions of social actors in multilevel structural contexts determine their options and their exercise of autonomy (section 2.3.2). Figure 4-1 shows the different levels of analysis and possible interrelations of contexts and main actors.

At the macro level, the focus is on international aid practices that govern relations between recipient countries and aid funders (sections 3.1.3 and 5.3). At the meso level, government policies and development strategies delineate the entitlements of individuals in communities (section 5.2 and appendices 1-A \& 1-B). At the micro level, it is useful to analyse separately the community and project context (e.g., sections 11.2 and 11.3) because each project enters into an existing community context, where individuals have different social roles and there is a formal political authority.

The emphasis of this study is on the relations at the local level that includes individuals (i.e., leaders and non-leaders, women and men), their communities (with formal and informal institutions), the local or municipal governments, and the projects (containing a series of actors, structures and practices). The bidirectional arrow in Figure 4-1 connects the community context with the aid project to signal the focus of this study.

\footnotetext{
${ }^{21}$ In this study, I do not examine within-household relations. Moreover, I did not contact children to participate in the focus group discussions in which events related to disasters would be discussed. I did not want to cause them anxiety, especially those children in Santa María.
} 
Figure 4-1: Defining multilevel contexts and analysis decisions

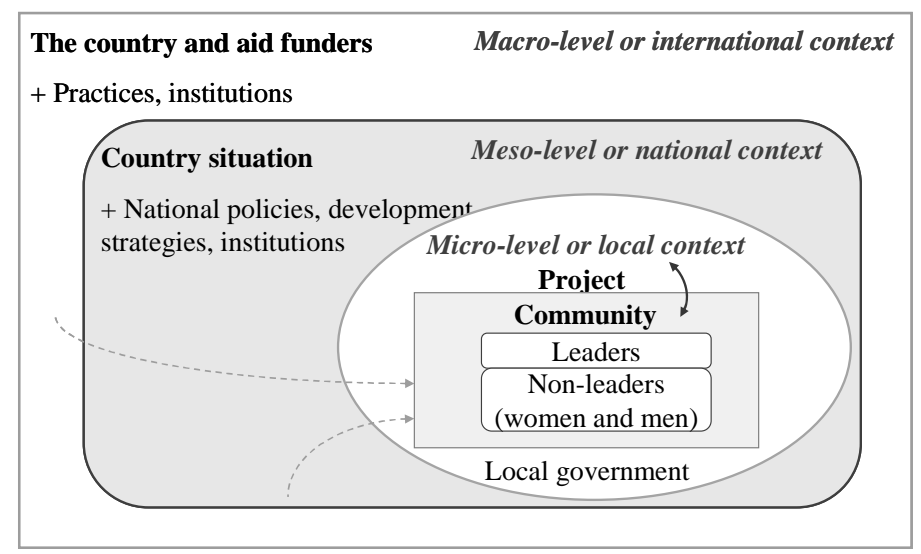

Given that the sites are relatively small and mostly located in rural areas, it is assumed that the influences of the international and national contexts on projects, individuals in communities and their contexts are unidirectional. In addition, many entities were involved in project activities, especially for reconstruction projects, and multiple relations would need to be mapped out.

\subsubsection{Selection strategies}

Selection decisions were made at different levels. In all cases, the selection was purposive. In Nicaragua and El Salvador, the Luxembourg bilateral aid is concentrated in three sectors: water supply and sanitation, health, and education (section 5.1.1). I selected two sectors. I selected water because project staff usually has more relation with final aid recipients in this sector than in others, more focused on large buildings or ministry staff. However, water projects rarely support autonomy in an explicit way, in contrast to health and education projects, with direct intended impacts on personal competence. In addition, water is the sector in which the Luxembourg aid agency, Lux-Development S.A. (LD), has had more experience in Central America. Its first water project in El Salvador started in 1993.

Reconstruction is not a typical sector, but I selected it because of its political relevance. The reconstruction project in El Salvador was focused on community participation and the integral recovery of San Agustín (as stressed by Luxembourg aid officers). In addition, the project was considered to have positive demonstration effects, which means that the project was deemed to provide conclusive evidence of what a good design implies for success.

Table 4-1 summarises the strategies at different levels. At the sector level, the strategy was to select a typical sector (water) and an atypical sector because of its political importance (reconstruction). At the project level, the criteria for selecting projects within these sectors were: (i) that all projects had at least a necessary minimum operational effectiveness and (ii) that at least one project in each sector had demonstration effects. Finally, I selected one project by country/sector. Within each water project, specific communities were selected following the same strategy. The projects were so large in terms of the number of households served and 
territorial dispersion that I could not cover all sites by myself. ${ }^{22}$ Besides, this study does not necessarily evaluate entire projects, but analyse project effects on autonomy.

Table 4-1: Selection strategies at different levels

\begin{tabular}{|c|c|c|}
\hline \multicolumn{2}{|l|}{ Level } & Strategy \\
\hline \multicolumn{2}{|l|}{ 1. Sector } & Typical and atypical sector \\
\hline \multicolumn{2}{|l|}{$\begin{array}{l}\text { 2. Project / } \\
\text { community }\end{array}$} & $\begin{array}{l}\text { Criterion of at least a minimum operational effectiveness } \\
\text { Demonstration effects }\end{array}$ \\
\hline \multirow{2}{*}{$\begin{array}{l}\text { 3. Individual: } \\
\text { (Non-leader) }\end{array}$} & $\begin{array}{l}\text { Focus group discussion } \\
\text { (FGD) participants }\end{array}$ & $\begin{array}{l}\text { 1. Level of involvement in the project and gender } \\
\text { 2. Maximum variation or heterogeneity }\end{array}$ \\
\hline & $\begin{array}{l}\text { Questionnaire survey } \\
\text { respondents }\end{array}$ & FGD participants + volunteers from assembly \\
\hline
\end{tabular}

Note: Please refer to Figure 4-2 for a better understanding of the strategies at the individual level.

Table 4-2 shows the selected project sites. Agua Fría and San Fernando were chosen among other sites because of the required minimum operational effectiveness criterion. The projects in San Agustín and San Fernando were expected to have demonstration effects. The project in Santa María was the only reconstruction project, next to the one in San Agustín, financed by Luxembourg, however several years earlier.

Table 4-2: Summary of selected project sites

\begin{tabular}{|c|c|c|}
\hline \multirow{2}{*}{ Sector } & \multicolumn{2}{|c|}{ Country } \\
\hline & Nicaragua & El Salvador \\
\hline Water & $\begin{array}{c}\text { San Fernando* }+ \\
(2003-2005)\end{array}$ & $\begin{array}{l}\text { Agua Fría+ } \\
(2002-2004)\end{array}$ \\
\hline Reconstruction & $\begin{array}{c}\text { Santa María } \\
(1999-2001)\end{array}$ & $\begin{array}{c}\text { San Agustín* } \\
(2002-2005)\end{array}$ \\
\hline
\end{tabular}

* Projects expected to have demonstration effects.

+ Project sites selected for a minimum operational effectiveness criterion.

The execution period in the sites appears between parentheses (may differ from formal project documents).

At the individual level, the basic distinction was among leader and non-leader participants who were contacted in different ways. In this study, a leader is a person who has formal or informal influence on many of the inhabitants of the locality. For example, (current or former) representatives of a community association, a school teacher, a priest, a doctor, a few older people or returning migrants in some towns can be considered leaders. The selection process for participants in the fieldwork activities is explained in section 4.2.1

\subsection{Data collection methods}

I used several methods to collect and generate data. The central tool of the fieldwork was the focus group discussions (FGDs). I also conducted a small questionnaire survey.

In order to investigate the national contexts, I consulted national strategy reports, research articles, official demographic and socio-economic statistics, and other documents. In order to reconstruct the history of the projects (Roche, 1999/2004), I consulted public information,

\footnotetext{
${ }^{22}$ The project in San Fernando covered five sites (one departmental head, three municipal heads and one canton) in two departments and, in its first stage, above 4,000 households (LD, 2005a). The project in Agua Fría covered thirteen villages in three cantons of San Alejo and above 950 households (LD, 2003a).
} 
such as newspapers articles or official speeches, and project information. Project progress reports, evaluation reports and personal communications with project staff gave me insights into the explicit logic of the projects (section 3.3.2). I elaborated individual notes, diagrams and causal charts for each project.

Project-related information was summarised in a project fact sheet, which contains: basic information about the project sites; official project data including financial information, organisation charts and logical frameworks; a timeline with key activities; and other relevant information such as comparable projects, reported problems and expected results. Shortened versions of the project fact sheets are shown in Appendix 2-B.

During the fieldwork, I recorded my observations in field notes, collected documentation and artefacts from different sources and prepared my own material. FGDs with leaders and non-leaders were audio taped and transcribed. Data collected and analysed per each project was kept in a case study database (Patton, 1987; Yin, 2003a); details appear in Box 4-1.

\section{Box 4-1: The case study database}

The case study database contains all major information used to analyse the case study and includes:

1. Project fact sheet;

2. Fieldwork general material: Organised field notes (e.g., with details like local words, stories of towns), diaries or journal of activities, summary reports per case, photographs, and others;

3. Public documentation: maps, local development plans, laws, media articles, etc.;

4. Project documentation: formulation and evaluation reports, progress reports and statistics, videos, and training manuals;

5. Tabular material: survey data (dataset 1 and 2), statistics, counts, individual scores of impacts, etc;

6. Archival records of interviews and FGDs: audio-cassettes, literal transcripts or summaries when no audiotape was recorded, observation notes, list of participants;

7. Process records: minutes of FGDs including flipcharts and drawings, (coded) narratives, analytical charts and personal records, structured transcripts; and

8. Physical artefacts: monographs (e.g., school research study, history of the village), promotion and educational material, etc.

In addition to final aid recipients, leaders and non-leaders, I contacted other stakeholders, ${ }^{23}$ such as local political authorities and staff of the contracted NGOs, public ministries and public water companies. I interviewed officers of the ministries of Foreign Affairs in Nicaragua, El Salvador and Luxembourg. I also contacted staff of the Luxembourg aid agency: the project chief (when available), employees at the regional office (in Nicaragua), and managerial staff at headquarters.

With respect to community leaders, I had three or four individual interviews per site, group interviews and one special FGD per site in order to understand the community dynamics and the role that leaders played during the project (see FGD protocol in Appendix 2-C). Verbal conflicts spontaneously appeared, in some cases, which was informative in terms of underlying power relations.

In sum, I held 30 semi-structured interviews (22 of them were audio recorded) and about 50 un-structured interviews, in some cases, including residents not enrolled in the other fieldwork activities. In total, more than 300 people participated in all the activities.

\footnotetext{
${ }^{23}$ For Bourne and Walker (2005) a stakeholder is anyone who can be affected by a project and has a moral right to influence its outcome. I focus on those whose cooperation and support was deemed vital for project success.
} 


\subsubsection{The strategy with non-leader participants}

This study pays special attention into participants' experiences of autonomy and their perceptions of change in autonomy, related or not to the project. The primary focus was on nonleaders. To contact them and to work together, I followed a sequential recruiting strategy depicted in Figure 4-2.

Figure 4-2: Data collection strategy with non-leader participants

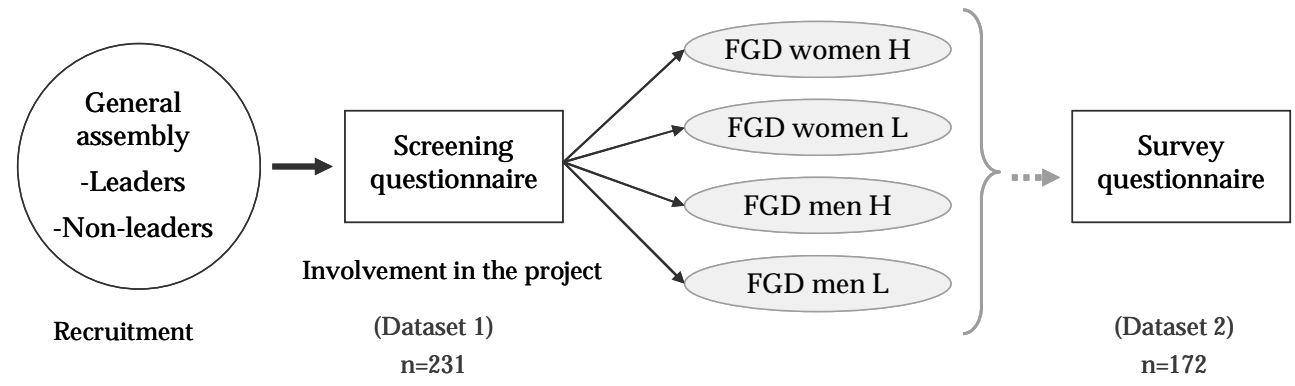

L refers to 'low' and $\mathrm{H}$ to 'high' involvement.

FGD: Focus Group Discussion

First, I contacted formal community leaders and asked them to call people for a general assembly. At the assembly, I informed residents about the study purpose and planned activities and filled in the screening questionnaire with non-leader volunteers. I flexibly adopted parallel strategies when this uniform strategy was not effective in a project site. For instance, in Santa María, leaders did not gather enough people in the community centre and I had to follow a door-by-door recruitment strategy. In San Fernando, leaders could not organise the assembly; they contacted their neighbours and filled in the screening questionnaires with them (except for one small recruitment meeting that did take place).

The questionnaire contained basic background questions and other questions related to the involvement of non-leaders in each project. Responses were combined into an 'involvement index' used to divide participants into groups of low or high involvement (Box 4-2).

Box 4-2: The index of individual involvement in the project

This index was a simple average of ratings assigned to five questions related to the project and the individual. The intensity scale for each question ranged from zero to three, where zero was equivalent to 'no', one to 'rarely', two to 'sometimes', and three to 'usually'. The questions were:

1. Did you use your abilities or practical knowledge during the project?

(Awareness)

2. Did you give your opinions about the project to your community?

(Opinions)

3. Did you receive the relevant information you needed about the project?

(Information)

4. Did you have the opportunity to share in decisions related to the project?

(Opportunities)

5. How frequently did you share in decisions regarding the project?

(Decisions)

Conceptually, the questions covered aspects related to (i) perceived agency (feeling aware of personal competence and self-confident to speak up), (ii) entitlements (access to relevant information), (iii) autonomy-supportive contexts (having the opportunity to share in decisions), and (iv) the exercise of decision-making. These aspects were explored deeper during the focus group discussions.

Second, I formed four groups of non-leaders per case, using primary and secondary variables (Billson, 2004). The primary variables were gender and the level of involvement (based 
on the involvement index). The secondary variables were age and literacy levels. I looked for maximum variation of these secondary variables within each of the four groups. Thus, the individuals were homogeneous in terms of involvement and gender but heterogeneous in other variables. Appendix 2-D shows some characteristics of FGD participants.

Third, some days later, I administered the survey questionnaire (Appendix 2-E) to FGD participants and a few non-FGD participants who had attended the assembly. This means that the latter self-selected themselves to be only individually interviewed at their homes (this was the case for many men in San Fernando).

\subsubsection{The focus group discussions and the questionnaire survey}

The FGDs were held in a common public place (an uninhabited house, an auditorium or a community centre) that was neutral in the sense that participants did not feel restricted in their opinions. Leaders did not attend the FGDs with non-leaders. Although I assured anonymity to the participants, I could not guarantee confidentiality as other participants could have shared topics and ideas discussed with outsiders after the meetings.

It worth mentioning that the local context in Santa María was tense, at the start of the fieldwork, because it was the former social promoter who introduced me to leaders and helped me to gather non-leaders for the activities. As I shortly discovered, many villagers did not trust the social promoter due to conflicts during the project, while some openly rejected the formal leaders. Hence, some people could have self-excluded from participation in the FGDs because of her or because of the recruiting strategy. However, neither she nor leaders participated in any of the activities with non-leaders (FGD or individual interviews).

Regarding the FGDs with non-leaders, the introductory part was dedicated to discussing their individual life experiences before and after the project. Here, indirectly, some elements of autonomy were discussed. Afterwards, we made use of:

- Group listing of project features, as an initial step to help participants reflect jointly. They listed positive and negative effects, classified in categories freely defined by them.

- An individual scoring exercise about four variables associated to autonomy: information, self-confidence, opportunities and decision-making (see Box 4.3). The exercise fostered discussions about whether the project influenced changes in those aspects. It also produced quantitative data.

- Group listing of elements of a 'strong' community and recommendations for future projects. The objective was to gain awareness of the current situation and reflect upon whether something had changed in the community because of the project or other events.

Box 4-3: Scoring exercise during the focus group discussions with non-leader participants

The objective of this scoring exercise was to know the participants' assessment of changes in some variables conceptually associated to individual autonomy. During the focus group discussion, each participant received five sheets so that he or she could assign individual scores to each variable using a vertical scale from 0 to 10 (see Appendix 2-C). Participants were asked to mark the number that most accurately expressed the extent of information that they received during the project, and the numbers that reflected their situation before the project ('before') and at the time of the fieldwork ('now') with regard to:

Information about relevant events or plans for the community; 
- Self-confidence, in terms of being able to give opinions and defend them;

Opportunities to make decisions in relation to ways how to improve their lives; and

The exercise of decision-making in significant life issues, without coercion and with responsibility.

After each sheet was filled in, each participant told his or her scores to the whole group in loud voice and I put a mark in the flipchart. The emphasis was on the changes. Then, the flipchart, besides numbers, had vertical arrows going up, down or horizontal arrows (meaning: no change). Based on these different directions of change, the group would discuss the changes with examples, reflecting on whether the project had explained or not, partially or totally, some of those changes.

The anonymous sheets were collected at the end of the exercise. The scoring exercise produced quantitative data (individual scores) but also qualitative data from the discussion generated.

Regarding the FGDs with leaders, the protocol included questions related to the history and context of the communities in order to cross-check baseline information. We used a group ranking of the effects of the project in the community (cf., Alkire, 2002; Roche, 1999/2004) that fuelled discussion and clarified the causal theories implicit in the projects. ${ }^{24}$

Regarding the survey, its purpose was to know more about the respondents' socio-economic situation, their experiences during the project and their perceptions and attitudes toward their community (see Box 4-4).

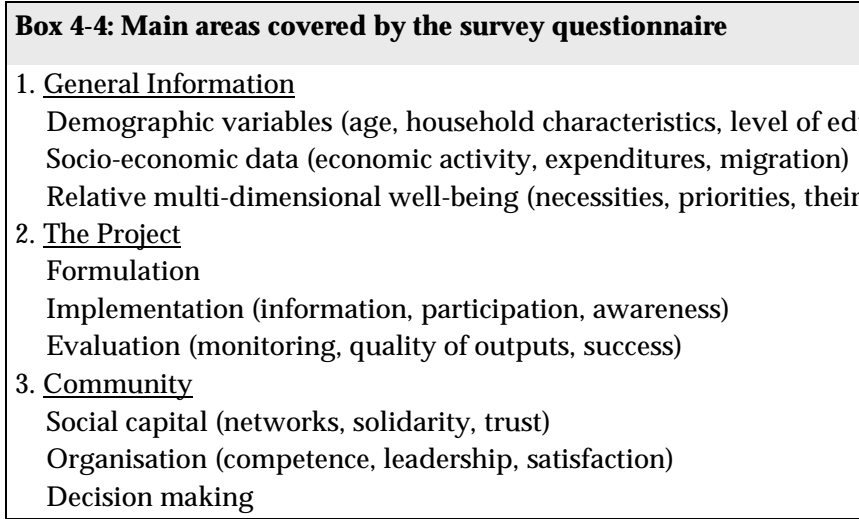

The survey was applied in the respondents' homes for several reasons. First, interviewing them in a known environment helped me to increase their trust and to observe their actual living conditions. Second, walking around all the time allowed me to be familiar with residents, hold informal interviews with people en route, and observe their informal social practices.

In some cases, I collected more valuable information by this means than by focus groups, as individuals felt they could say whatever they thought without exposing themselves to group sanctions (especially in Santa María and, to a lower extent, in San Fernando). The questionnaire became a guide for semi-structured individual interviews that could last up to one hour. The fact that the questionnaire had several open-ended questions and was not audio taped also contributed to build rapport.

\footnotetext{
${ }^{24}$ I also tried out a group ranking of impacts with non-leaders in Santa María (the first site visited), but people found it very difficult to deal with rankings. The situation might have been worse in the Salvadoran sites as the literacy rates of their inhabitants were lower.
} 


\subsubsection{Researcher's involvement in the sites}

The research study was carried out during four years, from April 2004 to November 2008. The first visit was between January and February 2005 and had the purpose of gathering in situ information to make the final selection of the projects. The second visit was the actual fieldwork and took place between June and September 2005.

The staff of the aid agency, especially for projects in San Agustín and in San Fernando that were still in execution during my first study visit, introduced me to leaders and political authorities at the sites. Some leaders became facilitators who gathered people for meetings.

During the fieldwork, I did not live at the sites. I spent the nights in larger nearby towns and commuted to the sites. I also interviewed stakeholders who where not located at the sites, mainly the staff of the executing NGOs or political authorities.

I trained a Nicaraguan sociologist in the conceptual model, research questions and the application of instruments. She assisted me with the logistics of the FGDs and co-moderated the FGDs with leaders. I did the initial interviews with stakeholders and both of us administered questionnaires. In addition, I planned to work with a local co-moderator for the FGDs with non-leaders in the reconstruction sites in order to build a sympathetic context. However, it was necessary only in Santa María (where the disaster was much stronger than in San Agustín).

\subsubsection{Research ethics}

During the assemblies and FGDs, participants were informed about the general purpose of the study. I emphasised that 'I was there to listen to their opinions as they were the experts to assess how the project might have affected their lives'. I purposely avoided using the 'autonomy' word during the FGDs because of the different meanings this could have. Moreover, I did not want to start a discussion on definitions, but to discover whether and how different determinants of autonomy did or did not appear in their story telling. After the scoring exercise, I explained that the elements analysed were relevant for increasing one's potential.

I did not request signed informed consents for participants as many respondents were illiterate $(44 \%$ of non-leaders in FGDs) and this requirement could have harmed their selfconfidence. I did explain verbally that this was an academic research study not a needs assessment for a new project (I was emphatic about this); that their names would not be associated to their statements, but that their collaboration would be acknowledged in a book; and that this was a voluntary activity that would take a pre-defined time. Because of budget limitations, I could not offer any payment. However, I provided light refreshments and cookies during the meetings and free transport to the meeting place. Before starting each FGD, I explained the reasons for using the tape recorder and promised that transcripts would be used exclusively for academic purposes and kept in my personal archives.

\subsection{Analysis methods}

This study is framed in the interpretive tradition. The objective is to understand changes in the lives of project participants (final aid recipients), based on their understandings. The existence of double hermeneutics requires that I search for alternative explanations recurrently 
as my own presuppositions could affect data gathering and analysis. ${ }^{25}$ As my subjectivity intervenes in the interpretation, I make explicit my interpretations and ground my findings in data, as much as possible.

I carried out an analysis at two levels: within each case and across cases. I applied primarily qualitative methods, complemented with quantitative analysis to triangulate data collection, produce complex data, and explore alternative hypotheses.

The analysis for each case included three broad steps:

1. A detailed description of facts, looking at people, structural contexts, project practices and activities;

2. The interpretation of facts by exploring alternative explanations and selecting the most suitable explanation based on evidence, and looking for disconfirming evidence; and

3. The identification of patterns across cases, to be contrasted to the conceptual model.

Case databases formed an effective basis to understand the logic of each project. The first analytical step was to construct the project fact sheets (section 4.2). Later, insights gathered from key informants about each project and its activities were contrasted with its fact sheet. In general, I can not know what really happened during the project but I do know what people considered important to tell me and what I observed as current practices.

When conflicting information appeared during the fieldwork, I cross-checked the fact sheet by asking other participants and stakeholders, revising documents as warranted. As Patton (1987) suggests, I compared what people said in public (in the FGDs) to what they said in private (individual interviews), and analysed the consistency between the two. During the FGDs, I did not look for agreements but paid attention to the elaboration (or not) of arguments for conflicting statements as inconsistencies and contradictions may show important areas of contestation and struggle (Nuijten, 1998) undergoing within the communities.

Triangulation was a continuous practice in order to assure data reliability and to come close to the correct interpretation of the perceptions of the respondents. Verification was also present at the level of researcher: my assistant produced parallel field notes and a complete report for each case while we were still in the field. Discussing our analyses allowed us to identify new pathways of research. As Einsenhardt (1989) states, overlapping of data collection and analysis facilitates making adjustments during the data collection process. When disagreements of interpretation arose, I searched for new evidence and I made use of different collection methods, depending on the context. For instance, in order to obtain a mapping of the relative well-being of individuals within the communities, I applied key-informant interviews (San Agustín and Agua Fría), FGDs (Santa María) and a 'basic capabilities survey' for water projects, with visual aids (section 4.3.3).

When data leading to new themes were feasible, I followed a 'controlled opportunistic strategy' (Einsenhardt, 1989). Because the objective 'is to understand each case individually and in as much as depth as is feasible..., not to produce a set of summary statistics about a set of observations' (ibid, p. 539), it is legitimate to be flexible regarding data collection to take advantage of the uniqueness of a specific case.

\footnotetext{
${ }^{25}$ Hermeneutics assumes that the internal meaning of texts or acts can be discovered through careful and personal interpretation by the researcher (Bernard, 1988, p. 22). 'Double' hermeneutics implies that (i) the participants themselves interpret the facts, and that (ii) I interpret (or understand) their interpretations.
} 
In each FGD, participants had the opportunity to engage in preliminary analysis regarding impacts and lessons learned. These analyses were compared across groups. Although the protocol was the same for all non-leader groups, in some cases, I introduced probes to allow participants to develop their arguments and elucidate their perceptions regarding the results from other groups. Then, the interviews were not 'value-free' because at some points I wanted to verify the emerging patterns (Riddell, 1990), which means that a kind of analysis triangulation was already under way (cf., Narayan et al., 1999, p. 46). Billson (1991) refers to this as the 'progressive verification method' or the interpretive analysis emerging from each focus group modified by the next group, and sequentially and progressively verified during the course of the study. This analysis was reassessed at later stages.

Beyond the transitive effect of facilitating analysis, the use of focus groups as a participatory tool (including group listings and rankings) also had valued and intransitive effects (cf., Alkire, 2002). ${ }^{26}$ Participants felt that they had learnt something by discussing together and that their values and opinions were being considered. Their analysis 'promoted critical reflection on past changes and generated new ideas for the future' (Roche, 1999 2004, p. 122).

The individual interviews were also transcribed (recorded via audiotape or notes) and analysed by using qualitative content analysis. Survey responses were tabulated and the openended questions coded, which yielded some basic descriptive statistics.

\subsubsection{Within case analysis}

For the within case analysis, I applied various strategies as shown in Table 4-3. The first research question was conceptually studied in Chapter 2 that explains the relation between autonomy and human development, based on literature review and the empirical study.

I analysed the FGDs from two perspectives. First, I used an inductive perspective when applying qualitative content analysis to literal transcripts for the first three research questions (about individual autonomy) and RQ five (about the expansion of autonomy). Second, I used a deductive perspective when analysing the transcripts guided by the protocol and carrying out the 'directed' content analysis for RQ four about project effects on autonomy. ${ }^{27}$

In addition, a Peruvian psychologist prepared 'commented' structured transcripts. I compared her interpretations with mine, as a way of providing an external audit and triangulating analyses. These reports have the following characteristics:

(i) Their structure follows the sequence of topics in the FGD protocol;

(ii) For each topic, they include the most relevant quotes together with a description of the context in which these were expressed;

(iii) There are comments about potential meanings of the quotes; and

(iv) Additional issues (not in the protocol) are presented with alternative explanations.

\footnotetext{
${ }^{26}$ I used FGDs as a participatory tool, not as a method. The themes in the protocol were generated in advance by me according to my research topic. The purpose of the meetings was supportive to my research study, not to the actual interests of participants. In contrast, participatory methods are integral, so that individuals actively engage in every stage of a project (Chambers, 1995).

${ }^{27}$ Hsieh and Shannon (2005) identify three approaches to qualitative content analysis: (i) the conventional, which is inductive and does not impose preconceived categories or theoretical perspectives, (ii) the directed approach, deductive because it aims to validate or extend a existing theory, and (iii) the summative content analysis, with the purpose of discovering underlying meanings of the words or the content (cf., Mayring, 2000).
} 


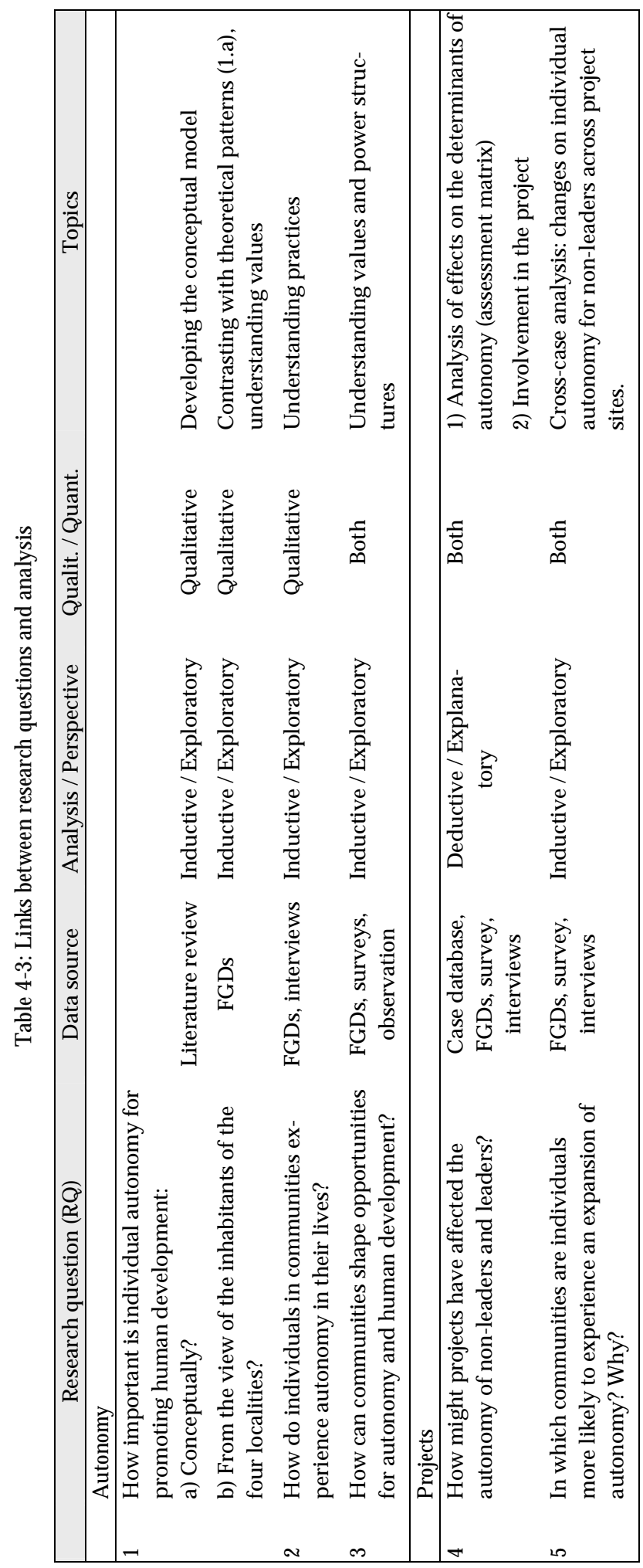


With respect to RQ four, the two topics (last column in Table 4-3) reflect a different method. The first method compares the actual and expected effects of the project, based on its explicit and implicit logic (section 3.3.2). The second method looks at different effects for groups with different level of involvement in the project. The hypothesis is: 'the higher the individual involvement the higher the expansion of autonomy'.

For the first method, the analysis process is presented via an assessment matrix (Table 4-4).

Table 4-4: Assessment matrix of project effects on the determinants of autonomy

\begin{tabular}{|c|c|c|c|c|}
\hline \multirow[b]{2}{*}{$\begin{array}{l}\text { Determinants of } \\
\text { autonomy }\end{array}$} & \multicolumn{2}{|c|}{ PROJECT LOGIC } & \multicolumn{2}{|c|}{ ACTUAL EFFECTS } \\
\hline & $\begin{array}{l}\text { Hypotheses on } \\
\text { effects }\end{array}$ & $\begin{array}{l}\text { Expected condi- } \\
\text { tions }\end{array}$ & Actual situation & $\begin{array}{l}\text { Assessment of } \\
\text { effect }\end{array}$ \\
\hline $\begin{array}{l}\text {-Entitlements } \\
\text {-Agency } \\
\text { (inc. self-confidence) } \\
\text {-Structural contexts } \\
\text { (e.g., communal } \\
\text { organisation, social } \\
\text { capital) }\end{array}$ & $\begin{array}{l}\text { Intended and } \\
\text { unintended, ex- } \\
\text { pected impacts } \\
\text { based on project } \\
\text { 'logic' (logical } \\
\text { framework and } \\
\text { project practices). }\end{array}$ & $\begin{array}{l}\text { Assumptions and } \\
\text { outputs that are } \\
\text { explicit and im- } \\
\text { plicit in project } \\
\text { logic. }\end{array}$ & $\begin{array}{l}\text { Actual conditions } \\
\text { or change in condi- } \\
\text { tions (in contrast to } \\
\text { expected condi- } \\
\text { tions) related or } \\
\text { not to the project. }\end{array}$ & $\begin{array}{l}\text {-Yes/no, partial } \\
\text {-Short or long-term } \\
\text {-Sustainable, at risk } \\
\text { (vs. hypotheses) }\end{array}$ \\
\hline
\end{tabular}

This matrix lists for each case:

i) The determinants of autonomy (i.e., entitlements, agency, and contexts) that could have been affected as result of the project according to its explicit and implicit logic;

ii) The tentative hypothesis related to the effects (intended or unintended) on these determinants expressed as potential benefits (or disbenefits) of the projects;

iii) The conditions that would explain changes in those elements, based on planned processes and expected material outputs, and the implicit assumptions for their fulfilment;

iv) The actual situation in terms of determinants of autonomy; and

v) My judgement about how the actual situation compares to the hypothesised situation thanks to the project, and to the situation before the project and the situation without the project.

This matrix is the basis to understand the changes (positive, negative, or null) and their causes. It explains the 'outcomes' after elucidating the 'mechanisms' that work or not in the context of the project sites (Pawson \& Tilley, 2000; Leeuw, 1999). The analysis covers the internal and external conditions that could promote autonomy as a combined capability (section 2.4), not necessarily a functioning or the exercise of autonomy. Because this analysis relies heavily in my own judgement, I consciously looked for the inclusion of multiple data sources and different perspectives.

\subsubsection{Cross-case analysis}

The fact of having several cases allowed me to look for replication of the latent theory (Eisenhardt, 1989), that is, whether every new case confirms or disconfirms the emerging relationships so that the latent theory is refined or extended and the reasons for the existence of such relationships are discovered. The aim is not to generalise factual conclusions from each community to others as 'the behaviours and attributes that signify empowerment [or expansion of autonomy] in one context often have different meanings elsewhere' (Malhotra et al., 2002, p. 17). Rather, it is to test and generate theory built from each case, based on data, following the rule of inclusiveness (Billson, 2004; Maxwell, 1992/2002). 
The cross-case analysis (Creswell, 1998) consisted in:

- Examining themes or categories across cases to identify the existence of similar or dissimilar themes (especially in RQ one to three);

- Contrasting explanations of specific patterns (RQ four and five) sequentially; and

- Comparing results from different analytical methods. The comparison is at the abstract level, not at the descriptive level (Pawson \& Tilley, 2000).

Most of the research questions are investigated at the individual case level and later across cases, as explained above. However, RQ five directly includes the individual and community levels. The task is to identify whether there are differences in autonomy expansion among individuals within each case and between the cases. Within each case the main variables to group individuals and analyse differences in effects were: leadership role, gender, and the level of involvement in the project. Between cases, candidate variables were the level of relative affluence, the strength of the community association, the relative connection to the market, among others. Sectoral differences are discussed in Chapter 10.

\subsubsection{Quantitative analysis}

The qualitative analysis was complemented with descriptive and associational quantitative analysis. There were two datasets: (i) dataset 1, responses to the screening questionnaire (preFGD) and (ii) dataset 2, responses to the survey questionnaire (post-FGD). Datasets are described in Appendix 2-F and 2-G, respectively.

Causality was interpreted qualitatively. The existence of causal conjunctures makes the impact of any single cause dependent on the presence or absence of other causal conditions; this is a complex reality with which the quantitative analysis can hardly cope (Ragin, 1997). However, the quantitative analysis helped me to identify association, explore spurious relationships, and generate alternative explanations. ${ }^{28}$ I consider the usage of statistical tools plausible in this study, although the selection strategy was purposive as I looked for maximum variation. I can assume randomness because 'the selection is unrelated to the outcomes'; $^{29}$ only in the case of San Fernando, it seems that the least poor households selfexcluded from fieldwork activities. Moreover, the patterns to be found in the sample are likely to exist in the population and are not only applicable to this sample. ${ }^{30}$

Regarding RQ three (communities and the shaping of opportunities), I used dataset 2 to explore intra-community relations. Regarding RQ four and RQ five (project effects on autonomy), I used dataset 1 to compare the different degrees of involvement in each project and analysed whether differences were significant; explanations came from the FGDs.

I also examined differences in the elements of the involvement index and elaborated two alternative indexes (section 10.4.3). The analysis supported the discussion on participation and involvement. The difference - for the purposes of this work - is that participation was defined only as physical work for most of project participants so that survey respondents

\footnotetext{
${ }^{28}$ Alsop et al. (2006) in reviewing five country studies and their application of empowerment, indicate that 'because of methodological problems - including the critical issue of endogeneity that is endemic to statistical analysis of highly interactive variables - in most cases [their] findings must be treated as indicative of associations rather than as definitive statements of causality' (p. 46).

${ }^{29}$ This observation was made by Denis de Crombrugghe (personal communication, August 21, 2006).

${ }^{30}$ Max Bergman (public presentation, July 21, 2006)
} 
would say that their participation was high when they worked a lot for long hours in many activities. In contrast, involvement refers to a high-quality participation that includes aspects related to autonomy and its exercise.

In the case of water projects, the survey questionnaire (dataset 2) included questions about priority areas of life based on 25 pre-selected items, in order to explore values and to assess individual well-being. This set of questions can be called a 'basic capabilities survey' (see Box 4-5). I did not use it with respondents in reconstruction projects because of the acute material poverty in which most households live (especially in Santa María). I did not want to embarrass those people if they had to speak loudly about their wishes and many lacks.

\section{Box 4-5: 'Basic capabilities survey' and multidimensional well-being}

The basic capabilities survey is based on Davies and Smith (1998) and Pantazis, Gordon \& Townsend (2000) who applied 'basic necessities surveys' to investigate poverty in Vietnam and the UK, respectively, based on need satisfiers (material goods and social events). In this work, I included other areas of life in addition to material needs. Global areas ranged from life and physical health to freedom of choice and action. These and their specific indicators (items) were selected following Robeyns (2002) and after discussions with informants during the recruitment stage in San Fernando. Finally, 25 items that represent dimensions of life expressed as doings, beings, feelings (capabilities or needs) and their satisfiers were included (see Appendix 2-E).

Respondents were given 25 cards with drawings that represented the items above and were asked:

1. Which of the elements shown in the cards do you think are necessary for everyone (that no one should lack them)?

2. Please, order the elements chosen above from the most to the least important.

3. Which of these elements do you have now?

The objective was to find out about well-being in terms of (valuable) capabilities and functionings. The elements chosen in question (1) and prioritised in question (2) are the capabilities or their satisfiers. The responses to question (3) indicate the functionings or achievements (yes/no). Based on these, two wellbeing indexes were obtained.

Priority items: A modified Borda count was used to obtain the ranking of priority items for all respondents in each project site. The weights for each individual depend on the total number of options (k) each individual chose to order (priorities). The first in the ranking got a weight of $k$; the second, a weight of (k-1), and so forth.

'10-top' well-being index: It was obtained counting the achievements ('yes' responses) of each individual in the 10 items considered necessary for most respondents. The index is a relative number that compares the individual weighted achievement with the maximum possible weighted achievement (weights are the same).

'Own' well-being index: It was calculated counting the achievements of each individual only in the items listed by him or her. It takes into account his or her individual weight. This index is also a relative number.

'10-top' index $\quad I_{j}=\frac{\sum_{i=1}^{10} w_{i} \times a_{i j}}{\sum_{i=1}^{10} w_{i}} \quad$ 'Own' index $I_{j}=\frac{\sum_{i=1}^{k_{j}} n_{i} \times a_{i j}}{\sum_{i=1}^{k_{j}} n_{i}}$

Where: $i=$ item, $j=$ individual, $a=$ achievement, $w=$ majority weight, $n=$ individual weight, and $k_{\mathrm{j}}=$ number of options for individual $j$. 
Using the majority weight (10-top index) simulates a result that could result from public deliberation (i.e., one of the results), while using the individual weight (own index) is more in line with an emphasis on individual autonomy. The inter-personal comparison, however, is harder using individual weights than using consensual weighs (see Sen, 1993). Then, I do not aggregate achievements of all respondents across dimensions, but all the achievements for each individual. This must be taken into account when the results are interpreted.

On the other hand, the use of quantitative data generated with the individual scoring exercise (section 4.2.2) about changes in information, self-confidence, opportunities and decisionmaking provided an indication of the direction of the changes in autonomy. Measures of central tendency for the changes in individual scores were analysed, comparing individuals by gender and level of involvement. Possible explanations were provided based on the participants' statements.

\subsection{Character and limitations of the study}

This study has two defined characteristics: it is exploratory and explanatory. It is exploratory because it aims to understand individual autonomy for people who participated in the projects (the importance they attach to it and how they experienced it) and how their communities might promote or restrict their individual autonomy.

It is explanatory because it looks for project effects on individual autonomy, based on selfreported situations, aims and hopes, and contrasts these effects with specific hypotheses based on the project logic. No similar study had ever been conducted on these communities, so there was no baseline data to compare statements before and after the project. However, the tools did work to assess impact. As Smulovitz and Walton (2002) assert:

When a poor farmer in a focus group expresses views on the effectiveness of a [project], the issue at stake for evaluation is still against an (explicit or implicit) counterfactual (p. 39).

The alternative of contacting similar communities to be used as 'controls' (holding FGDs with similar protocols) was discarded because my approach gives a large weight to structural contexts. I cannot compare one community with other and say that the only difference is that one had this specific project and the other did not. I cannot control for all meaningful variables. This is clearer in the reconstruction cases that were seen as 'symbolic' cases in their respective countries because of the magnitude of the disasters.

Furthermore, each case in itself is the subject of a whole study; the logic is not to work with a small sample of cases to make generalizations, rather to raise hypotheses. However, a detailed description of the cases facilitates the transferability to other contexts. In this way, elements of the contexts found to be significant in these cases can be compared to the contexts of other cases (Lincoln \& Guba, 1990/2002). It is worth noticing that the cases presented will be 'thinner real case studies' as characterised by Gasper (2000c) so that I present relevant details without overwhelming the readers with incidental or biased information.

This is a retrospective study that mainly uses data gathered during focus group discussions. The analysis relied on the participants' perceptions, their capacity to recall events, and their ability to evaluate change in their lives. Two aspects deserve caution: 
1. People may not regard their initial situation as they did before the intervention, because their understanding is influenced by their current lived realities and the process of development changes their valuations (value endogeneity), and

2. They may change their beliefs about their past experiences, or reinvent their old behaviours, in order to eliminate dissonances with current practices and perspectives. ${ }^{31}$

In the final analysis, their discourse is a 'representation of what [they] want the world to be, rather than a representation of how the world is' (Carver, 2002, p. 51), at least in part. Nevertheless, for an external observer it would be less feasible to assess a change in participants' lives than for them to do so.

The definition of autonomy contains both objective and subjective elements (section 2.3.2). The objective element is related to personal competence and entitlements on which competence is based. Entitlements are built on existing resources but include the readiness to use them (effective access) that depends on the context. Perceived agency is the foundation for initiating change when individuals are aware of their capacities. There is a subjective element: selfconfidence that depends on the existence of supportive contexts and personal factors.

Given this interrelation between objective and subjective elements, a combination of methods serves better the purposes of this study. ${ }^{32}$ Hence, I will not rely on either an asset index (as a proxy for agency) or autonomy scales (see Alkire, 2005, for a survey of subjective measures). Because structural contexts are crucial for this research study, I prefer methods that collect perceptions on autonomy that are contextualised (in personal interaction) instead of methods that consider only one-shot opinions related to empowerment and then seek common patterns (see Brown, 2003). I am interested not only in the expansion of autonomy, but primarily in how and why this might have occurred.

Therefore, I investigate respondent perceptions in the focus group discussions, individual interviews and the survey (self-reported subjective and objective indicators). I analyse external information about contexts and objective indicators, such as fulfilment of intermediate needs. Moreover, I use complementary secondary data regarding living standards and other contextual factors whose depth varied by community. I used triangulation in different aspects to ensure the correct interpretation of self-reports. Analysis was also made during the fieldwork period, which allowed on-the-spot response and new information collection.

Overall, this is a qualitative comparative analysis that relies on mixed data collection and analysis methods. Causality was interpreted qualitatively.

\footnotetext{
31 As time goes on, the original acts and behaviours are subject to further and further revision, reinterpretation, forgetfulness, murkiness, etc. This must be considered especially in the case of the project of Santa María that concluded in 2001, four years earlier than the fieldwork for this study.

${ }^{32}$ Alsop, Bertelsen and Holland (2006) also combine subjective and objective elements. At the intra-community sub-domain, they suggest direct measures of empowerment such as perceptual data on constraints to association and on mobility, and recall data on decision-making in the community. They also suggest indirect measures of empowerment: asset endowments and the existence of institutions.
} 


\section{Part II:}

The empirical study 



\section{Four case studies and their multilevel contexts: an introduction}

Part II of this study presents four project cases. They are presented in subsequent chapters following a chronological order (see Table 5-1).

Table 5-1: Basic coordinates of the projects

\begin{tabular}{|l|c|c|c|c|}
\hline Project site & Santa María & Agua Fría & San Fernando & San Agustín \\
\hline Period* & May.1999- Oct. 2001 & Oct.2001- Jan.2004 & Sep.2002- Jan.2005 & Oct.2001 - Mar.2005 \\
Sector & Reconstruction & Water & Water & Reconstruction \\
Country & Nicaragua & El Salvador & Nicaragua & El Salvador \\
Municipality & Posoltega & San Alejo & San Fernando & San Agustín \\
\hline
\end{tabular}

* The dates correspond to the time when project formulation started and when project staff left the site.

The projects in San Fernando and San Agustín were 'closed' (with evaluation missions) later.

This chronological presentation hast two advantages. First, it allows analysing short and long-term changes, although there are challenges. The project of San Agustín was completed in 2005, the year of the fieldwork study, so it is challenging to judge whether the effects on community organisation are sustainable. The project of Santa María was completed in 2001; some effects are quite clear, probably clearer than at the time of its completion, but there are several intervening factors that could explain the current situation.

Second, it is useful to analyse how the lessons from previous projects were incorporated into the design and practices of new projects. The selection of two projects in each sector and two projects in each country allows tracking practices across sectors and across countries. For instance, was there any change in the design of the projects in Santa María and San Agustín?

The main purpose of this chapter is to present the context for the individual case studies in Part II. As explained in Chapter 4, the contexts in which the projects took place are classified for the purposes of this study in: macro or international level (donor-recipient relationship), meso or country level (country situation and policies), and micro or locality level (social actors and organisations). This chapter discusses the first two levels, while the micro level for each case is analysed in detail in the case chapters.

The chapter is composed of four sections. Section 5.1 briefly describes the projects and localities studied. Section 5.2 introduces the meso-level contexts, focusing on those country features that influence the entitlements, livelihoods, and aspirations of the inhabitants of the project sites. Section 5.3 presents the general policies and practices of Luxembourg aid applicable to Nicaragua and El Salvador (part of the macro-level context), which are necessary to understand the design and organisation of the projects. Section 5.4 contains a note about the general approach of the case studies in Chapters 6 to 9.

\subsection{D escription of the projects and localities studied}

Santa María and San Fernando are located in Nicaragua. Santa María is a small town in the Posoltega municipality, department of Chinandega in the North Pacific region. San Fernando is a municipality centre in the department of Nueva Segovia, in the North highlands. Figure 5-1 shows the location of both in the political map of Nicaragua. 
Figure 5-1: The project sites in Nicaragua

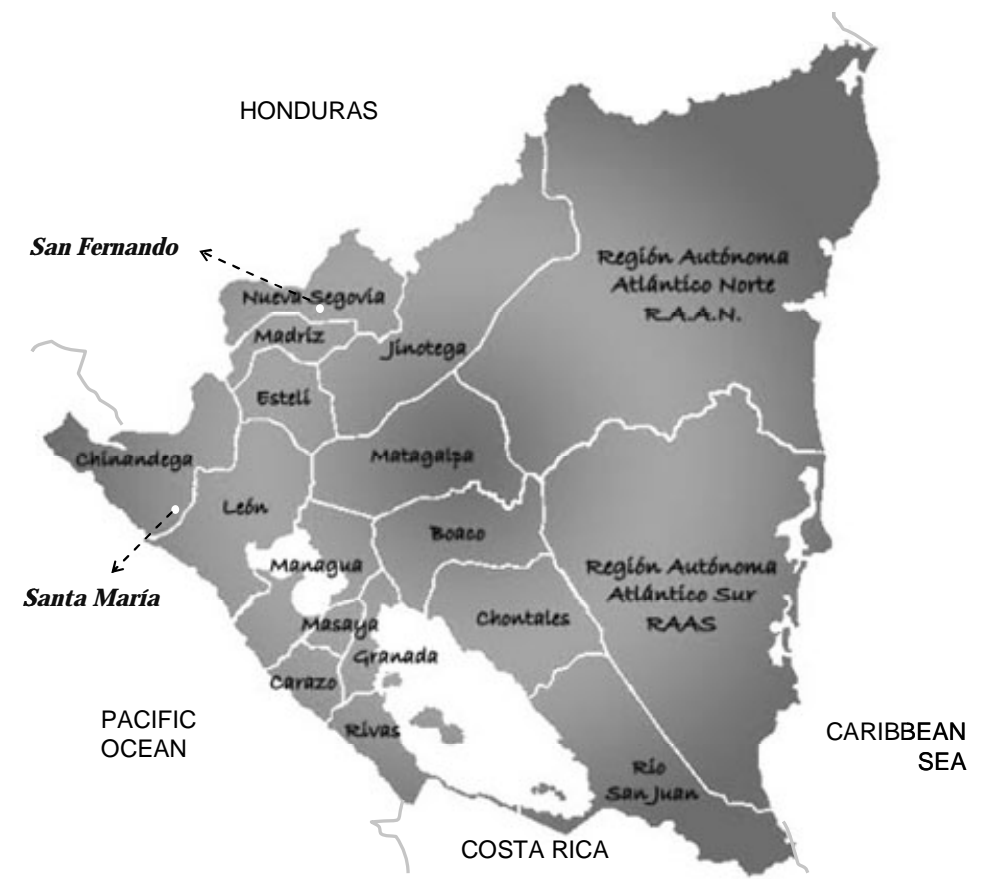

Based on AMUNIC (2006).

Santa Maria is the first reconstruction project carried out by LD. The intended beneficiaries were survivors of a mudslide of the Casitas volcano caused by Hurricane Mitch (1998). The mudslide destroyed their old towns and killed many of their relatives and friends. The trauma and difficult work and living conditions were constant during the project. An NGO managed this project and also two other projects in the same town, funded by other donors. Despite several problems, the project achieved its operational outputs in terms of housing and social infrastructure. Given the weak local institutional capacity, this can be called a project 'without an owner', a situation that over time led to elite capture.

San Fernando is a water project that benefited an urban centre in Northern Nicaragua. The project had two main components: the rehabilitation of the water system that had been badly damaged by Hurricane Mitch and technical support to the public water company. Community organisation was fostered in order to secure the project objectives related to sanitation infrastructure and hygiene habits. The work of women in committees, selfconstruction activities, and project workshops stressed traditional gender roles. However, some women felt more autonomous when they participated in the municipal development committee. Contexts were favourable to the project.

Agua Fría and San Agustín are located in the eastern region of El Salvador. Agua Fría is a canton in the San Alejo municipality, department of La Unión. San Agustín is a municipality in the department of Usulután. Figure 5-2 shows the location of both. 
Figure 5-2: The project sites in El Salvador

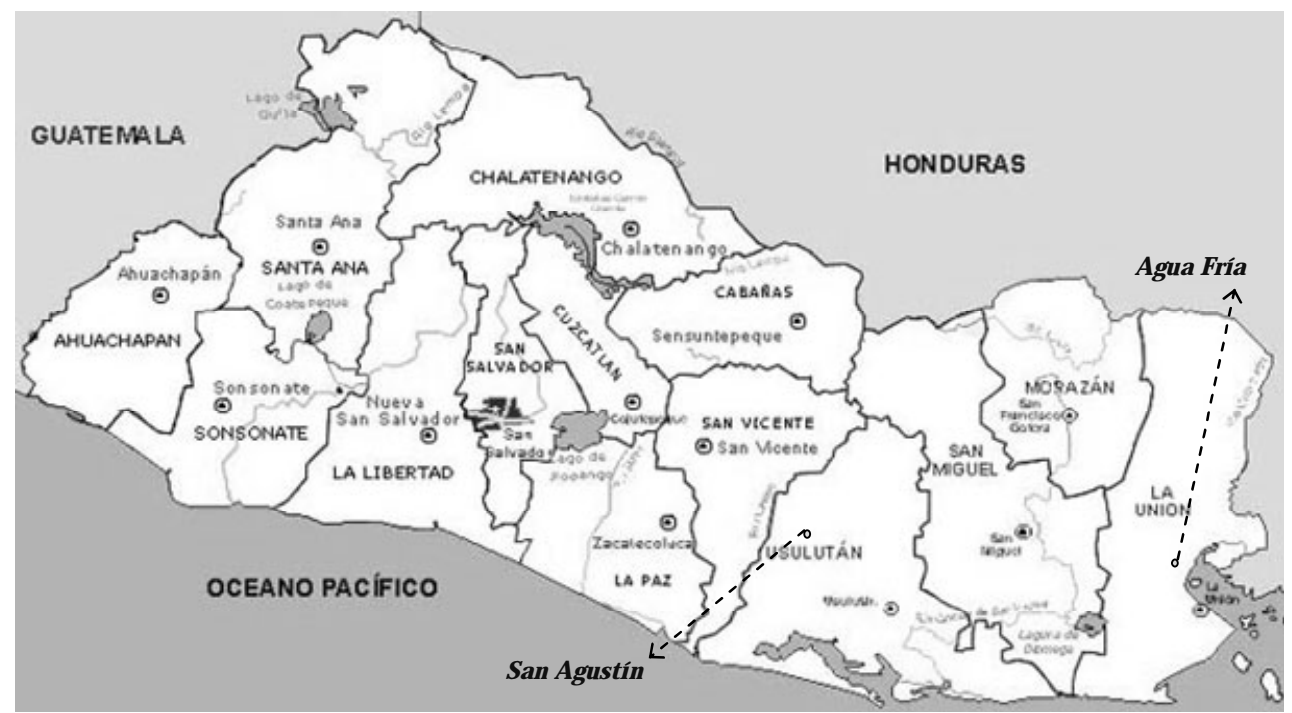

Based on AMSS (2007).

Agua Fría is a water project in a rural canton of El Salvador. In this sector and country, LD has had presence since 1993. The project had ambitious goals that covered aspects beyond the construction of water infrastructure such as the strengthening of community organisation and the promotion of sustainable agricultural practices. The project documents explicitly included self-construction activities as local contribution (reaching $9 \%$ of total budget). Certain project practices could have supported autonomy, but the contexts harmed this potential. Governance issues in the national and local contexts affected the project operational effectiveness.

San Agustin is the second reconstruction project. It covered a municipality marked by the civil war and almost destroyed by two earthquakes in 2001. It is the most complex project and the largest in terms of budget for one specific locality. Three entities worked in different components: the construction of homes and social infrastructure, the legalisation of property titles, and the elaboration of the municipal development plan. The project supported the management capacities of the community organisation, which worked together with the project chief, sharing in decisions during the project. The strengthening of the community organisation did not necessarily lead to community empowerment.

Table 5-2 summarises some characteristics that describe the living situation in the four localities, at the time of the fieldwork. It is worth noticing that the two countries have similar political divisions. Each country is formed by departments (clearly drawn out on the maps); in addition, Nicaragua has two autonomous regions in the Atlantic zone. Each department is composed of municipalities, which are formed by cantons and towns, smaller than cantons. Santa María is much smaller than Agua Fría in terms of land area. The latter is highly populated in relation to the two municipality centres (San Fernando and San Agustín). 
Table 5-2: Main characteristics of the localities

\begin{tabular}{|c|c|c|c|c|}
\hline & Santa María & Agua Fría & San Fernando & San Agustín \\
\hline Type of locality & Small town & Canton & Municipality centre & Municipality centre \\
\hline Households* & 350 & 424 & 421 & 438 \\
\hline Main features & $\begin{array}{l}\text { Post-Mitch settle- } \\
\text { ment; many killed; } \\
\text { psychological } \\
\text { trauma. }\end{array}$ & $\begin{array}{l}\text { High youth emigra- } \\
\text { tion; ageing popula- } \\
\text { tion. }\end{array}$ & $\begin{array}{l}\text { Traditional town; } \\
\text { large male-headed } \\
\text { households. }\end{array}$ & $\begin{array}{l}\text { Damaged by civil } \\
\text { war, destroyed by } \\
\text { earthquakes. }\end{array}$ \\
\hline Economic situation & $\begin{array}{l}\text { Landless farmers at } \\
\text { subsistence risk; } \\
\text { seasonal migration. }\end{array}$ & $\begin{array}{l}\text { The richest thanks } \\
\text { to remittances. }\end{array}$ & $\begin{array}{l}\text { Relatively well-off; } \\
\text { large income and } \\
\text { social inequality. }\end{array}$ & $\begin{array}{l}\text { Subsistence agricul- } \\
\text { ture; remaining } \\
\text { cooperatives. }\end{array}$ \\
\hline Political situation & $\begin{array}{l}\text { Sandinista orienta- } \\
\text { tion; political alli- } \\
\text { ance between lead- } \\
\text { ers. }\end{array}$ & $\begin{array}{l}\text { Opposition be- } \\
\text { tween communal } \\
\text { leaders and local } \\
\text { government. }\end{array}$ & $\begin{array}{l}\text { Contra guerrilla } \\
\text { heritage; political } \\
\text { polarisation among } \\
\text { residents. }\end{array}$ & $\begin{array}{l}\text { Guerrilla heritage; } \\
\text { strong community } \\
\text { organisation, weak } \\
\text { local government. }\end{array}$ \\
\hline
\end{tabular}

* Number of households covered by each project in that site.

Table 5-2 shows that the inhabitants of Santa María are the poorest, while those in Agua Fría are the richest (although still absolutely poor) thanks to family remittances. These situations influence their perceived agency. For instance, the trauma persists because living conditions are so difficult that the future is uncertain for Santa María residents. Youth emigration and family disruption affects the emotional situation of children who are raised by their grandparents in Agua Fría.

The political orientation of people in the four sites has affected how they interact with others and their perceptions about these interactions. For instance, San Fernando residents felt abandoned by the state because of their support to the contra guerrillas; this feeling explains the incredulity that they showed about a new project and their later happiness when it was implemented and completed. The leaders of San Agustín, with a long organisational experience during the civil war, either as cooperative members or guerrilla fighters, try to show a neutral political position in order to negotiate entitlements and reach their goals.

These characteristics underline the diversity of the four cases. Not only were the projects designed differently (as analysed in Chapter 10) but also people had very different sociohistorical experiences, linked to economic and political events in their countries and the power structures in their localities.

\subsection{The country contexts and their linkages with local contexts}

This section presents some unique features of Nicaragua and El Salvador. The footprints of traditional socio-economic structures, foreign political intervention by the US, devastating armed conflicts during the 1980s and part of the 1990s, and radical economic reforms persist. Some crucial events and long-lasting cultural features have to be known in order to understand the country or meso-level contexts in which individuals experience autonomy and form their perceptions of change. As will be seen in the coming chapters, any autonomyfocused assessment has to be informed by the socio-historical experiences that people live (Deneulin, 2006a). 
Table 5-3 presents some characteristics of the countries that highlight the need to understand the meso-level contexts. Although both countries experienced long armed conflicts, the causes and results were different.

Table 5-3: Comparative country analysis (selected characteristics)

\begin{tabular}{|c|c|c|}
\hline & Nicaragua & El Salvador \\
\hline Causes of armed conflicts & $\begin{array}{l}\text { 1974-1979: Sandinista guerrilla. } \\
\text { Authoritarian rulers controlling } \\
\text { economic resources; foreign inter- } \\
\text { vention. }\end{array}$ & $\begin{array}{l}\text { 1980-1992: Civil war. } \\
\text { Enduring social and economic exclu- } \\
\text { sion; powerful oligarchy protected } \\
\text { by authoritarian rulers. }\end{array}$ \\
\hline Political results & $\begin{array}{l}\text { FSLN governed the country (1979- } \\
\text { 1990) and lost power after } 1990 \\
\text { national elections; strong political } \\
\text { parties. }\end{array}$ & $\begin{array}{l}\text { FMLN (the party of the left opposi- } \\
\text { tion) was defeated in } 1994 \text { elections; } \\
\text { important opposition party, not fully } \\
\text { integrated. }\end{array}$ \\
\hline Peace accord negotiations & $\begin{array}{l}\text { After contra war: Sandinistas, politi- } \\
\text { cally weak, called elections with } \\
\text { international pressure. }\end{array}$ & $\begin{array}{l}\text { Negotiation between 'equals', the } \\
\text { conflict had reached a deadlock; } \\
\text { integral, promising peace accords. }\end{array}$ \\
\hline Agrarian reform & $\begin{array}{l}\text { Result of the triumph of the Sandini- } \\
\text { sta movement over the Somoza } \\
\text { dynasty. } \\
\text { Implemented by peasants. }\end{array}$ & $\begin{array}{l}\text { Government strategy to impede } \\
\text { social explosion given the large } \\
\text { numbers of landless peasants. } \\
\text { Implemented by armed forces. }\end{array}$ \\
\hline The footprint of the US & $\begin{array}{l}\text { Carried out a trade embargo, lobbied } \\
\text { to cut foreign aid, and financed the } \\
\text { contra guerrillas (1981-1990). } \\
\text { Exacerbated economic crisis. }\end{array}$ & $\begin{array}{l}\text { Financed illegitimate rulers in El } \\
\text { Salvador during the conflict (1980- } \\
1992) . \\
\text { Smoothed imbalances in fiscal and } \\
\text { external accounts. }\end{array}$ \\
\hline
\end{tabular}

Source: Appendices 1-A and 1-B.

The political influence of the former guerrilla movement is stronger in Nicaragua; political polarisation is vivid. Some disillusion exists among inhabitants of El Salvador given that the promised structural economic changes to favour rural farming economies did not take place. However, Salvadorians, especially those in the rural areas, are more willing to participate in formal organisations than Nicaraguans. This kind of participation was promoted after the peace accords, for instance, in decentralised rural education programmes managed by residents. In contrast, at the end of the Sandinista regime in Nicaragua, there was a process of demobilisation (Booth \& Richard, 2006) leading to now little associational life.

The presence of the US is strong in both countries due to economic reasons, not so much due to political reasons as during the 1980s and early 1990s. The US is the main trade partner and the main source of family remittances, in both countries. In terms of aid cooperation, the US is the main bilateral donor in Nicaragua and the second in El Salvador (after Spain).

Some of the topics covered in Table 5-3 are developed below with emphasis on their influences on the localities studied (see appendices 1-A and 1-B for further explanations).

\subsubsection{Nicaragua}

First, Nicaragua has a unique political culture (Álvarez Montalván, 2001) that has marked the lives of most of its inhabitants. Its history has had conflict and tragedy but also hope and effort. Conflict was evidenced not only by internal armed conflicts but also by decades of authoritarian governments, foreign intervention and economic exclusion. 
Tragedy has come also from natural disasters. The most harmful event has been Hurricane Mitch that caused the mass tragedy of the Casita volcano (see Box 5.1). Against these events, the population has developed hope in salvational events (Álvarez Montalván, 2001) and an attitude of applying their own capacities for their progress (UNDP, 2002). They rely on themselves because the state is perceived as politicised and corrupt (Latinobarómetro, 2005).

\section{Box 5-1: The Hurricane Mitch in Nicaragua}

Hurricane Mitch was until 2005 'the deadliest and most devastating Atlantic hurricane since 1780' (USAID, 2005, p. 3). After being detected as a tropical storm in October 21, it became a category-5 hurricane (Saffir-Simpson scale) by October 26. It caused huge human and material losses in Central America. About 3.5 million people were directly affected, 1.5 million were left homeless, 13,000 were wounded and 18,000 died or were missing (QUEST-Consult, 2001).

Honduras and Nicaragua were the two most affected countries, due to heavy rainfalls that caused floods and mudslides. In Nicaragua, the departments of León and Chinandega, in the Pacific region, were hit the hardest (see table below). About half of the population affected and over $90 \%$ of dead people in the country came from Posoltega, which suffered the landslide of the Casitas volcano.

People affected by Hurricane Mitch in Nicaragua

\begin{tabular}{|l|c|ccc|ccc|}
\hline & \multicolumn{4}{|c|}{ Affected by disaster } & \multirow{2}{*}{ Wounded } & \multirow{2}{*}{ Missing } & \multirow{2}{*}{ Dead } \\
\cline { 2 - 7 } & Families & Adults & Children & Total & & & \\
\hline León and Chinandega & 78,800 & 241,604 & 206,605 & 448,209 & 254 & 426 & 2,856 \\
Total & 153,833 & 473,027 & 394,725 & 867,752 & 254 & 885 & 3,045 \\
\hline
\end{tabular}

Source: GON (1999) citing the National Defense Office.

Estimates of material damages vary from USD979.1 million (ECLAC, 1999) to USD1,336 million (GON, 1999 ) and would be over $27 \%$ of 1998 's GDP. The largest costs were in transport and telecommunications, housing, and agriculture sector.

Second, despite the failure of its political model, the Sandinista revolution had relevant human development effects. It made accessible, to previously excluded groups, basic services such as health and education (especially important was the national-wide literacy campaign) and decision-making at grassroots levels (Brás, 1993; Rivas, 2001; Allison, 2006).

Its larger impact was political. The Sandinista National Liberation Front (FSLN) took power via military actions (1979), but was the only left-wing party that won fair elections (1984) in a convulsed Central American region. It implemented its plan in co-existence with opposition political parties. FSLN learned democratic practices and, finally, handed over government control to opposition forces in peace (Karl, 1995), but with international pressure.

Third, the agrarian reform marked the relationships between citizens and the state, and within communities. Initially, it gained legitimacy because it redistributed lands previously controlled by the Somoza family and because peasants themselves took over the haciendas and established their cooperatives. Already, in 1980, there were 2,647 cooperatives (Martí i Puig, 1997), including those in Posoltega. The reform lost support over time because it added expropriation criteria and the state centralised production and trading processes, breaking local economic practices and creating artificial markets (De Groot, 1993). The economic crisis triggered by the conflict with the contra guerrillas shook this vulnerable equilibrium.

The agrarian reform had important immaterial effects. On the one hand, it allowed peasants to develop organisational skills as in the Santa María case. People at the slopes of Casitas, with 
an active role at the start of the reform, promptly reacted and organised themselves to rescue survivors of the Casitas mudslide and to allocate humanitarian aid in the camps. On the other hand, the process of the agrarian reform harmed the causality orientation of small farmers because the state progressively controlled everything. Their managerial and negotiation capacities were affected as cooperatives were sustainable only with the state support (cf., Hirschman, 1984). Economic crisis completed the message that 'the cooperative model does not work', which was in the mind of participants of the Santa María project. They had learned that it was more secure to work individual plots than to share a large area.

Fourth, individuals in different geographic locations have different worldviews and engage in different, sometimes complementary, socio-economic relationships. During the civil war, the support of peasants from the North highlands to the contra guerrillas made sense in a context in which they perceived a risk of losing their lands and their traditional way of life that valued patronage traditions (Martí i Puig, 1997; Stoll, 2005; Bastiaensen et al., 2006). The inhabitants of San Fernando, small and medium landowners, supported the contra war. For this, they lived between two fires during the 1980s and felt abandoned by the state for many years because the 'development' promised with peace negotiations did not happen. In contrast, the inhabitants at the slopes of the Casitas volcano, landless agricultural workers, actively supported the Sandinista revolution.

Fifth, the current economic model privileges growth over equity (cf., Guimarães \& Avendaño, 2004). Growth is export-oriented and led by maquila and food exports. Small landowners or landless peasants cultivate subsistence crops and live in extreme poverty. For them, there is no credit or specific promotion policies, only a residual social protection system. Most residents of Santa María live in extreme poverty and even the residents of San Fernando (landowners, one-third of them) face harsh times because they do not have working capital to farm their owned or rented land.

Driven by economic reasons, many people emigrate. Many male inhabitants of Santa María are seasonal workers in Costa Rica. Migration is less frequent in San Fernando given its geographic location (highlands), higher family cohesion, and the relatively lower necessity to do so. Those who do migrate send remittances to their family and do not return home.

Sixth, social exclusion related to poverty, low interpersonal trust, perceived political corruption and increasing (urban) violence, has not downgraded the perception of democracy as an ideal government system (Booth \& Richard, 2006; Latinobarómetro, 2005). Local participation promoted by donors and institutionalised by the state offers the opportunity to exercise democracy and promote development at the micro-level. The challenge is how to integrate local actors in an inclusive way, not only to assure their formal presence. Political parties accompany this process. In Santa María, FSLN has preponderance but there are two communal associations with different political orientations. In San Fernando, people perceive exclusion, which they associate to their actions during the contra war. To avoid this situation again, there was no one communal association or committee. A new committee was required by the project and became part of the committee of communal development later.

\subsubsection{El Salvador}

First, no interpretation of the Salvadorian reality is possible without referring to and understanding the causes of the armed conflict that took place between 1980 and 1992 and was a 
breaking point in the lives of Salvadorians. The civil war was caused by economic and social inequalities and enduring exclusion of inhabitants of rural areas fuelled by land destitution (see Appendix 1-B). Violence has been underneath El Salvador's culture for decades: economic elites partnered military powers to achieve their goals. They institutionalised repressive practices to control a cheap labour force of landless peasants (North, 1981; ECLAC, 2001b; Martínez, 2005).

During the civil war, these practices reached the highest levels of violence. The army and paramilitary groups did not hesitate to persecute anyone (not only guerrilla combatants but also politicians, priests, peasant unions or 'collaborators') who was against their 'project' (TCES, 1993). About 75,000 people died and at least 5,500 disappeared during the conflict (Gutiérrez, 2007). San Agustín was among the most affected municipalities. In 1990, its population represented only one-fifth of the population existing in 1975 (MSA, 2004b).

Second, two political parties emerged from the war: Farabundo Martí National Liberation Front (FLMN), the former guerrilla movement, and Nationalist Republican Alliance (ARENA), a right-wing party formed by former death squad members. Both have strong presence in political life but most people do not feel identified with either of them.

Opinion polls show that Salvadorians do not trust the government, political parties, institutions, and the democratic system as a whole (Martel, 2003; Latinobarómetro, 2004). There is also a feeling of disillusion and frustration among many people because, although political changes occurred, political crimes enjoyed impunity and social and economic integration is not a reality (Cruz, 2003; CIDAI, 2002). Hence, inhabitants of San Agustín and Agua Fría do not express so openly their political sympathies as Nicaraguans do.

Political violence was replaced by criminal or social violence (Cruz, 2003). People feel afraid of violence in streets and in society in general. In Agua Fría, the more evident problem is youth gangs; while, in San Agustín, armed delinquents put at risk the security of project staff.

Third, the agrarian reform was dictated in the early 1980s with the aim to prevent social explosion. It was implemented by armed forces, which continuously coerced cooperative members (Envío Team, 1983; Spence, 2004). After the peace accords, more land was redistributed to make in total $20 \%$ of Salvadorian territory. However, high debts and weak management skills led cooperatives to parcel-out their lands and leave peasants with small plots mostly for subsistence crops (Kowalchuck, 2003; ISTA, 2005). This is the situation of many inhabitants of San Agustín. The reform also had impacts on the organisational skills of cooperative leaders.

Fourth, the post-civil war economic model is not so different than the previous one. Growth is export oriented. However, maquila industry has replaced traditional export crops such as coffee, absorbing unskilled labour, although with little links with other industries. The privatised financial sector focuses on manufacturing and trade activities. The agricultural sector has lost importance in the economy and credit to small landowners is scarce.

Fifth, international emigration continues triggered by economic reasons. Remittances have grown to cover trade deficits and replaced the role of aid flows (basically from the US during the civil war) as source of foreign reserves. They have tangible effects on the lives of the inhabitants of Agua Fría: they do not rely so heavily in agriculture as earlier and are switching to trade activities in a rapid urbanisation process (cf., UNDP, 2005b). 
Sixth, there is inequality in social opportunities within the country. Social programmes have been conceived to improve living standards and local participation is being promoted. Local development committees are spread across the country and share in participatory planning with local governments, for instance, in San Agustín. However, their sustainability depends on the existence of real economic opportunities and resources at the local levels (RDL, 2006).

Seventh, environmental degradation is a risk, somewhat higher than in Nicaragua. Pressure on natural resources, especially land, has grown in El Salvador; natural disasters are frequent. The earthquakes of 2001 (see Box 5-2) caused the destruction of all infrastructures in San Agustín. Its inhabitants, in extreme poverty, could not have rebuilt their houses without external aid because San Agustín is one of the poorest municipalities in the country.

Box 5-2: The earthquakes of 2001 in El Salvador

In January and February 2001, there were two earthquakes in El Salvador. The first earthquake had its epicentre $65 \mathrm{~km}$ South of Usulután, with magnitude $7.7 \mathrm{Mw}$ (Richter). The second had its epicentre 30 $\mathrm{km}$ Eastern South of San Salvador, with magnitude 6.6 Mw (Richter). The highest impacts were in the departments of San Vicente, La Paz, Cuzclatán and Usulután. The two earthquakes caused 1,159 deaths, injured 8,122 people and affected around 1.5 million people. Nearly 150 thousand houses were destroyed (GOES, 2001).

ECLAC (2001a) estimates the total economic costs of the earthquakes as about $12 \%$ of GDP. Of these, $65 \%$ were incurred by the private sector, with a higher weight of costs related to productive sectors (agriculture, industry, and trade and tourism). The highest material losses were in transport (3.3\% of GDP), housing ( $2.5 \%$ of GDP), industry, trade and tourism (1.9\% of GDP), and education (1.6\% of GDP).

Public and private costs caused by 2001's earthquakes in El Salvador

\begin{tabular}{|l|cc|cc|}
\hline & \multicolumn{2}{|c|}{ Economic costs } & \multicolumn{2}{c|}{ Share of total } \\
& USD million & $\%$ of 2000's GDP & Public & Private \\
\hline Social & 616.7 & $4.7 \%$ & 38.5 & 61.5 \\
Infrastructure & 472.3 & $3.6 \%$ & 36.2 & 63.8 \\
Productive & 339.3 & $2.6 \%$ & 4.5 & 95.5 \\
Other & 175.5 & $1.3 \%$ & 81.2 & 18.8 \\
\hline Total & $\mathbf{1 , 6 0 3 . 8}$ & $\mathbf{1 2 . 2} \%$ & 35.3 & $\mathbf{6 4 . 7}$ \\
\hline
\end{tabular}

Source: ECLAC (2001a, p. v).

In 2001, the real GDP grew slightly by $1.7 \%$ fuelled by reconstruction works and related industries; agriculture production fell by $2.6 \%$. UNDP (2003b) estimates that the earthquakes produced a 3-year setback in human development and poverty, on average. The setback would be of between five and ten years in some departments.

\subsubsection{Main events during the lifespan of the projects ${ }^{33}$}

There were some events during the implementation of the projects that might affect the coordination between the different stakeholders of the projects. Figure 5-3 shows two parallel timelines that depict different government periods at the national and local levels, the earthquakes in El Salvador, Hurricane Mitch and other events.

\footnotetext{
${ }^{33}$ The analysis does not include political events after 2005, such as the change of the national government in Nicaragua in 2007 and the change of municipal governments in El Salvador in 2006; economic events, such as the DR-CAFTA and its implications; and social events, such as the implementation of 'solidarity net' in El Salvador.
} 


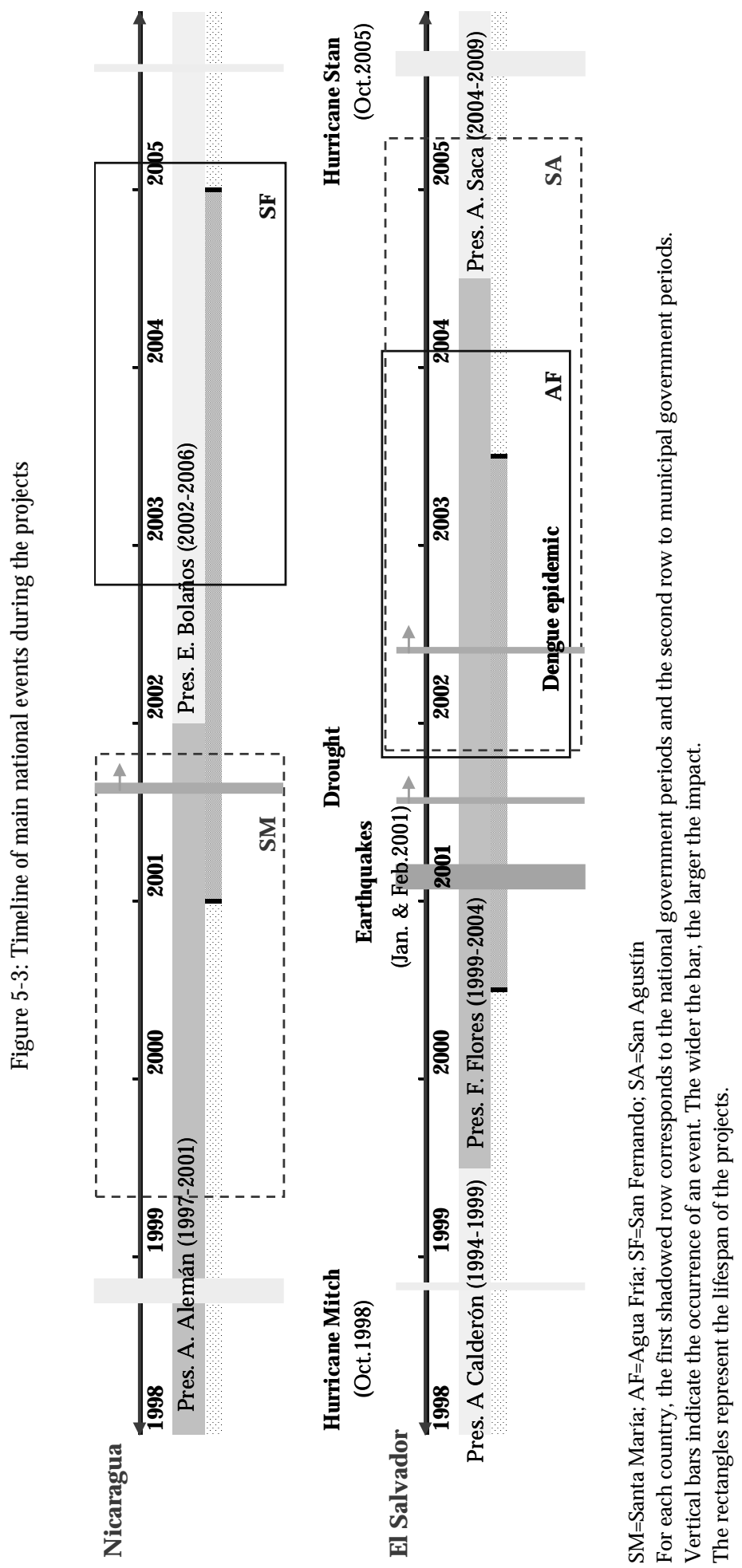


In Nicaragua, the political party in the national government during the study period was the PLC although with two different presidents. From 2002 onwards, Pres. Bolaños broke relations with his predecessor, A. Alemán, whom he prosecuted with corruption charges. Looking at the local governments, there were changes in 2001 and 2005. However, only in San Fernando, in 2005, was there a change of hands in the local government: a FSNL mayor replaced a PLC mayor. Although this change took place when the project was almost finished, it had a large impact for the formation of the communal committee. In the Santa María case, the mayors of Posoltega have always been from FSLN, but there were three different mayors during the project.

In El Salvador, ARENA has governed the country since 1994. However, the San Agustín project is the only one that faced the transition from one President to another. Changes of staff in some ministries and public institutions affected the inter-institutional coordination during the project. At the municipal level, there were elections in 2003 but the mayors of San Alejo (municipality where Agua Fría is located) and San Agustín were re-elected. The mayor of Agua Fría belongs to the Liberal Constitutional Party (PLC), which is a traditional party, former ally of the military; while the mayor of San Agustín was from ARENA.

Figure 5-3 also registers the drought suffered by the inhabitants of Nicaragua and El Salvador in 2001 that strongly hit the common planting by the Santa María inhabitants. The dengue epidemic of 2002 in El Salvador signaled the risks of not having adequate sanitation systems to the inhabitants of Agua Fría.

\subsection{The donor cooperation policy and general practices}

The official development assistance (ODA) from Luxembourg doubled during the study period, from EUR98.8 million in 1998 to EUR207.4 million in 2005 (MFAL, 2006b). In absolute terms, Luxembourg is a minor donor, with a share lower than $0.5 \%$ of the ODA of DAC countries (OECD, 2008a). In relative terms, it is a major donor, whose ODA has reached the UN target ratio of $0.7 \%$ of GNI in 2001 and a ratio of $0.82 \%$ in 2005 (MFAL, 2006b). In contrast, the ODA of DAC countries represented only $0.33 \%$ of GNI (OECD, 2008a).

The primary goal of Luxembourg aid is the eradication of poverty. Its actions are framed within the millennium development goals. Its focus is on social sectors, especially health, education, water and sanitation, and integrated local development (MFAL, 2003; 2006a). Three cross-cutting themes receive emphasis: environment, gender and good governance. Luxembourg endorses the Paris principles, especially those of country ownership, alignment and harmonization (GOL, 2008).

Luxembourg selects a group of ten privileged partner or 'target' countries, which are mainly chosen based on their composite human development index. With these partner countries, Luxembourg agrees a multiyear Indicative Cooperation Programme (ICP) that contains the main purposes of the bilateral cooperation and guidelines for other forms of aid. The 2006 survey on monitoring the Paris Declaration found that $77 \%$ of Luxembourg's aid flows are aligned to national priorities and $100 \%$ of aid is in the form of untied grants (OECD, 2008d, p. 51). However, Luxembourg aid is not aligned to the public financial management or procurement systems given its preference for project aid using its own systems (ibid). 


\subsubsection{Bilateral aid to Nicaragua and El Salvador}

Nicaragua and El Salvador are two target countries, the only ones in Latin America. In 2005, Luxembourg ranked fifth out of 22 bilateral DAC-donors in El Salvador and fifteenth in Nicaragua (OECD, 2008c). However, the partnership with El Salvador will be phased out in the medium term (MFAL, 2007; OECD, 2008d), given its condition of middle-income country. The commitment of Luxembourg to help El Salvador was explained by non-income related reasons such as vulnerability to climate and disparity in the distribution of resources (OECD, 2003, p. 25).

Nicaragua is much more dependent on foreign aid than El Salvador (section 3.1) with almost 40 donors present in the country (as reported by MFA officers). Luxembourg representatives participate in sectoral roundtables, set up in 2003, together with representatives of the government, civil society and other donors in Nicaragua. In this way, it supports donor harmonisation and country ownership.

In 2005, Luxembourg's total bilateral aid was about 73\% of its ODA to all recipient countries (OECD, 2008d, p. 6). Likewise, most ODA to Nicaragua and El Salvador is through bilateral project aid (see Table 5-4). The share of multilateral project aid has steadily grown in Nicaragua to represent $18.6 \%$ in 2005 . About $9 \%$ of ODA to Nicaragua corresponds to projects with NGOs, food and humanitarian aid, technical assistance and others. Luxembourg does not take part in general or sector budget support.

Table 5-4: Bilateral aid of Luxembourg to Nicaragua and El Salvador, 2000 and 2005

\begin{tabular}{|ll|cc|cc|}
\hline & \multicolumn{2}{|c|}{ Nicaragua } & \multicolumn{2}{c|}{ El Salvador } \\
& & 2000 & 2005 & 2000 & 2005 \\
\hline Total ODA & EUR million & 6.91 & 7.31 & 4.24 & 5.52 \\
Bilateral projects & EUR million & 6.30 & 5.30 & 3.99 & 4.51 \\
& $\%$ of ODA & 91.2 & 72.4 & 94.1 & 81.7 \\
\hline
\end{tabular}

Source: MFAL (2006b).

In February 2003, Luxembourg signed the 2003-2006 ICP with Nicaragua for EUR23 million and, in October 2002, it signed the 2003-2006 ICP with El Salvador for EUR26 million. Luxembourg's aid in Nicaragua and El Salvador is focused on three sectors: education, health, and water and sanitation. The reconstruction projects were specific cases.

In El Salvador, since 2000, Luxembourg has focused on the access to public services in the Eastern region of the country (where Agua Fría and San Agustín are located), the poorest and the most affected by the civil war (GOL \& GOES, 2002; Rubio-Fabián \& Valdez, 2004). There is no similar geographical targeting in Nicaragua.

\subsubsection{The organisation of aid delivery}

The bilateral aid agency, Lux-Development S.A. (LD), is responsible for the management of projects approved and financed by the Ministry of Foreign Affairs of Luxembourg (MFAL). Since 2000, LD has a Latin American regional office in Managua to coordinate the operations related to each project in Nicaragua and El Salvador. It provides technical assistance to projects and partner institutions and also has a public relations role.

The financing decisions are made at the macro level and captured in the ICPs. MFAL identifies projects, within the priorities set in the ICP, proposed by its counterparts in the recipient 
countries (in coordination with line ministries or public water companies). LD is responsible for the formulation and the preparation of the project document. The formulation is made by external consultants who do not participate in other stages of the project. A project document contains a project detailed description, logical framework, relevant financial details, and timetables.

After the approval by MFAL and its pairs in recipient countries, the project is executed. Upon completion, the MFAL carries out an external evaluation, independently of the internal (mid-term and final) evaluations by LD and the financial audits. External evaluations for the sector project portfolio and to the whole ICP are also carried out.

During the study period, the donor was migrating from a project-based to a programmebased approach (GOL, 2004) in line with the principles of alignment and harmonisation. At first, some stand alone projects, already in implementation were integrated into an ICP (Barahona \& Balanzategui, 2005; Rubio-Fabián \& Valdez, 2004). This is the case for Agua Fría and San Agustín. The San Fernando project, also included in the ICP during its implementation, was formulated taking into account the coming ICP. This brings direct consequences on project design. San Fernando was the only project (among the four) that had a mid-term evaluation and included a component of technical cooperation with a national entity (the public water company). The oldest project, Santa María, was outside a coordinated framework and even without the supervision of a regional office when its execution started (1999). The consequences of these organisational gaps are analysed in Chapter 6.

\subsubsection{Project management}

During the study period, the bilateral projects (excepting the Santa María project) were managed as depicted in Figure 5-4.

Figure 5-4: Basic relationships in the management of bilateral projects

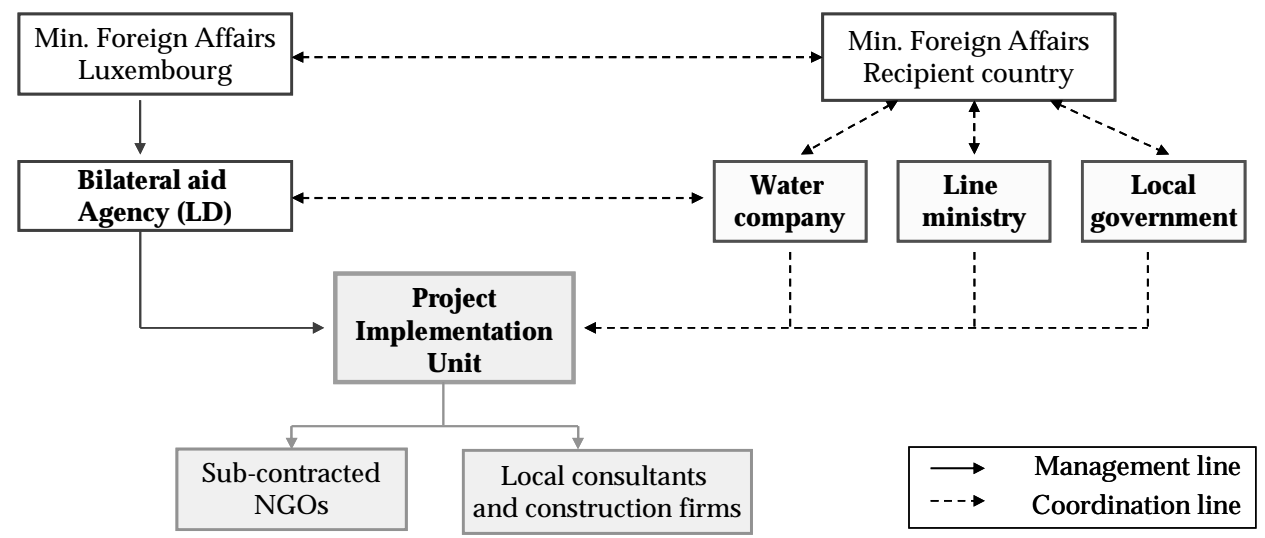

From the side of the donor, the executing agency is LD that hires a project chief (and sometimes also a technical assistant) who forms the project implementation unit (PIU) and subcontracts NGOs, local experts or firms to carry out different components of the project. The project chief coordinates the work of these sub-contracted entities. The regional office monitors the project chiefs in terms of operation and financial management, and procurement of works, supplies and services. The project officers, based in Luxembourg (LD) and special- 
ised by geographical regions, are responsible for the achievement of the project results; they visit the project sites periodically.

From the side of the recipient, the formal counterpart is a line ministry (e.g., education or health ministries), a public water company, or a local government (in the case of reconstruction projects). The coordination at the macro-level is between the ministries of foreign affairs of the donor and recipient countries. The composition of the PIU can vary depending on the entities involved, the level of involvement of the formal counterpart or the organised population (see case chapters).

\subsection{A note about the case chapters}

This chapter has described the projects briefly and introduced some country features that may have influenced the lived experiences of autonomy of the inhabitants of each project site. The chapter also explained the functioning of Luxembourg's bilateral project aid as of 2005. Now, it is time to explore in depth the case studies.

Chapters 6 to 9 describe and analyse the case studies from two perspectives: project practices and impacts, and the experiences of autonomy of the inhabitants of each project site. First, about the projects, the chapters present their characteristics, contexts and practices. The core part is the analysis of the project impacts on individual autonomy through the assessment matrix (section 4.3.1), which contains the elements of the explicit and implicit logic of the projects - derived from the project log-frame and practices, respectively - based on the conceptual model developed in Chapter 2.

Second, about the inhabitants of each project site, the chapters explore their lived and perceived experiences of autonomy and their expectations about community. In this way, each chapter responds to the question: how important do inhabitants in the locality consider individual autonomy for their development? It requires looking at values and power structures.

As explained in Chapter 4, the analysis is primarily qualitative. It covers some parts of the multilevel structural contexts with different emphases. Looking at macro-level aid practices may be more relevant for reconstruction projects in which several donors are involved. Looking at national governance is especially important for water projects in which public companies occupy a leading role. However, what matters to individuals is their perception about these contexts and external events so that I draw, when possible, upon their own voices. In the Santa María case, press information was valuable as the project was completed four years prior to the fieldwork study and the Casitas mudslide was broadly covered by the media.

When I refer to comments of inhabitants of the localities, these are non-leaders who participated in the several fieldwork activities, unless I specifically indicate that the person is a leader. When I name particular persons while describing events or citing their expressions, I use fictitious names. When citing expressions said by a person during a focus group discussion (FGD), I use the following codes: HIW for high-involvement woman, LIW for lowinvolvement woman, HIM for high-involvement man, and LIM for low-involvement man. Differentiating groups by level of involvement in the project and by gender is more or less relevant depending on the case. Most FGD and project participants were women so that their voices are more frequently registered than men's voices on this study. 


\section{The struggle for a livelihood in Santa María: The scars from the volcano}

Prior to the mudslide, we lived well, we had cows and other animals, we had all kinds of grains; we did not buy a stick of firewood because we had it. Nowadays, if we do not have coins, there is no firewood, there is no food, and there is no means to cook (HIW). ${ }^{34}$

Santa María is located in the Posoltega municipality, in the department of Chinandega, in north-western Nicaragua. The first time I visited Santa María was in January 2005. The technical coordinator drove with me. It was around 3 p.m. when we arrived; the temperature was above 40 degrees centigrade. From the highway, we took a non-asphalted auxiliary road and then we went by a trail bordering private property. The car raised dust along its way because it was dry season in this zone that has a savannah tropical climate.

The place looked to me like a colony; many small grey houses very similar, arranged in blocks. Most of them did not have finishes but some had improvements (painted, with grills, and annexed constructions). A few were closed (with padlocks and grills) and some others looked abandoned without doors. There were no plants and no people around in the colony. Finally, after strolling in the village for a while, we found one community leader and, after a brief chat, we went to the community centre.

The community centre had an auditorium, three small offices, and sanitary services. Around twenty teenagers were discussing jobs, leisure activities, and prevention of drug consumption. Five women were taking a class in dressmaking, although without sewing machines. There were also a few small children who were curious about our presence and jumping around us. They were registered in a day care programme financed by the government. These three groups were sharing the physical space in the auditorium. I talked with the responsible persons of these groups; they were young and showed commitment to their (voluntary) jobs. The vitality in the community centre contrasted with the emptiness of the town.

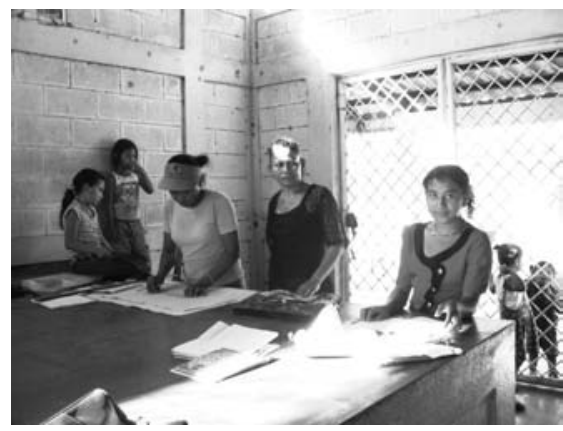

Photo 6-1: Women in classes of dressmaking at the community centre (January 2005)

\footnotetext{
${ }^{34}$ When citing expressions said by a person during a focus group discussion (FGD), I use the following codes: HIW for high-involvement woman, LIW for low-involvement woman, HIM for high-involvement man, and LIM for low-involvement man.
} 
Luxembourg has supported Nicaragua through bilateral projects since 1993. In 1998, when Hurricane Mitch hit the country strongly, Luxembourg decided to help the reconstruction efforts of local authorities in the Posoltega municipality, the most affected by the disaster.

This chapter presents the experience of the inhabitants of Santa María during the reconstruction project carried out between 1999 and 2001. The project benefited survivors of a mudslide who lived in two towns, Rolando Rodríguez and El Porvenir, at the slopes of the Casitas volcano. This project has special features:

1. It was the first reconstruction project financed by Luxembourg within a national context of high aid intensity (with multiple donors). The magnitude of the disaster surpassed local organisational capacities.

2. When the project started, Luxembourg's aid agency did not have a permanent regional office. A subcontracted NGO managed the project in the field.

3. The formal counterpart was the municipal government. However, in practice, the NGO had to rely on a nascent community organisation. Conflicts arose over time.

Thus, neither national, municipal government, nor the donor was able to lead the reconstruction efforts. Informal practices defined the character of the project in a very difficult context for survivors. Personal relationships between project staff, project participants, and communal leaders were crucial.

The main purposes of this chapter are to investigate the impacts of the project on the individual autonomy of project participants, and to explore their meanings of individual autonomy and community.

The chapter is organised as follows. Section 6.1 presents some background information about the participants: their lives in the origin towns, experience during the Casitas mudslide, and emergency situation. Section 6.2 describes the project objectives, organisation, and some contextual elements. Section 6.3 analyses the project practices. Section 6.4 explores the experiences of autonomy of Santa María residents and their understandings of community. Section 6.5 evaluates the project impacts on individual autonomy. Section 6.6 presents some preliminary conclusions.

\subsection{The communities and the landslide that transformed life forever}

Rolando Rodríguez and El Porvenir were located $3 \mathrm{~km}$ south from the Casitas volcano. They dated from 1979 when some peasant farmers took possession by force of lands that belonged to large estate owners. They acquired legal rights to those lands through the agrarian reform of the 1980s (Rocha, 1999a) and were organised as cooperatives. As consequence of recurrent economic crises (Appendix 1-A), residents kept the formal cooperative structure only aiming at promotional credits, not maintaining collective production. Instead, they parcelled-out the common land. Hence, in two decades, large coffee plantations had been replaced by small plots for basic grain cultivation (Areas Calvo, 1998).

Life prior to the mudslide was good

We had a good life because we had enough land to sow, we raised animals. Life was tranquil (HIW). 
Each household had at least half a manzana (more than 3,500 squared metres) for its house and land. When the family grew, parents would divide their land among their children, so that people were surrounded by relatives and at some distance from non-relatives. Agriculture was the main economic activity in these towns. Small farmers produced basic grains, cassava, and fruits for self-consumption. Most of them had chickens, pigs, goats, and cattle. Some others owned cows to consume and sell milk and clotted cream (cuajada). Some households also had small shops and traded their products in the markets, including the country's capital city, Managua. A man explains:

My dad sowed maize, rice, frijoles, stump, and any quantity of fruit-bearing trees. When the fruit was already mature, we cut it and we took it to the market. Once we sold it, we bought the rice, the sugar, the soap, the oil, and everything necessary for the house. From that we sustained ourselves, from the sowings (HIM).

The area was rich in pine trees and the climate was fresh. Residents were living within the boundaries of a natural reserve, decreed as such in 1983 (Barahona \& Mendoza, 1999), but they were taught neither sustainable natural resources management nor techniques for production in hillsides (Areas Calvo, 1998). They used the pine reserve as a source of firewood and construction material. Deforestation was leaving its mark.

Migration was not unusual

Living conditions had deteriorated over time as result of the economic adjustment policies. Paid work as daily labourer in nearby plantations was seasonal and more and more scarce due to the gradual closure of industries (Cruz, 2000). In 1995, seasonal work in coffee, cotton and sugarcane plantations employed only $21 \%$ of the labour force in the area (Barahona \& Mendoza, 1999).

The lack of promotional credit and the scarcity of local paid jobs had led some people to migrate to Costa Rica or El Salvador in order to earn money to finance their planting. However, sowing was getting harder due to recurrent droughts.

The access to basic services was improving

We were improving year to year. The town was becoming more urban, more populated. We had potable water... We were going to introduce electricity service. We had public transportation... Everything was getting pretty. Mitch frustrated every inspiration to grow and develop that what we had (Pedro).

Some houses were made of concrete with wooden roofs. Others were ranchos made of local materials (cane, the jaraguá grass and hay). Each town had its school where people also held community meetings. There was one health centre in El Porvenir with a permanent doctor.

In August, 1998, the first phase of a water project financed by the Swiss Agency for Development and Cooperation (SDC) and managed by CARE Nicaragua had been inaugurated. International aid agencies such as Save the Children provided food relief in drought events. There were small health and education projects financed by donors.

\section{Hurricane Mitch had unexpected and terrible effects in Posoltega}

I heard the mountain thundering. It was almost as if... twice as loud as if all the helicopters had suddenly come down from the skies. I had never been as afraid in my life as I was that 
day. I really felt that my life was slipping through my hands (a man cited by The White House, 1999, II 8).

The mudslide of Casitas in Posoltega was a national tragedy. The Casitas volcano is located in the mountain range of the Maribios, a volcanic chain $70 \mathrm{~km}$ long. During five days, Mitch triggered heavy rains that exceeded by five times the normal rainfall levels (Carreño Collatupa, 1998). Around 11 a.m. on October 30, 1998, a side of Casitas, which is 1,405 metres above sea level, collapsed and slid down, razing everything along its path (Figure 6-1).

Figure 6-1: The extent of the Casitas mudslide

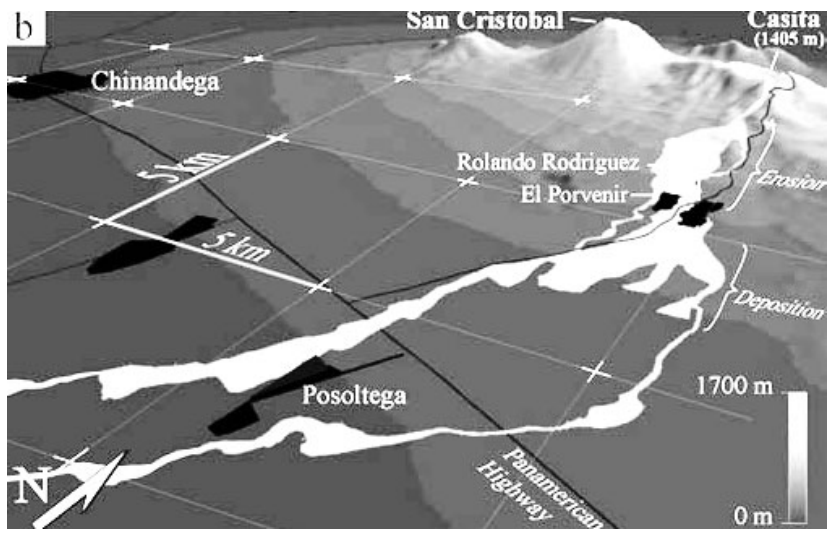

Source: Kerle, van Wyck de Vries, and Oppenheimer (2003, p. 332).

Several towns, including the municipal centre, were affected. Rolando Rodríguez and El Porvenir were wiped away by the mudflow. A wave of lahar, a mudflow of volcanic ash and water, ${ }^{35}$ including rocks of at least one metre in size together with trees, picked up a speed of up to 60 miles per hour. The maximum height of the wave reached three meters when it entered into El Porvenir. The width of the wave in its upper parts was about 1,500 metres. Roughly 80 square kilometres were covered by lahar. Deforestation made the mudflow's path smooth.

The effects were insurmountable. A community leader (cited by Rocha, 1999a) recalls that 2,513 people were buried, while another 2,800 people in 667 families were affected. In the whole municipality, some 1,500 houses, 50 wells and 650 latrines were destroyed. Over 2,000 hectares of crops were lost, together with 2,000 head of cattle, 2,000 goats and pigs and 3,000 chickens. A total of $119.5 \mathrm{~km}$ of rural penetration roads and 13 bridges were damaged.

The suffering got worse and worse

We prayed because we did not have [anything] to eat and we did not know how we were going to live... We thought that we were going to die (HIW).

National institutions were not well equipped to cope with the disaster effects. First, the central government had a delayed response to the catastrophe and thus it did not alleviate human suffering. The first reports of 1,000 deaths and extensive material losses by the mayor of Posoltega were called exaggerated (Sánchez Mondragón, 2000). The government

\footnotetext{
35 Oxford English Dictionary Online, 2 ${ }^{\text {nd }}$ version, 1989. Retrieved October 3, 2006 from http://dictionary. oed.com
} 
declared the 'state of disaster' belatedly (The Advocacy Project, 1999; CIDAI, 1998) and did not offer a prompt solution for burying the cadavers, ${ }^{36}$ which could have caused deeper health problems, in addition to the emotional stress. Survivors themselves rescued the injured people and disinterred the cadavers covered by lahar.

Second, the government lacked the capacity to effectively channel emergency aid to victims (CENIDH, 1998; Envío team, 1998). The social audit carried out by the Non-Governmental Emergency Relief and Reconstruction Coalition (CCER), formed by more than 300 local NGOs, confirmed this: four months after the tragedy, 30\% of the survivors declared that they had still received no aid, while $32 \%$ were surviving thanks to food-for-work programmes (Nitlápan-Envío team, 1999a). Only 'after the widespread complaint about the government's slow reaction and the fears of cases of corruption' (ACI Prensa, 1998, II 1), did the government delegate the distribution of emergency aid to the Catholic Church. Psychological support was not centralised by health authorities. Many NGOs intervened in the zone with a multiplicity of techniques, budgets and for limited time (except for a few religious groups).

Third, many donors were sceptical about the government capacity to coordinate reconstruction efforts and centralise decision-making. They preferred to deliver aid through nongovernment channels, especially well-known NGOs. This practice responded to doubts about the governance conditions in the country (section 3.1.3). However, many donors acting independently could obstruct local efforts to improve institutional capacities.

Fourth, reconstruction works started with delays. The Nicaraguan Institute for Territorial Studies (INETER) took over two months to define which areas were secure to build houses (Rocha, 1999a). The disaster of Casitas drew broad media coverage and many donors arrived. Landowners took advantage of the situation and increased the land prices dramatically, from USD200 and USD350 a hectare to USD2,000 a hectare (Rocha, 1999a; Potoy Rosales, 1998). Donors and NGOs faced hard price negotiations. The government showed neither political will nor capacity to solve the land problem to reallocate survivors.

\section{Political polarisation aggravated the emergency situation}

The Nicaraguan government, by delaying the declaration of the State of Emergency, by attempting to limit the flow of aid through the civil society and by directing aid to its favourite electoral zones illustrated all the risks. NGOs did not necessarily react in a concerted manner (Grunewald et al., 2001, p. 165).

Political differences, between the liberal president and the Sandinista mayors of Posoltega and other municipalities affected by Mitch, explained the passivity in relief and reconstruction efforts (Chamorro, 1999; The Advocacy Project, 1999). Resentment among survivors was widespread. Chamorro (1999) reflects about 'an inversion of values' because infrastructure such a highways and bridges were promptly repaired, while the affected rural families were abandoned in plastic huts. In addition, abundant rains during 1999 caused most reconstruction projects to start after the rainy season.

\footnotetext{
${ }^{36}$ On November 18, 1998, Father Benjamín Villarreal, priest of Posoltega, said that so far he had not seen government help to bury the dead, and added: 'The dogs, the pigs and the coyotes are giving a banquet with our brothers and this is macabre. Maybe more than thousand dead persons are unburied' (cited by Chávez \& Thomas, 1998, II 4).
} 
Rocha (1999a) explains that to make matters worse, 'after hurricane Mitch came hurricane Alemán'. Presidential decree 92-98 (December 9, 1998) declared the lands affected by the disaster in the public domain and confiscated them as insecure. The lands were used to host a memorial park to the victims of Hurricane Mitch. Rocha explains that compensation payments went to the former landowners, who had been expropriated during the agrarian reform and compensated in the early 1990s, not to cooperative members who had occupied and worked those lands for the last two decades.

The disaster pushed the formation of a community organisation

In September 1999, a group of six people constituted a NGO called Association of Casitas' survivors (ASCA), led by Pedro, a former inhabitant of El Porvenir who lost three daughters, his mother and other members of his extended family. Pedro gained media exposure because he talked with US President Bill Clinton during his visit to Posoltega (March 1999). He and others traveled to the US in order to explain the needs of survivors to some US congresspersons and to promote aid delivery to Nicaragua.

Desperation led people to act violently

When we were in the refuge [a school], they [national authorities] wanted to take us out of the school because children had to start classes. Then, the leader said: 'let's arm people to take these lands'. No one lived there... My sister went at night to take those lands. A part of the family stayed in the refuges and another came to El Tanque (LIW).

Survivors could not use their own lands, either declared as of high risk (Rocha, 1999b) or expropriated, and they did not receive any financial compensation. They were 'in panic' (LIW) because there was no certainty about the purchase of lands to construct houses. In their intent to gain access to land where they could live and sow grains, on 28 December 1998, 247 families took a finca (a large farm or plantation) known as 'El Tanque', which had around 500 hectares. A farmer (cited by Rocha, 1999a) explains the situation:

For us, the main problem is land... If we agree to live in urbanized $10 \times 20$-meter lots, we'll become thieves, because we're not going to let our children die of hunger. Instead of peasant farmers, we'll become lumpen ${ }^{37} \ldots$ We'll be the last ones to have houses, because no NGO is going to build without property titles, but we'll be the first to plant. Legally or not, we're going to plant (Rocha, 1999a, 'Complex problems, difficult solutions' section, II 2).

The uncertain and harsh situation forced these people to act violently because they felt that the available options neither provided them effective protection nor saved their dignity as people who wanted to sustain themselves (cf., Hofmann et al., 2004). When Finca Santa María was bought and the housing project was approved by Luxembourg, 84 families left Finca El Tanque (Rocha, 1999b) to participate in the project, hoping for a new future.

\subsection{The reconstruction project}

The goal of the project was to 'to contribute to the economic and social rehabilitation of 350 families of Posoltega, victims of the hurricane Mitch' (LD, 1999a, p. 14). Its objectives were that households have a roof and victims restart their productive activities.

\footnotetext{
${ }^{37}$ Lumpenproletariat, Karl Marx's term.
} 
The sister city of Bloomington (Indiana, US), CONA (Austria), the embassy of Austria, CARE, and Verbo Christian Mission bought Finca Santa María. Luxembourg financed the construction of 350 houses, a primary school with kindergarten, and a community centre. A private company built the school and community centre. Project participants constructed their houses assisting the hired bricklayers and making the blocks. The houses were single rooms without inner divisions and finishes. Each household built its own humid areas that consist of bathroom, lavatory and residual water disposal system (RWDS) behind the house, with the help of the project.

CARE International in Nicaragua managed and executed the project. It also was responsible for an agricultural project financed by USAID and a water project financed by SDC. At its formulation, the Santa María project was considered integrated (LD, 1999a, p. 19) because it provided housing, water and sanitation, social infrastructure, and work, through the cooperation of several donors.

\subsubsection{Organisation of the project and main stakeholders}

A project officer in Luxembourg was responsible for the project (Figure 6-2). LuxDevelopment S.A. (LD) did not set up a project implementation unit; rather a new regional office in Managua supervised and monitored the works since mid-2000, when a regional director was formally appointed. From November 1999 to March 2000, there was no technical coordinator. Instead, the manager of another project indirectly followed up the project from Managua. ${ }^{38}$ This situation affected the quality of the project because the houses were built from October 1999 to September 2000.

Figure 6-2: The organisational structure of the Santa María project

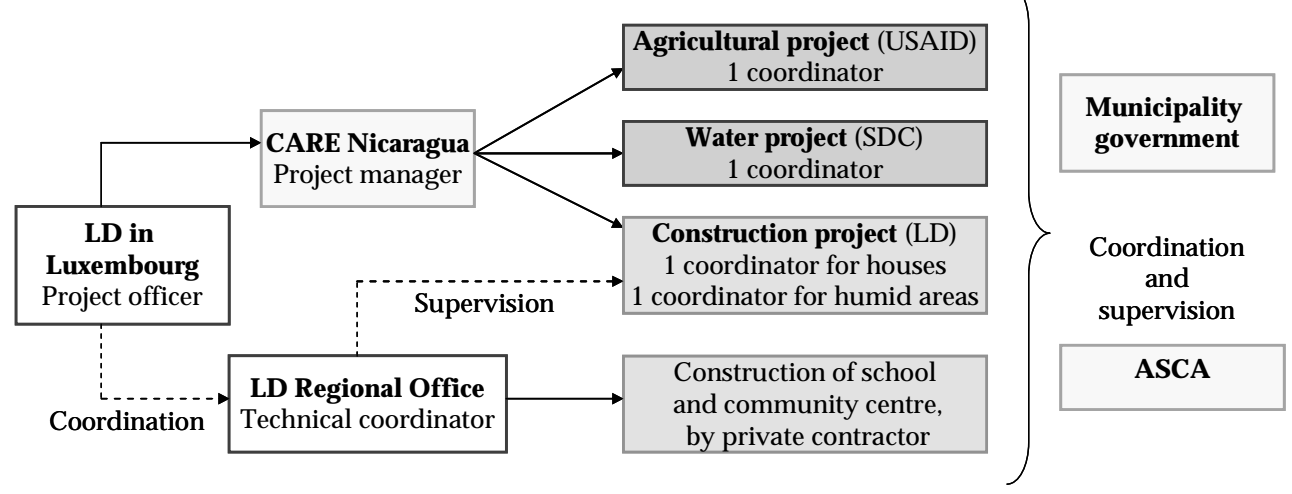

The project lasted more than two years and included several components. Continuous coordination among different entities was necessary, especially for identifying the beneficiaries and monitoring the activities. It was expected that the International Organisation for Migration (IOM) and Movimondo (already involved in the census of refugees) would coordinate all reconstruction projects in Posoltega because they were supporting the municipal government, which was elaborating a municipal development plan (LD, 1999a). Apparently, there were problems to harmonise donors' objectives and strategies, for instance, in defining a unique house design (according to a former regional director).

${ }^{38}$ This conclusion is based on Ausín Cantero (2001a) and individual interviews to LD regional staff. 
CARE appointed a manager for its three projects; each project had a single coordinator with its own staff in the field. For the construction project, the coordinator was an architect based in León (in another department), supported by an engineer, store-keeper, and social promoter in the site. The project hired eight contractors (maestros de obra) who brought in their skilled bricklayers; there were 150 bricklayers working in the busiest period. The CARE manager contracted the welders and carpenters for building the roofs, windows and doors. Table 6-1 shows the main actors participating in the project.

Table 6-1: Main stakeholders of the Santa María project

\begin{tabular}{|c|c|c|c|}
\hline Formal authorities & Donors and organisations & Project staff of CARE & Community members \\
\hline $\begin{array}{l}\text { National government } \\
\text { Municipal government } \\
\text { Ministry of Education }\end{array}$ & $\begin{array}{l}\text { LD, USAID, SDC, IOM } \\
\text { WFP, Save the Children, } \\
\text { Verbo and other donors } \\
\text { Local NGOs } \\
\text { Catholic Church } \\
\text { Civil society in general }\end{array}$ & $\begin{array}{l}\text { Project coordinator, } \\
\text { engineer, social promoter } \\
\text { Contractors, bricklayers, } \\
\text { carpenters, others }\end{array}$ & $\begin{array}{l}\text { ASCA, CDC } \\
\text { Survivors, displaced } \\
\text { people } \\
\text { Other projects' benefici- } \\
\text { aries and former land- } \\
\text { owners }\end{array}$ \\
\hline
\end{tabular}

CARE managed the construction of houses, but the construction of the school and the community centre was under responsibility of the municipal government. However, in practice, the technical coordinator of LD monitored the progress (Ausín Cantero, 2001a).

The municipality government was the formal counterpart of the project. The mayor had actively searched for housing solutions at early stages of the project, but supervising a large number of parallel projects was very difficult. Coordination was not effective, evidenced by the fact that projects differed so much. Moreover, there were three mayors during the project lifespan. The mayor who faced the disaster gained public notoriety, resigned in 2000 to run for the Congress, and was replaced by her vice-mayor. A new mayor was elected for 2001. Consequently, CARE was left with all the responsibility for the project; while the local government kept a distant role (Tórrez, 2001; 'Minutes', 2000). Project staff was overloaded and had to look for another partner.

ASCA took over the partner role in a context in which individuals were still grieving. At the beginning, ASCA's leadership was not challenged by project participants, but this situation changed over time, especially after some problems with CARE staff emerged (section 6.3.2).

\subsubsection{Micro-level context around the project}

The construction of the houses started in October 1999, one year after the disaster. During that time, survivors had lived in harsh conditions, first in schools of Posoltega used as refuges and later, in plastic huts. Emergency aid was being channelled jointly by the Catholic parish and the local government but it was insufficient to secure the subsistence of survivors and thousands of displaced people. Hence, some people travelled to other regions of the country to live with distant relatives and friends. Migration, especially of men, increased. When the project started, many people came back to register and work in the project.

At the beginning, there were over twenty specialised entities offering psychological help. However, their actions were disorganised and almost all of them had left by the end of 1999 (Quinn, 2000). CARE (2000c) reports that, less than two years after the disaster, no organisation was offering psychological help to individuals. 
Finca Santa María was divided into two areas, one for houses and social infrastructure (36 $\mathrm{mz}$ ) and the other for agriculture activities $(58 \mathrm{mz}$ ). During the construction of the houses, people stayed in a temporary camp in the central part of the finca, which was close to a well of drinking water. Life in the camp was difficult. There were problems of alcoholism, intrafamily violence, and sexual violence. These were symptoms of a deeper problem: the unresolved personal trauma, which was being not adequately addressed (Cabrera, 2002).

For some people, working in the project was like a therapy, 'to take [their] mind off [the pain] because they had to concentrate on constructing a strong house' (a woman leader). The start of the project brought happiness and hope, as a woman explains:

We were very happy when it was said that we were going to start and the [construction] materials arrived ... I felt that my heart was going to stop beating. I helped to build the first house. God is so wonderful that [when] one asks, He truly listens (HIW).

From the camp, project participants used to walk about four blocks to work in the housing project or the agricultural project. They benefited from a food-for-work programme executed by Save the Children and sponsored by the UN World Food Programme (WFP), which was withdrawn by mid-2000, according to FGD participants and the social promoter. ${ }^{39}$

By the end of the project, in September 2001, the Committee of Communal Development (CDC) of Santa María was founded, with the support of the local government. Then, there were two organisations in Santa María: ASCA and CDC. The political context during 2000 had been tense. Pedro ran for mayor in municipal elections as candidate of the liberal PLC, but the Sandinista candidate won. Some people consider that the new mayor formed CDC to counterbalance the power of ASCA in the town (Ausín Cantero, 2001a; 2001c). Another possible reason is that the mayor was following the guidelines of the national development plan, which promoted local participation (Appendix 1-A, section 2.d).

Two projects are relevant for comparative analysis: 'El Bosque', financed by the Spanish cooperation, and the project in El Tanque, financed by Medico International (see Table 6-2).

Table 6-2: Comparison of relevant reconstruction projects in Posoltega

\begin{tabular}{|c|c|c|c|}
\hline Project & El Bosque & El Tanque & Santa María \\
\hline Beneficiaries $\left({ }^{*}\right)$ : & $\begin{array}{l}\text { People displaced by } \\
\text { Casitas }\end{array}$ & $\begin{array}{l}\text { Survivors + displaced } \\
\text { people }\end{array}$ & $\begin{array}{l}\text { Survivors + displaced } \\
\text { people }\end{array}$ \\
\hline Number of houses: & 130 & 167 & 350 \\
\hline Lots per household: & $220 \mathrm{~m}^{2}$ & $\begin{array}{l}\text { Between } 1.0 \text { and } 2.25 \mathrm{mz} \\
\text { at least } 7,000 \mathrm{~m}^{2} .\end{array}$ & $\begin{array}{l}369 \mathrm{~m}^{2} \text { (average), } 364 \mathrm{~m}^{2} \\
\text { (standard) }\end{array}$ \\
\hline House dimensions: & $50 \mathrm{~m}^{2}$ & Not available & $45 \mathrm{~m}^{2}$ \\
\hline Houses built by: & Private company & Self-construction & Self-construction \\
\hline Services provided: & $\begin{array}{l}\text { Electricity, water and } \\
\text { sanitation }\end{array}$ & $\begin{array}{l}\text { Electricity, water and } \\
\text { sanitation }\end{array}$ & Water and sanitation \\
\hline
\end{tabular}

${ }^{*}$ ) Survivors refer to former inhabitants of El Porvenir and Rolando Rodríguez; displaced people are inhabitants of other towns also affected by the mudslide.

Source: Bolsa de Noticias (2000), Ausín Cantero (2001b; 2001c), González (2003), and Dávila (2005).

\footnotetext{
${ }^{39}$ In contrast, Ausín Cantero (2001c) reports that food was provided during the lifespan of the project. The social promoter reported that the programme was withdrawn because some people were selling the food, while others publicly claimed that 'they were starving' when there were delays in food provision.
} 


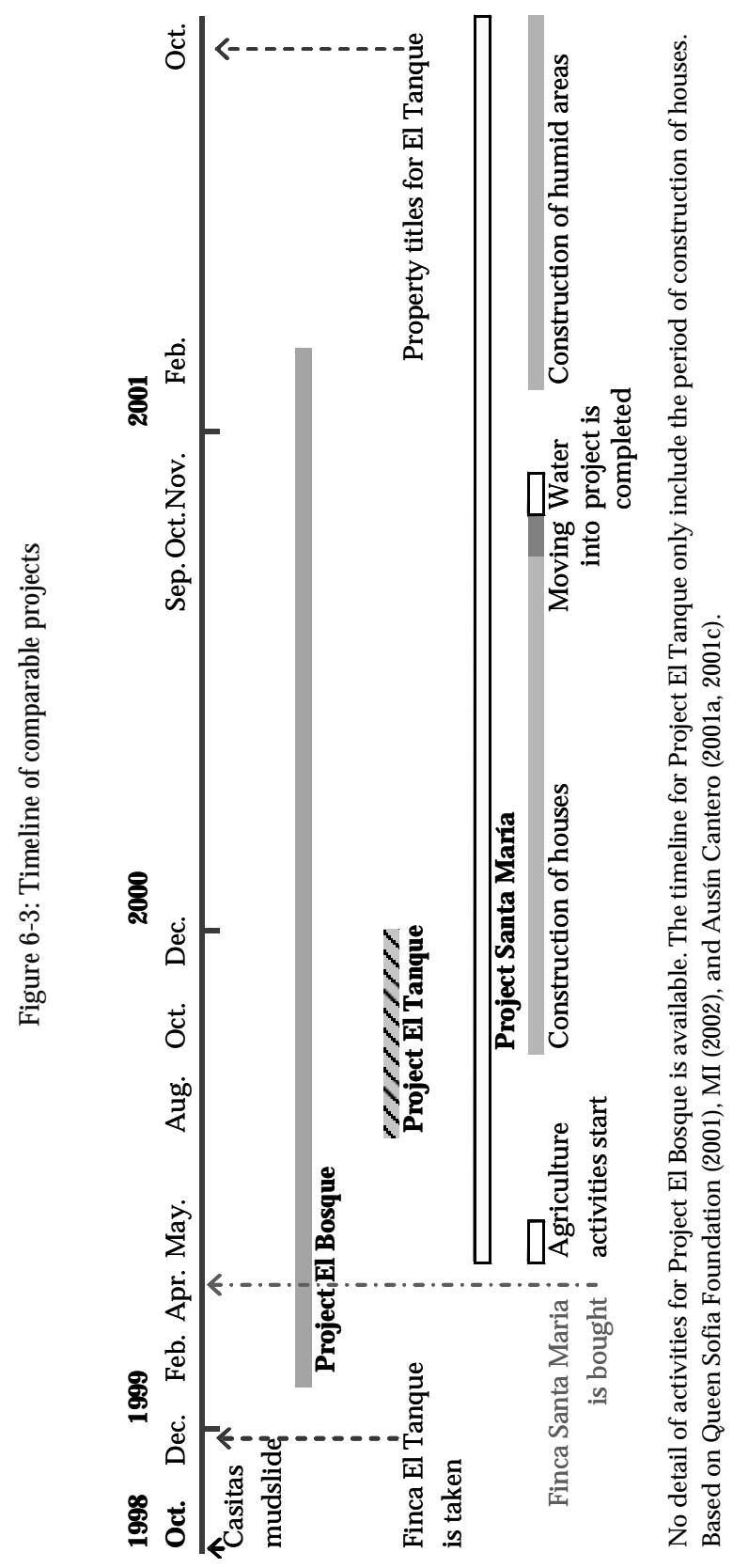


Both projects had a community centre, school, some medical facilities, and parks (social infrastructure was financed by several donors in Santa María). The analysis focuses on houses, as evaluated by FGD participants.

Figure 6-3 shows that the project in Santa María started and was completed later than the other projects. In El Tanque, the construction of the houses took only five months, but the quality is not comparable to that in Santa María or El Bosque. In El Bosque, individual plots were the smallest and there was no communal plot.

Houses in El Bosque were constructed by the largest construction company in Nicaragua; costs were much higher than those in Santa María because the design was more complex. ${ }^{40}$ Each house consisted of three bedrooms, a living-dining room, kitchen area, lavatory, and sanitary services. In contrast, houses in Santa María were one room without divisions and the humid areas were behind the house. El Bosque offered a more urban environment than Santa María as roads were asphalted and had gutters and platforms. During the construction stage, people in Santa María resented that their houses were simpler and that they had to work in the construction. This caused some turnover problems to the Santa María project.

El Tanque was another benchmark for Santa María residents because most of them had participated in taking over Finca El Tanque, in 1998. Those who stayed in El Tanque had difficult times, with permanent threat of expulsion, but counted on the support of Medico International and of German Bundestag representatives, who publicly denounced the desolate situation of survivors (MI, 2002; Nitlápan-Envío team, 1999b). This project was completed soon and beneficiaries received their property titles in October 2001 (MI, 2002). Nonetheless, the legal confrontation with the former landowner persisted some months later (MI, 2003).

El Tanque residents formed a cooperative, which offered revolving loans to members and bought seed at large scale. During the reconstruction period, Santa María residents regretted their decision of leaving El Tanque because that project was considered sustainable: it provided housing, water well and drainage system for all-year irrigation, sanitary services and land for agriculture work. This situation also harmed the mood during the Santa María project, although people were busy with agricultural work from May 1999 onward. There is no cooperative in Santa María as people do not legally own any land. However, not much land was available in the area after Hurricane Mitch.

\subsubsection{Other components of the project}

USAID financed a project of agricultural rehabilitation that benefited between 120 and 152 families in Santa María (CARE, 2001b; Tearfund, 2002; Ausín Cantero, 2001a). A revolving credit system would be managed by the community. The project supported activities for basic grain and horticultural production, crop diversification, fruit and forest trees, and the raising of chickens and pigs (USAID, 2001; Sullivan et al., 2000). It provided ecological wood stoves to reduce firewood consumption and started a pilot project to produce and trade ornamental plants (Ausín Cantero, 2001c). However, some observers foresaw problems of sustainability with these projects, given their small scale, which would require more structural solutions such as the provision of alternative lands (Sullivan et al., 2000, p. 11).

\footnotetext{
${ }^{40}$ The construction costs per house in El Bosque, including social infrastructure, were USD15,700; the costs in Santa María were USD3,600, without social infrastructure (Ausín Cantero, 2001b; Bolsa de Noticias, 2000).
} 
The water project was coordinated with ENACAL. Each house got a tap connected to an autonomous water system (artesian well). Residents worked as assistants and built their own latrines. Finally, the management of the water system was left in hands of a communal water committee. Perceptions about the work of this committee are diverse. It seems that there were problems with the water quality (Hernández Ramos, 2000; BloomingtonPosoltega, 2004), but no person commented on this during the fieldwork.

The project also aimed on paper at providing psychological support (LD, 1999a), but project staff did not act in this area, independently or in collaboration with other actors. CARE (2000h) reports that the situational diagnosis of families was not made because there was no financial contribution. According to the social promoter, during the first eight months, two local NGOs used their own funds to help.

\subsection{Project practices}

This section presents the practices that are significant to Santa María residents, as reported during the focus group discussions. These practices are selection and design decisions, conditionality, coordination, and accountability. Table 6-3 summarises the aspects to be analysed with respect to the construction project.

Table 6-3: Main practices during the Santa María project

\begin{tabular}{|lll|}
\hline Project phase & Practices & Aspect \\
\hline $\begin{array}{l}\text { 1. Identification and for- } \\
\text { mulation }\end{array}$ & Selection and design deci- & - The selection of local counterpart \\
\hline 2. Implementation & Selection and design & - The definition of a communal land \\
& Conditionality & - House design \\
& - Eligibility criteria \\
& Coordination & - Allocation of the houses (moving into them) \\
& - The control of workdays \\
& Accountability & - The supervision of infrastructure works \\
\hline 3. Evaluation and audit & Accountability & - House quality \\
\hline
\end{tabular}

\subsubsection{Selection and design decisions were finally made by outsiders}

Three decisions are important: the selection of ASCA as the local counterpart, the division of the land into a common rural and an urban area, and the house design.

- The selection of local counterpart

At that time, ASCA leaders worked well... they run around to get food from aid agencies... Now, I do not know if they forget or something happens, but they have the obligation to inform the community (HIM).

ASCA was the counterpart because it was formed by a group of leaders (survivors themselves) who were in control of the camps before the project (Ausín Cantero, 2001a). A man explained that, at the start of the project, there were three community boards (directivas) and it was difficult to organise the aid delivery. The situation improved after ASCA was formed. ASCA has a president, vice-president, secretary, treasurer, inspector and other member.

The president of ASCA, Pedro, affirmed that the mayor asked him to represent the community and that ASCA leaders found out that Finca Santa María was for sale. Pedro saw ASCA 
as the promoter of the project, so that when several donors presented their construction proposals at a meeting, '[they] chose... the proposal of CARE, which was godfathered by Luxembourg' because they had previous experience with CARE projects. ASCA members considered themselves competent enough to be the counterpart of CARE.

Likewise, non-leaders saw the construction project as a result of the efforts of ASCA leaders. Although they think that ASCA has caused some problems, they need it. One woman said: 'Now we realise that, one, we have our house, and two, we have to do and consent to do what they [leaders] request us... because we [do not want] to have shortage' (HIW).

People developed mistrust in leaders during the project lifespan (Tórrez, 2001; Ausín Cantero, 2001a). Individuals publicly accused leaders of bad handling of common resources, provided by several small projects at that time (see section 6.4.3).

\section{- $\quad$ The definition of a communal land}

We were sent to those lands to sow rice and to plant stumps...

We sowed rice and sugarcane; we cleaned the sugarcane as well... We had several parcels of maize. Whoever worked had the right to receive food (HIM).

The decision of having a communal plot was made during the formulation. Instead, Santa María residents would have preferred bigger individual lots to cultivate and to raise farm animals. It seems that donors or formulators wanted to (i) secure food for landless survivors who had to start planting as soon as possible, or (ii) promote union between people who needed to work together to advance. In addition, communal farming was considered feasible given the high levels of organisation shown by survivors during the emergency period.

One of the donors proposed the division between an urban area composed by house blocks and a communal plot. The director of Verbo Christian Mission in Nicaragua wrote:

Our suggestion was to create smaller lots, with simple houses, and dedicate $90+$ acres to intensive agriculture for self employment opportunities for the members of the community. It's not sufficient land for such a large community, but not all the refugees are real farmers, and some either through injury, illness, or family situations will not be able to work the land. The possibility of creating an agricultural community model does exist (Trolese, 1999, II 6).

Despite the donor's good intention, this decision did not consider that people were disenchanted of a cooperative model. They valued a country life style with individual plots for each household. The agricultural project in this land was first linked to a food-for-work programme so that motivation was extrinsic. The revolving fund only lasted one year (a woman leader). After several problems, years later, people informally divided the communal land; hence, each household holds lots of about $625 \mathrm{~m}^{2}$.

\section{- House design}

We chose among the three models... we were considerate and chose that one in the middle... but they [the engineer and bricklayers] made the worst, the one that they wanted (HIW).

The project built 350 houses arranged in 24 blocks. LD (1999a) established that each house would be of $50 \mathrm{~m}^{2}$ in lots of $250 \mathrm{~m}^{2}$, with divisions for bedrooms and common areas. There would be two models depending on the location of the plot; IOM would define the final design. In practice, it seems that the final house design was defined by the LD temporary coordinator and the CARE project manager, based on a model of $36 \mathrm{~m}^{2}$ that CARE had 
(Ausín Cantero, 2001a). The contract between LD and CARE did not include specific house designs or separate housing budget (ibid).

However, three designs were sequentially presented to beneficiaries during the project implementation. These multiple proposals created confusion. Some FGD participants recalled having seen two or three models of houses, but they agreed that their choice was not respected. Hence, consulting people about the house design did not promote ownership, it was rather disempowering. How did this happen? Two possibilities are:

(i) Most people 'accepted' because they were still grieving, too emotionally affected to attend meetings or make decisions. Several participants said that they realised how their houses were going to look, only when the construction works started.

(ii) CARE was not offering options or alternative models, but informing Santa María inhabitants of the feasible models at different stages, based on decisions made by CARE staff and others. The inhabitants never had 'process freedom'.

High-involvement women reflected on possible reasons for the change in house design. Some women thought it was necessary to provide houses to more people, so that simpler houses were given to each household. Another said that the 'engineer and their partners also wanted to take off a little piece each'. Most women agreed. They do not think that the donor would have chosen a house like that; it was an implementation failure. However, a leader said: 'We expected that houses would be a little more comfortable, but... What could we do? To accept... if that was the will of the donor' (a man leader in the FGD).

\subsubsection{Conditionality forced households to stay in the houses and wait}

There were some requirements that defined who would have (and keep) a house and when people could move into it.

\section{- $\quad$ Eligibility criteria}

Here, there are many people who did not suffer like we did, because they [leaders] took ordinary people, not registered, to add up the quota. Then, there are people who had their house in another place and came here (LIM).

To be a survivor of the Casitas mudslide was a formal eligibility criterion. However, other people also benefited from the project as several survivors stayed in El Tanque. In addition, one member of each household had to work 60 days in housing construction as a bricklayer assistant. The work was hard and people did not get much training (Ausín Cantero, 2000b).

In March 2001, the local government and LD formed a verification commission to check that houses were assigned to the neediest people. They assumed that if a house was empty, the household had another place where to live. Hence, in order to keep the house, people had to stay living in it. The commission was composed of a representative of the local government, a member of ASCA (later, replaced by CDC) and the CARE social promoter.

The process of verification brought conflict between CARE and ASCA, the main decision makers. The meaning of 'house' to each stakeholder was different. To people in Santa María and ASCA, the house was a right because they had suffered a disaster and survived. Then, it was legitimate to keep the house closed and go away to look for work options, as a survival strategy. To the donor and project staff, the permanence of beneficiaries in their houses was 
a signal of success. In this way, houses became a trap for people. The analysis of special cases was time-consuming; strange and variable rules applied. For instance, people working in Costa Rica could keep the house 'because they were far away', but those living in Chinandega or León (department capitals) had to come back to Santa María (Tórrez, 2001).

Beneficiaries criticised the commission's actions (ibid). ASCA blamed the social promoter for deleting names from the list, taking advantage of the dislike of many inhabitants for her due to the strict work control (section 6.3.3), and could have been 'inciting' people to complain (CARE, 2000d). Finally, ASCA withdrew from the commission. This situation affected further the emotional situation of participants, who developed different strategies. They denounced their cases to the mass media, called for the donor's intervention, developed nepotistic behaviours with CDC leaders to be privileged, or simply kept up working.

In August 2001, the verification commission reallocated 32 houses. The new beneficiaries had to compensate the old ones for their work in the houses. Tórrez (2001) reports that the payment was of around USD200, much less than the cost of the house (USD3,600). Some people still think that these 'newcomers' did not deserve to get the houses because they did not suffer, work or value the houses the same as survivors did.

\section{- Allocation of the houses}

At that moment we did not know which house would be for whom, but we all wanted to make it beautiful (HIM).

Houses were allocated by a drawing, among the families that had completed their 60 workdays. The logic behind this practice was that (i) inhabitants would work with the same enthusiasm on every house, if they did not know which one was theirs, and (ii) the distribution would be fairer in terms of location, whether close to the communal plot or at the village entrance. In general, the incentive seems to have worked, but some people resented that their houses were far from those of their relatives.

Families could move into the houses only after building the latrine. This condition was coordinated with SDC (water project), in order to promote the use of latrines because, when living in Casitas, people had only common latrines. It seems that some people did not understand the reasoning for this. One woman said: 'The promoter did not give keys until all houses were finished' (LIW). Thirty families, whose houses had been allocated in May 2000, moved only in August 2000. In October 2000, shortly after all houses were finished and assigned, people occupied their houses by force. A woman explains:

I entered through the window because there were some heavy rains that even destroyed the huts. Then, we came at night, without authorisation... because it was horrible; the huts were falling apart with the storm (LIW).

Some houses were not fully finished so that some corrections were made later. The construction of humid areas started once people were in their houses. Those who helped cleaning the communal areas would be the first in receiving materials for the humid areas. This means that project staff provided extrinsic motivation to engage people in communal works. The six bricklayers hired were residents of Santa María (Ausín Cantero, 2001a). 


\subsubsection{Weak coordination as result of organisational problems}

Coordination was difficult. Project staff did not have support to interact with national institutions, and faced difficulties with direct beneficiaries. The strict control of workdays did not support high-quality participation. Weak supervision affected the house quality and increased the workload of participants.

\section{- The control of workdays}

We never received any payment; we worked two months and fifteen days... They deleted the days [in the records] because either they made mistakes in the listings or they said that [we] had played clever (a woman leader in the FGD).

During the obligatory 60-day construction period, people worked in groups of 50 or 60 persons. Workdays were long, from 7 a.m. to 5 p.m. There was a record per household and attendance at work was checked twice a day. Working conditions were hard as there was no vegetation and weather was extreme, with hot temperature all year round and strong winds during the rainy season. 'There was no place with shade in which to rest' (said the social promoter). People considered that control was excessive, that the social promoter 'behaved as a foreman' (Tórrez, 2001), and that the record of workdays was not always accurate.

The climate was tense and no one offered help to others because 'there was no one [available], everyone had to work' (LIW). If someone could not work, he or she had to hire someone instead. One woman reflects: 'We had to work very hard; it was our duty because, otherwise, we could not afford a house like that' (LIW). However, FGD participants recalled lighter work conditions for those closer to leaders or to bricklayers. Some women said there were no exceptions for old-aged people, disabled people, pregnant women, and people with acute post-traumatic stress. One woman said: 'There was no justice there... laws were not obeyed in that job' (LIW) ${ }^{41}$

In fact, there were 'problems between the social promoter and some beneficiaries' (Ausín Cantero, 2001c, II 158). The social promoter explains that problems were due to the fact that other projects did not require community work (e.g., El Bosque), people were grieving, they were used to farm work with shorter shifts, and physical conditions were difficult. Regardless, the work had to continue, she affirms, because 'the project demanded community work as the counterpart contribution'. Hence, 'disciplinary norms' were taken to organise and 'control' participation (CARE, 2000a). The social promoter felt like a 'lightning rod' because, while other CARE workers did not fulfil their duties, she had to monitor physical results (not her function) and sacrifice the promotion activities (cf., Ausín Cantero, 2001a).

\section{- $\quad$ The supervision of infrastructure works}

A local supervisor is beneficial. .... [In fact], I told [the bricklayers and a contractor] that a piece of work would not do.... I was there [checking the work] because we were going to stay here. Later they did it good (HIM).

At the start of the housing project, the supervision was not adequate because LD did not have a permanent coordinator, the local government was little involved, CARE staff was

\footnotetext{
${ }^{41}$ The version regarding people with physical restrictions contradicts Ausín Cantero, 2001a, and the social promoter's version.
} 
relatively absent, and the ASCA inspector did not have enough skills. Consequently, there were defects, which beneficiaries themselves had to correct. One woman recalled:

I had to break floors because, in some houses, floors came out wrong. They [project staff] said that it was necessary to break those floors to make them again; the same [happened with] every thing that came out wrong (LIW).

Deleting workdays from the household records possibly was a strategy to get people to redo things. The problem was aggravated because Santa María residents were only assistants and did not know how to build houses, and less how to check the work quality. Moreover, there were problems with the provision of materials, the transportation of water to the construction site, and the availability of skilled labour and carpentry work (Ausín Cantero, 2001c). In short, nearly one-third of survey respondents said that supervision was bad (dataset 2). High-involvement men told about problems with the construction of the soak-away pits. Some men decided to dig deeper than what was instructed by the engineer; now, they feel satisfied because their soak-away pits do work while others do not work.

On April 2000, a technical coordinator was appointed in the LD regional office. Since May 2000 (seven months after the start of the construction project), an individual evaluation system for contractors was put in place. In October 2000, a new ASCA inspector who was bricklayer was selected (Ausín Cantero, 2000a). Hence, the construction of the school and community centre, which started in April 2000 and were executed by a private contractor, was well supervised (Ausín Cantero, 2001c, II 166). People were very satisfied (Ausín Cantero, 2001a). A councilman of Posoltega said: 'There is an auditorium in Santa María that has no equal in Posoltega, León, or any other municipality'.

\subsubsection{Poor accountability harmed local ownership}

Because the main output of the project was housing, this section focuses on the house quality and the legal entitlement of project participants to houses.

\section{- $\quad$ House quality}

We have a roof but we do not have a space to work, to sow. Houses need to be enlarged [because] the family grows.... There is no space to go around the house so that children can play. We only can cultivate little things (HIM).

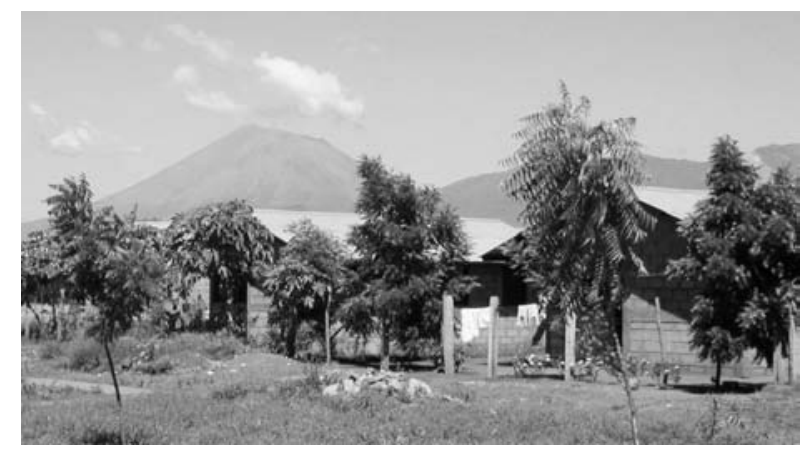

Photo 6-2: Houses in Santa María (November 2001) - Source: LD.

Santa María residents did not agree on a unique house design. They felt doubt. Women, who worked in the first houses, were unable to defend their chosen house design: 
The engineer said: 'This is beautiful'. 'Good', I answered him. 'If you like this, we will make it as you want. The public here is saying that it wants that one, but if you want to make this, make it, because you are the one who [knows how] and is going to make it' (HIW).

People did not understand why their houses looked like an incomplete cage, but they did not have a space to complain because leaders would not listen. They resignedly accepted, as woman said: 'Although the little house was like that, what could we do? We had to receive it anyhow because we needed it' (HIW). However, the ASCA legal advisor said that the final house design was chosen by consensus.

In general, people are very grateful, but, as expressed in FGDs and individual interviews, their expectations were not fully fulfilled. One-half of surveyed participants reported being very satisfied with the quality of their houses and no one said being completely dissatisfied (Table 6-4). There is a moderate and positive relationship between perceived quality and having expressed opinions during the project (Kendall's tau-b, $\tau=0.413, p<.01$ ), which suggests that the tense project climate could have restricted people to express their dissatisfaction as they did during the fieldwork years later. It is illustrative that low-involvement women listed 'do not be quiet, speak out' as one of the lessons of the project.

Table 6-4: Individual perception about the quality of the houses in Santa María

\begin{tabular}{|l|cccc|}
\hline & \multicolumn{4}{|c|}{ How satisfied are you with the quality of your house? } \\
Opinions & A little satisfied & Fairly satisfied & Very satisfied & Total \\
\hline No & 4 & 11 & 6 & 21 \\
& $(19 \%)$ & $(52 \%)$ & $(29 \%)$ & $(100 \%)$ \\
Yes & 1 & 5 & 15 & 21 \\
& $(5 \%)$ & $(24 \%)$ & $(71 \%)$ & $(100 \%)$ \\
\hline Total & 5 & 16 & 21 & 42 \\
& $(12 \%)$ & $(38 \%)$ & $(50 \%)$ & $(100 \%)$ \\
\hline
\end{tabular}

Table 6-4 can be read as follows: Out of 21 people who expressed their opinions during the project, 15 people reported to be 'very satisfied', 5 to be 'fairly satisfied', and 1 to be 'a little satisfied' with the house quality.

Source: Dataset 2.

Santa María residents saw themselves as partners of the executing NGO because they worked together. However, there was neither accountability with respect to processes, because residents were not even well-informed of decisions (made by external bodies), nor accountability with respect to outcomes, when the outputs were not satisfactory.

\section{- Legal ownership of the houses}

We gave money to him [Pedro] for the deed of the house, but we do not have the deeds and all that money from 350 houses is there... They do not tell us anything and we have already lived for six years in these houses! (LIW)

The infrastructures built in Santa María belong to the local government. It was planned that 'the municipal government [would] keep the property titles during two years with the purpose of avoiding speculation' (LD, 1999a, II 58). After that period, each household would receive its individual property title, which was an indicator of completion (ibid, II 38).

The titling process was under responsibility of the local government, with funds from Bloomington, Posoltega's sister city. Households paid about USD8 to cover administrative costs. However, ASCA leaders said that the donor backed away and, hence, they requested 
an additional payment that only a few could pay. Popular dissatisfaction with ASCA has grown and it is not clear how many residents have received their property titles. ${ }^{42}$

Project staff promoted a criterion for home ownership that privileged women and children, as agreed by the municipal government, LD, CARE and ASCA. This caused some conflict (e.g., the coordinator of CDC does not agree). However, the main issue is that Santa María residents feel insecure because they do not know how and when they will get their property titles. A woman explains: 'I sometimes think that I can be left... with the suitcase along the highway because... when one does not have the legal title, [it] is like not having anything' (HIW).

\subsection{U nderstanding individual autonomy in Santa María}

This section analyses the situation of Santa María residents as it was in July 2005, during the fieldwork, almost seven years after the disaster and four years after the project was completed. It explores their experiences of autonomy and the role of community.

\subsubsection{Poor living conditions constrain free choice to different degrees}

Poverty burdens us (a woman leader in the FGD).

Autonomy refers to being able to pursue what one considers significant in life. Santa María residents expressed that a good life is what they had before the mudslide. This life includes having food security, work activity, and social and economic infrastructure; being close to one's family; and feeling happy. They do not feel happy because they lost many family members, have less physical capacity to work, and cannot secure a worthy living standard.

The pain continues and staying together is more and more difficult

Family is the primary support network; family members can share important life events and work together. The disaster had a terrible emotional impact on the lives of Santa María residents. Some people lost up to 80 family members (parents, spouses, children, siblings, and other relatives), not to mention their neighbours and friends. The scar of the volcano (Photo 6-3) is a reminder of what happened (Tearfund, 2002).

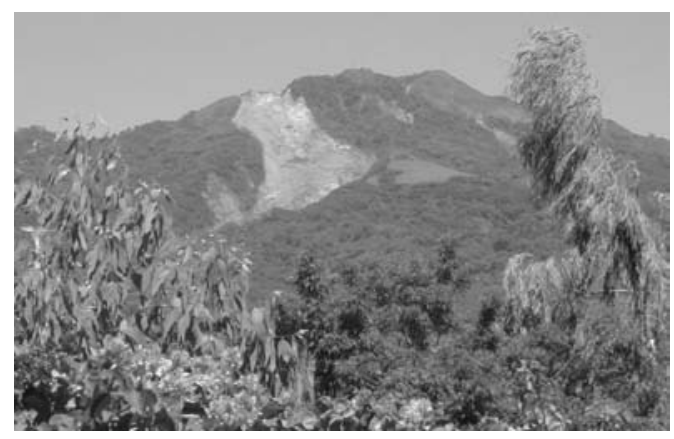

Photo 6-3: View of Casitas from the Memorial Park (November 2001) - Source: LD.

A young woman explains her pain:

\footnotetext{
42 The legal advisor of ASCA affirmed that 169 families already had their property titles. However, only one woman in the FGDs (out of 41 participants) said she had received the title.
} 
When staying in the tents, I trembled and could not sleep everytime it rained. I would fall asleep only when it stopped raining. Here, in the houses, [it is] the same thing.... I am still afraid when it rains, but not so much, I no longer tremble (LIW).

A report about post-traumatic stress in El Tanque, five years after the disaster, concluded that $52 \%$ of surveyed people had experienced sudden anguish crisis (González, 2003). Likewise, Santa María inhabitants have not fully recovered from the disaster and need more psychological help, although religious groups have helped over time. A woman tells:

During six years, I attended talks with psychologists who came to help us to overcome what happened. I took sleeping pills during four years. Those talks helped me a great deal and we still have them on Thursdays.... These help sessions are from the Presbyterian Church (LIW).

For those who survived, staying with their relatives at home is unaffordable. Their lives changed drastically. Nowadays, they have to work outside home to earn money and buy food; barter does not do. Seasonal migration is common among men who travel to Costa Rica to cut sugarcane or work in construction. However, some migrant workers do not return and families are split. Some young women work as housemaids in Managua. Hence, subsistence needs restrict other valued decisions such as the place of residence and work activities. People wish not to leave their children unattended, but they cannot do otherwise. A man tells:

Here, there is no place to work. We have to leave home to survive. It is difficult. Last time, I worked abroad for three years. I used to come every two or three months because my wife was here, in Santa María, but I only came for three days, which was the leave period (LIM).

People are less able to work and sustain themselves

Households have less physical strength to work than before. Their families are smaller, as a man explains: 'Before, it was easier to make a living because I had seven children that helped me; now they are not here. I feel that I am starting again; my children are little' (LIM). About $40 \%$ of households are female-headed; 43 these women 'work all the time' because they do not have help from other relatives.

The health status of Santa María residents is poor due to their extreme poverty, high malnutrition, and dirt in the village. People in an entire block of houses were affected by malaria in 2005. Small children suffer from respiratory diseases. A school teacher tells:

Almost everyday, you see cases of malaria, pneumonia, and bronchitis, due to mosquitoes. There are plenty of mosquitoes here. If you do not sleep with a bed net, you wake up full of bites. The mosquito transmits a large number of diseases (HIW).

People lost their lands in Casitas, which meant food security and small-scale trade. From living in farms of nearly 3,500 $\mathrm{m}^{2}$, they passed to living in lots of $364 \mathrm{~m}^{2}$ and houses of $45 \mathrm{~m}^{2}$. The scale of their farming production has sharply reduced. The common land has been unused since the time of the evaluation mission (November, 2001). Residents are dissatisfied with the productive projects (Ausín Cantero, 2001c).

\footnotetext{
${ }^{43}$ The same percentage appears in dataset 2 (post-FGD survey) and in the water committee's census of December 2004 .
} 
Alternative work activities do not provide food security

Some FGD participants said they have merely survived: 'living for living' (LIW), 'waiting for seeing what happens' (LIM). Some subsist by eating fruits from their trees, as a woman says: 'Sometimes we lack other food [meat], but normally we eat fruit' (HIW). In some cases, home-yard animals also provide sustenance:

Well, I get by because I fatten my little pig and I raise my small hen. Whenever it is to lay eggs, I am there picking up the egg to eat it up [laughs]. I do not have anyone to send to work because I am even a widow. I have children, but it is the same thing. There is not a single one who will work for me (HIW).

Many people work abroad seasonally, but they only earn money to subsist when they are at home. Only $15 \%$ of households reported receiving remittances (dataset 2). Then, a few can save money to rent a piece of land to plant. Some young men work as waged farm employees without stable contracts in nearby plantations. Others work at whatever they can find, as a young man explains:

I work in the Posoltega town but what I most like is to sow rice, maize, and frijoles. That is the work I most like... Before I worked in the farm and I no longer can. There are no opportunities [to work] as a farmer (HIM).

He cannot lead the life he values. Indeed, although most individuals do not plant, they still regard themselves as farmers and their idea of well-being remains grounded on the country lifestyle (cf., Mosse, 2005). Some older men risk their lives by working in their old plots, at the slopes of Casitas. ${ }^{44}$ They walk $15 \mathrm{~km}$ each day, leaving early morning and returning late. Alternatively, it is difficult to find a job in the nearby towns even for men with certain skills:

I have four occupations; I build blocks, I cut bricks, I weld, and I read plans. So I would have to look for a [non-farm job in] an enterprise, but... finding work is hard here in Santa María (LIM).

However, only $11.9 \%$ of household heads are merchants or have other skill than farming. Hence, individuals are exposed to multiple risks, by leaving their homes or working in dangerous conditions, because their basic material needs are not fulfilled. During the fieldwork, over $70 \%$ of households were living in extreme poverty, with an average expenditure of about USD0.50 per day per person; about $50 \%$ of household heads reported not having any income-generating activity (dataset 2).

Nevertheless, according to a leader in the FDG, some households have a better situation: nearly $1 \%$ of the households (four families) own small stores in the village and about $6 \%$ of the households have livestock remaining from projects. The worst off are single old age persons ( $3 \%$ of the current residents) who lost all their relatives and were integrated to other households.

\section{Access to social infrastructure opens some opportunities}

Having schools, health centres, and churches is important to Santa María residents. Children attend the primary school built during the reconstruction project, and currently managed by the Ministry of Education. Every morning, they hurry to school for receiving their free

\footnotetext{
${ }^{44}$ No one commented on the expropriation of their lands. Those who do not work their old lands gave the following reasons: it is too risky; lands are unusable, full of rocks; and there is no working capital.
} 
breakfast. Since May 2005, there is a health centre financed by a donor and under the management of ASCA that opens twice a week. Drugs were subsidised during one year. There were five non-Catholic Christian churches, in 2005, and eight churches in total, including a Catholic chapel, in 2007 (cf., Rocha, 2007).

The lack of a direct road to the highway creates the objective consequence of remoteness; Santa María residents can hardly access markets for their farm products. It also has subjective effects: residents feel 'lodged' because '[they] cannot go anywhere' (HIW). This means exclusion from outer communities. For instance, in July 2005, when the national official time was put one hour ahead, residents still carried out their daily activities with the old time.

The internal processes of agency make a difference for human development

Regarding temporal orientation, most people yearn for their previous lives; however, this does not mean that they are only past-oriented. For instance, migration is seen from two perspectives. Some individuals consider migration as an escape strategy to survive (practical-evaluative element) that causes suffering, but others regard migration as a well-reflected choice to provide a future for their families, that is, they are taking this decision with a projective element (i.e., focused on the future). Regarding causality orientation, which refers to the person's reasons for acting, many people have a control orientation (i.e., their actions are driven by external factors). Some people participate in meetings when they have a reward such as food, while others attend under obligation.

Some individuals have a projective orientation, aspirations and hope. There is a self-help group called 'Movement of leaders and social actors'. Members meet weekly and elaborate development plans, supported by a NGO. There are several NGOs active in the town (section 6.4.4). It seems that they are facilitating a change process born from an existing claim for autonomy of residents (section 6.4.3).

The exercise of autonomy could take several forms. Reacting to the passivity of leaders, one man suggests they have to act by themselves, without the involvement of leaders or donors:

I have asked CDC leaders to tell the mayor to build a stone wall to stop the water from coming from that garden to the houses, but those leaders are not useful... They do not care. Here, we have to do it by ourselves, all together, go with a spade and make that wall.... Nothing from outside because everything from outside has its procedures and we have to wait (LIM).

Another man had a broader idea of autonomy. He recalled what he told to the social promoter while complaining about the verification of beneficiaries:

One has been dragged by Casitas, but now I do not want to be dragged by you nor by any leader. Rather, I hope you can give me a hand in order for me to find work; a help for me to be able to go ahead (LIM).

He considers that he can advance by himself, but he needs a 'helping hand' from (powerful) others in order to build certain foundations for development. Thus, the impact of the microlevel structural context on agency varies among individuals.

\subsubsection{Community as solidarity but without trust or opportunity}

Santa María is not strong... because everyone looks at his or her own. There is no community here. If one house is falling apart, I tell the president [of ASCA] and nothing happens... If the 
house belongs to the president, then they call [us] to repair it. I wonder why I left my community [to be like that]... well, the leaders... (LIM).

In Santa María, other village members, social relationships with friends in other towns and donors, and community organisations are important for exercising individual autonomy.

Community suggested three kinds of meanings to FGD participants: 1) physical infrastructure, natural and material resources, 2) people, and 3) values. The existence of a complex of houses in an area that previously was desolate and uninhabitable is the basis for the existence of community. Residents value their houses because they built them with much effort and hope; they value the vegetation because they worked against the harsh natural conditions to grow it. They regard a community as strong when a certain level of economic progress is achieved so that residents have access to means (need satisfiers) to achieve wellbeing.

Regarding people, respondents argued there is no one community because there are different groups of people. Some people are survivors, others are displaced (lost their houses, but not family members), others are close to leaders but were not injured by the mudslide (i.e., they did not deserve a house), and others are newcomers (who bought houses later on).

FGD participants linked these different backgrounds to a mismatch of values. Some survivors experienced acute drink and intra-family violence problems, but were later converted to Christian faith. The most desperate people became thieves, understandable due to the lack of work opportunities, but not a justifiable situation. Lack of solidarity is primarily related to being a newcomer. In sum, participants said that there was not a real community.

Social relationships are more important now than before the mudslide because individuals have fewer resources on which to rely; however, many individuals do not have social networks outside their town, given that their lives centred on their plot and a closed group of relatives. A man who was a merchant before the mudslide reported that he could restart his business because his friends gave him some money; others said that migrating is easier because some friends are abroad now. Moreover, FGD participants value the fact that, during all these years, they have met people from different countries and organisations. Hence, their social networks can extend beyond the village boundaries.

However, the assessment of intra-community relationships made by Santa María residents is not positive. Figure 6-4 shows that trust is very low, which is related to the co-existence of several communities. Within the community of survivors, people reported good relationships because they shared the same tragedy and 'met each other in the trucks' (HIW) during the emergency situation. Hence, almost all (95\%) of those surveyed said that cooperation within small groups was greater than within the whole community. Regarding solidarity, within the whole community, a woman concluded that 'if someone did not eat, the neighbour does not care' (HIW). However, about two-thirds of survey respondents thought that their neighbours will help in case of serious need, such as severe illness or funerals. 
Figure 6-4: Perceptions about community in Santa María ${ }^{45}$

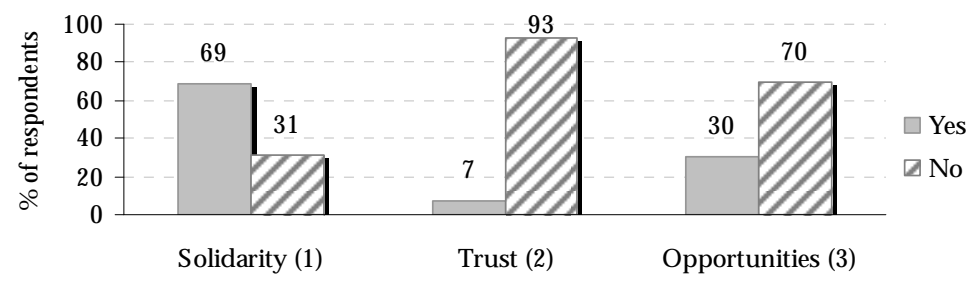

Source: Dataset 2.

People feel insecure because there is delinquency and no police station. In the leader FGD, a member of the crime prevention committee concluded that, in view of the disappearance of pigs donated by a project, they could only record how many pigs had been robbed, not to enforce any security measure. They finally laughed at the evidence of powerlessness.

Regarding community organisations, FGD participants expressed that any community needs leaders and organisation. Men elaborated upon the need for leaders: They 'have to be ahead of everything so that inhabitants can follow [them]' (LIM), and 'if the community has a good leader, it goes forward. He is like a father' (HIM). Some people considered that leaders are primary responsible for their living situation. This agrees with the perception of Pedro:

People put a leader because of his knowledge, experience, and wisdom, given by God. We have had that knowledge; we always have to lead them, and explain to them. Finally, they accept what we propose. It was so that the houses in Santa María had a happy end...

In contrast, others are trying to overcome the apparent disinterest of leaders to promote new projects (section 6.4.1). However, individual actions are not considered effective to promote change; it is necessary to have the support of powerful others. The most powerful are community leaders, about whom people in every FGD complained, so that $70 \%$ of surveyed people said that never or rarely did their community expand their opportunities. People have different perceptions of ASCA and CDC, however. CDC enjoys more legitimacy than ASCA given its broader base (see Box 6-1), while ASCA is a NGO closed to villagers other than its partners in terms of decision-making.

\section{Box 6-1: Committee of communal development (CDC) and the community council}

CDC was created in 2001 with the approval of the municipal government. CDC is managed by a coordinator (and deputy coordinator) who presides and supervises the work of six executive committees: infrastructure; health; production; education, culture and sport; environment; and disaster prevention. Each committee has one responsible person.

The general assembly includes representatives from each of the 24 house blocks, ASCA members, store owners, and other important people. The original idea was to promote the participation of neighbours through the block representatives and to include individuals with material resources as well. Residents in the general assembly elect the coordinator and executive committees by a show of hands. Nowadays, not so many people attend the assembly, so that representatives keep their positions.

\footnotetext{
${ }^{45}$ The corresponding affirmations or questions in the survey are: (1) 'Most people in your community are willing to help you if you need it', (2) the opposite of: 'In this community, you have to be alert or someone could take advantage of you', and (3) 'Do you feel that your community expands your opportunities?' For the latter, responses were collapsed into two categories: ['no' and 'rarely'] vs. ['sometimes' and 'usually']. This allows clearer interpretation, and certainly does not give a negative bias.
} 
The water management committee and a new crime prevention committee are not part of CDC. Representatives of these committees, ASCA, and CDC form a new entity called 'the community council', which coordinates strategies with the municipal government on behalf of Santa María residents. FSLN has a formal representative in the village, who participates in this council. The community council forms part of the municipal development committee of Posoltega.

Source: Ausín Cantero (2001c), individual interviews, and focus group discussions.

In contrast, when the water committee did not work well, people replaced all committee members in a process guided by FSLN political leaders, who have important presence in the town. However, many people did not know about the financial problems until the electric generator exploded and there were no reserves to buy a new one. One woman explains:

We fired the former operator [of the water system] because we could not stand him anymore, he did not inform the community... People selected the new members [of the committee] ... in a meeting at the start of the year (LIW).

People do not expect much from ASCA; they are disappointed after several bad experiences. Then, they are more critical when they complain about the CDC coordinator because they would expect more interest from him than from the president of ASCA.

It is worth noticing that the polarisation that existed during the project between ASCA and CDC has apparently disappeared. They have worked together in the community council already since 2003. There is a broker between them: Eduardo, brother of the mayor of Posoltega. By the end of the project, Eduardo was member of CDC and, currently, he is the legal adviser of ASCA. In addition, the current CDC coordinator was a member of ASCA during the project. It seems that he has a position subordinate to ASCA, being used to mobilise people. There has been an accommodation of forces, in the eyes of the villagers. However, in individual interviews, members of one organisation criticised members of the other and also criticised their co-members. These symbiotic relationships are very complex.

Non-leader inhabitants of Santa María consider that community organisations do not support their goals and hopes. Moreover, they feel coerced and are aware of power imbalances (Box 6-2). In their view, opportunities go directly into the pockets of leaders, so that 'when there is money for a project..., other people do not have opportunity to participate' (HIW). They report that being connected to leaders facilitate the access to resources and benefits of projects (cf., Molenaers, 2006). Summing up, based on their experience, a woman would advise other communities:

The leader [should] be someone whom you can trust, who communicates with the community, who provides the necessary information about what is going to happen. All inhabitants [should] be united because there is nothing without union (LIW).

Her statement reflects what she thinks is missing in Santa María: trust, communication, and union. Other values considered important by FGD participants were organisation, respect and consideration for others, and family union.

Box 6-2: A controlling climate that said more than a thousand words in Santa María

At my request, communal leaders called people to participate in an assembly meeting in the community centre. Only around 30 people attended; most of them were women. The meeting was extremely short as attendees did not ask questions or make comments, but accepted at once to participate in the fieldwork activities. More participants were contacted using a door-by-door recruitment strategy. 
Why were there so few people in that meeting? Leaders had pre-selected potential participants and instructed them, for more than one hour, on what to say. Even representatives of house blocks had not been told about the assembly. Later, FGD participants more or less timidly expressed their dissatisfaction about the control that leaders had on their lives. They showed relief every time they were disobeying leaders' instructions. One woman said: 'Here the problem is that there are many people who are used by leaders. [However], I am not going to tell you what they are telling me to say; I am going to tell the truth. If not, why I would attend this meeting?' (HIW)

The climate during the fieldwork was tense. ASCA leaders complained to the former social promoter that people were contacted directly and not only through them. One CDC leader disturbed a FGD meeting by contacting some participants during the break, behind the meeting centre, and delaying the restart of the meeting. The FGD with leaders had to be rescheduled twice. When it took place, some participants - who represented not only ASCA and CDC but also religious groups, neighbours' committees, political leaders, and a new self-help group - criticised several aspects of the community dynamics and the behaviour of some 'top' leaders, causing verbal confrontation. The situation was overcome, but their attitudes and discourses were indicative of a special controlling environment and the daily struggle of most people in Santa María to exercise their individual autonomy.

\subsubsection{The distinctive features of collective action in Santa M aría}

We are fighting for the road, for transportation... We get out [the village] on foot. If we sowed vegetables, we would not be able to get them out [without a road] (a woman leader in the FGD).

Santa María residents have a history of making crucial decisions in desperate situations, combining collective efforts. First, it was the appropriation of their plots from private landowners in 1979 at the slopes of the Casitas. Second, after the mudslide, it was the occupation of Finca El Tanque in December 1998. Given the difficult work and living conditions during the Santa María project, about 80 families led by Pedro tried to occupy some lands in El Tanque again. They stayed there between December 1999 and September 2000, and later left due to legal problems (Altamirano, 2001; 'German man threatens', 2001).

A third example of collective action was the denunciations of project participants against CARE project staff, led by ASCA leaders. They complained about mistreatments and eligibility criteria, and tried to get the social promoter expelled (Tórrez, 2001; Ausín Cantero, 2001a). Hence, the LD technical coordinator visited the village, a relative success to residents because 'to [them], it was important to know her' (LIM), to have contact with a representative of the donor. Nevertheless, when residents wanted to raise their voice against ASCA leaders, their actions were not effective. They publicly demanded ASCA to provide the property titles (Imhof, 2003), but Pedro petitioned in the Tribunal of Posoltega against four of the inhabitants for insults and slanders. The problem was not solved and 150 people presented a denunciation against ASCA members before public and civil society institutions (Imhof, 2004). FGD participants, remembering these events, concluded, laughing, that ASCA leaders 'almost put them in jail' (HIW).

A fourth event happened in 2005. People took a bordering terrain to make a shortcut to the highway. This event was promoted by the local government through leaders; most people complied without much information about the legal implications. Each household had to collaborate fencing the road, directly or paying someone. A man explains the situation:

Regarding the road, I was invited to the meeting with the mayor. He explained everything to us. There is money there, in the way. The land is not being invaded, but there are some pro- 
cedures to get the owner to accept [a free road through her property] because she owes some money to the municipal government and the mayor is asking her to achieve an agreement. Most people in Santa María do not know this issue (HIM).

There are three relevant points. First, despite their mistrust toward leaders, Santa María residents consider that they need them to reach valuable things. Indeed, having a direct road to the highway is important to access markets and other communities (section 6.4.1).

Second, the mayor, a survivor of Casitas mudslide himself, may be using neighbours to put pressure on someone else. Some people do not mind to be used if they can still get some benefit. Likewise, although people may resent the power of some leaders, they may work with them and develop a patron-client relation to secure certain benefits. Indeed, ASCA leaders have promoted and managed several projects over time (see project fact sheet in Appendix 2-B). They have learned how to interact with donors to get funds and how to 'play cards' with internal stakeholders when the time arrives.

Third, political resources are knowingly used by leaders. The sympathy that most inhabitants feel toward the FSLN, and the alliance (at least in the view of non-leaders) between ASCA members and the mayor, implies that people are willing to follow these formal leaders thought to be linked to the political authority.

\subsubsection{Motivations behind communal participation}

When we lived in La Rolando, there were meetings but they were very different from the activities here. Nowadays, [meetings] are about the well-being of the community (HIM).

The degree of participation of Santa María residents varies depending on whether it is collaboration in communal works or active membership in organisations. Over $90 \%$ of households (either the household head or a relative) reported collaborating in communal works; the main modality was cleaning and taking care of green areas. However, $71 \%$ reported being aware of the existence of any community organisation and only $21 \%$ of individuals knew about other groups.

Other groups active in Santa María are AMDES, Nehemiah, Verbo, and World Vision. AMDES has 25 members that meet to discuss intra-family violence. It is also the sponsor of the new self-help group. The Nehemiah Centre for Transformational Development, a joint project of the Food for the Hungry International (FHI) and the Christian Reform Church of North America, has several activities including a sewing and craftwork group to generate income and talks on reproductive health. Verbo Christian Mission offers psychological support and religious services. It also finances a productive project of watermelon, maize, and roselle (jamaica). In addition, many children in Santa María benefit from the sponsorship programme of World Vision ('godparents' in the US are arranged for them).

Less than $50 \%$ of surveyed people reported to participate in community organisations or programmes. It seems that women participate more than men ( $54 \%$ of women vs. $27 \%$ of men) ${ }^{46}$ from which women feel proud: 'We are braver, more courageous' (a woman leader).

\footnotetext{
${ }^{46}$ As my co-moderator was a member of AMDES and also former responsible for a no longer existing day care programme, it is likely that self-selected fieldwork participants were those closer to her and, hence, the most active in community life.
} 
How does a relative low participation in organisations link to high participation in communal works? Most people feel discouraged to participate in an organised way, but they will participate if leaders promote new activities for the well-being of all, that is, they can be mobilised. However, cleaning days promoted by leaders are not so frequent. One man complains: 'Those green fields should be watered, [but] no one does anything. If the scrub was cut with machete, Santa María would wake up clean' (LIM). Indeed, during the rainy season, the village looks dirty, with mosquitoes and puddles of grey and rain water.

Why would people accept to be mobilised by leaders? The distinction between 'chosen' (voluntary) groups and 'given' groups (Kabeer, 2000) is relevant. The survivors of Casitas mudslide shared a tragic situation that changed their lives completely; in some way, they share the same fate because they live in a semi-urban complex without options for agricultural work, that is, they form part of a given group. If there is something they can do to improve their material well-being (which is related to others' well-being) they will do it. This is not a signal of autonomy because they simply do not have a choice; it is a matter of survival. In contrast, people enrolling voluntary groups are trying to find a way to develop and they do it in a more committed way. This is the case of people in formal organisations, such as the new self-help group, and this path proves much harder to achieve.

\subsection{Assessing project impacts on autonomy}

This section analyses how the Santa María project affected the autonomy of non-leader residents. The deepest change in their lives was, in short, the loss of their livelihood. While people received foreign aid, they could survive; now, living is a daily struggle. As MI (2002) says, their strength was their agricultural knowledge and physical ability to make the ground produce. Now, this strength is useless.

Contributing to rehabilitate lives was an optimistic goal. In practice, the project focused on achieving tangible results, that is, the construction of 350 houses and social infrastructure, the start of agricultural activities, and the provision of an autonomous water system.

The analysis of impacts on different determinants of autonomy is based on some working hypotheses, which depend on the explicit and implicit logic of the project. It is worth noticing that its project logical framework does not include a list of assumptions. Table 6-5 includes these hypotheses or expected impacts, their assumptions and outputs, and an evaluation about their fulfilment. The conclusion is not about one impact on autonomy but about impacts on the determinants of autonomy. Some aspects in Table 6-5 are developed below.

\subsubsection{Entitlements to material resources not fully secured}

The direct effect of the project was the access to material resources for living and social activities, by providing houses, a community centre, and a school. People felt very much relieved when they got their houses because their living situation in the huts was very difficult. Most people consider that the materials are good and the foundations are strong (they built them). Nevertheless, they were dissatisfied with the design (section 6.3.1). 


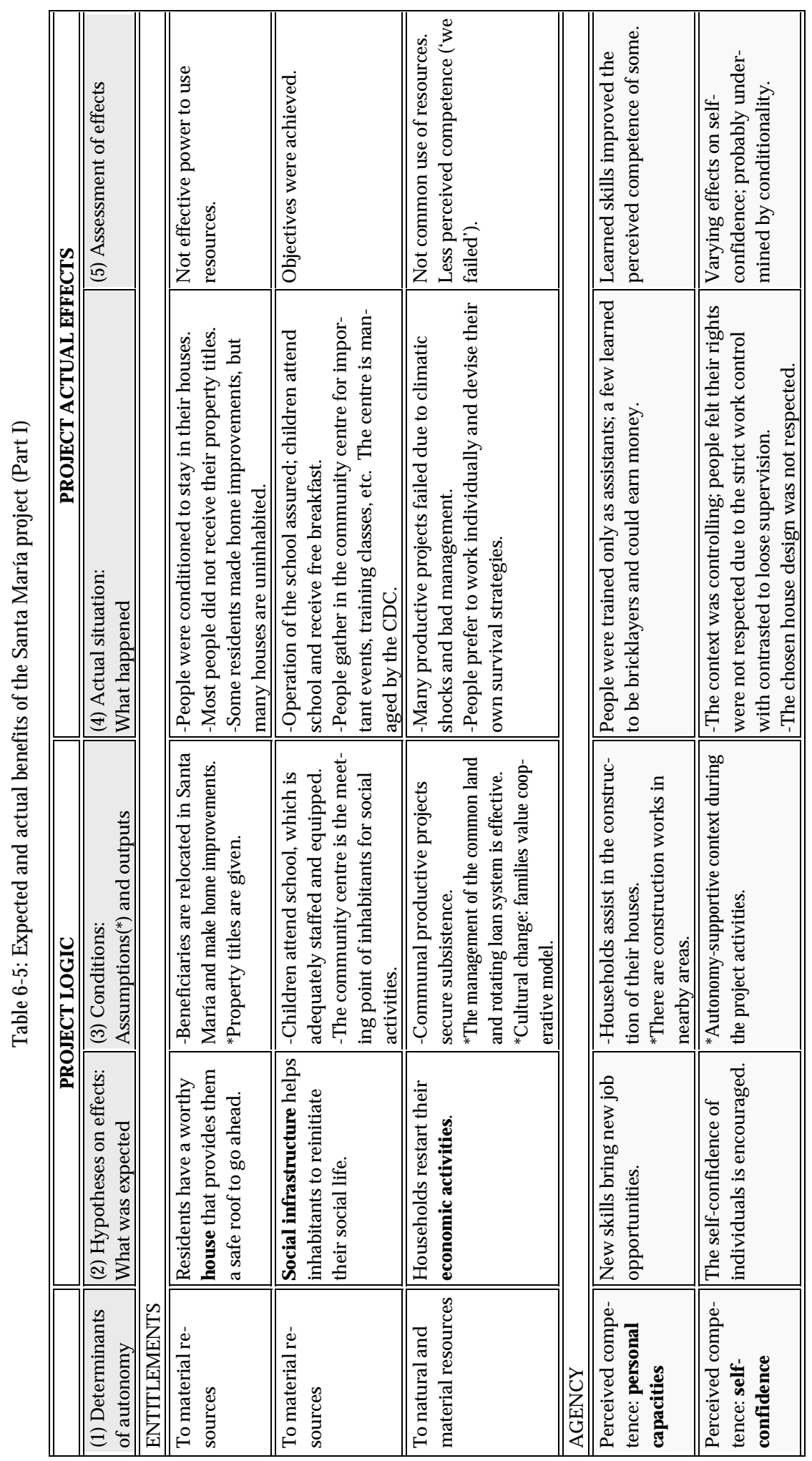




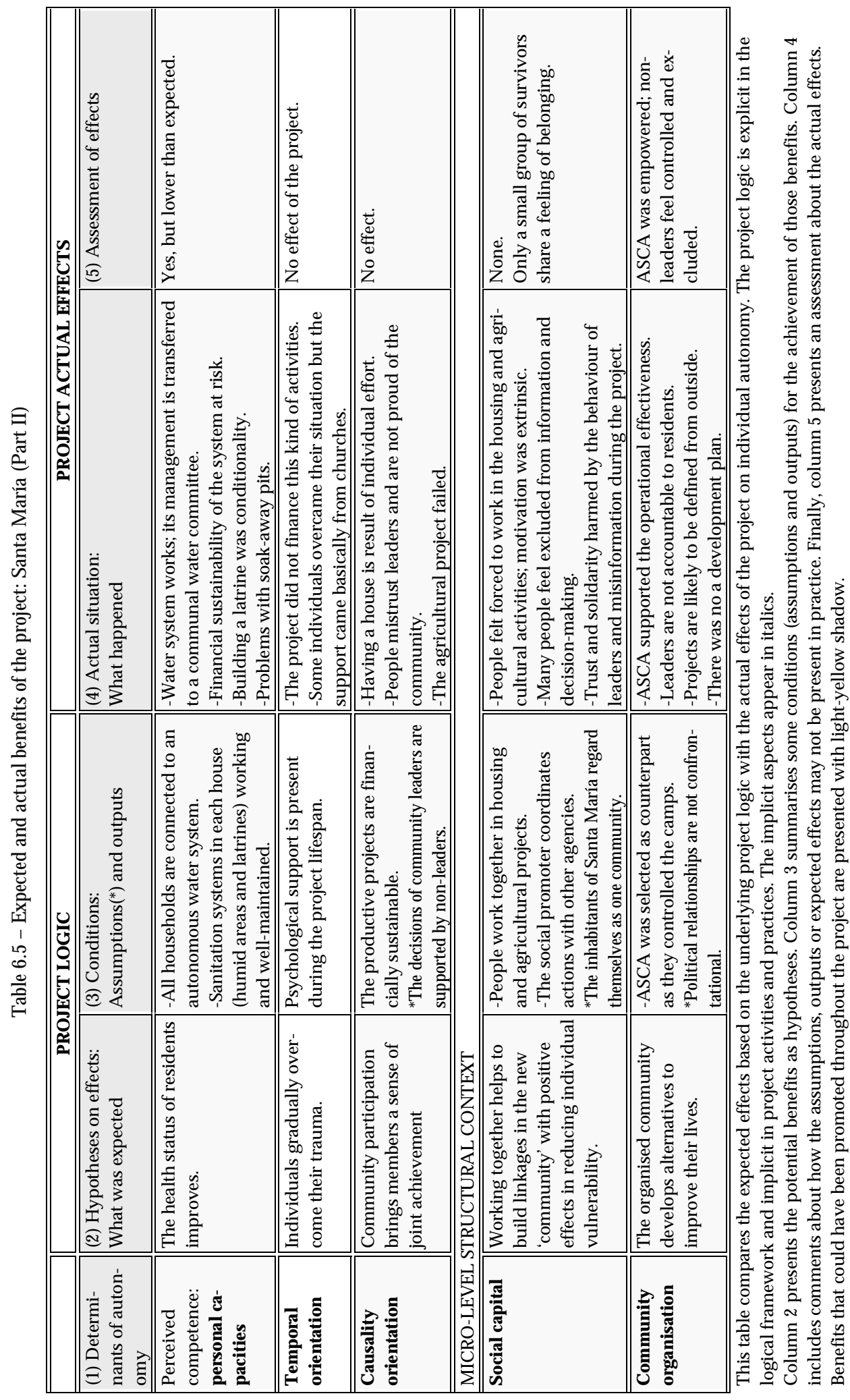


What worries people the most is that they do not legally own their houses. People were forced to stay in their houses until the completion of the project (section 6.3.2), which was a direct attack against their autonomy because they could not decide where to work to make a living. After a while, some preferred to sell their house to finance a trip to Costa Rica or to El Salvador that would open new work opportunities. Besides, many did not trust they would get their deeds anymore and considered cashing-out their houses as a more secure option.

In December 2004, 126 houses (36\% of total) were uninhabited because people had migrated to work. Rocha (2007) reports that, nine years after the disaster, around $45 \%$ of houses had added rooms, $12 \%$ had improved the floor, and 5\% had improved or expanded the roof, using different materials. However, the quality of these improvements is not comparable to the quality of the base house. Hence, although these households may feel more comfortable, they are not necessarily safer in case of events such as earthquakes.

Regarding social infrastructure, people feel very proud of their community centre. It is managed by CDC and used for assemblies and meetings. The centre hosted a day care programme during one and a half years, but was discontinued due to the lack of public funds. LD transferred the property of the school to the Ministry of Education, which assures its operation. Most children attend school. People are satisfied with the school, which had the highest impact according to high-involvement women. Minor infrastructure such as the sport court and the children's play park (funded by other donors) are not well maintained. A health centre was constructed years later; the small medical and psychological clinic in the community centre worked for some months, funded by local NGOs.

At the start of the entire project, the agricultural project and other productive projects (e.g., home-yard animals and livestock, agricultural training and equipment, ornamental plants) provided a means of subsistence and small trade (USAID, 2001). Soon, many projects failed due to a harsh drought in 2002. Moreover, several people complained about bad management of common resources. Women discussed the failure of several projects (sugarcane, bananas, and peanuts) and concluded that '[t]here, everything gets lost' (HIW).

The common land only provided a short-term benefit; it is not used as planned (section 6.3.1). People considered that the scarce profits were appropriated by leaders who select beneficiaries of projects. In contrast, leaders reported that only volunteers participated in productive projects. In any case, the emotional stress could have affected the prospects of other people to progress, as they would be less willing to participate.

\subsubsection{Agency is influenced by project and context factors}

During the project, people learned skills, which could mean broader work possibilities in the future. However, they were trained to be assistants, ${ }^{47}$ not bricklayers or other skilled workers. Few people, who showed special ability, drew further attention from bricklayers, as a man reported: 'I learned because the chief liked me, my work was to take out the blocks with the knife. I would get the block entire without waste' (LIM). Some people were later hired by contractors to build the humid areas and received a payment.

\footnotetext{
${ }^{47}$ Ausín Cantero (2001c, II 117) recorded that there were training sessions between October and November 1999; however, only 6 out of 42 persons surveyed during the fieldwork recalled having received any kind of training.
} 
Women gained respect from men of the community because of their hard work, which also improved their self-confidence, as a woman reported:

When the men arrived with the material [for the soak-away pit], they said, 'where are you going to make it?' I told them 'right here'. [They replied], 'Are you going to make it?' 'I am', I said, and I began to make it [laughs] (HIW).

One man recalled the hard work of women because 'they needed that their husbands work [to bring the food] so they worked in the construction instead of them' (HIM). Some women improved their self-confidence as result of their participation in meetings:

Earlier, I only [spent time] with my cows and that was it. I did not exchange words with anyone. Now, I talk more with my neighbours and other people (LIW).

However, there were some practices that might have hurt their self-confidence, such as the tough working conditions (section 6.3.3). The harsh living conditions during the emergency and reconstruction periods with episodes of physical and sexual violence also affected their feeling of self-worth and restricted the potential of the project to enhance agency. While women were telling about the mistreatments they had suffered, one woman concluded:

We have experiences that seem lies... I have worked in Managua, and I told my patrons what I did here and they got scared: 'How awful! Did you do that?' It seems a lie but is not; it was the reality that we lived (HIW).

More than anything, women and men resented that their choice of house design was not respected and that people who were not survivors also received a house. For them, the house was a right in view of being a survivor and not an act of donor benevolence (i.e., it was a kind of inheritance from their dead relatives); although, they are deeply thankful for their houses. Hence, 'confusion' about the allocation of houses was an act against their rights and autonomy.

Participants in all FGDs identified improvements in their self-confidence, which they mostly related to two factors: better relationships with neighbours, and inner peace from Christian faith. Some men told about their personal conversion that freed them to speak to others with respect. For instance, former alcoholic men are not ashamed of themselves anymore.

The health status of the population was expected to improve with the domiciliary connections to the water system, the sanitation systems, and latrines. However, Santa María residents have many health problems related to mosquitoes (especially malaria), explained by several causes. First, people do not use the soak-away pits correctly. These are not covered or not maintained and then, they overflow, so that people discharge the grey waters to the streets. Second, there are many uninhabited houses where the scrub grows. Third, there is no service of garbage collection. Fourth, some people have bad hygiene habits, as a man said: 'How can they play with the ball [in the sport court] if they have a heap of garbage there and nothing is done?' (LIM)

Temporal orientation is very difficult to change because it is related to the life experiences and cultural context of the person. However, religious faith had an important role in giving relief and hope. Some people are planning ahead, as discussed earlier (section 6.4.1). This is not a project effect as the project did not finance psychological support activities. 
Current dynamics in Santa María contribute to a control causality orientation as leaders carefully manage what information is given or not, and how it is done. This could be related to the controlling context during the project that imposed conditions for getting and keeping a house, sanctions in case of bad performance or absenteeism, and rewards for collaboration in community works. In addition, the failure of the agricultural project harmed the causality orientation of residents who had been forced to work in the common plot.

However, some people struggle for effecting change and exercise autonomy differently (section 6.4.1). Indeed, people do consider that they succeeded in defeating the adversity. As they used to do throughout their collective history (e.g., agrarian reform experience), when there are no supportive conditions, they envisage ways to express their claims.

\subsubsection{Changes in micro-level contexts depend on 'how you look at them'}

FGD participants identified impacts related to social relationships, friendship, and union. Earlier, they interacted primarily with their family members and during the project they knew other people because they worked together. They valued this increase in social interaction. A man explained: 'From being two communities, now we are one single community' (HIM). This impact applies to former inhabitants of El Porvenir and Rolando Rodríguez, not necessarily to all current Santa María residents because former survivors do not consider themselves belonging to one large community called Santa María (section 6.4.2). Only $62 \%$ of families living in Santa María are victims of the Casitas mudslide (Rocha, 2007).

During the project, the problems in management, the practice of decision-making by leaders or outsiders, and the strict work control by the social promoter framed a controlling context that restricted choice and also influenced an external locus of causality. A few years later, in 2005, the context in Santa María remained primarily controlling and did not evenly promote the sharing of information. People felt they are used by leaders, who do not give accounts of common resources and even threaten people when they protest against these behaviours.

ASCA is a community organisation born after the disaster, which has gained power over others as it has channelled several projects in Santa María. In a difficult social context, it is likely that ASCA became stronger by applying controlling practices that seemed to work during the project. Indeed, ASCA supported the operational effectiveness of the project given its control over people. The coercion that leaders exert on non-leaders is evident (section 6.4.2).

Over $70 \%$ of survey respondents think that their community is better organised, and those who expressed their opinions during the project are most likely to think so (Phi coefficient, $\phi=0.422, p<.01)$. Nevertheless, $74 \%$ of respondents said that the effectiveness of leaders to respond to their needs had not improved. It is likely that ASCA became stronger but the options of non-leaders were not expanded in the same way. Respondents feel that leaders prioritise their own objectives over group objectives.

\subsubsection{Differentiating impacts on autonomy among individuals}

This section discusses some different impacts for specific population groups considering the primary variables under analysis during the focus group discussions: leadership role, gender, and level of involvement in the project. 


\section{- Impacts on leaders: A stronger but less socially effective community organisation}

Impacts were different for leaders and non-leaders. As seen earlier, ASCA has been empowered in the sense that the project did not have a clear 'champion' and it were the local leaders who took the leading role in the reconstruction process. When people felt that project staff was not effective or was unfair, local leaders withdrew from the verification commission (section 6.3.2) to maintain their clients. Since then, ASCA has managed several projects over time on behalf of Santa María residents.

For these projects, people are grateful but they resent that leaders benefited much more than other people. Indeed, living so close to each other, people realise quickly who is getting richer, who travels abroad and where, who lives with whom, and how common resources are used. Interactions are highly personalised and there are plenty of chances for conflict (cf., Abraham \& Platteau, 2004). A woman heatedly expressed: 'Those who have brought the money [from donors] are the ones who have improved. We, how we are going to improve! If we sometimes eat, we sometimes don't eat' (HIW). Leaders use different networks through which they communicate different messages to political authorities, donors, other leaders, and non-leaders. Non-leaders do not have actual entitlement to highly valuable information related, for instance, to projects or municipal plans.

From a situation in which everyone had nothing (after the mudslide), inequality has increased. ASCA leaders are those who own more resources. This is clear, for example, when looking at the appearance of their houses, their owned mobile phones, and their mobility (frequency and destination of trips). This process is not an effect of the project; it is also hard to know whether power unbalances were so deep in their origin towns. The issue is that the project had organisational and management problems that facilitated the process. ASCA is the only community organisation who has managed projects directly; CDC only represents residents in formal meetings. The CDC coordinator declared: 'I am shouting at the sky for getting a job of anything because I cannot bear my living situation'.

- Impacts by gender: Quantity is different from quality of information especially for women

FGD participants discussed four elements conceptually linked to the exercise of autonomy: information, self-confidence, opportunities, and decision-making (section 4.2.1). Figure 6-5 plots the situations before and after the project, as perceived by FGD participants, with respect to those four elements.

The figure suggests that men felt positive changes in the four elements, but not significant for information. Women experienced contractions in the level of information and opportunities. Moreover, men reported higher values for each variable. With respect to decisionmaking, surveyed men felt more control than women, especially with respect to family decisions (Kendall's tau-b, $\tau=0.362, p=0.01$ ). Looking at both groups, the levels of information are not satisfactory. Women felt that they have low opportunities in their community, which is related to a negative perception of their living conditions and contexts. 
Figure 6-5: Average changes in variables associated to autonomy by gender in Santa María
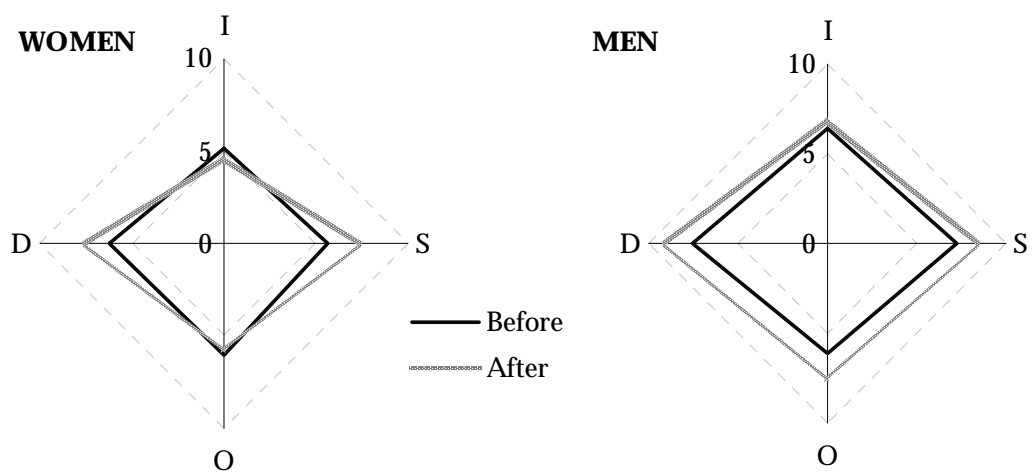

Legend: $\mathrm{I}=$ Information, $\mathrm{S}=$ Self-confidence, $\mathrm{O}=$ Opportunities, $\mathrm{D}=$ Decision-making.

Figure 6.5 shows the average values of the variables from scoring exercise, mixing high- and low-involvement groups. The scale is from zero to ten.

Source: Focus group discussions (scoring exercise).

The analysis below focuses on the information dimension because people reported problems during the project, in terms of the channel and quality of information (e.g., confusion about house design and eligibility criteria was constant), and the assimilation of information when things change too fast, people are emotionally affected and hence, their agency is harmed. This contrasted to the quantity of information available during the project: almost all people surveyed (95\%) reported to have received information during the project and most of them $(86 \%)$ during all stages of the project. The problem was not amount of information but its quality. Besides, controlling project practices did not favour transparency.

During the project, women received more information because they worked as construction assistants while most men worked in other activities (reforestation, agricultural project, road rehabilitation, etc.) or were abroad. Nonetheless, those men who stayed in the village for the whole period did get more information than women. Table 6-6 reflects that women, in general, expressed that they knew less about their community after than before the project. In contrast, men felt more informed after the project. It must be noticed that women represented $66 \%$ of FGD participants who completed the scoring exercise; so the picture for men could be skewed.

Table 6-6: Levels of information self-reported by non-leaders in Santa María

\begin{tabular}{|c|c|c|c|c|c|c|}
\hline & \multicolumn{2}{|c|}{ Before the project ${ }^{*}$} & \multicolumn{2}{|c|}{ During the project } & \multicolumn{2}{|c|}{ After the project* } \\
\hline & Women & Men & Women & Men & Women & Men \\
\hline Mean & 5.1 & 6.4 & 6.7 & 5.4 & 4.7 & 6.9 \\
\hline Standard deviation & 2.8 & 2.9 & 2.3 & 4.0 & 2.7 & 2.4 \\
\hline Median & 4.0 & 6.5 & 6.0 & 4.5 & 4.0 & 6.5 \\
\hline Respondents & & & & & $66 \%$ & $34 \%$ \\
\hline
\end{tabular}

* Information refers to community activities or projects.

Some people could not do the exercise because of their low literacy. Inconsistent scores were taken out $(n=35)$.

The scale is from zero to ten.

Source: Focus group discussions (scoring exercise).

This difference in information change underlines the importance of cultural features. Although the project mobilised everyone, because the project required communal work, things 
have not changed much in terms of participation in social life. Women occupy a second place. However, this relative lower information of women contradicts the higher participation that they have in organisations and social networks (section 6.4.4). A possible explanation is that FGD participants thought in terms of 'what leaders are doing' and not 'what we (non-leaders) are doing'. There is an emergent group of young literate women who are now creating their own space (most members of the self-help group are women) and trying to do what CDC 'has not done for years to get the community off the ground' (a woman leader). In any case, the project did not have a positive effect on information. Another explanation is related to the involvement of women during the project (see later).

It must be noticed that there is high diversity in the reported levels of information, with a median change of zero and values ranging from -7 to +7 (in a maximum scale of $+/-10$ ). This means that several people were not engaging in the 'right' networks; for instance, only a man non-leader in the focus group discussions knew about the situation around the taking of the private land in July 2005 (section 6.4.3), but he was one of the local bricklayers hired during the project. Having certain knowledge brings consequences when negotiating entitlements. The same case shows that how information is generated and used depends on the quality of the social relationships and power structures (Long, 1992a; Kothari, 2001/2004). Some people knew about the possible problems that taking the land could bring but preferred not to say anything to gain the compliance of others. Later on, a man said: 'I think that leaders should inform the community so that people stop telling odd stories; we should not be doing that, grabbing other people's lands' (HIM).

\section{- The level of involvement in the project: Not determinant for individual autonomy}

A working hypothesis is: The higher the involvement in the project the higher the chances for people to expand their autonomy and exercise it in valuable aspects of life such as community activities. Table 6-7 suggests that the hypothesis could be valid for high-involvement men, who experienced an expansion in each of the four variables. In contrast, lowinvolvement men had reductions. High-involvement women did not report improvements higher than those of low-involvement women. Moreover, high-involvement women feel that they have less information than before the project.

Table 6-7: The intensity of change in variables associated to autonomy by FGD in Santa María

\begin{tabular}{|l|cc|cc|}
\hline & \multicolumn{2}{|c|}{ Women } & \multicolumn{2}{c|}{ Men } \\
Involvement: & High & Low & High & Low \\
\hline Information & $\mathbf{( - )}$ & + & ++ & $\mathbf{( - )}$ \\
Self-confidence & & ++ & ++ & $(-)$ \\
Opportunities & & $\mathbf{( - )}$ & ++ & $\mathbf{( - )}$ \\
Decision-making & & ++- & 8 & 4 \\
\hline$N$ & 8 & 16 & + & \\
\hline
\end{tabular}

Note: + means that the effect is larger in this group in the comparison with the other same gender group, ++ means the effect is much larger, $+/$ - means the effect is a little larger, and (-) means the effect is negative. Source: Focus group discussions.

The situation of low-involvement men could be explained by the fact that they were absent for some periods during the project, but still taking part in it. The worsened economic situation, after the failure of productive projects and the withdrawal of relief aid, has increased migration. Hence, low-involvement men could be even less connected to the community 
activities given that their periods abroad could have extended. (However, the sample here of low-involvement men is very small.)

The situation of high-involvement women is better understood through their words:

(i) They need the meetings: 'Before we did not have meetings, but it was all right because we did not need them' (HIW).

(ii) They feel that they are able to participate in the meetings better than earlier: 'Before we, sometimes, were invited to meetings but we did not know how to participate or we just would go to learn from what was said' (HIW).

That is, women value the idea of community more than they did before because they need help from others to reach their goals (earlier they were self-reliant). In this sense, they value to have information about their community and to express their opinions, not only to listen. Although they could have more information in terms of quantity (e.g., attending more meetings) - which anyway is not the case here - they feel that they need to be more informed. The 'benchmark', to say how much informed they need to be, has increased.

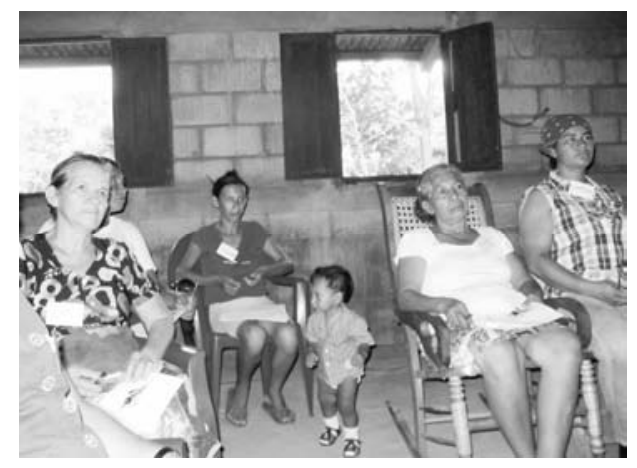

Photo 6-4: A focus group discussion with women (July 2005)

In summary, the level of involvement of non-leaders in the project did not explain different impacts on individual autonomy. On the contrary, it is probable that the project practices and the questionable quality of the community leadership framed a controlling context characterised by misinformation and inequality of entitlements and opportunities. Although it seems that alternative leaders are emerging, the courage of Santa María residents is not enough to overcome their situation: they still need to build a sustainable livelihood.

\subsection{Conclusions}

This chapter has presented the first case study, about people who benefited from a reconstruction project, in the North of Nicaragua. The project aimed to rehabilitate integrally the lives of survivors of a terrible tragedy in which each one had lost dozens of relatives and friends. After much pain and work, people built new houses, but their livelihood was broken: they do not have enough land to sow.

The idea of a communal land, where all could work together, has not succeeded. Nowadays, families develop their own survival strategies. Seasonal migration is the most common strategy. Some others risk their lives by planting in their old plots in Casitas. All households live in poverty and survival is a daily concern. 
Autonomy is valued by Santa María residents, who aspire for a better life. However, they face acute restrictions: lack of material resources and entitlements to common resources held de facto by the elite, few non-farm skills, and health problems. They perceive that their community does not expand their opportunities and that there is little trust; although a group of survivors regarded itself as one community and expressed solidarity. Nonetheless, leaders hold an important role because they are able to bring together people and to contact helpers given their broader social networks. People are willing to follow them if the goal centres on the well-being of all.

However, community organisations are not effective to secure this goal. Although ASCA has promoted several projects over time, residents do not trust it and suspect leaders of wrongly using common resources. Santa María inhabitants are not quiet; they have taken their chances to confront leaders and demand attention as a group but so far unsuccessfully. For instance, they still long for a legal property title, to have physical and emotional security.

The project apparently did not have effects on autonomy as an effective capability. It did provide the expected physical outputs, that is, the houses and social infrastructure that people most value (i.e., satisfiers), but the emerging context was controlling instead of autonomysupportive and individual involvement in the project was low.

People were given confusing or not sufficiently clear information; they felt mistreated, and apparently, made decisions that were not respected. Coordination problems at the macro level, with a multiplicity of donors and poor capacity of the central government, were replicated at the micro level and worsened by the lack of supervision during the first stage of the project.

People steadily lost ownership of the project, while others made decisions about eligibility, layout of the town, house design, and so forth. Then, people focused on doing whatever was ordered to get their houses finished and kept them. Psychological support, an explicit project goal, was ignored. Communal work, a requisite for the project, was mere mobilisation; people did not receive much relevant training and were extrinsically motivated.

High-quality participation of non-leaders was not promoted. Specific cases of high involvement were not linked to empowerment. It seems that high-involvement men improved their social position (to be better informed about communal life and to have more work options), in relation to women, although women tend to participate more actively in organisations.

After the project, leaders were more powerful, while others felt excluded and deprived. However, there is a diversity of effects. In the eyes of non-leaders, the ASCA leaders became more effective to promote their own goals. They control information through several channels and other leaders are subordinated to them. There is a complex network of reciprocity and patron-client relations among residents, which corresponds to an increased inequality of entitlements and opportunities. 


\section{The encounter of two worlds in Agua Fría: The role of local governance in a water project}

If we have made a little progress is because we are concerned about what happens in the community (LIW). ${ }^{48}$

I met a beautiful old woman in Agua Fría, doña Estela. The first time I saw her, she was wearing a simple but an impeccable dress and a knitted hat. She attended one of the focus group meetings, talking about how life had changed over the years in the canton. At times she wanted to criticise things related to the village. Others sometimes laughed at her, but she exerted her right to speak. Another day, I visited her house and we talked about her daughter who works in the US and her son who lives with her. She told me about the insecurity that came from someone stealing her hens some weeks ago; she knew who he was and had told his mother, without results. She showed me her garden and proudly said that her son can take care of it.

Some days after this meeting, I was walking with a man (leader) and doña Estela approached us. She was upset and sad because the same delinquent had entered her house, stolen all her chickens, and taken all her money (money that her daughter sent to her and she was saving to travel abroad). She looked at the leader trying to find a response, but he said that he could not do anything. Her face was filled with silent tears as she looked at me in agony. I could not say anything for some seconds. I asked the leader whether the whole community could do something - collect signatures, take the man to the police - and he said that everyone knew who he was and that even the policemen were scared. Silently, doña Estela walked away...

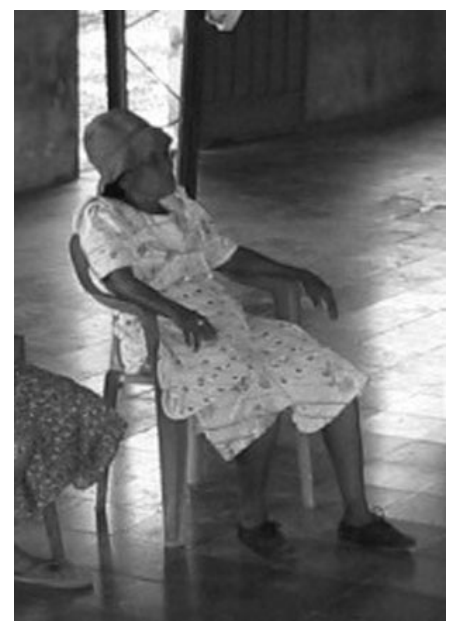

Photo 7-1: Doña Estela taking part in a focus group discussion at the communal house (August 2005)

\footnotetext{
${ }^{48}$ When citing expressions said by a person during a focus group discussion (FGD), I use the following codes: HIW for high-involvement woman, LIW for low-involvement woman, HIM for high-involvement man, and LIM for low-involvement man.
} 
During 2001 and 2003, Luxembourg financed a water supply and sanitation project in three cantons of the municipality of San Alejo. This chapter presents the experience of the inhabitants of the Agua Fría canton. They had a longstanding clamour for safe drinking water; many had never had access to piped water.

This case has three special characteristics:

1. The community was organised before the project; neighbourhood committees were managing two gravity water systems that covered a part of the population.

2. Leaders had actively searched for ways to get access to water; they had contacted the municipality government and the public water company.

3. A large portion of households receive family remittances from the US.

From the start, leaders had ownership of the water project. During the project, committees worked with project staff to create awareness among residents of the utility of the project; they also financed some activities running in parallel to the project.

The objectives of this chapter are to identify the project impacts on individual autonomy (based on project activities and practices), to understand the role of community in supporting or restricting opportunities, and to explore how individuals experience autonomy.

Section 7.1 describes the situation of Agua Fría residents before the project. Section 7.2 presents the project, its objectives, organisation and context. Section 7.3 analyses the project practices. Section 7.4 explores the meaning of autonomy for Agua Fría residents and their intra-community relations, which forms the context in which individuals exercise their autonomy. Section 7.5 analyses the project impacts on determining factors of individual autonomy and discusses if different individual characteristics and levels of involvement in the project explain different impacts. Section 7.6 presents some preliminary conclusions.

\subsection{Agua Fría before the project and the issue of water}

Agua Fría is one of the eighteen cantons of the municipality of San Alejo, located in the department of La Unión, in the Eastern region of El Salvador. It is home to almost $8 \%$ of its population. The canton is composed of four main villages: Agua Fría, Piedra Gorda, Trinchera, and El Llano. The canton quarters (called Agua Fría as the canton itself) has an urban layout, while the other villages have a rural layout.

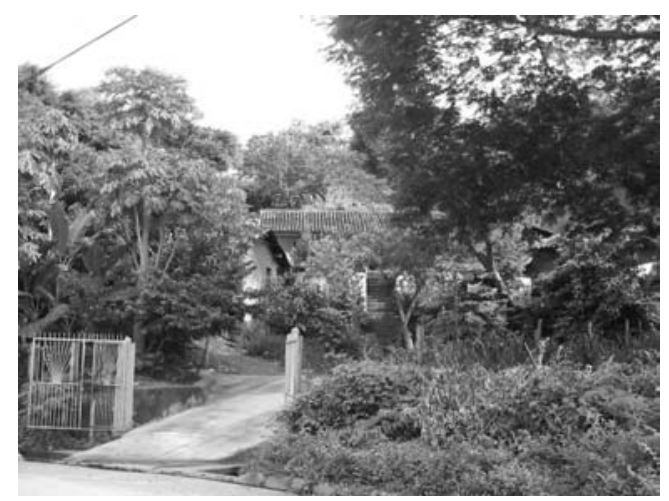

Photo 7-2: Some houses at foot of the road in Trinchera (August 2005) 
In 2002, there were 2,263 inhabitants and 479 households in the zone. About $52 \%$ of households lived in Agua Fría, 22\% in El Llano, 17\% in Trinchera, and 9\% in Piedra Gorda (according to figures of the health promoter). Agua Fría is composed by three neighbourhoods; El Llano can be included as another because of its proximity (CODECA, 2001).

The villages are well-connected to other localities except during rainy season

The municipal mayor has its offices in San Alejo, the municipal centre. Agua Fría (the canton quarters) is located $4.7 \mathrm{~km}$ from San Alejo, $2.6 \mathrm{~km}$ from Piedra Gorda, and $2.0 \mathrm{~km}$ from Trinchera (see Figure 7-1). Public transportation is available, with buses connecting Agua Fría with San Alejo and La Unión five times a day, but the roads are not paved. During the rainy season, it is hard to access Agua Fría because there are no bridges to cross the small streams that are formed when the water flow increases. Connecting the villages with each other and the municipality centre is risky during that time.

Figure 7-1: The location of three villages in Agua Fría

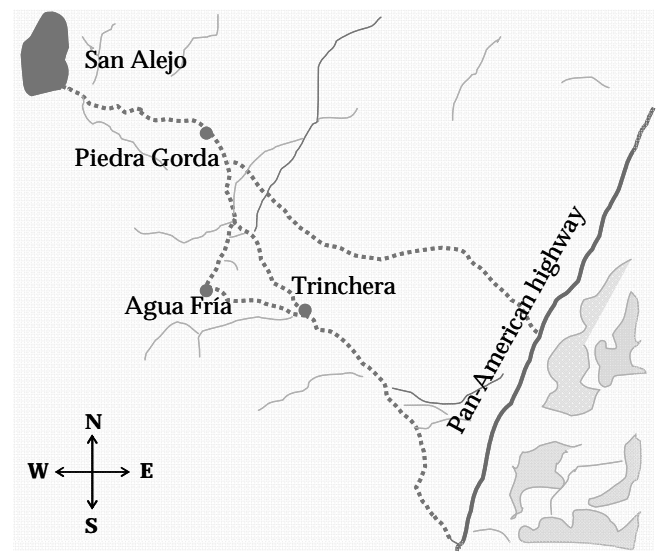

Neighbours were organised in local associations or committees

One community development association (ADESCO) in Agua Fría had been constituted in 1995 and had its own communal house. There were also health and police support committees. El Llano had its own neighbourhood committee. In the other villages, there were some active (informal) leaders organised for specific activities.

ADESCO of Agua Fría forms part of the municipal development committee (Appendix 1-B, section 2.d) and is composed by not less than 25 members in total; there is a board of directors that includes a president, vice-president, treasurer, inspector, a secretary and 12 other members. Some women in Piedra Gorda were organised in the 'healthy school' programme; ${ }^{49}$ they used to prepare school lunch for their children with public transfers and managed small infrastructure improvements in their school (e.g., kitchen-stores, latrines).

\footnotetext{
49 This programme aims at reducing student desertion rates and improving nutrition. It offers preventive and curative health care, provides vitamin supplements and food, and finances basic infrastructure.
} 
Basic social infrastructure was available, especially in the Agua Fría village

Regarding education, the school in Agua Fría is the largest in the canton and it is the only one that offers all classes of primary education, from first to ninth grade. There are multigrade primary schools in the other villages. The only secondary school is in San Alejo, so that children have to travel daily there to continue their studies.

Regarding health, there is only one health post in Agua Fría with one permanent physician assistant and one itinerant general doctor who attends people once a week. The health post was founded in June 1999 on a land donated by a neighbour, as result of the effort and insistence of leaders and the rural health promoter. The promoter says:

First, the health post worked in a house. The leaders and I went to San Miguel to look for a doctor, [but] they said that the doctor needed [some comfort]. I collected money. The leaders and I bought a little table, chairs, mops and brooms... Finally, the doctor came and everyone was happy; he attended 50 or 60 persons per day.

Agricultural activities were important but hard to finance

Inputs are expensive; the interests are too high and we have to pay weekly (a man leader).

In 2001, more than two-thirds of households owned their land (CODECA, 2001). The extensions of the plots ranged from 0.25 to $50 \mathrm{mz}$. Almost $72 \%$ of households had between 1 and 3 $\mathrm{mz}$, while the average extension was $5 \mathrm{mz}$. Small farmers produced for self-consumption and small trade in San Alejo and La Unión. The main products were maize and sorghum (maicillo), to feed farm animals. Only $10 \%$ of the households owned cattle, 239 head of dairy cattle and 284 head of beef cattle.

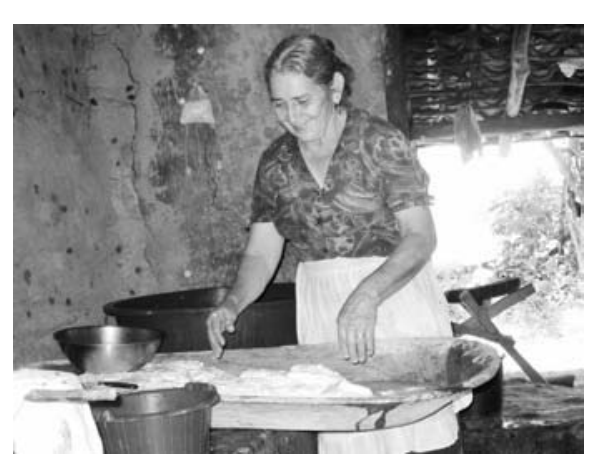

Photo 7-3: A woman preparing clotted cream in Agua Fría (August 2005)

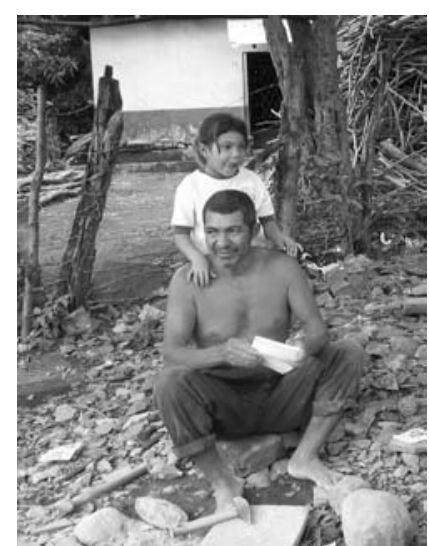

Photo 7-4: A man with his daughter working the stone in Piedra Gorda (August 2005)

Financing agricultural activities is expensive, with interest rates above $18 \%$ annually (San Alejo Culture House, 2005), so people develop alternative activities. There are re-sellers of fish and crafters of milling stones, in Piedra Gorda (with a stony land). Some residents work six days a week as salaried workers: five hours per day in agriculture, with a USD5 daily wage, and eight hours per day in livestock care with a USD7 wage. 
Remittances from emigrants in the US opened new opportunities

We have help from the US... I feel happy because I am not a slave of anyone; I receive up to USD4 per day and this is quite a lot here (HIM).

Remittances have been the main source of household income and range between USD50 and USD250 per month (CODECA, 2001). The average amount is almost USD155 (UNDP, 2005c). Migration is an ongoing process in the Eastern region first fuelled by the civil war and later, by the lack of economic opportunities (section 5.2.2). Between 2001 and 2003, the population in the canton decreased by $23 \%$, while the number of households fell by $31 \%$ (see Table $7-1$ ).

Table 7-1: Short-term evidence of migration in Agua Fría (2001-2003)

\begin{tabular}{|lcccc|}
\hline & \multicolumn{2}{c}{$\mathbf{2 0 0 1}$} & \multicolumn{2}{c|}{$\mathbf{2 0 0 3}$} \\
& Households & Inhabitants & Households & Inhabitants \\
\hline Agua Fría & 441 & 1,709 & 305 & 1,395 \\
Trinchera & 108 & 438 & 79 & 351 \\
Piedra Gorda & 63 & 333 & 40 & 163 \\
\hline Total & 612 & 2,480 & 424 & 1,909 \\
$\%$ change & & & $-31 \%$ & $-23 \%$ \\
\hline
\end{tabular}

Source: CODECA $(2001,2003 \mathrm{~b})$.

Residents did not have access to safe drinking water and adequate sanitation

No more than 50 persons benefited from the old water system (LIM).

Agua Fría residents did not have potable water. There were two gravity water systems, one in Agua Fría and other in El Llano, under the charge of the community leaders. However, they provided untreated water only during three hours a day and on alternate days (CODECA, 2001). These waters were used for human consumption, while alternative sources were used for domestic chores and livestock breeding. In Trinchera and Piedra Gorda, the situation was worse; residents had to buy water in dry season and collect it from alternative water sources in rainy season (see Table 7-2).

Table 7-2: Access to water per site before the project

\begin{tabular}{|c|c|c|}
\hline Site & Source of water & Quote \\
\hline Piedra Gorda & $\begin{array}{l}\text {-River (walking down to the river's } \\
\text { edge) } \\
\text {-Buying water or paying others to } \\
\text { collect water from the river }\end{array}$ & $\begin{array}{l}\text { 'Some of us carried water at } 4 \text { a.m., others at } \\
\text { noon. To wash [clothes] ... we would leave for } \\
\text { the whole day and come back around } 5 \text { p.m.' }\end{array}$ \\
\hline Agua Fría & $\begin{array}{l}\text {-Two (spring) gravity water systems: } \\
\text { - 'La Mate' (Agua Fría) } \\
\text { - 'La Ciénaga' (El Llano) } \\
\text {-Gulch water, river }\end{array}$ & $\begin{array}{l}\text { 'At first, everyone had [water] and the flow } \\
\text { was strong; later, it was not working... Now, } \\
\text { only a little bit [of water] falls'. } \\
\text { 'My wife had to go to wash up there, to the } \\
\text { source of water; my children went behind [her] } \\
\text { for a bit of water'. } \\
\text { 'I had to make wells; there was no water for } \\
\text { taking a bath...!' }\end{array}$ \\
\hline Trinchera & $\begin{array}{l}\text {-Holes in the gulch, rainwater } \\
\text {-Private wells with electric bomb } \\
\text {-Buying water }\end{array}$ & $\begin{array}{l}\text { 'There was anxiety because the little well was } \\
\text { not enough. Water slipped into the soil and we } \\
\text { had to dig deeper ... sometimes, [until] seven } \\
\text { in the evening...' }\end{array}$ \\
\hline
\end{tabular}

Source: LD (2001a, 2003a) and focus group discussions. 
Collecting water from rivers, gulches, spring eyes (ojos de agua) or manual wells was harder over time because of deforestation and soil contamination. Some people could spend many hours queuing to collect water for nothing. This situation caused conflict and pain because people had to compete for water.

In addition, there were unmet sanitation needs. Only $61 \%$ of households had a latrine and $94 \%$ of them were pit latrines (CODECA, 2001). There was neither a sewage system nor a municipal garbage collection system, so that there were puddles of grey waters in the streets and 17 open areas where garbage was thrown.

Main actors and institutional leakages in the water provision

The public water company, ANDA, primarily serves people in urban areas or adjacent rural areas that represent $88 \%$ of the population with water access (ANDA, 2007). Rural areas are covered by municipal governments financed by the social investment fund (FISDL), local water committees aided by NGOs, cooperatives, and decentralised utilities.

Prior to the project, regulation was not well-developed in aspects such as water quality and the protection of water sources. ANDA was as a provider and its own regulator. The legislation was mixed and the responsibilities between actors were not clear (UNDP, 2001; Moreno, 2005; WB, 2005).

A changing environment for the water sector

After the 2001 earthquakes, 13 decentralised utilities were created as part of a pilot project (Cuéllar \& de Larios, 2001). These utilities were managed by local communities with the support of ANDA and FISDL; their management was considered good in operational, technical, and financial terms (WB, 2005). Hence, there was an ongoing debate about the feasibility of a large-scale decentralisation of the water service. In parallel, ANDA was starting a devolution process for which regional offices were responsible for their own operational and economic efficiency; this change reduced the incentive to invest in disperse rural areas.

\subsection{The water project}

The project covered three cantons of the San Alejo municipality (see Box 7-1), but the focus of this study is on one canton: Agua Fría. The overall goal of the project was 'to contribute to the improvement of the health and living conditions of the inhabitants' (LD, 2001a, p. 4), specifically through the provision of stable access to drinking water service and the improvement of the environment via sanitation and environment protection actions.

Regarding the drinking water service, the project financed in Agua Fría:

- The construction of a re-pumping station in Trinchera (with a suction tank) and three distribution tanks in each village: Trinchera, Agua Fría and Piedra Gorda; and

- The distribution pipes for the domiciliary connection of 509 houses, with their respective water meters.

Regarding sanitation actions, the project financed composting latrines (or eco-latrines) that recover waste by separating urine and faeces to be reused in soil fertilisation. It also promoted the construction of a residual water disposal system (RWDS), to be financed by each household, composed of a grease trap and a soak-away pit (see Glossary, Appendix 3-B). 


\section{Box 7-1: Coverage of the entire water system in San Alejo}

The water system covers the cantons of Cercos de Piedra, Mogotillo and Agua Fría, in the municipality of San Alejo. There is a main well and pumping plant in La Maltez II (Cercos de Piedra canton) and two main distribution pipelines, one for Mogotillo and other for Cercos de Piedra and Agua Fría. The system has six distribution tanks and three re-pumping stations (one in Trinchera). The figure below shows the relevant infrastructure; the one of Agua Fría is highlighted.

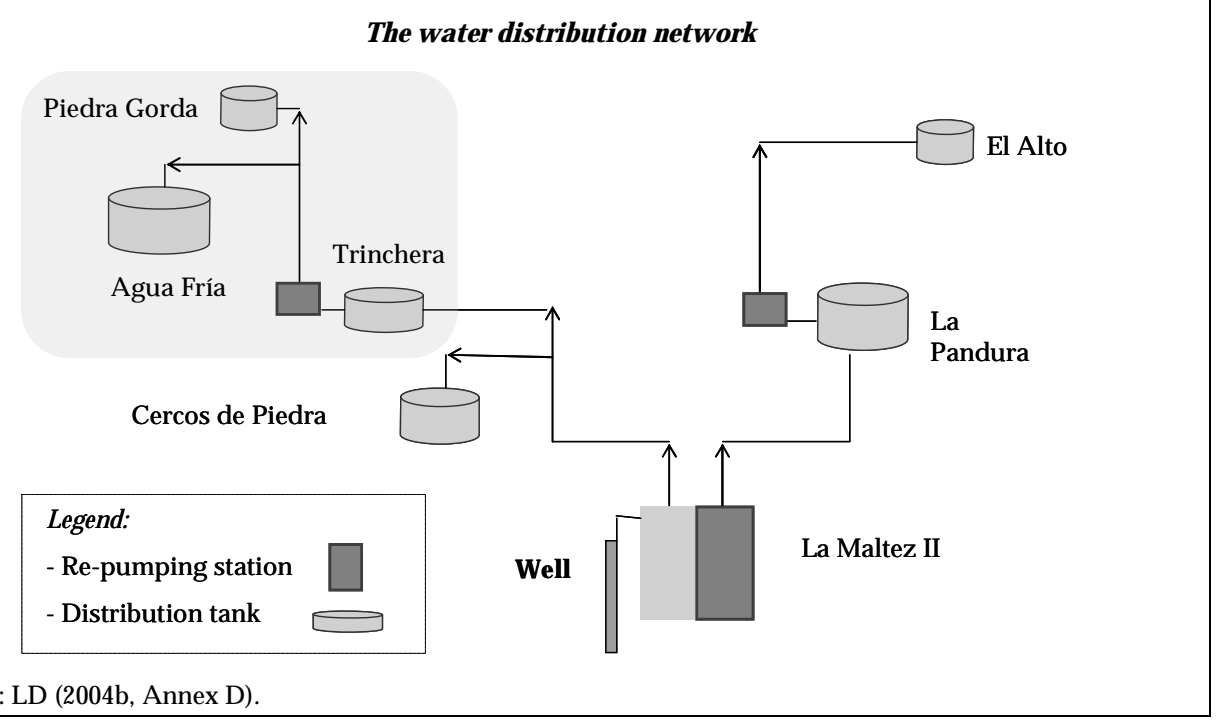

Regarding environment protection actions, the project included:

(i) Ecological wood stoves, which would reduce the firewood consumption and produce ash to clean the latrines.

(ii) Reforestation activities, such as planting agro-forest species in plots, fruit-bearing trees in backyards, and forest vegetation in the sides of the rivers and the area around the reservoir.

(iii) Forest barriers, stone barriers, dikes or stone walls, individual terraces and hillside canals, to protect the arable land.

(iv) One reservoir of $8,000 \mathrm{mt}^{3}$ to store rain water during rainy season, water livestock, and irrigate plots during dry season. Later, the reservoir was used to raise fish.

These activities were carried out by residents. They were organised in work teams for reforestation, protection of natural resources, and the construction of the reservoir; they received a salary. The project financed the ecological wood stoves and latrines, which were constructed with mutual help by households serving as assistants to the bricklayers.

The project promoted environmental awareness among school students, who participated in some reforestation activities, training sessions and two pilot projects. One project consisted of implementing a school vegetable garden from the reuse of grey waters (reedbed). The other project was the recycling and treating of solid wastes (garbage). 


\subsubsection{Organisation of the project and main stakeholders}

A project implementation unit (PIU) was in charge of the management of the project. It consisted of a project chief, appointed by LD headquarters and an administrative assistant. They were based in San Miguel (28 km from Agua Fría). Figure 7-2 shows the main actors in the field.

Figure 7-2: The organisational structure of the Agua Fría project

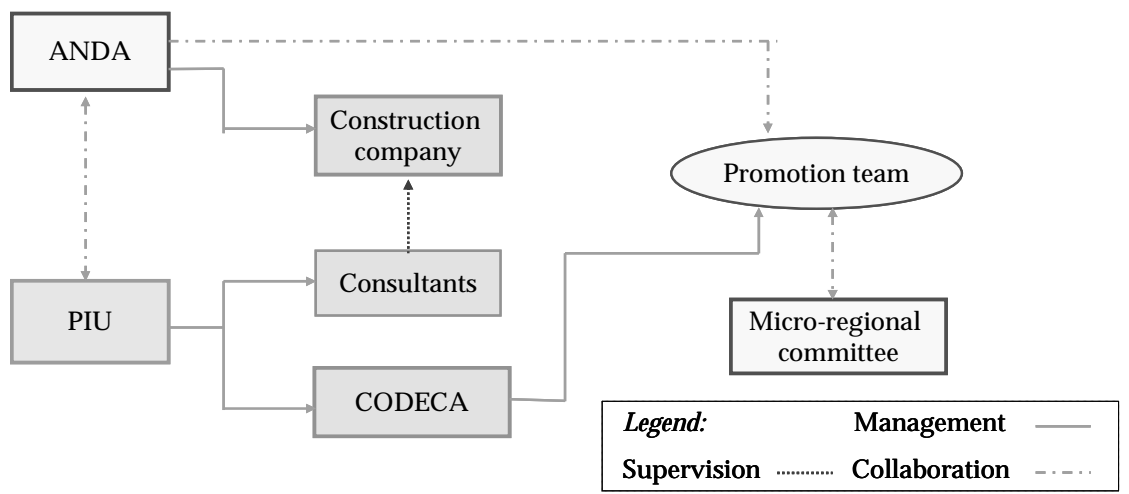

The formal counterpart and executor was ANDA. It hired a private company for constructing the water infrastructure. A consulting company, hired by LD, complemented the supervision of ANDA. During the construction, the three firms had daily follow-up meetings. Once a month, the project chief brought all executing actors together (LD, 2003a). However, LD (2004b) reports problems with the original water system design and with the construction company itself. In addition, ANDA had serious governance issues: accusations of corruption in its largest project involved its president (Urquilla, 2006; Henríquez, 2006b) and were followed by investigations and high rotation of staff (Herrera, 2003). LD (2004b) tells:

Due to the internal restructuring of ANDA, its organisational inefficiencies, the lack of motivation of some employees and the frequent changes in the technical staff involved in the project during the last months of 2003 the project suffered delays and setbacks... (p. 26)

CODECA was responsible for the other components: sanitation, environment and awareness campaigns in the Agua Fría canton. It had a coordinator located in La Unión and a technical assistant and a health worker in Agua Fría. There was a promotion team formed by the two CODECA employees, two local promoters (proposed by the community committees), and one (engineer) promoter appointed by ANDA. There was an operative office in Agua Fría and one store in each other village under the responsibility of the local promoters.

The project chief supervised CODECA and CODELUM, its pair in the other two cantons. CODELUM had a bad performance rating and was dismissed after a financial audit. Since December 2002, CODECA worked in the three cantons served by the project.

A micro-regional committee was formed by five members from Piedra Gorda, six from Trinchera, and six from Agua Fría. It supported the work of CODECA and met at least once a month to coordinate activities. Leaders brought together neighbours for the meetings, organised work teams and explained the project's benefits to people. A leader tells: 
We had to support ANDA employees when they came to measure; we had to explain to people that it was not going to harm them at all (one man leader in the FGD).

In some cases, in Agua Fría, leaders took over the tasks of the local promoters due to security concerns as female promoters were scared of youth gangs and drunken people. One local promoter reflects: 'The members of ADESCO were like promoters themselves'.

Other institutions collaborated with the project staff. For instance, the rural health promoter, employed by the Ministry of Health, organised cleaning campaigns; CENDEPESCA advised on fish agriculture; public schools engaged their students in several activities; the Ministry of Environment and the National Police participated in environment protection actions. Table 7-3 shows the main actors directly or indirectly related to the project.

Table 7-3: Main stakeholders of the Agua Fría project

\begin{tabular}{|llll|}
\hline Formal authorities & Intervening actors & Project staff & Community members \\
\hline MFA Luxembourg & LD & PIU: project chief & ADESCO and commu- \\
MFA El Salvador & Construction company & CODECA staff & nity committees \\
ANDA & Consultants (several) & Two local promoters & Non-leader residents \\
Departmental govern- & Providers of equipments & Construction workers \\
ment & Promoter of health & School students \\
Municipal government & ministry & Donors of lands \\
& Other public institutions & Other villages \\
\hline
\end{tabular}

Each actor had different motivations and perceptions of the work of others. Community leaders and ANDA were part of the promotion team, while the municipal government was an outsider (see Box 7-2). The project chief was the formal 'champion'. The local promoters were hired by the NGO, but they also were beneficiaries (daughters of leaders of Piedra Gorda and Trinchera).

Box 7-2: The impasse with the municipal mayor from the perspective of Agua Fría residents

Some FGD participants said there were conflicts between the mayor, project staff, and Agua Fría residents during the formulation stage. A man leader recalled a harsh exchange of words during a meeting in the communal house between the project formulators and the mayor. For many residents, this impasse had negative effects on the pace of the project; specifically for the usage of a well in the canton and the initial operations. Regarding the well, it seems that there was a misunderstanding: The reason for not connecting that well to the system was its low flow (LD, 2001a), not the fact that the local government owned the land (as stated by a man leader). Regarding the operations, a man leader explained that the mayor brought a lawsuit against 'the project' and even stopped the machineries, but the departmental authorities intervened and the works continued.

In contrast, the CODECA coordinator reported that the NGO staff did not have problems with the mayor. However, 'the municipal government was invited several times to participate in the project but it did not have any interest. Only once, it lent a truck for a garbage collection campaign' (LD, 2003a, II 127). Although the mayor could have not disrupted the project execution, he was not so collaborative.

Possible reasons for non-collaboration are elaborated by a woman: 'The mayor did not help us. He attended the first meetings in Agua Fría, but he got annoyed... When he reaslised that [he could not] manage the project, he did not attend the meetings anymore. They [leaders] did all arrangements, but we lacked his signature to form the community association, which is very important to the community. He said he did not know us' (HIW). 
She and other residents consider that the mayor put obstacles to the formation of community committees in Piedra Gorda and Trinchera and of a NGO integrated by leaders of the three villages, based on the micro-regional committee. These have negative effects on their development prospects.

Source: LD (2001a; 2003a), focus group discussions and individual interviews.

\subsubsection{Micro-level context around the project and main activities}

The gestation of the project can be seen from two perspectives. From the donor view, the story is short. The identification mission took place in April 2000, the first formulation mission brought together local authorities and residents in participatory workshops, in May 2000; but several technical changes were made. The project started only in October 2001 (see Figure 7-3); it was formally presented to the population at the end of 2001 with participatory workshops, followed by a census to determine the operative targets of the project.

From the community leaders' perspective, the story is longer. They had tried for several years to obtain safe drinking water: 'We had requested [a water project] already 18 years earlier and we were waiting' (HIW). With the support of the Salvadoran government, they brought the gravity water systems under their management, which did not cover all households, however.

Since June 1997, when ANDA first requested financing to Luxembourg for a project in La Unión, residents were waiting for a new project in their villages. Other projects were prioritised, but they were patient. One man leader of a neighbouring canton explains:

We were having meetings for three years... and brought ANDA staff to [show] that we were organised and interested in the project. Every three months we met up, our leaders and the leaders of other villages, so that they [ANDA] would see our commitment.

Meanwhile, leaders turned to the municipality government. The mayor built one well that would be under municipal management, but the water was not suitable for human consumption (It was 'hot water', according to residents). Given the unfeasibility of the solution planned by the mayor, leaders opted for the new project, to be implemented by donors:

There was a meeting... the governor and a congressman came here [because] we asked them to be observers... We voted and - that was very important because if the result was 'no', the project would have been stopped - the opportunity was there: out of 80 , we got 65 votes in favour (one man leader in the FGD).

Considering the long interval between 1997 and 2001, people grew sceptic. The CODECA coordinator recalls: 'People did not believe; we arrived to talk about the water and they did not pay attention to us [until] they saw the machinery was entering'. In this context, the project began.

Figure 7-3 shows the main project activities. The soak-away pits were built during the first five months of 2002 because they were a requirement to provide the domiciliary water connections. The first reforestation activities took place between June and August 2002; however, several plants died due to the El Niño phenomenon. Several soil conservation activities took place between May 2002 and July 2003. The reservoir was built toward the end of the project. 

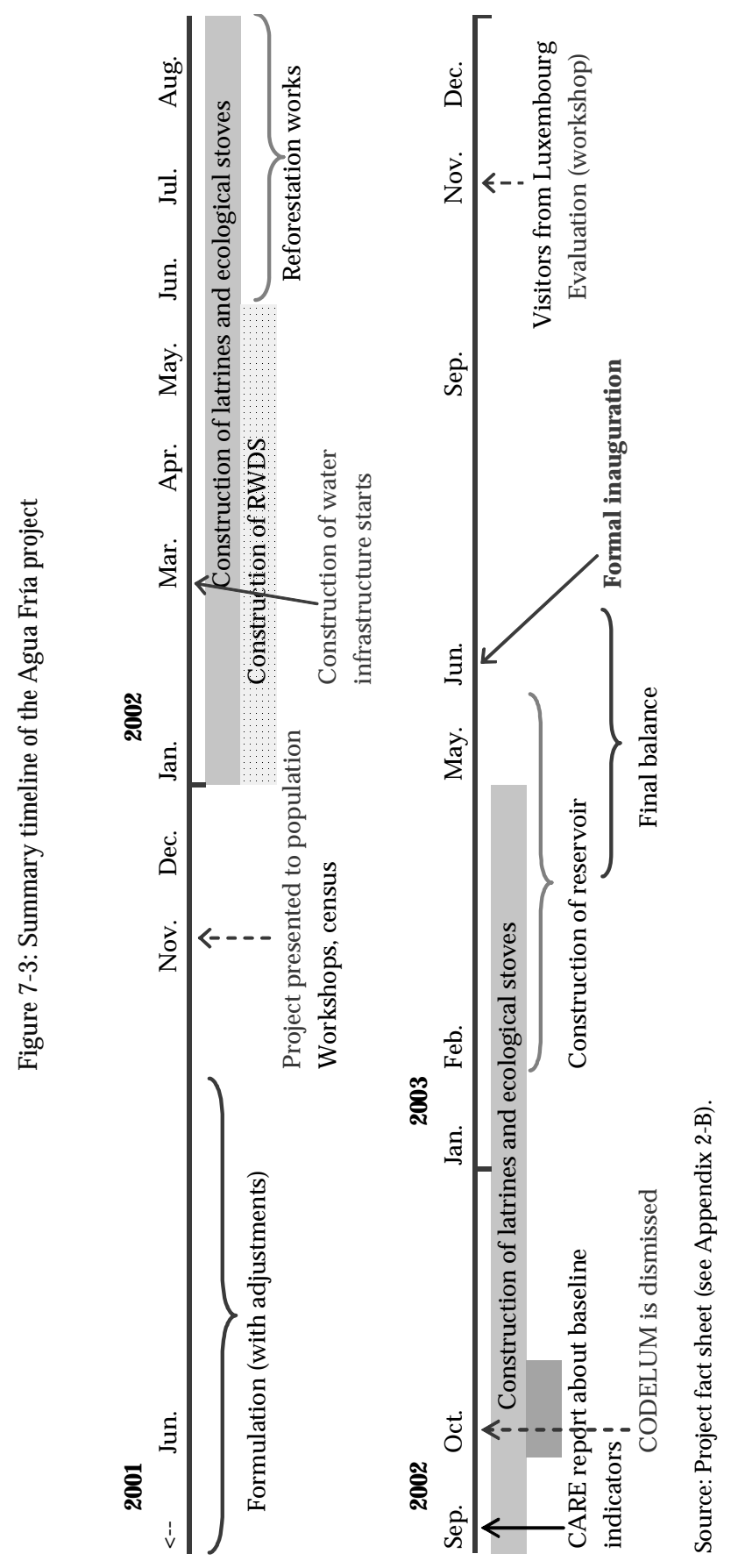
The construction works were completed by May 2003. Since then, the operation and maintenance of the water system was transferred to the East regional office of ANDA (with its headquarters in San Miguel). A commercial office in La Unión is in charge of collecting payments and handling claims.

The remaining money was used by CODECA for training sessions, the production of educative material, campaigns of garbage collection, pour-flush latrines for schools, and field visits of some residents to other communities to share experiences.

The project was inaugurated in June 2003 by the project chief and representatives of ANDA. However, what people recall as 'inauguration' is the visit of the Duke of Luxembourg in November of the same year, who arrived with three helicopters accompanied by authorities of his country and of El Salvador. Soon after, there was an evaluation mission with participatory workshops to assess the benefits of the project with the residents of the canton (among other activities). Later, the same month, the first water bills arrived.

\subsection{Project practices}

This section discusses some practices considered significant by Agua Fría residents, primarily related to sanitation promotion, environmental awareness and community organisation. Table 7-4 summarises the aspects to be analysed.

Table 7-4: Main practices during the Agua Fría project

\begin{tabular}{|lll|}
\hline Project phase & Practices & Aspect \\
\hline $\begin{array}{l}\text { 1. Identification and formu- } \\
\text { lation }\end{array}$ & decistion and design & - Participatory diagnosis \\
& & - The selection of a local counterpart \\
\hline 2. Implementation & Conditionality & - Implicit targeting through conditionality \\
& & - The residual water disposal system \\
& Coordination & - Local participation in work teams \\
& & - The role of ANDA in the promotion team \\
& Accountability & - Special treatment to donors of lands \\
\hline 3. Evaluation and audit & & - The reservoir and the fish agriculture project \\
& & - The utility of project activities \\
\hline
\end{tabular}

\subsubsection{Selection and design decisions excluded important stakeholders}

The project formulation took less than two years in formal terms, but more than four years for community leaders. During this time, decisions related to the water system were made by outsiders. Some events resulted in the unintended exclusion of the political authority and potential beneficiaries.

\section{- Participatory diagnosis}

The participation of the residents was limited in quantity and quality. The diagnosis was induced toward the activities of the project, [and then it was] perceived like a promotion of its activities; in other words, the residents did not have options on what to discuss (CODECA, 2003a, p. 22).

At the start of the project, formulators organised workshops to know about the water issue in the canton and to promote awareness about health and sanitation among residents. Other 
issues such as delinquency, high living cost, bad roads and lack of bridges were also raised during those workshops, but not addressed by the project.

\section{- The selection of a local counterpart}

To assure the durability of the project effects, the partners [NGOs] will take charge of organising and advising local committees... The participation of local population as a whole will be promoted and considered a guarantee for the durability of the actions (LD, 2001a, p. 33).

The mayor of San Alejo did not participate in the project, apparently due to conflicts (Box 7.2). The mayor expressed, in an individual interview, that he was excluded because of political interests of ANDA. He said that he neither received the plans of the water system nor was asked about the routes to use. He considered that the project was good, but 'with the participation of the municipality government several problems could have been solved'.

The local counterpart was the organised community. However, the project did not directly aim at making the existing committees stronger; these were seen as means to produce sustainable effects on health and environmental awareness (LD, 2001a). Moreover, political support was not regarded as necessary for the sustainability of the committees, as evidenced by the distant relation with the mayor.

Rubio-Fabián and Valdez (2004) reflect that the initial resistance to the project from the local government could have been overcome by promoting broad-based participation. This was not the case. Leaders supported by CODECA planned to formalise a NGO called 'Association for the development of Agua Fría' to promote and manage small projects in the canton. However, after the water project, this NGO was not approved by municipal ordinance and residents did not benefit from projects or relevant infrastructure improvements.

\section{- Implicit targeting through conditionality}

A huge problem in these communities is the large economic differences among persons. Some persons have much more unmet needs than others who receive remittances from the US (the CODECA coordinator).

The project officially targeted all households of the three villages, but, in practice, there was a bias against the poorest. Households had to invest in a residual water disposal system (RWDS), the domiciliary connections that run from the water meters to the interior of the house, and the lavatories or tubs. These components are costly.

Table 7-5: Number of private water connections in Agua Fría

\begin{tabular}{|l|cccc|cccc|}
\hline & \multicolumn{4}{|c|}{ Households } & \multicolumn{4}{c|}{ Houses } \\
& Total & With PWC & Without $\%$ connected & Total & With PWC & Without & $\%$ connected \\
\hline Agua Fría & 305 & 263 & 42 & 86.2 & 463 & 356 & 107 & 76.9 \\
Trinchera & 79 & 68 & 11 & 86.1 & 111 & 105 & 6 & 94.6 \\
Piedra Gorda & 40 & 33 & 7 & 82.5 & 67 & 48 & 19 & 71.6 \\
\hline Total & 424 & 364 & 60 & 85.8 & 641 & 509 & 132 & 79.4 \\
\hline
\end{tabular}

PWC = Private water connection /Unoccupied houses: 217 or $34 \%$ of total.

Source: CODECA (2003b).

Table 7-5 shows that 60 households were not connected to the water system. CODECA (2002b) reports that some people did not opt for the project because they lived abroad most of the time, had a private protected well, or were connected to the old gravity systems. 
Nonetheless, many emigrants connected their houses to the new water system: 145 out of 217 unoccupied houses.

More than being abroad, it seems that the high cost of a RWDS was the crucial factor: 'They did not want to make the pit because they said it was too expensive, now, they regret' (LIM). The system cost between USD50 and USD100 (LD, 2004b), a high amount for the $40 \%$ of households whose monthly revenues were below USD90 (CODECA, 2001). Moreover, not all households received remittances.

The project design allowed the project staff to employ some residents so that they could afford these costs (LD, 2001a). This was the case for several (next section), while others borrowed money or materials to build their RWDS. In 2005, the costs for a private water connection were at least USD300 (said by an ANDA employee), without including the cost of a RWDS. These amounts are unaffordable to most residents.

\subsubsection{Conditionality harmed intrinsic motivation and operational outputs}

The main conditionality was that people had to finance their RWDS. In contrast, manual work in some collective activities was remunerated.

\section{- $\quad$ The residual water disposal system}

The only requirement to receive the project was that every house had a soak-away pit.... These pits were [built] first, so that other [grey] waters would not contaminate (HIM).

The water infiltrates in one place, not in other places. The water pours out and smells; we cannot stand it at home so that we throw that water away. Right now, there are pits that are full, pouring out; we cannot use them... (LIM).

The Ministry of Health states that each household has to have a RWDS before being connected to the water system (LD, 2003a). The project financed neither the materials nor the labour. These costs were considered part of the local contribution. LD (2001a) valued these systems and local labour in all activities at $9 \%$ of the project budget.

Residents were taught how to build a RWDS, but they did not think water would infiltrate in some areas because of the soil quality. Despite LD (2001a, p. 30) aimed at certain flexibility, one specific system design was put forward (CODECA, 2002a, p. 14). The CODECA coordinator elaborates on two reasons. First, many households could not afford deeper soak-away pits or modified designs, as one man says: 'I did not build the pit with cement due to lack of money; the pit collapsed' (HIM). Second, alternative solutions were out of place: 'In some cases, reedbeds could be more suitable... but the problem is that when a project is already defined, it has to be done' (the coordinator). ${ }^{50}$ This comment recalls the lock-frame problem (section 3.2.2). To address the infiltration problem, local promoters advised people to water plants with the water stored in soak-away pits.

Moreover, project staff felt pressure to get the RWDS first than anything else. Then, some systems do not have a grease trap (HIW), which affects the sustainability of the soak-away pits because soap, grease or other residuals get deposited in the base of the pit. Besides, watering vegetables in backyards with unfiltered grey water is risky for human health.

\footnotetext{
${ }^{50}$ I could not cross-check this with the project chief. 'Reedbed' is a system that allows reusing the filtered grey waters planting non-food crop plants (see Glossary).
} 
Neither residents nor CODECA staff believed the systems would work. Predictably, several do not work: water spills; the soak-away pit crumbles, where the soil is porous; or people do not maintain the grease traps. Already in May 2003, almost a quarter of soak-away pits had this problem (CODECA, 2003f) that was 'not fully solved' (LD, 2003a, II 56). Some people water plants from the soak-away pits, while others simply leave grey waters to go into the streets or gulches. Many soak-away pits are closed, including those of two leaders.

\section{- $\quad$ Local participation in work teams}

I was part of the work squads until the project was finished. They gave us work and paid per hole. The more [holes] the more payment; they paid on Saturday. We also sowed; we carried the trees to the hill.... After a while, no [trees] were left, well, some (LIM).

Households worked in the assembling of pipelines, the construction of tanks, and the reforestation actions. The work was voluntary but remunerated. Most probably those who had more difficulties to finance their RWDS worked in these activities. A man in Trinchera expressed that the salary paid by the construction company was low and did not correspond with the long and hard workday so that only foreign workers accepted such a work. For reforestation and soil conservation activities, people were extrinsically motivated: They worked because they would earn money; they did not necessarily value those activities.

\subsubsection{On-site coordination could be better}

Two issues were highlighted by FGD participants: the role of ANDA in the promotion team and the situation of the donors of lands.

\section{- $\quad$ The role of ANDA in the promotion team}

They told us that the bills would correspond to the amount [of water] spent in cubic metres... Once, my bill came very high. They checked the water metre and [found out that] they had written [an incorrect number]... I did not pay that bill; they had to inspect (LIW).

Agua Fría residents considered that the support of an ANDA engineer to the promotion team was useful. They learned how to manage their consumption, read the water metres, and complain, if necessary.

Regarding the soak-away pit, the promotion team put more emphasis on how to build it and less on why and how to use it. A man reports:

One person from ANDA came to watch the [construction of the] soak-away pit. If one made a mistake, he would say: 'Do it in this way and that day I will come to see how it is'. He came how he had said (LIM).

It seems that the local promoter and the engineer had two different messages. A leader says:

I do not know very well how to use it [the soak-away pit]. Some people say that it is useful to water [plants]; others say it is to be infiltrated... When it is left for a long time, it has bad odour and we have to wash it (a man leader in the FGD).

The confusion originates because CODECA advised people to water plants given that the design was unsuitable to the soil quality. In addition, some people mistrusted ANDA. A man leader declares: 'They [ANDA] said that the water had to infiltrate because it was convenient to them'. He means that households would pay more if they did not water their plants using the water stored in the soak-away pits. 


\section{- Special treatment to donors of lands}

I opened the land to the project for the well-being of the community (LIW).

Residents were not sure about who was responsible for the fulfilment of certain commitments from the part of project staff. The donors of the lands for water tanks complained because they had been promised they would not pay for their water consumption, but they were requested to pay. A woman donor tells:

The person who came to write everything told me ... 'you will have one connection, but you are not going to pay anything [for the water]'. But the bill always came... They [the water company] came to cut off the water [service], but the community leaders said that it was not fair because I had the right. Then, they re-connected [the service] (LIW).

The donor in Piedra Gorda did not have this support, so she pays her water bills every month. She reflects that it happens because there is no formal ADESCO in her village to defend her rights. ANDA was responsible for respecting such agreements. In fact, lands for all water facilities had to be owned by ANDA (LD, 2001a, p. 40) and some residents donated their lands to ANDA. However, given that no formal authority was involved in the process, the voice of residents in defence of their rights is hardly heard.

\subsubsection{Poor accountability as result of institutional weaknesses}

This section tells about two aspects valued by participants, the water and the reservoir, and their assessment of other activities. The public water company and the community association, not supported by the local political authority, did not fulfil their expectations.

\section{- Quality of the water service}

There have been like seven [water] leakages from Piedra Gorda to Trinchera. The last time, they had to break the paving stones of the road in order to fix the pipeline (HIM).

In general, people are satisfied with the water quality, but they are highly dissatisfied with the regularity of the service. About water quality, $32 \%$ of the survey respondents reported that it was very good and $65 \%$ reported that it was fair. These responses are positively associated to the literacy status of the respondent (Kendall's tau-b, $\tau=0.359, p<.01$ ). About $46 \%$ of literate people and $15 \%$ of illiterate people gave the highest grade to the water quality.

About the regularity of the service, people in every FGD and individual interviews complained about the explosion of pipes and the non-continuity of the water provision in some neighbourhoods. They explained that there were water leakages when the project staff was still in the canton. ${ }^{51}$ To them, this problem is due to the material used in the pipes, the polypropylene that some called 'plastic', or the design of the water system (see Figure 7-4).

People store water in tubs because they are afraid of water cut-offs. Hence, water is vulnerable to contamination by dust, handling, or external objects. Some people put abate inside them, an insecticide to kill mosquitoes that transmit dengue, or small sardines called chimbolos that eat the mosquito larvae. This water is used for cooking and washing clothes. However, not every household takes care of water, for instance, covering the tubs.

\footnotetext{
${ }^{51}$ Damiani (2003b, 'executive summary' section) writes: 'In several occasions the company [ANDA] has had to intervene to fix leakages in the main pipe (linea de impelencia)'. CODECA (2003f) reported that people complained of leakages in the pipelines and that rains had eroded the soil and left some pipes uncovered (p. 1).
} 
Figure 7-4: Local diagnosis of causes of the unreliability of the water service (Agua Fría)

VISIBLE PROBLEMS

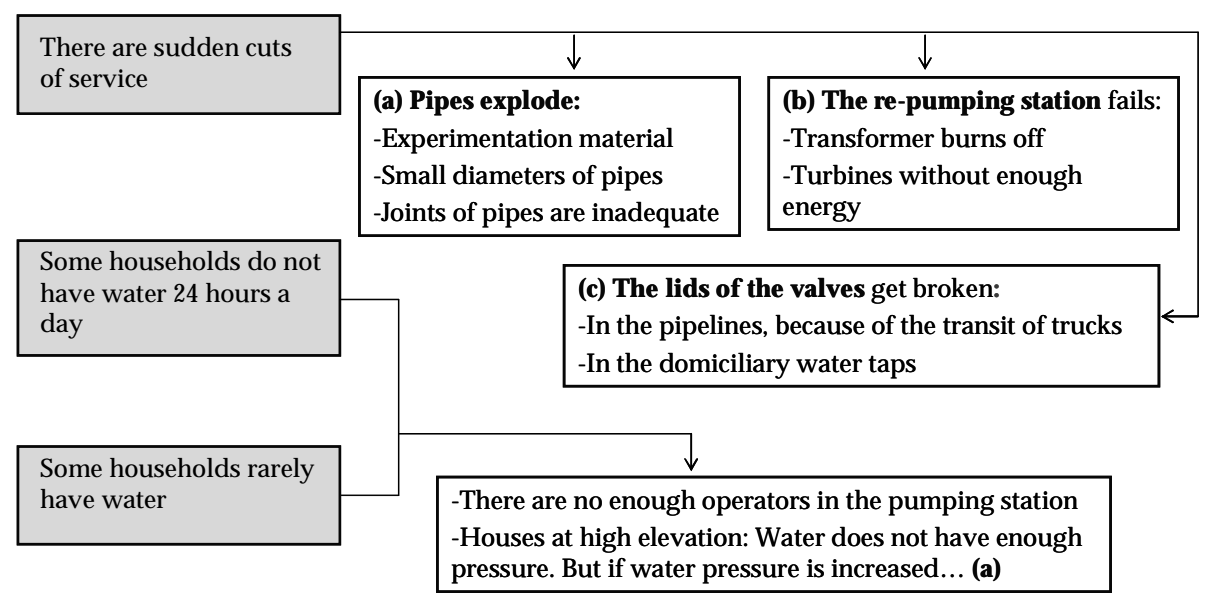

Source: Focus group discussions.

Less than $10 \%$ of participants complained about the water tariffs. In fact, ANDA has a subsidy for households consuming less than 20 cubic metres per month $\left(\mathrm{m}^{3} / \mathrm{mo}\right)$ and many residents are subsidised. In 2003, the average consumption was $15.6 \mathrm{~m}^{3} / \mathrm{mo}$ (LD, 2003a, Annex D). However, residents resent to have to pay when the service is irregular. A man explains: 'They cut off the water; we have spent two or three days without water... Why do we receive so high water bills if there is no much water?' (LIM). Between April and August 2005 , about $10 \%$ of residents presented complaints to ANDA; in several cases, consumption had been badly recorded (according to an ANDA claims handling officer).

\section{- The reservoir and the fish agriculture project}

In summer, it was beautiful to sit there and to receive the breeze (a man leader).

As designed, the reservoir is used to water livestock. However, during the project execution, leaders started a business of raising tilapias in the reservoir. They invested much effort and resources. They bought 3,500 fry, which added to the 2,500 donated by CENDEPESCA to create the critical mass for raising tilapias. Water from one gravity water system was channelled to the reservoir using a plumbing system, which residents built with pipes donated by the project staff. Two leaders were in charge of feeding the fish and enjoyed the activity of 'watching them grow' (a man leader).

A neighbour from El Llano donated the land for the reservoir; he felt that 'opened frontiers' to other villagers of the canton because before the project the interpersonal relations between El Llano and the canton quarters had been a little conflictive. He became a member of ADESCO. Hence, the reservoir had a symbolic value of unity for Agua Fría residents.

Nevertheless, the business of raising tilapias did not succeed because the reservoir poured out with heavy rains, some people stole the adult fish and '[fish] were eaten by some people of the community' (LIW). Moreover, residents lacked the funds to pay a private guard and set up a security hut, necessary because the area was insecure. This failure harmed everyone, but especially leaders because they had invested the most. 
This failure put in evidence other issues. The donation of the land was through a 'commodatum' (or bailment) agreement, signed between the owner and ADESCO, according to CODECA (2002a). However, the owner stated that 'the project' had not paid the agreed annual fee to him. Given that he is still the owner and there is no fish anymore, he wanted to sell it. It seems that the unity brought through the reservoir was led by economic interests.

\section{- $\quad$ The utility of project activities}

They planned the reforestation project. In winter, they sowed trees and watered them. But, in summer, how were they going to water? Then, they did not obtain any benefit, but spent money (LIM).

In general, residents valued the project positively, but they regarded some activities as a waste of time or resources. They stated that the reforestation works were abandoned, that there was no significant change in the riversides, and that most activities targeting the areas surrounding the reservoir were not successful. In contrast, they are very satisfied with the fruit trees (oranges, lemons, papayas, etc.) that they planted in their backyards.

Building stoves and latrines was optional and materials were free to everyone, but some people felt them as conditions (see section 10.4.4). However, those who preferred pour-flush latrines to composting latrines did not get any financial aid. Finally, out of the 509 houses connected to the water system, nearly $80 \%$ had an ecological wood stove and a composting latrine. About $82 \%$ and $75 \%$ of households adequately used their stoves and latrines, respectively (CODECA, 2003c). Opinions about their utility depend on how correctly people use them. The assessment of training activities was positive, in general.

People valued the fruit trees, their latrines, and above all, the water connection. They did everything to get water: building a RWDS, attending training sessions, working in cleaning campaigns, and participating in work teams. However, the water service is unreliable.

\subsection{U nderstanding individual autonomy in Agua Fría}

The analysis below is based on the fieldwork carried out in 2005, two years after the project's completion. This section discusses aspects considered important to Agua Fría residents, their experience of autonomy, and the role of community.

\subsubsection{Improvements in living standards bring more autonomy}

Earlier, we did not make [real] decisions.... We had to move to a hacienda [to work]; this was a decision led by hunger. In contrast, now, we choose our responsibilities. We stopped working for others... Everyone works for his or her well-being, family and community (HIM).

FGD participants did not directly refer to autonomy. When talking about impacts, participants in high-involvement groups said that life is new, different and valuable because they have water; 'water is life' (HIW). This life is better for individuals and the community as a whole. They rediscovered a sense of solidarity that had been hurt by the struggle for collecting water. A man referred to the importance of relations to do things with others, such as to transport and sell maize: 'Thanks to God, many friends have prospered; they have their pick-up van so that we can carry our maize to La Unión without struggling' (HIM).

Having resources for living was emphasised by high-involvement men. They considered that sufficient resources bring a sense of happiness, security, and freedom. Having a worthy job 
is crucial: 'Thanks to God I work; I am not enslaved by anyone, I work freely' (HIM). They recognise that solidarity and relationships are important, but having a source of income is the ground for further development.

Residents value a mix of material and immaterial needs, not equally satisfied or realised

To know more about their values, survey respondents were asked about the most important or necessary things that everyone should have. Respondents listed resources and several personal capacities. Table 7-6 shows a priority ranking and the percentage of respondents who declared to have fulfilled those aspects.

Table 7-6: Ranking of valuable life achievements in Agua Fría

\begin{tabular}{|clc|clc|}
\hline Rank.(1) $^{(1)}$ Aspect & \% necessary & Rank. & Aspect & \% necessary(2) $^{(2)}$ & 80.8 \\
\hline 1 & Having a house & 90.2 & 6 & Having a job & 74.5 \\
2 & Feeling inner peace & 86.3 & 7 & Being healthy & 78.4 \\
3 & Being well-fed & 84.3 & 8 & Having a land to cultivate & 72.6 \\
4 & Having drinking water & 90.2 & 9 & Being literate & 74.5 \\
5 & Having a family & 76.9 & 10 & Having electricity & . \\
\hline
\end{tabular}

(1) Ordering was obtained by using a modified Borda count (see Box 4-5 in Chapter 4).

(2) The percentage represents how many respondents regard this concept as necessary to everyone's well-being. Source: Dataset $2(n=54)$.

The most valuable achievement was having a house; about $90 \%$ considered a house necessary and $94 \%$ reported having one, although less than half would legally own a house (CODECA, 2001). It is worth noticing that feeling inner peace, an immaterial need, is second in priority. Nearly $75 \%$ of survey respondents thought that being healthy was important, but only $74 \%$ of them reported to have good health, despite that they said to be well-fed and to have basic services.

Almost $81 \%$ of respondents considered having a job important; however, only $74 \%$ of them reported to have one: $80 \%$ of men declared to be farmers and $83 \%$ of women to be housewives. Likewise, $78 \%$ said that having land to cultivate was important, but only $46 \%$ of them actually owned land, which means that many still work for others. The situation of farmers who do not have a job is only partially compensated by remittances.

About $73 \%$ of respondents valued literacy, but only $61 \%$ of them were functional literate. This rate is lower than the municipal average literacy rate of $66 \%$ (UNDP, 2005c), given the age profile of Agua Fría residents: $80 \%$ household heads were 45 years or older, and many could not attend school at their childhood.

\section{Remittances have improved material well-being over time}

Migration is crucial for the livelihood of Agua Fría residents. Some residents emigrated during their youth and bought lands or started small businesses with savings from their work period abroad. There are couples whose children work abroad and send money back home. About $48 \%$ of the survey respondents declared to receive cash remittances (may be under-reported). In-kind remittances such as electric appliances and second-hand clothes are frequent. It is possible to find a colour TV in a house made of bahareque (walls with cane and mud). Inequality has risen; a pick-up van can be found besides of an adobe house. Several emigrants plan to return home and new houses are being built. 


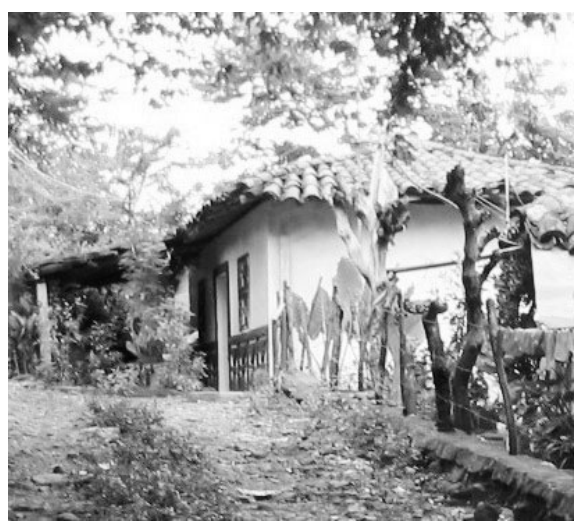

Photo 7-5: A traditional house (August 2005)

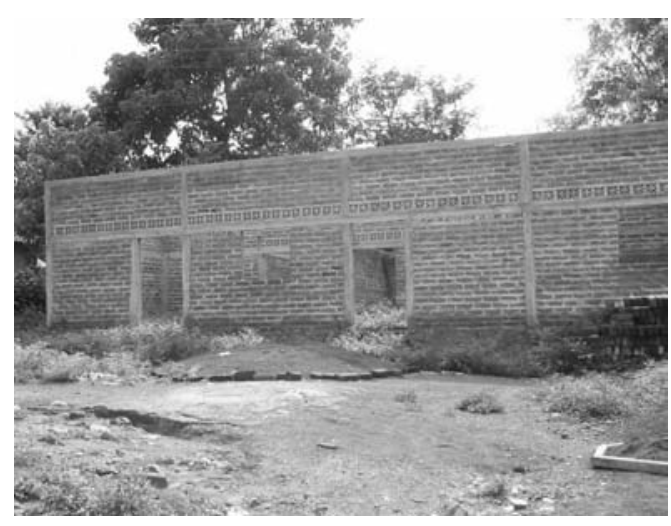

Photo 7-6: A house in construction (August 2005)

Self-reported monthly expenditures indicate that about $17 \%$ of households live in extreme poverty and at least $54 \%$ live in total poverty. ${ }^{52}$ Figure $7-5$ shows that $20 \%$ of households with expenditures below USD 93 and more than $50 \%$ of households with expenditures above that amount received remittances. It seems that although remittances help to improve material well-being, the poorest are less likely to receive remittances. Moreover, receiving remittances does not eliminate monetary poverty in this canton.

Figure 7-5: Household expenditures and remittances in Agua Fría

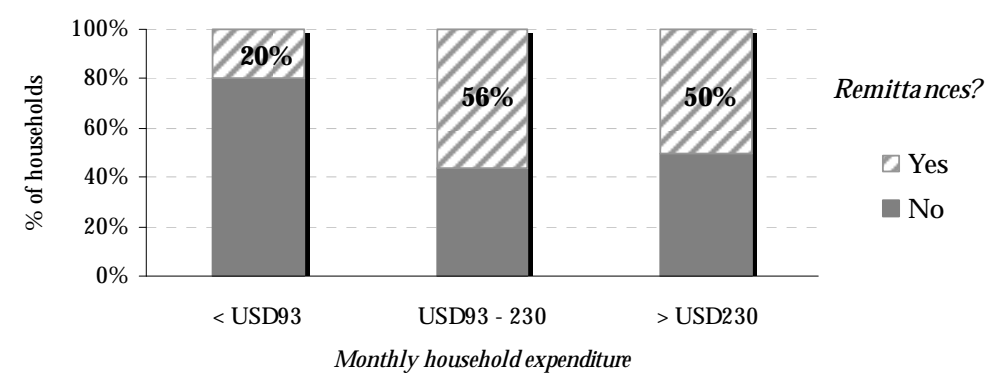

Source: Dataset 2.

Agua Fría residents seem to fulfil the majority priority needs better than their own priority needs

Through the basic capability survey, respondents reported on their subjective well-being in different life dimensions. Figure 7-6 consists of two parts. Part (a) shows the distributions of the 10-top index and the 'own' index. The 10-top index was obtained counting the achievement (yes/no) in each of the ten valuable aspects listed in Table 7-6. The 'own' index was calculated counting the achievements only in each of the items valuable for each respondent (Box 4-5). Part (b) plots the relationship between the own index and self-reported expenditures classified into four categories.

\footnotetext{
52 For rural areas, the national extreme poverty line and non-extreme poverty line were USD87.53 and USD175.06, respectively, in year 2005 (DIGESTYC, 2007).
} 
Figure 7-6: Distribution of self-perceived achievements in Agua Fría

(a) Two well-being indexes

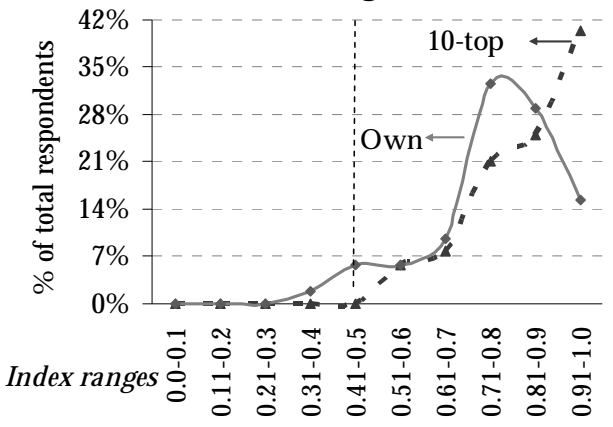

(b) Own index and expenditures

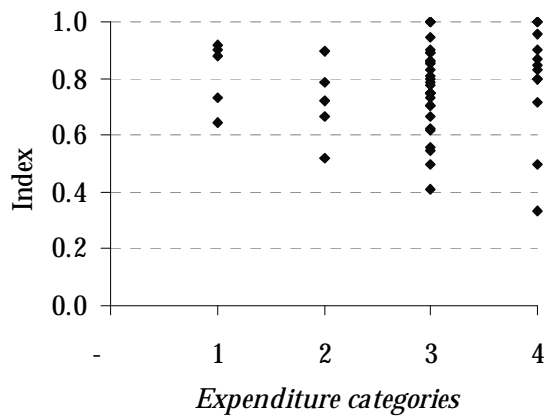

Note: The four levels of expenditure self-reported by the respondents are: (1) equal or lower than USD37, (2) between USD38 and USD92, (3) between USD93 and USD230, and (4) higher than USD230.

Source: Dataset 2.

The 10-top index includes a relational aspect to be interpreted as 'how well am I doing with respect to others?', because the 10 items are the most valued by the majority of survey respondents. The own index considers only one's judgements about valuable aspects. These indexes show that people judge their situation with different standards. For instance, although no one got a 10-top index lower than or equal to 0.5 (the vertical line in part a), around $8 \%$ seem to be doing badly in subjective terms, with an own index in that bracket. Looking at the upper extreme of the distribution, only $15 \%$ of respondents got an own index above 0.90 , in contrast to $40 \%$ of respondents who had a 10 -top index in that range.

This means that survey respondents have the common priority (or 10 top) needs relatively better covered than their own priority needs. For instance, a woman with almost all the common priority needs covered reported that she did not have support to raise their children, did not have access to credit, did not belong to any organisation, and did not have the possibility to travel abroad; and that these things were important to her.

There is no association between the own index and the self-reported household expenditures. The same holds for the 10-top index. However, it seems that there is a larger dispersion for the wealthier cases, which might reflect different life expectations. Many receive remittances, especially the wealthier, so that Agua Fría residents are informed about different lifestyles (mainly from the US), which could influence their assessment of their own life experiences. Being a recipient of remittances has a weak positive association with the 10-top index, not statistically significant, but none with the own index.

\subsubsection{Community strength threatened by physical insecurity}

A leader has to be supported by whatever is needed. We have to be sincere, of good heart; there must be love [among people]. If one person stands up and another stands down, no thing can be done. Hence, there must be good disposition and love, to go forward (HIM).

A community is weak when it lacks resources and cannot obtain them (LIM).

Community was associated to values, resources, and organisation. Regarding values, FGD participants considered that union, solidarity, trust and communication were the basic ingredients to form a strong community. Only when members share a set of common values, 
life without conflicts is possible. This life also requires minimum conditions or resources such as basic services, job opportunities, good relations, and good projects that in turn expand the access to resources. Relations are instruments to reach goals, for instance, to sell products on the market, to get a new project, or so on; these have to be built 'with people bigger than oneself' (HIM).

Finally, a community requires organisation to manage these resources. Good leaders learn from others and communicate to others; they motivate and generate commitment in their neighbours, and act with honesty and responsibility for the well-being of all. FGD participants identified a virtuous circle:

Resources + Values $\rightarrow$ Community $\rightarrow$ Organisation $\rightarrow$ Values

Residents talked about leadership to reach common goals within a community and to joint efforts with other communities. Men explained that leaders have to be good because, when there are projects, 'there are always people who block' (HIM). In the case of a neighbouring village, 'the community paid for bad informed leaders' (HIM) who did not accept to be part of the project during the formulation mission. Women stressed the collaboration between the three villages that existed during the project: 'We were three communities as if we were just one. Three communities united are powerful like the little ants that work together' (HIW).

In general, people feel that they have a formal organisation that works, although people's support to leaders has declined over time: 'There is organisation... a different matter is that sometimes, people do not support it' (LIM). In Agua Fría, some neighbourhood committees are not active; the last cleaning campaigns led by the health authorities were not supported by ADESCO (reported by the physician assistant of the health post). Hence, participants expressed their doubts about the role of the community; only $50 \%$ said the community would expand their opportunities (Figure 7-7).

Figure 7-7: Perceptions about community in Agua Fría

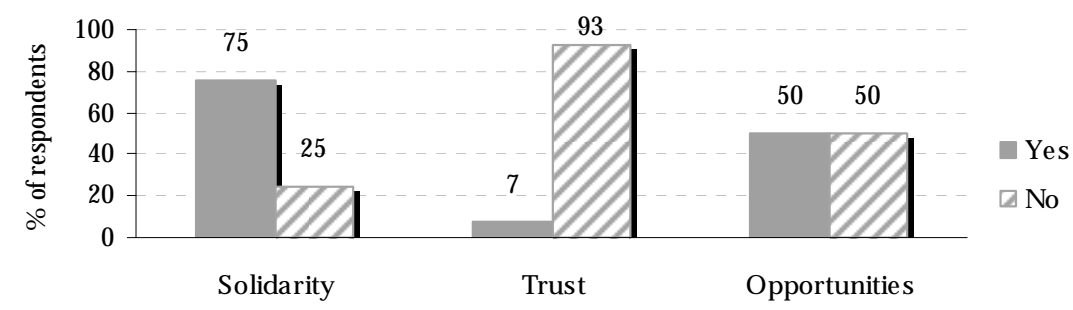

Source: Dataset 2.

Trust is by far the variable with the worst rating, which is related to the perceived insecurity in the canton. Nearly $93 \%$ of the survey respondents considered that they have to be alert because someone could take advantage of them' (closed-ended question). Residents consider that Agua Fría is the most dangerous of the three villages. Vagrants take advantage of their neighbours by trespassing, robbing goods and money, and scaring people in the plots and around the reservoir. A man leader said that some people 'show the gun' when they are asked to pay for the old gravity water system. Even in Piedra Gorda, a quieter village, some women reported that youth gangs go 'sniffing' and ask for money under threat of stealing 
the water metres. As many people in this canton receive remittances, cash in the house is not unusual; the thieves steal the cash, especially from female household heads.

There is no police station in the area; the closest one is in San Alejo, outside the canton. In any case, rural policemen are powerless because they need witnesses and people are afraid of delinquents. The positive side is that most people (75\%) still think that, in case of need, neighbours would help. Solidarity is higher in the smaller villages. For instance, in Piedra Gorda, nine out of ten respondents said that neighbours would help.

\subsubsection{An organised community brings more opportunities to many, not to all}

A strong community board is able to face anything that arrives and people from outside (HIM).

Upon being asked about which organisations they recalled, without prompting, almost $67 \%$ of the survey respondents listed a community association (e.g., ADESCO) and 35\% named religious organisations. There are several churches in the canton: one catholic in each village and evangelical churches in Agua Fría and Trinchera.

Less than $10 \%$ of the respondents also named associations of school parents, alcoholics anonymous (AA), football teams. The low percentage signals the positioning of these institutions, not necessarily people's awareness. For instance, football matches take place every Sunday in Agua Fría and Trinchera and act as informal socialisers (cf., Hirschman, 1984) that reinforce bridging social capital.

About $57 \%$ of the survey respondents reported to participate in at least one of these organisations, more men than women (67\% versus $45 \%$, respectively). However, in smaller circles, women would have more influence. When asked about how much control they had in certain sorts of decisions, about one-half of women said to have a certain control (fair or nearly full) in personal and family daily decisions, while a little less than one-third of men said so. In community decisions, both groups reported having low control, despite the high communal participation. In fact, $62 \%$ of women and $40 \%$ of men said to have no influence at all.

The participation of individuals differs within the canton and among individuals. Household composition, religious affiliation, and other factors may explain different behaviours. In Piedra Gorda, the smallest village, women manage the 'healthy school' and feel very proud of their work. They receive maize, frijol, and milk to prepare lunch for their children. Men work together in the plot following an unwritten reciprocity rule. When someone needs help, others work for free. That rule does not hold in Agua Fría; relatively richer farmers have to contract seasonal workers. According to one leader, some young remittance recipients do not work and landowners have to offer high wages in order to attract them.

Leaders, formally organised into ADESCO, are stronger in Agua Fría. They arrange social activities such as parties and raffles in the communal house, beach trips and soccer matches, which everyone enjoys. Leaders have authority that also brings them responsibility. People appeal to them when something goes wrong, that is, when pipes explode, the fixed telephone or electricity services are cut-off, or when there is a robbery. Most leaders have relatives abroad and receive remittances; they frequently finance their organisational expenses with their own resources. This means that an implicit requirement to be a leader is to have time and economic means, which bring prestige to them. 
Non-leaders are somewhat disappointed about the capacity of leaders to expand their opportunities, mainly due to high physical insecurity and the lack of new projects. Moreover, it seems that there is conflict between villages and within the canton quarters. To some extent, this conflict could have been fuelled by the mayor. A leader in Piedra Gorda was, in the eyes of leaders of the other villages, 'named' by the mayor; they did not recognise him. He did not join other leaders in meetings during the fieldwork. However, above all, leaders of the three villages are tired of ineffective efforts, while most people feel at a disadvantage regarding other cantons of the municipality because they do not receive the help they need.

Persons with larger social networks are more optimistic about the role of community. First, people engaged in organisations have a better perception of their community (Kendall's tau$\mathrm{b}, \tau=0.286, p=0.049)$. About $60 \%$ of the respondents active in associations, sometimes or usually, feel that their community expands their opportunities (Table 7-7). Second, almost two-thirds of remittance recipients are more or less satisfied with their community. As said, most leaders receive remittances that make a difference in terms of autonomy.

Table 7-7: Communal participation and perceived opportunities in Agua Fría

\begin{tabular}{|l|ccccc|}
\hline Do you participate & \multicolumn{4}{|c|}{ Do you feel that your community expands your opportunities? } \\
in organisations? & No & Rarely & Sometimes & Usually & Total \\
\hline No & 4 & 9 & 2 & 3 & 18 \\
& $(22 \%)$ & $(50 \%)$ & $(11 \%)$ & $(17 \%)$ & $(100 \%)$ \\
Yes & 0 & 10 & 13 & 2 & 25 \\
& $(0 \%)$ & $(40 \%)$ & $(52 \%)$ & $(8 \%)$ & $(100 \%)$ \\
\hline Total & 4 & 19 & 15 & 5 & 43 \\
& $(9 \%)$ & $(44 \%)$ & $(35 \%)$ & $(12 \%)$ & $(100 \%)$ \\
\hline
\end{tabular}

Source: Dataset 2.

\subsection{Assessing project impacts on autonomy}

This section analyses how the project affected the autonomy of non-leaders. Table 7-8 makes explicit the full logic of the project. It includes some hypotheses or expected impacts, their assumptions and outputs, and an evaluation about their fulfilment. The analysis does not lead to one impact on autonomy but to several influences on the determining factors of autonomy: entitlements, agency, and micro-level structural contexts.

\subsubsection{The entitlement to safe drinking water was not fully secured to everyone}

The main output of the project was the access to safe drinking water. However, the poorest could have been excluded because they did not have money to construct a RWDS. Moreover, water service is unreliable and not permanent, even during 'normal' conditions.

The solution to these problems is not under the control of residents. They feel unable to help themselves. Some people talked with water operators about possible causes and solutions, others got their domiciliary water pipes inspected, but they cannot do more. They depend on ANDA's operational performance. An assumption of the logframe: 'ANDA trains the water operators and takes care of the network maintenance' (LD, 2001a, Annex B), held weakly due to the management crisis experienced by this institution (section 7.2.1). 


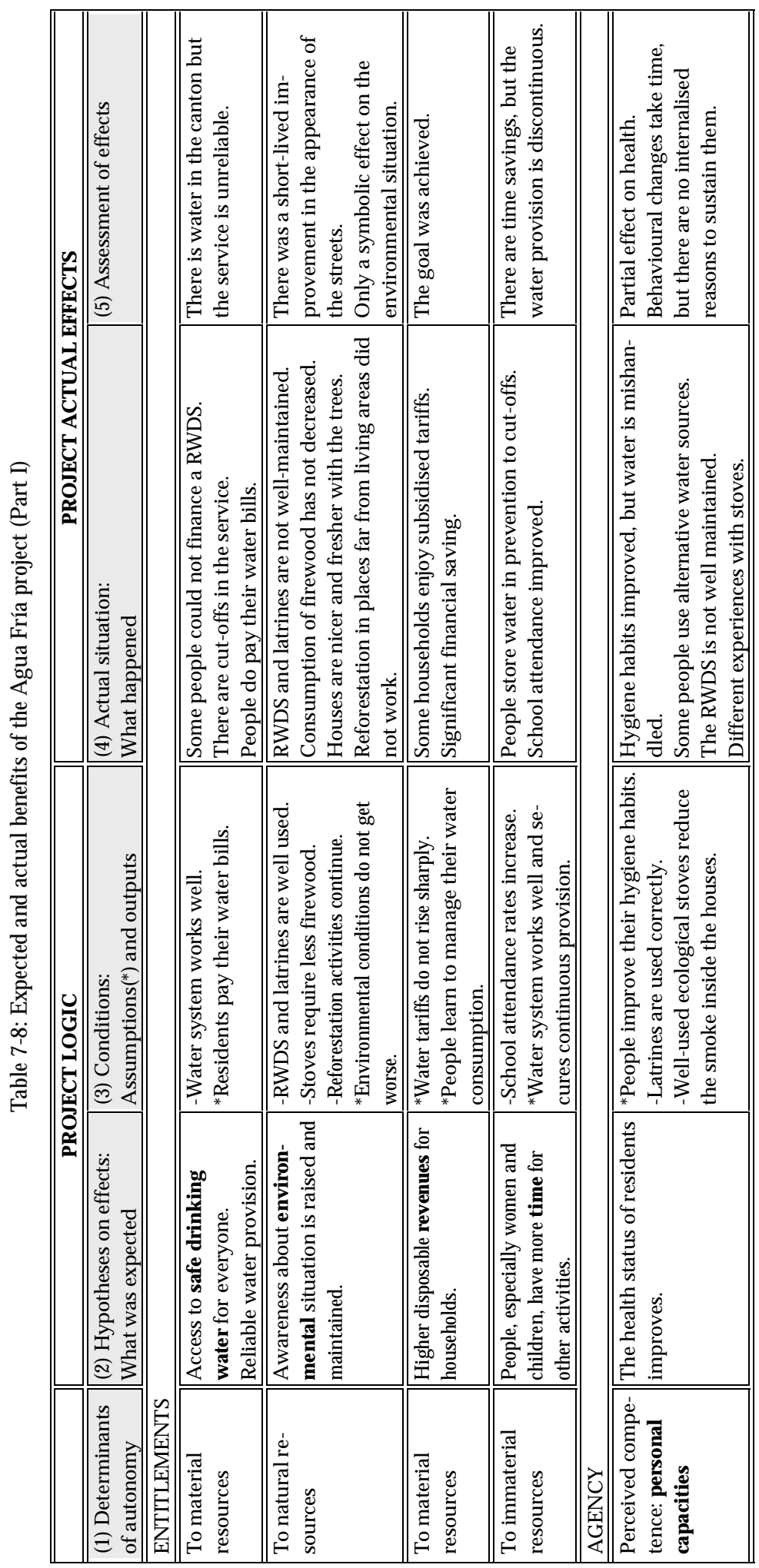




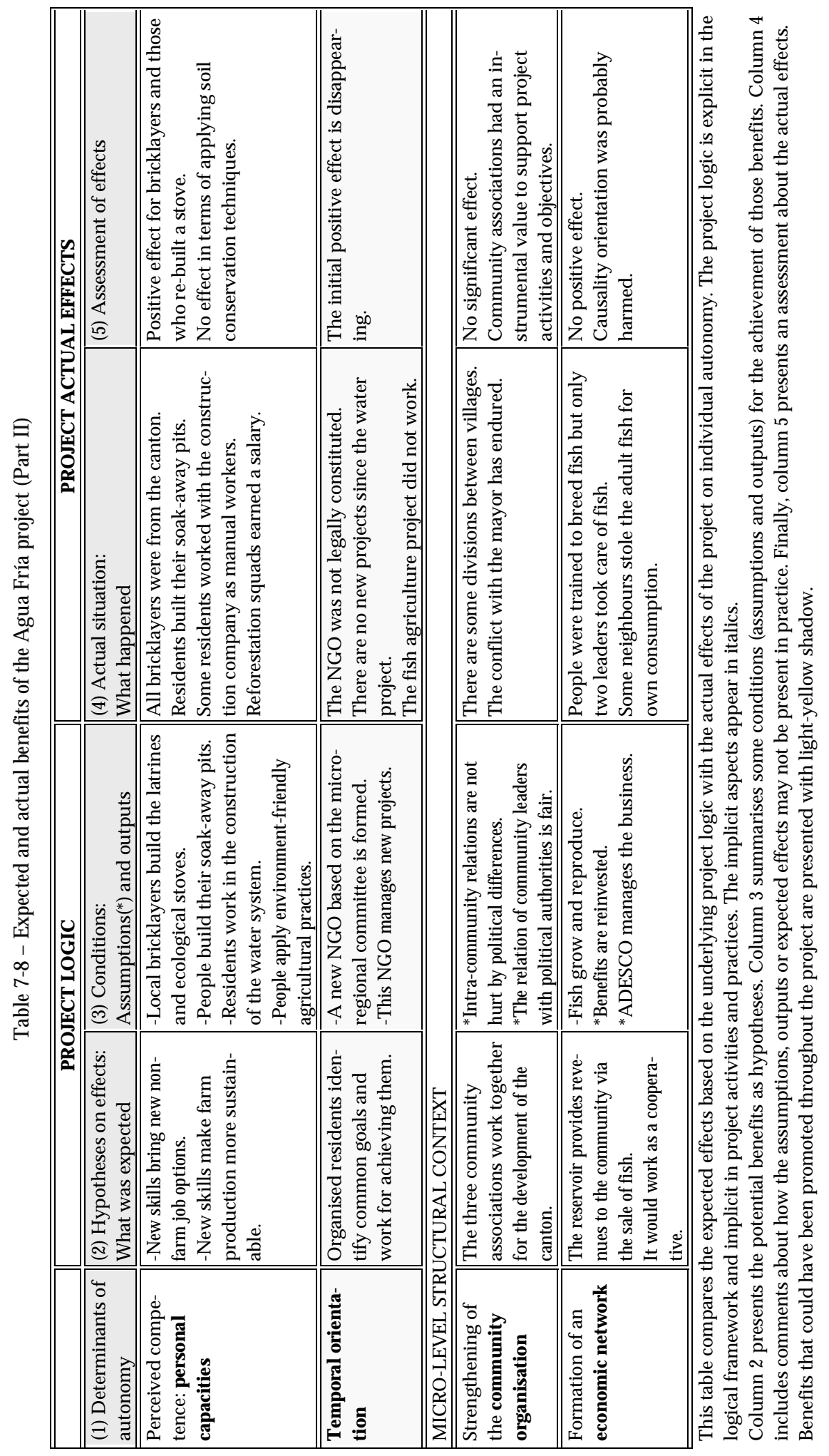


Some residents wish they were taught how to fix the pipes in the re-pumping station because: 'Let's imagine that these people (ANDA)... get bored of fixing [the pipes]; the community does not have anyone, no technicians [to fix them]' (HIM). Others think that the community, instead of ANDA or the municipal government, should manage the water system, as they expected:

The people from Luxembourg who were teaching us [during the project] said that ANDA was going to keep [the water system] for one or two years. Later, they were going to train people so the system would pass to the community associations; the community itself would manage it (HIM).

However, leaders would not accept this task as they already have had problems to maintain the old gravity water system, which they cannot purify with chlorine due to the lack of money because people do not pay their bills.

Another project goal was to improve the sanitation and environmental conditions, but conditionality did not result in sustained effects (section 7.3.2). People do not use the sanitation systems properly and there are puddles of grey water again in the street. Likewise, soil conservation techniques and reforestation activities do not continue as the motivation was extrinsic, even the cleaning campaigns are not very frequent.

Stoves and latrines were relatively well used at first. According to LD (2003a, p. 28), the saving in firewood consumption with the ecological stoves could be between $8 \%$ and $50 \%$ compared to traditional wood stoves; however, some people said that there was no saving because they were not using the stoves as indicated. A man tells: 'I brought firewood for three months, but it was used up in one month. At home, we do not use that stove because it consumes too much [firewood]' (LIM).

A highly valued effect was having fruit trees at home. People enjoy the beauty and freshness that trees bring to their homes; they can also eat the fruits. A man leader said, 'I would like to have a photo of my house before the project to show you how much different it is now. It looked like a desert before'. Similar joy could have brought the reservoir as a place of recreation, but the fish agriculture project failed (section 7.3.4).

The project had intended economic impacts. In the short-term, available household revenues increased as some people worked as bricklayers or members of the work squads. Besides, some women sold food to manual construction workers (HIW). In the long-term, they consume more water at much lower and known prices. The average household consumption tripled, from 28 litres to 113 litres per person per day, but the new average monthly water expenditure fell to a tenth of the old one (LD, 2003a, Annex D). A saving of USD25 per month represents around one-fifth of the monthly wage of farm workers. An unintended effect, underlined by leaders, is that the market value of houses has increased as the villages look more urban, with all public services available, and prettier with the plants.

A large impact was on time availability, specifically for women and children who used to collect the water, as a woman says:

In the community there is always something: there is a meeting in the church, there is a sick person, there is a deceased person ... But I had to say: 'I cannot leave now because I have to collect water for my house, I need it'. Now that there is water, we are available! (LIW) 
Women feel that they have more options. First, they are more informed of events because they are 'more available'. Second, they can exercise autonomy because: 'I have the opportunity to decide what to do with the time because I have the water here [at home]' (LIM). Regarding children's time, CODECA (2003b) recorded that due to the project 'school attendance improved by $14 \%$ ' (n.p.).

\subsubsection{The positive effect on agency was lower than expected}

The project was expected to promote physical capacities, through an improved health status, and intellectual capacities linked to works of bricklaying, soil conservation, and agriculture.

There was a direct positive effect on health; however, some habits are difficult to change, especially when messages are too many or confused. The message regarding hygiene and health was not clearly transmitted to the population and maybe not well understood by local promoters (LD, 2003a, II 77). In addition, although residents felt relatively well informed during the project, about one-quarter of the survey respondents declared that the information was not easy to understand. Especially illiterate people expressed this problem (Cramér's V, $V=0.347 ; p=0.012$ ).

Poor cleaning habits, together with infiltration problems of the soak-away pits, suggest that the positive effects on reducing parasitic and mosquito-transmitted diseases could be shortlived. Besides, too many activities were carried out, many of them regarded as requirements, extrinsic to get the water access. Hence, the project had a limited effect on environmental awareness or health outcomes in the long run. A man leader says: 'CODECA trained us; it is a pity we are lazy'. One woman complains: 'Not everyone uses the pit how it should be used... they turn a deaf ear' (HIW).

Figure 7-8: Number of reported cases of acute diarrhoeal disease (ADD) in Agua Fría

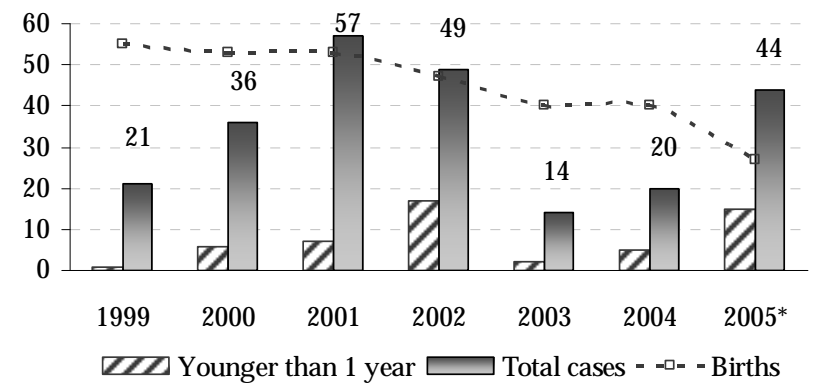

* Data for year 2005 until August 27.

Source: MSPAS (2005) and Agua Fría health post (2005).

After a sharp reduction in the number of cases of acute diarrhoeal disease (ADD) with the introduction of water, this number grew to reach pre-project levels in 2005 (see Figure 7-8). The cause for such increase is not the population growth because the number of new births has decreased, while the incidence of ADD among infants has increased. Returning emigrants could partly explain this phenomenon (not captured yet in Table 7-1, with figures until 2003). However, according to the health promoter, residents of other cantons are using the services of the health post. 
Some people do not drink the potable water because they complain of the chlorine, so they use an alternative source. The physician assistant of the health post suspected that the chlorine levels were not adequately checked in the pumping plant, which saw as a possible cause for the increase of gastroenteritis cases. Some people drink water from 'La Mate', while others leave the water 'to rest' in a container some days.

In addition, according to the project logic, the community organisation would monitor the hygiene and sanitation practices of households, but this is not happening as leaders themselves seem confused about the use of sanitation systems (section 7.3.3). There is only one health rural promoter for the whole canton who advises on the maintenance of the tubs, but she is busy with vaccination campaigns, check-ups for pregnant women, and so forth.

Regarding skills, nine local bricklayers were trained to build latrines and ecological stoves. In turn, the residents of Agua Fría learned to build the stoves; they could build a new one later or make repairs, which some did. Each household built its RWDS, based on the training and supervision visits of the promotion team.

None of the FGD participants reported having applied his knowledge on soil conservation or that on sustainable agriculture practices, after the project. However, they did say that because of the organic fertiliser, their trees could grow in the stony soil. Environmental awareness was promoted among school students through symbolic activities.

There is a positive effect on self-confidence, related to both the arrival of water and the process how the project was implemented (see section 7.5.4).

Effects on temporal orientation were not intended by the project. These effects could be related to the output itself (water) or to the process (project implementation). Regarding the output, FGD participants expressed that water brought them a 'new life' and the hope that many things can change, which is the initial point to project different scenarios, to plan ahead, and aspire for a better life. A woman points out: 'Now, I have much more to learn' (LIW). Regarding the process, the role of the micro-regional committee was valued by residents, but the failure to formalise the NGO brought a feeling of powerlessness. Non-leaders are gradually losing faith in leaders as promoters of change (section 7.4.3). Remittances are regarded as the only means to secure a better future. Hence, a visible projective element of agency is not only related to the arrival of water, but also to emigration.

The project was not intended to influence causality orientation. Water was the main goal and people took part in project activities to comply with requirements (soak-away pits) or to receive a reward (soil conservation works). In addition, there is no evidence that non-leaders had shared on decision-making. Similarly, they use to delegate decisions to leaders within the community associations.

\subsubsection{Social and political micro-level contex ts do not always go together}

Community organisations were considered pillars to assure the sustainability of the project effects (section 7.3.1). Project staff could have supported them in several ways: offering some skill training courses, helping leaders to legally formalise a stronger entity, or working in partnership so that leaders could share in decision-making. The decision was to carry out the two first actions. Leaders were taught about organisation and management issues. However, it seems that the NGO was seen as an alternative to 'the refusal of the mayor of San 
Alejo to support the organisational development of the [associations]' (CODECA 2003f, p. 11). The relation was confrontational (section 7.2.2), while project staff was unable to catalyse joint energies and help to consensus building. Although leaders elected the board of directors and agreed on the articles of association, the NGO was not formalised.

Another expected effect was the formation of an economic network based on fish agriculture. Despite the investment of own resources, the specialised advice from research institutes, and field visits to other localities with similar experiences, this small project failed (section 7.3.4). This project was the first one to be managed by the nascent NGO. Leaders expected a gross profit of about USD4,800 (a 60\% return rate) that would sustain the operative costs (CODECA, 2003f). If the business had succeeded, causality orientation could have become more autonomous because it was a project carried out by the community with intrinsic motivation; they had their hopes pinned on it and made the efforts.

The previous two expected benefits were not realised, but there were other effects on social capital, migration, and relations with other communities.

The effect on social capital was immediate. The scarcity of water sources and unequal access to drinking water, before the project, had fuelled conflict among residents (section 7.1). As a man explains: 'I wanted to leave because I did not want to fight for a little amount of water' (LIM). The water project changed this situation, 'it came to liberate' (LIM). However, due to the problems in water provision (section 7.3.4), 'not everyone receives the same quantity of water' (LIM). On the other hand, mutual trust was favoured as result of the participation of residents in mutual help teams.

FGD participants explained that migration outflows reduced and even that some people immigrated because of the availability of water, electricity, and telephone. Likewise, emigrants living abroad are constructing new houses to come back home in the future.

People saw an improvement in their relations with other communities and they also value having had the chance to know people from other regions and countries that they could not have imagined to meet before. A man reports:

Earlier, the cantons did not help each other; now they are brought close together [because] all worked together to achieve the water [access]. We are better off because we look after the community. Many people arrive here because of the community [spirit] (LIM).

\subsubsection{Differentiating impacts on autonomy among individuals}

This section discusses some different impacts on individuals grouped according to their leadership condition, gender, and level of involvement in the project. It is worth noticing that the two low-involvement groups were formed by residents of Agua Fría, while highinvolvement women were from Piedra Gorda and high-involvement men from Trinchera..$^{53}$ It is important to keep this in mind because the living situations in each village are different.

\footnotetext{
${ }^{53}$ The leader from Piedra Gorda did not want that his neighbours go to Agua Fría, due to security concerns. Then, I had to plan one high-involvement group there. Actually, all project activities started in Piedra Gorda; the Duke of Luxembourg and their companions arrived there for the closure of the project.
} 


\section{- Impacts on leaders: Their best effort is not enough to promote well-being}

The impact of the project, in terms of agency, was stronger on leaders than on non-leaders. They worked harder and had more responsibilities during the project, although they were not considered equal partners in the eyes of project staff. Leaders worked with project staff because they saw this was their best option to get the yearned access to water service. This decision, however, meant the closure of other possible options provided by the mayor. They learned about organising and tried to form an NGO that, however, could not work.

Highly motivated to get water access, they were mobilised to carry out several project activities. At some point, they could have felt that activities and events were coming from outside, but it is more likely that they wanted to take advantage of everything. A local promoter, daughter of one leader, says: 'the project was so good that it was scary [to think that] they would not benefit from it'. Hence, they proposed the fish agriculture project in the reservoir. Their case could be considered of 'active learning' (Ellerman, 2001) because they had autonomy causality orientation. The investment decision was based on reflection about their own situation, needs and expectations. They learned from their peers in other cantons and taught what they had learned to others based on their experience.

In fact, leaders worked a great deal, but they did not develop linkages with formal institutions or donors who could support their future projects. On the contrary, the impasse with the mayor has been a burden that deteriorates their capacity to improve the well-being of their neighbours. They only rely on themselves to promote new activities as they lack political resources.

At first, they felt themselves as 'owners' of the project because they had looked for several solutions for the water problem for years. A man leader says: 'People do not know. They think that [the project] was sent by heaven [but] it has a start. We eagerly looked for it.' In contrast, by the end of the project, some results were out of their control: the water service is unreliable and they cannot solve the problem. Moreover, the business in the reservoir failed.

However, their neighbours bestow them certain success: $91 \%$ of the survey respondents considered that the community was better organised as a result of the project and $88 \%$ reported that the leaders responded more effectively to the needs of the community. As other villagers, they had direct benefits in terms of material resources. These factors could fuel their intrinsic motivation: 'the commitment... with the community is higher' (a woman leader).

Nevertheless, the micro-level context is adverse. The difference between agency and autonomy is clearer than ever in this case. A subjective feeling of empowerment will disappear, sooner or later, as the actual contexts continuously obstruct their development efforts.

\section{- Impacts by gender: Different values attached to project outputs and processes matter}

Participants in every FGD reported positive changes in the four dimensions related to the exercise of autonomy: information, self-confidence, opportunities, and decision making. Looking at the average values of self-reported scores, with the restrictions that this kind of analysis has - led by the higher proportion of women $(63 \%)$ in a small sample -, it is worth noticing two aspects: (i) the highest absolute change was for women, with respect to opportunities, and (ii) women reported a higher positive change in each dimension, except in selfconfidence. 
First, women felt that their opportunities expanded a great deal, even more than for men because women used to carry the water for cooking and washing. After the project, they can more easily do their home chores, have trees and breed their patio animals. The more time available the more chances to decide what to do (section 7.5.1). This finding links to the higher control that women feel to make decisions in personal and family domains. Men also saw their opportunities expanded, but they focused on agriculture production. They can decide what to plant because they have water:

If one thinks to plant pumpkins, frijoles or butter beans, one can do it because it is easy to water, even in summer. Before, it was very difficult to think of planting anything; nothing would survive (HIM).

Second, there are several factors that had influence on self-confidence, related to the process (practices during the project) and the output itself (having water). Related to the process, it seems that men perceived that their role was more valuable as they worked in several activities (construction, reforestation or soil conservation) and became aware of their abilities, learned skills or applied them (see Table 7-9). Furthermore, after the project, their participation in social life has not reduced as much as for women, who traditionally stay at home. The positive effect prevails. There is a moderate association between gender and awareness (Cramér's V, $V=0.329 ; p=0.035$ ). About $69 \%$ of those who reported having applied their skills were men, and $64 \%$ of men reported having given their opinions during the project. Nonetheless, opinions are not necessarily heard or have influence on others, as the issue of the soak-away pits illustrates.

Table 7-9: The awareness of personal skills by gender in Agua Fría

\begin{tabular}{|l|c|c|c|}
\hline \multirow{3}{*}{ Gender } & \multicolumn{3}{|c|}{ Did you use your practical skills during the project? } \\
\hline Women & No & Yes & Total \\
Men & 8 & 9 & 17 \\
& $(67 \%)$ & $(31 \%)$ & $(41 \%)$ \\
Total & 4 & 20 & 24 \\
& $(33 \%)$ & $(69 \%)$ & $(59 \%)$ \\
& 12 & 29 & 41 \\
& $(100 \%)$ & $(100 \%)$ & $(100 \%)$ \\
\hline
\end{tabular}

Source: Dataset 2.

FGD participants talked about their day-to-day relation with project staff, but there were discrepancies, especially between comments in groups and those in individual interviews. However, men perceived more positively this relation. A man said:

Meetings filled us with happiness... we have met many people.... There has not been another project like this one. The person who led the project was very dynamic, made us to feel big, to develop, and gave us strength, support... (HIM).

Especially illiterate people expressed that they did not have a chance to give opinions; some felt discriminated against for being poor.

Related to the output (having water), both women and men identified positive effects on self-confidence. They can wash their clothes and take a bath inside their homes, while earlier they had to take shifts to do these in the river. A man leader says: 'When one is taking a shower, it seems like a dream; earlier we had to beg for a pot of water'. Their hygiene has improved. They 'feel better' and 'look better' so that their self-image has improved. Men 
emphasised this relation between hygiene, personal appearance and self-confidence, while women stressed the relation between hygiene and health.

Women elaborated on the reasons for a positive change in self-confidence. It was related to trust in other people and trust in the project, because it was realised. Another aspect was crucial, especially to high-involvement women: learning as a result of the project. Women of Piedra Gorda felt particularly proud and happy because they learned and shared their experiences with other communities (e.g., regarding the use of the ecological stoves), because 'the project started [t]here' (HIW). Moreover, they felt that they shared in decision-making: 'In meetings, we decided together' (HIW).

\section{- The involvement in the project: Different effects on individual 'autonomies'}

When referring to changes brought about by the project, participants in high-involvement groups focused on personal effects, while those in low-involvement groups also focused on group effects.

High-involvement groups were formed by residents of the two smaller villages. Their situation before the project had been more difficult and insecure as some Agua Fría residents had untreated water from two gravity systems, but they did not. A man explains: 'Before, many women had to leave [home] to carry the water, when it was still dark, because we [men] had to go to work. Then, children stayed alone... it was dangerous for everyone' (HIM). Their larger necessity and smaller population size (with respect to Agua Fría) led them to work harder and be more involved.

Participants in low-involvement groups are Agua Fría residents. They talked of effects on organisation, in contrast to other participants who did not. Indeed, ADESCO in Agua Fría was the most active community association during the project, and the reservoir is located in Agua Fría. These groups also listed positive effects on values. A man explains: "There is peace among us... and we can expect help from others... there is more unity now' (LIM).

The level of involvement in the project was expected to be associated to positive changes in four dimensions conceptually linked to the exercise of autonomy. Table 7-10 suggests that this would be the case only for men. High-involvement men reported larger expansions in every dimension than low-involvement men. For women, the relation is less strong with information and not existing with self-confidence.

Table 7-10: The intensity of change in variables associated to autonomy by FGD in Agua Fría

\begin{tabular}{|l|cc|cc|}
\hline \multicolumn{1}{|c|}{ Involvement: } & High & Low & High & Low \\
\hline Information & + & $+1-$ & ++ & \\
Self-confidence & & & ++ & \\
Opportunities & ++ & ++ & 10 \\
Decision making & ++ & 19 & 6 & \\
\hline$N$ & 8 & + & + \\
\hline
\end{tabular}

Note: + means that the effect is larger in this group in the comparison with the other same gender group, ++ means that the effect is much larger and $+/$ - means that the effect is a little larger.

Source: Focus group discussions (scoring exercise).

Regarding information about community, value endogeneity could play a role, that is, women could attach a higher value to this information after the project than earlier. Besides, the motivations behind communal participation, which could lead people to search valuable 
information, are diverse. These motivations could not necessarily have explained involvement in the water project. However, it seems that some high-involvement women would tend to have a high score for valuable information after the project through an equally high social participation. For instance, a woman, who saw herself as not so involved in the project (because she could have done more), teaches to read and write and work in church activities, 'which allows [her] to talk with other people, to look after the community' (HIW).

Regarding self-confidence, some reasons for change were explored earlier. It seems that the effect of having water, the output, is stronger than the process, for women than for men. Hence, involvement (process) is not such a relevant factor. Besides, as Figure 7.9 shows, women, in both low and high-involvement groups, reported scores for pre-project selfconfidence much dispersed. High-involvement women reported post-project scores more dispersed than low-involvement women. The former are spread out on a 6-10 point range, while the latter are concentrated in an 8-10 point range. The distribution of self-reported scores in both cases displaced toward higher scores. These findings suggest that selfconfidence is affected by several factors, not necessarily and not only, by the level of involvement in the project.

Figure 7-9: Distribution of self-confidence scores reported by women in Agua Fría
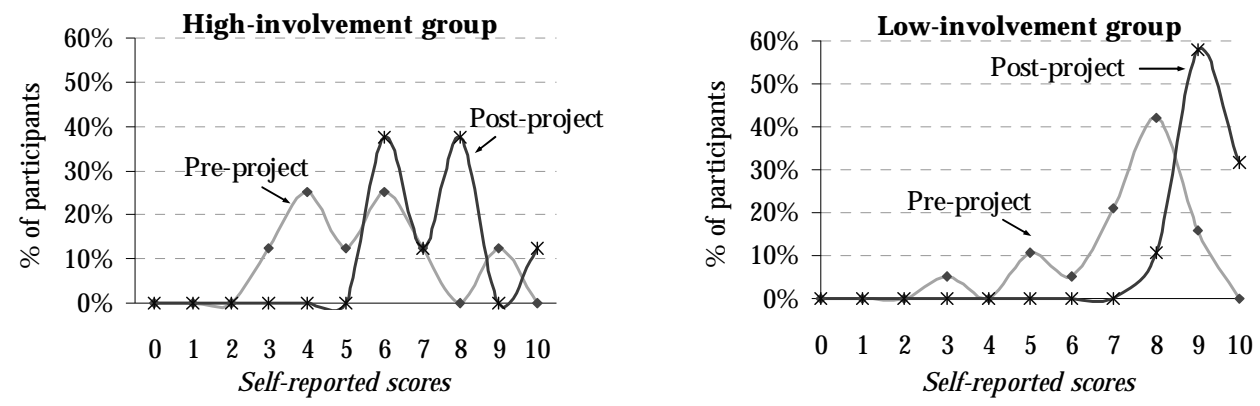

Source: Focus group discussions (scoring exercise).

Above all, involvement in the project seems to positively influence individual autonomy because high-involvement people reported to have higher opportunities and to exercise more decision-making than low-involvement people. Nevertheless, the meaning of which decisions are relevant and what qualifies as opportunities depends on each individual. Looking at the kind of effects that each group emphasised, it seems that residents of the smaller villages considered that they were more able to decide on individual matters, while those in Agua Fría, with a strong ADESCO, considered that they were more able to decide on group matters. Not surprisingly, expansions of autonomy in Agua Fría are more difficult than in Piedra Gorda or Trinchera, as 'autonomy' has different meanings.

\subsection{Conclusions}

This chapter has presented a case study in water and sanitation in a canton at the East of El Salvador. The project's overall goal was to contribute to the improvement of the health and the living conditions of the residents of Agua Fría. It provided access to safe drinking water and autonomous sanitation systems and promoted environmental awareness through several reforestation and soil conservation activities. This project was not heaven-sent; residents 
had looked for ways to get water. Two gravity water systems were in function, under the management of two neighbourhood committees, but water was untreated.

This case was challenged by two important issues. First, at the country level, the reorganisation and the management crisis of the official counterpart, the public water company (section 7.2.1). It harmed the quality of the water design and, later, the operation of the system. People experienced sudden water cut-offs even before the formal completion of the project. Second, at the local level, the impasse with the mayor occurred since the project formulation (section 7.2.2). The project came to break a status quo, in which the mayor was the most powerful actor and had expectations to manage a water system in the locality.

In the face of this institutional context, the project was externally designed and included many activities, which required local support. Community leaders had ownership of the project, at first, and collaborated with project staff in everything as they longed for getting water. This collaboration did not evolve to partnership, however (section 7.5.3). When leaders exerted relevant influence, the fish agriculture project, they were not successful.

The core problem was a weak understanding of the local governance by the part of formulators and project staff. Facing a difficult country context and, probably, trying to avoid local political influence, project staff seemed to pursue a change in the power relations at the local level. By opting for the donor, instead of the local political authority, leaders secured the realisation of the water project, but seriously limited their options for the future. This is a world not seen by project designers. During the execution, project staff did not aim at building consensus but focused on producing the operational outputs, with a 'tunnel vision'.

Agua Fría residents see many valuable aspects in life that include resources and agency capacities; however, remittances are the resource that makes a difference when it comes to communal participation. Values are also crucial for intra-community relations. People value organisation, but it is not considered enough to expand their opportunities (section 7.4.2) because there are structural factors such as physical insecurity and politics that affect their development. However, having social networks (either taking part of associations or having relatives abroad) brings some optimism about the future of the community.

The project had positive effects on individual autonomy. As expected, there were financial savings and time savings; residents look better and feel better because their hygiene has improved, they acquired new skills and social capital was strengthened. However, the water service is not very reliable (section 7.3.4), the poorest were implicitly excluded from the project (section 7.3.1), many sanitation systems collapsed (section 7.3.2), and the positive health effects were lower than expected (section 7.5.2). Being so busy working in multiple activities and receiving sometimes confused information, people did not internalise the importance of some hygiene and maintenance practices.

The recurrent problems with the water system, the lack of political resources and the insecurity in the canton (a leading cause for the failure of the fish agriculture project) affect the causality orientation of leaders and might diminish their authority in front of the community. The project had the potential to do much more, as the specific project context was autonomy supportive, especially in the smaller villages. However, it seems that the (actual) role of community as promoter of individual autonomy (section 7.4.3) was not valued by project formulators and managers. Hence, the local political support that the community 
associations needed for their long-term sustainability was not searched for. In 2005, Agua Fría was facing an impasse hard to solve. 


\section{W omen building up community in San Fernando: A water pro- ject that fuelled hope}

Before the project, we were not organised. Now, if there is a project, the committees look for us, we are aware of more things (LIW). ${ }^{54}$

The water project covered five sites in two departments. In my first meeting with the chief and the technical assistant for this project, they suggested that I should study the San Fernando case because the community organisation had been strengthened, the locality was relatively small (with less than 500 households), and its inhabitants were the most accessible of all other sites. My first visit to San Fernando was auspicious; the technical assistant introduced me to a community leader who had worked on the project throughout its lifespan. The former social promoter enthusiastically told me about her experience and gave me some advice.

Some months later, when I came back for my fieldwork, I realised how many different meanings the word 'accessible' can have. Indeed, the inhabitants of San Fernando had worked a great deal, but they were also tired and fed up of meetings. I soon learned that they did not like to go out, to participate in meetings or to waste time because they were busy with their lives. Of course, they were always gentle and showed gratitude for the project, but I understood the message: 'We participated [in the project] because we needed [water]'. The meeting with leaders had to be rescheduled twice because they were busy and the general assembly never happened because people would not listen to the leaders' convocation. Finally, I had to rely on a door-by-door recruitment strategy contacting neighbourhood leaders for help. I also learned how many different meanings the concept 'organisation' could have in a semi-urban context.

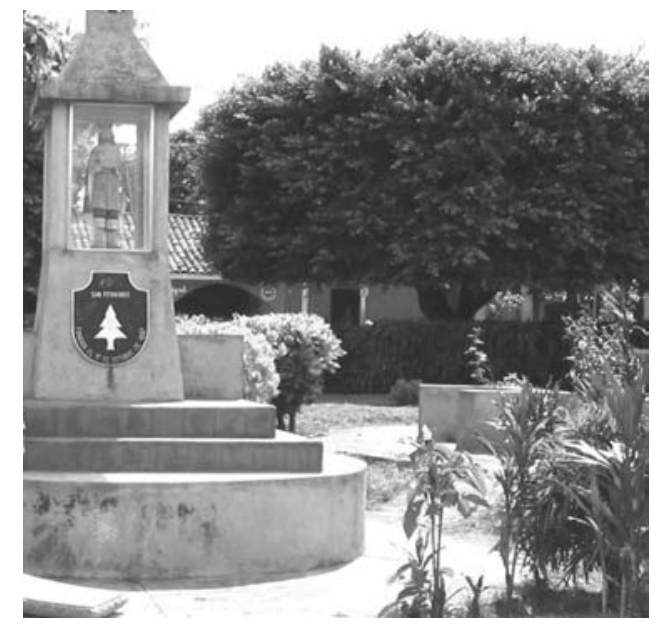

Photo 8-1: Detail of the central park of San Fernando, the patron saint (July 2005)

\footnotetext{
${ }^{54}$ When citing expressions said by a person during a focus group discussion (FGD), I use the following codes: HIW for high-involvement woman, LIW for low-involvement woman, HIM for high-involvement man, and LIM for low-involvement man.
} 
This chapter presents the experience of the inhabitants of the urban centre of San Fernando, Nicaragua, within the water supply and sanitation project that took place between 2003 and 2005. This project was a response to the lack of a good quality drinking water service in the city as a consequence of severe damage to the water infrastructure during Hurricane Mitch, in 1998. Hence, it foremost was a project of rehabilitation, although it also included the construction of minor infrastructure.

The objectives of this chapter are to investigate: (i) the meanings of autonomy for San Fernando residents starting from the dimensions of life they consider important, and how they experience it; (ii) the perceived role of community in supporting or restricting opportunities; and (iii) the project impacts on the determinants of autonomy: entitlements, agency and structural contexts, based on the project activities and practices.

This case has three special features:

1. The public water company (ENACAL), not a communal management committee, would be in charge of water facilities;

2. The inhabitants had not participated (as an organised community) in the search for alternatives to regain access to safe drinking water; and

3. Given the lack of a communal counterpart, the project promoted the formation of local committees that collaborated in many project activities.

In sum, community involvement in the water service was low. Inhabitants regarded themselves as water consumers and were highly unsatisfied with the public water company. This dissatisfaction became a partial motivation to participate in the project because individuals mistakenly perceived that the project 'came from' someone else: the donor.

The chapter is organised as follows. Section 8.1 describes the situation of San Fernando residents before the project. Section 8.2 presents the project, organisation and context. Section 8.3 analyses the project practices. Section 8.4 explores the meanings of autonomy and the intra-community relations. Section 8.5 discusses the project impacts. Section 8.6 presents some preliminary conclusions.

\subsection{San Fernando before the project}

San Fernando is one of the fourteen municipalities of the department of Nueva Segovia, in the central north region of Nicaragua. The water project covered the main urban centre of the municipality, which is where the administrative and political offices area located.

San Fernando is a poor municipality with low human development indicators

In 2001, San Fernando was a municipality with high poverty: ${ }^{55} 68.7 \%$ of its inhabitants lived in poverty (more than the $45.8 \%$ at national level), including $30.3 \%$ in extreme poverty. San Fernando was classified with low-medium human development, in a four-category classification of low, low-medium, low-high and high human development (UNDP, 2002). San Fernando residents had relatively higher access to water than other Nicaraguans, but their health and education indicators were worse (Table 8-1).

\footnotetext{
55 The poverty map (GON, 2001a) classifies municipalities in four groups of severe, high, medium and minor poverty, considering the incidence and depth of poverty.
} 
Table 8-1: Selected indicators of the San Fernando municipality (2000/2001)

\begin{tabular}{|lcc|lcc|}
\hline & SF & Country & & SF & Country \\
\hline Population (inhabitants) & 7,413 & & & & \\
Territorial extension $\left(\mathrm{Km}^{2}\right)$ & 236 & & Density (inhabitants $\left./ \mathrm{Km}^{2}\right)$ & 31.4 & 43.3 \\
\hline Life expectancy at birth (years) & 66.9 & 69.5 & Drinking water coverage $(\%)$ & 75.6 & 70.5 \\
Literacy rate (10 yrs. + ) & $71.0 \%$ & $79.5 \%$ & Combined school enrolment rate & 48.6 & 56.7 \\
\hline
\end{tabular}

${ }^{*}$ Gross enrolment rate of pre-primary, primary and secondary level education Source: UNDP (2002).

Most people work in agriculture, with different living standards

We live by what we sow. I am a farmer... We have some critical months when our economy is affected (LIM).

In 2001 , about $77 \%$ of the total population worked in agriculture, either as land owners $(20 \%$ of total workers), permanent workers $(16 \%)$ or temporal workers $(64 \%)$. In the $2000-2001$ agricultural year, according to INEC (2002a), there were 339 farms owned by single producers. About $64 \%$ of the farms were smaller than $20 \mathrm{mz}$, and $31 \%$ had between 5 and $20 \mathrm{mz}$.

The main products were basic grains (frijol, maize and sorghum) and coffee. Small producers plant more basic grains than coffee, in contrast to large producers. In 2000/2001, 36 out of 39 farms of at least $1 \mathrm{mz}$ cultivated basic grains and only 4 produced coffee. About $60 \%$ of inhabitants planted frijol and maize (informed by the mayor). In 2000-2001, 56\% of the owners had their legal property title. Those with larger extensions of land were more likely to have legal stability in contrast to small owners (INEC, 2002b).

Large pine reserve is at risk in San Fernando

The main pine areas of Nicaragua are located in Nueva Segovia. The biggest forest fires take place in dry season, due to uncontrolled agricultural burnings (Lorío, 2006, II 11).

Almost two-thirds of total land in San Fernando consists of natural and cultivated grasses and forests. Five licensed sawmills exploited the forest, but informal exploitation had been exaggerated and forests depleted by weevil plague and fires. In 2000, half of pines dried out due to the peeling weevil plague (reported by the mayor). However, the population was not fully aware of the environmental situation, the consequences of their agricultural practices, and their implications for future water provision.

The urban centre had access to basic social services

The availability of basic social services was similar to the existing after the project. The town has a health centre, a primary school, a secondary school, a library, a community house, a central park, and a baseball stadium. There is a Catholic church in the centre. There is one public telephone next to the municipality hall and some people have mobile phones.

San Fernando is well-connected to other towns via a paved highway (Ocotal-Quilalí) that crosses the urban centre and connects it to all towns of the Nueva Segovia department and to other regions. There are public buses that pass every fifteen minutes in their way to Jalapa, in other municipality, and Ocotal, the departmental capital (Figure 8-1). 
Figure 8-1: Map of San Fernando in the department of Nueva Segovia

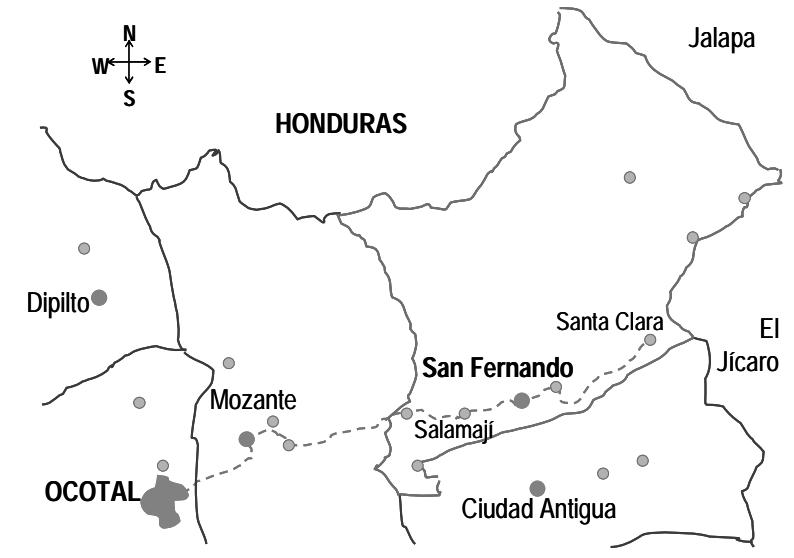

Heterogeneity in living conditions within the urban centre

The population of the urban centre represented about $28 \%$ of the municipality's total population. In 2005, there were 2,047 inhabitants, living in 459 houses (Table 8-2).

Table 8-2: Neighbourhoods in San Fernando's municipality centre (2005)

\begin{tabular}{|lcc|lcc|}
\hline Neighbourhood & Num. Houses & $\%$ total & Neighbourhood & Num. Houses & $\%$ total \\
\hline 1. El Arrayán & 36 & 8 & 5. Central & 122 & 27 \\
2. Mgr. Julio C. López & 26 & 6 & 6. La Milagrosa & 66 & 14 \\
3. Col. San Martín & 48 & 10 & 7. El Estadio & 46 & 10 \\
4. Sandino & 63 & 14 & 8. Las Flores & 52 & 11 \\
\hline
\end{tabular}

*Two neighbourhoods were recently merged to form the 'Central'.

Source: Local social promoter and community leaders.

The neighbourhoods had material differences. The first two (Table 8-2) were located somewhat far from the city centre. El Arrayán and Col. San Martín had a rural character; some people had small farms. Mgr. Julio C. López was inhabited mostly by single mothers and children who benefited from a housing project to former contras and their families. Sandino was the poorest section, followed by El Estadio. Central hosted the wealthier families.

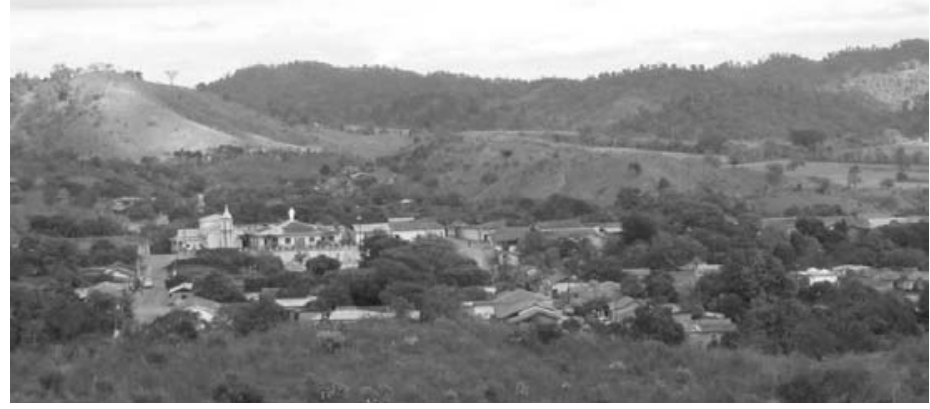

Photo 8-2: Panoramic view of San Fernando's urban centre (February 2005) 


\section{San Fernando had not benefited from many projects}

Some people say that San Fernando does not need projects because there is money here. They say so because Salamají is at the entrance; the houses are pretty there because their residents have more [resources]. But, there is a lot of poverty in the neighbourhoods. Maybe this is why not many projects have come to San Fernando (Liliana).

Salamají is a western village (Figure 8-1) where richer families live. Some have their own coffee processing plants (beneficios). However, inequality is high in San Fernando; many residents work for these rich landowners, seasonally. According to the social promoter, residents did not benefit from social projects earlier because San Fernando was not considered a municipality of severe poverty to which social assistance could target.

The water system in San Fernando became unusable after Hurricane Mitch

The water was dirty, contaminated and undrinkable (a woman leader).

Hurricane Mitch caused heavy rainfalls and floods in San Fernando, resulting in severe damage to the water infrastructure that was left unusable. After several weeks of interruption, the water service was of low quality, no longer suitable for human consumption.

In 1999, the social investment fund (FISE) financed a radial collector well (LD, 2002a) with pumping equipment, but it failed to secure continuous and safe drinking water. The water flow was insufficient; the water was turbid, containing high iron levels. Consequently, the public water company (ENACAL) did not charge for the service. The well operator had to pump water as much as twenty hours a day just to provide water for half the town; residents had water on alternate days and not for long hours.

Water was so visibly impure that people used to collect water from rivers, from gulches located in neighbouring fincas, or from the mountains (those with cars). Only a few could afford bottled purified water for specific uses. In general, carrying water on foot was a daily activity since the hurricane hit. In winter time, rainwater was also used, which caused skin diseases especially in children. One woman leader explains: 'My daughter had very ugly spots in the back.... Sometimes we collected rainwater because it was cleaner - we said and it turned out to be the most harmful for the skin'.

Only $56 \%$ of the households had sanitation facilities (LD, 2005a). Although some post-Mitch projects had provided latrines, many needed to be replaced. Besides, there was no municipal garbage collection and disposal system. People threw the garbage away in the rivers or left it beside their homes. Without a sewage system, there were puddles of grey waters in the streets, threatening the health of the residents.

\subsection{The water project in San Fernando}

The overall goal of the project was to 'to contribute to the improvement of the health and living conditions of the inhabitants' (LD, 2002a, p. 4), through the improvement of the quality of the water service and the conditions of sanitation and environment. The project covered five sites in two departments, but this study only analyses the case of San Fernando.

Regarding the water service, the project included the following components: 
- Rehabilitation of the water infrastructure: infiltration galleries affected during Hurricane Mitch;

- Construction of a treatment station to purify the water, whose turbidity increases in rainy season; and

- Reorganisation of the distribution system, from the source-network-tank sequence to the source-tank-network sequence, in order to improve the efficiency of the water use by identifying leakages in tanks.

To improve the water quality and to guarantee a continuous water provision, the project included activities to support the operational capacity of ENACAL. These activities were classified into technical and commercial diagnosis, technical adaptations, commercial adaptations, and direct technical assistance. The first three were carried out by an external consultant, and the latter by the PIU.

Regarding sanitation, the project financed the construction of individual on-site sanitation systems, that is, minor infrastructures to allow households to dispose of excretes and grey waters by using the soil as treatment medium. The project financed latrines and a residual water disposal system (RWDS) per household. Depending on the soil characteristics, the RWDS could include a soak-away, infiltration trenches or a reedbed.

Regarding environment, the project promoted some reforestation activities with the participation of adult inhabitants and school students in areas closer to the San Fernando river. It also supported the formation of a micro-enterprise by six women who would collect the solid wastes and take them to a controlled tipping outside the urban centre. The project financed part of the costs of the controlled tipping; the land belonged to the municipal government.

The project through its social promoters started work teams of neighbours who actively participated in the activities. In this way, the project wanted to strengthen communal organisation and to promote behavioural change in relation to the efficient use of water, preventive health, sanitation practices, and environment awareness.

\subsubsection{Organisation of the project and main stakeholders}

The project was managed by a project implementation unit (PIU) formed by a project chief, a technical assistant and an administrative assistant. They were based in Ocotal, $22 \mathrm{~km}$ from San Fernando, and had the administrative support of the LD regional office. The formal counterpart and co-executor was ENACAL. Several areas of this company were involved since the time the project was first proposed, during the design of the aqueduct, bids for contractors and consultants, and so on.

Figure 8-2 shows the main actors intervening in the project execution. For the water component of the project, the private construction company was supervised by a consulting company. Once its contract expired, ENACAL and the PIU took over its role. The provider of the equipment for the treatment station gave some basic training to the operators. During the construction of the water system, there was a follow-up committee composed of representatives of the PIU, ENACAL, the supervision and construction companies; they had joint visits every two weeks (Acuña, 2004a). However, it seems that the follow-up committee did not participate in the monitoring of other components of the project (LD, 2005a, p. 8). 
Figure 8-2: The organisational structure of the San Fernando project

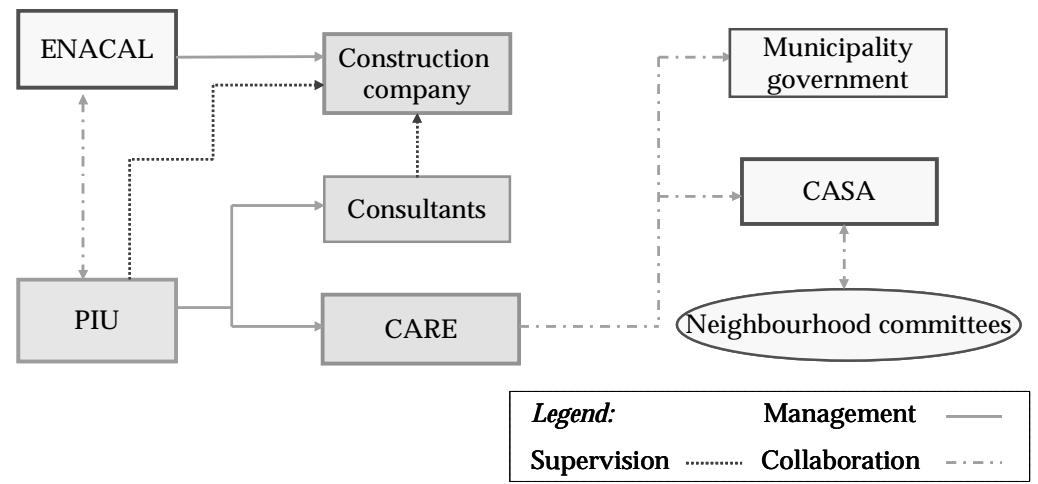

Given the coverage and complexity of the entire project, many actors took part in the project, such as consultants, providers of equipment and materials, and employees of the water company from different units. In San Fernando, the technical assistant supervised the activities and had contact with some leader residents; while the project chief focused more on the formal relation with ENACAL.

For sanitation, environment and communal organisation, CARE was the responsible. The CARE team, in Ocotal, was formed by a project manager, a technical supervisor, a solid-waste supervisor and a community organiser. On the ground, there were two social promoters, one local promoter, one store keeper, and up to three bricklayers. By October 2004, there was only one social promoter who stayed in San Fernando until January 2005, when she was replaced by an itinerant social promoter until the project completion. There were several changes in staff. Three persons had the position of project managers during the project lifespan; one social promoter was replaced in September 2003, almost at the start of the project. Figure 8-2 shows ENACAL at a distance from CARE because there was little coordination between them (see section 8.3.3).

The municipality government had relation with the CARE team for specific activities, such as cleaning campaigns. They coordinated the operation of the controlled tipping and the constitution of the garbage collection micro-enterprise. In contrast, the new communal organisation, CASA, had a more important role. It represented residents and worked together with neighbourhood committees (see section 8.3.1).

Other institutions took part in the project, such as the Ministry of Health, in cleaning campaigns and workshops, and the Ministry of Education, through the participation of public schools in environmental activities. Table 8-3 lists the main stakeholders.

Table 8-3: Main stakeholders of the San Fernando project

\begin{tabular}{|llll|}
\hline Formal authorities & Intervening actors & Project staff & Community members \\
\hline MFA Luxembourg & LD & PIU: project chief, techni- CASA, committees \\
MFA Nicaragua & Construction company & cal assistant & Inhabitants of urban \\
ENACAL & Consultants (several) & CARE project manager(s) & centre \\
Municipality government & Providers of equipments & CARE other staff & Inhabitants of cantons \\
& & Social promoters & \\
\hline
\end{tabular}




\subsubsection{Micro-level context of the project and main activities}

The process of formulation took more than two years, from August 2000 to October 2002 (see project fact sheet in Appendix 2-B). In between, there was a new national government and many details had to be arranged with ENACAL (concerning the water sources). The project was formally presented to San Fernando residents at the end of April 2003, more than two years after the workshops of the pre-feasibility study were carried out (see Figure 8-3). After so long, people did not believe that the project would be a reality. Liliana, the vice-coordinator of CASA, explains:

Most people told us: 'You are silly; projects always stay in words'. The emotion was big when, in the middle of a coordination meeting, the social promoters were telling us: 'the project is coming' and then, a truck full of cement arrived... People were excited.

This means that the project started in the middle of doubts: 'There were rebellious people. They said: what it is for? They only come to bother' (HIW). However, given the necessity for water, residents slowly started to attend the meetings. Mistrust toward leaders in committees arose over time and, in some cases, leaders were replaced through new elections. These problems were reflection of an adverse social environment:

Because the community is small, everyone realises what happens. In my neighbourhood, we replaced three committees... There were gossips from others... They said that the first committee was fraudulent... The truth is that [inter-personal] relations were not so good (HIW).

The work of the social promoters was hard and constant. One woman in particular initiated such parallel activities as birthday parties with leaders and their spouses in order to produce a good environment. ${ }^{56} \mathrm{~A}$ woman leader explains:

She had a whole-day work. She taught us well because she was very active and she motivated us. She made us 'to dance in one nail' [to work quickly and dynamically]. She woke us up.

The relation between the social promoter and the leaders was so friendly that the latter prepared a surprise party for her at the end of the project.

In May 2003, a census was carried out to define the number of RWDS and latrines to build and the residents' payment capacity, but the initial incredulity of residents produced misleading data that had to be corrected. A socio-economic survey was administered later (see section 8.3.4).

Women participated more than men since the start. Because the initial training sessions lasted the whole day, men could not attend. Moreover, the last workshops were between October and December 2004, when 'men were cutting coffee' (a woman leader).

The project offered more than 40 workshops about leadership and organisation (to committee members), health and environment, latrines, soak-away pits, micro-basins, management of solid wastes, and 'multipliers of solid wastes'. However, only a few FGD participants recalled these workshops. A woman leader expressed that not many people attended; others added that 'these workshops were not offered in all neighbourhoods'.

\footnotetext{
${ }^{56}$ From here onward I will refer to one social promoter, to whom people referred during the fieldwork.
} 


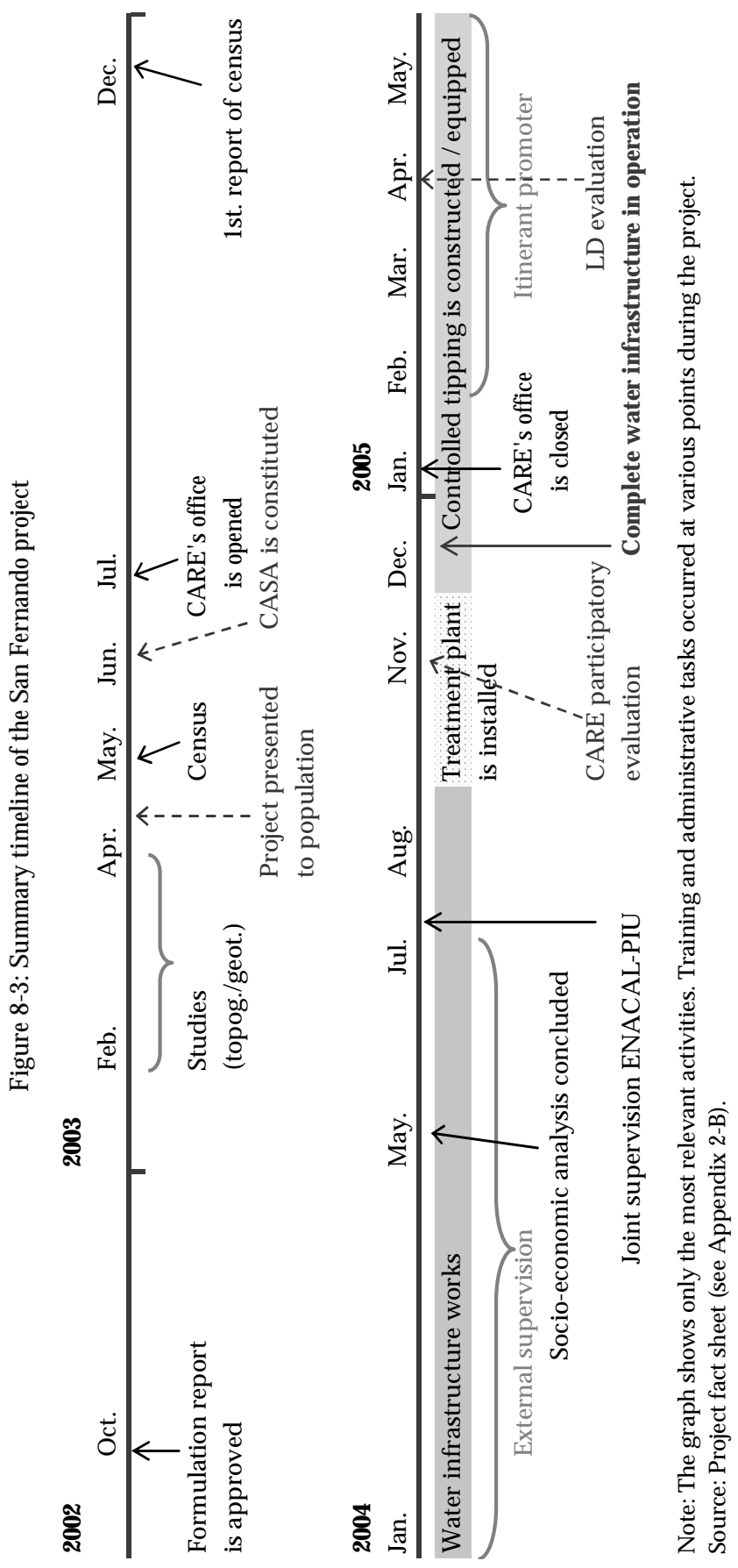


In November 2004, municipal elections took place; they marked a crucial political change because the local government changed hands: the FSLN candidate with $50 \%$ of valid votes replaced a PLC mayor. The political campaign was intense, ${ }^{57}$ affecting the participation during the project because people were politically polarised.

Water was provided since August 2004, but residents were warned that the treatment station was not yet finished. In December 2004, they finally had access to safe drinking water. Residents received the water bills only in March 2005. Hence, during three months, they were not aware of their consumption expenditure which they would have to control later.

The project was evaluated three times. The first was a participatory evaluation carried out by CARE with members of CASA and the support committees (in November 2004). The second and the third were formal evaluations that correspond to the medium-term evaluation and the final evaluation of the entire project and were carried out by external consultants in April 2005 and September 2006, respectively. Regarding the second evaluation, people had just received their water bills and were not satisfied; leaders hoped to solve this problem in their meeting with the Luxembourg representatives (see section 8.3.4).

\subsection{Project practices}

This section discusses some of the practices during the project lifespan. The analysis covers activities related to the promotion of sanitation, environment awareness, and communal organisation. Table 8-4 summarises the aspects to be analysed.

Table 8-4: Main practices during the San Fernando project

\begin{tabular}{|c|c|c|}
\hline Project phase & Practices & Aspect \\
\hline $\begin{array}{l}\text { 1. Identification and formu- } \\
\text { lation }\end{array}$ & $\begin{array}{l}\text { Selection and design } \\
\text { decisions }\end{array}$ & $\begin{array}{l}\text { - The selection of the local counterpart } \\
\text { - The definition of targets for sanitation systems }\end{array}$ \\
\hline 2. Implementation & $\begin{array}{l}\text { Conditionality } \\
\text { Coordination } \\
\text { Accountability }\end{array}$ & $\begin{array}{l}\text { - The formation of committees } \\
\text { - The common work in project activities } \\
\text { - The involvement of ENACAL } \\
\text { - The allocation of latrines } \\
\text { - The quality of residual water disposal systems }\end{array}$ \\
\hline 3. Evaluation and audit & Accountability & $\begin{array}{l}\text { - Water quality } \\
\text { - Water tariff setting and actual payments }\end{array}$ \\
\hline
\end{tabular}

This study does not cover technical issues regarding the water system. The investment decision was made a priori without long-term financial analysis because the project was conceived as an emergency project. However, during the project, the PIU and ENACAL prepared an analysis of financial equilibrium of the aqueduct.

\subsubsection{Formulators defined a local collaborator to assure project goals}

The selection of the local counterpart for the sanitation and environment activities was made at the start of the project. The targets for sanitation systems made at the formulation stage had to be adjusted during the execution.

\footnotetext{
${ }^{57}$ A signal of this would be that the number of votes in San Fernando doubled in the 2004 elections with respect to the 2000 elections (deduced from figures in Grigsby, 2004).
} 


\section{- $\quad$ The selection of the local counterpart}

CARE will set up and promote actively a CASA (water, health and environment committee). CASA will have the responsibility of organising the community so that people's participation is assured (LD, 2002a, II 369).

The project targeted inhabitants of the urban centre where political authorities were well constituted. However, the project did not involve the municipal government in the project activities. LD (2002a) does not refer to the municipality government as partner of the project. However, as a sub-output of the project, CASA leaders and municipal authorities were expected to write a municipal development plan (LD, 2002a, II 372).

It was preferred to promote grassroots organisation to motivate people to work in project activities. CASA was formed in general assembly at the start of the project. Next, support committees were formed in each neighbourhood. Then, CASA members 'started to do the training sessions with the help of [these] committees' (a woman leader in FGD).

CASA and the support committees were composed by a coordinator, vice-coordinator, a secretary, a treasurer, a health responsible, and a forest responsible. Two features of this organisation are worth mentioning: the gender composition and the electoral practice. First, in 2004 , six of ten CASA members and $73 \%$ of members of the support committees were women. In fact, social promoters especially targeted women due to their expected role in teaching hygiene and sanitation practices within the household (LD, 2002a). Women's presence in committees increased over the project lifespan because some male members had to work in seasonal agriculture activities (cutting coffee) and others emigrated in search of jobs abroad.

Second, new CASA members were elected by the neighbourhood committees, not in assembly as the first time. In several cases, these committees were left with fewer members than required as people were not so willing to take a leadership position. During the fieldwork, in the FGD with leaders, ten of fourteen participants were women; this composition reflects the proportion of women to men leaders who were active in communal activities.

\section{- The definition of targets for sanitation infrastructure}

At first, there were problems with the latrines because we were not well coordinated. The social promoter did not know the neighbourhood needs.... Later, when we started working with our committee representatives, we went house to house preparing the lists (LIW).

In principle, all households were targeted for water provision; however, not all got latrines or individual sanitation systems. In the case of latrines, the target was $100 \%$ of the households and there was certain flexibility to provide latrines or toilets with septic tank. However, this target was not achieved due to (i) the old-dated figures in the formulation report, which did not consider a possible immigration fuelled by the new water project, and (ii) the lack of interest of the residents to give accurate information during the formulation and the census.

The census took place in May 2003, but corrections were made given certain 'incongruence' in the responses (CARE, 2003c). For instance, an interviewer could fill out the forms without entering the houses so that an old latrine would be recorded as in good condition when it needed to be fixed. This happened because interviewers were strangers to people and residents did not know the purpose of the census (reported by a woman leader). The census had 
questions about willingness to pay for the water and garbage collection services so that residents felt that these strangers were going to take their money and decided not to collaborate. This attitude changed during the project and the real needs became more evident when neighbourhood committees started functions; however, the project had a set budget that limited the coverage (see section 8.3.3).

LD (2002a) planned to provide residual water disposal systems for only $80 \%$ of the households, probably, foreseeing problems of space in the houses or soil quality. The target was adjusted following the awareness of actual needs and aiming to cover all households. Finally, the project provided 436 soak-away pits, 5 infiltration trenches, and 5 reedbeds - instead of the 332 originally budgeted sanitation systems (LD, 2002a; 2005e).

\subsubsection{Women had to work and changed their habits}

FGD participants did not explicitly talk of conditionality that could hurt them. However, the fact that they had to organise themselves in groups and work together to receive a tangible benefit, the water access, was the main issue.

\section{- The formation of committees}

The objective of the project was to organise us to get the project that they were offering and that we remained [organised] for other projects (a woman leader in FGD).

We all, who were going to be benefited by the project, committed to everything, the cleaning, the reforestation... (a woman leader in FGD).

Leaders felt they had to form the committees in order to keep the project. They have had previous experiences of unrealised projects and they wanted to change this situation. The social promoter explained that other bilateral donors had tried to 'generate' participation and, finally, carried out a project in only one neighbourhood of San Fernando. A group of leaders vividly expressed: 'The project was not gone because we stuck together'. Hence, they felt 'happy, but very sweaty because [they] had to count, to have a list of all the materials...' (a woman leader).

For this hard work, leaders wished they had received an acknowledgment from the donor, such as a party or a formal closure ceremony. This might signal that leaders did not necessarily saw their participation as an enjoyable situation by itself, they needed a reward.

\section{- $\quad$ The common work in project activities}

When people are asked to do something, they want to be paid.... [Reforestation] brigades were voluntary; they planted but, after [the project] everything was lost (the local ENACAL officer).

Residents built their own sanitation systems. They had to collect the materials, built their soak-away pit (or alternative system) and assemble their latrine, under the guidance of bricklayers, who basically showed them how to start the works and, later, acted as supervisors. The main requirement to get the materials was to attend the training sessions. As seen earlier, the training was intensive and, basically, targeted to women. Although, they did not express to feel obliged to attend, they did say that they 'did not like to go out of the house a lot' (HIW). 'They did their work grumbling and grumbling' (the social promoter) but, finally, they changed their habits and learned to meet others in order to be benefited by the 
project. Leaders received the training first and later, they 'had to give talks of what [they] had learned' (a man leader).

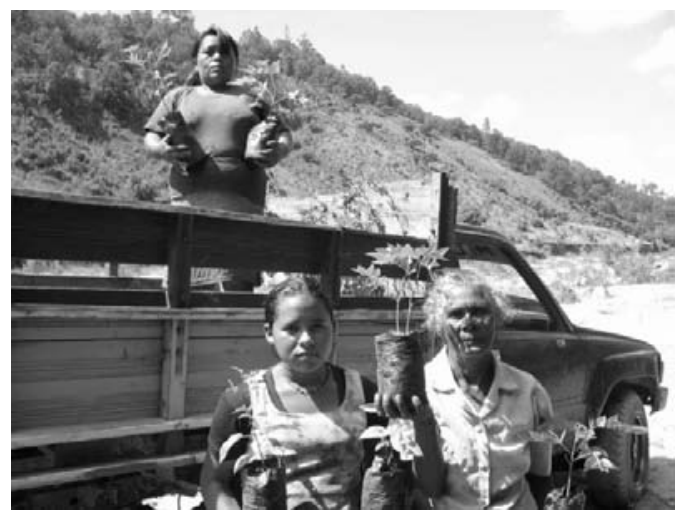

Photo 8-3: Women taking part in reforestation activities (August 2003)

Source: CARE (2003b).

The water access was not explicitly conditioned to the participation in reforestation and environment activities. Moreover, people did not get any remuneration for this. On the contrary, the social promoter tried to motivate people with celebrations. For many, the happiest moment was 'the carnival of garbage', in October 2004. Two neighbourhoods prepared a coach with people disguised as wastes (of garbage) and other neighbourhoods joined them. The coaches and people marched across the town; there was music and a competition to find the 'king of the garbage'. A man recalls: 'the carnival [was] a terrific party; that night [we had] a drink and later [everything was] calm'. Another adds: 'after the parade, the party [started and then] everyone went to dance!'

\subsubsection{Poor coordination harmed the entitlement to water and sanitation}

Two aspects are especially relevant: the institutional coordination between the project staff and the formal counterpart (the water company) and the internal coordination between social promoters, committees and beneficiaries.

\section{- The involvement of ENACAL in the promotion activities}

'Donating' means 'giving'. Then, why do they charge us for the water? (HIW)

People say that this is a project from a donor and it is not fair that ENACAL comes and cuts off the water service. That is, only ENACAL is benefiting from this water project (a woman leader in FGD).

Apparently, CARE failed to communicate to residents that ENACAL had first proposed the project and it was not only a wish of the donor; that ENACAL was participating in several actions; and that it would manage the water system after the project completion. In consequence, "ENACAL appear[ed] as "the bad guy in the movie" at the time of charging the bills' (LD, 2005a, p. 20).

It seems that, at a later stage, the PIU tried to include ENACAL staff in the workshops about water consumption and payments. However, the workshops did not reach everyone or the 
message was not well explained (LD, 2005a). ${ }^{8}$ Hence, when people complained about their water bills (see section 8.3.4), they were explained again how the water metre works (reported by the local ENACAL officer). A man concludes as a lesson for future projects: 'Projects should be well-explained, especially the issue of tariffs and payments' (LIM).

\section{- The allocation of latrines}

In the end, everything was done [as planned], but the organisation failed to see who had more necessity .... People who were closer [to leaders] had more benefits (LIW).

Table 8-5 shows how the target of latrines changed over the project lifetime. CARE (2004c) reports that the target in column (B) was defined in assembly considering the available budget resulting from the inaccurate estimates (section 8.3.1); however, FGD participants did not mention this meeting. During the FGD, leaders openly disagreed about the criteria (if any) for the allocation of the latrines, but they acknowledged the fact that the project staff showed certain flexibility and offered more than what was originally planned.

Table 8-5: Planned and actual number of latrines allocated in San Fernando

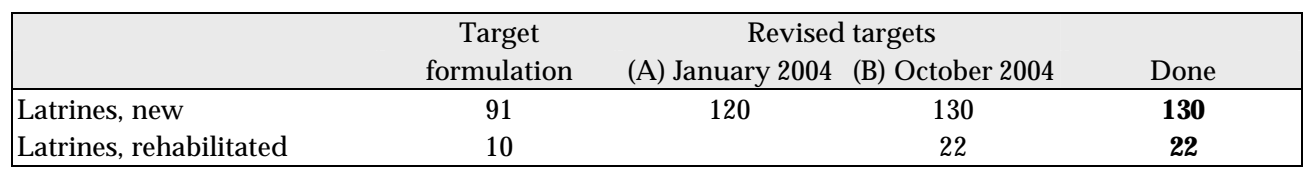

Source: LD (2002a) and CARE (2004b; 2004c; 2005e).

Regarding flexibility, some households received limited materials to build new latrines or to fix their old latrines. Hence, instead of 91 new latrines, there were 100 standard latrines (according to the project model) and 30 new latrines with adapted materials. The number of rehabilitated latrines was also higher than planned (Table 8-5). Moreover, some households received materials for bathrooms and lavatories that were connected to their individual sanitation systems.

Regarding the allocation criteria, the social promoter and some CASA leaders expressed that latrines were given to the people most in need who were inhabitants of Sandino, because 'they did not have latrine; they used to dig a hole and excrete there' (the social promoter). However, leaders in the FGD did not agree; some refuted that there were very poor people within other neighbourhoods as well. Besides, some non-leaders complained that not all who attended the workshops on latrines received them and that the 'fastest' people received latrines. Hence, around $45 \%$ of the survey respondents reported that these workshops were not useful or little useful, in contrast to the other workshops that were highly valued.

These comments may reflect the allocation criteria was not communicated but, given that leaders themselves did not agree on the allocation made, it seems that it was the social promoter who made the last choice, with a small group of leaders. This was contestable because, despite the existing income inequality in the locality, the value of the latrines was high in relation to the payment capacity of most residents. The project provided ventilated improved pit (VIP) latrines, which in contrast to the simplest pit latrines (that most people earlier had) have a ventilating pipe that reduces the odour and the agglomeration of mos-

\footnotetext{
58 There is incongruence among three data sources: Acuña (2004d) registers a new workshop in the fourth quarter of 2004; CARE (2003c) reported this kind of workshops earlier, with the support of ENACAL; and CARE (2005b) does not include this kind of workshop in the overall list of workshops.
} 
quitoes and flies. The materials were of high quality so that the total cost of each latrine was about EUR125, much higher than the cost of a pit latrine of about EUR40 (LD, 2006, p. 25).

\subsubsection{Accountability is about processes and outcomes}

People felt thankful for the regained access to safe drinking water; however, many had trouble to pay their bills and some households did not get functional sanitation systems.

- The quality of the residual water disposal systems

In a neighbourhood, the soak-away pits did not work because the soil does not absorb [the water] (LIW).

Some FGD participants, especially those living in Las Flores, explained that soak-away pits did not infiltrate or were not useful. The itinerant social promoter found that sixteen soakaway pits were not working due to the soil quality (CARE, 2005c). CARE (2005f) reported that four had been closed. However, the assessment of supervision during the project was good and almost $90 \%$ of the survey respondents considered that the training on soak-away pits was fair or very good. It seems that people based their assessment on the overall outputs of the projects and that training was good because they learned how to build their systems. Recurrent complaints about the sanitation systems during the fieldwork could be related to the fact that people were very angry about the water bills. Moreover, there was a plague of mosquitoes in 2005 and people blamed the soak-away pits for this.

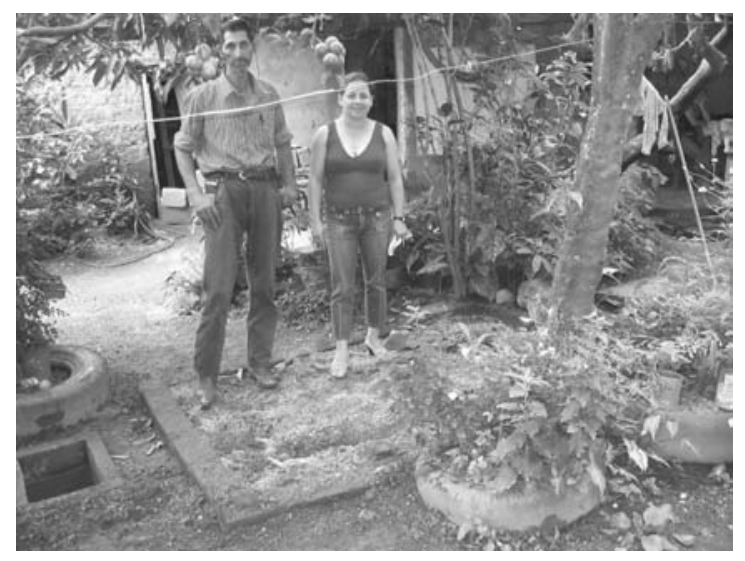

Photo 8-4: Leaders showing a sanitation system (reedbed) in a backyard (July 2005)

\section{- Water quality}

Now, it is good water; earlier, it was dirty. Now, when we fill a glass up, the water is crystal clear (LIW).

People were happy with the water quality because they knew how bad it was before; they were informed in workshops with purity test results and statements from doctors. Around $70 \%$ and $30 \%$ of the survey respondents said that water quality was good or very good, respectively. Awareness about the water quality is so high that a group of secondary school students prepared a monograph about the project (that got the maximum score) in which they explained the process of collection, purification, and distribution of drinking water in 
San Fernando (Herrera Hernández et al., 2004). They defended the arguments for a treatment station.

However, a woman leader warned about the fact that the pipelines were not changed: 'They used the same pipeline that we have had since the beginning, [which are] 35 years old at least. The water was resulting with tartar, because of the old pipeline'.

\section{- Water tariff setting and actual payments}

The truth is that we were so used to not be charged anything [for water] that we spent very much and wasted [water]. Then, when the bills arrived, we got a fright (HIW).

The month that I saved water, I paid the most (LIM).

Given the poor living standards in San Fernando, the PIU prepared a proposal to ENACAL to set subsidised tariffs for some households (see Box 8-1), but only about half of the households categorised as poor were subsidised. In addition, households connected for the first time to the water system (around 30\% of total), paid a reduced connection charge of C $\$ 50$ (a little more than EUR2) or just $11 \%$ of the actual commercial cost.

\section{Box 8-1: Water subsidies in San Fernando}

Based on the socio-economic census, households were classified in three categories (non-poor, nonextreme poor, and extreme poor) according to their self-reported monthly income and the physical condition of their houses. Suspecting that respondents under-reported their revenues, these data were cross-checked with results from a survey to $20 \%$ of the households, which collected detailed expenditure information. Finally, some expenditure was imputed to the census results by applying some criteria, tested in the survey sample, linking the self-reported income levels and the physical condition of the houses. The table below shows the partial results at three different times.

Distribution of households by income level in San Fernando

\begin{tabular}{|llccc|}
\hline & & Extreme poor & Non-extreme poor & Non-poor \\
\hline 1. Census results & Self-reported revenues & $45 \%$ & $24 \%$ & $31 \%$ \\
2. Survey results & Consumption expenditures & $14 \%$ & $42 \%$ & $44 \%$ \\
3. Final results & Adjusted revenues & $5 \%$ & $38 \%$ & $57 \%$ \\
\hline
\end{tabular}

The final results indicated that $5 \%$ of the households lived in extreme poverty and $38 \%$ lived in nonextreme poverty. The number of households to be subsidised was calculated considering the criterion of financial sustainability of the aqueduct, that is, that the expected payment collections would cover the operation and maintenance costs. About $20 \%$ of the households were subsidised. They were categorised as: (i) extreme poor and (ii) poor households with a house in very bad, bad or regular conditions and with a (self-reported) monthly income lower than $\mathrm{C} \$ 520$ (around half the national extreme poverty line). For this group, the water cost would be at minimum $6.7 \%$ of the reported household income, assuming a consumption of $15.75 \mathrm{mt}^{3}$.

Source: Guglielmi (2004), LD (2004a) and personal communication with the technical assistant (March, 2006).

People were informed about the price of each cubic metre of water and provided a rough estimation of their monthly payments based on a 'normal' household consumption. This information was important because (i) people had not been paying for water since Hurricane Mitch (section 8.1), and (ii) it was the first time they would have a 24-hour service, so that they would need to administer their consumption. However, some people were confused; for instance, a man expressed: 'they said that [they] would pay only C\$50 per month' (LIM), but that was the connection charge for the new users. 
When residents received the water bills the surprise and lack of conformity was widespread. The consumption levels recorded were very high and the monthly bills were beyond the payment capacity of many. The local officer of ENACAL explains: 'The first two months, I had a terrible explosion of overdue bills'. Actual waste of water, mistakes in consumption registration, and leakages in domiciliary pipes could explain this. The fact that the water micro-metres were not tested when given to households (reported by the LD project coordinator and several residents) raised suspicions: 'From my point of view, the water metres do not work well. I have tested them.... When I close the tap, the water metre still runs' (LIW).

FGD participants in all groups (including leaders) and around 30\% of the survey respondents complained about the high water bills. Some participants said that they could not afford the payments any longer and that they did not have water; a woman leader said that the water service had been cut off to 22 households. Others reported that they turned to collect water again from rivers of gulches for non-cooking uses in order to control their expenses.

In July 2005, the residents were upset and wanted to find a solution with the intervention of the mayor. A woman leader reflects: 'projects should not go to the hands of ENACAL, but to the municipality government because the mayor would set a [fixed] tariff and we would agree to work all together'. They considered that the water company was making profits at their expense, which is a sign of the discrediting of ENACAL. Leaders recalled that during the evaluation mission, they wanted to talk calmly about this issue with the representatives of Luxembourg, but it was not possible because people were so furious that they wanted to enter the meeting place so that the meeting had to be concluded. Some months later, the residents supported by the donor reached an agreement with the water company that included the physical inspection of domiciliary pipes so that water bills were reduced and debts restructured (as reported by the project technical assistant).

\subsection{U nderstanding individual autonomy in San Fernando}

This section discusses aspects of life considered important to the residents of San Fernando, their experiences of autonomy, and the role of community. The analysis is based on the fieldwork of July-August 2005, that is, when the project had been completed and the residents were paying their water bills.

\subsubsection{Low monetary revenues influence but do not define priority needs}

If we do not pay the water, it is not because we do not want but because there is no money. In summer, it is different because he [the husband] works and receives a weekly payment; we are more punctual in our payments, then. But, right now, we cannot (LIW).

FGD participants did not directly refer to autonomy. However, they discussed how the high water bills restricted the achievement of valuable goals because they have only seasonal paid jobs and paying the water bills significantly reduces their available cash. 
Already, CARE (2004a) reports that the average household income was C $\$ 1,105$ or USD70, almost the same as the extreme poverty line. ${ }^{59}$ In 2005, more than three-quarters of the survey respondents reported a monthly household expenditure below this threshold.

Emigration is not so extended yet. About one-tenth of the survey respondents reported to have travelled abroad; the same proportion declared to receive remittances. Hence, primarily relying on farm work, residents face harsh times during certain months of the year.

Important material needs are poorly satisfied

Table 8-6 shows that people valued having resources and also emotional, physical and intellectual capacities. From these, feeling inner peace was the most important; this result could be related to the strong Catholic beliefs of most people.

Table 8-6: Ranking of valuable life achievements in San Fernando

\begin{tabular}{|clc|clc|}
\hline Ranking(1) $^{(1)}$ & Aspect & \% necessary & \multicolumn{3}{|c|}{ Ranking } \\
\hline 1 & Feeling inner peace & 81.1 & 6 & Having drinking water & \% necessary \\
2 & Having a job & 83.8 & 7 & Having a family & 83.8 \\
3 & Being well-fed & 81.1 & 8 & Having a land to cultivate & 84.9 \\
4 & Being healthy & 78.4 & 9 & Having electricity & 70.3 \\
5 & Having a house & 78.4 & 10 & Being literate & 70.3 \\
\hline
\end{tabular}

(1) Ordering was obtained by using a modified Borda count (see Box 4-5 in Chapter 4).

(2) The percentage represents how many respondents regard this concept as necessary to everyone's well-being. Source: Dataset $2(n=37)$.

Most survey respondents (84\%) considered that having a job was necessary although only $52 \%$ reported having a permanent job. As seen earlier, agriculture is the main economic activity. More than $80 \%$ of the household heads reported being farmers and considered that having a land to cultivate was necessary. However, only $33 \%$ said that they owned land so that most people either rented a land or worked for others. In 2004, more than half of residents had home-yard animals and one-tenth had livestock (CARE, 2004a).

Being healthy was also valuable but, among those who considered this necessary, only $62 \%$ reported having good health; this response was not related to age. In fact, during the fieldwork, several people had contracted dengue, which is endemic in the area, because of the frequent and heavy rains that favoured the propagation of mosquitoes. Being well-fed was related to being healthy enough to work. Among those who considered it was necessary, only $63 \%$ said they were well-fed.

Regarding family, most respondents felt to have fulfilled this aspect satisfactorily. In general, households are male-headed and have, in average, six members. Half of household heads are aged between 30 and 44 years and about one-third are aged between 45 and 59 years old. Gender roles are marked: women stay at home and men work outside the home; $90 \%$ of the women surveyed reported to be housewives.

\footnotetext{
${ }^{59}$ The individual extreme poverty line in 2001 was $C \$ 224.25$ (INEC, 2003). Updating this figure with the consumer price index and considering an average household size of 4 members, the poverty line for 2004 would be about $C \$ 1,135$.
} 


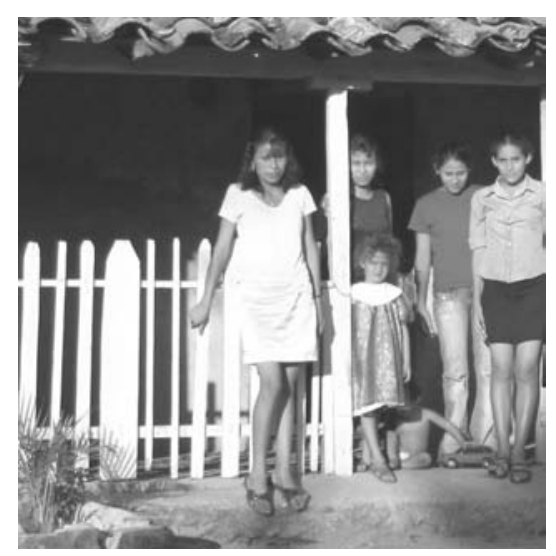

Photo 8-5: A family in El Arrayán (July 2005)

Being literate was also considered necessary and $76 \%$ of the household heads were literate. However, $64 \%$ of literate residents did not finish primary school. In a FGD, two women explained that, because the leader in their neighbourhood was illiterate, they could not communicate their needs very well with the social promoter.

Unequal individual fulfilment of basic needs, not necessarily related to household economic situation

Figure 8-4 shows the extent to which survey respondents achieved the things that they consider necessary for their well-being, through an index of achievements that aggregates only those aspects listed by each respondent (the 'own' index in Box 4-5) ${ }^{60}$ Part (a) shows the distribution of achievements among the surveyed people, with a mean index equal to 0.55 and a median index equal to 0.53 . Part (b) plots the same index and the brackets of household expenditure.

Figure 8-4: Distribution of self-perceived achievements in San Fernando

(a) Distribution of achievements

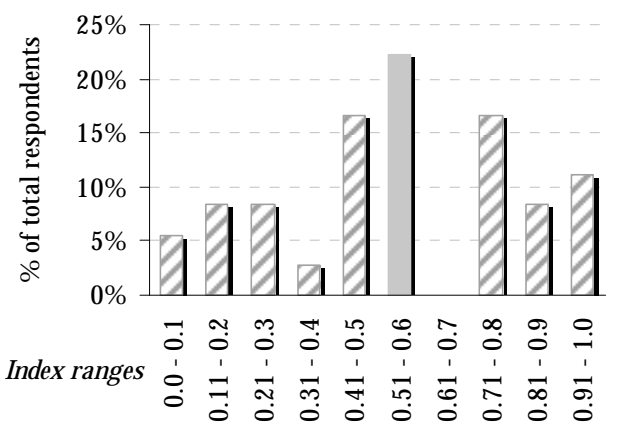

(b) Well-being index and expenditures

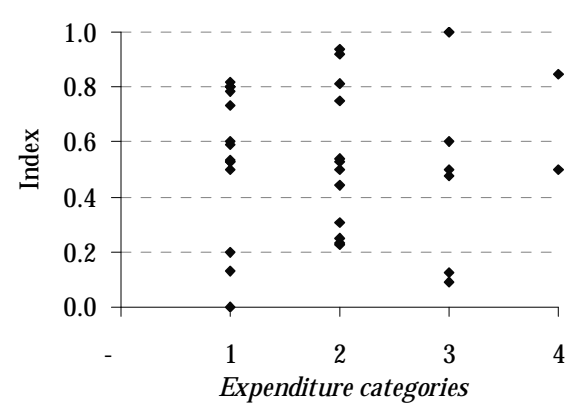

Note: The four levels of expenditure self-reported by the respondents are: (1) equal or lower than C $\$ 400,(2)$ between $C \$ 400$ and $C \$ 1,000$, (3) between $C \$ 1,000$ and $C \$ 2,500$, and (4) higher than $C \$ 2,500$.

Source: Dataset 2.

There is a large dispersion of outputs among respondents and there is no association between the index and the self-reported expenditure. Although all households live in mone-

${ }^{60}$ If someone lists five items and another fifteen, the index aggregates five and fifteen items, respectively. 
tary poverty, there are different degrees of 'poverty' in relation to the value of the index. For instance, if the median index was considered as a poverty threshold, around $53 \%$ of the respondents would be 'the poor'.

\subsubsection{Individual features influence the quality of intra-community relations}

People should look into a person, to what he or she is like - it does not matter rich or poor so that [a community] should serve persons without making differences between them (LIW).

Some characteristics of San Fernando residents explain the particular way in which they experience autonomy: cultural resources and political relations.

First, their physical features and last names are unusual in the region. Many residents are called 'cheles' (or 'white people') because of their light-coloured skin, which they relate to their Spanish and North American heritage. The urban centre was originally a hacienda founded by people with Spanish origin; there was no indigenous population. People seem proud of having the last names of the founders (Herrera, Ortez). In addition, the town was occupied by US troops between 1927 and 1931, during the confrontation with General Sandino.

Second, the political environment is polarised. During the 1980s, a large group of residents supported the contra guerrillas; many confrontations took place in its surroundings. Marked political differences were born during those years.

In consequence, residents felt to be perceived as different and to have been abandoned by the state for many years due to their political sympathies and old material wealth. Political polarisation continues and could be stronger than family ties, as a woman explains: 'We are one family but, with respect to politics, there is no family'. She added that during the political campaign of 2004, there were sharp divisions among close relatives. However, people are reserved; they do not show in public their differences.

Social class also affects how individuals perceive their community. There are two differentiated groups: the traditional families, with the Spanish last names that have or had lands, and the newcomers, those who came to work on the lands of others and stayed with their families or raised their families in San Fernando. The traditional families protect themselves through marriages between people of the same origin so that most of them are relatives. This situation brings differences in their relations with others. A young man explained, when introducing himself, that although he had a traditional last name, he was mixed, not pure. The newcomers have fewer social networks and are less likely to participate in committees, in some neighbourhoods. Social class linked to last names is more important than wealth for many; some leaders were respected because of their last names although they belonged to the poorest segment of the population.

Meanings of community were associated with people, social networks, and organisation. Regarding people, FGD participants explained that the more people the stronger a community is. Also, leaders should be good, hard-working, active and experienced. Regarding social networks, they considered that individuals should share ideas and doubts with others, trust each other, help each other, and have good relations among neighbours. Residents value union and solidarity, but they expressed that they needed to improve: 'Sometimes we live side by side and we do not know to live well together' (HIW). 
Regarding organisation, they considered valuable to have a community organisation, but stressed that it requires the will of residents to participate when needed. Also, good contacts outside the village allow new projects. Men stressed that a community needs work opportunities and that when things are well done, there is a feeling of common achievement that strengthens the community and its members. However, they did not think that the water project was carried out so well.

Leaders included other elements to the meaning of community: good social services and security. Entitlements to health and education are not real when there are no medicines or education materials. Security is a growing problem because of small young gangs. In this respect, a woman non-leader, living far from the centre, explained her case. Her husband works six days a week in their farm in the mountains. Because she is afraid of youth gangs, she sleeps at night in one bedroom with her teenager daughter, her female neighbour and her two dogs. She keeps a machete (a large heavy knife) close to her for protection at night.

Figure 8-5 shows the perception that survey respondents have about their community. Trust is low, influenced by the socio-historical experience of their inhabitants. More than $80 \%$ of the survey respondents considered that 'someone could take advantage of them'. However, women were more optimistic than men. While all male survey respondents agreed with that expression, $22 \%$ of the female respondents did not agree.

Figure 8-5: Perceptions about community in San Fernando

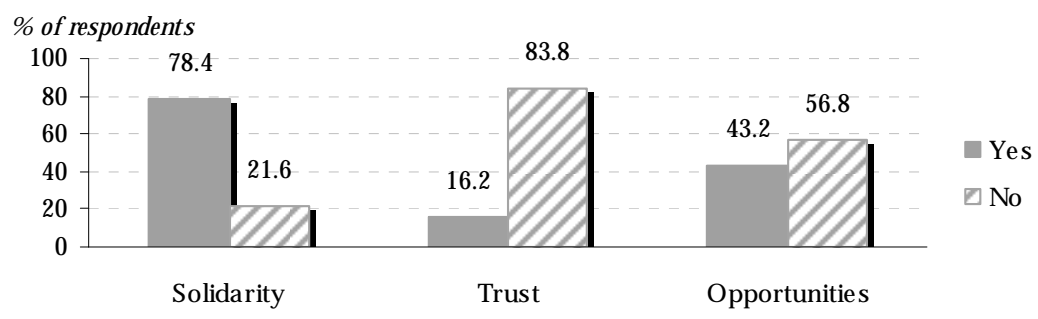

Source: Dataset $2(n=37)$.

Despite the low self-reported trust, $78 \%$ of the respondents said that in case of need, neighbours would help. Moreover, more than half of participants reported that community would expand their opportunities. They seem to expect more support from small groups than from the community as a whole. A man explains: 'There are people with more resources, but they have very private projects, so that the community is not benefited' (LIM).

On the other hand, the poorest are excluded from opportunities open to most community members. For instance, a woman explains:

Projects sometimes arrive to the community, but the poorest people do not take advantage of them because they do not [answer] the call that they receive. So [the leaders] have to put the relatives of the families that are not in need. The poor people do not go because they cannot travel daily, because they live far away and then, they do not show interest in it (LIW). 


\subsubsection{Women are more optimist about the supporting role of community}

The decisions made by the community together are not the same as the decisions made by leaders. Sometimes, leaders decide and, later, they inform to the community. People [should] express what they think, concerning whether what leaders do is good or not (LIW).

Regarding everyday life, San Fernando residents consider themselves centred on their personal issues and their family. However, women participate more in organisations because, while they stay in the town, men work in the plot. None of the interviewees reported to participate in solidary work.

Table $8-7$ shows that $37 \%$ of the survey respondents participate in networks and most of them are women, who collaborate in activities promoted by local committees. There is a moderate negative relation between communal participation and gender (Phi coefficient, $\phi=$ 0.341 , Fisher's exact test, $p=0.06$ ). However, this response is more related to identification with committees because most interviewees are little aware of the existence of other organisations besides CASA and local support committees.

Table 8-7: Communal participation by gender in San Fernando

\begin{tabular}{|l|ccc|}
\hline \multirow{3}{*}{ Gender } & \multicolumn{4}{|c|}{ Do you participate in a community organisation or social programme? } \\
\hline Woman & No & Yes & Total \\
& 12 & 11 & 23 \\
Man & $(52 \%)$ & $(48 \%)$ & $(100 \%)$ \\
& 8 & 1 & 9 \\
Total & $(89 \%)$ & $(11 \%)$ & $(100 \%)$ \\
& 20 & 12 & 32 \\
& $(63 \%)$ & $(37 \%)$ & $(100 \%)$ \\
\hline
\end{tabular}

Source: Dataset 2.

These committees were set up during the project and some members have changed. Residents identify more with the particular persons leading the committees than with the committees as such. The relations between these new leaders and non-leaders are horizontal as residents regard leaders as equals. However, some people considered that, during the project, leaders had certain control over resources so affecting, for instance, the allocation of latrines (section 8.3.3). In this case, residents expressed that leaders should be watched and their decisions should be approved by the community. Those who declared to participate in associations were more optimistic about the role of community to promote opportunities: $67 \%$ of those who participate and $35 \%$ of those who do not participate perceived that the community sometimes or usually expanded their opportunities (Kendall's tau-b, $\tau=0.303, p$ $=0.07)$.

Other organisations are active within the municipality: AMUNSE (association of municipalities of the Nueva Segovia department), CNOR (National Coordinator of Retired Officers), and FUNDEMUNI (foundation of municipal development of Ocotal). AMUNSE gave training to the women that would form the micro-enterprise for garbage collection in San Fernando. CNOR collaborated on the start of a project of ecological wood stoves in several localities of the municipality (including the urban centre). FUNDEMUNI was organising a project to re-integrate gang members. In contrast to the other micro region of the municipality (with urban centre in Santa Clara), small landowners living in the San Fernando urban centre are not organised in a productive cooperative. 


\subsection{Assessing project impacts on autonomy}

This section analyses the project impacts on the autonomy of San Fernando residents. Table 8-8 makes explicit the full logic of the project. It presents some hypotheses and expected impacts, assumptions and outputs, and an evaluation about their fulfilment. As in previous cases, the analysis explores impacts on several determinants of autonomy.

\subsubsection{Access to safe drinking water restricted by high water bills}

The main output of the project was the permanent access to safe drinking water. However, in July 2005, some households could not afford the water bills and the water service was being cut off (section 8.3.4). While project calculations estimated that $5 \%$ of the households were extremely poor and $38 \%$ were poor, official poverty rates were $30 \%$ and $69 \%$ of the inhabitants, respectively. This implies that many poor households could have been left out without tariff subsidy.

In addition, some FGD participants criticised that school students, who had participated in reforestation campaigns, did not have water access as the school directors could not pay the bills. They concluded: 'The school, the church and the health centre should not pay for water' (LIW). Several reasons could explain the high water bills, however, during 2005, 'there was a progressive change in [water] consumption habits and leakage repairs by users under the "pressure" of the cost of the service' (the project technical assistant).

The reforestation activities had small impact on securing the long-term provision of water. The plants sown were not taken care of after the project and the species turned out to be not resistant to dry season weather. A woman recalls: 'The trees were gone when they made the highway... or the cows ate [the trees] or the tractor took them away' (LIW). The foreseen reforestation action plan was not elaborated and the sources of the rivers were not protected, for instance, through negotiating with the owners of those lands (the CARE project manager). These activities had symbolic value because they gathered together adult residents and school students.

Regarding environmental awareness, workshops about micro-basins and reforestation campaigns played a role, but a higher impact was expected from the adequate use of the sanitation systems and the operation of a micro-enterprise to collect solid wastes and process them in the controlled tipping. Despite the fact that the project provided a user's manuals to each household, some households do not maintain well the sanitation systems and some soakaway pits do not work (section 8.3.4). Moreover, the micro-enterprise for garbage collection did not work by lack of funds, problems with the garbage cart, low payment capacity of users, or other operational and physical limitations (LD, 2006).

\subsubsection{Perceived agency supported by the realisation of the project}

The project was expected to influence physical capacities (improved health), intellectual capacities (learned skills from minor constructions and organisational experience), and emotional capacities (self-confidence, improved as result of the work done). 


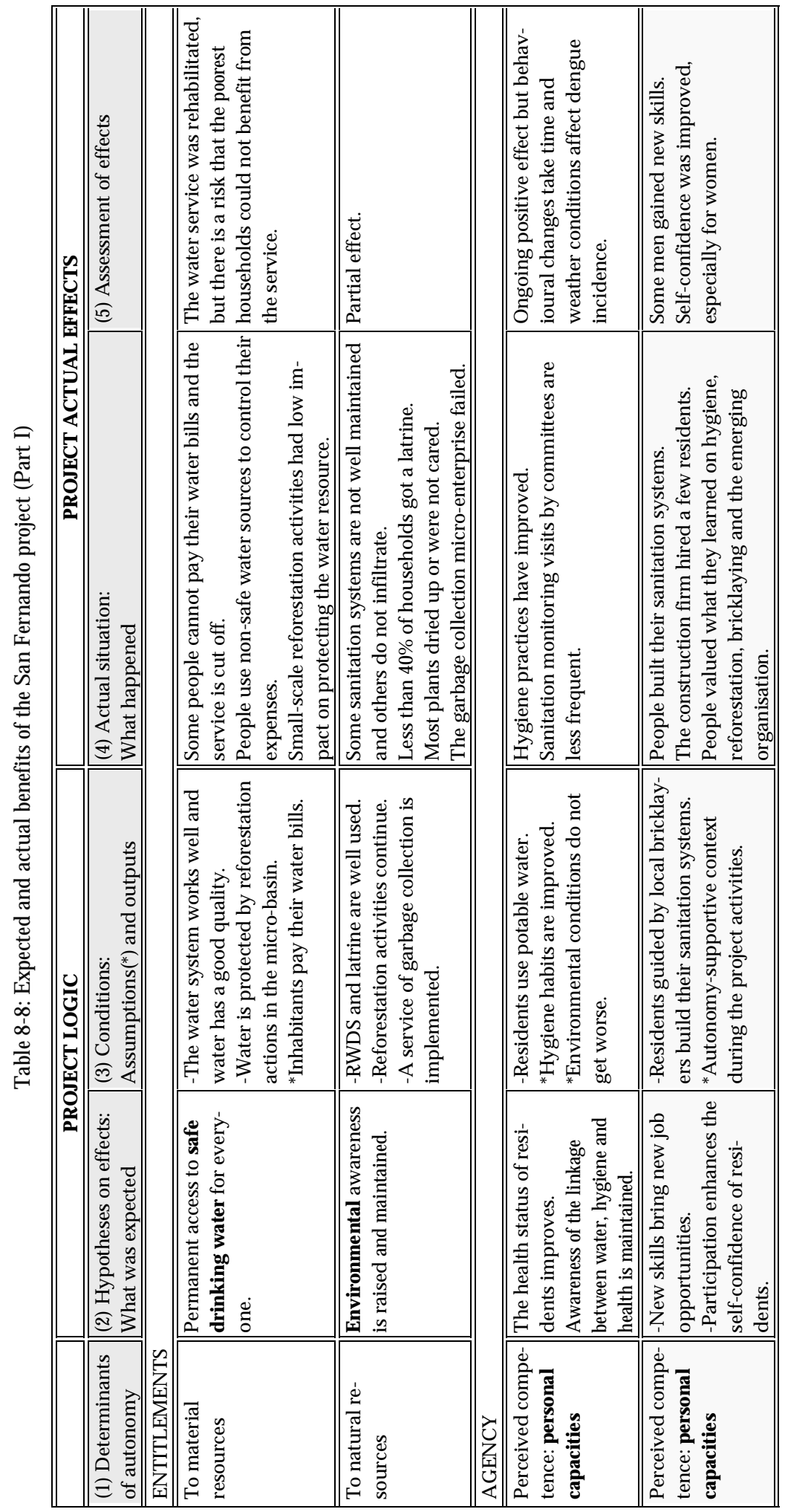




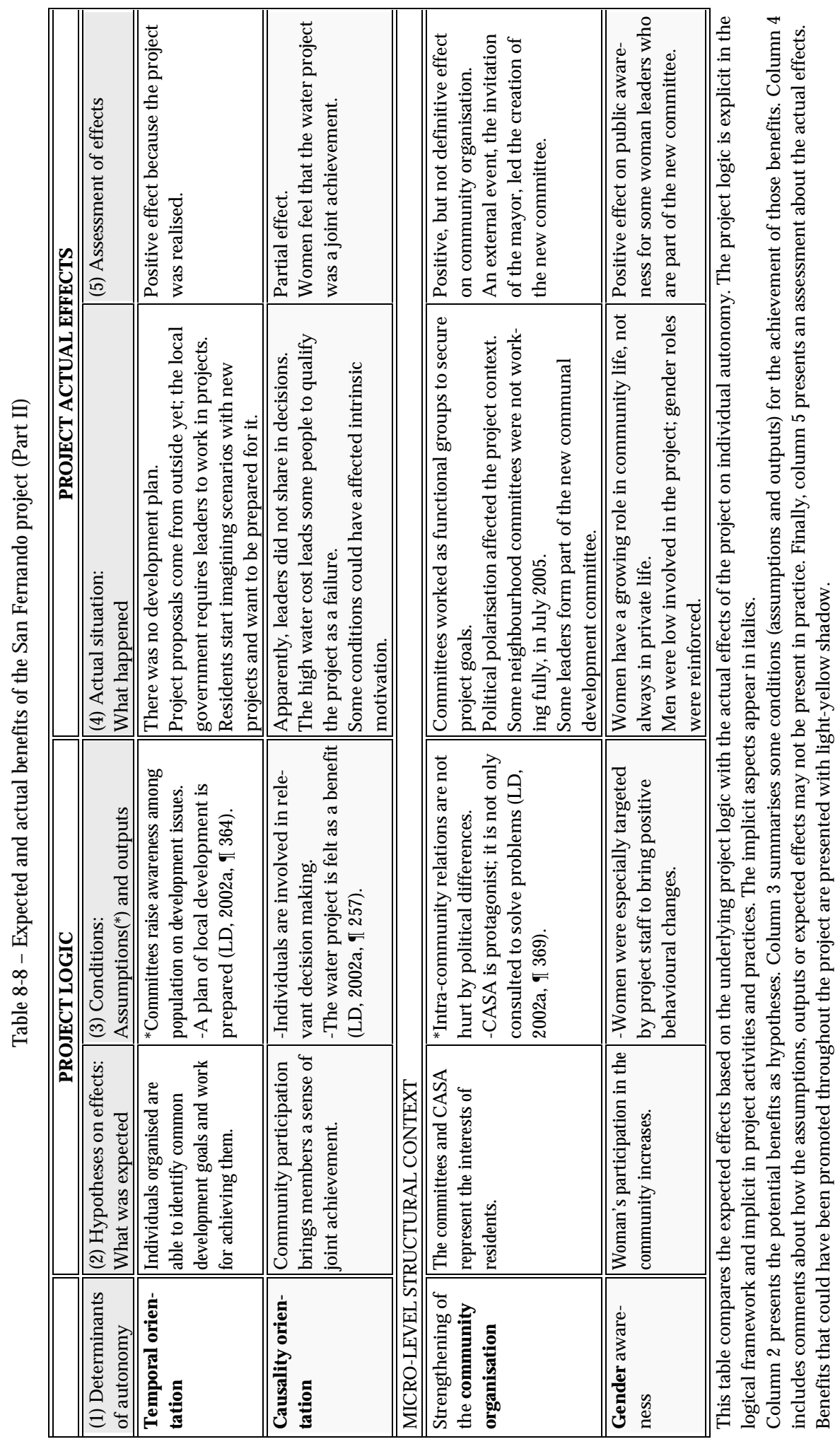


Regarding health, the impact is not so direct because changing habits takes time. It seems that practices such as washing hands before eating or before and after using the latrine were welcomed because people knew them but could not apply them earlier as they lacked good water. A woman explains: 'Earlier, one knew some things, but without practice it was the same as nothing. Now, it is better because there is practice' (LIW). Nonetheless, not everyone received a latrine (section 8.3.3) so that the positive effect is lower than expected.

Likewise, practices related to the disposal of garbage have improved, but the fact that the planed garbage collection and treatment system did not work harms their sustainability. A woman explains:

There has been a big change related to the garbage. I realise that with school children. Sometimes the garbage collector does not come; then, children bring the garbage inside their backpack to the house and they throw it in the garbage can (HIW).

In contrast, the sanitation systems were not so valued and maintenance was not frequent. During the fieldwork, leaders seemed tired of their (monthly) monitoring visits and less motivated due to the negligence of some neighbours. A woman leader explains:

If the soak-away is not washed and cleaned, there are mosquitos. But there are mosquitos even in clean water, if it is not covered. The problem is the cleaning!

On the other hand, endemic diseases, such as malaria and dengue, are transmitted when the forest grows and when there are solid wastes on the surface. The 2005 rainy season was harsh, 'the heaviest continuous rains in thirty years' (the CARE project manager) and several people had dengue. In the whole department of Nueva Segovia, the dengue morbidity rate grew almost three times in 2005 with respect to 2004 (MINSA, n.d.).

Endemic diseases caused by insect vectors are difficult to combat with individual projects, especially when fumigation is not frequent during rainy season. The effect on waterborne diseases is more direct and traceable. CARE (2005f) reported that acute diarrhoeal diseases (ADD) decreased from 473 cases in 2002 and 368 cases in 2003, to 205 cases in 2004.

As seen earlier, not all households had entitlement to safe drinking water given their low payment capacity for the high registered consumption. This brings two consequences on health. First, some people make sacrifices to pay the bills thus harming their health for not being well-fed, as a woman explains:

When one has some pennies to eat, already one has to set them aside to pay the water. What is left? Stay hungry in order to pay the water; otherwise, they cut off [the water service] (LIW).

Second, some households use alternative non-safe water sources, such as river water, to control their expenses so that 'people have diseases again because the river is dirty' (LIM).

Regarding skills, men stressed that some of them became bricklayers based on their experience constructing the sanitation systems. However, the company that constructed the aqueduct did not necessarily hire local workers. Women did not talk of individual skills, but of new knowledge, in general: 'we are seeing the light about different things' (LIW).

Regarding self-confidence, women were explicit about a positive impact. They said that promoters asked their opinion, gave them the opportunity to share ideas. A woman explains: 'It is like the group gives strength, the union helps one to feel relieved' (LIW). Another com- 
plements: 'We learned a lot and had a lot of joy in the community' (LIW). That is, the group gives support and learning brings joy. They had not experienced these prior to the project.

The project was expected to have a positive effect on temporal orientation by supporting the elaboration of a municipal development plan (section 8.3.1). However, it was not elaborated. During the fieldwork, the municipal government was working to involve CASA members and leaders from other cantons in participatory planning following national participation guidelines (Appendix 1-A, section 1.d). The projective temporal orientation of some leaders was promoted mainly because of the invitation of the mayor to become part of a new committee (see section 8.5.3).

People considered that the water project was the most important event in recent times because it had several components and everyone worked to benefit the whole community. They reported that, in contrast to projects managed by the municipality governments that select a few households, when projects are direct, 'the people most in need come and they are benefited' (LIW). The fact that the project was realised fuelled their hope for future projects and aspirations for a better life: 'We trust that other projects will come' (HIW). Besides, the construction skills learned 'can be applied in a new project' (LIM).

Regarding causality orientation, the project assumed that it would be enhanced over time as result of the community organisation that would feed aspirations and joint efforts (see logframe in Appendix 2-B). However, the nascent organisation is not consolidated yet and furthermore, there was no explicit emphasis on how the project could promote individual causality orientation through their practices. It seems that the committed work of the social promoter focused on creating a relatedness-supportive, not necessarily an autonomysupportive context: social activities were promoted, but not significant decision-making (e.g., the latrines case). ${ }^{61}$ Woman leaders were like promoters themselves; inter-personal relations improved, but not significantly as people 'participated because they needed water' and the pre-existing social context was adverse (section 8.4.2).

On the other hand, the project had some controlling elements that could have externalised intrinsic motivation, in some cases. After water, latrines were the most valued element by everyone. Latrines were conditioned to constructing sanitation systems and the latter were conditioned to attending training sessions. Hence, it is understandable that some people forgot or did not apply what they had learned. For other activities, rewards were offered: a prize for the most beautiful coach in the 'carnival of garbage', another prize for the neighbourhood that planted more trees, and so on. At last, less than $40 \%$ received latrines and the competitions' winners did not get the prizes. Some residents complained that they did not get any of the photos, apparently meant for outsiders (NGO staff, press or donors), which they could have treasured with pride to fulfil their need of recognition.

\footnotetext{
${ }^{61}$ Regarding the supportiveness of the context to expand autonomy, signaled by the possibility of speaking up in the first place, the two datasets have divergent results. Almost three-quarters of the respondents of dataset 1 reported not to have given their opinions during the project, while almost the same proportion of the respondents of dataset 2 reported to have done so. This divergence could be related to the phrasing of the question, the interviewer (in the first case, local leaders; in the second case, my assistant and myself) and the sample (larger in the first case). This divergence leads me to conclude that 'voice' was restricted.
} 
Although, people do consider that the project was done due to their own efforts, the high water tariffs were a disturbing factor, which lead some people to perceive that the project was not a benefit: 'To have had this project is useless... if we cannot pay' (HIW).

\subsubsection{The mayor backed the emerging community organisation}

There was an expected positive impact on community organisation. Passing from nothing to a working group (of mostly women) engaged in development plans would be a big achievement. However, the effect was lower than expected because the project left leaders with follow-up responsibilities without formal institutional support. Hence, during the fieldwork, several support committees were not working and some leaders were tired of their voluntary tasks. Most likely, the committees will be restructured again.

Nevertheless, an important effect, propitiated but not determined by the project, was undergoing at the time of the fieldwork: some leaders were invited to form part of a new communal development committee (see Box 8-2). The nascent community organisation found the supportive conditions to grow and leaders were very happy: 'We have voice and vote in the meetings with the councilmen' (a woman leader). Their attitude is changing. While during the project they felt that they had to work to not lose the project, they were starting to feel that their participation is important per se (not only instrumentally). They felt more committed.

Box 8-2: The formation of the new communal development committee

In June 2005, the mayor invited some leaders to be members of the communal development committee (CDC), part of the municipal development committee (CDM). Hence, they would hold periodic meetings with the municipality authorities and leaders from the cantons to elaborate multi-annual development plans and operative plans.

The mayor addressed the leaders who had worked during the water project, apparently following the advice of the CARE social promoter. She recounted that she told the incoming mayor: 'Do not release the already formed committees; followed them up and give them work and training. All this motivates them.' Liliana, the vice-president of CASA, recalls:

'They formed this communal committee, from CASA and the neighbourhood committees; that is, we did have credibility. They asked us: What do you say; can we take the same people? If a project arrives, can you support us? I said: Let's work together because people are organised. Seeing the projects, people are mobilised.'

Participants in all groups expressed that the community is better organised than it was before the project. This opinion was equally shared by women and men. However, it is necessary to build stronger relations and improve participation: 'Most people are always with excuses [to not participate]' (HIW). Leaders recognise that there are 'political distinctions

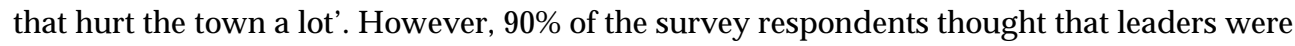
able to respond to their needs better than earlier, which is also linked to the fact that after the water projects, there was a small project of ecological wood stoves and they expected to receive new projects in the near future.

There were effects on social capital. One effect was on the members of the committees, who became friends because they used to work together and also shared happy moments (e.g., birthdays, Christmas) in parties motivated by the social promoter. Another effect was on the large community because they finally recognised that committee members were working for 
their well-being and they participated. As leaders explained, residents are more open and less self-centred than earlier: 'Now, they welcome visitors; earlier, they would not open the door (a woman leader)'. To show the new information channels built, a woman enthusiastically said in a FGD: 'If something happens in the town right now, in half an hour everyone knows' (LIW). Another woman explains that the kind of information transmitted matters: 'It is better now because we talk of what is necessary and not only gossip. We help each other' (HIW). These new behaviours could be the foundations for building trust and social networks in the community (at least for women). Nonetheless, the social context is still difficult. During the project, there was 'discord, due to one of the families' (LIW) about the allocation of project outputs.

Regarding gender awareness, the project especially targeted women (section 8.3.1). Women have improved their position in public life, especially CASA members. However, in private life, husbands decide whether their wives can participate in communal activities. Some women saw their bargaining power increased with respect to family issues, but they try to show in public that their husbands continue in control of the situation so that their prestige is safeguarded (cf., Kabeer, 2000).

\subsubsection{Differentiating impacts among individuals}

This section discusses the impacts on individual autonomy for the new leaders and for nonleaders by gender. In contrast to previous chapters, this section does not analyse different impacts by level of involvement in the project given that women had more chances to be involved given that they worked more in the project.

In this case, in contrast to other cases, there was only one (not two) focus group discussion with men. They did not want to participate in a matter that engaged women in the first place. However, they were willing to be interviewed at home, after their farm work. ${ }^{62}$

\section{- Impacts on leaders: High perceived competence to continue working}

The change experienced by leaders in terms of individual autonomy was much higher than that of non-leaders. In the first CASA, two persons occupied each position (e.g., two coordinators, two vice-coordinators) because they were afraid of failing. Moreover, the first push came from a foreign woman residing in the town. Liliana publicly acknowledged her:

She started [because], as she said, we had fear. We had never been organised; we used to stay at home, working for ourselves; we had never left home, we were afraid to speak; we had never had that opportunity. Then, we had that (the fear) inside our heart. She motivated us. Now, we can speak wherever and to whomever what we think, right?

Someone from outside San Fernando started the change; it tells how difficult was, for locals, change deep-rooted cultural patterns. Later, women, who earlier were fearful, were proud to express their ideas, even in formal meetings at the municipality hall. However, in their private life, they still are reserved. As a woman leader explains: 'We are all housewives and we cannot neglect the housework. Our husbands may tell us "yes" [to participate], but soon they may say "no"...' This authority that the husband has over his wife was also observed

\footnotetext{
${ }^{62}$ Hence, the proportion of men in the survey questionnaire $(28 \%)$ is much higher than that in the focus group discussions $(9 \%)$.
} 
by the social promoter. When the itinerant promoter arrived, 'they said that they were not going to work with a male social promoter because their husbands would not allow them'.

Leaders considered that women's participation and communal organisation were the most important effects of the project. However, women did not agree on the value of the higher participation of women. Two woman leaders expressed contrasting points of view:

There is less fear; the myth that these things are only for men has been broken. We [women] learned to organise ourselves; we can develop any project that comes.

The only problem in reality is that women have had more participation than men.

The first woman is proud of her role, while the second woman considers the work as a load that should be shared by men. It is true that women worked more than men because of their traditional role (taking care of the house, meals, and children) that includes securing the provision of water. However, the internalisation of their participation differs. The first woman has an autonomy (causality) orientation, while the second has a controlling or extrinsic one, and both are leaders.

Nonetheless, all leaders showed the determination to continue working: "If they tell us: "you are needed in a meeting in the mayor's office", we leave the tortilla that we are making and we go' (a woman leader). Leaders in group added: 'We are going to work in any project because we had the experience with Luxembourg and we got used [to work in projects]'. After the invitation of the mayor, leaders felt very proud. However, their participation in the municipal development committee was partial because they have home chores and the water project already distracted them from their work.

On the other hand, the problem of the high water bills affected leaders in a special way. They would like to complain the way consumers who are affected can do, but they receive the complaints of their neighbours and feel accountable to their neighbours for having enrolled them in the project. In some way, they feel disappointed, punished instead of rewarded.

Overall, the main impact on leaders was that they learned to participate and to mobilise people; however, their actual decision-making during the project was relatively low. A woman leader in a neighbourhood committee said: 'CARE would call us and then they would tell us what we had to do'.

\section{- Impacts by gender: Women experienced subjective empowerment}

Figure 8-6 shows the self-reported change in four dimensions related to autonomy: information, self-confidence to express and defend one's ideas, opportunities to make significant choices, and actual decision-making in valuable domains. FGD participants provided scores to assess these four dimensions before and after the project.

In every dimension, women reported greater improvements than men. Women received more information because they were working in the project, while their husbands were in the plot. Women were most likely to attend workshops: about $85 \%$ of the surveyed women, but only $30 \%$ of the men reported receiving any kind of training. There is a moderate and significant association between receiving training and gender (Cramér's $\mathrm{V}, V=0.531$; Fisher's exact test, $p<.01)$. 
Figure 8-6: Average changes in variables associated to autonomy by gender in San Fernando
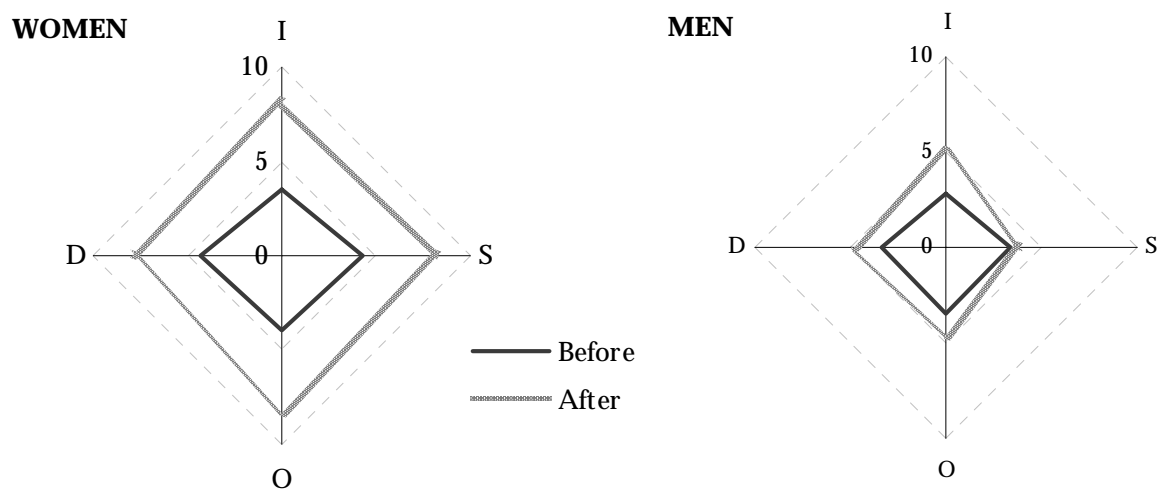

Legend: I=Information, $\mathrm{S}=$ Self-confidence, $\mathrm{O}=$ Opportunities, $\mathrm{D}=$ Decision-making.

Average values of the variables from scoring exercise, mixing high and low involvement groups.

Source: Focus group discussions.

Women were more self-confident because they became aware that they could learn, enjoy and work for the well-being of their families and community (section 8.5.2). Table 8-9 shows that they could also consider their contribution higher than that of men: $45 \%$ of the female survey respondents reported that their participation was high in contrast to the $10 \%$ of the male respondents (however, the statistical association between gender and overall participation is weak and not statistically significant).

Table 8-9: Overall participation in the project by gender in San Fernando

\begin{tabular}{|lcccc|}
\hline Gender & Low & Fair & High & Total \\
\hline Woman & 9 & 6 & 12 & 27 \\
& $(33 \%)$ & $(22 \%)$ & $(45 \%)$ & $(100 \%)$ \\
Man & 4 & 5 & 1 & 10 \\
& $(40 \%)$ & $(50 \%)$ & $(10 \%)$ & $(100 \%)$ \\
\hline Total & 13 & 11 & 13 & 37 \\
& $(35 \%)$ & $(30 \%)$ & $(35 \%)$ & $(100 \%)$ \\
\hline
\end{tabular}

Source: Dataset 2.

Regarding opportunities, women saw an expansion at three levels. At the personal level, they have learned things useful for their household (e.g., hygiene, sanitation) so they do more than 'going in circles in the house, from the kitchen to the living room' (HIW). At the family level, they can communicate better with their partner: 'Before we did not have couple talks; we talk more relaxed now' (HIW). At the community level, they are organised for projects; after having worked in the project, they feel ready to work again in new projects.

However, not everyone in San Fernando has the same perception and access to opportunities. Two points are important:

(i) There are still differences in the community based on religion, politics, class, and relative wealth, which implies that not all have equal opportunities (section 8.4.2); and

(ii) Man non-leaders still have broader decision-making power than woman non-leaders, despite the fact they were less likely to have opportunities for decision-making during 
the project. It seems that working in the water project was considered a women's work and, as such, involvement in the project was regarded as a lower level activity.

Women were more optimistic than men about their effective capacity to make decisions in their daily life and with respect to their family. The percentages of survey respondents who reported to have fair or nearly full control over daily life's decisions and over family decision were $59 \%$ and $44 \%$ for women in contrast to $30 \%$ and $20 \%$ for men.

Nevertheless, men reported to have more decision power on community issues. This could be related to the fact that through their participation in the project, women aimed at improving their individual (or family) well-being, not so much reaching community's goals.

Before the project, women had very 'private' lives, as mentioned earlier. In an environment of restricted options, an expansion of opportunities for decision-making would be positively related to actual expansion in decision-making. Looking at women with different levels of involvement, high-involvement women felt a higher expansion in the four variables related to the exercise of autonomy.

Table 8-10 shows that high-involvement women were more informed during the project and also experienced, in average, a higher expansion in each variable than low-involvement women. They keep close relation with leaders and, most likely, they are the ones who could replace leaders in the new support committees.

Table 8-10: Levels of information self-reported by women in San Fernando

\begin{tabular}{|l|cc|cc|cc|}
\hline & \multicolumn{2}{|c|}{ Before the project* } & \multicolumn{2}{c|}{ During the project } & \multicolumn{2}{c|}{ After the project* } \\
& High & Low & High & Low & High & Low \\
\hline Mean & 2.3 & 4.0 & 9.5 & 6.9 & 8.2 & 8.1 \\
Standard deviation & 0.5 & 2.4 & 0.5 & 3.6 & 0.8 & 1.7 \\
Median & 2.0 & 4.0 & 9.5 & 8.0 & 8.0 & 8.0 \\
\hline Respondents & \multicolumn{4}{|c|}{} & $29 \%$ & $71 \%$ \\
\hline
\end{tabular}

* Information refers to community activities or projects. High and low corresponds to the involvement level.

The scale is from zero to ten. $(n=21)$

Source: Focus group discussions (scoring exercise).

Considering the supportive political context for the development of committees and the positive perception that most residents have about leaders (section 8.5.3), there is a fertile ground for continuous expansion in autonomy along communal participation, especially for women. However, specific socio-cultural features of San Fernando restrict some people's choices. A sustainable expansion of autonomy will require significant change that opens up opportunities to the excluded people. This change will not occur overnight, but it is ongoing since the project.

\subsection{Conclusions}

This chapter has presented a case study in water and sanitation in Nicaragua. The project aimed at improving the health and living conditions of inhabitants of the urban centre of San Fernando via the rehabilitation of water infrastructure, seriously damaged by Hurricane Mitch, and the improvement of sanitation and environmental conditions. This project had a strong sectoral focus with a fixed number of activities designed at earlier stages. Technical assistance was offered to support the sustainability of the water system. Unlike other cases, the political context was more or less neutral; project staff developed their activities without 
impasses. At the community level, project staff found that the community was not organised, given the previous political experience of the inhabitants.

CASA and support committees were formed by requirement of project staff (section 8.3.1) and worked in every promotion activity, enrolling their neighbours. However, their role was more instrumental to assure the project goals. The project was realised and most outputs were allocated, although without an agreed criterion (section 8.3.3); leaders felt proud of their new abilities and the high public profile gained.

A disturbing factor, however, was the high water bills, which harmed the actual entitlement of many residents to safe drinking water (section 8.3.4). This happened despite that project staff had invested so much effort on studying and negotiating tariff subsidies. Apparently, the rush to finish the construction works and to connect the taps, constrained project staff to plan and carry out simple operating tasks that could have avoided this problem. Moreover, the coordination with the water company in the promotion team was poor (section 8.3.3). This situation was untenable, during the fieldwork, putting at risk the positive health impacts, harming the causality orientation of residents, and affecting the influence of new leaders on their community.

Nonetheless, the formation of the communal development committee (section 8.5.3), and the arrival of a new project, soon later, fuelled the hope of residents about new projects and the solution of the problems with the water bills. Leaders who accepted to be members of this new committee felt more motivated. The impact could be important on the community if the role of the committee extends beyond formal required activities.

Looking at the experiences of autonomy, San Fernando residents have particular features that determine their intra-community relations and their possibilities. The economic aspect has a high priority in their lives as their living standards are poor and most households do not have income sources other than farm work; however, they also value emotional, physical and intellectual capacities and non-material needs such as 'to feel inner peace' (section 8.4.1).

The project had positive impacts on the autonomy of the residents (section 8.5). Health improved through the access to safe drinking water and, to a lesser extent, via sanitation infrastructure. Self-confidence was enhanced as a result of the work done and the joint achievement. The new communal organisation was positively perceived by the residents (section 8.5.3) and, after the project completion, was backed up by the municipal government. The higher participation of women determined a potential change in social relations. Women felt more informed, confident and organised than men, which brought them more possibilities for autonomy and empowerment.

In sum, there are conditions in place to promote individual autonomy. The project initiated the process of building up a community of people in search of common goals. Whether this new community is effective to promote actual opportunities is to be seen. 


\section{Reconstruction after the earthquakes in San Agustín: The awakening of a community}

After the earthquake, everything was different. We suffered with the disaster but, at the same time, it seems that it was beneficial because all residents have a worthy house... based on our own effort (HIM). ${ }^{63}$

In our way to San Agustín, my assistant and I went first to a neighbouring municipality called San Francisco Javier to meet the mayor who would provide us with a police escort to San Agustín, as there were concerns about assaults along the auxiliary road. He received us warmly and commented on his contacts with the project chief, with Luxembourg (in previous projects) and, of course, told us stories about the life during the armed conflict, the cooperatives, and so on. Finally, he took us to San Agustín just to demonstrate that, because rural police are patrolling the area, it was now safe. Before leaving, I observed that some people arrived to the municipality hall, signed in, and collected bags of seeds for their plot. The mayor explained that it was a government agriculture programme and that farmers could also get credit for fertilisers that they could repay after the harvest. He took us directly to the municipality hall of San Agustín and said goodbye.

Some days later, I observed large bags of forage and people meeting in the community centre discussing an agriculture project. O ne of the leaders explained to me that they were going to allocate this forage among farmers and that a new government programme was coming, besides other programmes organised by two universities. This made me recall the experience in San Francisco Javier. What the mayor was doing in San Francisco Javier (managing programmes) is what CRD M was doing in San Agustín. I realised that CRD M had overtaken many functions usually controlled by the local political authority. It was important to know how and why.

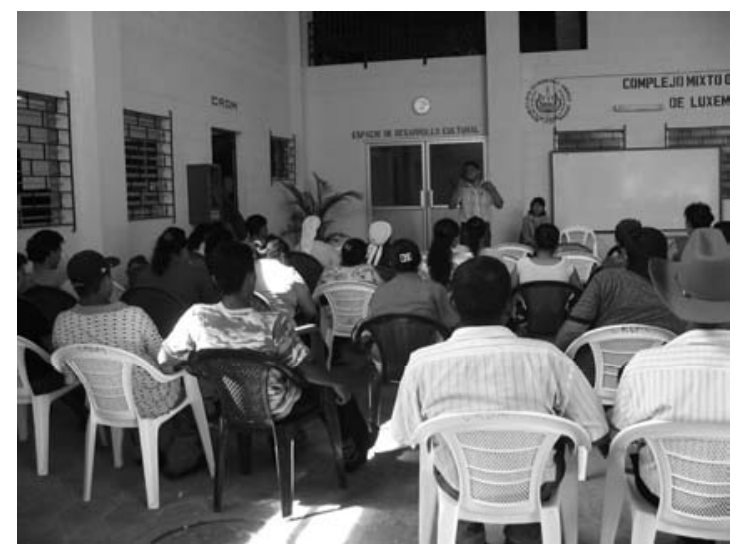

Photo 9-1: Assembly at the multi-purpose communal centre (September 2005)

\footnotetext{
${ }^{63}$ When citing expressions said by a person during a focus group discussion (FGD), I use the following codes: HIW for high-involvement woman, LIW for low-involvement woman, HIM for high-involvement man, and LIM for low-involvement man.
} 
After the earthquakes of 2001, Luxembourg financed the reconstruction of the urban centre and two cantons of San Agustín, which had been destroyed. The project was executed from November 2001 to March 2005. This project has some important characteristics:

1. Before the project started, there was a clear leadership by community leaders in the reconstruction efforts, organised into a municipal committee (CRDM).

2. There were several projects taking place at the same time in the whole municipality and CRDM was coordinating all of them.

3. The project established a functional partnership with CRDM.

Thus, community organisation was highly involved in the reconstruction and it was supported by a local NGO. The project did not have to start from scratch.

This chapter completes the analysis of the individual case studies. It focuses on the impacts of the project on the individual autonomy of the residents of San Agustín, based on the project activities and practices, and their experience of autonomy during the fieldwork.

The chapter is divided into six sections. Section 9.1 describes the situation of the inhabitants of San Agustín before the project. Section 9.2 presents the project and its context. Section 9.3 analyses the project practices. Section 9.4 discusses the meanings of autonomy and the relationship between individuals and community. Section 9.5 analyses the impacts of the project on autonomy. Finally, section 9.6 summarises some preliminary conclusions.

\subsection{San Agustín and the earthquakes that reactivated 'energy'}

San Agustín is located in the department of Usulután, $28 \mathrm{~km}$ from the departmental capital, in the Central East region of El Salvador. It is composed by 16 cantons, 16 inhabited villages, 6 human settlements or colonies and 1 urban centre with 3 neighbourhoods (see Figure 9-1). The access to the urban centre is through a $9 \mathrm{~km}$ non-asphalted road from the highway.

Figure 9-1: Map of the San Agustín municipality

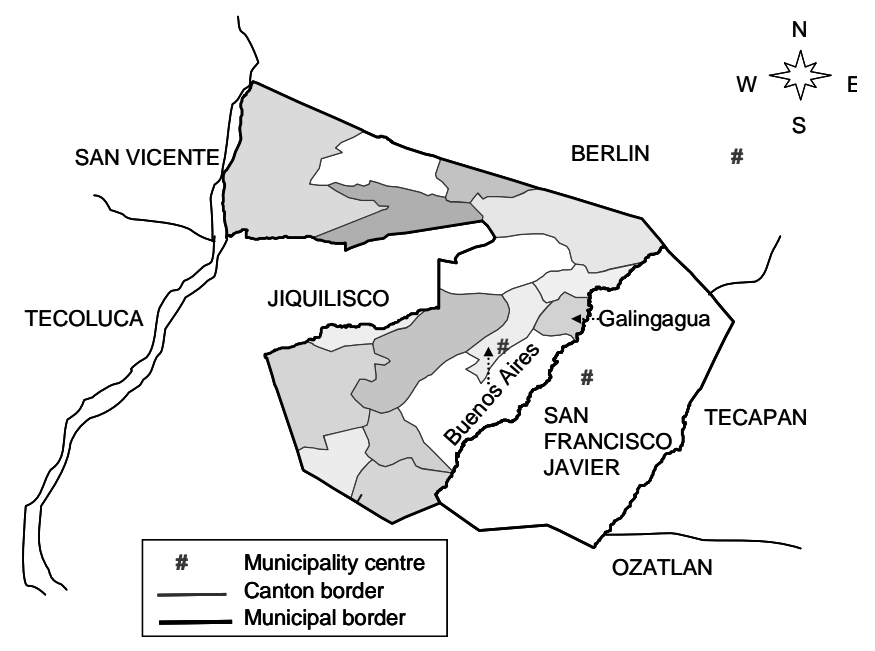

Source: MSA (2004b). 
The civil war left a deep mark in San Agustín

San Agustín was severely affected by the civil war (see Appendix 1-B); guerrilla fighters occupied the land or military forces attacked the residents in their homes suspected of belonging to the guerrillas. This situation led to massive emigration, during part of the seventies and the eighties. Figure 9-2 shows the sharp population decrease.

Figure 9-2: Population trend in the San Agustin municipality

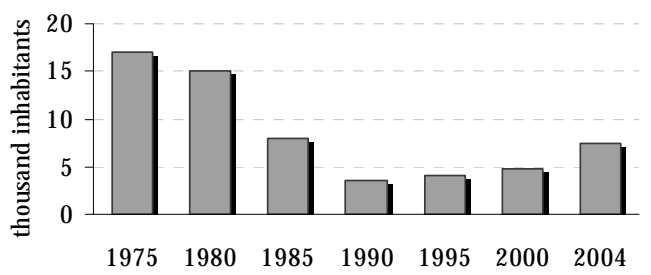

Source: MSA (2004b).

Those who remained in the municipality, the poorest, had lives full of insecurity and exclusion. Being caught between two fires, they trusted no one, even not relatives. Cooperative members were brave, but many died in hands of paramilitary forces (Hernández, 2007). A man leader explains his difficult position: 'we were in the middle, telling to this one: "calm down", and to the other: "calm down that we want to work".

When the conflict ended, former combatants, mainly from the FMLN, benefited from the land transfer programme (ISTA, 2005). However, poor management skills and the international coffee crisis led to the failure of cooperatives and the parcelling out of common lands. Working in smaller plots, many barely survived, producing basic grains instead of coffee, while other stayed in cooperatives to pay their debts.

San Agustín was one of the poorest municipalities in El Salvador

We lived in an isolated town.... We lived in desperation due to the poverty (LIW).

Residents felt that their lives were desperate, without work opportunities or trade. They felt sick, unhappy and 'just sleeping'.

In 2004, San Agustín was a municipality with severe extreme poverty, the worst situation in a four-type classification (FLACSO, 2005a), that combines the monetary poverty rate with the number of under height first-grade school students. Among the 32 poorest municipalities (12\% of total), San Agustín is at an intermediate position considering an integrated marginality index (IIMM) that combines several human development indicators (see Table 9-1).

Table 9-1: Comparison of municipalities with severe extreme poverty in El Salvador (2004)

\begin{tabular}{|lccccc|}
\hline Municipality & Department & $\begin{array}{c}\text { Extreme poverty } \\
\text { rate }^{*}\end{array}$ & Poverty gap & $\begin{array}{c}\text { \% under- } \\
\text { height }\end{array}$ & IIMM* $^{*}$ \\
\hline Torola & Morazán & 60.4 & 55.2 & 37.1 & 53.9 \\
Potonico & Chalatenango & 47.2 & 42.8 & 5.1 & 34.5 \\
San Agustín & Usulután & 46.6 & 41.2 & 11.9 & 37.8 \\
San Esteban Catarina & San Vicente & 43.1 & 43.1 & 19.6 & 37.9 \\
\hline
\end{tabular}

*The municipalities selected are those with extreme values in poverty rate and IIMM in the group with severe extreme poverty rate. Source: FLACSO (2005a) and MFA El Salvador (n.d., a, b, c, d). 
Agriculture was the core economic activity in San Agustin

We worked the maize field only for our sustenance; [we did not produce] large amounts of crop; we earned minimum wage to maintain our homes (LIM).

The main agriculture products are coffee and basic grains such as maize, sorghum and frijol. Agriculture is a seasonal occupation that generates scarce revenues. Most people produce for self-consumption, excepting small coffee producers who sell their crop to middlemen.

In 1999 , about $67 \%$ of the households working in agriculture owned their land, while $28 \%$ rented a plot and $4 \%$ participated in a cooperative. Only $45 \%$ and $47 \%$ of the households in the municipality and in the project area, respectively, owned land (see Table 9-2). In 2001, considering the population inflow, only $35 \%$ and $38 \%$ of the households, respectively, would have owned land. Individual owners had, on average, between 3 and $5 \mathrm{mz}$; collective owners had up to $16 \mathrm{mz}$. Rented plots were smaller (between 1 or $2 \mathrm{mz}$ ). Nonetheless, large extensions of lands were not used due to the lack of working capital or property titles to mortgage lands. There were around 2,480 cattle heads in 1999.

Table 9-2: Land ownership in San Agustín, 1999 and 2001

\begin{tabular}{|c|c|c|c|c|c|c|c|}
\hline & \multicolumn{5}{|c|}{ Year 1999} & \multicolumn{2}{|c|}{ Year 2001 (2) } \\
\hline & \multicolumn{3}{|c|}{ Number of households } & \multicolumn{2}{|c|}{ Owners as \% of } & \multirow{2}{*}{$\begin{array}{l}\text { Number of } \\
\text { households }\end{array}$} & \multirow{2}{*}{$\begin{array}{l}\text { Owners as } \\
\% \text { of total }\end{array}$} \\
\hline & Land owners & Farmers & Total & Farmers & Total & & \\
\hline \multirow{2}{*}{$\begin{array}{l}\text { Project area }{ }^{(1)} \\
\text { Municipality }\end{array}$} & 245 & 315 & 521 & 77.8 & 47.0 & 643 & 38.1 \\
\hline & 401 & 595 & 894 & 67.4 & 44.9 & 1,153 & 34.8 \\
\hline
\end{tabular}

(1) The urban centre and the cantons of Galingagua and Buenos Aires.

(2) Assuming that new residents did not own land.

Source: FUNDAMUNI (1999) and MSA (2001).

From when the peace accords were signed (1992) to 2004, the population more than doubled. However, the municipality has not reached the progress it enjoyed during the peak of the coffee and cotton industries. Some people long for the old times, as a woman explains:

Earlier, the saint patron's party lasted two days.... Those times were happier because there were wealthy people. Now, we all are poor because every wealthy person left (HIW).

An important change was underway fuelled by water projects since 1999

If there had not been a water project in San Agustín, it would already have been a ghost town (a man leader).

From June 1999 to March 2005, USAID financed a water project called 'Agua', ${ }^{64}$ which was executed by a consortium of local NGOs and benefited 18 municipalities in 3 departments. USAID (2006a) set four main project outputs: (i) improved quality of water resources, (ii) improved performance of water delivery systems, (iii) more effective citizen actions to address water issues, and (iv) greater municipal participation in water resources management.

In Usulután, FUNDAMUNI was the main partner to support the last goal. At the local level, it promoted the creation of user committees or self-managed water systems in each rural canton served. At the municipal level, it supported the participation of residents through the creation of development committees and advised them on their coordination with local

${ }^{64}$ Initials in Spanish for 'access, management, and rational use of water' (USAID, 2006a, p. 4) 
governments. At the inter-municipal level, it started the 'El Borbollón' sub-basin management committee to coordinate the sustainable use of water (FUNDAMUNI, 2005).

In 2000, $L D$ executed a project that covered 12 sites in the municipality. It provided 836 water domiciliary connections, 704 soak-away pits, 200 VIP latrines and 739 ecological wood stoves; reforestation and soil protection activities were included. A local NGO was responsible for the sanitation systems activities and the awareness campaigns. The community associations got some training in organisation and helped project staff by informing residents on project activities, updating the census and enrolling the beneficiaries (LD, 2002b).

Local leaders were mobilised and the access to water attracted people to the area. Leaders were elaborating a municipal development plan supported by FUNDAMUNI, although with some resistance because 'after the experience of the armed conflict, organisation was considered a bad word' (reported on many occasions by several leaders).

Large differences in common resources between residents of the urban centre and the rural areas

There was shortage of basic services: $75 \%$ of the households in the urban centre had electricity, compared to only $26 \%$ in the rural areas. Since 2000 , the urban centre and some cantons had access to potable water, but the deficit was still high in most rural areas.

There were twelve schools in the municipality. The only high school and health centre were located in the urban centre. There were also sport committees, community education associations (ACE) and religious associations in some cantons. However, out of the 16 cantons, 6 were uninhabited.

Two earthquakes caused strong material damage

On Saturday 13 January at 11:33 a.m., there was an earthquake at $65 \mathrm{~km}$ South of Usulután, with magnitude 7.7 Mw (Richter). A second earthquake, one month later, and several later replicas had their epicentres in more distant places, causing less material damage but increasing the feeling of insecurity for most inhabitants.

Fortunately, there were not many human losses as the earthquake occurred during the day on a non-working day, so that people could escape easily and children were not at school. However, the earthquake destroyed almost all adobe houses.

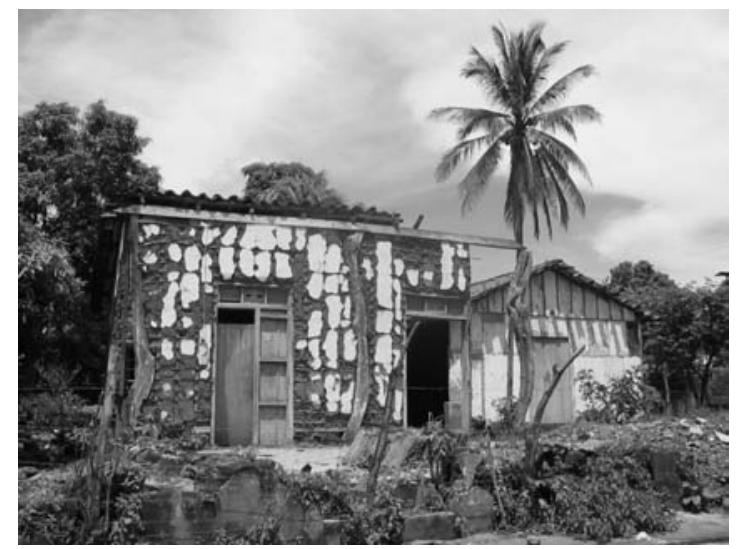

Photo 9-2: Houses affected by earthquakes in San Agustín's urban centre (September 2005) 
In addition, 98 micro-enterprises, 7 churches, and 13 public buildings were damaged - including the municipality hall, community centre, and the Catholic parish (GOES, 2001). Out of 12 schools, 4 were completely destroyed and 5 were severely damaged. Basic services were little affected in the urban centre (El Diario de Hoy, 2001). Eight hours after the earthquake the water service was available. Electricity and telephone services were also available, shortly after the disaster.

\section{Relief aid arrived soon, but livelihoods were hurt}

I had my barn of maize; the earthquake brought it down to the ravine (LIM).

People received emergency aid from several institutions, channelled via the Catholic parish and the municipality government, with the active support of the organised population. The parish managed an emergency health fund to attend injured people because the health centre was destroyed. NGOs already active in the municipality supported the local efforts, for instance, providing psychological support for children.

With the loss of their houses, San Agustín residents also lost their livelihood. They had to sell the seeds, which they kept for the new crop, to satisfy their material intermediate needs. Moreover, many lost their whole maize crop (Gonzalez, 2001). For months, people lived on food aid beside their collapsed houses in tents with sheet metal roofs and wooden walls.

The earthquakes motivated people to organise themselves and to overcome past enmities

The earthquakes helped us to convince people that organisation was the only solidary solution (Lucho, former president of CRDM).

Considering the violent experiences lived during the civil war, many residents still regarded their neighbours as enemies. However, when the first earthquake hit San Agustín, people realised the need to work together. In February 24, 2001, CRDM was legally created with the support of FUNDAMUNI - as planned within the framework of the Agua project. CRDM replaced an inactive existing municipal development committee and, in contrast to that one, it was integrated by people from different political affiliations (former guerrilla and former army fighters, former cooperative members) and religious beliefs.

The process to integrate local leaders was hard. One Catholic priest supported CRDM by encouraging local leaders to participate because, he explains, the foundations of the organisation were strong though hidden, and 'people were wakening up'. Finally, there was one local committee by canton, sending representatives to CRDM. An action plan was approved in June 2001. The earthquake was the trigger for broad-based participation: 'It accelerated the process of community organisation' (the FUNDAMUNI promoter). The residents of San Agustín were already experiencing a 'change process' when the project financed by Luxembourg started. The stocked energies had been mobilised (cf., Hirschman, 1984).

\subsection{The reconstruction project in San Agustín}

The overall goal of the project was to contribute to the reduction of the vulnerability of the population of the municipality of San Agustín (LD, 2001c). Although initially linked to natural disasters (logframe), the meaning of vulnerability included social and economic aspects. The project identified as weakness the complete dependence of the population on subsistence agriculture, which was hurt by landslides following the earthquake, and the scarcity of 
municipality revenues to finance investment. The project aimed at reconstructing houses and social infrastructure, but also at strengthening the community organisation and the municipality government. It looked for 'an integral, sustainable and participatory development' (ibid, II 115).

The main physical outputs of the project were 438 houses in the municipality head and in the nearby cantons of Galingagua and Buenos Aires and social infrastructure in the urban centre, which consisted of:

- $\quad$ A multi-purpose community centre (hosting the culture house and CRDM);

- A social lodge-hospice;

- A main square park with a bus terminal;

- Four small canteens and eight small shops in a covered market area, on one side of the main square;

- A metallic structure in the centre of the park with the three bells rescued after the earthquakes;

- $\quad$ Restoration of a 13-metre high tower clock in the centre of the park;

- Public sanitary services;

- An autonomous sanitation system for the above infrastructure (waste digester or biodigestor);

- Walls to protect the police station and to divide the lodge-hospice from the priest house; and

- A metallic fence for the football court.

The construction activities were carried out by the residents themselves. The project hired local bricklayers, carpenters, welders and electricians. All intended beneficiaries worked in the construction of their houses through the modality of directed mutual help, for which at least one member of each household or a paid manual worker assisted the hired bricklayers.

\subsubsection{Organisation of the project and main stakeholders}

The project was run by a project implementation unit (PIU) based in San Agustín and composed by a project chief and a secretary. The technical assistant was replaced by a local assistant who was the president of CRDM. The partnership between the project chief and the community organisation was crucial to foster people's participation in the activities.

Figure 9-3: The organisational structure of the San Agustin project

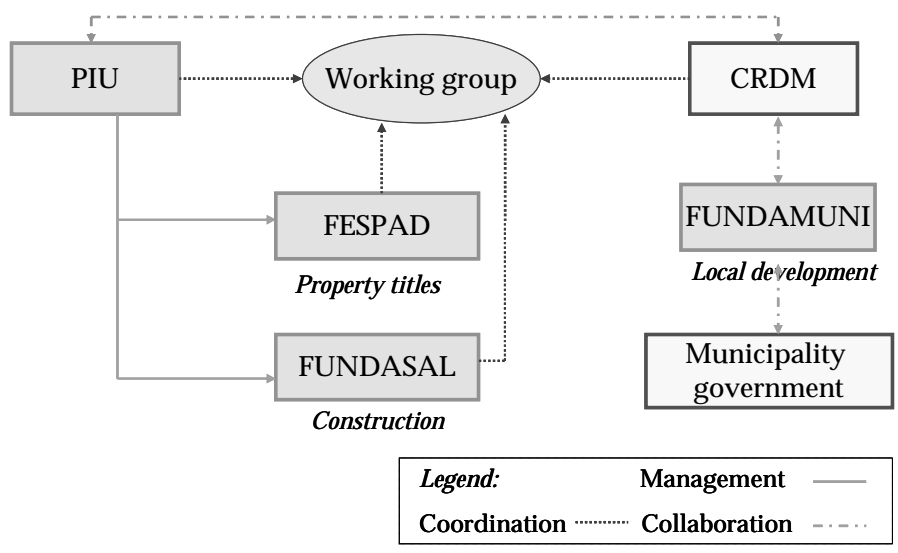

The PIU supervised the work of two local NGOs: FESPAD, in the legalisation of property titles, and FUNDASAL, in the construction of the houses and social infrastructure (Figure 9- 
3). FUNDAMUNI continued as catalyser in the relation between CRDM and the municipality government; it was hired by the PIU to facilitate the elaboration of a new municipal development plan.

FESPAD gave legal support to the PIU and each household. It had one central coordinator, one field coordinator and lawyers who covered the four zones in which beneficiaries were grouped. During the project, a consultant was hired to support the registration process There were several changes of staff, explained by the central coordinator, due to the unsafe environment and the lack of experience of some lawyers in this type of work that required continuous working days: lawyers had to contact beneficiaries, engage them in the process, and accompany them to the public entities to process their legal documents. Burri (2003a) reports that, during the first year of operations, FESPAD had changed the main coordinator once, the field coordinator three times and had hired three new lawyers.

FUNDASAL had, in the field, one resident engineer, one central store keeper (with his assistant), one social promoter, one technician for social infrastructure and chief bricklayers. The resident engineer was removed by the project chief (July 2003), after an internal audit.

The municipality government was the formal local counterpart. A direction committee integrated by the mayor, the board of CRDM and the project chief would manage the project. Nonetheless, the role of the mayor decayed over time. A permanent working group was set up instead and was the main decision maker. It was formed by the project chief, two representatives of CRDM, a representative of FUNDASAL and another of FESPAD. They met once a week. Sometimes, a representative of FUNDAMUNI or another of the municipality government would join. Depending on the topic, other institutions could also be invited. Many other institutions were related to the project. Table 9-3 presents only the main actors.

Table 9-3: Main stakeholders of the San Agustin project

\begin{tabular}{|c|c|c|c|}
\hline Formal authorities & Intervening actors & Project staff & Community members \\
\hline MFA Luxembourg & LD & PIU: project chief & CRDM \\
\hline MFA El Salvador & FUNDAMUNI & Assistant & ADESCOs \\
\hline Departmental government & Health centre, churches & FUNDASAL staff & Non-leaders \\
\hline Municipality government & $\begin{array}{l}\text { National Police, ANDA } \\
\text { Other public institutions }\end{array}$ & FESPAD staff & Inhabitants of cantons \\
\hline
\end{tabular}

The project chief addressed several institutions to settle the legalisation process, such as the national registration centre, specialised institutes, and the National Assembly. He also coordinated with public ministries (e.g., education, housing and health,) and other institutions (e.g., the water company, the national culture council). He even helped CRDM to contact potential land donors. The personal commitment of the project chief was high: the construction was an accessory element of the project, the legalisation of properties and the social aspect received more attention (Burri, 2003d). This attitude was called by an officer of the MFA of Luxembourg 'devotion for the people of San Agustín'. A woman leader expressed that the project chief 'put his intelligence and his heart'. A woman non-leader recalls:

I was not included in the list of beneficiaries because I did not have land. However, the project chief from Luxembourg told me: 'We cannot leave you out. Look for a relative to give you a piece of land. We will make you the house, even in that mountain'. (LIW) 


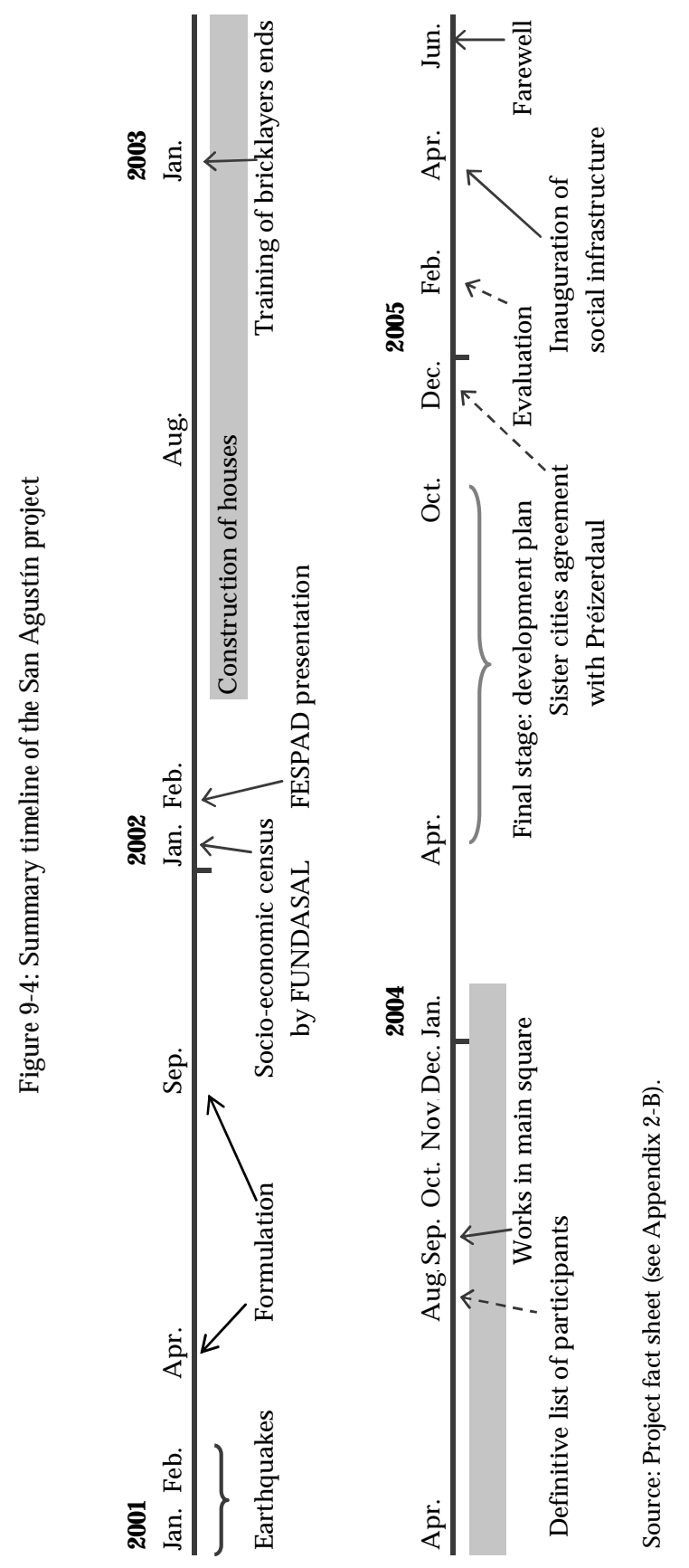


It is worth noting that the president of CRDM had strong leadership in the community and was a former guerrilla commander. This could have caused certain mistrust from political authorities, at the start of the project.

\subsubsection{Micro-level context around the project and main activities}

Figure 9-4 shows the main activities during the project. It started, in practice, one year after the earthquakes, when the project chief arrived. By then, people had received relief aid and built temporary huts. The project lasted three years. The construction of houses started in April 2002 and ended in January 2004. This delay was caused because $85 \%$ of the properties were not legally registered (reported by leaders); cases were diverse (section 9.2.3).

Despite the delays, residents were patient. They trusted Luxembourg would help because they felt to share a special relation. They had benefited from a water project recently; they got a formal commitment when Luxembourg representatives visited San Agustín, three days after the second earthquake; and they had participated in the project formulation. Residents also waited because they wanted to own their houses legally.

Several construction projects were carried out in the municipality, but this project was the largest and the most relevant. The urban centre hosted the oldest houses and had the highest population concentration so that the devastation brought by the earthquakes was huge. The houses financed by this project represented $44 \%$ of the 987 houses reconstructed in the municipality, until December 2004 (Figure 9-5) and 80\% of the houses in the urban centre, Galingagua and Buenos Aires.

Figure 9-5: Houses reconstructed in the San Agustín municipality

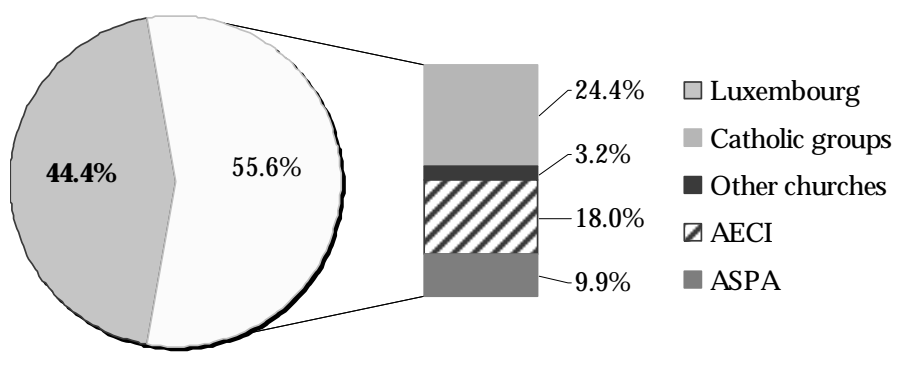

Note: The blue of Luxembourg (44.4\%) is in contrast to the yellow area that comprised all other sources of aid $(55.6 \%)$. AECI is the Spanish Agency of International Cooperation; ASPA is the Andalusian Association for Solidarity and Peace.

Source: CRDM (2004).

Aiming at helping the neediest people, the working group decided the construction of alternative types of housing: two human settlements in Galingagua and Buenos Aires, on lands donated by the priest and the mayor, respectively; thirteen removable prefabricated houses for landless households settled on lands used under commodatum; and one social lodgehospice to solve the problem of 'around 30 single individuals identified as dependent or old age people without resources who lived in extreme poverty' (Burri, 2002b, p. 2).

Some communes of Luxembourg also helped: Bettborn financed the construction of a high school in the urban centre and Préizerdaul financed a water system in the Galingagua can- 
ton. Furthermore, in December 2004, a sister cities agreement between San Agustín and Préizerdaul was signed in Luxembourg (section 9.2.3). In addition, several official visits, and especially the visit of the Great Duke (in November 2003), strengthened the identification of residents with Luxembourg.

The approval of the municipal development plan and the inauguration of the social infrastructure were the last activities. One evaluation contracted by LD was carried out in January 2005, and another arranged by the MFA of Luxembourg took place in November 2005. In June 2005, a farewell to the project chief was organised by the CRDM leaders at the communal centre, with the presence of leaders from the local committees.

It is worth noticing two contextual elements that harmed the pace of the project: food and physical insecurity. First, food aid was withdrawn shortly after the start of the construction works. A man reports: '[They said]: "Find out how you solve [the problem] yourselves". The trucks with food did not come anymore' (LIM). The problem was more acute for people working in the human settlements because they worked for a longer time (see section 9.3.2) and only received food in two or three occasions (FUNDASAL, 2003b).

Second, organised bands assaulted and hijacked people on the road that leads to the urban centre; people were very frightened (Fuentes, 2002; 2003). Then, the project chief coordinated special measures with the departmental government and police forces. Only in June 2005 did the rural police start to patrol the area because 'delinquency had appropriated [the town] in the last years' (Marquez, 2005, II 6).

\subsubsection{Other project activities}

This section describes two aspects: the legalisation component of the project and the sister cities agreement that would finance small projects in the future.

The legalisation of property included two actions: (i) the registration of the land where the houses were going to be built and (ii) the registration of the new house. Diverse intermediate steps were taken before the registration of the lands because many people were 'possessors but not legal owners'. Some families had inherited lands from generations of colonos (former plantation workers) and had never registered their properties. Others simply could not afford the costs of property legalisation. Moreover, a fire in the municipal hall, in 1980, during the civil war, destroyed many documents.

The project carried out an 'integral legalisation', which focused on the person and the property. First, owners obtained their personal identity document and later, they could legalise their property. During this process, several sub-outputs were arranged, including birth, death and marriage certificates, recognitions of paternity, inheritance-related documents, sales contracts, donations, cancellations of mortgages, and so on. Moreover, large households that before the earthquake cohabited in crowded conditions took advantage of the project to split nuclear families in separate houses (and then, there were land partitions, inheritance advances, etc.). Without an integral treatment, the project could have ended up with less than one-third of the targeted number of houses (according to the project chief). However, not all legal cases were solved; only 438 houses were built or $80 \%$ of the initial target of 550 houses. 
The sister cities agreement between San Agustín and Préizerdaul would finance projects related to professional training, the promotion of economic, micro-enterprise, and technological development and the improvement of hygiene and sanitation conditions (FISDL, 2005) up to USD250,000 over five years. In San Agustín, a tripartite supervisory committee was formed by the municipal government, CRDM and other social actors such as health and education ministry representatives and local churches. They were responsible for managing the funds from the agreement (reported by a leader and the FUNDAMUNI promoter).

The first project under this agreement took place between December 2004 and April 2005 and cost around USD42,000. It provided potable water to 43 households in the Galingagua canton (LD, 2005c). A distribution tank with a water pump was built and connected to the water system financed by Luxembourg in 2000. The organisational structure was simple: one external consultant as project manager, one resident engineer and one chief bricklayer who was a member of a local committee. CRDM was in charge of the construction works. Residents worked as bricklayers and as assistants in mutual-help groups, receiving a salary of USD 4 per day, paid every 15 days.

\subsection{Project practices}

This section discusses some of the practices during the project lifespan that were relevant to San Agustín residents and other stakeholders, based on information gained in interviews and focus group discussions. Table 9-4 summarises the aspects to be analysed.

Table 9-4: Main practices during the San Agustin project

\begin{tabular}{|lll|}
\hline Project phase & Practices & Aspect \\
\hline $\begin{array}{l}\text { 1. Identification and formu- Selection and design } \\
\text { lation }\end{array}$ & - Participatory formulation \\
\hline 2. Implementation & Conditionality & - Directed mutual help \\
& & - Directed mutual help \\
& Coordination & - Family property \\
& & - Local counterpart \\
& & - Intra-project coordination \\
& Selection & - Extra-project coordination \\
3. Evaluation and audit & Accountability & - The municipal development plan \\
& & - The quality of the owned houses \\
& & - Utility of social infrastructure \\
\hline
\end{tabular}

\subsubsection{Leaders decided on crucial features of the project}

Almost every project feature was designed during the participatory formulation. One important decision was the work modality of 'directed mutual help'. Moreover, during the implementation, a municipal development plan (not envisaged as such) was elaborated.

\section{- Participatory formulation}

People have their house and they know how they have their house, because they were allowed to choose how they wanted their house (Lucho).

For the formulation, an external consultant contacted the CRDM leaders, who defined the selection criteria (in Box 9-1), the model and materials of their houses, the partner institutions (FESPAD and FUNDASAL), and the social infrastructure to be built. 


\section{Box 9-1: Selection criteria in the San Agustín project}

- To have been hurt by the earthquakes;

- To have lived in the municipality at least for two years before the earthquakes occurred;

- To be owner of the land where the house would be built;

- To have lost all household revenues, not compensated by external help, or to have revenues lower

than two minimum wages (i.e., around USD120 in 2002, still below the national poverty line);

- To have availability to work in mutual help;

- Not to count with an offer by other donor or aid agency;

- To be a household of four or more members;

- To be a single-headed household (only mother or father or sibling household head); and

- To have a disabled, old-aged or chronically ill member.

Source: LD (2001c, II 89).

In a first stage, meetings were held at the remains of the Catholic parish and at the seat of the departmental government. Leaders from each local association brought their designs and discussed them in assembly (reported by a priest and leaders). In the second stage, the consultant met leaders, local and government authorities, the priest, representatives of the vice-ministry of housing and other public institutions to discuss the formulation terms.

To select the construction materials, leaders visited ten houses built by FUNDASAL with different construction materials (LD, 2001b) and, finally, chose the use of reinforced concrete, which they regarded as safer.

Luxembourg found an organised community willing to lead their own reconstruction. One officer of LD, who participated in the formulation mission, explains:

The government had the tendency to guide us to the private sector, building the houses through a company because it would do it faster... We, based on the dialogue with the communities, convinced the government to try a different model.

\section{- $\quad$ Directed mutual help}

[Directed] mutual help was proposed by the community. We believe that constructing with mutual help improves the organisation and the relations among neighbours. Then, the majority of the projects in the municipality have applied this system (Lucho).

Directed mutual help and the selection criteria were applied to all reconstruction projects coordinated by CRDM, except the one financed by the Spanish aid agency, which started in May 2001. Leaders framed this feature within their philosophy: 'San Agustín for San Agustín' (Burri, 2002c; FUNDASAL, 2002d). In turn, LD (2001c) considered that this work modality would support ownership because people 'worked' for getting their houses.

First, FUNDASAL contacted skilled construction workers and those trained by a national institute, soon after the earthquakes. It tested their skills during the construction of the first five houses - the offices of LD, FUNDASAL and CRDM and the houses of the project chief and the FUNDASAL field staff - identifying training needs (FUNDASAL, 2002c; Burri, 2002a). Many construction assistants became bricklayers; skilled workers improved their abilities through practice and close monitoring. By mid-2003, there were 122 bricklayers, 5 electricians and 10 welders of good performance (FUNDASAL, 2003b).

Second, participants were organised in groups of between four and six people. Each group had a coordinator, a secretary and a store-keeper with different roles. Basically, the coordi- 
nator was the speaker of the group, in close communication with the chief bricklayer. He or she had to allocate tasks within the group, solve problems, set participation rules and supervised the works. To improve the community organisation, the social promoter and leaders would identify among group coordinators those to receive a 'new leaders' training on leadership, organisation, work methods, and gender issues. To improve the social context, groups were advised to apply mutual help to other activities such as solidary farm work.

\section{- $\quad$ The municipal development plan}

The plan is designed to harmoniously adapt the economic activities to the population needs.... It builds into a cyclical and permanent process of participatory planning, which strengthens the capacities of the entities that are responsible for its implementation (MSA, 2004b, p. 5).

The project had envisaged the elaboration of a 'plan of environmental protection and disaster prevention' (output 5 in the logframe) but, during the implementation, residents worked on a municipal development plan, based on the plan of June 2001. Its elaboration was coordinated by FUNDAMUNI and its reach was extended to cover a 10-year horizon.

The elaboration of the plan was influenced by local dynamics and particular motivations that defined the quality of the participation. The formation of many local associations was driven by necessity after the earthquakes. Some leaders looked for short-term rewards, 'to have a house where to live' (a CRDM leader). Others served as leaders because no one else was willing to do so, especially in the urban centre. Associations were not necessarily representative. For instance, in a rural canton, a Catholic chapel was considered the top priority in a meeting mostly attended by members of religious groups (reported by a CRDM leader).

The elaboration of the first action plan followed FUNDAMUNI's methodology, which is participatory and departs from residents gaining knowledge of their municipality to the formation of a development committee. It aims at promoting the involvement of different actors to plan and pursue common goals. Box 9-2 shows the different steps in detail.

\section{Box 9-2: FUNDAMUNI's strategy to support processes of local development}

1. To know the municipality: the lands, the population, the local government, how people are doing and what they have;

2. To ground the foundations: generate an attitude of looking for understanding and to share information about the municipality;

3. To build instruments to guide the work: facilitate the elaboration of the action development plan by representatives of all communities;

4. To generate permanent instruments of participation: participants elect and form the municipality development committee, with a role of coordination between municipality government, communal committees and general population;

5. To inform and involve the population: all inhabitants are aware of what is happening and can give their opinions and suggestions;

6. To inform and involve the institutions: to know the possibilities of each institution to support the plan; and

7. To follow up and strengthen the process: workshops about organisation, project management, etc.

Source: FUNDAMUNI (2001).

To update the action plan, in 2003, FUNDAMUNI organised meetings in each canton with groups of between 30 or 40 people, leaders and non-leaders. In these meetings, each canton 
identified their needs and prioritised them. The three most important needs for each canton passed to be voted by general assembly of CRDM. In this assembly, the priorities for the whole municipality were defined in the four sectors in order to devise long-term strategies to satisfy intermediate needs: infrastructure, social, economic and environmental. These strategies were first discussed at canton level and later in general assembly (see section 9.3.3).

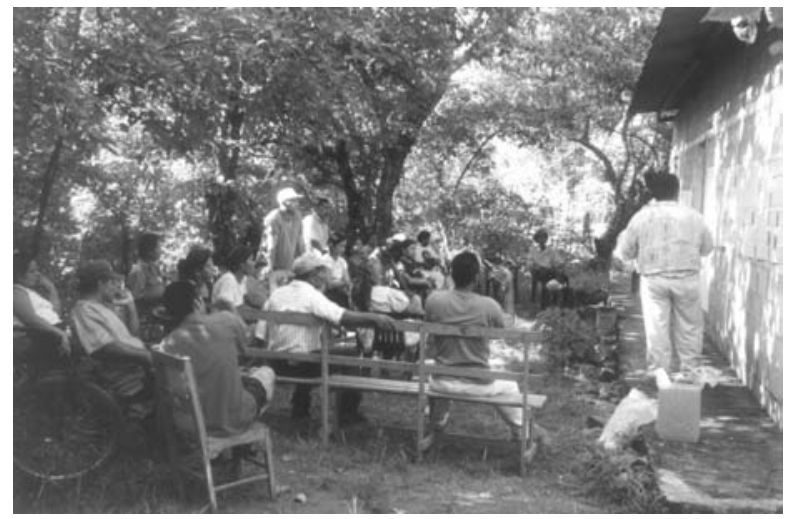

Photo 9-3: People in a canton meeting in San Agustín - Source: MSA (2004b).

\subsubsection{Perceived conditionality could externalise intrinsic motivation}

Households had to meet several requisites to benefit from the project. Most importantly, they had to be the owners of the land where the house would be built and they had to participate in the construction activities. Once the house was built, the project encouraged that the property be registered as 'family property'.

\section{- $\quad$ Directed mutual help}

It cost us many tears and wood because the land there is very ugly; we had to do many things to get the material down to use it (HIW).

Here, no one can say 'this house was given to me like that', rather, it cost quite some sacrifice to everyone (HIW).

Although this work modality was chosen by leaders, some residents felt obliged to work without compensation. Some people complained of the social promoter. The situation worsened when food aid was withdrawn. A woman recounts: 'I cheered myself up [when] I watched other ladies working' (LIW). However, some FGD participants recalled moments of happiness when materials arrived and when houses were finished. For some residents, their work was a sign of gratefulness (LIW).

To construct the houses, each group worked, on average, three months. The work was hard because some lands were loamy; residents had to stabilise the lands and dig deep to put solid foundations. People who would live in the human settlements worked longer, more than two years, and harder. They first protected the lands, built terraces because the lands were not horizontal, improved the hillsides, built contention walls, and carried the materials in this difficult geography. After the houses were constructed, they paved the access road and worked in a small water project (for this last work they were paid). 
In two-parent households, women took the responsibility of constructing the houses and men went 'to earn the frijoles to eat' (LIW). Single mothers did not have anyone to help them: 'Some days we stood being hungry... and our children walked behind us...' (HIW); they would eat mangoes for months. There were 'problems of relationships and understanding' (FUNDASAL, 2003a, p. 5) and 'uneasiness and fatigue..., non-attendance to work and negative behaviours' (ibid, p. 6). People needed time and energy to work in agriculture, which they did not have. Food channelled by the Catholic parish was insufficient. Some specific and short-lived initiatives took place: a public institute donated seeds and the parish priest provided fertilisers to help households to sow something in the colony. Finally, some people from other cantons helped in the construction because the situation was unbearable.

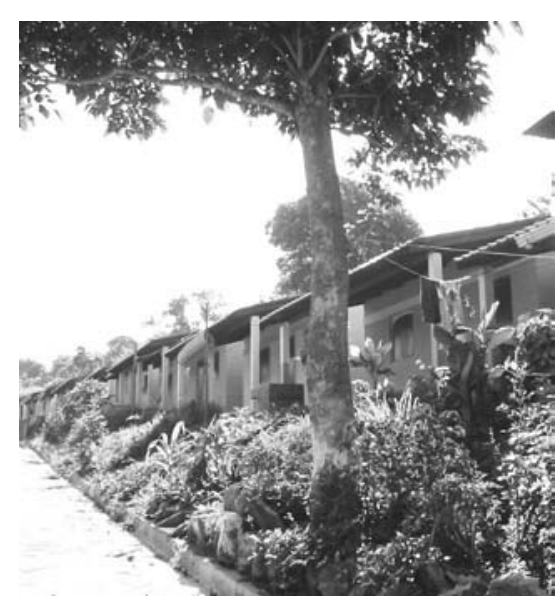

Photo 9-4: Human settlement in Galingagua (LD, August 2004)

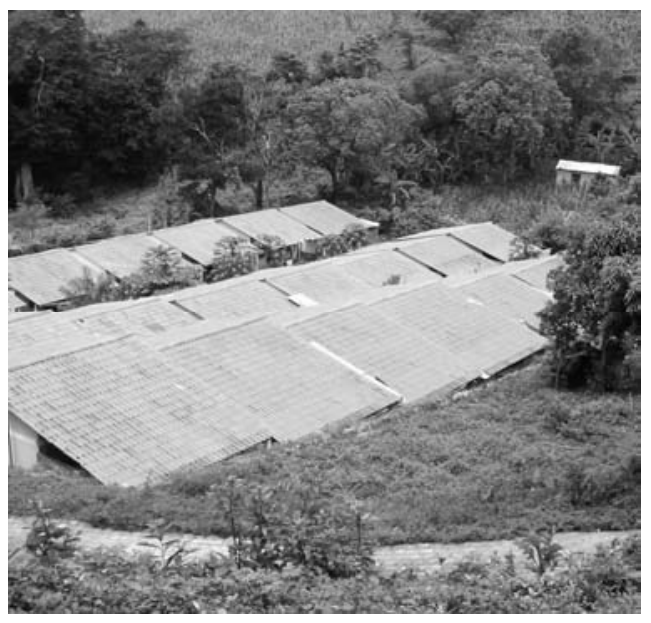

Photo 9-5: Human settlement in Buenos Aires (September 2005)

In contrast, some wealthier people hired manual workers to take their place in the mutual help group. It was the case for $35 \%$ of beneficiaries in the urban centre, but less than $4 \%$ of beneficiaries in the cantons of Galingagua and Buenos Aires.

To construct the social infrastructure, residents also collaborated as unskilled assistants. However, the scale of mutual help was lower because people were very tired. A man explains: 'we also had to work [in the park] without earning any money.... We worked everywhere, in the houses, in the septic tank, even in the street' (LIM). The residents of eight rural villages, not served by the housing project, worked in the common infrastructure. In addition, many external bricklayers were hired. Moreover, some residents did not attend the inauguration of the main square and community centre, not expressing any regret or sadness for this, which could reflect that they did not value such infrastructures or did not share a sense of community. Working hard for a long time could have explained this lack of interest.

\section{- $\quad$ Family property}

A drunken man cannot leave his family in the street (LIM).

Family property means that the house 'cannot be mortgaged, burdened in any way, donated, sold, exchanged or alienated' (FESPAD, 2002c, citing 'the Family Property Law', 
section 12, subsection 1) until the younger child is 18 years old. The project promoted this feature since the formulation. LD (2001c) states:

The Salvadorian society has cultural patterns with low recognition of gender equity.... Efforts to overcome this situation are required, such as the elaboration of legal documentation to share rights and give law security to the woman and the family as an integral unit (II 163).

Family property became a condition for all reconstruction projects to be considered of national interest, according to decrees dictated by the Salvadoran government (Burri, 2002d).

Only men talked about the family property during the fieldwork. Some men valued its role to protect children and wives, but others reported not having been aware of its economic consequences, at first. A man, in an interview, resented: 'This is my land, my work and, on top of that, I cannot mortgage my house to get credit'. He added: 'If they had explained well, many people would not have accepted'. Information problems might be explained by a deficient coordination between leaders at the start of the project (FESPAD, 2002b) and the low attendance of residents to the information sessions (FESPAD, 2003a; 2005a). It seems that some people accepted the family property as a requisite to have a house, as they were not well informed.

\subsubsection{The working group faced coordination challenges at several levels}

The project was supported by complex relationships among different private and public entities. This section focuses on CRDM, which was the functional local counterpart, and on the dynamics of inter-institutional coordination.

\section{- Local counterpart}

The proposal promotes the probability of reaching a sustainable development via the insertion of beneficiaries as much in the decision-making as in the whole process of formulation and implementation of the reconstruction plan (LD, 2001c, II 98, [emphasis added]).

The Committee of Reconstruction for the Development of the municipality of San Agustín, CRDM, led all the reconstruction activities in the municipality. CRDM does not intend to replace the role of the municipality government; rather, CRDM has a complementary role to guarantee 'representativeness, equity and democracy in the processes of local government' (MSA, 2004b, p. 54). This committee was composed of three entities (Table 9-5).

Table 9-5: Organisational structure of CRDM (San Agustin)

\begin{tabular}{|lllll|}
\hline Entity & Role & Function & Members & Meeting \\
\hline $\begin{array}{l}\text {-General as- } \\
\text { sembly }\end{array}$ & $\begin{array}{l}\text {-Maximum repre- } \\
\text { sentation }\end{array}$ & $\begin{array}{l}\text {-Long-term } \\
\text { planning }\end{array}$ & -5 representatives per locality & Quarterly \\
\hline $\begin{array}{l}\text {-Executive } \\
\text { committee }\end{array}$ & $\begin{array}{l}\text {-Representation } \\
\text { and execution }\end{array}$ & -Strategies & $\begin{array}{l}-2 \text { representatives per locality + } \\
\text { mayor + other councilperson }\end{array}$ & Monthly \\
\hline $\begin{array}{l}\text {-Board of } \\
\text { directors }\end{array}$ & -Execution & -Operations & -6 members & Every 15 days \\
\hline
\end{tabular}

Source: CRDM (2001).

Each locality (a canton or a neighbourhood of the urban centre), organised in a local association or ADESCO, assigns five representatives to the general assembly. The members of the executive committee and the board are elected in assembly to serve for a two-year period. The board of directors is composed by a president, a vice-president, a secretary, a pro- 
secretary, a syndic and a pro-syndic. The first board was re-elected in 2003; a new one was elected in 2005. There are also invited members (without voting rights): the priest, the director of the health centre, a representative of the education sector, one of the police, one of the tribunal, and two of FUNDAMUNI. Contractually, the municipality government takes part in the executive committee; in practice, its involvement is relatively low.

The project supported CRDM through two main channels. First, the project chief defined an incidental objective: to support CRDM in its management of other projects and coordination with other agencies (Burri, 2002a, p. 4). Under his auspices, CRDM leaders learned to interact with several public and private institutions. Second, the project contributed with money to train local leaders on organisation and register four local associations. The support was indirect, not affecting the intra-community relations.

During more than three years that the project lasted, the representativeness of CRDM developed as new local organisations were formed and joined the committee. It explains that FUNDASAL (2003c) reported organisational problems such as lack of commitment of leaders to monitor project activities, low support of CRDM to local committees, certain indifference of the municipality government, and anger of some residents toward members of CRDM. ${ }^{65}$ These problems reflected that most people felt poorly informed in terms of what they initially expected (dataset 1), ${ }^{66}$ although information levels varied. It seems that, after decisions were made by the working group, leaders did not consult or inform others about design or management issues. Pedro explained that delinquents tried to highjack the project chief twice and that he himself was shot when driving the project's motorcycle. In this context, they did not want people to know how much money and other resources they were managing or which new projects were being planned because, as project staff and community leaders, they would be more attractive to delinquents.

\section{- Intra-project coordination}

Sometimes, the problem of FUNDASAL was the employees. There was no an institutional identification with the communities (the FUNDAMUNI promoter).

In the context of social housing... the focus is usually the cost-benefit ratio. I am asked to try to give more solutions, more adequate, to the majority of people (the FUNDASAL construction department chief).

In theory, the partner NGOs shared the same goal: promoting sustainable development with a focus on human beings as agents (see Table 9-6). In practice, they faced different pressures from external institutions, which influenced their interactions within the working group. The project chief institutionalised a consensus building style, for which each entity had the chance to contribute or complain. However, although the three NGOs initially seemed to share a vision, it was difficult to align their objectives.

\footnotetext{
${ }^{65}$ From interviews, it seems that the municipality government was more active immediately after the earthquake than during the project, probably due to the lack of resources; however, it donated lands.

${ }^{66}$ On the contrary, according to dataset 2, everyone received information during the project. The question in dataset 1 is more precise (information that they needed) and there is an intensity scale, while dataset 2 only allows a binary response.
} 
Table 9-6: Characteristics of the NGOs involved in the San Agustin project

\begin{tabular}{|c|c|c|}
\hline & Mission: & Main points in favour: \\
\hline $\begin{array}{l}\text { FESPAD } \\
\text { (Legal) }\end{array}$ & $\begin{array}{l}\text { 'To contribute to the development of a social } \\
\text { coexistence that is harmonic, fair and democratic, } \\
\text { based on the State Constitutional Law and the } \\
\text { respect of human rights' (FESPAD, 2003e, p. 1). }\end{array}$ & $\begin{array}{l}\text { - Experience in the defence of hu- } \\
\text { man rights during the civil war. } \\
\text { - Contacts with judicial entities in } \\
\text { Usulután. }\end{array}$ \\
\hline $\begin{array}{l}\text { FUNDASAL } \\
\text { (Construction) }\end{array}$ & $\begin{array}{l}\text { 'To contribute to the improvement of popular } \\
\text { habitat is the means to reach people's participa- } \\
\text { tion in decision-making' (FUNDASAL, n.d., II 4). }\end{array}$ & $\begin{array}{l}\text { - Experience since } 1968 \text { in popular } \\
\text { housing with emphasis in mutual } \\
\text { help. } \\
\text { - } \text { Relative low construction cost. }\end{array}$ \\
\hline $\begin{array}{l}\text { FUNDAMUNI } \\
\text { (Local partici- } \\
\text { pation) }\end{array}$ & $\begin{array}{l}\text { 'To facilitate processes of local sustainable devel- } \\
\text { opment... by opening spaces... to make possible } \\
\text { the participation and consensus building in stra- } \\
\text { tegic decisions of the municipality' (FUNDA- } \\
\text { MUNI, 2005, p. 1). }\end{array}$ & $\begin{array}{l}\text { - } \text { Already supporting CRDM; pro- } \\
\text { moted its creation. } \\
\text { - Present in the region since } 1999 .\end{array}$ \\
\hline
\end{tabular}

Based on FESPAD (2003e), FUNDASAL (n.d.), FUNDAMUNI (2005), and LD (2001c).

The sequence to identify beneficiaries was defined during the project execution. First, the leaders and the PIU checked the fulfilment of the selection criteria. Second, when there were borderline cases, the decision was taken by the working group. Third, when there were 'social' or special cases, the working group consulted the general assembly. For instance, the health centre director, the high school director and the mayor received a house, although they did not fulfil the selection criteria, as decided by the assembly due to their role in the community. Another example is the construction of smaller houses or one room as an annex to a house to provide solutions for single people with a small piece of land or without lands.

Once the beneficiaries were identified, the following steps continued:

- $\quad$ FESPAD made the legal diagnosis and delivered a list of feasible cases to the project chief;

- The project chief gave the list to FUNDASAL;

- FUNDASAL inspected the land (where to build the house) and collected socio-economic information about the household; and

- If the household qualified, it was prepared to participate in the directed mutual help.

The construction pace was marked by the work of FESPAD, which in turn depended on public institutions. Delays in the legalisation of land titles, caused by the complexity of the cases, brought certain tension between FUNDASAL and FESPAD. When the experience and contacts of FESPAD were insufficient to speed up the process, the project chief intervened at a high level before public entities. These delays increased costs for FUNDASAL, whose attitudes were misread by others as a lack of commitment. ${ }^{67}$ However, FUNDASAL lacked experience in complex buildings such as the multi-purpose communal centre (predictable), so that the project chief kept a close supervision.

\section{- Extra-project coordination}

Every month, we had a meeting here [at the departmental government seat] where the institutions presented their issues.... With mutual support, we reached a communication system

\footnotetext{
${ }^{67}$ Based on individual interviews with the three NGOs, the project chief, other stakeholders and project documents, it seems that the interactions within the working group evolved over time to the detriment of FUNDASAL, whose voice was slowly disappearing from discussions (cf., Mosse, 2005).
} 
from the grassroots.... Our work was to coordinate this process, help with some resources, and integrate efforts (the departmental governor).

Many entities were directed or indirectly related to the project. The number of contacts increased because the project chief decided (i) to support CRDM in much more than what the terms of reference indicated, and (ii) to provide houses to as many people as possible despite the complexity of their legal situation (e.g., looking for land donors or alternative solutions).

In practice, coordination was difficult (Burri, 2004d) because of the initial lack of support of political authorities, bureaucracies in public organisms and private companies and the lack of administrative staff in the PIU. Nevertheless, as the project consolidated, the departmental government of Usulután and the Ministry of Foreign Affairs of El Salvador became the facilitators of the project at the national level.

\subsubsection{Accountability for outputs had several sieves}

The houses and other infrastructure are the tangible project outputs.

\section{- $\quad$ The quality of the owned houses}

I did not dream to have a house like this one (LIM).

I had never owned land; with their help, I got a house and a deed (LIM).

People feel secure in their houses because they know that the foundations are deep and the materials are good, as leaders selected the best. Moreover, they legally own the houses. There were three models of houses depending on the extension and slope of the land; some individual adaptations were also made. Even those who received prefabricated houses expressed that their 'houses [were] beautiful and very fresh' (HIM).

Residents were very satisfied with the quality of their house ( $80 \%$ of the survey respondents said so), as a man tells: 'We do not have to change sticks, beams or gates, which we used to do every year, before rainy season. It is not necessary to repair' (LIM). Furthermore, the pastel colours of their houses make their towns to look more beautiful.

Nevertheless, some residents who live in the human settlements or worked in the last groups complained about delays to receive the materials. A man reports: 'They did not give importance to the last houses' (HIM). Another man adds: 'In contrast to the first groups... we had to make the pavement around the house; we had to finish our houses' (HIM).

However, looking back, no one wished to benefit from other donor but Luxembourg.

\section{- Utility of social infrastructure}

The little market place was not needed inside the park. It was better to get another little piece of land and put the market place there (HIM).

In general, people are grateful with the project, but some aspects must be highlighted. First, the social lodge-hospice, built on a land of the Catholic parish, was empty during the fieldwork. A probably reason is that potential guests (old age people without relatives) would not want to risk losing the support of their temporary families in case of moving out, given that no public institution could secure food for them. Several forms of management were under consideration (Burri, 2003c), including a joint management by different churches. 
Second, the multi-purpose communal centre is a high-quality construction of two floors. It hosts CRDM and the culture house. It has an auditorium, stores, offices, a library, meeting rooms, toilets, and so on. There is also a mini-department for visitors. The centre is fully furnished and well-equipped, with several computers, printers, faxes, and water dispensers. People feel very proud of it. However, there are two troubling points: (i) its modern infrastructure contrast with others, including the municipality hall, and (ii) its maintenance costs are high and residents can hardly cover them. The municipality government committed to make a monthly transfer to CRDM to cover administrative costs, but only did it once as it was highly indebted (Lopez, 2006). The revenues of CRDM, coming from contributions of the local committees, are not enough to cover these costs.

Third, there were different opinions about the main square and its infrastructure. Basically, people like the high tower clock and the bells. The tower clock had the imprints of projectiles from the armed conflict and had been damaged by the earthquakes but, after restoration, it became a symbol of renovation. In contrast, some people complained about the covered market area, whose design they did not know in advance.

\subsection{U nderstanding individual autonomy in San Agustín}

This section explores the meanings of autonomy for San Agustín residents and its importance in their lives. This analysis is based on the fieldwork carried out during September 2005, the same year that the project officially finished its operations.

\subsubsection{Low access to economic resources restricts their autonomy}

We are poor here due to the lack of work. We keep on by sowing grains (HIW).

FGD respondents talked of several aspects of agency: physical capacities, such as being well versus being ill (as they felt during the civil war); intellectual capacities, such as being literate and learning new skills; and emotional capacities, related to feel respected versus to feel desperate or unhappy. They valued to be taken into account, to be able to express one's needs, to be respected by others, and to have good relations with their neighbours.

Access to resources and support from others promotes autonomy

Residents emphasised that having access to resources brings security for a life with dignity. Food and income security are means to have this life. Having a basic nourishment level makes possible 'to be able to work' (HIW). Having an occupation is a core resource to advance by oneself. Basic services and infrastructure open opportunities (HIM).

Their poverty limits their autonomy, which they exercise to some extent: 'We are very poor, but with effort and everything, we get along' (LIW). Participants highlighted that the support from others, such as the municipality government, a partner organisation or a donor is necessary to expand the access to services such as education for children, and to be able to pursue their common goals.

Skills and income sources alternative to agriculture are valued

Most household heads contacted during the fieldwork declared to be farmers or agriculture workers ( $80 \%$ of male heads, but $13 \%$ of female heads). Hence, land ownership is crucial. However, residents need credit to sow and make a living, which is scarce. 
Then, residents wished they could have work options to not depend on subsistence agriculture. Acquiring new skills is valued. For instance, a man reflects: 'those who did not learn anything [during the project] are still [t]here, sowing maize to survive' (HIM). Unfortunately, residents do not have many chances to acquire skills, especially agriculture workers without stable contracts. A man explains his experience, soon after the earthquakes:

I started the electrician training, but I could not finish because I had too much work in the lemon finca... If I left the finca, I could not enter again.... [The training] was interesting, but I opted for the finca, planning to follow it on another occasion (HIM).

He did not find another opportunity to retake the training.

Being educated promotes social participation

Literate people can be better informed about opportunities as they face less difficulty in public meetings (LIW). Nevertheless, the official adult literacy rate for the municipality is only $65 \%$, below the national rate of $83 \%$ (UNDP, 2005c), and the rate for the survey respondents is even lower: $52 \%$ (dataset 2). This could explain that about $20 \%$ of the respondents declared that the information provided during the project was not easy to understand.

Most people live in poverty, but the situation of female-headed households is the worst

Most residents live in poverty and do not receive remittances. In the municipality, about $66 \%$ of the households are poor and $14 \%$ receive remittances (UNDP, 2005c). ${ }^{68}$ In the project area, around $83 \%$ of the households would live in extreme poverty, but only $8 \%$ reported to receive remittances (dataset 2). Many people cannot afford to go abroad.

Figure 9-6: Socio-demographic characterisation of project beneficiaries (2005)

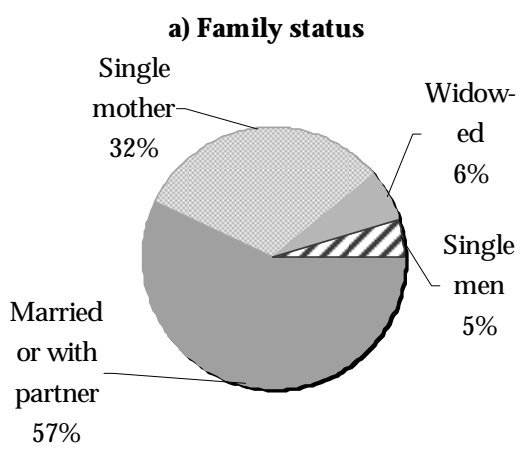

\section{b) Occupation}

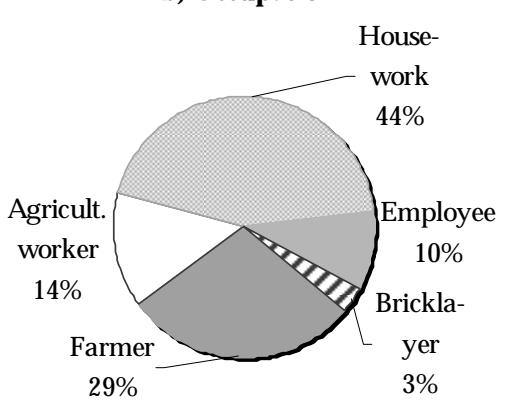

Note: It shows data for all 438 beneficiaries served by the project (female=220, male=218).

Source: FUNDASAL (2005b).

Figure 9-6 shows that almost one-third of beneficiaries were single mothers. ${ }^{69}$ During the fieldwork, $36 \%$ of the household heads contacted were single mothers. Most of them de-

\footnotetext{
${ }^{68}$ The poverty rate has several estimation and methodological problems (WB, 2005; UNDP, 2007). Moreover, official population projections indicate that there were 4,470 inhabitants in 2005 , while the census prepared by CRDM in 2004 indicates that there were at least 7,835 people.

${ }^{69}$ Beneficiaries are not necessarily household heads (e.g., the wife inherits the land from her parents). In addition, the number of houses is not equal to the number of households. For instance, siblings living in one house can economically depend on an uncle living with his nuclear family in another house.
} 
scribed their situation as very difficult because they could not afford to rent a plot, so that they make a living from growing vegetables and raising chickens in their gardens or washing clothes for others. Nearly $60 \%$ of the female heads declared to be housewives, without any certain income source.

\section{Special agency features support aspirations}

Two characteristics are crucial for most people in San Agustín: their capacity to fight and their optimism. About the first, the governor said: 'these are fighting people; they do not get scared' because despite the civil war, the years of abandonment, and the disasters, they try hard to improve the lives of their families. About the second, the parish priest underlines:

Amid the ashes, they always restart with happiness... At the time when they were sleeping in the huts, I would find them in the street, calling people with the sound 'chhh', in the midst of hardship.

These characteristics are important inputs for initiating any change. Soon after the earthquake, a woman (cited by Moreno, 2001, II 7) explained:

The media said that San Agustín was destroyed and disappeared. But San Agustín has not disappeared; we are here, only the houses disappeared and we are going to rebuild them.

\subsubsection{Cultural and social factors influence intra-community relationships}

If we are not united, there is no force; there is nothing without union (HIW).

A community without organisation is not a community (HIM).

This section analyses the relationship between individuals and their community from two perspectives: normative, or what the respondents think the community should be, and practical, or what they perceive the community's role is in their lives.

From the first perspective, FGD participants associated community with notions of values, organisation, and resources. Values and organisation were closely linked in their statements. Among values, the most important was union, together with responsibility and communication. Residents expressed that a community must be united and that each person has to fulfil their commitments with responsibility. This is possible when all pursue the same goal, which has to be 'good', that is, a goal that does not create differences among people and that brings all leaders together (LIW), CRDM and local leaders. Ideas of solidarity, working together and helping each other were associated with such a pursuit. Some men expressed that the organised community has to be able to make decisions and reach agreements (LIM), which might be a lesson from the project. Resources are relevant because people have suffered hardship since the civil war; having a work was the core resource.

From the second perspective, most people (especially women) perceived more collaboration within small groups than in the whole community. For the most part, they felt that people were solidary (around $72 \%$ of the survey respondents). However, around $87 \%$ expressed that 'someone could take advantage' of them. These results could mean that people trust certain individuals or neighbours, but they perceive the global context as insecure (cf., Escobar, 2007; Fuentes, 2003).

Table 9-7 shows that most survey respondents feel to have low control over their lives at three different levels. Women perceived to be less in control; a feeling related to patriarchal family 
style (men take decisions in the household) and lower options to participate in public life. This is corroborated by the low participation rates of women in CRDM. In 2001, when CRDM was constituted, only $15 \%$ of the assembly members were women. In 2004, when the municipal development plan was approved, participation rates of women in the board, executive committee, and general assembly were $13 \%, 19 \%$ and $28 \%$, respectively. Even among leaders, only single women or widows participate in local associations. A leader in the FGD expressed that 'when women are accompanied, they do not participate anymore' because their husbands would not let them.

Table 9-7: The extent of control on decisions by gender and social domain in San Agustín

\begin{tabular}{|lcccc|}
\hline & \multicolumn{4}{c|}{ Extent of control (\% of respondents) } \\
Women & No & Little & Fair & Nearly full \\
\hline a) Own life & 34.6 & 38.5 & 19.2 & 7.7 \\
b) Family & 15.4 & 57.7 & 19.2 & 7.7 \\
c) Community & 57.7 & 23.1 & 15.4 & 3.9 \\
\hline & \multicolumn{4}{c}{ Extent of control (\% of respondents) } \\
Men & No & Little & Fair & Nearly full \\
\hline a) Own life & 0.0 & 61.5 & 30.8 & 7.7 \\
b) Family & 7.7 & 53.9 & 30.8 & 7.7 \\
c) Community & 23.1 & 53.9 & 7.7 & 15.4 \\
\hline
\end{tabular}

The questions were: How much control do you feel that you have over a) your own life's decisions, b) your family decisions, and c) decisions that affect the development of your community?

Source: Dataset 2.

On the one hand, respondents seemed to value their community's organisational structure and $26 \%$ of the survey respondents said that they could participate more. On the other hand, they are not as active as they were during the project. Furthermore, most FGD participants and people individually interviewed expressed that they felt powerless to affect their lives and expect help and initiatives from others. This could reflect that, in contrast to leaders, they did not exercise decision-making in significant matters during the project (see section 10.4), but contributed to the project with their manual work.

Figure 9-7: The role of community as enabler of opportunities in San Agustin

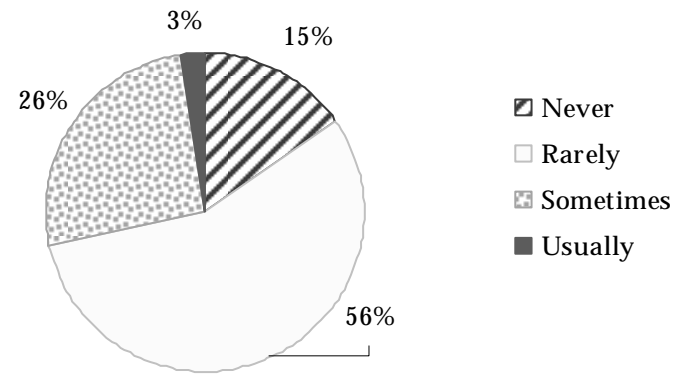

The question is: How frequently do you feel that the community expands your opportunities? Source: Dataset 2.

Figure 9-7 shows that more than $70 \%$ of the respondents consider that their community rarely or never expands their opportunities. This result, in comparison with the previous elements, suggests that respondents felt that they cannot help their community and do not receive enough support from it. Considering that the project had just finished and that mutual help and consensus building were the most relevant practices, it seems that the upper level struc- 
tural contexts and their poor living conditions have stronger influence on their expectations than the closer social context, which improved with the project.

\subsubsection{Communal participation is low but people can be mobilised}

The organisation is not functional or strong because we are the same, a few people, who participate (a man leader).

This section discusses how the non-leader inhabitants of San Agustín participate in associations. Asked to list the existing associations in their community, without prompting, about three-quarters of the survey respondents identified one: CRDM. Only four people (out of 39) listed a religious organisation, the culture house, the police support committee or a cooperative. There are other organisations that people do not recall immediately as leaders are the most likely to interact with cooperatives, NGOs or employees of public programmes.

Only $18 \%$ of the survey respondents declared to participate in community organisations (men more than women). Although $54 \%$ said that they collaborated in communal works (e.g., cleaning), 18\% said that there were no longer any communal works, so that 'people only clean around their homes' (a non-leader man). Only some people in the human settlements cleaned the stairs and cut the forest. In fact, several stakeholders commented that participation decayed after people got their houses. Motivation was extrinsic for some, as a woman non-leader recounts: 'The mayor hired someone to take care of the park; hence, we are not obliged to participate'.

This relative apathy contrasts with the enthusiasm showed during the project by most people and suggests that residents expect leaders to promote new actions. Given the timing of the fieldwork (three months after the farewell to the project chief and when the municipality government had failed to transfer resources to CRDM), leaders were facing economic difficulties to sustain the organisational structure.

Leaders were feeling tired, but they had developed some tools to identify 'new' leaders. For instance, a youth group, initially focused on sex education, now deals with topics related to organisation. A woman, member of one local committee, belonged to this group.

Times are changing; people are friendlier with neighbours and think of working together if necessary. A man reflects: 'Now if we find someone in the street, we greet him or her. We know how to live together' (HIM). However, their past experience of insecurity and mistrust related to the armed conflict still affects their communal participation. What they do is different from what they say they should do (values) or what they perceive they do. The low communal participation is coherent with the majority's perception that the community does not expand their opportunities. However, $84 \%$ of the respondents declared that their leaders are more effective in responding to their needs than what they were seven years ago. They could listen to leaders and act based on their call, 'assuming their responsibilities' (HIM).

The legitimacy of CRDM relies on its broad base and explicit political neutrality as it was formed by people with different political and religious orientations. In August 2005, the recently voted CRDM president resigned his position, pleading conflict of interests, because he was employed by the ministry of education (as director of the culture house) and did not want to put in risk the political independence of CRDM. The general assembly replaced him by the candidate who placed second in the elections. 


\subsection{Assessing project impacts on autonomy}

This is a complex project with multiple objectives defined during the formulation and implementation. Working hypotheses about the potentials impacts of the project on determinants of autonomy, their assumptions and outputs, and their evaluation appear in Table 9-8.

\subsubsection{Physical security but not economic entitlement to houses}

The main output of the project was the houses. Residents are satisfied with their quality (section 9.3.4), which is similar for every beneficiary. Likewise, they value to have legal ownership of their houses, which gives them emotional security (cf., FESPAD, 2005a). Nevertheless, opinions about the family property are diverse (section 9.3.2). Those who registered their house as family property (one-half of the cases) cannot mortgage their houses to obtain credit, which limits their economic entitlement.

On the other hand, some people were confused about the selection criteria. They knew they 'were favoured' because they had or got the property title, but ignored the other criteria. Being able to get a house was, in part, a matter of good luck. In fact, the census was checked four times to avoid opportunistic behaviours (reported by the project chief), as some people came back to San Agustín, after years living somewhere else, only to receive a house. At times, project beneficiaries felt the envy from others who 'did not achieve anything' (LIW).

Social infrastructure built during the project had a positive effect on the whole community. As expected, it symbolises the continuity of the town and its strength (section 9.3.4). However, maintenance costs of the multi-purpose community centre are high in relation to the resources of San Agustín inhabitants.

\subsubsection{The positive effect on agency could be lower than expected due to con- trolling project practices}

An intended outcome of the project was the development of construction skills by nonleaders. Less than $20 \%$ of the survey respondents declared to have received formal training during the project, but they received only general guidelines about their work. In-work training was an explicit practice with positive results (section 9.3.1). However, project participants were not aware of this method, so that, they associated their acquired skills with the good will of bricklayers who gave them the chance to learn (HIM) or their own interest to learn despite the stressful context (LIM).

With respect to soft skills, the intended effect on identifying new leaders based on their work (section 9.3.1) did not occur. Local leaders pre-selected the participants of training sessions on organisation and management. In addition, in some occasions, having high responsibilities in a work group constrained the training options. Two coordinators of the human settlements expressed that they were overloaded with multiple tasks A woman, coordinator and store-keeper, kept working despite everything:

I did not mind; they even insulted me... and I still had to help them, after everything that they did to me and told me.... They even made me cry (HIW). 


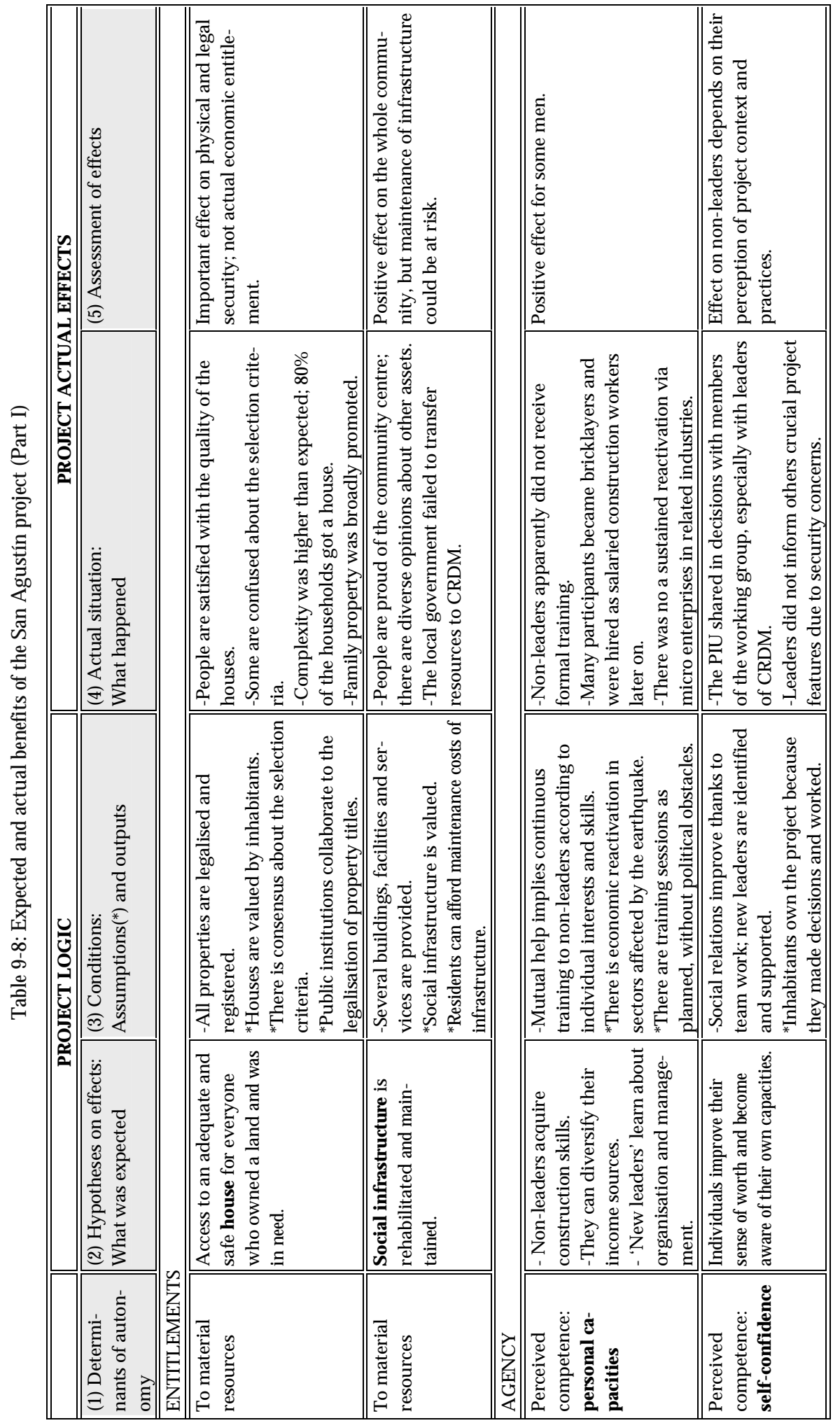







She was so busy that could not have any training. Besides, some people made fun of people in training (HIW). Many people could not attend meetings because they had to provide for their families.

On the other hand, there was a short-term economic impact for (i) residents who learned construction skills and were hired to build the social infrastructure or took part in other housing projects in the municipality, and (ii) inhabitants of the human settlement in Galingagua who worked during the small water project and received a payment. However, after the reconstruction period passed, most people cannot find job as a bricklayer in the region because there was not a sustainable economic reactivation. For doing what they know best (agriculture), San Agustín residents did not receive support from the project. The economic vulnerability of the households did not decrease.

A negative aspect related to the controlling context in the work groups is that people had low chances to work and to be well fed. A man recounts:

Here, one felt that one was not going to earn for oneself... One worked here and down there [in the plot]... I felt that it was a lot [of work] (LIM).

The physical health and strength of people in the human settlements was at risk, thus delaying the works and harming interpersonal relations, in opposition to the intended positive effect of the mutual help practice. Indeed, self-construction activities for long periods 'are extremely difficult if targeted beneficiaries are poorest of the poor and cannot become involved unless they have alternatives to support their daily life' (Osti, 2004, p. 8). However, there were signs of solidarity: 'The one who had [food], cooked and gave us a tortilla; when we worked together, we did not feel hungry' (LIM).

In terms of self-confidence for non-leaders, there were several positive impacts related to: i) the joint work in mutual help groups, when members organised their work, discussed problems and safeguarded the good quality of their house, ii) the awareness of personal skills, and iii) the satisfaction of having a beautiful house. Nevertheless, the final effect depends on the individual perceptions of the project context and practices, which in turn are related to the process how these practices evolved. As leaders did not transmit some crucial information to their neighbours (section 9.3.3), several felt obliged to work thus feeling harmed. However, others saw their work as part of a community commitment. Through leaders, many felt that they were able to express their needs, so that they felt confident (LIW).

The effect on self-confidence was only partially captured by the survey questionnaire. An increase in self-confidence is not necessarily expressed openly..$^{70}$ People might not speak up, but they can still feel more confident because they are doing by themselves something good for their families and community. In addition, legal information was difficult to understand and, most likely, people did not have a chance to argue about their cases. A man explains:

We did not have the deed and we had to wait almost one year. We ignored all the process.... We came to ask and, finally, the NGO told us that these issues were common (HIM).

About $82 \%$ of the respondents said that their participation was sufficient or high. This selfreported degree of participation was positively associated with giving opinions (Kendall's

\footnotetext{
${ }^{70}$ This element of 'voice' was explored through the question: 'did you express your opinions during the project?' The question was asked in both surveys (pre- and post-focus group), but the results were contradictory.
} 
tau-b, $\tau=0.332, p=0.03)$ and with applying their skills during the project $(\tau=0.372, p=0.02)$. This could mean that those who gave their opinions during the project felt more involved in the project, so they applied their knowledge and participated more.

The elaboration of the municipal development plan (section 9.3.1) could have fuelled a projective temporal orientation as this plan defined long-term objectives and strategies. However, the effect was larger on leaders who were more involved in its elaboration. No one nonleader, during the fieldwork, talked about the plan. It seems that, in some cases, the participation of non-leaders was low or driven by extrinsic motivation. In contrast, residents did talk about the sister cities agreement with Préizerdaul and have positive expectations of the continuity of the relation with Luxembourg. In any case, expectations could be too high as the fund available is small in relation to the identified projects (section 9.2.3).

The participatory logic of the project implied that local actors would feel originators of their actions through effective decision-making, that is, the project would support an autonomy causality orientation. However, non-leaders delegated many decisions to their representatives and focused on the most relevant tangible output: their houses. They were informed about their legal situation and took decisions about small modifications in the house design because they were working for their houses. They feel originators of the success in achieving a worthy house. In contrast, leaders shared in decision-making about other aspects relevant for the community, but at different levels.

Non-leaders did not express intention to carry out projects by their own initiative, during the fieldwork. Some non-leaders feel incapable to initiate change and do not feel support from their community (section 9.4.2), unless they have the help of external actors. The role of the leaders vis-à-vis external actors is perceived differently by residents. Some respect their leaders, while others regard their relation with the donor with suspicion. For instance, a man criticised that the former president of CRDM had worked as project assistant and earned a salary, when everyone else worked in the project based on commitment. In many cases, residents do not know the role of CRDM in the working group and, to them, 'Luxembourg is everything' (reported by a Catholic priest).

\subsubsection{The project supported an undergoing change in the micro-level context}

The project had an intended positive effect on community organisation. LD (2001c) expected:

A strengthening of self-worth, awareness of the latent potentialities of the community and confidence in their own capacities by the actors [that would allow them, with the adequate training,] to propose, manage and implement future interventions and projects by themselves (ibid, II 101)

When the project started, the residents of San Agustín were already living a change process; so that CRDM was leading the reconstruction efforts. Taking advantage of the resources and dynamism, brought by many proposals to help after the earthquakes, the project supported the organisation as a partner, respecting their process (CAMIRE, 2005) in order to achieve sustainable actions (cf., Ellerman, 2006). As the governor affirms, 'they already had the seed, which flowered during the project'.

For the first time, leaders are better able to hold political leaders accountable given the wider information available to them, not only about the project but also about the financial situation of the municipality. Besides financing training courses, registration costs for asso- 
ciations and the elaboration of the development plan, the project covered some administrative costs of CRDM (e.g., transportation, electricity and a monthly salary for the CRDM president). However, a most crucial achievement is that leaders gained connections with external actors (cf., Johnson, 2001) and became empowered through relationships. They learned how to address people, to whom ask what and how to ask the things. These skills would be important after the completion of the project. Nowadays, they have the motivation 'to undertake other activities, to initiate contacts with other organisations and to engage in dialogue with anyone at any moment' (as expressed by a LD officer), so that:

Some public institutions do not turn to the municipality government, despite that it belongs to the national government party; they come to CRDM to carry out some formal processes (the FUNDAMUNI coordinator).

There were important effects on social capital, not necessarily intended by the project, at least at the interpersonal and the community level. First, people who were open enemies before the project became reconciled because they faced the same problems, had to work together, and shared the same enthusiasm for advancing in the building of their houses. Nevertheless, during the project, there were some difficult times with verbal aggressions, physical threats (e.g., to coordinators of mutual help groups) and robberies of construction materials. Second, at the community level, the legalisation process itself 'reconstructed the population identity, their history' (said an officer of the MFA of El Salvador). Communal identity also was supported by the rehabilitation of the main park with the bells and the installation of the culture house.

The project did not succeed to reduce the economic and financial vulnerability of the municipality government because there was neither economic reactivation (i.e., no rise in tax base) nor improvement in management capacities as result of training activities. The training planned for the municipality staff did not take place due to political matters. ${ }^{71}$ The diagnosis of the municipal financial potential, prepared for FUNDAMUNI, established a baseline but did not evolve to a plan.

\subsubsection{Differentiating impacts on autonomy among individuals}

This section discusses some different impacts on individuals grouped according to their leadership condition and gender. In contrast to other cases, the level of involvement in the project is not a variable of analysis here because the focus groups were relatively small. However, it is worth mentioning that there were no clear-cut differences in the listing of effects identified by participants with different levels of involvement.

\section{- Impacts on leaders: more capable leaders to do what?}

Leaders shared in decision-making during the project, especially through CRDM that was the local counterpart of the project and member of the working group. Leaders exercised negotiation skills when interacting with other institutions and management skills with the support of the project chief throughout the three-year project. Some leaders improved their sense of worth and self-efficacy, especially the CRDM president (and project assistant). The

\footnotetext{
${ }^{71}$ First, the cause was the electoral period (elections in March 2003) and then, the management moved to a small house while the municipal hall was rebuilt (March - October 2004). Finally, in September 2004, the LD regional director decided that the time had passed (Burri, 2004c).
} 
latter, at some point, thought of running for municipal mayor but desisted after recognising intents of co-option.

It seems that 'groupthink' (Cooke, 2001/2004) developed, to a certain extent, influenced by the long stay of the project chief in the village who became an insider (Crocker, 2004). Groupthink could have explained some failed investment decisions that, although responded to real needs, were solutions unattached to cultural norms and social practices such as the unoccupied social lodge-hospice or the covered market area in a side of the central park. The project chief and assistant even developed their own 'development' discourse (de Vries, 1992), which gained symbolic power overt time but dramatically changed when the project was completed. The CRDM president's self-reliance and optimism during the project transformed into a feeling of hope to do the best. In fact, leaders recognise that their lack of resources and large family responsibilities restrict their opportunities to deepen the influence of the community organisation because the same people always led the efforts (section 9.4.3).

As seen earlier, the project financed several courses for local leaders and new leaders. Formal training came from FUNDAMUNI, FUNDASAL and CRDM and covered topics so varied as project management, municipal law or English language. Sessions about human rights, to be offered by FESPAD, were stopped due to political reasons (as reported by a priest). In addition, CRDM was channelling small projects in agriculture.

The reconstruction project was the means to facilitate awareness of capacities. This was the case for leaders, who experienced 'a change of vision' (Burri, 2002b, p. 2), but not for all nonleaders. Local leaders in rural cantons and urban neighbourhoods were not as involved in project activities and decisions as CRDM leaders. This has consequences for community identification and participation. One man leader explained though that overall, the main impact was that people now have aspirations: they 'talk of development', whose vision is captured in the development 'master' plan. This assertion does not hold for most nonleaders. In contrast, leaders did strengthen their autonomy causality orientation.

Leaders listed the three most important impacts of the project on the community:

1. Solidarity, linked to the mutual help modality of work;

2. Security, for having a worthy house, well built and with good materials; and

3. Trust in foreign cooperation, because the aid was channelled directly to the community (without leakages) and because there is a long-term relation through the sister cities agreement with Préizerdaul.

It is worth mentioning that the municipality government was relatively permissive to every initiative led by CRDM and also weaker in terms of resources and relationships. This situation favoured the strengthening of CRDM and the development of its linkages with aid agencies. Nevertheless, it is contestable that the municipality government had received fewer resources than the community organisation, which is visible just by looking at the community centre and municipality hall. It seems that the long stay of the project chief in the locality created an identification, which went beyond the necessary empathy to understand local needs and expectations. This identification could be better channelled by promoting some productive activities, not only infrastructure building, to support the capacity of people to sustain their committees and help themselves. Truly, it requires flexibility to 
introduce changes in the original design, based on the identification of priorities made by residents themselves (and explicit in the municipal development plan).

\section{- Impacts by gender: perceptions of change depend on the starting point}

Figure 9-8 shows the average individual scores by gender for four elements analysed by FGD participants: information, self-confidence, opportunities and decision-making.

Figure 9-8: Average changes in variables associated to autonomy by gender in San Agustín

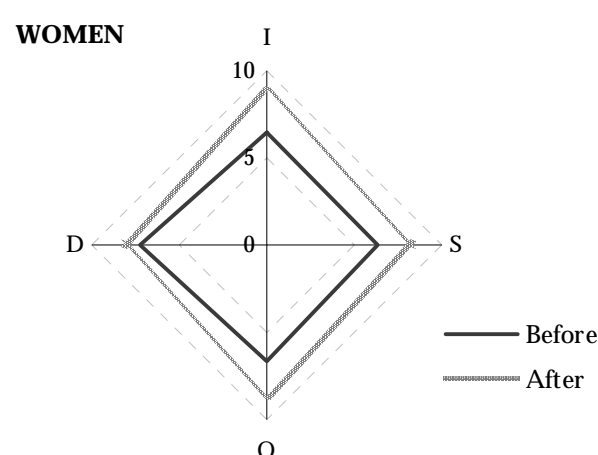

$\mathrm{O}$

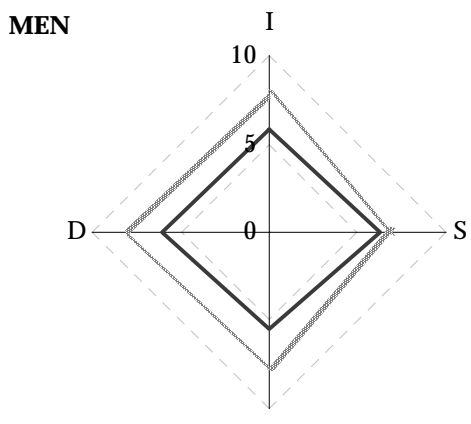

$\mathrm{O}$

Legend: $\mathrm{I}=$ Information, $\mathrm{S}=$ Self-confidence, $\mathrm{O}=$ Opportunities, $\mathrm{D}=$ Decision-making.

Average values, mixing high and low-involvement groups. Inconsistent or missing values were taken out. Source: Focus group discussions (scoring exercise).

Women reported a higher positive change in self-confidence, while men reported a higher positive change in decision-making. In addition, women's scores had a higher dispersion. This difference might be related to the fact that women had low participation in their community before the project,72 but now feel they are more respected because they are 'invited to meetings' and have the chance 'to express what they need'. It seems that both women and men had the same possibilities to make decisions during the project, especially regarding their houses. However, it might be that men, who traditionally have a higher participation and more say in family and community decisions (section 9.4.2), kept this intensity of decision-making while women suffered a retraction after the construction activities ended.

Although survey data (both datasets) did not show a significant difference between genders in terms of self-confidence (section 9.5.2), women in FGDs reported a higher expansion in terms of the situation before and after the project, which could mean that their participation was more significant in comparison to the role they usually had in patriarchal households. It explains their illusion when expressing: 'We learned what we did not know' (LIW) or 'we have also changed; we talked with the engineer about things' (LIW).

It is worth analysing one aspect related to self-confidence: the awareness of personal skills. Table 9-9 suggests that more men than women reported applying their knowledge during the project (Phi coefficient, $\phi=0.341$, Fisher's exact test, $p=0.04$ ), basically working as assistants or bricklayers. Respondents living in larger households had a higher sense of aware-

\footnotetext{
${ }^{72}$ Low participation related to cultural features, in relative terms. I am not referring to the score that women and men self-reported regarding information about their community before the project.
} 
ness ( $\rho=0.371, p=0.03$ ), which could be related to more pressing demands that fuelled their participation.

Table 9-9: The awareness of personal skills by gender in San Agustín

\begin{tabular}{|l|ccc|}
\hline \multirow{3}{*}{ Gender } & \multicolumn{4}{|c|}{ Did you use your practical skills during the project? } \\
\hline Female & No & Yes & Total \\
& 10 & 14 & 24 \\
Male & $(42 \%)$ & $(58 \%)$ & $(100 \%)$ \\
& 1 & 11 & 12 \\
Total & $(8 \%)$ & $(92 \%)$ & $(100 \%)$ \\
& 11 & 25 & 36 \\
& $(31 \%)$ & $(69 \%)$ & $(100 \%)$ \\
\hline
\end{tabular}

Source: Dataset 2.

There are several influences on self-confidence (not all measurable); it is then highly relevant to evaluate the starting point when changes are compared. The improvement in selfconfidence reported by women in focus group discussions might be larger than that of men or more relevant, but men can still be more able to express their voice in society. In contrast, considering the higher decision-making power of men (section 9.4.2), an improvement for men certainly means that their role in this social context has improved with respect to women. The project has strengthened previous gender roles, although it introduced the family property to protect women and children and equally enrolled women and men in project activities (there is no statistical association between the extent of participation and gender).

For women, the project was more significant and their effects more permanent than for men. Nevertheless, men recalled more cases of when their self-confidence was promoted. For instance, they referred to different channels of information (leaders or NGOs) and asserted that information continues flowing in the community at the same level as during the project (HIM). Two men expressed that, during the meetings, they could give their opinions and that they were encouraged to do so. Furthermore, a man remembered with appreciation one of the bricklayers. Others referred to the skills learned; one even said that his group finished the house in record time: one month, when the average was three months.

Both, women and men, reported low communal participation, but a high appreciation for the role of leaders and their effectiveness, indicating that their community is better organised. However, these improvements are not enough to secure a sustained expansion of opportunities because they are lacking the resources, as leaders also recognised.

\subsection{Conclusions}

This chapter has analysed the case of the inhabitants of San Agustín, who suffered the effects of two earthquakes in 2001 that destroyed almost all the houses and social infrastructure. Nevertheless, the earthquakes were considered by people as an 'opportunity' because they brought resources and public attention toward a town that had been abandoned and left in severe poverty since the armed conflict (1980-1992).

The community organisation was in a consolidation process when the project started. The project supported the ongoing process by providing the context to exercise decision-making in the project's working group. 
The experiences of individual autonomy of San Agustín residents are rooted in their recent history. They have suffered hardship, but they do not limit the meaning of autonomy to material resources. They highly valued to be respected by others and to have good relations with their neighbours. Despite living in extreme poverty, they make efforts to improve their lives. However, they realise that they require support from others to be able to pursue their common goals.

Many attitudes are changing as a result of the reconstruction efforts: former enemies have reconciled and residents have regained trust in organisations as institutions. However, they are still very poor. First, they need economic entitlements to secure subsistence in order to pursue any goal; this means food, land and work. The project has provided the foundation for a livelihood: a house and social infrastructure, but many basic resources are needed.

Non-leaders value organisation and community. However, in practice, they have low participation in organisations because they perceive that their community does not expand their opportunities and that they in turn are unable to help. Hence, for them, effective help must come from outside to be effective. In contrast, many leaders at the municipal and the canton levels believe that they can initiate change (autonomy causality orientation). They have elaborated a development plan and managed projects since the reconstruction period. There is, then, a mismatch between what leaders of various existing groups and non-leaders are doing. Although non-leaders think that community organisation has improved and leaders work more efficiently, they are not ready to support it with intrinsic motivation.

The project was conceived as participatory and supported the community organisation. However, information was not shared widely enough among the population, resulting in the fact that non-leader individuals made decisions about their houses, but not about alternative plans. This is related to the community dynamics (linked to cultural aspects) and the insecurity lived during the project (micro-level structural context). The consequence is that project activities and practices were not internalised by many non-leaders, because they did not shared in decisions.

This means that non-leaders do not fully realise what they can do with their joint effort and how they can participate in shaping projects, although these came from external sources. They hope that new projects will 'arrive' to help them and they also hope that their leaders will work well, but they do not know exactly how. In contrast, leaders feel that they know what they can do and how. Only leaders experienced an expansion of autonomy in the intra-community domain. Some non-leaders experienced an expansion of autonomy at the individual level, but in terms of the intra-community relationships and what they can do for their development, only leaders improved. 


\section{Part III:}

Discussion 



\section{An autonomy-focused assessment of four aid projects: A com- parative study and a proposal}

The poor, unless their condition is deliberated (like a monk), already have a history of ineffectual action to better their condition, so any kind of assistance that reinforces that perceived inability to help themselves is simply the wrong kind of assistance, no matter how well-intended (Ellerman, 2006, p. 127).

This chapter has two main objectives. First, it proposes an analytical framework of project effects on individual autonomy, based on this research's findings following an inductive perspective. Second, it presents the qualitative comparative analysis, especially focusing on research questions four and five:

- How might projects have affected the autonomy of non-leaders and leaders?

- In which communities are individuals more likely to experience an expansion of autonomy? And why?

The chapter presents project features that may influence individual autonomy, either enabling or restricting it. Project practices matter in interaction with other variables: group dynamics, which affect individual and community involvement in the project; personal factors, such as the degree of internalisation of conditions and perceptions about community; and entitlements, defined by previous interactions. Individuals have different experiences of autonomy. They perceive the strategies of other actors, project practices and contexts in different ways, so they perceive different impacts on their lives.

This chapter presents the most salient micro-level factors across cases, both common and divergent, in a comparative fashion. The analysis focuses on the micro-level context, but some upper-level relations are acknowledged and analysed such as the coordination among donors and that between national and local governments.

The chapter is divided into seven parts. Section 10.1 summarises some features of the communities and projects. Section 10.2 presents the analytical framework. Section 10.3 discusses values, practices and relationships, which are crucial in the framework. Section 10.4 examines participation and the exercise of individual autonomy. Section 10.5 compares differences in effects by sector. Section 10.6 concludes about project effects on autonomy from the cross-case analysis. Finally, section 10.7 summarises the main conclusions.

\subsection{Antecedents of the communities}

This is an introductory section. It presents some features of the communities before the projects and characteristics of the projects, in order to facilitate the comparative analysis.

- The four communities before the projects

The fieldwork study affords knowledge of special features of the communities (Table 10-1) before the execution of the projects that would later make a difference in the residents' perception of the project, their level of involvement, and project practices. Indeed, projects do not start from 'blank slates' (Ellerman, 2006). 
Table 10-1: Communities before the project implementation

\begin{tabular}{|c|c|}
\hline \multicolumn{2}{|r|}{ Reconstruction projects } \\
\hline Santa María: & $\begin{array}{l}\text { - The survivors of the Casitas disaster came from two different towns. Most of them } \\
\text { were grieving without adequate psychological support; there was much uncer- } \\
\text { tainty and material lacks. } \\
\text { - New self-nominated leaders emerged and led all efforts, including attempts to } \\
\text { invade private lands to establish a new town. }\end{array}$ \\
\hline San Agustín: & $\begin{array}{l}\text { - Community leaders had clear leadership in the reconstruction efforts, organised in } \\
\text { a municipal committee (CRDM) that united different local committees with the } \\
\text { support of a local NGO. } \\
\text { - Several projects were taking place at the same time in the whole municipality and } \\
\text { CRDM was coordinating all of them. }\end{array}$ \\
\hline \multicolumn{2}{|r|}{ Water projects } \\
\hline San Fernando: & $\begin{array}{l}\text { - Inhabitants had had access to safe drinking water prior to Hurricane Mitch. By } \\
\text { design, the public water company (not a communal management committee) } \\
\text { would be in charge of water facilities. } \\
\text { There was no previous formal organisation; hence, inhabitants had not searched } \\
\text { for alternatives to solve the lack of water service. }\end{array}$ \\
\hline Agua Fría: & $\begin{array}{l}\text { - The community organisation was developed. Committees were managing two } \\
\text { gravity (untreated) water systems that covered a small part of the population. } \\
\text { Leaders had being actively searching for water alternatives with different institu- } \\
\text { tions (i.e., the municipality government and the public water company). }\end{array}$ \\
\hline
\end{tabular}

In Santa María, there was no sense of shared community; people felt too hurt by the mudslide. Nevertheless, they could take extreme measures led by desperation at having nothing, not even government emergency aid - although they received offers from many donors. In San Agustín, people stayed in the same locality after the earthquake - they were not relocated as in Santa María - and as such, they had developed an active, broad-based community organisation, integrated by former guerrilla fighters, former soldiers, and cooperative leaders. While for the residents of Santa María, the disaster was a 'tragedy', for the inhabitants of San Agustín, the disaster was an 'opportunity' because foreign aid arrived promptly and leaders felt ready to take the necessary measures.

The inhabitants of Casitas had taken the land where they lived during the agrarian reform (1979). They were known as combative and proud people that used collective action to pursue their goals. The inhabitants of San Agustín had suffered the worst of the civil war in El Salvador. Their municipality was a battlefield and many had emigrated; only the poorest were left to stay in an environment of fear and mistrust. Nevertheless, recent water projects in the area had attracted people again.

In San Fernando, many people had supported the contra guerrillas during the 1980s and, since then, strong political divisions had emerged. People felt they were considered different and wealthier, for which they were abandoned by the state. The water project had a symbolic value for them: it was the first aid project that would benefit everyone.

In Agua Fría, communal committees had a long history and leaders were respected. However, there was a growing insecurity from the presence of youth gangs in the canton centre. The social context had been difficult, with confrontations, due to the scarcity of water sources and the unequal access to the gravity water systems, which covered only around $10 \%$ of the households. 
Beyond these special features, all localities have something in common: a rural character. Some sites may be considered 'urban', because they serve as municipality centres or due to their spatial layout, but most households in all sites depend on agriculture. Households plan their activities in relation to agriculture. In order to support this activity, they invest resources such as communal solidary work, children's work and remittances savings. They partially overcome shortage periods related to the agriculture seasonality through migration, housemaid work or petty trade activities.

In terms of differences, San Fernando and San Agustín are municipal centres (headquarters of the municipal government and the mayor) and, as such, they had better social infrastructure and physical and economic connections with other villages. Community organisations in these sites could have more chances to participate in local development strategies than those in Santa María and Agua Fría (see section 11.1.1).

With respect to relative monetary affluence before the disasters, San Agustín was the poorest locality. People suffered of long-term poverty associated with years of exclusion during and after the civil war. Agua Fría was the less poor locality given that most households relied on remittances. The inhabitants of San Fernando had relatively better living standards than those of Santa María, at the slopes of Casitas volcano. The latter enjoyed a life without acute lacks, based on self-consumption farming in privately used plots and small trade, with recently improved social infrastructure and the presence of NGOs. However, they lived in atrisk land and could not afford to leave. The mudslide of Casitas caused by Hurricane Mitch changed everything.

Figure 10-1 compares the situation of the households in the four localities after the disasters. The effect of the mudslide for (generally less affluent) people in Casitas was so destructive that survivors (relocated in Santa María) became the poorest, despite that their prior situation was better than the one of San Agustín residents and similar to that of San Fernando residents (signalled by the arrow in Figure 10-1). ${ }^{73}$ The earthquakes in San Agustín hit hard, but life in the municipality was already harsh. The households in San Fernando and Agua Fría (generally more affluent) were less affected by disasters. In sum, the poorest people were more likely to participate in the reconstruction projects because the disasters had a more profound impact on their lives than on the lives of the more affluent.

Figure 10-1: Cases compared by relative affluence and disaster impact

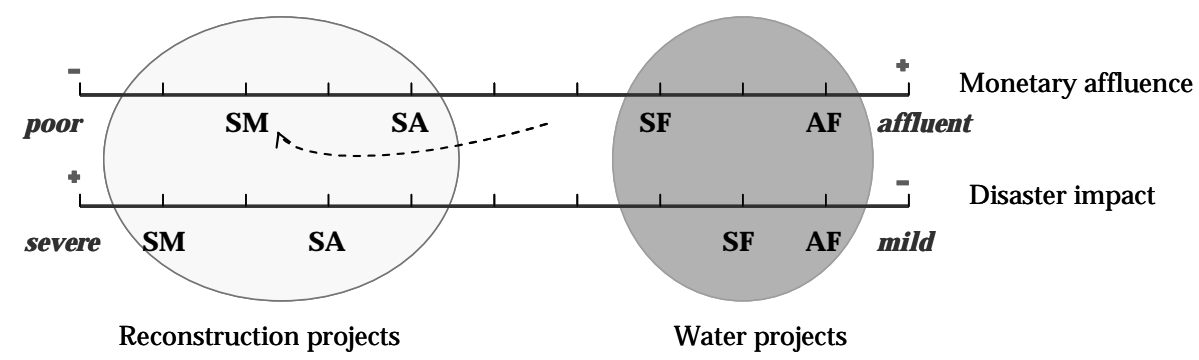

Legend: $\mathrm{SM}=$ Santa María, $\mathrm{SA}=$ San Agustín, $\mathrm{SF}=$ San Fernando, and AF = Agua Fría

\footnotetext{
${ }^{73}$ I could not find reports about the living conditions in Casitas. FGD participants reported to have owned larger plots than those in San Agustín and counted on projects run by NGOs (not the case in San Fernando).
} 


\section{- An overview of the projects}

Table 10-2 summarises some distinguishable features of the projects. It is worth considering that they were implemented in different years so that, at the time of the second study visit, the Santa María project was four years past completion but the San Fernando and the San Agustín projects, only a few months.

Table 10-2: The four projects at a glance

\begin{tabular}{|c|c|}
\hline \multicolumn{2}{|r|}{ Reconstruction projects } \\
\hline $\begin{array}{l}\text { Santa María: } \\
(05 / 99 \text { - 10/01) }\end{array}$ & $\begin{array}{l}\text { - Goal: Economic and social rehabilitation of households. } \\
\text { - Components: Housing construction, water and agriculture (three different donors). } \\
\text { - Main results: } \\
\checkmark \text { Tangible outputs were achieved. } \\
\quad \text { × Agricultural project was not sustainable. } \\
\text { × Residents do not have the property titles of their houses. } \\
\text { - Special factors: Conflict between national and local government, and between } \\
\text { community leaders and project staff. } \\
\text { - Main positive influence on autonomy: Awareness of personal competence. }\end{array}$ \\
\hline $\begin{array}{l}\text { San Agustín: } \\
(10 / 01-03 / 05)\end{array}$ & $\begin{array}{l}\text { - Goal: Reduction of the vulnerability of the municipality. } \\
\text { - Components: Housing, legalisation of property and participatory municipal plan. } \\
\text { - Main results: } \\
\checkmark \text { Supported an ongoing process of social change. } \\
\checkmark \text { Good quality houses and social infrastructure. } \\
\quad \text { × No effect on reducing the financial vulnerability of the local government. } \\
\text { - Special factors: Partnership between the project chief and CRDM; a local NGO } \\
\text { acted as social intermediary smoothing the local government /community relation. } \\
\text { - Main positive influence on autonomy: More autonomy-supportive local context. }\end{array}$ \\
\hline \multicolumn{2}{|r|}{ Water projects } \\
\hline $\begin{array}{l}\text { San Fernando: } \\
(09 \text { /02 - 01 05) }\end{array}$ & $\begin{array}{l}\text { - Goal: Improvement of health and living conditions of residents. } \\
\text { - Components: Water, sanitation; technical cooperation. } \\
\text { - Main results: } \\
\checkmark \text { A permanent service and good quality water. } \\
\checkmark \text { Some women can participate in the municipal development committee. } \\
\quad \text { × High water tariffs put at risk the entitlement to safe drinking water. } \\
\text { - Special factors: The project required neighbourhood committees. } \\
\text { - Main positive influence on autonomy: Health and self-confidence. }\end{array}$ \\
\hline $\begin{array}{l}\text { Agua Fría: } \\
(10 / 01-01 / 04)\end{array}$ & $\begin{array}{l}\text { - Goal: Improvement of health and living conditions of residents. } \\
\text { - Components: Water, sanitation, natural resources protection, fish agriculture. } \\
\text { - Main results: } \\
\checkmark \text { Access to good quality water. } \\
\quad \text { × Low operational effectiveness (unreliable water service). } \\
\text { x The intended micro-regional NGO was not legally constituted. } \\
\text { - Special factors: Conflict between the mayor and project staff (and leaders); govern- } \\
\text { ance issues within the water public company. } \\
\text { - Main positive influence on autonomy: Material resources (lower water costs). }\end{array}$ \\
\hline
\end{tabular}

Note: The components listed are not necessarily in the original design (e.g., fish agriculture in Agua Fría).

The four projects had several outputs and effects, already discussed in Part II. This summary highlights the most crucial factors. Moreover, the main positive influences on autonomy are not comparable in magnitude across cases; there were countervailing influences in each case, such as the controlling project context in Santa María that harmed self-confidence. 
Despite their uniqueness in regard to location, institutional context or community dynamics, the cases have important similarities. First, households worked in self-construction activities. In the reconstruction projects, one member of each household worked in small teams (between five and six people) during two or three months as an assistant bricklayer to build his or her house. In the water projects, each household built its autonomous sanitation system, assembled its latrine with the guidance of bricklayers and performed other works; participants attended training sessions in groups (between 25 and 40 people) and worked in teams.

Second, community organisations participated during the implementation of the projects although to different degrees. Both features indicate that planners considered participation as valuable, even though the kind of participation was not explicit in all cases. Section 10.4 explores this issue.

\subsection{An analytical framework of project effects on individual autonomy}

Part II analysed the effects of the four projects by looking at individual autonomy as a combined capability so that its three determinants (entitlements, agency and structural contexts) were central to the analysis in each assessment matrix (introduced in section 4.3.1). The framework here proposed explicitly integrates individual values and goals in the analysis. In addition to evaluating effects on the capability, the framework considers whether individual values and goals were taken into account during the different stages of the project. It means that the exercise of individual autonomy, the functioning, is also important.

Individual empowerment was defined as the expansion of autonomy, evidenced in the degree of effectiveness of authentically motivated actions' (section 2.4.1). The definition then was related to process freedom (control) and opportunity freedom (power). If individuals share in the decision-making during a project (control) and this project is effective (power), one could conclude that they were empowered.

However, this argument would be inaccurate. Individuals cannot control every aspect of a project and do not wish to do so because not every aspect is important to them. Therefore, it is necessary to understand their values and motivations for participation that are rooted in the dynamics of specific communities (Cooke \& Kothari, 2001/2004). Besides, people are not always effective when they do something for the first time, which was the case for many participants working in self-construction activities.

Figure 10-2 shows a framework to analyse project effects on individual autonomy considering: (i) the changes in the determinants of individual autonomy, (ii) the explicit valuation of participants on certain project processes, and (iii) the achievement of personal goals.

This framework incorporates some aspects of the logframe (section 3.2.2) because it looks at the inputs, outputs and outcomes of a project; however, these outcomes now are in terms of individual autonomy. Another crucial difference is the focus on individuals as agents of change, not on projects designed to produce change, or even on change in people's behaviours. The emphasis is on practices and relations, not only on activities and expected outputs. This is because aid recipients interact with project staff and act intentionally in multilevel structural contexts thus affecting change and the processes of change.

Figure 10-2 shows an 'action chain' that starts with individual goals and ends with effects that are evaluated with regard to these goals. It also indicates that multilevel structural con- 
texts, not only project outputs, have effects (this is shown by the two thicker arrows at the right-side). Then, the effects on autonomy depend on how the project is carried out.

Figure 10-2: An analytical framework of project effects on individual autonomy

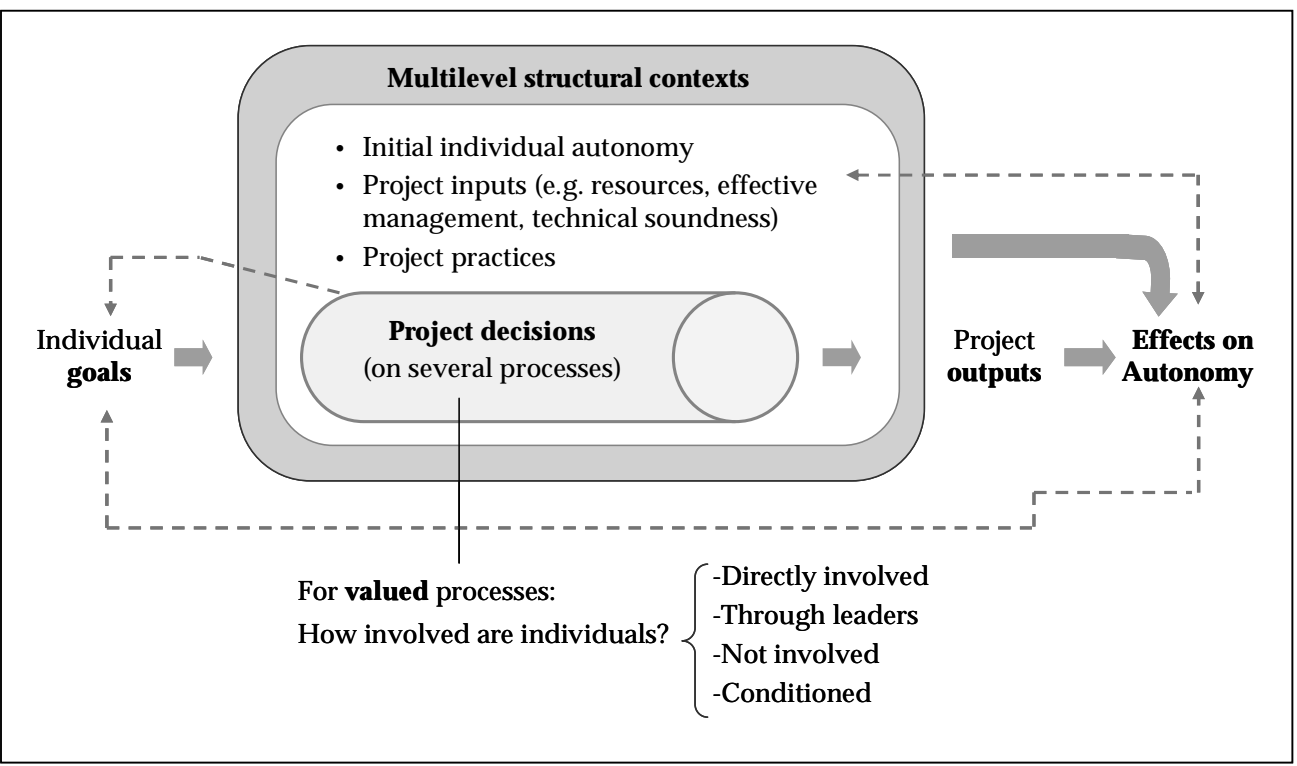

The central distinguishable aspects of this framework are: the understanding of previous experiences of autonomy and goals; the identification of project inputs, practices and contexts, which explain the conditions in which a project is carried out; and the analysis of project decisions and valuable processes, by which people are motivated to participate.

\subsubsection{The initial situation in terms of autonomy and individual goals}

The previous experiences of autonomy of project participants affect their interactions, project practices and their effects. Moreover, initial individual goals might change over time as a project generates new expectations for local people given its outputs and interactions with other actors (value endogeneity). However, the question is, which goals have to be promoted so that project effects are assessed in relation to their achievement?

Project beneficiaries could have diverse goals (different from pre-defined project goals), on which they evaluate project effectiveness and, furthermore, some of these goals could be opposite or normatively contestable. Therefore, the criterion of human autonomy effectiveness proposed here (section 3.3.1) requires that the expansion of autonomy does not contract other priority capabilities (Alkire, 2002, p. 180). It is then necessary to discuss and agree on a capability hierarchy so that secondary goals that would constrain valuable capabilities are not pursued (see discussion in section 2.1.1 on the criteria to assess well-being).

Project planners and managers have to understand the local cultural and institutional context, the project participants' livelihoods and aspirations, and 'to find where positive change is underway on its own to address pressing problems' (Ellerman, 2004, p. 163) in order to support this change. They have to respect the change process of the participants, not to impose 
values that are 'accepted' as result of conditionality (i.e., incorporated in formal practices but not internalised), and to encourage their internal efforts to exercise voice (Appadurai, 2004).

\subsubsection{Project inputs, practices and contex ts}

Projects should be designed in a way that responds to the needs of the intended beneficiaries in congruence to their values. Such projects have to be operationally effective (i.e., to provide the expected outputs) so that aid recipients can fulfil their intermediate needs related to health, sanitation, security, and so on. Then, it is necessary to identify how well endowed a project is to reach its stated objectives and which their inputs are: availability of resources, existence of effective management, a committed staff, the suitability of the technical solution chosen and their implementation, and so on (Riddell et al., 1995).

In addition to material inputs, project staffs develop informal practices to carry out the planned activities. These practices evolve over time as result of the actions of social actors so they depend on the power relations in specific communities and between local stakeholders and project staffs. Practices affect the definition of entitlements (see section 10.3.3) and are crucial to understand the mechanisms behind certain effects. To elaborate an assessment matrix (as the ones presented in the case chapters, based on Table 4-4) is necessary not only to identify project practices and to analyse their implications, but also to understand their process of formation.

Figure 10-2 highlights the importance of contexts. They have effects on individual autonomy directly or through project practices; likewise, contexts can be affected by project elements. This means that a project replicated in other locations might well have different effects. Therefore, the assumptions about contexts should be explicit in the logical framework of the projects. These considerations add complexity to the issue of attribution because the interactions between structural contexts and project practices might explain different individual effects. The case to use mixed analysis methods is stronger (section 4.4).

The analysis of the contexts is sometimes avoided so that so-called 'good practices' are spread with disregard for specific circumstances (cf., White, 2005, p. 9). Even worse, a controlling context in which an organised elite can assure the success of a project (in terms of material outputs) has sometimes been seen as desirable, without considering the goals of those who are not part of the elite. Thus, different contexts are more or less supportive to promote autonomy and more or less supportive to promote other goals. Any classification of contexts requires a previous definition of priority goals in order to evaluate later how the context, which evolved around the project, contributed or not to the realisation of such priorities. Even assuming a consensual prioritisation, certain 'new' priorities could be imposed during the project by means of controlling practices. For instance, administrative controls to comply with tight deadlines could be interpreted by project staff and other participants as if tangible outputs are more important than positive effects on human lives. The assessment matrix, by looking at the implicit and explicit logic of the project, allows the identification of these 'hidden' priorities.

\subsubsection{Project decisions and valuable processes}

This analytical framework requires the explicit identification of valuable and non-valuable processes, which is possible with the concourse of participants as of the identification and formu- 
lation stages. The extent of choice possible to be exercised by participants in these valuable processes has to be analysed, considering that choice implies the existence of relevant and affordable alternatives. Likewise, needs for training must be identified together with local people so that they can be better involved in valuable processes. Moreover, like goals, valuable processes may also vary over time.

The cases suggest that once the valuable processes are identified, people have to be involved in these valuable processes, either directly (via participatory tools) or through leaders (when they are representative and respected), depending on cultural features. If people are not involved, these processes and its activities will be considered conditions that restrict their autonomy, although the final output aimed to expand the access to entitlements. Motivation could become extrinsic and, furthermore, there could be a 'motivational spill over effect' (Ellerman, 2006, p. 46), if this impossibility to be involved in valuable matters (related to the project) extends to other community or personal spheres.

\subsection{U nderstanding values, relations and practices in structural contexts}

This section examines three topics. First, it analyses the relevance of understanding the participants' values in order to better design and execute projects that support their goals. Second, it discusses the consequences of the organisational design on the relations of project staff with social actors in multilevel structural contexts. Third, it explores how certain practices defined personal entitlements and influenced autonomy as a combined capability.

\subsubsection{Needs, livelihoods and values}

The analytical framework requires that the determinants of individual autonomy are assessed and understood before the project implementation (e.g., an analysis similar to the one presented in Chapter 11). The same holds for values and participants goals, which are related to their conception of a good life: the farmer's life, for most people in the four cases.

\section{- Responding to the needs and goals of aid recipients?}

If a good life is related to agricultural activity, it is relevant to analyse whether and how the projects gave attention to productive projects. Only two cases, Santa María and Agua Fría (neither in the same sector nor in the same country), incorporated small-scale productive projects. In both cases, the small businesses would be managed by the community leaders. However, the originators of the initiatives and the attitudes of non-leaders toward the communal productive activity were different.

In Santa María, donors decided to start a cooperative agricultural project; smaller productive projects were included over time. Indeed, project participants valued agriculture activities, but not the common tenancy and management of the agriculture production, after the failed experience of the Sandinista cooperatives (Appendix 1-A). In addition, in the early stages of the reconstruction project, working in the communal plot was a condition for receiving food; the motivation to work was extrinsic. Because the project faced difficulties (section 6.5.1) and the reward was missing, residents did not have incentives to continue the activities.

In Agua Fría, the project staff supported leaders to implement their idea to use the reservoir to farm fish - originally aimed only to collect rain water during the winter to water cattle in 
summer. Furthermore, the leaders invested in this project and people agreed with a communal management. This event shows a certain flexibility of project staff to support a local initiative. Nevertheless, the project failed because adult fish were stolen.

In contrast, the project in San Agustín did not incorporate any small productive projects, despite the fact that the project staff stayed in the town for more than three years, knew people's needs (explicit in the municipal development plan) and had available resources that could have been reallocated from other less-valued components. In San Fernando, the project staff neither identified itself with the inhabitants, nor understood their livelihoods. Furthermore, men, who are traditionally more concerned on productive activities than women, did not engage in training sessions so that their concerns were not integrated. The project staff wrongly approached people only as water customers (see section 10.5.2).

\section{- How can livelihoods and values change?}

A project is not the only element that might fuel a change of values. The inhabitants of the localities studied were affected by disasters to different extents. The sudden occurrence of disasters changed their living conditions immediately. This means that the initial entitlements (and the related level of autonomy) were neither fully constructed nor fully negotiated.

The damages were stronger in Posoltega and San Agustín, in which people were also poorer. However, they had something that had not been active: organisational skills which had been formed more than one decade ago during the civil wars. The villages at the slopes of Casitas originated from production cooperatives and the leaders in San Agustín were either cooperative leaders or former combatants. These skills emerged before the profound necessities fostered by the disasters. These disasters 'activated' certain energy (cf., Hirschman, 1984) ${ }^{74}$ but this energy was not the same. In Santa María, the (immaterial) community was destroyed by the disaster, leaving human losses and sorrow. People did not form one community of people and it was not accurate to assume that one association without clear representativeness would fairly lead the project actions. The 'energy' awakened by the disaster could have been biased toward leaders and, as such, entropic or in deterioration. In contrast, in San Agustín, the community was being reconstructed since the water projects and many leaders had returned home after years of exile.

However, in both cases, how each individual could benefit from this energy varied according to his or her position in the community. They were constructing a new reality, with acute material lacks and the arrival of different external actors. Some people were doing this more successfully than others as a function of the magnitude of the disaster and their degree of vulnerability (see section 12.1.1).

\subsubsection{Formal institutional arrangements and coordination}

Project staff counts on an organisational structure and formal coordination mechanisms to achieve project objectives. The organisational structure describes the responsibilities and relations in place. In all cases, except in Santa María, a project implementation unit (PIU) managed the operations (section 5.3.3). The NGOs responsible for awareness campaigns and small infrastructure works were selected prior to the arrival of the project chief.

\footnotetext{
${ }^{74}$ Hirschman (1984) uses 'the principle of conservation and mutation of social energy' (p. 42) to explain that certain skills and aspirations can be renewed and are not wholly new outbreaks.
} 


\section{- $\quad$ The counterpart defined by bilateral aid practices}

The municipality governments and the public water companies were the formal counterparts for the reconstruction and water projects, respectively. In the water sector, although some donors promote decentralised water systems managed by users' committees, Luxembourg finances medium- or large-scale water systems to be operated by the public provider.

Luxembourg bilateral aid was migrating from stand alone projects to projects coordinated through a sector-wide approach (section 5.3.2). The common practice was to finance public investments through ministries or public water companies, not directly to independent project structures or communities. The cases of Santa María and San Agustín were exceptional as reconstruction was an atypical sector for Luxembourg aid (section 4.1.2).

In turn, national institutional arrangements were changing. When the water projects were being designed, there were legislative proposals to extend the responsibilities of local governments, which could manage small infrastructure projects and later operate water systems. Other proposals aimed at reforming the public water companies (section 7.1, appendices 1-A \& 1-B). Given this uncertainty, bilateral aid practices prevailed over national institutional trends. The water projects, since the start, were linked to the public water companies that would act as counterparts, supervisory and execution entities.

Consequently, municipality governments were not as much involved in the water projects as in the reconstruction projects. In Agua Fría, there was an unsolved impasse with the mayor (section 7.2.1). In San Fernando, the municipality government had a secondary role, only referred to organising the solid waste collection. Indeed, the design of the water projects had risks of confrontation with the mayors because it excluded them from the decision-making process and disturbed the local political status quo (cf., Hirschman, 1967/1995).

In call cases, community organisations worked during the project implementation stage with different levels of involvement (see section 10.4.2), but in the reconstruction projects, the community organisations became like 'formal' counterparts and took over the role of the municipality governments in important aspects. This pattern was more evident in San Agustín given the representativeness of the organisation and its closeness to local population. The situation was different in Santa María, especially toward the completion of the project.

\section{- Project management and coordination}

The four projects had different coordination practices, which were related to (i) their organisational structures, entities involved, reporting chains, and responsibilities; (ii) their goals, which differed in number, complexity, and coverage of population and territory; and (iii) the informal relations that actually sustained the projects. Table 10-3 shows the basic features of each project's organisation (my assessment).

Internal coordination refers to the PIU and the other executing actors. All projects required high coordination efforts because they involved several partner NGOs (San Agustín), many components (Santa María, San Agustín), or several sites (San Fernando). Coordination needs were high in Agua Fría because the water company faced management problems following accusations of corruption (section 7.2.1). This situation badly affected the work of the PIU and the technical soundness of the project (see Glossary). 
Table 10-3: Project organisation and coordination needs

\begin{tabular}{|c|c|c|c|c|}
\hline & \multicolumn{2}{|c|}{ Reconstruction } & \multicolumn{2}{|c|}{ Water } \\
\hline & Santa María & San Agustín & San Fernando & Agua Fría \\
\hline \multicolumn{5}{|c|}{ Project management and design } \\
\hline PIU & No & Yes & Yes & Yes \\
\hline Geographic scale & Small & Medium & Large (5 sites) & $\begin{array}{l}\text { Medium but dis- } \\
\text { perse population }\end{array}$ \\
\hline Visibility of the PIU(1) & Non applicable & High & Low & Medium \\
\hline Complexity of project & $\begin{array}{l}\text { Medium (several } \\
\text { donors involved) }\end{array}$ & $\begin{array}{c}\text { High (construction, } \\
\text { legalisation, par- } \\
\text { ticipatory plan) }\end{array}$ & $\begin{array}{l}\text { Medium (several } \\
\text { components incl. } \\
\text { technical cooper.) }\end{array}$ & $\begin{array}{l}\text { Medium (many } \\
\text { components) }\end{array}$ \\
\hline \multicolumn{5}{|c|}{ Counterpart and partners } \\
\hline Executing counterpart & $\begin{array}{l}\text { Community or- } \\
\text { ganisation }\end{array}$ & $\begin{array}{l}\text { Community or- } \\
\text { ganisation }\end{array}$ & $\begin{array}{l}\text { Public water com- } \\
\text { pany }\end{array}$ & $\begin{array}{l}\text { Public water com- } \\
\text { pany }\end{array}$ \\
\hline $\begin{array}{l}\text { Municipal govern- } \\
\text { ment }\end{array}$ & $\begin{array}{c}\text { Present } \\
\text { (3 mayors during } \\
\text { the project) }\end{array}$ & $\begin{array}{c}\text { Present } \\
\text { (1 mayor during } \\
\text { the project) }\end{array}$ & $\begin{array}{c}\text { Present } \\
\text { (2 mayors during } \\
\text { the project) }\end{array}$ & $\begin{array}{c}\text { Absent } \\
\text { (1 mayor during } \\
\text { the project) }\end{array}$ \\
\hline Partner NGOs ${ }^{(2)}$ & $\begin{array}{l}1 \text { international } \\
\text { NGO with experi- } \\
\text { ence in the zone }\end{array}$ & $\begin{array}{l}3 \text { local NGOs with } \\
\text { mixed experience }\end{array}$ & $\begin{array}{l}1 \text { international } \\
\text { NGO without } \\
\text { experience in the } \\
\text { zone }\end{array}$ & $\begin{array}{c}1 \text { local NGO } \\
\text { with experience in } \\
\text { the zone }\end{array}$ \\
\hline Local staff( ${ }^{(3)}$ & $\begin{array}{c}\text { No } \\
\text { (leaders) }\end{array}$ & $\begin{array}{c}\text { President of CRDM } \\
\text { (leaders) }\end{array}$ & $\begin{array}{c}1 \text { social promoter } \\
+ \text { Committees }\end{array}$ & $\begin{array}{c}2 \text { social promoters } \\
+ \text { ADESCOs }\end{array}$ \\
\hline \multicolumn{5}{|c|}{ Actual coordination needs } \\
\hline $\begin{array}{l}\text { - Internal coordina- } \\
\text { tion }\end{array}$ & High & High & High & High \\
\hline $\begin{array}{l}\text { - External coordina- } \\
\text { tion }\end{array}$ & Medium & High & Low & Medium \\
\hline
\end{tabular}

(1) For non-leader inhabitants.

(2) Experience in the zone refers to having worked in the specific municipality or neighbouring municipalities.

(3) In the water projects, community associations collaborated with project staff as if they were promoters.

The projects integrated residents in their activities. Both water projects mobilised residents with the support of existing or new community organisations. In Agua Fría, the local promoters were daughters of community leaders. In San Agustín, the project chief worked in partnership with CRDM, keeping a relation based on mutual trust and respect (cf., Hailey, 2001/2004). It improved the project's chances of success given the authority of the main leader among the population and helped to overcome the shortage of project staff.

External coordination refers to the relations between the project (the PIU, its counterpart and partners) and other stakeholders such as line ministries, public organisms, judiciary institutions, military forces or other villagers. San Agustín demanded the highest effort from the PIU given the integral approach chosen (three components: construction, legalisation and participatory planning) and the change of hands in the national government in 2004. In contrast, San Fernando required the lowest effort because the project staff was focused on providing water and sanitation services without including so many components (as Agua Fría) or multiple donors (as Santa María). There was political stability in the municipality. 
In Santa María, the interaction of actors in meso-level and micro-level contexts was problematic. The political confrontation between the national and municipal governments restricted the aid delivery to the zone. Moreover, national institutions were not well equipped to cope with the disaster effects (section 6.1). Over twenty donors carried out projects in the municipality, but there was no single entity able to coordinate all the efforts efficiently.

This case suggests that a sub-contracted NGO managing a multi-component project (construction, water and agriculture) and facing complex multilevel structural contexts is at high risk of failure. However, an independent PIU is not the best solution. Even with the support of a formal counterpart, such a PIU could be at risk if the counterpart faced organisational or political problems thus becoming isolated. This happened in the Agua Fría case, also affected by the impasse between the project staff and the mayor.

Moreover, both reconstruction projects were complex, required high negotiation skills from project staff and also creativity and flexibility to deal with multiple uncertainties coming from macro-level contexts. The role of community organisations was crucial, but they behaved differently and the projects had different degrees of human autonomy effectiveness.

In sum, considering national trends toward decentralisation (appendices 1-A and 1-B), the partnership of municipal governments in the projects is advisable (cf., LD, 2006). In this way, potential conflict could be managed and translated into informed decision-making with the involvement of local social actors (e.g., community organisations). This need is even higher in complex reconstruction projects.

Furthermore, formal institutional support from the central government favours external coordination (cf., Rubio-Fabián \& Valdez, 2004). This support should be explicit from the start and not only the result of the project chief's leadership. San Agustín illustrates the fact that, after initial reservations, the strong commitment of the MFA of El Salvador was important to the success of the project.

\subsubsection{Entitlements defined by practices}

Defining selection criteria is a sensitive issue especially for income-poor localities where almost all people are in need. It is problematic to include criteria controlled by an external entity or elite that could have an agenda to favour certain groups (e.g., in Santa María). It is also difficult to define co-payments when projects aim at securing basic intermediate needs, such as safe drinking water, and assumptions about capacity to pay might be mistaken.

\section{- $\quad$ The definition of selection criteria and conditionality}

For the reconstruction projects, selection criteria were defined by a board composed by community representatives, the municipal government, and an external entity. In Santa María, new criteria were introduced during the project implementation. The external entity was the executing NGO supported by the LD coordinator. In San Agustín, the criteria were fully defined at the formulation stage, but some conditions were relaxed by consensus of the working group or CRDM assembly, in consideration for special cases (section 9.3.3).

In Santa Maria, there was leakage. Some people, who were not survivors, were enrolled in the project to fill the places of those who stayed in the nearby private land. Conflict arose around the legitimacy of claims or who deserved to receive a house in terms of the harm suffered (section 6.3.2). In San Agustín, there was under-coverage. Among several criteria, bene- 
ficiaries had to be poor, according to a monetary ceiling, and to own the land where the house would be built. However, not poor enough households (officially income-poor but with incomes higher than the ceiling) could neither get a house nor afford a house comparable in quality to the one offered by the project. Moreover, not all legal cases were solved. Finally, only $80 \%$ of houses originally budgeted were constructed.

For the water projects, a crucial conditionality was defined externally by the public water company and the project formulators. It is a norm that rural households connected to water systems have an autonomous sanitation system so that grey waters infiltrate to the soil and do not contaminate the environment. Each household had to build a soak-away pit (the most common) with their own funds (Agua Fría) or with project funds (San Fernando). The initial connection cost was covered by the project (Agua Fría) or by households with a subsidy from the project (San Fernando).

In Agua Fría, the construction of soak-away pits as a condition to access water could have meant the exclusion of the poorest, who did not receive remittances and could not afford the materials or the loss of a working day. Finally, $14 \%$ of resident households were not covered by the project (section 7.3.1). In San Fernando, all households were connected to the water system, but there were problems with the allocation of latrines due to the inaccurate census and the disagreement about who was poor enough to receive a latrine (section 8.3.3).

\section{- Implications of targeting for individual autonomy}

Previous practices implicitly targeted certain households and defined individual entitlements, which also depend on the intra-community relations marked by common history and culture. It is important that both the selection criteria and their process of definition are known by everyone prior to the project execution. The need to involve non-leaders in the process depends on cultural features that influence values. Some people in San Agustín would delegate to leaders, but people in Santa María would not.

For the reconstruction projects, relevant issues were the value of the entitlement and the definition of the selection criteria. People had lost their land in Santa María so that the selection of beneficiaries was more politically sensitive there than in San Agustín, where residents kept their land. However, most people did not realise how entitlements were being defined and negotiated, at first, because their agency was deeply harmed by the disaster.

In Santa María, people did not understand why and how others, who had suffered less (and deserved less, from their view), had the same or more benefits. Furthermore, they felt imprisoned inside their houses as they were forced to stay there to keep them. The clash between the communal leaders and the project staff in regard to the list of beneficiaries suggests that selection criteria were not respected. Consequently, non-leaders were not sure about what they had to do in order to keep their houses (section 6.3.2). In San Agustín, the selection criteria were clear, but some non-leaders were confused about how the selection criteria were decided. Information did not flow so evenly (section 9.5.1) due to the insecure local context and the hierarchical nature of the relations between CRDM, development committees, and non-leaders (which project staff tried to respect).

For the water projects, the issue was how people perceived the 'soak-way pit requirement'. Several people did not internalise this condition. The situation was worse in Agua Fría because households had to finance the materials for something that they did not consider 
useful. In San Fernando, delays in the execution explained that workshops focused more on how to build the sanitation infrastructure than on why to have them. At the time of the fieldwork, many non-leaders did not maintain them adequately.

In all cases, who was poor enough to receive the benefit was a recurrent criterion topic. Considering that the projects covered poor communities in which all households had the same need or had been hit by disasters, it was not necessary to further differentiate between poor enough and not poor enough households. If people were already categorised as not poor enough, they could not do much to become eligible (e.g., to receive a latrine in San Fernando). The definition of a consensual poverty threshold (if any, in the water projects) was problematic. Given the relative high value of the expected benefit, people would lie about their revenues to become eligible (e.g., in the economic census of San Agustín), although within certain limits. By the same token, in the short run, they did not have incentives to improve their economic situation because then they would become ineligible. This kind of aid that erodes the incentives for self-help is 'unhelpful' (Ellerman, 2006, 2007). In the long run, it could have negative effects on autonomy, if people linked the continuity of projects to the existence of a visible material lack of well-being and were 'likely to portray themselves as passive recipients' (Harvey \& Lind, 2005, p. 22).

\subsection{Participation and the exercise of individual autonomy}

The participation of stakeholders, those affected directly or indirectly by the project, and especially final aid recipients is considered important for:

(i) Instrumental or transitive effects in terms of achievement of goals of effectiveness, efficiency and sustainability, with respect to the project's objectives (UNDP, 2007; Narayan, 2002);

(ii) Intrinsic effects related to enhancement of capacities, gained understanding of local values and priorities, and their incorporation in the project (Alkire, 2002; White \& Pettit, 2004; Chambers, 1995); and

(iii) Intrinsic effects related to personal satisfaction with participation.

Across the cases, individual and community participation were expected to produce these instrumental and intrinsic effects. Instrumental effects in terms of effectiveness were associated to individual and group participation in construction works. The causal link was that participation would assure the good quality of project outputs because beneficiaries themselves work and monitor on site the construction process, with the interest that only an owner not a third-party has.

Instrumental effects in terms to sustainability were related to personal commitment to maintain, repair or improve infrastructures and to community supervision of good maintenance practices such as the cleaning of community centre or the correct use of soak-away pits. Community organisations were also deemed crucial for sustainability. For instance, in San Fernando, leaders felt that 'the finalisation of project activities meant the start of a new project' because they became responsible for the monitoring of behavioural changes in hygiene practices and the maintenance of sanitation systems.

There was no clear link between participation and efficiency in the logic of any of the projects. Although using local labour instead of contracting external workers brought immedi- 
ate monetary savings, the work of residents as unskilled construction workers could have caused delays (in San Agustín) or the waste of material (in Santa María).

Regarding intrinsic effects, residents were expected to improve skills other than farming skills, which in turn would allow them to diversify their income sources. These acquired skills were also necessary to guarantee effectiveness. However, local supervision was not always good (e.g., Santa María).

At the community level, there were other effects, envisaged only in the San Agustín project documents, related to increased self-confidence from successful joint work and improved capacity to generate and manage future development initiatives.

\subsubsection{Participation has different modalities}

The effects of participation vary in relation to the kind of participation (Arnstein, 1969; Guaraldo Choguill, 1996). Whether people were informed or consulted, made 'decisions' under a coercive context or decisions that were not respected, or made informed decisions that were taken into account, makes a big difference. The relevance of decisions also matters. For instance, asking about everything all the time would give the impression of chaos and would certainly delay the operations (critical in the case of construction projects).

Another consideration is the initial capacity of participants to make decisions. Consensus could be unreachable at early stages of a project because a community organisation was new. Nonetheless, if people were not involved in decision-making since the start they could lose the chance to engage later in a significant manner, that is, more than only following indications from project staff or being mobilised to work.

There is a short-term trade-off between efficiency goals (e.g., to finish in the planned time) and capacity building goals. However, in the long-term, it makes sense to support the latter goals to promote the autonomy of individuals. As a first step, projects could awaken aspirations (e.g., in San Agustín) so that participation can become 'transformative' (Cornwall, 2003). This kind of participation builds political capabilities and awareness, leading to critical autonomy in political, community and social spheres (cf., Gaventa, 2004).

The contexts are complex and people are different across localities and within localities, existing different groups and hierarchies. However, the participatory design was uniform for non-leaders (self-construction) and more diverse for leaders. It is then relevant to understand how people participated in the projects. Was participation more than working hard on multiple tasks for a fixed period? Did people feel obliged to work? Did they work in order to show their gratefulness to the NGO, social promoter or donor for the help provided?

These questions are related to (i) the interaction between project staff and community members (during different stages of the project life), qualitatively different for leaders and nonleaders, (ii) the role of community leaders in defining, opening or restricting spaces for nonleaders, (iii) the role culturally assigned to leaders concerning decision-making, and (iv) the representativeness and legitimacy of leaders as perceived by non-leaders. This means that there is a joint effect of project and community factors on the perceptions of non-leaders of their entitlements (regarding the projects) and what they were expected to do.

Some people would prefer to delegate important decisions and supervision to leaders. This seems to be the case in San Agustín and Agua Fría, where community organisations had a 
longer history than in San Fernando (no previous organisation) or Santa María (selfnominated leaders). However, the delegation of decision-making and respectful attitudes might cover long-lasting social inequalities (Cleaver, 2004b).

Below, the extent of decision-making by inhabitants according to their leadership role and to the kind of non-leader participation is discussed.

\subsubsection{The decision-making of leaders varied across projects}

Table 10-4 contains a qualitative assessment of the participation in decision-making by project and role of leadership. Identifying the moment when participation initiates is important to assess its quality and authenticity, especially when it is launched by outside change agents (Goulet, 1989, p. 167-8).

Table 10-4: Decision-making by leadership status and project (at different project stages)

\begin{tabular}{|c|c|c|c|c|c|c|}
\hline & \multicolumn{2}{|c|}{ Formulation } & \multicolumn{2}{|c|}{ Implementation } & \multicolumn{2}{|c|}{ Evaluation } \\
\hline & Leaders & Non-leaders & Leaders & Non-leaders & Leaders & Non-leaders \\
\hline \multicolumn{7}{|c|}{ Reconstruction projects } \\
\hline Santa María & Yes(+) & Yes(-) & Yes $(++)$ & Yes(-) & No & No \\
\hline San Agustín & Yes $(++)$ & No & Yes $(++)$ & Yes(+) & Yes $(*)$ & No \\
\hline \multicolumn{7}{|l|}{ Water projects } \\
\hline San Fernando & No & No & Yes(+) & No & Yes $(*)$ & No \\
\hline Agua Fría & $\operatorname{Yes}(*)$ & No & Yes $(+)$ & No & $\operatorname{Yes}(*)$ & No \\
\hline
\end{tabular}

Legend: (-) means that the decisions were not respected, $\left({ }^{*}\right)$ means that people were informed or consulted, (+) means that the extent of decision-making was low, and (++) means that decision-making was high.

Source: Individual interviews, FGDs and project documents (using iterative cross-checking).

At the formulation stage, only in San Agustín did community leaders make decisions through a participatory formulation (section 9.3.1). The self-nominated leaders of Santa María had relevant participation during the emergency, but after many discussions and a 'parade' of donors, decisions on project design were top-down (e.g., on village layout).

In contrast, the leaders in Agua Fría were only consulted over taking up the project as designed, but this decision was very significant to them. They reflect on the positive effects of this decision every time that they watch the living conditions of people in a nearby town, whose leaders did not accept the project and later 'were regretting' their choice. In San Fernando, there were no formal leaders until the project started.

At the implementation stage, the leaders in the water projects carried out functions similar to those of social promoters. In this way, project staff became more familiar to aid recipients, and also transferred some costs to the leaders (cf., Cooke \& Kothari, 2004). The leaders in the reconstruction projects were more active. However, while in San Agustín their role was positive and constant, it became disruptive in Santa María due to political interests.

At the evaluation stage of the water projects, leaders were only informed about project results even though they wanted to discuss and solve issues such as the explosion of pipes (in Agua Fría) and the high water tariffs (in San Fernando). There were no evaluation workshops in the reconstruction projects, but leaders in San Agustín were informed through the project chief. This is especially disappointing because this project had started with a novel (for recipients and donor) participatory formulation. 
With respect to non-leaders, across cases, the participation was low and instrumental to reach project goals. However, in the reconstruction projects, residents were asked their opinions on several occasions during the construction stage as the projects concerned them directly: they were building their houses and their social infrastructure. The case of Santa María is special because, according to non-leaders, they were consulted over some crucial decisions (not the case in San Agustín), but these decisions were not respected later on.

The participation of leaders had different effects on the community dynamics, which are analysed in Chapter 11 (section 11.2). The effects for non-leaders are analysed below, from an individual perspective.

\subsubsection{The quality of the participation of non-leaders was low}

In this study, an 'involvement' index was used to assign non-leaders to each FGD, with the expectation that the experiences of individuals with high and low involvement in the project would be qualitatively different from each other. This index aggregated self-reported scores to five variables: information, opinions, awareness, opportunities and decisions (section 4.2.1). By definition this index captures more than 'hard' work; it would identify individuals who more likely exercised their individual autonomy during the project. Table 10-5 shows some descriptive statistics of the index.

Table 10-5: The level of involvement of non-leaders by project

\begin{tabular}{|c|c|c|c|c|c|c|}
\hline Project & Mean & Std. Dev. & Median & Min. & Max. & $\mathrm{N}$ \\
\hline \multicolumn{7}{|c|}{ Reconstruction projects } \\
\hline Santa María & 1.26 & 0.66 & 1.4 & 0 & 2.8 & 84 \\
\hline San Agustín & 1.17 & 0.57 & 1.1 & 0.2 & 2.4 & 36 \\
\hline \multicolumn{7}{|l|}{ Water projects } \\
\hline San Fernando & 1.11 & 0.65 & 1.0 & 0 & 3.0 & 76 \\
\hline Agua Fría & 1.31 & 0.72 & 1.4 & 0 & 2.4 & 35 \\
\hline Total & 1.20 & 0.65 & 1.2 & 0 & 3.0 & 231 \\
\hline
\end{tabular}

The involvement index is composed by five equally-weighted variables. The range of values is from 0 to 3 . Source: Dataset 1.

The levels of involvement in the project were relatively low in all projects and statistically behaved in similar ways. ${ }^{75}$ At first sight, this finding seems strange because the four projects included self-construction activities and, on the other hand, participation was perceived as 'fair' by respondents (in an ordinal scale that included: low, fair and high; dataset 2). The explanation could be that (i) the respondents understood participation as workload during the project or to what extent they worked in all the activities organised by project staff, ${ }^{76}$ and (ii) manual work was not translated into high involvement. In fact, workload was higher for participants of the reconstruction projects: $41 \%$ and $27 \%$ of the survey respondents in the reconstruction and water project sites, respectively, reported that their participation was high.

Table 10-6 presents a rough qualitative assessment of workload and involvement. In the case of the reconstruction projects, the ranking is different from each perspective. In the case of

\footnotetext{
75 The Kruskal-Wallis one-way analysis of variance by ranks indicates that data of four projects would show similar distribution ( $\mathrm{p}=0.249$, for Chi-squared with ties). See Siegel and Castellan (1988, p. 206-212).

${ }^{76}$ Many respondents considered that participation was necessary. Then, if they fulfilled their commitment, their participation was fair.
} 
the water projects, the ranking is the same and Agua Fría is the project in which individuals worked harder and were more involved.

Table 10-6: Comparing levels of participation in the projects (rankings by sector)

\begin{tabular}{|c|c|c|c|c|}
\hline \multirow{2}{*}{ Ranking: } & \multicolumn{2}{|c|}{ Reconstruction projects } & \multicolumn{2}{|c|}{ Water projects } \\
\hline & Workload & Involvement & Workload & Involvement \\
\hline $\begin{array}{l}\text { First } \\
\text { Second }\end{array}$ & $\begin{array}{l}\text { San Agustín } \\
\text { Santa María }\end{array}$ & $\begin{array}{l}\text { Santa María } \\
\text { San Agustín }\end{array}$ & $\begin{array}{c}\text { Agua Fría } \\
\text { San Fernando }\end{array}$ & $\begin{array}{c}\text { Agua Fría } \\
\text { San Fernando }\end{array}$ \\
\hline
\end{tabular}

Note: Participation at a basic level is understood as workload in project activities. Involvement refers to highquality participation because it includes shared information, awareness and decision-making.

The involvement index might be mixing two different aspects: (i) the extent to which the project context favoured the sharing of information and supported self-confidence (whether people gave opinions and felt that they had applied their own skills), and (ii) the extent to which people could exercise decision-making.

Figure 10-3 shows the expected link between workload and involvement, and between involvement and individual autonomy (only with respect to subjective or personal effects). The analysis that follows suggests that high workload was not followed by high involvement in the project and that different levels of involvement were influenced by different contexts and practices that, however, did not promote the exercise of individual autonomy.

Figure 10-3: Expected logic chain from participation to individual empowerment

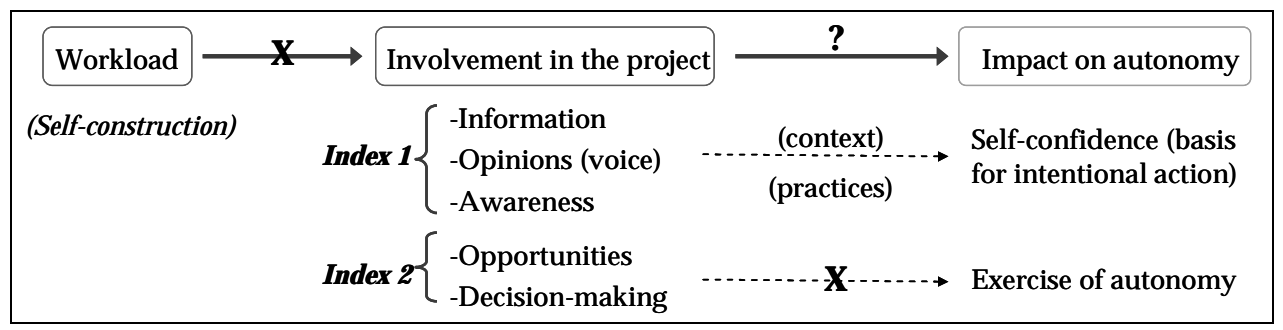

The five variables, previously used to form the involvement index, were re-grouped into two indexes so that Index 1 reflects factors related to the micro-context of the projects, while Index 2 reflects the exercise of decision-making (see Box 10-1).

\section{Box 10-1: Two indexes of individual involvement (quantitative cross-case analysis)}

Based on the five variables conceptually related to involvement in the project (in dataset 1), two indexes were calculated, as follows:

Index 1: Information $\cup$ ( Opinions $\cap$ Awareness )

Index 2: Opportunities $\cap$ Decisions

Where $a \cup b=\operatorname{Max}(a, b)$ and $a \cap b=\operatorname{Min}(a, b)$

The intersection operator $\cap$ was used when the association between the variables was moderate or strong and the union operator $\cup$ when it was weak.

In the case of Index 1, opinions and awareness had a Kendall's tau-b of $0.45(p<.01)$. The same statistic for opinions and information was $0.27(\mathrm{p}<.01)$ and for information and awareness was $0.38(\mathrm{p}<.01)$. In the case of Index 2, the association between opportunities (for decision-making) and decisions was not surprisingly strong: a Kendall's tau-b of 0.73 ( $\mathrm{p}<.01)$. $\mathrm{n}=231$.

The mean value for Index 1 is 1.60 and the mean value for Index 2 is 0.88 . 
Values for Index 1 and Index 2 were significantly higher for the individuals with high-involvement than for those with low-involvement. High-involvement respondents represented $49 \%$ of the total in Agua Fría, 38\% in Santa María, 25\% in San Agustín, and 22\% in San Fernando.

Looking at the different variables across cases, the causal relationship between the variables opinions and awareness was not spurious. The Somers' D statistic (for opinions to explain awareness) was 0.462 , while the same statistic for information (to explain awareness) and decisions (to explain awareness) were 0.388 and 0.386 , respectively. This means that people who expressed their opinions during the project were very likely to feel that they had applied their personal skills. The effect of having made decisions was lower in the self-perception of personal capacities. In the same way, the extent of information had lower effect on awareness.

Although information was more or less evenly provided - considering how important these projects were for the lives of residents and how many people were mobilised-the extent to which the contexts of the projects promoted self-confidence, either allowing giving opinions or respecting them, differed. There might be links between workload and individual involvement in the projects, fuelled by the joint work and the exchange of ideas within each work group. In this sense, the Santa María and the San Agustín projects could have had the potential to generate higher levels of individual involvement. However, the contexts there were more controlling than those in the water projects, especially in Santa María (with information problems as well). In the case of the water projects, the Agua Fría project would have higher effects considering both contexts and workload (Table 10-6).

With respect to Index 1, the respondents in San Agustín reported scores very similar to those in Santa María, although people in Santa María reported to have given their opinions a little more frequently. The respondents in Agua Fría reported higher scores than those in San Fernando in every element (information, opinions and awareness). The difference was larger in terms of information: $66 \%$ of the survey respondents in Agua Fría said to have received 'sometimes' or 'usually' the information they needed during the project versus a $47 \%$ of the respondents in San Fernando (detail of responses in Appendix 2-F).

With respect to Index 2, the respondents in all projects reported very low levels of decisionmaking involvement (the mean value for Index 2 was 0.88 out of 3.00). However, it was somewhat higher in Agua Fría and Santa María than in San Fernando and San Agustín, respectively. More than $40 \%$ of the respondents in the two latter projects reported not having made decisions during the project.

Figure 10-4: Comparing Index 1 and Index 2, the cases with the highest overall involvement
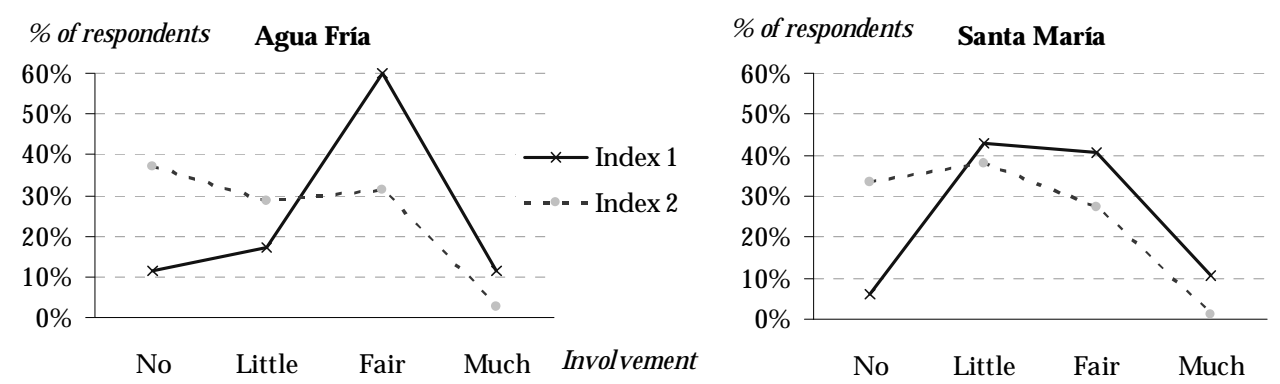

Index 1 aggregates information, opinions and awareness. Index 2 aggregates opportunities and decisions.

Source: Dataset 1. 
Figure 10-4 shows the two indexes for the cases with the highest overall involvement level in each sector: Santa María and Agua Fría. Also in these cases, Index 2 was lower than Index 1. Besides, the micro-level context of the project in Agua Fría was more favourable for autonomy expansion than the context in Santa María.

In sum, regarding the quality of participation of non-leaders:

(i) High workload did not necessarily produce a high involvement in the project;

(ii) The low levels of involvement were related to low decision-making exercised by individuals during the projects; and,

(iii) The intrinsic effects of participation would be restricted for non-leaders and, if present, these effects would be mainly related to the awareness of having used their personal skills during the project.

\subsubsection{Participation, conditionality and valuable processes}

The analytical framework proposes the identification of valuable processes in which people want to be involved (section 10.2.3). However, high-intensity participation (hard work only) could be confused with high-quality participation (involvement) if the reasons to participate are not analysed. On the one hand, self-construction activities could be differently interpreted by final aid recipients and have different effects on individual autonomy. On the other hand, the construction process could be differently valued and so would involvement.

- The degree of internalisation of work commitments

Project participants could interpret their work in self-construction as:

1. A condition imposed by an external entity that has to be fulfilled, independently of one's opinion (e.g., 'we had to do it'; 'our opinions were not taken into account'; 'they [leaders] decided for us');

2. The fulfilment of an agreement to achieve a valuable goal, but they are doing what they are supposed to do (e.g., 'it was our contribution'; 'I did everything that was asked for');

3. The fulfilment of an agreement that brings happiness and pride because they are making an effort to improve their own lives (e.g., 'we did not leave the project to decay'; 'San Agustín for San Agustín');

4. The fulfilment of an agreement whose process (the work) they are enjoying because they are learning a new skill, engaging with people 'bigger than them', sharing experiences with neighbours or working together (e.g., 'we were three communities that became like only one').

The extent to which individuals agree with any of the previous interpretations depends on how they internalise their commitments (section 2.2.4 on the SDT). In the first case, there is not internalisation; people perceive their tasks solely as obligations because they did not share in the decision to do them or, if they did, the contexts were so controlling that they felt they were working for someone else, not for themselves. Some people in Santa María perceived that their manual work became a commodity to be provided uniformly, without consideration to special cases, for which they did not get a 'fair' compensation (section 6.3.3). Furthermore, expressing their opinions did not help much. 
In the second case, people know that an agreement (in which they participated, directly or through their leaders) was reached because the final goal was valuable. However, the activities linked to this agreement became obligations. In the water projects, participants highly valued the water connections and latrines, but they also worked on everything requested (e.g., sanitation systems, woodstoves) in order to get water. This is the case for most people in Agua Fría.

In the third case, people are fulfilling a commitment, but they 'have in sight' the final outcome. They feel happiness and pride because there is something in reach that they can do to help themselves and their community. They are intrinsically motivated (section 2.2.4). This is the case for most people (mainly group coordinators) in San Agustin, despite the suffering for harsh work conditions. It is also the case for some people in Santa María and work squads in Agua Fría while constructing the reservoir. In Agua Fría, people had autonomy causality orientation as leaders (not the project) had the initiative to raise fish in the reservoir. If successful, this activity would have resulted from their efforts (section 7.5.4).

In the fourth case, people are also enjoying the process of working together. It was basically women who expressed this in San Fernando and Agua Fría because they shared time in training sessions, organised themselves for project activities (e.g., the garbage carnival in San Fernando) or told other people about their experience (e.g., field trips in Agua Fría). It was less common in the reconstruction projects, which had harder work conditions.

This discussion confirms that the internalisation of work commitments depends on the practices and interpersonal contexts during the projects, in addition to personality factors. Some remarks follow.

First, project contexts can make an initially internalised commitment feel like an external imposition (section 2.2.5). For instance, the effects of controlling practices on autonomy were quite different in Santa María and San Agustín. In San Agustín there was a charismatic and committed project chief, while in Santa María the project was managed by a sub-contracted NGO. Despite legal delays, the residents of San Agustín knew in advance the design and quality of their houses and trusted the project. In contrast, the residents in Santa María did not feel support from the executing NGO (the donor was distant) and organisational problems caused uncertainty about crucial project features. For many of them, motivation was externalised.

Second, transforming project features deemed as externally imposed into internalised commitments is difficult. In Agua Fría, the NGO found it hard to change the perception that soak-away pits, latrines and ecological woodstoves were part of the same bundle and a requisite to get the water connection. This perception was caused by the bad experience of neighbours in cantons served by another NGO that forced people to take up all these components even though those people were not convinced of the utility of such outputs.

Third, the internalisation of commitments depends also on local perceptions of the role of a community organisation in originating crucial project features (or a project itself), although these perceptions are not always accurate. For instance, people could ignore how decision-making takes place due to specific community dynamics. In San Agustín, some people considered that project staff had a larger weight in decision-making than community leaders so that fulfilling their work commitments was a sign of gratefulness. This perception was related to 
the high visibility of the project chief and the poor information sharing between leaders and non-leaders.

Lastly, in relation to the instrumental effects of participation, the extent to which work commitments are internalised directly affects the achievement of project outputs and indirectly affects individual autonomy. For instance, the degree of acceptance of soak-away pits, and knowing why they were important, would have a positive impact on health if people used and maintained them adequately. Therefore, it is important to explain to people the reasons why certain fixed features of projects are necessary and to incorporate the local knowledge to promote a sense of self-worth and also to achieve results. For instance, welcoming comments about the soil quality could lead to adapt the sanitation systems so that people would consider them useful. Then, the sustainability of the project outputs and, most importantly, the expected effect on health, physical capacity and autonomy would be improved.

\section{- Different reasons for involvement and valuable processes}

Authentically motivated people look for more involvement in those aspects that they value. Participants in the reconstruction projects were more involved in the selection of the house design than in decisions regarding social infrastructure. In San Agustín, based on the basic models selected by leaders, some people introduced small changes in coordination with the bricklayers that would fit better the shape of their plot and their customs. However, their motivation to work in common buildings was lower (section 9.3.2).

People who perceive that they have the right to be benefited look for more involvement, al though the relative level of involvement may differ. The inhabitants of Santa María felt that they were the most hit by the Hurricane Mitch in Nicaragua and that their experience had fuelled aid flows to the country. The inhabitants of Agua Fría knew that their leaders, together with other leaders from neighbouring cantons, had fought long to get safe drinking water. Therefore, if project staff or other actors did not open spaces for participation, residents would put pressure to speak up or to be informed about decisions. Furthermore, they had made a choice. In Santa María, they chose between staying in an invaded private land and accepting the offer of the donor. In Agua Fría, they chose between this project and the option offered by the mayor. Furthermore, 'the arrival' of the project was a result of their insistence (i.e., internal locus of causality). Then, projects were not acts of charity to be accepted as they came, there was a responsibility from national institutions and donors.

The higher involvement of non-leaders in Santa María and Agua Fría in comparison to the other two cases would be the result not only of the willingness of project staff, but also of their exercise of autonomy in those contexts. The potential to enhance autonomy in these two cases was larger than in the others because the motivation existed; it was not supplied by the donor (Ellerman, 2004; 2006; 2007). As such, this kind of participation (i.e., exercising voice) had a moral or nonmaterial incentive 'as a promise of future negotiation power' (Goulet, 1989, p. 175) that induced people to negotiate material incentives to improve their wellbeing such as the productive projects. Unfortunately, other factors such as political opposition and the failure of these productive projects put obstacles to this empowering process. 


\subsection{Sectoral features: different impacts on autonomy?}

This section explores differences in project effects between the reconstruction projects and the water projects. It also discusses the relevance of assessing impacts using different categories: country, level of involvement, role of leadership, and gender.

One could group projects by country, but Part II has shown that people had gone through very contrasting life experiences. In Nicaragua, San Fernando is a traditional society that had been isolated since the civil war until recently, while people in Santa María had been long in the centre of political action and were the centre of public attention following the Casitas disaster. In El Salvador, San Agustín was one of municipalities most hit by the civil war, while Agua Fría was much less affected. These experiences determine differences in autonomy because abandonment (translated as lack of minimum living conditions), violence, and insecurity harm the possibilities for its exercise.

A conceptual distinction was the level of individual involvement in the projects. However, involvement was low across projects and there was no significant decision-making for nonleaders (section 10.4.3). Moreover, the FGDs indicate that, in some cases, low-involvement participants reported higher expansions in elements conceptually linked to individual autonomy than high-involvement ones. Also, there was not a distinguishably different pattern between men and women, for example, to say that low-involvement women and highinvolvement men had higher expansions in autonomy across projects. The differences between high- and low-involvement groups are not discussed further here; when relevant they were already discussed in the individual case chapters.

Other variables that might explain different impacts were the role of leadership and gender, which were already discussed in each case chapter. Here, it is worth stressing that leaders, in general, experienced a greater expansion in autonomy than non-leaders, given a growing awareness of their joint capacities and increased temporal and causality orientation. This holds true despite the fact that, in some aspects, the projects were not as effective as they could have been, as signalled by the technical problems in Agua Fría, the high water tariffs in San Fernando, and the failed agricultural project in Santa María. Santa María is the most extreme case in which non-leaders felt excluded and exploited because entitlements over common resources over the years have been concentrated in the hands of a small group.

Regarding gender, none of the projects had an explicit objective of gender equity. However, the case of San Fernando marked a difference for women who took the responsibility to integrate the committees and to assure that their houses would be connected to the water service. The reason for their participation and the relative absence of men during the project was more cultural than it was due to the project practices. Indeed, participation of women leaders depended on the good will of their husbands (cf., Cornwall, 2003) and they had to participate in order 'to keep the project' that they so much needed.

Having discussed potential sources of differences, it is time to comment on some specific sectoral features of the reconstruction and the water projects.

\subsubsection{The reconstruction projects}

As seen earlier, the disasters had different meanings for project participants of Santa María and San Agustín: tragedy and opportunity, respectively. Moreover, the foundations of for- 
mal leadership positions were different: self-nominated leaders in Santa María and broadbased community organisation in San Agustín (section 10.1). In both cases, the projects started one year after the disasters occurred and people had been receiving emergency aid. Nonetheless, relief (food) aid was cut off during the projects and people had to find alternative ways to make a living in a context where projects required them to work in selfconstruction activities and other common efforts.

This section discusses some topics related to relevant decision making, basic entitlements, self-construction activities and houses as entitlements more in depth.

\section{- Crucial decisions, decision makers and social contexts}

In Santa María, people had lost their livelihoods. They could not work in their old plots in Casitas which were inaccessible, insecure and expropriated by the government. Nevertheless, working in the agricultural project had provided them with food and the hope of future trade activity with the crops produced and other parallel productive projects. Donors saw common agricultural work as the only way to develop joint capacities of self-reliance in the long term and considered that the time spent in productive activities (started earlier than the actual construction works) would help to build trust among people who before the tragedy were strangers. This integration process would be supported by self-construction activities.

In San Agustín, residents did not have the capacity to cultivate their own or rented plots because the last agricultural season had been lost and there were no profits to reinvest or accessible credit. However, they hoped that the economic activity around the construction activities would generate some profits. Then, leaders considered that hiring skilled manual workers from San Agustín for the largest possible number of activities could keep the money flowing in the municipality. In addition, working together in self-construction activities was seen by the leaders as a proof of commitment to their own development and as a way to build solidarity in a town were people 'did not trust even in their relatives'.

In both cases, people spent months working in mutual help groups. They worked not only in house construction but also in agriculture activities (in Santa María), levelling of land (in both cases), days of cleaning and reforestation activities (in both cases) or the construction of the community centre (in San Agustín).

In Santa María, donors decided that residents would work in a communal plot managed by leaders. In San Agustín, representative leaders chose self-construction activities. In Santa María, motivation was extrinsic; in San Agustín, it was an agreed commitment.

In Santa María, not only was the disaster a dramatic change (i.e., deaths, suffering, and relocation), but also the project logic indicated the creation of an ideal cooperative-kind society that was against the values of people who had preferred larger individual plots like the ones in El Tanque. Cleaver (2004a) explains that 'solidarity' models assume some underlying commonality of interest that might not be present. Moreover, there are processes of conflict and negotiation, inclusion and exclusion, especially when people are facing such stressful situations. Social capital was initially built as result of the shared a tragic experience, but it was harmed by the capture of common resources by the leaders over the years.

In San Agustín, social relations improved; trust and solidarity were slowly built over the almost-four year period that the project lasted. The key differences between these two cases 
were the leaders, their representativeness and behaviour during the project, and the project staff, specifically the presence of a committed project chief in San Agustín.

\section{- Securing basic entitlements after disasters}

The modalities of food aid used in each case were different. In Santa María, there was a food for work programme. In San Agustín, food aid was unconditional to everyone. However, food aid was interrupted before the projects were completed.

In Santa María, survivors were forced to work in order to survive. Furthermore, they did not have adequate psychological support, so that work was seen as an escape from sorrow. In any case, this escape was only temporary because many people could not deal with their loss adequately and, still years after the mudslide, were heavily affected in their personal relations (e.g., intra-family violence, drinking problems) and agency (section 6.2.2). They miss their old life, perceived as happier, and cannot initiate new actions without the support of others so communal participation is the only way to survive. Their individual plots are too small to support subsistence farming.

Had the project been formulated as more participatory, the voice of the inhabitants would still have been small. In this sense, a first immediate step after the land was located and people moved into the huts would have been to provide extensive psychological support and unconditional food aid. If the goal is to guarantee a minimum level of autonomy, the fulfilment of basic intermediate needs (THN) cannot be restricted (cf., Harvey \& Lind, 2005). How could the inhabitants of Santa María have had proposals or hopes if they were not able to think on their own clearly? Furthermore, every time that they were asked to give their opinions and these were not taken into account, the project staff or leaders were harming even more their already diminished agency.

In San Agustín, residents faced a somewhat similar scenario in terms of living conditions during the project. They had to split their activities in order to generate some income or food as well. The situation of single mothers was the worst because they lacked the means to feed their children and themselves. For people in the new colonies, who worked over two years, the situation was unbearable. Although this situation (i.e., the withdrawal of food aid) was unpredictable and the construction was assumed to be quicker, the project staff should have had the flexibility to re-allocate some resources to hire paid bricklayers at least to work in the colonies so to protect their subsistence.

\section{- The role of self-construction activities}

Either by decision of donors or leaders, both projects incorporated the residents as assistants of bricklayers in construction activities. These activities in a harsh situation were perceived as a strong condition to get a house, depending on the individual degree of internalisation (section 10.4.4). People spent time, put their subsistence at risk, and exhausted their energies in these activities. This situation contrasted with the reality of the beneficiaries of projects financed by other donors, whose houses were built by private construction companies.

On the other hand, self-construction is not a necessary condition to secure ownership (cf., CAMIRE, 2005). For instance, the ownership of the community centre by Santa María residents was high despite it was being constructed by a private contractor. In contrast, San Agustín residents benefited by the project were not so willing to collaborate in the construction of the community centre (section 9.3.2); in most cases were too tired to 'help' anyway. 
Most importantly, people engaged in self-construction did not have a chance to expand their capacity to choose according to their values and goals because they were doing their utmost, given the situation. Even accessing information about decisions made by leaders was hard because they were too busy and contexts were controlling. If instead of having all households working in construction, residents who already were bricklayers had worked and monitored the construction works, autonomy and effectiveness would have been promoted.

One expected effect of the self-construction activities was that people would acquire an alternative skill to reduce their economic vulnerability. A crucial point is whether they had real opportunities to apply this new skill. Some men temporarily worked in this project and in nearby construction projects. However, when the disaster-related reconstruction in the area ended, most of them could not find a job as bricklayers again. Many returned to work as farmers, while others migrated to find job because they live in poor areas with little construction activity.

Becoming bricklayers brought a short-term economic benefit for some men. Nevertheless, the overall negative effect on the rest of the residents was larger. They could not work in what they needed for their subsistence (agriculture), they were not helped with agriculture projects later on, and most importantly, they could not work in what really mattered: the development of their communities through effective participation in community decisions. This participation could have fuelled their critical autonomy.

During the project implementation stages, some adjustments could be made to reduce the livelihood trade-offs (Ashley \& Hussein, 2000), for instance, adapting the timing of obligatory activities so that people could secure their subsistence (cf., Osti, 2004). This is especially important in the case of Santa María and the human settlements in San Agustín.

\section{- Houses as real entitlements}

The main output of these projects was to provide a house to every household. In this sense, the project in Santa María was more successful because the coverage was $100 \%$ versus $80 \%$ in San Agustín. This difference was explained by complications to register the legal property titles in San Agustín. Legal ownership was highly valued by the project participants in both localities, but only the San Agustín project addressed this issue.

In Santa María, registration was the responsibility of the municipality government (that expected financial support from a donor) to be made a couple of years later because the project logic indicated that people had to keep the houses for a while. The same logic led to the verification process that forced people to stay in the town, to not lose their houses (section 6.3.2). At the time of the fieldwork, four years after the completion of the project, most people did not have their property titles and felt insecure for this reason. Therefore, the project failed to provide psychological security through the tenancy of the houses.

In San Agustín, households with young children had to register their houses as 'family property' (section 9.3.2) so that they could not sell or mortgage the house freely. It meant that the house could not be used as an asset to back a productive loan.

In sum, in both cases, houses were not real entitlements because they could not be traded or used to fulfil other needs. It seems that project formulators and legislators assumed that people would misuse their houses and put at risk the security of their families so restrictions were enforced. People did not have a choice but to accept the houses with the restrictions. However, 
in Santa María, this was not the biggest problem. The loss of land to cultivate is what caused the long-term deprivation in which people live. As Cernea (1997) asserts, for farmers, the 'loss of land generally has far more severe consequences than the loss of a house' (p. 1573).

\subsubsection{The water projects}

Water projects have fewer components than reconstruction projects because their objective is narrower: to provide access to safe drinking water. However, the technical aspects add complexity. Over the years, water projects have evolved to include sanitation infrastructure and hygiene education to complete what is called an 'integrated approach' (Nicol, 2000), with the expectation of securing positive health effects.

In addition, nowadays, water systems require consumers to finance at least the maintenance and operation costs. This feature is part of a demand-based approach, in which service is provided according to the purchasing power or the willingness to pay, in contrast to a supplybased approach, in which public providers aim to assure a minimum level of water provision to every household (Kleemeier, 2000). When systems are managed by local communities, financial sustainability is a requirement for the continuity of the service.

The water projects financed by Luxembourg correspond to the demand-based approach with an explicit criterion of financial sustainability of individual water systems; these systems are backed by the public water companies. This design brings consequences to the final aid recipients because their payment capacity determines their actual access to water. Below, four issues related to participatory formulation, the attitude of project participants, water prices, and operational effectiveness are discussed.

\section{- The role of participatory formulation}

The leaders in the water projects were less involved than their peers in the reconstruction projects during the formulation of the projects. However, in both water cases, residents were invited to participatory workshops to talk about their needs. In Agua Fría, although residents commented on issues such as the lack of working capital for agriculture work or schools and hospitals, the discussion was oriented toward the need for water and sanitation and their positive effects on health (CODECA, 2003a). Indeed, participation in these events was conditioned by the perception of project deliverables (cf., Mosse, 2004; 2005).

In this sense, the participants' deeper or more valuable needs were not addressed by the consultants who did not offer them solutions. Was it necessary to raise expectations during the discussion? What was the impact on willingness (or even refusal) to participate in future events? There is not a single response to these questions. The argument here is that if the project had been defined beforehand, it did not make sense to call for a participatory needs assessment. It had been better to communicate the project objective to residents and ask them in which ways the design could have been improved in those issues that they knew more (e.g., soil quality and alternative sanitation systems, or variety of plants for reforestation activities). In this way, the project staff would have shown their respect for the local people (Manikutty, 1998) and built the necessary rapport.

Exaggerated positive expectations must be avoided especially when, for technical or bureaucratic reasons, the start of project could be delayed. In San Fernando, people felt deceived at the start of the project due to continuous delays (section 8.2.2). Hence, they did not 
provide reliable information for the census and did not attend the training sessions. If this situation had not been overcome by the social promoter, the project would have failed.

In addition, if communities are not going to manage the water system (because technologies are complex, population is dispersed, etc.), if water prices or connection costs are not going to be defined, or if residents are not going to choose a specific technology, the need to hold 'pseudo-participatory' meetings is nil (cf., Botchway, 2001).

\section{- $\quad$ The attitude of project participants: customers versus suppliers ${ }^{77}$}

In San Fernando, the residents were 'water customers' because they had been connected to potable water prior to Hurricane Mitch and paid water bills at that time. Their previous experience with the public water company was negative. However, a project backed by a foreign donor and managed by a reputed NGO was felt as a guarantee of success. Before the project there were no leaders and almost no one, except the municipality government, knew in advance about the project. In contrast, in Agua Fría, it would be the first time that they would have access to potable water. Leaders had been searching alternatives (section 7.2.2) and two community committees were managing small gravity water systems. Their mentality was that of 'water suppliers'.

Hence, when some problems arose (high water tariffs in San Fernando and the explosion of pipes in Agua Fría), residents addressed different institutions. In San Fernando, they asked the mayor for help and even suggested that the municipality government, not a communal committee, could manage the water system. In Agua Fría, residents directly asked the staff of the water company to repair the pipes, talked with technicians to know more about the problems and asked them to check their domiciliary pipes. However, they could not do more. They resented that they were not taught technical matters to be able to solve the problems by themselves. Leaders would not accept to manage the water system either as they face difficulties to finance the old water systems.

The argument here is that different contexts call for different solutions and that, in some cases, when a community organisation is well-prepared (during the project), it can manage the water systems jointly with municipal governments. There is mixed evidence about the effectiveness of community-managed water systems. Kleemeier (2000) explains that community groups might be able to make small (not so recurrent) repairs but are unable to maintain the aquifers, except for the smallest ones. This capacity is constrained by the residents' economic situation; a poor village could hardly sustain a water system (Botchway, 2001). Implementing a community-managed water system in these conditions would, after failure, harm their autonomy causality orientation. Indeed, the leaders in Agua Fría already had problems to collect payments; while, in Santa María, a tractor was sold to maintain the well and repair the electric generator and pipes. This indicates that 'local organisations have to have links with political and administrative centres in order to be effective' (Kleemeier, 2000, p. 942) in managing water systems.

\footnotetext{
77 This analysis refers to the access to water for human consumption. In no one of the project sites, people expressed concerns about the lack of irrigation systems. Basically, they water their crops in rainy season and do something else in dry season because water is not available for agricultural uses at that time.
} 


\section{- The definition of the water tariffs and subsidies}

In San Fernando, the high water tariffs were a cause of confrontation between residents and the water company; several people had the water service cut-off during the fieldwork. The main issue is the criterion of financial sustainability applied to a poor municipality. The project financed studies to propose subsidised tariffs (section 8.3.4) but the projected maintenance and operation costs put a limit to the share of people who could be subsidised. It is likely that poor people that would need a subsidy were left out (section 8.5.1).

International aid should precisely expand water coverage in geographic areas where partner countries would not invest due to the lack of resources and the lack of demand to justify a profitable investment. Truly, the criterion was to reach a break-even point between revenues and maintenance and operation costs, but the residents' economic situation cannot assure this. Evaluating the project as an independent system eliminates the chances for crosssubsidy that is one of the main benefits of national-wide providers.

Without an integral reform of the water sector, in both countries, it is unfair that households in the capital cities pay much less than households in poor rural areas because the latter were financed by donors and have water micro-metres at home. Most importantly, people who cannot afford to pay the water bills (assuming a reasonable demand) have three options: to pay the bills and starve, to control their consumption by collecting water from alternative unsafe sources, or to get the service cut-off. In all cases, health and basic autonomy would be harmed. Hence, a decentralised water system managed by a community organisation or by a municipal government would still require the support of a central water operator (or regulator) that transfers resources from surplus to deficit water systems.

In contrast, the water tariffs were not so high for people in Agua Fría because many households receive remittances and they used to pay more to buy water. In addition, the water tariffs in El Salvador had been stable for years and relatively low in international terms. ${ }^{78}$ In Agua Fría as in San Fernando, around 20\% of the households were subsidised, but the tariff setting systems were different. Moreover, in general, the consumption levels were higher in Agua Fría than in San Fernando. ${ }^{79}$ Hence, the access to water service for the inhabitants of San Fernando was more limited than for those in Agua Fría due to their lower payment capacity. However, in the latter case, the main problem was the discontinuity of the service.

There is a problem difficult to reconcile. Everyone should have access to safe drinking water to promote their well-being, for equity reasons, but market supporters consider water as an 'economic good' and claim for 'efficiency' in terms of monetary purchasing power (see discussion in Mehta, 2006).

\section{- Multiplicity of project objectives and technical soundness}

The projects in San Fernando and Agua Fría had different components. In San Fernando, the focus was on water and sanitation and on technical assistance to the water company, even discarding other planned elements such as the local development plan. The scale was also

\footnotetext{
${ }^{78}$ In nominal terms, the water tariffs are similar in Nicaragua and El Salvador. Considering the purchasing power of households, the tariffs in Nicaragua are the highest (nominal tariffs in SIECA, 2005.)

${ }^{79}$ In Agua Fría, the consumption was 113 litres/person/day. In San Fernando, it was 75 litres/person/day, recorded during the dry season.
} 
larger, covering five sites in two departments. Being the most recent project, lessons from previous projects, including Agua Fría, were incorporated although not fully.

The project in Agua Fría included too many activities to be effective in each one (see Table 10-7). There were technical problems with the water system and the soak-away pits were inappropriate to the soil quality. In addition, the project staff organised many reforestation and soil protection activities in order to protect the water sources and promote sustainable agricultural practices, which were not continued after the project completion.

Table 10-7: Comparison of project activities in San Fernando (SF) and Agua Fría (AF)

\begin{tabular}{|lcccccccc|}
\hline Water & $\begin{array}{c}\text { Sanitation } \\
\text { service }\end{array}$ & Latrines & Reforestation Soil protec- Solid wastes & Reservoir & $\begin{array}{c}\text { Eco-wood } \\
\text { tion }\end{array}$ & mgmt. & stoves \\
\hline SF & Yes & Yes & Yes (-) & Yes & No & Yes & No & No \\
AF & Yes (-) & Yes (-) & Yes & Yes (+) & Yes & No & Yes & Yes \\
\hline
\end{tabular}

Note: (-) means that the project had a worse performance or lower coverage, (+) means that activities were much higher in quantity and coverage.

The project mobilised the existing community associations and provided people with chances for informed participation. This second factor, however, did not improve project effectiveness because the inhabitants (including the leaders) did not internalise the hygiene and maintenance practices for sanitation infrastructure. In San Fernando, that aspect was addressed with education campaigns prior to the start of the construction. Unfortunately, the project had top-down logic and people did not feel that their opinions would be heard. The formation of the neighbourhood committees and CASA was the big achievement; however, it was not legally registered as association or NGO. Moreover, project staff in San Fernando did not consider productive initiatives (as was the case in Agua Fría).

The last point might be related to the composition of project staffs and the nature of local leadership, which coloured the character of the projects. In San Fernando, the field project staff was formed basically by two female social promoters who contacted women to participate in committees. In Agua Fría, the field project staff was a team formed by three male engineers (one from the water company) and two female social promoters. The community leaders were like promoters themselves. The leaders in San Fernando were more concerned on home chores, while the leaders in Agua Fría paid more attention to economic activities.

In short, the project staff in San Fernando was focused on material outputs and operational effectiveness. The project staff in Agua Fría was involved in many things, lost track of technical aspects (in a climate of reorganisation of the formal counterpart) and did not promote the internalisation of good practices. However, participation in Agua Fría was not only higher in terms of workload but also more significant in quality (section 10.4.3). Unfortunately, the opportunity to promote autonomy causality orientation and community empowerment was lost in Agua Fría because, despite the involvement of residents and their ownership of the project since the start, the project did not produce the expected outcomes. The saying fits this case: 'Don't bite off more than you can chew'. In Hirschman (1967/1995)'s words, the project was 'pseudo-comprehensive' because it aimed to provide all solutions and, at the end, only partially achieved its goals. 


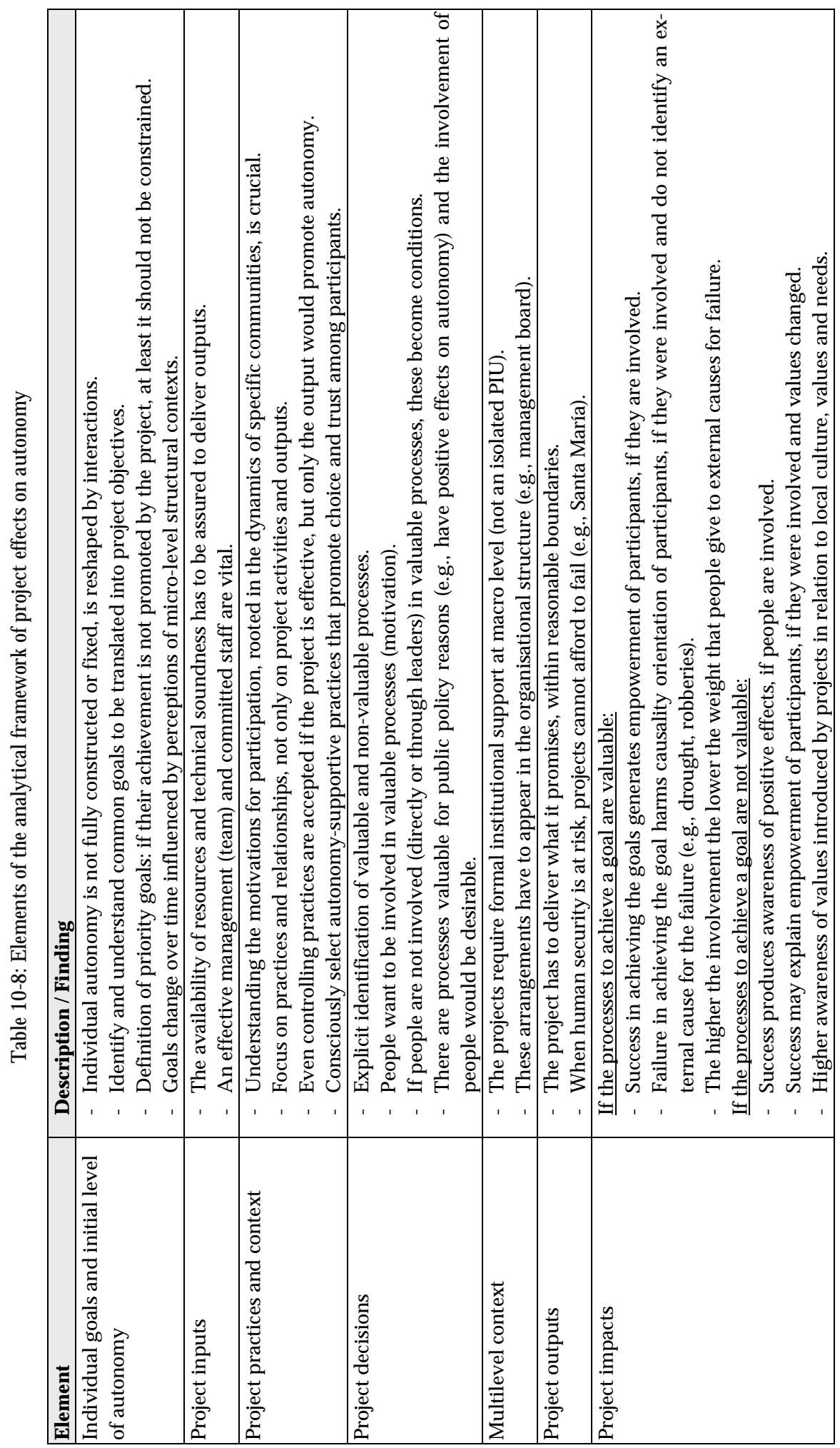




\subsection{Summing up project effects on individual autonomy}

This section discusses the interrelation between individual autonomy and (i) project inputs and outputs, (ii) practices and contexts, and (iii) decision-making in valuable processes. The section also clarifies the links between empowerment and participation. Table 10-8 presents some elements to take into account when applying the analytical framework.

\subsubsection{Project inputs and related outputs have several effects on autonomy}

The project in San Agustín was better endowed than the project in Santa María because the former was managed by a committed project chief and had a higher budget than Santa María. The comparison between San Fernando and Agua Fría is difficult because the scale of operations, in terms of the number of targeted households and geographical dispersion, and the technical solution were different. However, in San Fernando, financial resources did not reach to finance latrines for all households, while, in Agua Fría these resources were more than enough. ${ }^{80}$

The quality of material outputs has a direct relation with the amount of resources and the technology used. Both reconstruction projects delivered the houses, more or less according to the target, and were regarded as successful. Nevertheless, the difference in the quality of the outputs had effects on autonomy via the security of entitlements and perceived agency. ${ }^{81}$

The residents of San Agustín legally own their houses, which they regard as beautiful, wellconstructed and safe so that they dream of improving their houses. In contrast, the residents of Santa María have fewer incentives because they are not owners, only tenants. Moreover, although the materials were good, people were not so happy with the appearance and spatial distribution of the houses (section 6.3.4). This situation affects their self-confidence as they compare their houses with those offered by other projects. They felt that, although they worked hard in self-construction activities, they could not assure outputs of a better quality.

Looking at the water projects, their distinct technologies could explain the differences in the quality of the water service. The low reliability of the system in Agua Fría has a lower than expected positive effect on health and harms the perceived agency of the residents who 'eagerly' had looked for the project.

\subsubsection{Project practices and contexts are interlinked}

Conditionality practices had the stronger negative effect on perceived agency. Its depth depends on personal and contextual factors, in relation to project operational effectiveness.

- The achievement of formal goals influences the perceptions of project practices

In San Agustín, those practices were agreed with community leaders, while, in Santa María, these were initially imposed and later contested by the community leaders (openly) and the non-leaders (more quietly). In the water projects, practices were accepted gratefully by the residents and challenged only when the project failed to provide the expected benefits, that

\footnotetext{
${ }^{80} \mathrm{I}$ did not have access to financial data disaggregated by project site.

${ }^{81}$ The houses in Santa María cost USD3,600, while those in San Agustín cost around USD4,700 in nominal terms (not in purchasing power parity terms).
} 
is, when tangible outputs were not allocated evenly (e.g., latrines) or the access to water service was at risk (e.g., broken pipes or high tariffs).

In this way, practices (even the most restrictive ones) could be accepted to the extent that the project delivered what was offered. Therefore, project operational effectiveness is a necessary condition for the internalisation of project practices. If not only practices but also objectives are set in agreement with local populations, the effect of a successful project (in terms of achieved objectives) is the enhancement of autonomy causality orientation.

This means that operational effectiveness can have two main effects: (i) a direct effect on entitlements via the provision of social infrastructure (e.g., water plant, communal house, school, etc.) and on agency through personal competence (e.g., enhanced work and organisation skills, better health status, and physical security), and (ii) an indirect effect on causality orientation and self-confidence, when participation in the project is rewarded with the achievement of the goals for which people have worked. In addition, the immaterial benefits related to social capital (i.e., increased trust and solidarity) spread out when the project is effective but shrink when it is not (Hirschman, 1984).

Formal institutional arrangements at several levels are highly relevant to support operational effectiveness (section 10.3.2), a necessary but not sufficient requirement for human autonomy effectiveness. Likewise, the identification of the different stakeholders and their possible role during the project is necessary in order to uncover conflictive views and build partnership from the start.

\section{- Contexts are dynamic and complex}

Contexts are the result of the interaction of many actors. Project stakeholders are not always physically present at the sites, but their actions affect local contexts. In Santa María, the lack of coordination at the macro-level among donors and public institutions increased uncertainty, which further affected the residents' emotional capacities. In Agua Fría, the confrontation between the municipal government and the water company at the meso-level, which triggered the impasse with project staff and residents, affected the pace of the project and probably, the quality of the service delivered.

Looking at the micro-level contexts, controlling practices could have had a stronger harmful effect on self confidence for beneficiaries of the reconstruction projects than those of the water projects because the former projects (especially the one in San Agustín) took a long time to be completed. Furthermore, both reconstruction projects started one year after the disasters occurred and people had been living in difficult conditions.

This study proposes that it is necessary (i) to consciously select autonomy-supportive practices that promote choice and trust among participants (see similar argument by Ellerman in section 3.2.4), something rather marginal in international aid, and (ii) to facilitate the internalisation of conditions that are necessary for public policy reasons such as an autonomous sanitation system or reforestation and soil conservation activities.

Controlling practices such as obligatory long and harsh workdays in self-construction activities, if undertaken, should be combined with respectful treatment and clarity in the definition of entitlements. However, as much as possible, these controlling practices should be avoided as they could externalise the motivation. People own the project when this is a result of a genuine motivation, not when they work in everything related to the project. 
On the other hand, the political context is important as the cases of Santa María and Agua Fría suggest (see section 11.3.2). In Santa María, the political divergences created obstacles to the project and originated the existence of two community organisations. In Agua Fría, the lack of agreement with the municipal mayor eliminated the chances to form a joint NGO for all villages of the canton. Therefore, next to intellectual skills, political awareness, tolerance and cultural understanding are necessary.

San Agustín is a positive example in this respect. Given the large budget allocated, the project had been perceived by some stakeholders as too powerful. Then, the project chief realised a kind of 'institutional gardening' (Bastiaensen et al., 2005), that is, he developed a 'finetuned engagement with local politics and institutions' (ibid, p. 990) to solve misunderstandings and enrol stakeholders in the project. This example evidences that individuals can have different perceptions of the same contexts and that these perceptions influence their goals and value choices. Therefore, a 'need assessment', on which a judgement about the project's relevance is based, is not a one-time exercise.

Certainly, the projects cannot fulfil every new demand, but they must not restrict the options of people to pursue other priority goals that might emerge (section 10.2.1). Seasonal migration in Santa María and agricultural work in San Agustín were priority ways to make a living. Having time for private affairs in San Fernando and entrepreneurship in Agua Fría were important for subjective well-being. The time invested in self-construction activities had an opportunity cost too high for the poorest households (section 10.5.2). Then, it is necessary to securing valuable negative freedoms with the concourse of several social actors during the projects.

\subsubsection{Individuals aim at making decisions in valuable processes}

The projects required intensive work from residents, but this work did not imply a highquality participation or involvement in decision making (section 10.4.3). The impacts of this design choice differed depending on how valuable different decisions were for local people.

There are several processes in each project in relation to its several expected outputs. Among the cases, Agua Fría had the largest number of goals, but these were not equally valued by residents. The access to safe drinking water was the most important goal, but residents perceived that it had requirements such as the construction of the autonomous sanitation system, the attendance to training sessions or the construction of ecological wood stoves. They valued having a sanitation system but considered that the pre-selected modality (i.e., soak-away pit) would not be effective given the soil quality and geography of their localities (section 7.3.2). The leaders could have shared in this selection decision as nonleaders trusted them. However, they were not involved and most residents deemed the sanitation systems as conditions to get the water connection, without practical value.

In contrast, the construction of the reservoir acquired a new dimension thanks to the involvement of leaders: they saw it as an opportunity to generate revenues via the trade of fish to be raised in the reservoir. Nevertheless, the failure of this small project, in which they had invested effort and material resources, had a negative impact on the causality orientation of leaders and many of the residents.

In Santa María, a valuable process was 'the provision of means to make a living'. Residents valued having a land to cultivate and needed it, but the decision of a cooperative agricul- 
tural project was made by the donors (section 10.3.1). The failure of this project was not as important in terms of causality orientation as it was in terms of personal competence: it put at risk the survival of the whole community. Since then, and with the consequent failures of other small productive projects, people have struggled for survival. In these limit situations, some mistakes are inevitable, but the involvement of local people could have been fruitful. Projects with ambitious goals, including the development of personal skills and community advance, should provide extra space and support to participants' emerging needs.

A process non-valuable for inhabitants might in contrast be highly valuable for project designers due to public policy reasons. For instance, the reforestation activities in San Fernando were relevant for at least two reasons: (i) environmental awareness and actions, and (ii) sustainability of the water source. First, the region is a natural reserve of pines, but disasters such as fires have been recurrent. This situation is aggravated by the existence of illegal sawmills and indiscriminate pruning to produce firewood for household consumption (section 8.1). Therefore, higher local awareness and involvement in reforestation activities was necessary. Second, the water source is superficial, a river, so the watershed required to be protected. Nevertheless, project staff and participants only carried out reforestation activities for symbolic reasons; people were not involved in the process of choosing the kinds of plants or the areas in which these would be planted. ${ }^{82}$ The failure of such activities (section 8.5.1) did not harm the autonomy causality orientation of residents. For them, 'the project' failed and resources were wasted; they did not fail.

A concern about autonomy goes beyond subjective or psychological elements. In the example above, the poor results of the reforestation activities constrained future expansions in individual autonomy because the water access is not sustainable. What could have happened if residents were told about the fragility of the water aquifer and the need to protect the watershed, and if they had been asked their views about ways to protect it? What could have happened if the men -usually those who deal with economic production decisions - had been more involved in the project instead of only the women? Maybe people would have chosen drought-resistant trees, which would survive in dry season, and invested time in meetings to decide on sites where to plan them most productively.

Residents rely on project staff to make certain valuable decisions. As said earlier, people cannot be involved in all types of decisions, although they value the related processes. For instance, water infrastructure requires technical knowledge that residents hardly have. Therefore, the commitment of project management to make technical decisions and supervise the work of subcontracted firms is crucial. In Agua Fría, the first technical problem occurred at the end of the project. It could have been possible to evaluate in situ the situation and implement remedial actions before the closure of the project. Nonetheless, the positive effects of this project on autonomy (e.g., on self-confidence, awareness of their own capacities, and trust in community organisation) were harmed by the low reliability of the water service.

\subsubsection{Participation is a necessary but not sufficient condition for empowerment}

Similarly to the discussion above, empowerment refers to (i) a goal-oriented action that is authentically motivated in strategic or valuable aspects of life and (ii) the achievement of

\footnotetext{
${ }^{82}$ It must be noticed that there was a high rotation of staff in the executing NGO. There were three different NGO project managers and it was not clear who took these decisions.
} 
intended outcomes. When the outcomes are the expected ones and individuals have acted to achieve them, there has been a qualified expansion of autonomy defined as empowerment.

\section{- Perceptions of project outcomes depend on the quality of individual participation}

An expansion of individual autonomy may be possible thanks largely to the efforts of others, without the person having control or process freedom. For instance, a project could provide free access to safe drinking water without any work from beneficiaries. However, people value helping themselves by taking part and sharing in some relevant decisions about the project (although criteria of what is relevant might differ). This capacity to help oneself is strengthened only when it is exercised. This motivation led the leaders in San Agustín to propose the mutual help work modality and the leaders in Agua Fría to build the old gravity water systems and to collaborate in whatever was requested, during the project.

A project could fail for many reasons. Indeed, managing a project requires the identification of uncertainties and remedial actions in case hazards occur (Hirschman, 1967/1995). Nevertheless, not all failures are equally perceived by people, just as not all processes are equally valued. As seen in the previous section, the failure in non-valuable processes does not harm perceived agency, but it can damage actual competence. In contrast, failures in valuable processes do harm perceived agency and, hence, the motivation for initiating change. When the failure occurs because of processes in which people were involved (with genuine motivation, not conditioned), the impact of the failure is a drop in autonomy causality orientation.

On the other hand, the achievement of unexpected positive effects, not valued prior to the project but identified as good after the project, might lead to an expansion of autonomy. In San Fernando, the creation of CASA and neighbourhood committees fuelled friendship among new leaders (mainly women) and awareness of their joint capacities to effect change. They also had higher opportunities for communal participation. This was a big change in their lives because they used to stay at home and worry only about their private affairs. After the project, they felt empowerment because they 'discovered' things. To the extent that they may lead new projects, their community would also be favoured.

Most likely, this change in values is a product of the participation of people in the processes that led to such unexpected outcomes. If this was the case, the success in unexpected outcomes would lead to empowerment. This means that aid projects can introduce certain elements that are valuable for outsiders and affect the valuations of local people. In this way, it is a matter of social responsibility and ethical conduct to carefully analyse which elements the projects introduce in communities, considering local culture, values and the level of needs satisfaction.

For example, in San Agustín, the houses constructed and the community centre were of high quality, with materials, construction methods and physical appearance that residents never dreamt to have. Later, people identified the amelioration of the physical appearance of their locality and the aesthetic pleasure as one valuable project effect (but not the most valuable). Earlier, this effect would have seemed superficial to aim toward, given the multiple deprivations lived over the years. Probably unconsciously, the project was introducing wrong priorities in a very poor municipality because no resources were allocated to productive activities to support local livelihoods (section 10.3.1). Consequently, in 2005, people talked about their well-equipped community centre with pride, but also remembered with sadness the suffering during the project due to the lack of subsistence. Clearly, this wrong ranking of priorities was not internalised because 'to work, [they] need first to eat'. 


\section{- A high level of individual involvement amplifies the effect of successes and failures}

Participation and empowerment are usually regarded as good things. Participation has even been considered the means for empowerment. ${ }^{83}$ However, participation can make a project riskier. In terms of operational effectiveness, the project can be very successful or very unsuccessful. This observation is more striking in the case of infrastructure projects that rely on an organised community to carry out construction or supervision activities.

If the project was successful, participation would be seen as a cause or a facilitator for the success and people would be willing to participate again in future endeavours, independently of the quality of participation, as in San Fernando (low quality participation) and San Agustín (high quality participation but only of the leaders).

In terms of human autonomy effectiveness, a failure in reaching valuable outcomes has a larger psychological impact (via causality orientation) when the individual is involved in the process than when he or she is not involved. Furthermore, if the failure follows a sequence of continuous failures, it could slowly deactivate one's capacity to aspire because the links between aspirations and outcomes would loosen (Appadurai, 2004, p. 68).

Nonetheless, people have a perception of the reasons for failure, whether these are a drought, the misappropriation of resources by leaders or an executing NGO, an inefficient project management, the lack of flexibility in project design, or robberies. When reasons for failure outside the project are easily identified, the negative impact of failure on the individual autonomy would be lower. This means that causality orientation is the link between participation and empowerment. This link is very fragile and subjective, although it has concrete foundations: project effectiveness and involvement in the project.

\subsection{Conclusions}

This chapter has proposed an analytical framework of project effects on autonomy and presented a cross-case analysis of the four projects. The main conclusions are presented below.

1. The framework proposed gives a central role to the identification of values and goals to assess project effects on human lives. The focus is on individuals as agents of change, not projects designed to produce change on individuals (section 10.2).

2. Project planners and managers have to understand the livelihoods and aspirations of project participants. They have to respect their change process, not to impose values that are 'accepted' as result of conditionality, and encourage their efforts to exercise voice (section 10.2.1). This implies, for instance, that some adaptations to the original design of a project should be possible during the implementation.

3. The designs of the four projects included self-construction activities in order to promote local capacities. However, at the implementation stage, the role of local promoters and leaders was mostly instrumental to mobilise people and reach project goals. The experience of leaders in San Agustín was qualitatively different (section 10.4.2).

\footnotetext{
${ }^{83}$ See, for instance, Cooke and Kothari (Eds., 2004) and Hickey and Mohan (Eds., 2004) for several cases that illustrate positive and negative sides of 'participation'.
} 
4. Manual work was not translated into high involvement. Most non-leaders did not exercise decision-making during the project. For them, the intrinsic effects of participation would be restricted and mostly related to the awareness of having used their personal skills during the project (section 10.4.3).

5. The degree of internalisation of work commitments directly affects the achievement of project outcomes and, indirectly, affects autonomy (e.g., the adequate use of sanitation systems to have positive health outcomes). Controlling practices harmed intrinsic motivation, in some cases more than in others, depending on the contexts and individual perceptions (section 10.4.4).

6. In the case of the reconstruction projects, controlling practices also had negative longterm effects on critical autonomy because people could not reflect on development plans, given the stress to survive. Only leaders or more resourceful people, with relatives or social networks, could participate in community decisions (section 10.5.1).

7. When projects lack formal institutional support, the sustainability of the intended effects is at risk (section 10.3.2). Most importantly, there is a lost opportunity: the integration of communal leaders in a political network that could increase their influence to defend the residents' needs and pursue common goals in the future (section 10.6.2).

8. Individual empowerment is linked to participation only under certain circumstances (section 10.6.4). Involvement is higher and participation more authentic when people are intrinsically motivated, not when they are externally induced to work. The potential to enhance individual autonomy is larger when motivation exists and when people can make decisions in valuable processes.

9. Operational effectiveness is a requisite for a project to promote individual autonomy. A project that favours the exercise of autonomy and improves the social context still need concrete foundations (section 10.6.3). Intrinsically motivated participants could feel harmed if they fail to reach project goals, in addition to the objective consequences of not having secured the access to certain resources (e.g., reliable water service).

10. Impacts should be assessed over a term that exceeds the usual timeframe of an aid project. This implies that several factors, other than the project practices and context, will have an influence on autonomy. The effect of a project on dynamic contexts and on the achievement of other valuable goals has to be explored because expanding autonomy should not restrict the options to reach other valuable goals (section 10.2.1).

11. Basic infrastructure projects would not have problems to mobilise people given the important needs that they address. The challenge is to transform this mobilisation into a qualified high participation. A project designed and implemented in order to promote autonomy (in addition to other goals) could become the 'opportunity' to fuel a change process that was underway or was temporarily frozen by the lack of financial resources. 


\section{Experiences of individual autonomy}

Agency (and power) depend crucially upon the emergence of a network of actors who become partially though hardly even completely, enrolled in the projects and practices of some other person or persons (Long, 1992b, p. 23; Long \& van der Ploeg, 1994, p. 66).

This chapter presents a cross-case analysis with regard to the experiences of individual autonomy of the inhabitants of the four project sites as at 2005, during the fieldwork. It focuses on research questions two and three:

- How do individuals in communities experience autonomy in their lives?

- How can communities shape opportunities for autonomy and human development?

The chapter investigates the factors that characterise their experiences of individual autonomy based on the conceptual model proposed. It also explores the individual and relational aspects that influence autonomy as a combined capability. The micro-level contexts receive special attention. Given that these experiences were affected by aid projects, the determinants of autonomy are analysed in dynamic terms. People reflected about changes in their lives in relation to the specific projects and other events, which had influence on or were influenced by the intra-community relations.

The chapter is divided in four sections. Section 11.1 analyses entitlements and agency as foundations of autonomy. Section 11.2 examines how people exercise autonomy in the local contexts in which they live. Section 11.3 explores the link between individual empowerment and self-confidence, discusses the internal and external factors that could support empowerment and their inter-relations. It highlights the difference between having the latent capacity to choose and pursue valuable goals, and actually achieving them. Section 11.4 presents the main conclusions.

\subsection{The foundations of autonomy: entitlements and agency}

This section presents some elements that influence the individual entitlements and agency of the inhabitants of the four localities.

\subsubsection{Entitlements}

Having an entitlement is being able to use a resource for one's goals. Entitlements make the exercise of autonomy possible. Entitlements refer to the individual, not to the collective - although the resource in question can be in collective 'ownership'. For instance, Santa María residents had different entitlements over the proceeds from the communal land even though it was owned by the community as a whole. As Devereux (2001) finds, individuals with different personal characteristics and types of relationships within institutions can exercise distinct claims over the same resource (p. 253).

There is a cultural dimension in the definition of entitlement that determines the conversion rates in the entitlement-mapping. For example, the woman leaders in San Fernando had a limited control over an individual resource: their own time. Some of them, including the leaders, had to request permission from their husbands to participate in project activities, 
especially when men other than their husbands would be present in those activities. A young lady in Agua Fría, whose husband was working abroad, could not attend the Sundays' football games in the common sport court because 'people would say: what is she looking for going out alone if she is married? She should be at home'.

Resources can generate certain entitlements in given circumstances. The resources here analysed are: common resources, household resources, and social and cultural resources.

\section{- The availability of common resources has different effects on development prospects}

The endowment of natural resources depends on the geographic location of the sites. The San Fernando municipality has a better location with forests; sawmills pay taxes to the local government. San Fernando and San Agustín have the most fertile lands.

Common material resources depend on the type of locality, whether it is a municipality centre or a canton. The inhabitants of San Fernando and San Agustín have more access to health services, education (from kindergarten to secondary school) and recreational infrastructure (baseball stadium or football court, public parks) than the inhabitants of the other sites. Public transportation is also more accessible. The relative geographic isolation of Santa María and Agua Fría (in winter time) has direct consequences for the timely and continuous provision of social services, such as health and education.

Regarding other services, the access to telephone service is not related to the type of locality. Agua Fría has the largest (fixed and mobile) telephone network because most people have relatives abroad who finance long-distance phone calls. In Santa María, there is no fixed telephone service in the town, but most leaders have a mobile phone. This is a sign of the high income inequality existing within the village. Public and private electricity and drinking water services are available in the four localities; however, not every household can afford these services. As seen earlier, some households in in San Fernando got the water service cut off that due to high tariffs.

With respect to economic linkages that could generate material resources, all villages except Santa María have some trade of agricultural products. The labour situation is very difficult for Santa María residents. Manual male work is traded under unfair conditions (without permanent contracts and without social security benefits) with middlemen that collect workers for large-sized farming industries. This is an example of what Copestake (2007) calls 'coercive inclusion' in the economic sphere and exclusion in the political sphere because they do not have bargaining power to obtain better work conditions. In San Fernando, although some households rely on salaried agricultural work, their geographical location makes it easier for men to find alternative non-farm jobs.

Common resources also depend on the historical experience of the inhabitants of each site that explains their integration to the political system, among other features. It is possible to talk of political resources that, although are not available to all, could be used by leaders to promote activities in their villages: linkages with political authorities and linkages with aid agencies and donors.

Regarding linkages with political authorities, the extreme cases are Agua Fría and Santa María. The leaders in Agua Fría do not have linkages with the mayor due to the impasse during the project. The leaders in Santa María, in contrast, had family or friendship bonds with the mayor (2005-2007) who was himself a survivor of the Casitas disaster. However, at the mo- 
ment of the fieldwork, these bonds were not an entitlement to carry out projects in the town because of the lack of resources of the municipality.

San Fernando and San Agustín, as municipality centres, have a resident mayor who is the local political authority. However, their connections at departmental and central government levels at the moment of the fieldwork were relatively low. This situation might have changed with political elections after 2005. ${ }^{84}$

With respect to linkages with aid agencies and donors, the leaders in the reconstruction project sites had more connections. Even before the mudslide, the residents at the slopes of Casitas had benefited from a water project financed by SDC and used to receive food aid at times of (recurrent) drought. In 2005, ASCA in Santa María was managing some projects financed by the Spanish cooperation agency. Before the earthquakes, San Agustín had benefited from water projects financed by Luxembourg and by other donors. In 2005, connections were active: the sister cities agreement with Préizerdaul could assure financing for small projects.

In San Fernando, the water project was the first relevant project in the town, and there were perspectives of future projects through the municipality government. The situation in Agua Fría was dramatically different. After the water project completion in 2003, no other had been formulated, while the leaders did not have contacts with either local NGOs or donors abroad. Family remittances were used in some occasions to finance communal activities.

From this description, some observations arise:

i) The remoteness of Santa María reduces the possibilities of residents for trading activities and explains their feeling of being 'trapped', thus hurting their self-confidence. The relations of leaders with donors are resources that could be used to benefit the community - although it seems that leaders first benefit themselves.

ii) The lack of relations of leaders with authorities or donors is the main factor restricting development options in Agua Fría. However, intra-community relations are valued and have effect on what people can do or feel that they can do (see section 11.2.3).

iii) The inhabitants of San Fernando and San Agustín have more access to material resources than those of the other sites. Although both are municipal centres, the financial situation of the local government is stronger in San Fernando.

iv) The linkages with donors that the political and the communal leaders in Santa María and San Agustín had before the disasters are resources that they used (more efficiently in the case of San Agustín). The reconstruction projects strengthened these resources.

\section{- Household resources depend on the existence of reliable income sources}

The access to common resources does not determine the entitlements of households and individuals. Although most inhabitants of the four project sites depend on agriculture, households enact several strategies to make a living.

\footnotetext{
${ }^{84}$ In Nicaragua, since 2007 the Sandinista party heads the national government which means that the municipal governments in Posoltega and San Fernando (from the same party) could receive stronger support than earlier. In El Salvador, since mid-2006 there is a new mayor from the left-wing party (FMLN) in San Agustín, in opposition to the national government but closer to the ideology of communal leaders. The mayor in Agua Fría was re-elected again so that he has three consecutive periods in power; nothing would change there.
} 
Table 11-1 shows that most of the household heads surveyed (55\%) said that they were farmers. Some of them were independent farmers, owning or renting a plot, and others were dependent farmers, with or without formal contracts. The outlier is Santa María, with only $29 \%$ of households declaring to work mainly in agriculture, explained by the lack of available land to cultivate, either owned or rented. However, most migrants are seasonal agricultural workers (included as 'other').

Table 11-1: Economic data of households by project site (2005)

\begin{tabular}{|l|cc|cc|c|}
\hline & \multicolumn{2}{|c|}{ Reconstruction projects } & \multicolumn{2}{|c|}{ Water projects } & \multirow{2}{*}{ Total } \\
& Santa María & San Agustín & San Fernando & Agua Fría & \\
\hline Main work activity, \% & & & & 61 & 55 \\
-Agriculture & 29 & 56 & 76 & 9 & 5 \\
-Trade & 5 & 3 & 3 & 7 & 7 \\
-Dependent work & 9 & 5 & 5 & 17 & 19 \\
-Housework & 29 & 23 & 8 & 6 & 14 \\
-Other & 28 & 13 & 8 & 100 & 100 \\
Total & 100 & 100 & 100 & 68 & \\
\hline Land ownership, \% & 0 & 38 & 33 & 48 & 23 \\
Receive remittances, \% & 14 & 8 & 11 & 54 & 172 \\
\hline Number of observations & 42 & 39 & 37 & \\
\hline
\end{tabular}

Note: Figures of land ownership come from CODECA (2001) for Agua Fría, and own calculations based on FUNDAMUNI (1999) and MSA (2001) for San Agustín.

Main source: Dataset 2.

Regarding land ownership, Santa María and Agua Fría were the extreme cases (see Table 111). The households of Santa María lost their lands in the mudslide, although some people have returned to cultivate subsistence crops at the slopes of Casitas fuelled by the lack of job opportunities. They feel entitled to these lands although they do not legally own them. Land concentration is higher in San Fernando; large landowners hire salaried agriculture workers for coffee production. In contrast, large estates are in hands of former cooperative members, in San Agustín.

The existence of reliable income sources other than farming explains differences in the incidence and the depth of poverty. Periodically-sent remittances support household income in Agua Fría (relatively, the least poor among all sites) but seasonal migrant work cannot assure a living for Santa María residents (relatively, the poorest). Remittances are less frequent in San Fernando and San Agustín. Most households of Santa María and San Agustín live in extreme poverty, in terms of either national or international poverty lines. Even in the least poor locality, Agua Fría, more than half of the population lives in poverty.

The economic situation of a household is a decisive factor to define its entitlements. The case of land is clear. Without working capital, several landowners in San Agustín and San Fernando cannot work their lands. In contrast, the farmers in Agua Fría manage to work their lands either calling for solidarity work, in the smaller villages, or hiring seasonal workers among their neighbours (in the case of first-generation migrants). In some cases, social and economic resources generate actual benefits.

\section{- Social and cultural resources are foundations for other resources}

Social and cultural resources influence the definition of individual entitlements. Formal leadership role, social status, and closeness to leaders were important in the four cases. 
Formal leadership roles are more permanent in Santa María and Agua Fría, in which the community organisations have longer history and the nomination of positions is more rigid than in the other cases. ASCA and ADESCO have a fixed number of associates among which the executive board is elected.$^{85}$ Leaders manage projects or channel resources from foreign donors and local private resources, respectively. However, people have different perceptions about the goodness of current social arrangements (see section 11.2.2). The situation is different in San Agustín because the delegates of each canton or neighbourhood represented in CRDM do not have to belong to the association of their locality; 86 they are proposed by each association.

Social status, a cultural resource, is obtained by applying material and social resources. The social status is determined by the relative visible wealth (in Agua Fría and San Fernando), the type of employment (e.g., in Agua Fría and San Agustín, people would prefer non-farm activities), the family origin (in San Fernando), the religion (in San Fernando and Agua Fría), the political links (in Santa María), the connections with donors (in Santa María and San Agustín), and the contacts with public authorities (in San Agustín). Most people in the two Nicaraguan sites strongly show their preference for farming activities over other activities although these did not secure an adequate living standard.

Individuals with higher social status have priority access to common resources and leadership roles. For instance, a person with the 'right' last name in San Fernando can influence others' decisions, can belong to the communal committee, and can run for political positions. In Agua Fría, successful returning migrants are members of ADESCO. Although they did not participate in communal activities because of staying long periods abroad, they could make decisions that affect the whole community. This situation is not challenged by other residents because these leaders are the ones who contribute financially to the community organisation. It seems that people invest in keeping this kind of relations with powerful partners. The same strategy could have explained that the leaders 'accepted' to have only an instrumental participation during the project (see section 10.4.2) because their compliance with project staff requests was seen as a good investment (cf., Carmen, 1996, p. 150).

Closeness to leaders, a social resource, is relevant when leaders exclude large parts of the population as in the Santa María case. There, being able to participate in projects managed by ASCA is a prize that brings immediate material consequences. Client-patron relationships are present even among people with different political backgrounds. In general, being close to leaders during the project could have brought certain benefits (cf., Devine, Camfield \& Gough, 2006) such as being selected to participate in certain activities (e.g., leadership workshops in San Agustín) or to receive certain assets (e.g., latrines in San Fernando). People realise this possibility so that they are alert to activities in which leaders are active or 'try to be quick' (as said by a woman non-leader in San Fernando).

People's capacity to enjoy entitlements is also linked to their participation in formal and informal political processes (Bastiaensen et al., 2006). Moreover, by publicly showing certain political preference or declaring themselves as 'neutral', people can increase their chances to

\footnotetext{
${ }^{85}$ ADESCO refers to the community organisation of the urban centre of Agua Fría. The associations in the other two villages of the canton were not legally formalised and their influence was much lower than that in the canton quarters.

${ }^{86}$ San Agustín is a municipality, while Agua Fría is a canton. Each canton has an association and all associations gather in a development committee at the municipal level.
} 
be informed or to get collaboration from institutions. In Santa María, FSLN political leaders have strong influence.

\subsubsection{Actual and perceived agency}

The formation of goals, the actions and their results depend on the actual capacities of individuals or what they think that they can achieve. Hence, agency is analysed from two perspectives: actual and perceived agency.

\section{- Competence has direct influence on actual agency}

Actual agency is related to physical, intellectual and emotional capacities, which can be assessed without influence of personal feelings or interpretations, with quantifiable indicators (e.g., of cognitive skills, physical strength, and mental health). Having certain capacities might be a matter of 'luck', such as having good vision, good hearing capacity or practical reason. Other capacities are developed over time when certain conditions are present. Project participants referred to innate and developing capacities, when they explained what was required to have a good life. Then, the hopes of many are in their children, who should have the means to develop their capacities to be healthy and to be educated, so that they would be 'better than [them]'.

In all cases, physical health was considered necessary to have a good life. However,

(i) Diseases cannot be controlled because they arrive without prior notice, such as mosquito-transmitted malaria and dengue fever; and

(ii) Diseases terribly affect their lives when the illness of a household member requires long-term care that depletes the assets and energies of caregivers.

The body is for many the main resource because they rely on their physical strength to work. The disability or sudden death of the breadwinner could push households to utter poverty (Chambers, 1995; Narayan et al., 2000; Cleaver, 2005). Especially tragic was the case of Miguel, a man non-leader in Santa María. His two sons died in the Casitas mudslide and his younger son was born sick:

Before [the mudslide] my life was beautiful, when I had my two grown-up sons. After [the mudslide], a male child was born; now our life is a hell... The doctor in Managua told me that he had a 'shadow' in the brain and had to be operated. My wife, who before used to help me working in the plot, has to stay with him; she cannot work outside home. I sold my house to obtain the money [for the surgery] because for the life of a child, one gives his own life. Nevertheless, for me, this child is a cross.

In contrast, in San Fernando a young married woman, daughter of a relatively wealthy political leader, has the chance to go abroad to have a necessary surgery. She lives with her parents, while her husband works abroad and sends remittances. She has an able-bodied husband and parents to provide means for survival. Miguel in Santa María has no one available to help him. He lacks social resources.

Personal capacities also depend on household characteristics (see Table 11-2). San Fernando is characterised by its traditional large-sized and male-headed households. The households of Santa María are the smallest among all sites, even including seasonal migrant workers. 
Table 11-2: Socio-demographic data by project site (2005)

\begin{tabular}{|c|c|c|c|c|c|}
\hline & \multicolumn{2}{|c|}{ Reconstruction projects } & \multicolumn{2}{|c|}{ Water projects } & \multirow{2}{*}{ Total } \\
\hline & Santa María & San Agustín & San Fernando & Agua Fría & \\
\hline Household & & & & & \\
\hline Average household size & 4.0 & 4.9 & 6.5 & 4.7 & 5.0 \\
\hline Avg. dependency ratio & 0.7 & 0.6 & 0.5 & 0.5 & 0.6 \\
\hline Female-headed, \% & 41 & 39 & 8 & 24 & 28 \\
\hline Household head & & & & & \\
\hline Average age & 41 & 43 & 45 & 55 & 47 \\
\hline Literate, \% & 79 & 56 & 76 & 52 & 65 \\
\hline These have, \%: & & & & & \\
\hline -Incomplete primary & 49 & 65 & 64 & 62 & 59 \\
\hline -Complete primary & 21 & 25 & 18 & 31 & 23 \\
\hline -Other studies & 30 & 10 & 18 & 7 & 18 \\
\hline
\end{tabular}

Dependency ratio is the number of (under-12) children divided by the number of adults.

Source: Dataset 2.

In both sites affected by disasters, Santa María and San Agustín, female-headed households accounted for around $40 \%$ of the total households. Overall, most female household heads declared to work at home (on average $67 \%$, and not less than $60 \%$ in each site). This finding highlights the difficult situation of these women without alternative source of income. Although $28 \%$ of all the women respondents declared to be household heads and to work at home, only $4 \%$ of them said to receive remittances. Moreover, female-headed households in these sites had higher dependency ratios than those in the water project sites. This means that the physical and emotional demands for these women are large, affecting their agency. Household heads were older in Agua Fría than in other sites that is related to the ongoing emigration of young people. Female household heads were much older (63), mainly widows or single women who have adult relatives working abroad.

Regarding intellectual capacities, Table 11-2 shows that household heads in the Nicaraguan sites had higher literacy levels than those in the Salvadoran sites. ${ }^{87}$ It seems that women (either heads or spouses) were also better educated in the Nicaraguan sites. Among the female survey respondents, $76 \%$ were literate in the Nicaraguan sites versus $47 \%$ in the Salvadoran sites. However, several people who said to be literate had lost their ability to read and to write due to lack of practice.

Let us consider the relation of personal capacities to resources or entitlements:

i) Santa María residents have the highest educational achievements among people in all sites, but they could not apply these capacities in non-farm activities such as services or industries. They have the cognitive capacity to farm, but they do not have land. These capacities are only resources, not entitlements ready to be used.

ii) Women in Santa María are relatively well educated (73\% were literate and among them, about $42 \%$ attended secondary school), but they do not occupy as many formal leadership positions in the community as men do. Several women participate in informal selfhelp groups, so that, gradually, they are applying their skills and thus generating an en-

\footnotetext{
${ }^{87}$ This observation differs from national figures that show higher adult literacy rates in El Salvador than in Nicaragua. The analysis of the reasons for this fact goes beyond the purpose of this study. Besides, the project sites in each country are not representative in national terms.
} 
titlement to participation. On the other hand, the fact that many household heads are housewives hints that they cannot apply their skills in income-generating activities, which would be so useful for them given that survival is at risk.

iii) The inhabitants of the two Salvadorian sites, who valued non-farm activities relatively higher than the inhabitants of the other sites, are less equipped for such activities given their low literacy levels. They have neither the capacity nor the resources.

iv) The women in San Fernando were more involved in the project than the women in the other localities, mainly due to the presence of the woman leaders. Women's literacy levels in San Fernando are much higher than the average for the other project sites $(78 \%$ versus $56 \%$ ).

The San Fernando case deserves a closer analysis. Girls stay at home while their brothers work on the farm; for this reason, women have more years of schooling than men. Parents invest in the education of girls because they are the foundation of good homes; they apply their knowledge by raising their children, which is very valuable. However, the participation of women in the water project allowed them to use their knowledge in a different manner: the neighbourhood committees. Hence, women gained a new entitlement over the same resource: the use of their educational skills in issues related to community development.

At first sight, men were comfortable with this change, given that the issue first discussed was water, which is related to domestic work. This indicates that the project at first simply emphasised traditional gender roles (cf., Riddell et al., 1995). However, the participation of the women in the communal development committee, sponsored by the municipality government, is an opportunity to develop this new entitlement further. It would be advisable to evaluate in the long-term the involvement of the women in several community issues to conclude about the sustainability of this new entitlement - and remembering that it is unevenly distributed among the (women) non-leaders and leaders.

People who are illiterate may be disadvantaged when they interact with other people. For instance, they are more likely to be cheated in case of disgrace and some of them might follow leaders because 'they know' (e.g., San Agustín). Although being illiterate does not necessarily restrict the access of individuals to leadership positions in small groups, this condition would affect their full participation in decision-making, the opportunities of their subordinates, and their capacity to face formal institutions.

Emotional aspects are important because one's actual competence is affected by one's emotional status. Many people in Santa María still suffer the traumatic effects of the disaster. A continuous heavy rain triggers their fears. People in San Agustín recall the 'low value' that their lives had during the civil war (1980-1992), that is, how they could have died at any moment or been abused. This experience was much stronger to them than the material losses after the 2001 earthquakes. Both events, the mudslide and the civil war, have marked the lives of these peoples who recognise that their lives are not the same and they are not the same'. Their capacities have changed. They are less happy, less united, and less wealthy than before. Even after the projects, non-leader participants perceived that their opportunities to improve their lives were few. This perception affects what they can be and can do because the self-confidence of many is diminished (see section 11.3.1). This links to the concept of perceived agency. 


\section{- Perceived agency is based on individual, relational and symbolic factors}

First, perceived agency is related to how capable individuals feel that they are to undertake new endeavours or just to manage their lives under the circumstances in which they are. A person with the skills to lead his or her community could be frozen by emotional pain and undermined self-confidence. To break this blockage, this person needs help from others (and absolutely, not a project with controlling practices).

In Santa María, Rosa had lost her whole family in the mudslide (her husband, her parents and her three children) and 'during two years she was practically going mad'. With the support of religious groups and NGOs, she channelled her capacities to different activities and tried to overcome her situation. Nowadays, Rosa lives with a new partner and is member of a new self-help group (neither ASCA nor CDC). With only three years of primary schooling, she works as a health promoter, gives lectures about intra-family violence in other towns (financed by an NGO), and promotes small income-generating activities (handiworks prepared by women). If others had given up on her, she could not have accomplished all the good work that she is doing nowadays. However, her case is exceptional - many people did not get continuous psychological or spiritual support - and she has not adequately managed her deep pain: she tries 'to be busy for not thinking of what happened'.

Second, self-perception is influenced by how one is perceived by others or, more exactly, by how one thinks to be perceived by others. There is an ongoing inter-subjective process for which self-perception develops from the interactions with others (Anderson \& Honneth, 2005, p. 131). For instance, there was only one person in the focus group discussions (FGDs) who was under-aged - the target participants of the FGDs were adult heads of households or their spouses (section 4.1). The reason is that she had participated in the activities of the water project in San Fernando, on behalf of her family. Her mother was illiterate, her father and her younger brother used to work in the finca (far in the mountains) during weekdays and she had completed primary education. Her mother was very proud of her daughter and of 'how much she had learned because of her daughter'. An autonomy-supportive family context had a positive impact on her participation during the project (as several women said), as it had on her active participation during the fieldwork activities.

Third, the self-perception is linked to the social standing that the person has in wider social networks and related factors such as ethnicity, class and gender (cultural resources). The main leader in San Agustín had a high perceived agency, also perceived by their neighbours, based on his status of former guerrilla commander. This status was also backed by the resources managed through CRDM that he presided (cf., Uphoff, 2005).

The social standing is built over time and is not equally distributed, even among leaders. The woman leaders in San Fernando used their social resources to address their neighbours after the project was completed. They would ask the mayor to invite residents to meetings, the doctor to convince neighbours to maintain their soak-away pits, and so on. It seems that they did not develop an authority by themselves, but were respected because of the project. Hence, after the project completion, they had to develop different strategies to try to keep their roles and fulfil their responsibilities by using proxy agency (Bandura, 2000). This is a signal that even when they belong to the new communal committee, they do not have symbolic power (Lukes \& Haglund, n.d.) to influence other people on their interests. Further- 
more, man leaders from rural neighbourhoods have more influence on residents than woman CASA leaders.

Fourth, individual achievements and personal growth also influence self-perception. Several single mothers who worked in the projects considered that they learned and did a good job despite the social exclusion suffered due to their family situation. In some cases, this perception of self-worth helps them to overcome the difficult environment that they still face: they showed that they were as capable to work in the project and succeed as anyone.

\section{- Perceived agency is affected by subjective well-being and actual living conditions}

The 'basic capability survey', administered in San Fernando and Agua Fría, identified those aspects that people value the most and their level of relative satisfaction. A person who considers having achieved fewer valuable things out of his or her whole valuable set, might feel less competent to lead his or her life than others and then, less motivated (Deci \& Ryan, 2000) to face challenges and less happy. In this sense, subjective well-being is a proxy for perceived agency.

The individuals in San Fernando reported a lower well-being than those in Agua Fría (see Figure 11.1). The index of subjective well-being is on average higher among the survey respondents of Agua Fría (0.69) than among those of San Fernando (0.55). For the respondents in Agua Fría, the dispersion was lower (as evidenced by the flatter slope of its curve) and the median achievement was higher (50\% of the respondents in Agua Fría had an index of 0.79 or higher while the same percentage in San Fernando had an index of 0.53 or higher).

Figure 11-1: Distribution of subjective well-being*

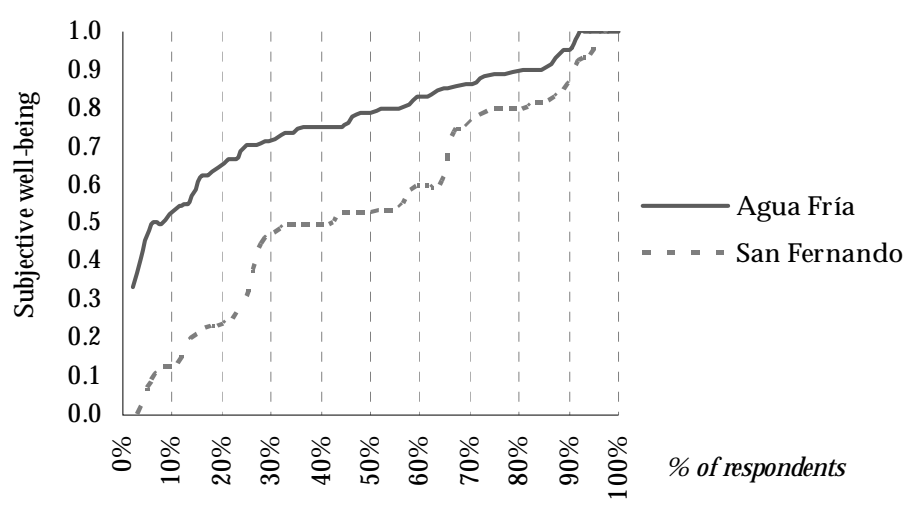

*Cumulative frequency distribution. Subjective well-being is approximated to the selfreported fulfilment of valuable needs or 'own' index (see Chapter 4, Box 4.5).

Source: Dataset 2.

Despite different expectations of life, it seems that most residents of Agua Fría are achieving more than residents of San Fernando in those aspects that they value the most. Furthermore, the levels of need satisfaction among people in San Fernando are highly unequal, which could reflect very different priorities or very different living standards that go beyond monetary concerns - there was no correlation between this index and household expenditures (section 8.4.1). Those whose priority needs are not fulfilled could have lower perceived agency than others. 
On the other hand, perceived agency is based on the actual reality that people live. For instance, Olivia is a single mother in San Fernando who takes care of her old-age sick mother and her child. She does not have economic resources (not land, not a wage-paid job) or relatives to help her; she works washing clothes for others. Olivia values to have a well-constituted family, which she does not have because her partner abandoned her; to be healthy, which she does not feel to be because she is all the time tired; and to be part of a group or association, which she tries by engaging in every possible meeting when she is not too busy. Her achievements in these and other valuable dimensions are low and this affect how she interacts with others. For instance, her 7-year-old son attends school with other less poor children, but they hit him and make fun of him. Olivia does not feel able to face the other children's parents, but she manages to talk with other women in her little group and to express her situation to me, an outsider.

\subsection{The exercise of autonomy in micro-level contexts}

Structural contexts are crucial to define what someone could do, achieve or become. This section focuses on micro-level contexts: community organisations and interpersonal relations, in order to understand for project participants, whether their community promotes or constraints their individual autonomy.

This section is divided in three parts. The first analyses the role of community organisations. The second part explores individual experiences of living in community, relations and communal participation. The third part discusses motivations for communal participation and the possible effects of the projects on it.

\subsubsection{The role of community organisations in promoting autonomy}

Community associations or development committees are the main institutions in the localities studied. In everyday interactions, their presence is strong as people clearly identify the representatives and their roles. Some people try to be close to them because they consider that this relation could bring material benefits. Of course, there are also altruistic motives to 'collaborate' with leaders, but, in all the cases, residents need external support to carry out their development initiatives given their restricted material entitlements.

\section{- A strong community organisation is not enough to promote individual autonomy}

This section introduces the notion of relative strength of community organisations. A priori, this is a neutral concept related to the efficacy of the organisation to reach its goals (as seen in section 2.3.1, organisations are social actors and they have agency). However, when the activities of community organisations are contextualised, we see the need to evaluate whether their goals are in line with the needs and interests of community members.

The efficacy of a community organisation depends on its length of existence, management experience, political and financial support, and social support from community members which could be linked to their degree of representativeness. Box 12-1 describes some factors to understand the relative strength of the organisations in the four localities studied.

ASCA in Santa María is relatively stronger because of its management experience and length of existence. Their members have developed the skills to interact with donors, prepare project proposals and get funds so to become 'development brokers' (Bierschenk et al., 
2000, as cited by Bastiaensen et al., 2005). However, ASCA has developed a rigid closed structure that excludes other residents from the most crucial decisions (cf., Eklund, 1999). Even worse, ASCA gets funds on behalf of the whole community, but it is not accountable to anyone except to donors. Hence, the legitimacy of leaders has been questioned by residents. A strong community organisation, with organisational experience and dynamism is not necessarily positive for the autonomy of non-leaders. On the contrary, the power of ASCA over the non-leaders affects their self-confidence and causality orientation because they feel disrespected, deceived, and incapable to promote and defend their well-being (section 6.4.2).

\section{Box 11-1: The relative strength of the community organisations}

Several factors characterise the communal committees or development associations (see table below). In Santa María, the two existing organisations have formal existence and manage resources. ASCA was formed immediately after the mudslide; $\mathrm{CDC}$ was founded by the end of the reconstruction project and coordinates the management of the water system. In contrast, in Agua Fría, only ADESCO of the canton quarters is formalised. The planned NGO that would consolidate the committees of the three villages has not been constituted.

\begin{tabular}{|clccccc|}
\hline & Locality & \multicolumn{2}{c|}{ Santa María } & San Fernando & Agua Fría & San Agustín \\
Factor & Community organisation & ASCA & CDC & CASA & ADESCO & CRDM \\
\hline 1 & Representativeness & 1 & 0 & 2 & 2 & 3 \\
2 & Frequency of meetings & 2 & 1 & 2 & 1 & 3 \\
\hline 3 & Length of existence & 3 & 2 & 1 & 3 & 2 \\
4 & Management experience* & 3 & 2 & 1 & 2 & 3 \\
\hline 5 & Support of local government & 2 & 1 & 2 & 0 & 1 \\
6 & Available funds & 2 & 1 & 0 & 1 & 2 \\
\hline
\end{tabular}

Scale from 0 to 3 where $0=$ none, $1=$ low, $2=$ medium, and $3=$ high

*It includes the experience during the projects

Source: Own assessments by fieldwork assistant and me.

Regarding the first two factors, CASA and CRDM are better ranked. ASCA holds frequent meetings in contrast to the apparent inactivity of CDC that meets only when problems arise.

Regarding management experience, CRDM and ASCA are better ranked because they have managed several projects since the start of the reconstruction activities. CRDM coordinated all the reconstruction efforts since 2001 in San Agustín, while ASCA worked from organising the survivors' camp to managing several small-scale projects even after the housing project was completed. In contrast, despite their length of existence, ADESCO in Agua Fría was not so involved in the water project.

Regarding external support, ASCA and CRDM are again in better situation, managing donor funds. Moreover, ASCA had close bonds with the mayor. CASA could receive formal support from the local government because several CASA leaders sit on the municipal meetings and discuss on investment plans, participatory budget and so on. ADESCO has the worst prospects.

CRDM in San Agustín is also strong but its membership base is broader. There are sixteen committees watching the decisions of the board of directors. Furthermore, a tripartite supervisory committee (section 9.2.3) has to approve the use of the funds from the sister cities agreement. However, two aspects worry the leaders: (i) how CRDM can maintain its political independence, given that the mayor forms part of the executive committee, and (ii) how CRDM can finance its operating costs given that the local government has a weak financial situation and hardly transfers the resources committed to CRDM. The situation is difficult because, as agreed, donor funds cannot be used for administrative expenses and the quotas of local committees cannot be raised given the low incomes of residents. 
CASA in San Fernando was the weakest organisation. It lacks funds of its own and has no legal status as a civil organisation so that it cannot channel aid funds. Furthermore, during the project, it was not CASA but certain individuals who mobilised people according to project needs and took some operative decisions. In 2005, the communal committee had not been constituted yet.

ADESCO in Agua Fría is a little weaker than ASCA and CRDM because it lacks political and financial support, although it enjoys the recognition from local residents. The impasse with the mayor weakened the organisation in the long run because the leaders could not carry out their projects in collaboration with the leaders of the two other villages as they had planned.

It is also important to know the practices and motivations of committee members, which are linked to particular styles of leadership (Uphoff, 2005). For instance, the role of leaders to assure the entitlement to health care was quite different in Santa María and Agua Fría. In Santa María, the health centre was financed by donors (not part of the project here studied) who delegated its management to ASCA. The doctor was paid with donor funds and medicines were subsidised, but only for a short period. The leaders said that if they asked the ministry to be in charge of the centre, they would need to transfer the property of the building to the health ministry. This was not of their interest. In contrast, in Agua Fría, leaders together with the rural health promoter received a donated land and worked hard to get a health post, under the management of the health ministry. The health post grew in terms of number of served persons, attracting inhabitants of other areas, and in budget allocations although in physical terms, it is smaller than the health centre of Santa María. The decision made by the leaders about the management of health facilities and the availability of donor funds have effects on the long-term provision of health care services to residents.

\section{- Community organisations and projects: a not always mutual supporting relation}

As seen in Chapter 10, these organisations participated in the projects to different extents. First, did they support a process of autonomy expansion during the projects?

(i) There was no link between previous organisational experience of committees or associations and their involvement in the project; and

(ii) Their participation seems to have supported the operational effectiveness of the projects, but not necessarily the individual autonomy of residents.

In San Agustín, a well-organised committee (CRDM) was able to participate actively in the project. In contrast, in Agua Fría, a community organisation with longer management experience (ADESCO), had an instrumental role to achieve the project goals, despite that it enjoyed (i) a more favourable social context than in San Agustín, where residents were still harmed by the civil war, and (ii) a better economic situation, supported by remittances.

The composition of the project staff and the spaces for community involvement in the project design (linked to sectoral features) can explain these different experiences. In San Agustín, the leadership and coordination role of the project chief was clear and CRDM was part of the project working group. In Agua Fría, the project chief had low visibility, the presence of the water company was strong but residents did not trust it. However, ADESCO was slowly gaining space, as the small fish agriculture project indicates. 
Figure 11-2 compares the relative strength of the community organisations, their involvement during the project, and the time lapsed after the project completion. This last variable is important because a longer existence time could signal that the organisation has more chances to endure. For Santa María, only ASCA is considered.

Figure 11-2: Relationship between community organisations and projects
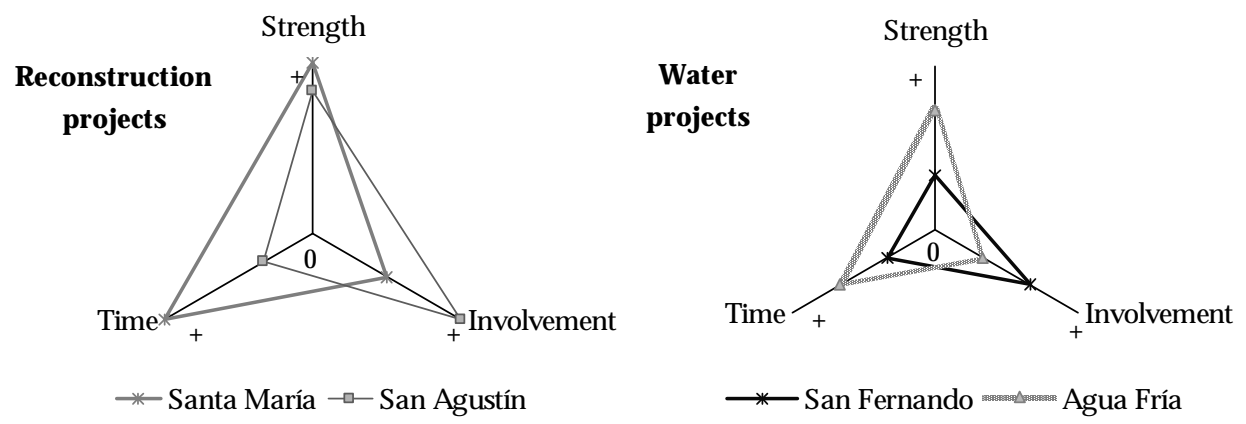

Legend: 'Strength' refers to the relative strength of the community organisation at the time of the fieldwork, 'involvement' refers to the involvement of the community organisation in the project, 'time' refers to the time lapsed between the completion of the project and the fieldwork.

Only in San Agustín was there a strong organisation (CRDM) with high involvement in the project. The involvement of ASCA in the Santa María project decreased over time (section 6.3.2), but its influence on residents continued through other projects that they administered. In Agua Fría, the opportunity to genuinely involve the leaders was lost. It seems that project staff worried for project operative results and for 'empowering' the associations through the constitution of the NGO that did not occur, however. Both aspects were not linked. The nascent committee in San Fernando was relatively more involved.

The cases of San Agustín and Santa María suggest that strong communal organisations as counterparts can improve the operational effectiveness of the projects (i.e., the instrumental value of participation) when the local government lacks the capacity and resources to attend the multiplicity of demands that a disaster originates (section 10.3.2). Nevertheless, an organisation effective in delivering material results is not necessarily effective in promoting individual autonomy. Both ASCA as counterpart and the controlling practices promoted by project staff had negative long-run effects. In contrast, in San Agustín, the support of a committed project chief to CRDM was determinant in the process of political and social reconciliation. This support was expressed in several ways: financing courses on project management, facilitating contacts with public and private institutions, and even covering administrative costs of the committee, that is, reducing the relative costs of participation.

The Santa María case highlights some risks that external aid agencies face when interacting in new environments (cf., Kelsall \& Mercer, 2003) and in stressful situations. One reason for selecting ASCA as counterpart was that they 'controlled' the survivors' camp and, then, it was expected that they would assure a quick mobilisation and the material results so needed after the disaster. Other possible reason is that the donor or contracted NGO aimed at respecting 'the community self-determination' so that the naturally emerging leaders would have the helm and coordinate the efforts. However, not everyone was in emotional 
and physical conditions to work in the project given the profound distress; it was difficult to know in advance how those who were able to do so would behave over time.

Second, the project effects on community organisations were qualitatively different in each case. Most survey respondents said that their community was better organised as result of the project. However, regarding whether their leaders were more effective in addressing their needs in 2005 with respect to 1998, there was a clear contrast between Santa María and the other sites. In Santa María, only $26 \%$ of the respondents said that the leaders were more effective, while this percentage was on average $88 \%$, in the other sites. Despite the existence of small projects that ASCA has managed over time, people do not consider that these leaders are delivering the most necessary things. The list of those projects includes productive and health projects that are basic, but the mistrust toward leaders is huge in Santa María.

In the other sites, several stakeholders agreed that information sharing and solidarity improved, especially during the projects. ${ }^{88}$ The representativeness of the organisations was considered high, but effective control of the non-leaders over common resources and surveillance were considered still low (this observation is not applicable to CASA).

In San Fernando, the assessment of all consulted stakeholders about the change in the organisation of the community (responsibilities, relationships, and effectiveness) is positive. However, the foundations of CASA were not well laid. The woman leaders were left with the responsibility to monitor the behaviours of their neighbours related to the use and maintenance of water infrastructure without institutional support or earmarked financial resources. This situation and the increasing complaints about the high water tariffs were undermining the authority of several of the leaders during the fieldwork.

\subsubsection{How living in community changed}

What people believe how their community should be or what they should be doing, do not always match with what they actually do and how they interact with others. Project participants agreed that members of a community should have values and access to resources and that a strong organisation is necessary to promote their development. Some people stressed that leaders should be good and responsible and other members should collaborate with them. However, the degree and quality of participation in common activities varied across individuals in each site and between project sites. These differences could be related to the nature of intra-community relations (e.g., sense of belonging, trust, etc.), their entitlement to information, or more particular reasons.

\section{- Communal participation was not affected by projects}

Some improvement in communal participation and in intra-community relations would be expected given that the participants in every project worked in mutual help teams. Communal participation is defined here as membership participation in a communal organisation or association of any type (economic, religious, social, sportive, etc.). There was a weak but significant difference in the levels of communal participation reported by residents (Cramér`s $V=0.28, p<.01$ ). The lowest level of communal participation was found in San Agustín (18\%). Although participants identified the political reconciliation among residents

\footnotetext{
${ }^{88}$ Stakeholders include project staff and NGO staff in San Fernando; NGO staff in Agua Fría; project staff, representatives of partners NGOs and other actors in San Agustín.
} 
as one important benefit of the project, there are no incentives for people to participate at an organised level, beyond a spontaneous participation as the one fuelled by the earthquakes. ${ }^{89}$

Figure 11-3 shows the levels of communal participation for each locality. The low level of San Fernando (38\%) appears related to the personality of people who expressed again and again that they liked to keep their lives private. However, this level could be lower; some people reported their level of identification with committees, not necessarily their actual participation, as some committees were not active during the fieldwork.

Figure 11-3: Communal participation by project (\% of respondents)

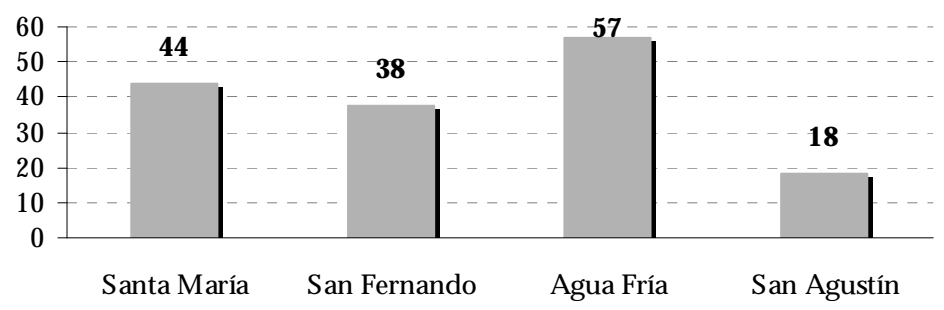

Source: Dataset 2.

In contrast, Santa María (44\%) and Agua Fría (57\%) have more formal organisational structures. In Santa María, living conditions are harsh and collective action is the only solution feasible to improve them. ${ }^{90}$ Associations are basically linked to religious groups and NGOs that have been intermittently in contact with inhabitants since the aftermath of Casitas. In Agua Fría, people have a strong culture of communal organisation.

Therefore, it seems plausible to say that the projects did not influence communal participation for most non-leaders..$^{91}$ On the contrary, the history and the culture of people in the sites determine their participation. This links to the concept of socio-historical agency (Deneulin, 2006a) that considers that the socio-historical reality in which people live and their 'country's collective self-identity' (Ellerman, 2006, p. 102) frames their possible choices.

\section{- $\quad$ The access to information on community issues tells about the quality of leadership}

Table 11-3 shows the scores for information about community issues: the level after the project and the change. First, in Santa María, the access to information is very unequal. Only $37 \%$ of the FGD participants said that they had more information than before the project and some cases were critical (falls of several points!). Some leaders, who have gained power and knowledge over time, use several networks through which they communicate different messages to political authorities, donors, other formal leaders, and non-leaders. Non-formal leaders use informal gatherings (especially among women). However, for many, information was biased and incomplete as formal leaders condensed the most relevant information. It seems that the micro-level context restricts opportunities even at a basic level.

\footnotetext{
${ }^{89}$ ECLAC (2007a, p. 91) classifies participation in three types: formal (e.g., elections), spontaneous (e.g., triggered by emergency situations) and organised (e.g., formal associations).

${ }^{90}$ It must be noticed that only the beneficiaries of the reconstruction project took part of the fieldwork activities. As stated by the FGD participants, newcomers are not integrated to their community.

${ }^{91}$ In addition, there is no statistical association between the self-reported levels of participation in the projects (overall participation) and communal participation ('networks' variable as proxy).
} 
Table 11-3: Levels of information about community by project

\begin{tabular}{|c|c|c|c|c|c|c|c|c|c|}
\hline & \multicolumn{2}{|c|}{ After the project } & \multicolumn{5}{|c|}{ Change compared pre-project } & \multicolumn{2}{|c|}{ Mean change } \\
\hline & Mean & Median & Mean & Median & Min. & Max. & $\begin{array}{c}\% \text { who report } \\
\text { positive change }\end{array}$ & Women & Men \\
\hline $\begin{array}{l}\text { Reconstruction } \\
\text { Santa María }\end{array}$ & 5.5 & 5 & -0.1 & 0 & -7 & 7 & 37 & -0.4 & 0.5 \\
\hline San Agustín & 8.5 & 9 & 2.2 & 2 & -1 & 7 & 67 & 2.3 & 2.0 \\
\hline $\begin{array}{l}\text { Water } \\
\text { San Fernando } \\
\text { Agua Fría }\end{array}$ & $\begin{array}{l}7.5 \\
8.4\end{array}$ & $\begin{array}{l}8 \\
8\end{array}$ & $\begin{array}{l}4.1 \\
2.5\end{array}$ & $\begin{array}{l}4 \\
2\end{array}$ & $\begin{array}{c}0 \\
-2\end{array}$ & $\begin{array}{c}10 \\
6\end{array}$ & $\begin{array}{l}89 \\
77\end{array}$ & $\begin{array}{l}4.6 \\
2.5\end{array}$ & $\begin{array}{l}2.2 \\
2.4\end{array}$ \\
\hline
\end{tabular}

Information includes also that transmitted through different informal and formal channels.

Self-reported scores range from zero to ten. During the FGDs the emphasis was not in the exact number but in the change (post-project level minus pre-project level).

Source: Focus group discussions (scoring exercise).

Second, participants in San Fernando reported the highest change; 89\% said that information increased, which is explained by the low levels of information that they had before the project, when there were no neighbourhood committees.

Third, in the cases of Agua Fría and San Agustín, the change in information seems less striking. These FGD participants reported the highest levels of information about their community both before and after the project, which are result of the relative strength of the community organisations. In San Agustín, the project started one year after the earthquakes when CRDM had already been founded. In Agua Fría, communal participation was already high and people considered having the information that they needed.

Also important are differences in informational needs or demands and in the processing of information. In Santa María, people feel that they need more information to hold the formal leaders accountable; in order to acquire this, they try to engage in different networks. In San Agustín, project participants received a great deal of information but not all felt that they could follow every indication. Furthermore, 'for information to fuel change, however, it needs to be generated in an institutional context that encourages reflection and action' (Alsop et al., 2006, p. 78). The contexts are analysed below.

- Intra-community relations are complex, dynamic and are influenced by structural contexts

In Chapter 2, social capital was included as a leading factor for community empowerment because individuals could 'use' it to secure entitlements. However, social capital is inherently relational, it is not the exclusive property of any one individual (Woolcock, 2001; OECD, 2001). Relations can exist at different levels: (i) bonding, among family members and close friends; (ii) bridging, with distant friends and colleagues; and (iii) linking, between people in different social positions (i.e., a vertical dimension).

Community organisations constitute the main formal networks. Across localities, men were more likely to be formal members except in the San Fernando case, in which the project staff targeted women. The Santa María case suggests that the woman informal leaders were gaining some space for discussion but not yet for relevant decision-making. 
Norms are 'a standard or pattern of social behaviour that is accepted in or expected of a group'.$^{92}$ There are norms that are hidden to an external researcher who spends a short time in the communities. It is also hard to compare norms between communities because residents may exhibit different degrees of openness during the fieldwork activities. Despite differences in communal participation, respondents in all project sites showed similar opinions with respect to solidarity and trust. Around $74 \%$ said that, in case of emergency, their neighbours would help. However, around $90 \%$ had fears about people who could take advantage of them.

Statements from FGDs and field observations signal that solidarity seems to be weaker in Santa María and San Fernando than in the other towns. In Santa María, there is solidarity among a group of survivors, but they do not consider themselves part of one big community. Their bonds are strong and they are likely to participate in associations, but they are not willing to build bridges unless a material output is envisaged. In San Fernando, although the existence of committees has improved the quality of interpersonal relations, there are still differences of political or class nature, sometimes evident even within the neighbourhood committees.

An aspect in which responses slightly differed among sites was interpersonal trust (related to bonding social capital) versus community trust (connected to bridging social capital). On average, $78 \%$ of the survey respondents said that they expected more cooperation from smaller groups than from the whole community, but this percentage was lower in the cases of Agua Fría and San Agustín. This result suggests that in these two Salvadoran towns, people would be more likely to perceive benefits from belonging to a wider community. This finding is not associated to levels of communal participation in San Agustín, where people would rather delegate activities and decisions to leaders.

The basic capability survey adds insights about the value of close interpersonal relations and broader community organisations (see Table 11-4). Both aspects were considered necessary for a larger proportion of the survey respondents in Agua Fría than in San Fernando.

Table 11-4: Valuable aspects of life and relative achievements (selected elements)

\begin{tabular}{|ll|cc|cc|cc|}
\hline & & \multicolumn{2}{|c|}{ Friendship } & \multicolumn{2}{c|}{ Group /association } & \multicolumn{2}{c|}{ Physical security } \\
\cline { 3 - 8 } & & $\%$ & $\mathrm{~N}$ & $\%$ & $\mathrm{~N}$ & $\%$ & $\mathrm{~N}$ \\
\hline \multirow{2}{*}{ San Fernando } & Necessary $^{(1)}$ & 60 & 22 & 49 & 18 & 54 & 20 \\
& Achievement( $^{(2)}$ & 59 & 9 & 33 & 12 & 40 & 12 \\
\hline \multirow{2}{*}{ Agua Fría } & Necessary $^{(1)}$ & 75 & 38 & 57 & 29 & 63 & 32 \\
& Achievement( $^{(2)}$ & 45 & 21 & 48 & 15 & 53 & 15 \\
\hline
\end{tabular}

(1) Percentage and number of total survey respondents that considered each aspect necessary, basic for life.

(2) Percentage and number of respondents that declared to have satisfied each aspect, out of those who considered it necessary

Source: Basic capability survey in dataset 2 ( $n=37$ for San Fernando and n=51 for Agua Fría).

In Agua Fría, 75\% of the respondents considered that friendship was necessary. Furthermore, belonging to a group or association was regarded as a priority by $57 \%$ of the respondents. The percentage of people engaging in group activities was much larger there than in San Fernando. Physical security was also considered important for most respondents, but

92 Oxford English Dictionary Online, Draft revision, December 2003. Retrieved February 25, 2008 from http://dictionary.oed.com 
only half declared to fare relatively well. However, this perception could have improved in comparison to the situations that they experienced during the project because, since 2005, the rural police patrol the region (not the case in San Fernando) and ADESCO had organised a committee to support the police. In Agua Fría, people enjoy recreational activities in groups more than in San Fernando.

Box 12-2 discusses changes in micro-level contexts with some possible factors explaining such changes. The main messages are: (i) contexts are dynamic because social actors shape them in daily interactions, and (ii) several factors, not only the project, influence changes.

\section{Box 11-2: The dynamics of micro-level contexts}

Multilevel structural contexts are important for the definition of individual autonomy. At the micro level, it is necessary to differentiate at least between the social context, more related to interpersonal relations, and the political context that proved to be relevant, especially in Santa María and Agua Fría.

The existence of an aid project in each locality allows introducing dynamics to the analysis of microlevel contexts. The table below presents a simplified picture of the contexts for the four cases. The social context is classified as more inclusive or exclusive depending on how non-leaders are able to participate in their community. It includes aspects related to information, social capital and organisational structure, among others.

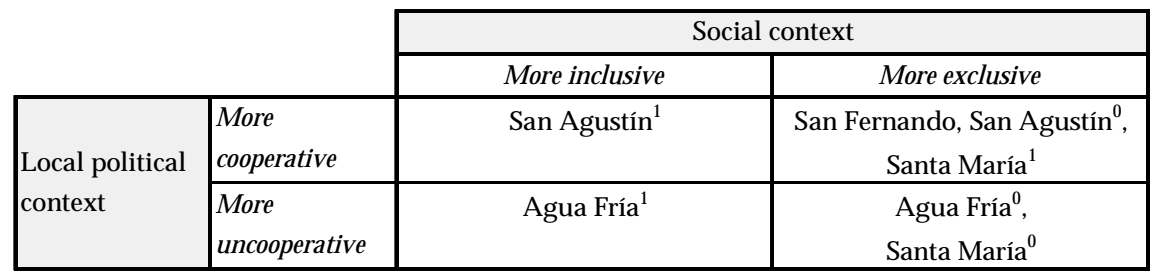

${ }^{0}$ refers to the situation before the project and ${ }^{1}$ to the situation during the fieldwork.

Note: There are graduations for each criterion.

No one context has reached the maximum level of inclusiveness or openness.

The local political context basically refers to the relationship between individuals and local governments and its consequences. It is more cooperative if there is support and more uncooperative if there is confrontation, competition or abandonment.

The table shows the transition from one state of affairs to another. In almost all cases, there was a significant change. In San Fernando, project staff and new leaders expressed that there was a little improvement in the social context, but this perception was not shared by most non-leaders. The context is still somewhat exclusive. Non-leaders expressed that some groups were discriminated against for the allocation of benefits, which did not contribute to social cohesion (section 8.3.3).

In Agua Fría and Santa María, both local political and social contexts were adverse, at the start of the projects (left-bottom corner). Nevertheless, two external events, not related to the project, favoured the openness of the political context in Santa María: The leaders of the two communal organisations that were in political opposition during the project became partners and, later, a new municipal mayor who was a survivor of Casitas himself arrived and gathered the leaders around him.

In Agua Fría, the change in the social context was related to the project outcomes. Water brought peace and unity among neighbours who earlier competed for water and during the project worked together. The opposition of the mayor continued after the project completion.

San Agustín had a favourable political context despite the ideological differences between the mayor and the communal committees and within CRDM itself. When the project started, the transition toward a more inclusive social context was taking place. The project supported an undergoing process. 
On the other hand, only Agua Fría had high levels of communal participation and relatively high community trust. This case illustrates the need of looking at the multilevel structural contexts when referring to social capital: The apparent indifference of the municipal government toward the needs of the residents could have strengthened the bridging social capital (in their intent to confront political opposition by joining efforts), although not all associations are formally registered and they lack linking social capital. The failure to register the NGO signals the weakness of the (formal and informal) organisations in Agua Fría to confront opposition of a powerful political authority.

Overall, most people in all sites considered that interpersonal trust was more relevant than community trust and this explains why solidarity was highly valued, in terms of attitudes (in contrast to actual practices in some sites), despite high levels of perceived insecurity.

Power relations within the community are important. The distinction made between leaders and non-leaders is only a pragmatic one to facilitate the analysis. Actually, power relations are complex and changing (Bastiaensen et al., 2005). For instance, in Santa María, the informal leaders in the self-help group also have power over the non-leaders (in addition to 'power with'), but lower than the ASCA leaders. They interact in informal gatherings and influence others' perceptions and values. They hold a kind of symbolic power, while the formal leaders keep their institutional power because they still maintain the 'rules of the game'. Some CRDM leaders have clearly more influence than others and control information. The same distinction applies for Agua Fría and San Fernando. Power is linked to social status and the factors that influence it.

\section{- The projects had low effect on the chances of non-leaders to participate in community decisions}

What effects did the projects have on intra-community attitudes and relations (section 3.3.3), which might in turn have promoted individual autonomy?

For non-leaders, perceived agency was enhanced via the awareness of their own skills. In addition, some people underlined a kind of perceived 'collective agency' (Bandura, 2000) or a belief that with their common efforts they could produce results. For instance, in Santa María, a woman said about social infrastructure: 'Everything that we have that is very beautiful, we have achieved'. Asset mapping - an inventory of assets, talents and abilities of individuals (Jasek-Rysdahl, 2001) - could increase the options of people in communities because their awareness of common entitlements (that may be used to enact goals) could lead to collective action that, if successful, would improve self-confidence. This kind of analysis was implicitly done in San Agustín, where the CRDM leaders have detailed information of each household's socio-demographic data, economic information, and skills which were applied during the reconstruction project and identified since the moment of the census (well in advance to the start of the project).

An important point was made by a woman in Agua Fría: 'If one trusts oneself, one can trust other people as well. Because the project did take place, it gave us trust'. She means that selfconfident individuals are more likely to engage in joint efforts (cf., Carmen, 2000) and that, if realised, these efforts further enhance their self-confidence. 


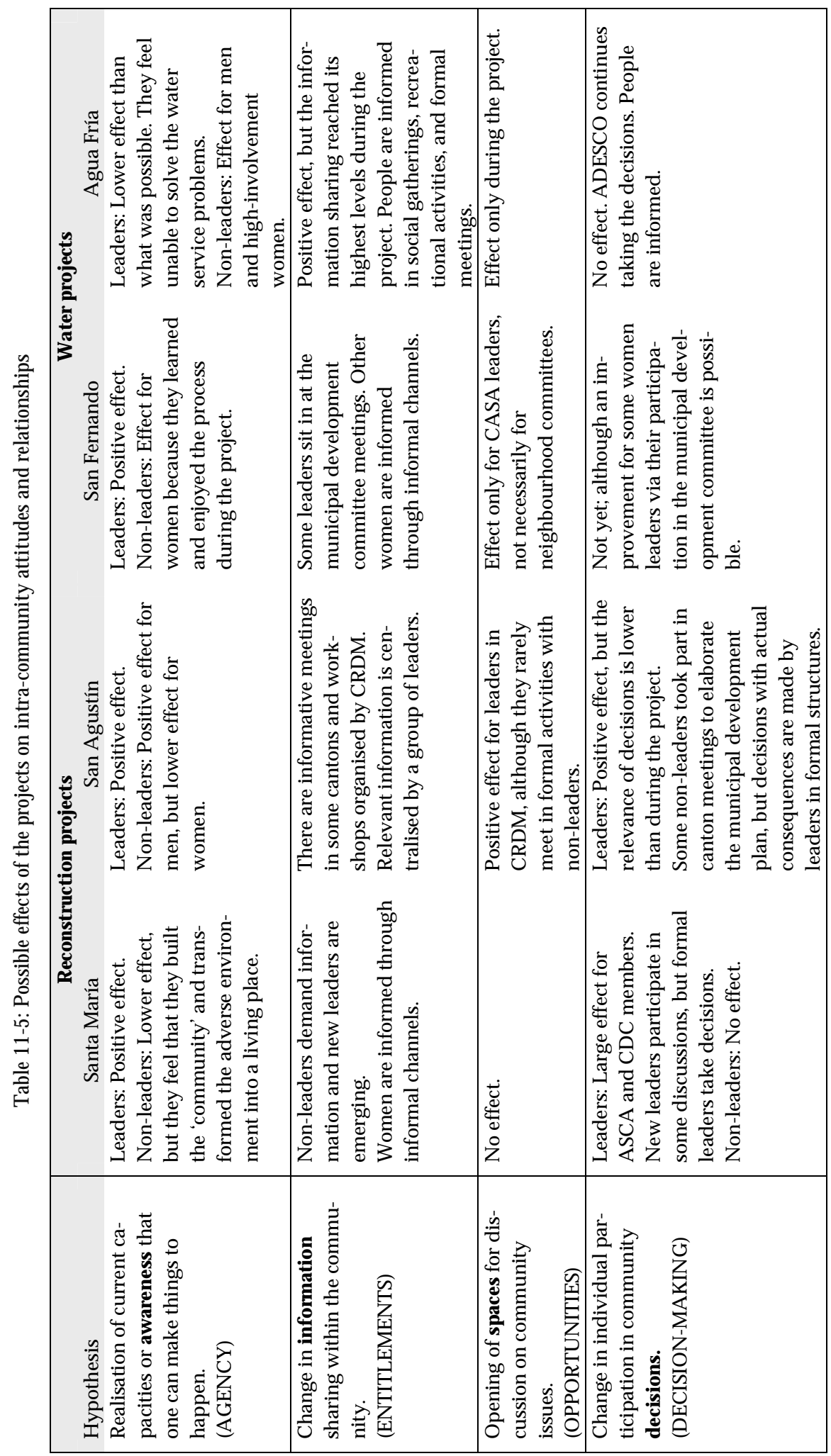


Table 11-5 indicates that impacts were different for leaders and non-leaders. Clearly, leaders had more voice and larger chances to influence micro-level contexts. The effects about entitlements to information about community were distinct. In all cases, although to a lesser extent in San Fernando, people got used to have periodic formal meetings and receive news about projects. Non-leaders rely on informal channels to be informed.

With respect to opportunities for and the actual exercise of decision-making on community issues, there was no change for non-leaders. The projects could have offered a space or a new political arena for people to exercise their autonomy (Bastiaensen at al., 2006), but this was not the case as most people had low involvement during the projects (section 10.4.3); there were not practices to promote their autonomy in significant matters.

\subsubsection{Motivations behind communal participation}

This section explores the links between communal participation and two kinds of variables: (i) community variables, related to the specific contexts in which people interact, support each other or promote well-being, and (ii) project variables, related to the participation during the projects.

Not all the individuals considered it important to be member of an association or network, but still they could be satisfied with the entitlements secured by current arrangements and leaders. As a way to explore the value that they attached to their community, the survey respondents were asked 'how frequently they felt that their community expanded their life opportunities' (perceived opportunities). The responses are plotted in Figure 11-4.

Figure 11-4: Communities and perceived opportunities by project site

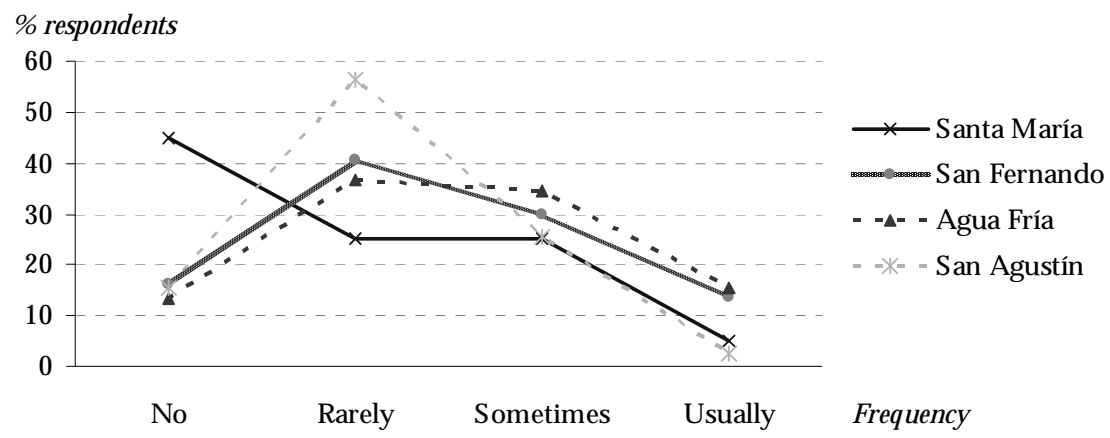

Source: Dataset 2.

On average, the above assessment was not positive. Only $39 \%$ of the survey respondents said that their community 'usually' or 'sometimes' expanded their opportunities. The extreme cases were Santa María, with the worst perception, and Agua Fría, with the best perception about community. These cases were significantly different from each other. ${ }^{93}$

\footnotetext{
93 The Kruskal-Wallis test indicates that 'perceived opportunities' was statistically different across projects. Mean ranks for Santa María and Agua Fría would be different at 5\% significance level.
} 
Perceived opportunities and other factors could explain communal participation. The hypothesised relations between different factors are in Figure 11-5. The analysis below suggests that the factors associated to communal participation act jointly, not independently.

Figure 11-5: Possible factors explaining communal participation

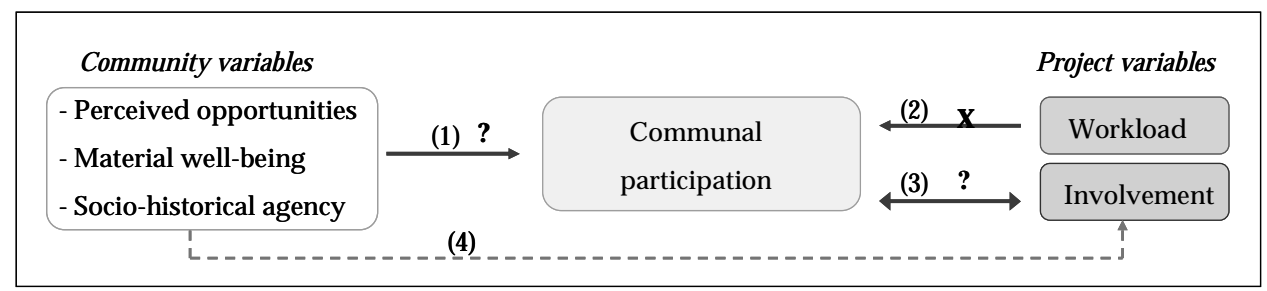

- Relation 1: Communal participation and perceived opportunities

Despite the very low perceived opportunities in Santa María, more people engaged in networks there than in San Agustín and San Fernando. Only in the case of Agua Fría was communal participation positively associated to perceived opportunities: Around $60 \%$ of those who participated in communal organisations felt 'usually' or 'sometimes' that the community expanded their opportunities. Furthermore, only in Agua Fría did perceptions about control on personal and family decisions appear to be influenced by perceived opportunities enabled by the community. ${ }^{94}$ This finding suggests that, in Agua Fría, the role of community would be positive in promoting individual autonomy.

\section{- Relation 1: Communal participation, material well-being, and socio-historical agency}

In the Santa María case, it seems that acute material ill-being fuels collective action because its residents have long-dated experience of collective action since the agrarian reform times. In contrast, the inhabitants of San Agustín, the second poorest of the four localities, are still affected by the turmoil lived during the civil war; organisation has slowly been re-valued. With so contrasting experiences, the concept of socio-historical agency acquires relevance, even to differentiate between localities in the same country. In the San Fernando case, for most people, meetings are still 'a waste of time' (in contrast to the Santa María case).

\section{- $\quad$ Relation 2: Communal participation and workload in the project}

There was no uniform relation across cases between communal participation and workload. For instance, despite the high intensity of common activities during the project, participants in San Agustín (the most recent project) do not participate in organisations as much as those in Agua Fría do.

\section{- Relation 3: Communal participation and involvement in the project}

The non-leaders of both Agua Fría and Santa María had higher involvement in the projects than those in the other two projects, which was associated to their tradition of organisation and collective action, that is, their internal contexts of agency (section 10.4.4). The projects could have reinforced existing agency features. The reported high communal participation suggests that the residents of these two sites are willing to act collectively. This reinforcing effect is shown in Figure 11-5 with a discontinuous line, to denote an emerging relation 4.

\footnotetext{
${ }^{94}$ Somers' $D$ for perceived opportunities to explain control on personal decisions was $0.38(p<.01)$ and to explain control on family decisions was $0.45(p<.01) . \mathrm{n}=52$ (Agua Fría).
} 
There are several factors that explain communal participation. Interestingly, localities with high communal participation, Santa María and Agua Fría, also have the highest incidence of migration. This observation raises the questions: How can such different behaviours be present at the same time? If migration is fuelled by material deprivation or is an 'exit' strategy led by discouragement with current social structures, how can those who stay or return be willing to engage in collective action? These issues are discussed below.

- Communal participation and diverse motivations to migrate

Autonomy is qualified effective agency, being able to make choices in significant matters (section 2.3.3). A major decision in life is where to live and whether or not to migrate. This decision can have effects on communal participation via a disintegration of social capital. This analysis is focused on Santa María and Agua Fría, localities in which not only migration but also involvement in the project was higher than in the other two localities.

First, the effectiveness of migration to assure an adequate level of well-being is different in each case; it is much higher in Agua Fría than in Santa María (section 11.1.1). Migration is a livelihoods strategy carried out by households together with other strategies, not individuals alone. The relatives of migrants and returning migrants do engage in networks; collective action is valued. This behaviour is not replicated at national levels, where participation in social and political organisations is low and signals an erosion of voice that has led millions to exit their countries (Deneulin, 2006b).

Second, the possible choices of individuals within each locality are different and their reasons to stay in their localities could be different. Some could stay due to commitment because they had the chance to leave definitively, but they preferred to return. Communal participation could be explained by solidarity or identification reasons, that is, authentic motivation (in Agua Fría). However, others could stay due to lack of money to travel or fear of losing their properties (in Santa María), that is, in situations when negative freedom is harmed. In such situations, communal participation would be explained by desperation given the lack of individual entitlements to secure a worthwhile life. Individuals have to engage in relations with others in order to secure minimum entitlements. Hence, clientelism with leaders develops to different extents despite the fact that, in Santa María, the non-leaders may complain in public. Here, voice is residual as the exit option is not possible (Hirschman, 1970).

\subsection{Self-confidence and conditions for individual empowerment}

Self-confidence is an important element of agency that frames opportunities to expand one's own potentials. Empowerment requires a qualitative change in personal attitude concerning one's capacity to achieve change in one's life (Kelsall \& Mercer, 2003, p. 293). This section discusses elements that affected self-confidence, including both community and project contexts.

\subsubsection{Exploring what influences self-confidence}

Self-confidence fuels intentional action. This links to the concept of psychological or internal empowerment (Diener \& Biswas-Diener, 2005). Sometimes, individuals with admirable skills could not apply them just because they did not think that they could be successful. 
FGD participants reported changes in self-confidence defined as the capacity to express their ideas to others and defend them' and considered the first step to autonomous action. ${ }^{95}$ On average, participants in all projects reported a growth of self-confidence. The reasons, as reflected by the participants themselves, were related to several factors:

1. The outputs of the projects, whether valuable or successful, that is, whether they feel better due to the water system, the quality of their houses and the layout of their town, the work they did, what they learned, the recognition of others, and so on. Project effectiveness may produce a positive effect on their expectations for the future.

2. The context at the moment of the assessment, referred to actual living conditions, perceived economic opportunities, and intra-community relations. This is the result of actions not necessarily related to the project; for instance, having remittances is an opportunity. Although, some project outputs influence the context. For example, learning a new skill opens up job opportunities, having water reduces conflict, and so on.

3. The micro-context during the project, which was result of intra-community relations and project practices. Controlling practices undermined self-confidence of some people when they felt that they could not argue or defend themselves. In other cases, their self-confidence increased due to their 'success' to persist until the end of the project despite everything.

4. A process of personal growth, especially for the youngest and for those whose relatives died or migrated and had to learn to support themselves and make their own decisions.

5. The relative educational attainment, which was mainly related to being literate. People tended to compare themselves with others (e.g., brother, neighbour) and to explain failures to undertake new things due to the lack of education. However, higher educational attainments were not always related to higher levels of self-confidence (e.g., Agua Fría).

6. Personal capacities related to physical appearance and good health that are visible to outsiders. ${ }^{96}$ If they look bad or poor, they are discriminated against (cf., Narayan et al., 2000), which further decreases their chances to improve their conditions.

Table 11-6 shows descriptive statistics of the levels and change in self-confidence, as reported by FGD participants. First, San Fernando is an example of the positive effect that an effective project and perceived opportunities can have on self-confidence. The improvement in selfconfidence reported by participants was the highest of all cases, mainly led by the positive expectations of women. Their self-esteem grew because they worked in the project and were successful. CASA was considered a project output that remains as a signal that new projects could arrive. The feeling that they proved (as a community) to everyone that San Fernando could advance was stronger among the woman leaders.

Although participants felt a relative lower sense of well-being than those in Agua Fría (section 11.1.2), they were at the time of the assessment very optimistic, which could be also related to their internal contexts of agency and to the timing of the assessment. People from

\footnotetext{
95 The drawing used during the FGDs to denote 'self-confidence' (Appendix 2-C) showed a big person going forward with long steps thus reflecting the idea that someone with self-confidence, in addition to other factors, could advance.

${ }^{96}$ Other skills were not named. It seems that people felt shame of talking in public about their skills or were afraid of being considered pretentious. This is a feature of the cultural context of agency.
} 
that region, in general, are happy and cheerful. ${ }^{97}$ These features could influence their optimism and positive bias when assessing their life circumstances, perceived competence and self-confidence (Lyubomirsky, 2001, p. 241). About timing, one month prior to my second study visit, the mayor had called some CASA members to form the communal committee. ${ }^{98}$

Table 11-6: FGD scores for self-confidence and related data

\begin{tabular}{|c|c|c|c|c|c|c|c|c|}
\hline & \multicolumn{2}{|c|}{ After project ${ }^{*}$} & \multicolumn{3}{|c|}{ Change compared pre-project } & \multirow{2}{*}{$\begin{array}{l}\text { Obs. } \\
\mathrm{n}^{(1)}\end{array}$} & \multirow{2}{*}{$\begin{array}{c}\% \\
\text { women }\end{array}$} & \multirow{2}{*}{$\begin{array}{c}\% \\
\text { literate }^{(2)}\end{array}$} \\
\hline & Mean & Median & Mean & Median & $\begin{array}{l}\% \text { who report } \\
\text { positive change }\end{array}$ & & & \\
\hline \multicolumn{9}{|c|}{ Reconstruction projects } \\
\hline Santa María & 7.8 & 8 & 1.6 & 2.0 & 57 & 35 & 66 & 61 \\
\hline San Agustín & 7.9 & 8 & 1.5 & 2.0 & 70 & 30 & 69 & 48 \\
\hline \multicolumn{9}{|l|}{ Water projects } \\
\hline San Fernando & 7.5 & 8 & 3.5 & 3.5 & 81 & 26 & 81 & 69 \\
\hline Agua Fría & 8.6 & 9 & 2.0 & 2.0 & 86 & 43 & 62 & 50 \\
\hline
\end{tabular}

* Scale from zero to ten

(1) The number of participants was higher but the inconsistent values were taken out.

(2) Literacy rates for the total number of FGD participants that differs from the number of survey respondents.

Source: Focus group discussions (scoring exercise).

Certainly, optimism without solid material bases will dilute over time. This would be the case if the communal committee (former CASA) did not get formal institutional support, if new projects were not undertaken in San Fernando, and mainly, if organised neighbours were not able to increase their influence, independent of the political affiliation of the municipal government (cf., Drydyk, 2006; Florisbelo \& Guijt, 2001/2004; Max-Neef, 1992). Political polarisation was high in San Fernando (section 8.4.2) but the initiative to form the communal committee based on CASA came from the mayor. What will happen if a different party captures the local government in 2009 ?

Second, the participants of the reconstruction projects reported lower increases in selfconfidence than those in the water projects. ${ }^{99}$ This finding could signal (i) the long-term impact of negative life experiences (the mudslide and the civil war), and (ii) the short-term negative effect of the high workload and controlling practices during the project. The second factor could have reinforced an enduring feature of the internal context. Project outputs apparently did not have direct impact on self-confidence; the poor living standards of the participants had a stronger effect.

People in Santa María were not happy with their lives due to the psychological pain suffered, the material deprivation lived and the abuse from leaders (section 6.4.2). The aggregate positive change in self-confidence (1.6 pts. on average) could be explained by a process of personal change because, as several participants said, a regained Christian faith gave them trust and helped to carry on with their lives (in absence of stable psychological support). In terms of the concept of 'response shift' (Sprangers \& Schwartz, 1999), there would be a change in standards or an adjustment of preferences due to their long term deprivation,

\footnotetext{
${ }_{97}$ Project staff and some residents from neighbouring villages expressed this on several occasions. The FGD with leaders in San Fernando was the most active and amusing of all.

98 This is one additional reason why this kind of studies should take place at different intervals, not only once.

${ }^{99}$ It is worth noticing that post-project scores for self-confidence are very high. Participants might have assigned these high values as if they indirectly were grading themselves, thus introducing a bias to the analysis. I insisted during the FGDs on discussing the changes, not the absolute scores.
} 
in addition to a re-conceptualisation of a valuable life, for some people. People in San Agustín also reported a relatively low improvement in self-confidence despite the facts that the quality of the infrastructure was much better than in Santa María, that their new houses were much nicer and safer than the ones they had prior to the earthquake, and that the context in San Agustín was more autonomy-supportive than in Santa María.

Third, Agua Fría is an example of the positive effect that a project context can have on the awareness of individual skills and self-confidence (section 10.4.3). Two reasons could explain this. First, social promoters were inhabitants of the same canton; the horizontal relationships with their neighbours could have influenced the sharing of ideas. Second, FGD participants explained that having access to safe drinking water for the first time made them not only 'look better' but also 'feel better'. These effects could have overcome the negative impact of conditionality practices if they regarded these practices as a 'lesser evil' to reach their goal and their causality orientation was not changed (section 10.6.2). However, the age profile of the participants in Agua Fría, relatively older that those in other sites, could limit the range of expansion in self-confidence (already with a high score) with respect to the other cases. ${ }^{100}$

\subsubsection{Perceived agency and contexts}

Perceived agency has a concrete foundation in personal competence, but the contexts in which people interact affect their self-perception and causality orientation. This section presents a classification of which factors in each context (project and community) are more significant for assessing perceived agency and can be facilitators for individual empowerment. Based on findings of the SDT, self-confidence is supported by contexts that promote choice (autonomy-supportive) and undermined by those that control behaviour (controlling). A comparison of the characteristics of the contexts in the localities studied and the change in self-confidence reported by FGD participants is included.

\section{- Characterisation of micro-level contexts: a proposal}

Four kinds of factors in the micro-level contexts influence perceived agency. Supporting the development of personal capacities and extending the access to resources are direct ways to promote agency, but there are other intervening factors related to the processes and circumstances of such actions (see Table 11-7).

Table 11-7: Some factors relevant to perceived agency in micro-level contexts

\begin{tabular}{|ll|ll|}
\hline \multicolumn{2}{|c|}{ Community context } & \multicolumn{2}{c|}{ Project context } \\
\hline \multicolumn{1}{|c|}{$\begin{array}{c}\text { Opportunities } \\
\text { Enabling }\end{array}$} & \multicolumn{1}{c|}{$\begin{array}{c}\text { Social } \\
+ \text { inclusive }\end{array}$} & \multicolumn{1}{c|}{$\begin{array}{c}\text { Involvement } \\
\text { Enabling }\end{array}$} & \multicolumn{1}{c|}{+ permissive } \\
\hline -Economic situation & -Interpersonal relations \\
-Success of previous & -Communal organisa- & -Information & -The definition and \\
collective actions & tions & -Opinions & $\begin{array}{l}\text { clarity of entitlements } \\
\text {-Expectations of new }\end{array}$ \\
projects & -Power structure & -Awareness & -Workload \\
-Physical security & -Values and norms & the exercise of decision- & -The extent of choice vs. \\
\hline
\end{tabular}

$\left(^{*}\right)$ Practices characterise autonomy-supportive or controlling contexts.

\footnotetext{
100 Only 13\% of the FGD participants were younger than 30 years in Agua Fría, while this percentage was around $26 \%$ in the other sites.
} 
Relevant factors in the community context

Two types of factors in the community context are: (i) the perception of opportunities for improving life, and (ii) the social environment that can be more or less inclusive. The perception of life opportunities depends on the economic situation of people in the village, their links with outside towns, the common resources to which people have access (and whether they are a result of collective action) or might have access (depending on expectations of future actions), and general life conditions such as the level of physical security. The assessment of the social context depends on personal entitlements, social position, the quality of interpersonal relations, and satisfaction with community dynamics. ${ }^{101}$ For instance, if people live in a secure environment with relatively low levels of poverty and social exclusion, in which people are free to speak their minds, they will have a higher perceived agency than others who live in risky contexts with material deprivation and norms that discriminate against certain groups of people.

\section{Relevant factors in the project context}

Two types of factors in the project context are: (i) the involvement in the project that already implies a certain exercise of autonomy, and (ii) the practices, which are more or less permissive. A person with high involvement in a project has access to relevant information, can give opinions which are listened to and taken into account, has opportunities and exercises decision-making. The level of involvement was low across cases because significant decision-making was not exercised (section 10.4.3).

\section{The internalisation of practices depends on several factors}

Project practices might be internalised differently by project participants. Respectful treatment and the general motivation and commitment of project staff toward participants (Riddell et al., 1995) promote the perceived agency of participants. It must be noticed that project practices are result of the interaction of participants, project staff and other stakeholders who have their own values, objectives, entitlements, perceptions, and power (Long, 1992b).

Project practices and the projects themselves can be categorised as external events for participants (section 10.4.4). Getting the house or the water connection can be perceived as a big reward that justifies any effort. An organisational process, such as the formation of CASA in San Fernando, can be perceived as a controlling event or as an autonomy-supportive event. The first case would apply if the only reason to act were 'to keep the project'. The second case would apply if the leaders received positive feedback from the social promoter that fuelled their self-confidence to continue working together after the project is completed.

From the point of view of non-leaders, the workload can be highly controlling if they are mistreated and their progress is evaluated with respect to fixed standards that they cannot influence (e.g., with delays in the allocation of materials). In these contexts, if supervisors are pressured to make them to perform as planned, supervisors themselves become more controlling of those below them (Deci \& Ryan, 1987, p. 1030), as the Santa María case suggests. In contrast, a potentially enjoyable activity, such as a cleaning activity, could be per-

\footnotetext{
${ }^{101}$ Both elements, perceived opportunities and social context, correspond to the micro-level structural context in the conceptual model. However, most people related opportunities to economic resources and networks (e.g., cooperatives, projects) and social context to social networks, power and cultural features (an internal context of agency). This observation signals the close linkages between entitlements, agency and contexts.
} 
ceived as controlling if people were motivated with rewards after completion or if they did it to show their 'good' behaviour to the donor in an official visit (cf., Mosse, 2005). Hence, repetitions of such activities after the project, without the reward, would be not so probable.

Power relations may explain 'good' behaviour

Power relations built during the projects are important, especially because all projects avowed participation, which requires respect for project participants' opinions. Respect here implies to open up spaces for learning and conflict so that participation is genuine (Kelly, 2004; Florisbelo \& Guijt, 2001/2004). Moreover, power relations are not only between local actors but also between participants and project staff. A man non-leader in Agua Fría explained: 'We learned that we have to be humble because the engineers know more than we $\mathrm{do}^{\prime}$. Truly, engineers have technical skills that residents do not have, however, local knowledge is important for certain activities and different abilities can be complementary (e.g., to improve the performance of soak-away pits). Likewise, local executing NGOs could significantly improve the project relevance and impact, if given the chance and if the project is not 'locked' in a design frame (section 3.2.2).

When local opinions are not heard, participants could develop a strategy of doing everything as ordered without complaints in order to secure benefits (Wood, 2003). ${ }^{102}$ This behaviour would not necessarily undermine their self-confidence, if it was related to good performance to get a reward (i.e., success in securing benefits). Statements of man non-leaders in the reconstruction projects like 'everything that they asked me to do, I could do' and 'I succeeded in everything I did' suggest this. Also, the meaning of events, not events themselves, has effects on perceived agency. ${ }^{103}$ However, a positive self-perception (or temporarily enhanced perceived agency) based on one's being able to show good performance is not indicative of individual autonomy, if one has not appropriated the solution but acted on extrinsic reasons (see Ellerman, 2006, Chapter 6).

\section{Comparative analysis}

Table 11-8 shows rankings for projects in each sector according to the four factors and the assessment on self-confidence made by FGD participants. As expected, people in San Agustín had better chances to improve their self-confidence than those in Santa María: the perception of community context is better and the project context was less controlling. The higher involvement of people in the Santa María case was related to their socio-historical agency (section 11.2.3). However, the comparison between Agua Fría and San Fernando signals the strong influence of perceived opportunities in a relatively more recent project.

In Agua Fría, it seems that the condition of self-financed soak-away pits, the many parallel activities and the problems of the water service reduced the positive effect that the relative higher individual involvement in the project could have had on self-confidence of the participants. The impact of failures (in contrast to successes) on the causality orientation of project participants is related to the involvement that they had in the processes (section 10.6.4). If they felt that they could not influence the results, the harmful impact would be

\footnotetext{
102 The discussion in Wood (2003) about agency and time preference behaviour in the context of livelihoods strategies is pertinent. People can settle for less 'voice' to secure short-term priority benefits thus undermining their capacity to speak up and to participate in the 'making' of their own development in the long-run.

103 This refers to the meanings of participants, not those of project staff or field researchers. Hence, it is necessary to 'discover' meanings from behaviours and discourses (difficult task!) to assess impacts.
} 
lower. This seems to be the case in Agua Fría with respect to the water service (for almost all participants) and to the reservoir (for non-leaders), in contrast to Santa María where people said that 'they failed' with the sowings in the communal plot.

Table 11-8: Comparing micro-level contexts (rankings by sector)

\begin{tabular}{|c|c|c|c|c|c|}
\hline & \multicolumn{2}{|c|}{ Community context } & \multicolumn{2}{|c|}{ Project context } & \multirow{2}{*}{$\begin{array}{l}\text { Self-reported } \\
\text { change }^{(2)} \text { in } \\
\text { self-confidence }\end{array}$} \\
\hline Ranking & $\begin{array}{c}\text { Opportunities }^{(1)} \\
\text { Enabling }\end{array}$ & $\begin{array}{c}\text { Social } \\
+ \text { inclusive }\end{array}$ & $\begin{array}{c}\text { Involvement } \\
\text { Enabling }\end{array}$ & $\begin{array}{l}\text { Conditions } \\
+ \text { permissive }\end{array}$ & \\
\hline $\begin{array}{l}\text { Reconstruction } \\
\text { First } \\
\text { Second }\end{array}$ & $\begin{array}{l}\text { San Agustín } \\
\text { Santa María }\end{array}$ & $\begin{array}{l}\text { San Agustín } \\
\text { Santa María }\end{array}$ & $\begin{array}{l}\text { Santa María } \\
\text { San Agustín }\end{array}$ & $\begin{array}{l}\text { San Agustín } \\
\text { Santa María }\end{array}$ & $\begin{array}{l}\text { San Agustín } \\
\text { Santa María }\end{array}$ \\
\hline $\begin{array}{l}\text { Water } \\
\text { First } \\
\text { Second }\end{array}$ & $\begin{array}{c}\text { San Fernando } \\
\text { Agua Fría }\end{array}$ & $\begin{array}{c}\text { Agua Fría } \\
\text { San Fernando }\end{array}$ & $\begin{array}{c}\text { Agua Fría } \\
\text { San Fernando }\end{array}$ & $\begin{array}{c}\text { San Fernando } \\
\text { Agua Fría }\end{array}$ & $\begin{array}{c}\text { San Fernando } \\
\text { Agua Fría }\end{array}$ \\
\hline
\end{tabular}

(1) FGDs suggest that people of San Fernando perceived more opportunities but survey results indicate a better assessment for Agua Fría, in terms of opportunities promoted by the community (section 11.2.3).

(2) Based on focus group discussions (scoring exercise).

Table 11-8 suggests that there are interrelations between several factors. Controlling practices could harm the intrinsic motivation of project participants, their causality orientation depending on their level of involvement and their perceived agency (the most in Santa María). Perceptions of life opportunities and social contexts depend on the actual living conditions of participant in all cases, except for San Fernando.

\section{- Self-assessments of individual autonomy}

FGD participants discussed about four variables conceptually related to individual empowerment (see section 4.2.2), in terms of changes. Two variables referred to the support that the community context provides (changes in information about community issues and in life opportunities related to means to improve well-being) and two were related to perceived agency (change in self-confidence and in personal decision-making). The latter do not 'measure' empowerment because having made decisions does not necessarily indicate that such decisions were effective in reaching goals.

Figure 11-6: Perceived agency and micro-level contexts by project site

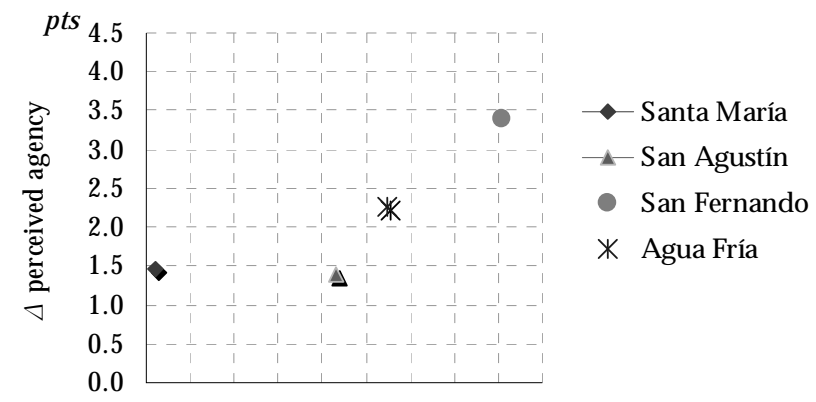

0.00 .51 .01 .52 .02 .53 .03 .54 .04 .5 pts

$\Delta$ context support

Source: Focus group discussions (scoring exercise). 
Figure 11-6 plots the average change in each of the two aspects on a 10-point scale. In Agua Fría, for example, people reported a positive change of 2.7 pts in context support and a change of $2.3 \mathrm{pts}$ in perceived agency.

The individuals in San Fernando were the most optimistic about improvements in both aspects. In contrast, the participants in Santa María were dismissive about the context, although their perceived agency improved a little (comparable to the increase in San Agustín). It seems that the project participants in Santa María feel that their worth is more related to their personal competence than to the micro-level context in which they live. Indeed, they succeeded to survive despite the context which constrains their individual autonomy.

\subsubsection{Being capable but powerless to promote human development?}

The two previous sections have dealt with self-confidence, its link with perceived agency and how this can be affected by micro-level contexts. The community context was analysed based on the perception of life opportunities and social environment. In this section, two aspects are included: political context and power relations. These aspects are important to distinguish (i) what is being capable, that is, having the capacity to undertake authentically motivated decisions, from (ii) what is being powerless, that is, not being able to put into action these decisions or to sustain the positive outcomes resulting from such decisions.

In Agua Fría, the opposition of the mayor to the formation of the NGO blocked the options of residents to develop plans together and obtain funds. In San Fernando, CASA is not even registered as an association (in contrast to ADESCO in Agua Fría), but leaders seem not to worry because they prefer that the political authority takes care of the projects and plans.

In Agua Fría, people had aspirations to improve their well-being by joining group efforts; in San Fernando, people formed CASA as a response to the need to have drinking water at home. In the Agua Fría case, the decision to form an NGO and later to carry out new projects was not in the hands of people because formal power holders would not allow this. The leaders in Agua Fría felt competent and had the experience to work together, but they were powerless to promote their common goals for the development of their village.

The involvement of the local government in the project could have facilitated the collaboration from national institutions and, most importantly, provided the means to assure project effectiveness. Nonetheless, the political impasse in Agua Fría undermined the individual autonomy of residents in the long run because their options to improve their well-being by themselves were reduced.

Community organisations are particularly important to achieve common goals in the case of poor people whose individual actions are likely to be ineffective (Stewart, 2005; Uphoff, 2005). It is important to prevent elite capture (e.g., Santa María) by helping people to create the means to hold leaders accountable, especially when leaders are managing common resources. Indeed, for individuals to be empowered requires 'also interpersonal, social and political skills' (Eklund, 1999, p. 44) to influence or enrol others in their projects (Long \& van der Ploeg, 1994; Long, 1992b, 2001), and to assure that these others are not using common resources solely for their own benefit. 


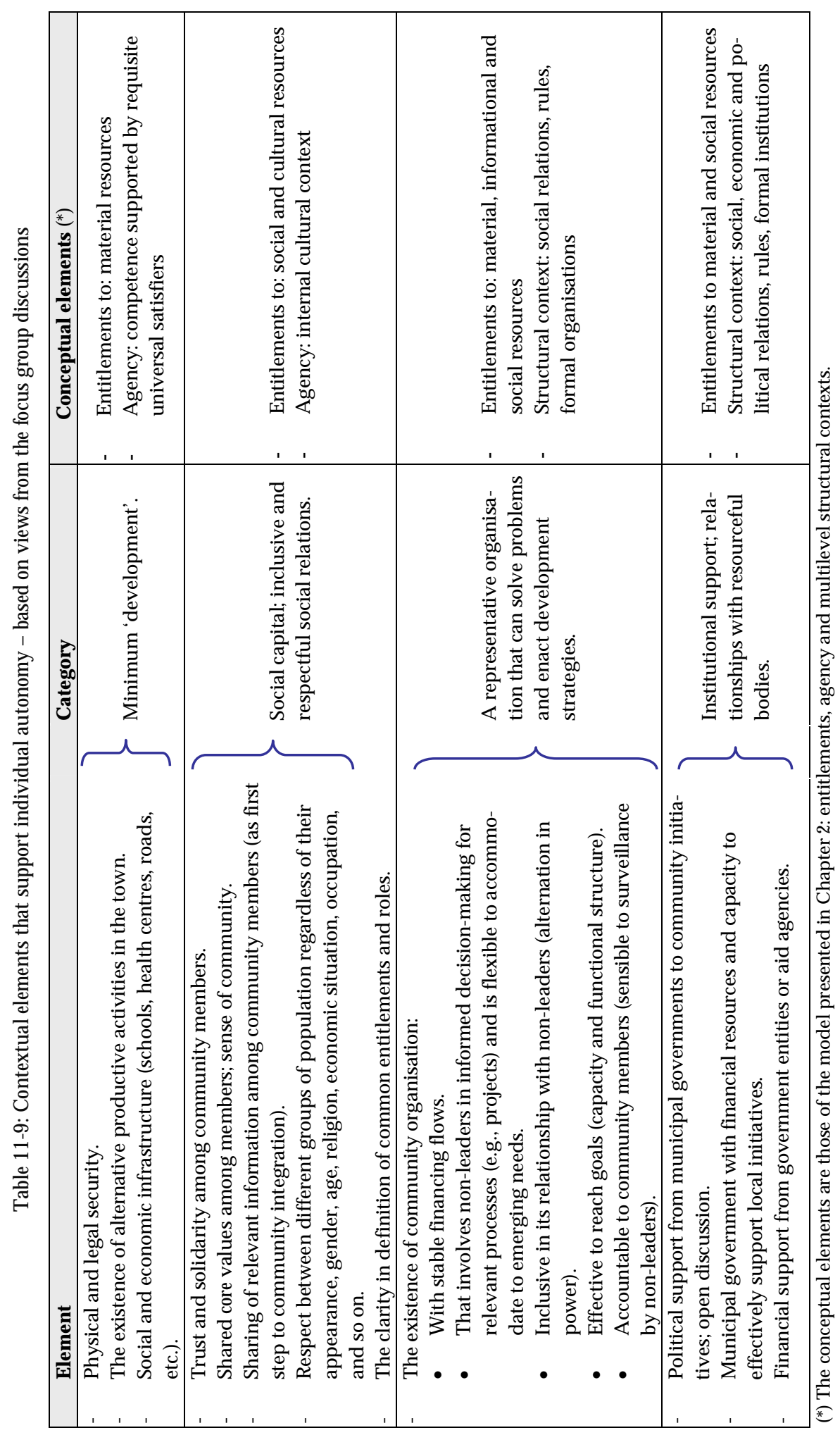


The situation of the community organisations varied across cases. ASCA in Santa María was the strongest but the more restrictive in terms of individual autonomy. CRDM in San Agustín was the most representative and relatively strong in relations with powerful bodies, but not necessarily effective in promoting individual autonomy. In between, CASA in San Fernando was in an embryonic stage, while ADESCO in Agua Fría was weakened by a political impasse, but had the potential to positively influence individual autonomy.

Table 11-9 summarises the most relevant elements of these contexts that enhance individual autonomy, based on the experience of people themselves, as expressed in the focus group discussions, and on my conceptual model.

Some general observations arise: trust and solidarity were lacking in Santa María and this situation would harm any intent of forming a new organisation; physical insecurity seriously affected the possibilities of Agua Fría residents; major differences among population groups in San Fernando were still evident; the lack of alternative productive activities and economic resources in general affected the autonomy of the individuals in San Agustín that otherwise would have great hopes because of the sister cities agreement. These several constraints in each case indicate that different actions are necessary to promote development and, hence, no simple policy model will be widely relevant.

Certain elements in Table 11-9 concern the macro-level context. Community initiatives do not easily influence decisions on publicly-funded infrastructure; legal security in terms of individual identification and property registration of real estate; productive activities to be promoted by development banking, municipal laws, and so on. In these cases, aid projects may have a role.

Some elements belong to the structural context and cannot be changed at once. However, project practices that respect local values - project staff first needs to identify them, with participants - can promote inclusive participation in relevant decision-making. For this, the selection of the counterpart and partner NGOs, which have to be representative (the former) and respectful of the local people (both), is crucial.

At the start of this section, self-confidence was considered crucial to frame opportunities. The analysis above confirms that people even in the most deprived situations are able to judge their situation, to identify means to promote their goals - to find synergic satisfiers as proposed by Max-Neef et al. (1991) - and to carry out actions. However, it is difficult for individuals (e.g., in San Agustín) and groups (e.g., in Agua Fría) to influence contexts because of their relative weak position in social structures and individual vulnerabilities.

\subsection{Conclusions}

This chapter has presented an account of the lived experiences of individual autonomy in the four localities studied. The chapter has analysed the elements of the conceptual model, with emphasis on the relationship between self-confidence (as crucial element of agency) and micro-level structural contexts. The main findings are presented below.

1. Perceived agency is not detached from the lived reality of individuals. Gains in selfconfidence require real foundations to be sustainable (as e.g., in San Fernando). Individual achievements and personal growth promote perceived agency and the exercise of 
decision-making. However, the effectiveness of intrinsically motivated decision-making depends on individual entitlements and group support.

2. Micro-level structural contexts are dynamic: social actors shape them in daily interactions and several factors influence changes in these contexts. The political factor is crucial in defining limits for participation (e.g., Santa María, Agua Fría), prospects of external collaboration (e.g., San Agustín), or new hopes (e.g., San Fernando).

3. Different leadership styles and local power structures influence the potential of community organisations to contribute to human development. Some communal organisations may be strong but not effective to promote individual autonomy (e.g., Santa María), while others might be more autonomy-supportive but weak due to rigid structural contexts (e.g., Agua Fría).

4. Communal participation can be expression of (i) genuine motivation, thus reflecting the value that individuals attach to their geographical communities, (ii) urgent needs, which oblige people to engage in networks even under unequal conditions, or (iii) mistrust of leaders, leading people to watch them from close or to challenge their power by joining efforts with others. However, for the latter cases, the socio-historical agency of people determines whether people themselves take action or whether they wait for resourceful entities to come to help.

5. In all cases, projects were important events that initially increased the hopes and the aspirations of people. However, the different involvement levels of leaders and nonleaders and the project practices explained different impacts on individual autonomy that could cause disappointment. External aid agencies face multiple risks when interacting in new environments (regions of developing countries) and stressful situations (emergency relief). A large risk is that strong community organisations that seem effective in operational terms are ineffective in human development terms.

6. The projects did not influence communal participation. On the contrary, it is the history and the culture of people in the sites that determine their participation. Hence, looking at the two Salvadoran villages in which inhabitants regard their leaders and their community organisation positively, only Agua Fría had a high level of communal participation. In San Agustín, the civil war left such a deep mark on its inhabitants that they would still prefer to stay away from public life.

7. At the time of the fieldwork, participation during the project seemed to have resulted in an elite capture in Santa María, directed mobilisation in San Fernando and Agua Fría, and partnership between residents and project staff in San Agustín. The Agua Fría case highlights the importance of understanding local governance and managing conflict in a respectful way. The San Agustín case signals that the strengthening of communal organisations may not influence individual autonomy if individuals lose their motivation because the leaders centralise all decisions, even when the context promotes mutual trust and respect.

8. There are no easy answers to how communities can promote opportunities for autonomy and human development. The cases showed a variety of manners how opportunities could not be shaped or were shaped only partially or temporarily. In the case of relatively small rural villages, it seems that collective action can play an important role to 
strengthen the self-perceived competence of people engaged in such an action. The future challenge though is to understand how people could change the structures that constrain them and how to help them along their way. 


\section{The development path: reducing vulnerability and enhancing critical autonomy}

Development is not just about 'coping'... or 'surviving'... nor 'muddling through'. It is about life, and about the space and freedom we create (Carmen, 1996, p. 147-8).

The most basic human need of poor people is the freedom to define their own needs, to organize to meet them, and to transcend them as they see fit (Goulet, 1983, p. 620).

This chapter deepens the conceptual discussion started in Chapter 2 in light of the findings in Chapter 11 about the lived experiences of autonomy of individuals in the four project sites. It discusses two topics that are fundamental to promote human development: the reduction of vulnerability and the enhancement of critical autonomy, which makes critical participation possible.

Human beings face risks of diverse nature, many of which are inevitable. While some regions of the world, like Central America, are more prone to certain natural and environmental risks than other regions (UN Millennium Project, 2005), the world is getting more insecure everywhere as result of human activity. The negative effects of climate change are already evident (UNDP, 2007b) and the intensity with which international financial and trade crises spread grows as the national economies are more interrelated. Nicaragua and El Salvador are small players in this complex world reality.

This chapter proposes that human development or the path to sustainable improvements in well-being requires that (i) the falls in well-being as consequence of the occurrence of risks are minimised, and that (ii) individuals are able to recover promptly after these events.

The first requirement implies that a set of measures is in place before the occurrence of a risky event and a group of social actors is ready to be involved. These measures and actors must be present in the multilevel structural contexts. Given the low levels of need satisfaction of the inhabitants of these four localities, the macro-level and meso-level context are the most relevant. All projects, except the Agua Fría project, were responses of the international community to falls in well-being due to natural disasters. The case chapters have indicated that issues related to donor coordination, accountability, and local institutional capacities had a large influence on the outcomes of these projects.

The second requirement, the rapidity of recovery, is related also to individual capacities and intra-community relations. The instrumental role of autonomy to promote human development is underscored: the higher the levels of autonomy experienced, the faster individuals will recover because they will be better able to act purposively and they will use the resources at hand more effectively. Clearly, they will already be intrinsically motivated to improve their situation unless a profound emotional shock freezes them (e.g., Santa María).

Section 12.1 discusses the relation between risks, vulnerability and individual autonomy at the micro-level. Individuals experience individual autonomy in relations with others. This section then explores the links between vulnerability and collective action to focus on how collective action can overcome individual vulnerabilities and promote the common goals of a group. 
Human development is related to the expansion of valuable human potentials. Once a certain adequate level of individual autonomy is reached, individuals can decide on which potentials they want to promote for themselves, their families, and communities (cf., Nussbaum, 2000). However, the exercise of autonomy does not have to wait until every other need is realised at a certain level because autonomy is instrumental to promote other potentials. Basic autonomy and critical autonomy must be continuously supported and developed.

Section 12.2 discusses (i) how the individuals of the four localities could have expanded their critical autonomy, (ii) how some of them made use of political resources, and (iii) how people can organise themselves to engage in critical participation, with the support of others, to promote significant change in their lives and the lives of others.

\subsection{Two sides of the coin: vulnerability and individual autonomy}

Vulnerability is related to a situation of insecurity during which people experience lower levels of autonomy. This section explores the risks that affect households and how people with fewer entitlements or lower agency are more vulnerable to falls in well-being. It also analyses collective action as a way to reduce individual vulnerability.

\subsubsection{Risks, vulnerability and individual autonomy}

Individuals face risk and uncertainty about the future. If the occurrence of a certain event is not predictable or unexpected, the individual is uncertain about this and the event arrives as a shock. If there is a known or estimable probability of occurrence for that event, the individual is at risk. There are means how individuals can ex-ante protect themselves, although to different extents. For instance, floods during rainy season are risks or hazards for which individuals, families, communities, the states or other social actors can take preventive actions. Earthquakes such as those that struck San Agustín in 2001 were unpredictable, so these are shocks. The mudslide of Casitas volcano triggered by Hurricane Mitch was a risk because the region is prone to hurricanes and the Casitas volcano had been publicly declared an at-risk zone in 1997 (Rocha, 1999b) which means that people living at the slopes of Casitas had been warned about the danger of staying there. However, the magnitude of the disaster exceeded all expectations.

\section{- Classes of risks and their manifestations}

There are several classifications of risks (e.g., de Neubourg \& Weigand, 2000) according to the population potentially affected and to their effects. In one classification, there are universal, life-cycle, and categorical risks. Universal risks affect everyone, but some individuals can be high-risk (e.g., accident-prone). Life-cycle risks are specific to individuals of certain age or at certain stage of their lives. Categorical risks are specific to people within certain groups such as construction and mining workers, those living in certain regions, and so forth.

In a second classification, there are three kinds of effects: incidental or temporary (e.g., short-term unemployment), lifetime or long-term (e.g., disability), and intergenerational effects that are passed on to next generations. Some risks can have a temporal effect for some people but long-lasting effects for others.

Risks can also be classified according to their source (natural risks or those resulting from human activity such as social and economic policies), the correlation among individuals 
(from idiosyncratic to covariant risks as the scale of the effect grows), the correlation with other risks (uncorrelated or correlated risks), and the frequency/intensity relationship (catastrophic risks, with low frequency but severe losses in well-being, or non-catastrophic risks, with high frequency but low effects). Table 12-1 presents some examples of risks and shocks that can affect individuals.

Table 12-1: Examples of risks and shocks

\begin{tabular}{|c|c|c|c|}
\hline Source of risk & Idiosyncratic risks & Covariant risks & Shocks \\
\hline Natural & & $\begin{array}{l}\text { - Rainfall, landslides, } \\
\text { droughts, floods, hurri- } \\
\text { canes }\end{array}$ & $\begin{array}{l}\text { - Earthquakes, volcanic } \\
\text { eruptions }\end{array}$ \\
\hline Human health & - Illness, injury, disability & - Endemic disease & - Epidemic \\
\hline Social & $\begin{array}{l}\text { - Crime, domestic violence, } \\
\text { fall in community support }\end{array}$ & $\begin{array}{l}\text { - Terrorism, gangs, criminal } \\
\text { violence }\end{array}$ & $\begin{array}{l}\text { - Civil war, social convul- } \\
\text { sion }\end{array}$ \\
\hline Economic & $\begin{array}{l}\text { - Unemployment, wage } \\
\text { variability, harvest failure, } \\
\text { business failure }\end{array}$ & $\begin{array}{l}\text { Economic crisis, policy } \\
\text { changes in real, labour } \\
\text { and financial sectors, } \\
\text { trade liberalisation }\end{array}$ & - Terms of trade shocks \\
\hline Political & $\begin{array}{l}\text { - Ethnic or class discrimina- } \\
\text { tion }\end{array}$ & - Institutional reforms & - Coup d'état \\
\hline Environmental & & $\begin{array}{l}\text { - Pollution, deforestation, } \\
\text { fragile ecosystems }\end{array}$ & $\begin{array}{l}\text { - Plant and livestock dis- } \\
\text { eases and pest infestations }\end{array}$ \\
\hline
\end{tabular}

Source: Holzmann and Jørgensen (2000), Prowse (2003), and Siegel (2005).

All individuals are exposed to idiosyncratic risks, although to different extents. Covariant risks, that affect many people at the same time, are directly identifiable. Unfortunately, the residents of the four localities can face all those risks listed in Table 12-1. In addition to recurrent natural risks and human health risks (Box 12-1), environmental risks are high.

\section{Box 12-1: An account of macro-level risks and shocks}

Central America is the region with the highest mortality risk due to natural hazards in the world, 1.4 times higher than the risk faced by South Asia and the East Asia \& Pacific regions (UN Millennium Project, 2005). Nicaragua and El Salvador have experienced recurrent events such as floods, heavy rainfalls and storms, and droughts. According to WFP (2002), more than 2.6 million people live in a drought corridor in Nicaragua and 1.3 million in El Salvador. Areas in the drought corridor receive considerably less rain than others in normal conditions, drought is locally recurring (especially with El Niño phenomenon) and people face severe food insecurity.

In addition, there have been periodic large-scale tragic events. In Nicaragua there were earthquakes in 1972 and 1992, and in El Salvador, in 1986 and 2001. During the period studied, there were two important hurricanes. The most severe was Hurricane Mitch, in October 1998, which affected all Central American countries but hit Honduras and Nicaragua the hardest. The other hurricane was Stan, in October 2005, which mainly affected El Salvador.

Some diseases are endemic. Since 2002, when an epidemic was detected (PAHO, 2007), the dengue fever is a continuous health threat in El Salvador. Malaria is still present in the northern regions of Nicaragua.

Bad agricultural practices (e.g., intensive use of pesticides, over-utilisation of lands, singlecrop farming) and the inadequate management of natural resources, in both countries, have deteriorated the soil quality and increased the food insecurity. The environmental risks are 
higher for the inhabitants of Santa María, in the drought corridor (Box 12-1). The droughts of 2001 and 2002 were an important cause of the failure of the agricultural project.

On the other hand, the growth strategies pursued by governments in both countries have privileged exports and trade liberalisation, negatively affecting the situation of small subsistence farmers. Then, economic crisis and external shocks may cause more damage to the livelihoods of the inhabitants of these four localities than to other groups. The situation was relatively better in the Salvadorian sites where some agricultural credits were available.

Social risks are significant in all sites but the most insecure one, due to the high levels of crime and the existence of youth gangs, is Agua Fría. People try to prevent robberies but their actions are ineffective as the case of doña Estela told (at the start of Chapter 7). She was robbed several times and despite her claims to leaders, they could not help her as even the policemen were scared of the delinquents.

Over time, Nicaragua and El Salvador experienced important and tragic political events: authoritarianism by military or civil rulers, foreign armed intervention (Nicaragua), revolution, civil war, and rebellion. These events were linked to marked political polarisation and economic and social exclusion that are ongoing (Appendices 1-A and 1-B, section 1). From the perspective of inhabitants of small rural or semi-rural villages, most of these risks are beyond their control. Most likely, they will need the support from others such as governments, aid agencies, private institutions or migrants to recover when threats strike.

\section{- Vulnerability and threats to individual autonomy}

In this study, vulnerability is understood as a state of insecurity related to the low capacity of individuals to face risks without damaging loss in present and future well-being (see Chambers, 1995; Alwang, Siegel \& Jørgensen, 2001; Wood, 2007).

Vulnerability can be defined in terms of its three components: risks, strategies to deal with risks or risk responses, and outcomes in terms of loss in well-being. The outcome of these risky events depends on two main factors: (i) the exposure to the risk that is related to the characteristics of the risks (its magnitude, frequency and duration) and the contexts in which individuals live, and (ii) the capacity to develop risk management strategies.

Risk management strategies aim to prevent, mitigate or cope with risks (see, e.g., Holzmann and Jørgensen, 2000). Although all individuals are able to envisage strategies, the variety of strategies that individuals can develop and their effectiveness depend on their entitlements and the structural contexts in which they interact (e.g., whether they can be insured).

Table 12-2 shows that, like autonomy, the concept of vulnerability has an internal and external element: resilience and exposure to risks.

Table 12-2: Relationship between concepts of autonomy and vulnerability

\begin{tabular}{|lll|}
\hline Concept & Internal element & External element \\
\hline Autonomy & Agency & Structural contexts \\
Vulnerability & Resilience & Exposure to risks \\
\hline
\end{tabular}

Source: Chapter 2, Chambers (1995), Holzmann and Jørgensen (2000), and Alwang et al. (2001).

Resilience refers to the capacity to deal with the risk and to recover without damaging loss in well-being (Chambers, 1995). The opposite is defencelessness. An expansion of autonomy qualified as empowerment enhances resilience because it implies that the risk management 
strategies enacted are more effective. For instance, the experience gained by CRDM in San Agustín during the reconstruction period helped this community committee to manage the small water project in Galingagua (section 9.2.3). When Hurricane Stan hit El Salvador, people were promptly organised.

The exposure to risks mostly depends on external circumstances. For instance, the inhabitants of San Agustín could not emigrate during the civil war because of the lack of economic and social resources and then, were exposed to multiple risks against their personal safety.

\section{Vulnerability is accompanied by low entitlements}

A related concept is that of sensitivity or the extent to which the resources are prone to depletion after risk management strategies are pursued (Alwang et al., 2001). Miguel in Santa María (section 11.1.2), sold his house to finance the medical treatment of his ill son. It was his response to the manifestation of the risk. Although he wished to migrate to El Salvador to work, he could not afford the trip expenses as he sold the only resource he had.

This case indicates that extending the access to resources not only promotes autonomy but also, depending on the context, can reduce sensitivity. Poor people have fewer strategies to their reach because they have fewer entitlements over individual and common resources. In addition, the resources available to them are less productive. ${ }^{104}$ For example, poorly fed individuals who look weak or sick are not enrolled to work in large farms as daily labourers. Likewise, their chances to get a job diminish as they grow old. This is the case of some landless household heads in San Fernando.

Having knowledge about community events that would affect one's well-being is crucial in order to devise risk management strategies, especially in rural contexts. For instance, in Santa María, if people knew about the bad financial situation of the autonomous water system, they could have monitored the management team more closely, thus avoiding the collapse of the system that happened. As Alwang et al. (2001) indicate: 'the ability to cope [and prevent risk] is information contingent' (p. 20).

\section{Present vulnerability harms future well-being}

A high frequency of risks and the use of resources over time to mitigate these risks can cause long-term vulnerability, in the same way as catastrophic risks can drastically reduce resources. Recurrent droughts can have long-term effects on individuals' well-being because, in order to survive, they can trade productive resources (e.g., sell tractors, as in Santa María), take debt with informal lenders, or postpone investments in human capabilities (i.e., taking children out of school to work in non-farm jobs). During no-drought periods, they farm their plot intensively to satisfy urgent needs, so that future harvests produce fewer crops over time, which in turn affects their resilience.

It has been argued that because the poor people experience an exaggerated sense of uncertainty related to their limited means to manage risks and recover after shocks, they are willing to trade present well-being for future well-being, thus exacerbating their long-term vulnerability in their intent to cope with present risks (Wood, 2007). However, this would be

\footnotetext{
${ }^{104}$ In asset-based approaches of poverty, a crucial problem of the poor people is not only the lack of assets but also the low productivity of their assets (Siegel, 2005). Examples include poor-quality education (that restricts possibilities of high-paid jobs), over-utilised lands (that reduce the scale of the future harvests), among others.
} 
the most desperate cases. Chambers (1995) points out that it is outsiders and less the poor people who take a short-term view. On the contrary, when a food shortage threatens, poor people eat less and worse in order to protect their livelihood assets in the bad times to come (ibid, p. 192). However, this strategy affects their physical strength and their capacity to work and sustain themselves in the future, thus increasing their risk to higher falls in wellbeing in the future.

\section{- Vulnerability to loss in well-being and negative freedom}

The negative outcomes of vulnerability can be defined in terms of monetary poverty (vulnerability to loss in consumption levels), food security (vulnerability to hunger and malnutrition), livelihoods (vulnerability to loss in livelihood), and so on (Alwang et al., 2001). The approach used here is to define the outcome as the loss in well-being, which may include 'becoming or being physically weaker, economically impoverished, socially dependent, humiliated or psychologically harmed' (Chambers, 1995, p. 190).

Individuals in such circumstances lose their self-confidence, their capacity to aspire, and their capacity to bargain with power holders. Moreover, 'closely related to the experience of vulnerability is the state of being resigned to always remaining poor' (Aliber, 2001, cited in Prowse, 2003, p. 11), leading to an impersonal causality orientation: people would feel their actions as beyond their intentional control (section 2.2.4; Table 2-4). This was the case for many non-leaders in Santa María of older generations, for whom 'life is not the same anymore'. Hence, in emergency contexts, as Hofmann et al. (2005) argue, aid should not only ensure human survival but also 'sustain and develop a core psychological coping capacity in population under stress' (p. 20). The role of external agents may be crucial to re-activate aspirations of individuals trapped in the negative cycle of long-term deprivation (cf., Carmen, 2000; Burchardt, 2004).

\section{Perceptions on sources of risks explain the nature of risk prevention strategies}

Vulnerability can be defined with respect to different sources of risks. People living at the slopes of Casitas were at high-risk to loss in well-being because of their lack of entitlements. They did not have other place where to go and had fought hard to get those lands during the agrarian reform. Years after the disaster, several returned to their old plots because 'farming is what [they] know to do' and they perceive that a landslide of such magnitude would not happen again in several decades. They fear droughts more than a new hurricane because droughts are recurrent and undermine little by little their agency. Rocha (2007) points out that, eight years after Hurricane Mitch, people in Santa María were less vulnerable to poverty from natural disasters than before Mitch because (i) people depend more on remittances and (ii) their relation with land has changed. Not owning any land, they rent land, farm for others or work their old lands in risky conditions. This means that they have less to lose. This analysis deserves three comments.

First, vulnerability to monetary poverty is not the only kind that matters. The current wellbeing of Santa María residents is much lower than before the disaster also because the negative psychological impact has endured (section 6.4.1). Migration is a strategy to cope with the increased risks, but migration brings new risks such as family distress, accidents, and so on. Not all can afford to migrate because it requires bridging social capital with people outside the village helping to find jobs. 
Second, Santa María residents have less to lose in monetary terms because their consumption levels are so low. They have less to rely on when facing risks. For instance, inflation hits them stronger than before the disaster. They have to buy their own food while, earlier, they produced their crops. Vulnerability to loss in monetary income from natural disasters may be lower for a few, due to remittances, but vulnerability to loss in monetary income from economic risks is higher. Also, the poor face correlated risks, that is, risks reinforce one another. Hence, their intensity and negative effects increase (Wood, 2007).

Third, how people perceive the risks determines the strategies that they will develop. If people in Santa María think that 'they were already punished' (Rocha, 2007, 'Four inalterable principles' section, II 2) and 'no one can do anything when the time to die arrives because only God knows it' (ibid, II 6), they will be less motivated to work in risk prevention measures. People may perceive in different ways the risks that they face depending on their social-cultural contexts and personal experiences.

In addition, people are more likely to perceive risks in those aspects that matter the most to them. They are motivated to be involved in processes that they value (section 10.6.3) and they would aim at developing skills to manage risks that could affect those valuable aspects. What about real but not perceived risks? Informing people about risks is a task for political authorities and leaders. In San Fernando, for instance, none of the FGD participants talked about environmental risks despite that the reserves of pines are under threat of overexploitation and seasonal fires, which could affect the water access in the long run.

People feel vulnerable when they 'know [that something] is going to happen but at the same time [they] are unable to face [it]' (Narayan et al., 2000, p. 153). This is the feeling in Agua Fría. Residents wish they could know how to repair the water system for the next time that it will fail. In this case, the poor operational effectiveness of the project and the institutional weakness of the water company brought a sense of defencelessness to residents.

\section{Reducing vulnerability expands negative freedom and promotes autonomy}

Positive freedom requires negative freedom (section 2.2.2), so that a person is free from a restriction to do or to achieve his or her goals. A reduction of vulnerability implies expanding negative freedom because it reduces insecurity and the constraints attached to fear and anxiety of not being able to cope with risk (Narayan et al., 2000, Chapter 8). This is a necessary but not sufficient condition for positive freedom. Reducing vulnerability is a step to promote individual autonomy that requires other supportive elements.

Such elements come from multilevel structural contexts. The state could secure rights and provide information about them (e.g., regulating labour contracts and carrying out work inspections), ease the communication between citizens and public institutions (e.g., punishing discrimination, promoting water users' association, etc.), regulate the use of collective resources (e.g., forests, basins, etc.), assure physical security (e.g., making police stations accessible to rural people), and so on.

The state could extend formal social protection schemes to rural areas so that people are protected from idiosyncratic risks (e.g., illness, work injury or old age) and make public services more accessible to rural people. In Nicaragua and El Salvador, the access to social services has improved (appendices 1-A and 1-B, section 2), but the low fiscal revenues constrain the improvement of coverage and service quality. The responsibilities delegated to 
local governments do not have their correlate in actual revenues so that, to different degrees, mayors appeal to nationals living abroad or donors to finance social infrastructure.

More autonomy in turn reduces vulnerability by supporting resilience

An expansion in autonomy supports the resilience of individuals in different ways. First, individuals with higher entitlements have more means to cope with risks. Second, individuals with improved physical and intellectual skills can develop more creative and effective strategies to deal with risks. Third, individuals with emotional skills and strong ties can recover more quickly after a loss in well-being. Besides, their perception of insecurity is lower than that of people who are isolated, excluded, or who do not have family or friends around. Hence, the predictability of relationships provides security (Narayan et al., 2000, p. 151) that would support individuals in groups to develop strategies to pursue their current goals and improve their future well-being. This point is pursued in the next section.

\subsubsection{Vulnerability and collective action}

Collective action can have several motivations (section 11.2.3), ranging from (i) securing mere survival, so that collective action is driven by desperation, to (ii) pursuing valuable goals that expand human development, in cases when basic needs are better fulfilled.

When individuals have a lower than adequate fulfilment of needs (or functionings), the collective action is extrinsically motivated because it is considered a means to achieve certain priority needs with the support of others. In contrast, once these needs are fulfilled to a certain degree, individuals engage in collective action with intrinsic motivation or internalised extrinsic motivation - because they consider it interesting or important (Deci \& Ryan, 2000, p. 230). Acting with extrinsic motivation, in the first case, individuals feel that they have to join the group. Acting with intrinsic motivation, individuals feel that they have the choice to join and they can do so because of their common goals or values. There is a relation between the type of motivation and the causality orientation, but these variables are not perfectly correlated. People can act with both intrinsic and extrinsic motivations and have a self-determined behaviour if the locus of causality is internal (SDT) or the intrinsic motivation remains in the foreground (section 2.2.5).

People close to destitution, with very scarce entitlements, might engage in collective action to maintain client-patron relationships that secure their livelihood (Wood, 2007; Bastiaensen et al., 2005; Platteau, 2004; and others); although they knew that some people would receive a higher proportion of benefits than they would (Abraham \& Platteau, 2004). They take what is on offer and engage in relationships with asymmetrical loyalty, under constrained conditions of choice (Wood, 2007, p. 115-9) motivated by long-term self-interest. For instance, despite their criticisms to formal leaders, Santa María residents followed the call to take over a private land because a free road was considered a necessity (section 6.4.3), but this forced (and illegal) action could have harmed their autonomy in the long run. In circumstances of high interdependence among people in different power positions and structural inequality, Cleaver (2004b) points out that 'the exercise of agency by the poor can only be partial, intermittent and cumulatively ineffectual' (p. 273). Indeed, this strategy was ineffective.

When people depend strongly on social networks, they may want to maintain their reputation of being collaborative in front of power holders (cf., Bardhan, 1993). In such cases, the reward for joining a group would be the protection of leaders. The motivation to cooperate 
would be extrinsic because people have the outcome in sight, which is long-term reciprocity; collective action could mask individual vulnerabilities and power relations. In other cases, people may willingly join collective endeavours because they value the group or identify with it (Thorp, Stewart \& Heyer, 2005), less because they need it. This seems to be the case in Agua Fría. Another possibility is that people, while engaging in collective action driven by necessity, could develop group consciousness (Duncan, 1999, p. 614). This seems to be the case for members of the self-help group in Santa María and some CASA leaders in San Fernando, with both extrinsic and intrinsic motivations.

\section{- $\quad$ The propensity to engage in collective action}

Figure 12-1 graphs the collective action propensity. The horizontal axis represents a set of different balances between extrinsic and intrinsic motivations, which could be linked to survival or development concerns, respectively. The vertical axis plots a scale of perceived vulnerability that includes both the internal (resilience) and the external (exposure to risks) elements. The lines have negative slopes to reflect that the lower the perceived vulnerability, the higher the propensity to engage in collective action with intrinsic motivation. $\mathrm{P}_{\mathrm{i}}(\overline{\mathrm{a}})$ is an individual's collective action propensity for a given level of collective action $(\bar{a})$. Individuals in situations A and B have the same perceived vulnerability ( $\left.\mathrm{v}^{\prime}\right)$ but different combinations of extrinsic and intrinsic motivations. The individual in situation $A$, with propensity $\mathrm{P}_{2}(\overline{\mathrm{a}})$, is more likely to join a group in order to develop potentials. The individual in situation B, with propensity $\mathrm{P}_{1}(\overline{\mathrm{a}})$ is more likely to join to secure entitlements with the support of others.

Figure 12-1: Vulnerability and individual motivations for collective action (conceptual link)

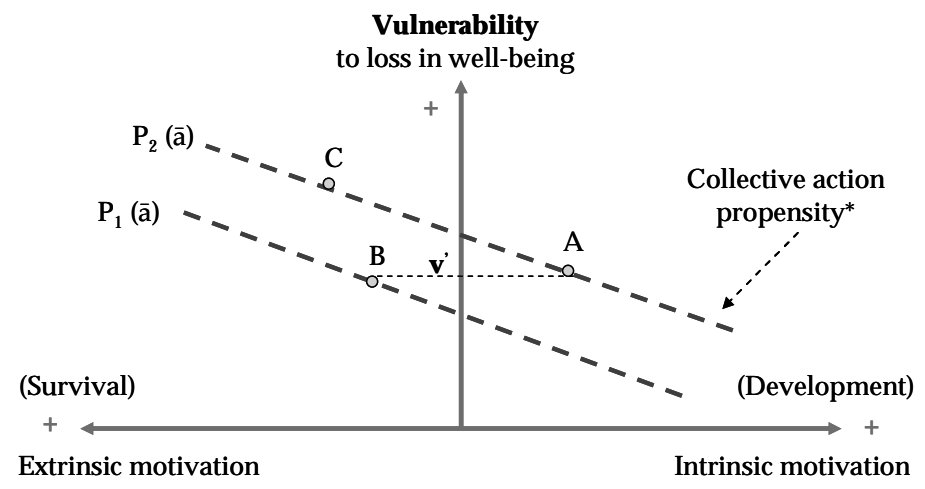

* The line represents those points with equal collective action propensity $P_{i}(\bar{a})$ for individual 'i'; $P_{2}(\bar{a})>P_{1}(\bar{a})$ The collective action propensity is defined for a given preference to cooperate that depends on the internal contexts and processes of agency (including socio-historical agency) of individuals.

The collective action propensity reflects individual preferences, values, and internal contexts of agency that form individual identity. The 'socio-historical agency' (section 11.2.3) is part of these internal contexts and influences values. Comparing the cases of San Fernando and Agua Fría (the least poor communities), individuals in San Fernando could have a propensity $P_{1}(\bar{a})$ in situation $B$, while individuals in Agua Fría could have a propensity $P_{2}(\bar{a})$ higher than $\mathrm{P}_{1}(\overline{\mathrm{a}})$, as being part of a group or association was more valued in Agua Fría than in San Fernando (section 11.2.2). However, individuals within each community are different and so are their propensities. For instance, two woman leaders, members of CASA in San Fernando, had different perspectives about their participation during the project that 
reflect their distinct causality orientations (section 8.5.4). It must be noticed that perceived vulnerability is not perfectly correlated with relative wealth because the exposure to risks depends on the probability of facing risks, which have several sources.

Comparing the cases with the highest communal participation, Agua Fría and Santa María, the ADESCO leaders in Agua Fría could be in situation A. In contrast, the members of the self-help group in Santa María could initially have been in situation $C$ with more extrinsic motivation. However, if they developed group consciousness, their collective action propensity could have risen to a new $\mathrm{P}_{3}(\overline{\mathrm{a}})$ higher than $\mathrm{P}_{2}(\overline{\mathrm{a}})$.

In most cases, the lower the entitlements, the more risk adverse (WB, 2001) and the less willing to engage in collective action individuals are, but personality features determine different propensities within each locality. It is possible that some relatively poor persons (but not those on the edge of deprivation) be willing to risk the few resources and strengths that they have to pursue their goals in groups.

Collective action also has transaction costs (Johnson, 2001). The costs for some leaders in Agua Fría and San Agustín, cases with the best regarded community organisations, were very high. Although most leaders receive remittances, a few subsist from their agriculture work. For example, Mariana is a female leader, widow, in her fifties, whose only daughter had just stopped sending her remittances as result of an undesired pregnancy. Mariana and her 11-year-old grandchild have to live from their farming. She is a very enthusiastic leader, with good interpersonal relations, but Mariana was getting physically very tired of her leadership role because of the time consumed and the other activities that she needed to do.

Leaders in San Agustín have their own difficulties. During the project, the project chief covered the operating costs of CRDM and its president was employed as the project assistant. After the project completion, the local committees that formed CRDM had to finance the high maintenance costs of the community centre, since the municipality government had failed to do so. The former president almost emigrates to look for a job, which could have been a tragedy as CRDM depends a great deal on him. A man leader explains:

There is work ahead, we are willing to do it but it is exhausting.... No one earns anything for being a member [of the board of directors of CRDM]. This is the reason why people do not want to take a position. One neglects the family, the work... We are willing to continue... but it is not easy... We have children and tomorrow they will ask: 'What did you do to change San Agustín?' Other people will say: 'Nothing'. We will proudly say: 'I did this and that. We did not get $100 \%$ of what we wanted but we achieved many things'. We will have - and we already have - the moral solvency to tell this not only to our children but also to everyone who wants to know.

This leader has intrinsic motivation to participate in the committee, despite the costs, because of his children and everyone in his community.

Collective action also implies risks, which depend on the perceived group efficacy, the relative power of opposition groups and the group dynamics. Probably, the emergence of new groups in Santa María took so long, because the power of formal leaders was strong. Likewise, the rise of a new competing association in San Agustín would be difficult because of the risks involved in a still complex political context. 
Certainly, there are more incentives to cooperate when people expect immediate direct benefits, such as the provision of water service. However, collective action requires trust in others, especially in those who are leading the efforts (cf., Lubell et al., 2006), and in their efficacy to achieve goals. In San Fernando, participation in the project was significant only when the construction equipment and materials arrived at the urban centre because, prior to that, most people did not trust the project staff or the recently designed leaders. In addition, the transaction costs of collective action, such as transport and time away from productive activities, are relatively higher for those whose fulfilment of intermediate needs is at risk than for others. This explains that some of the poorest households self-excluded to participate in both water projects, in San Fernando and Agua Fría.

Furthermore, poor people facing adverse environments for a long time will become more and more vulnerable and could develop 'collective pathologies' (Max-Neef, 1991) of frustration or fear, which destroy creativity and generate resentment, apathy and lack of selfesteem. In these conditions, people might not engage in collective action at all because their locus of causality would be impersonal and their vulnerability could be the highest. However, as Hirschman (1984) observes, even the poorest people in those situations, if treated with injustice, could develop 'unsuspected capacities for indignation, resistance and common action' (p. 33).

A key message is that it is necessary to understand why people would or would not engage in collective action (cf., Lyons, Smuts \& Stephens, 2001). Individuals might self-exclude from groups as a way to challenge and confront the power relations embedded in them, that is, their non-participation could reflect an exercise of autonomy (cf., White, 1996). As Kothari (2001/2004) points out, this 'exclusion can be empowering and even necessary in order to challenge existing structures of domination and control' (p. 151).

\section{- Collective action and the reduction of vulnerability}

There are limits to the effect that collective action can have on reducing vulnerability in the case of poor people. First, having scarce entitlements and depending so heavily on their diminished bodily strength (Cleaver, 2005), they may not be able to deliver anything on sufficient scale. This is called 'low value reciprocity' by Wood (2007, p. 122). Second, their capacity to manage risks is constrained by the unequal social structures in which they are embedded. Third, the actors engaged in such action are usually all poor, which means that they face covariant risks (Prowse, 2003).

People without social networks (one kind of poverty) have fewer resources on which to rely so that they can lose everything that they have to cope with hazards. Hence, developing autonomy-supportive relations reduces vulnerability by improving resilience. Likewise, autonomy can be hurt if there is damage in the social relations that support it. Anderson and Honnet (2005) put forward that autonomy depends 'on the establishment of relationships of mutual recognition' (p. 131). This means that not only having relations but also the nature of these relations is important for one's self-respect, self-trust, and self-esteem. This matters when evaluating the impact of collective action on reducing individual vulnerability.

\section{Groups can support resilience under certain conditions}

Bridging social capital that extends beyond close friends or neighbours is useful to cope with risks and get ahead, but linking social capital can make possible that a group recovers 
more quickly after a disaster because it promotes the interests of group members with people of influence (Cleaver, 2005). This is the crucial difference between San Agustín and other cases: the project chief became a 'local' or 'insider' (Crocker, 2004) who facilitated the links of CRDM with other institutions besides the donor. Schneider and Zúniga-Hamlin (2005) finds that 'coalitions between empowered poor actors and middle-class sectors with access to resources, skills and organisations' (p. 568) can be a major success factor for social transformation. This kind of alliance can be more effective to reduce individual vulnerability than unaided individual efforts.

Nevertheless, power based on socioeconomic differences can mean that 'the rich use their leverage to impose on others a solution that meets their own interests' (Abraham \& Platteau, 2004 , p. 225). Elite capture could occur even when need assessment studies of an aid project are carried out. How can these risks be minimised?

Groups will be more effective if they have supporting rules that facilitate their four basic functions: (i) decision-making, (ii) resource mobilisation and management, (iii) communication and coordination, and (iv) conflict resolution (Uphoff, 2005, p. 233). In these localities, CRDM had formal rules in place regarding all these functions, except conflict resolution; minority groups in opposition would most likely withdraw from discussion as reported during the project at times (FUNDASAL, 2003c). Decision-making and management is centralised in ASCA while exclusory and coercive practices characterise communication and coordination (e.g., threats and public accusations). ADESCO has informal group rules set up in relaxed social environments. CASA relies on informal communication and coordination rules within the group.

This short review signals that the internal dynamics of community organisations are important. The stronger the organisation the more likely that it could develop a rigid structure that restricts the opportunities of other members of the community (cf., Uphoff, 2005). This is a latent risk in the San Agustín case. As White (1996) points out,

Even if power relations have been challenged by a successful exercise of participation, there is a danger that new patterns of domination will emerge over time. This is particularly so where the project itself creates new positions, with some people being far more involved than others (p. 11).

Cooperative behaviour within groups is necessary for individual autonomy and empowerment

Like community empowerment (section 2.4.2), group empowerment refers to achieving common objectives and expanding the individual autonomy of group members. They need support to negotiate rules within the group and create the rules, when necessary, that allow the group to perform its four basic functions. In this way, the empowerment of individuals can be promoted and the vulnerability of individuals to damage in community support, reduced.

Empowerment should be born from within individuals (Ellerman, 2006; Friedmann, 1992; White, 1996, and others) and facilitated by social actors and institutions in multilevel structural contexts. Groups can promote critical autonomy by spreading information, training and opportunity (Lyons et al., 2001). As Chambers (2004) points out, leaders could turn power over into power to empower (section 2.4.1) and be 'surprised' when non-leaders change the rules of the game. In these situations, when collective action is effective, the process lived could have a symbolic value, as an 'act of self-affirmation that fills people with 
pride and may even be felt as a beginning of liberation, particularly by long-suffering and long-oppressed groups' (Hirschman, 1984, p. 59, [italics added]).

\subsection{Critical autonomy to promote significant improvement in well-being}

The concept of critical autonomy has been developed by Doyal and Gough (1991). Critical autonomy requires a higher-order capacity to reflect on one's life and cultural rules, a capacity to argue with others and mobilise resources to change rules, if necessary, and a critical awareness of knowing when to act to bring about change or 'when to confront powerful others and when to avoid them' (Rappaport, 1985, cited in Eklund, 1999, p. 42).

Critical autonomy is developed by individuals when they exercise their critical thinking in interactions with others in society. Some individuals are better endowed to achieve change (with more capacities and entitlements) or more motivated because they were exposed to alternative points of view and had access to the rules and knowledge of other cultures, based on which they can assess their own lives. Therefore, formal education has to extend beyond one's local culture to facilitate the discussion of different cultural traditions (Doyal \& Gough, 1991; Gough, 2004). Then, individuals could not only learn about other social realities but also develop curiosity, respect and acceptance for the plurality of traditions and identities (Giri, 2000), which is necessary for living with others. Life experiences can provide opportunities for cultural exchange that formal education generally cannot.

The implementation of an aid project can be an opportunity for fruitful cultural exchanges, for which the micro-level context has to be autonomy- and relationally-supportive so that people are self-confident and regard themselves authoritative to exercise critical thinking. If this is the case, for instance, beneficiaries of aid projects will not disregard valuable aspects of their culture just because outsiders seem more successful in life or tell them 'what is best'. Ideally, they will be able to say 'no' (Mohan, 2001/2004), if the manner how a project is designed and implemented and their foreseen (intended and unintended) effects seem likely to harm their cultural traditions and values (Alkire, 2004).

This section discusses elements that foster critical autonomy, explores the formation of political resources on the basis of relations, and deepens the concept of critical participation with evidence from the localities studied.

\subsubsection{Self-awareness, critical consciousness and intercultural knowledge}

Having an understanding of oneself and awareness of one's position in the social, economic and political structures is a foundational element of agency (section 2.3.1). This awareness requires critical thinking about one's cultural context and how this context shapes one's identity. Critical thinking implies not only analysis but also evaluation, scrutiny and reconstruction of previous judgements; it is a higher-order reflection capacity that goes beyond what is a minimum required for survival. Critical thinking is exercised by responsible citizens (Nussbaum, 2006) that are able to support an ideology, to propose a public policy or to decide on participating in social or political movements.

Self-awareness refers to being conscious of one's values, beliefs, and motivations so that one is able to understand how one is similar or different to others that hold their own traditions and engage in distinct practices and why one behaves in certain ways. Cultural understanding (Doyal \& Gough, 1991) is important for self-awareness because individuals interpret and 
evaluate others' practices influenced by their own cultural norms. Moreover, through engaging with (unequal) others even in their own country (e.g., people from other regions, immigrants), individuals recognise themselves. This process of self-awareness is continuous and, once relevant information is accessible and subject to critical thinking, it can develop into critical consciousness so that people may 'move from a position of unquestioning acceptance of the social order to a critical, and perhaps transformatory [sic], perspective on it' (Kabeer, 1999, p. 9).

\section{- Political culture and critical consciousness}

Political culture is crucial to critical consciousness. Political culture is 'a combination of ideas, feelings, values, information, attitudes and political capabilities that is expressed in the way in which citizens, groups, leaders and communities practice politics, create historical memory and process the political, social, cultural, and economic situations of a country' (Calderón \& Szmukler, 2004, p. 282). It influences the interactions and the negotiation of entitlements in a society because it sets the boundaries for participation, which things and how things can be said, done and pursued. Political culture 'exerts control on distribution' (Douglas, 2004, p. 91). Furthermore, 'collective memories of political action can inspire contemporary forms' (Hickey, 2005, p. 10) of participation.

Nicaragua and El Salvador faced important changes in their political systems as result of opposite views on the social and economic-political national structures, which led to armed conflicts during the 1980s. The consequences of such changes have been different for each country and each of the localities studied as the case chapters have revealed.

Public opinion polls suggest that Nicaraguans value democracy more than Salvadorians (Latinobarómetro, 2004). However, citizens of both countries have an equally negative perception of the state. Nicaraguans seem more willing to join efforts to promote well-being despite the demobilisation process that took place during the 1990s - although the leadership styles at local levels resemble the old patronage tradition. Political and social polarisation is stronger in El Salvador. However, in both countries, as in other Latin American countries, the political culture of inequality persists - either based on origin, gender, wealth, education or access to the market (Calderón \& Szmukler, 2004).

Regarding aid projects, leaders are usually more in contact with project staff and more likely to learn about their cultural traditions. Then, they have a special role in the development of critical consciousness of other community members. Indeed, their own critical consciousness is evident when they understand the larger historical experiences that frame their realities, when they are able to develop linking social capital, when they have a vision of change, when they learn from their mistakes and when they are able to motivate others to formulate and pursue their hopes and needs (Goulet, 1983). Furthermore, when they are conscious of their motivations to effect change or to maintain the status-quo because they have reflected on this, they are exercising critical autonomy. These characteristics are not always present.

Project staff, contracted local professionals or foreign consultants are responsible for communicating with local people with integrity and respect, without 'selling' their traditions as the best or their culture as 'the most developed'. In this way, they will be enriching the cultural understanding of local people, their self-awareness and critical consciousness. 


\section{- Experiences of intercultural knowledge}

The inhabitants of the four project sites have limited access to formal education (around 35\% of the survey respondents are illiterate), but their different life experiences provided them with some elements of other cultures that would enhance their cultural understanding. In the lower extreme, San Fernando residents have lived in a closed environment and most people do not seem to criticise or challenge current norms. In the upper extreme, several Agua Fría residents have travelled abroad or have relatives living abroad with whom they have frequent (phone) contact.

In all cases, an important way people got into in contact with other cultures (besides media) was through aid projects. The inhabitants of Santa María and San Agustín were the most exposed to these contacts given the large number of donors active in the reconstruction efforts and their longer stay. Their personal experiences varied according to the role of leadership and the opportunity to coordinate actions during the projects.

\section{Chances for intercultural knowledge were higher in reconstruction projects}

Santa María residents, with strong political preferences, use different discourses depending on what they think their interlocutor is expecting from them (cf., White, 1996) and the probability of getting certain tangible benefits. They know how to behave with donors. Otherwise, leaders compel them not to deviate.

Some leaders of Santa María travelled abroad and talked with world and national politicians shortly after the Casitas disaster to help the government to raise funds for the reconstruction. The president of ASCA, Pedro, tells about his first experience with foreign donors:

Many NGOs arrived and even the President Clinton came. I welcomed him on behalf of all the survivors and we talked a lot. I was taken to the US Congress to make a presentation to a group so that the aid to Nicaragua through USAID was approved... The consul [of Nicaragua] in Miami offered me a job. He told me: 'I have a restaurant chain and I want to give you a job; you can bring your family'. I replied: 'I need the job... but I want you to understand something: I am here on behalf of the survivors. In this moment, my people trust me to do something for them...' In that moment, I chose. [At my return], I met the municipal authorities and proposed that what we needed most was land to build our houses.

Pedro could have stayed in the US, as other leaders did according to some FGD respondents, but he decided to return home because of his commitment (he had been a communal leader for 20 years) and the hopes that they could get important help. Indeed, his committee was very active at the initial stages of the reconstruction project. However, as seen in Chapter 6 , the intra-community relationships deteriorated over time.

San Agustin residents, who were caught between two fires during the armed conflict, avoid talking of politics. However, leaders express strong views about failures of current political parties and try to look politically neutral. A leader of CRDM declares:

[Before the earthquakes], there was a committee of municipal development. It was created by the former mayor and was committed to a certain political thinking. CRDM is born independently of any political affiliation or religious credo. As the name itself says, reconstruction committee, it is open to everyone with the aim of contributing to the reconstruction and development of the municipality. 
It is leaders who had contact with foreign donors. Moreover, a small group of formal representatives travelled to Luxembourg, whose political structure and economic development they admire. The former president of CRDM, Lucho, says:

I have always had a social-democrat political thinking. I like that society of Luxembourg because it is working under that system. Europe has many governments that promote development under that thinking; they build consensuses.

Day-to-day interactions said more than words for non-leaders

In contrast, non-leaders had more contact with the staff of the three NGOs, all of them urban professionals, than with the project chief. It seems that their pre-judgements about urban people (as more knowledgeable and wealthier) were reinforced to some extent and the feeling of exclusion persists. In contrast to the statements of leaders, the inhabitants of this locality are the least optimistic about their personal capacities, as suggested by the low reported levels of perceived agency (section 11.3.2). Their perception of vulnerability is the highest among all localities, though their living standards are better than those in Santa María.

Some inhabitants of Agua Fría had contacts with people of other communities through field visits during the project. Some men recalled having taught construction techniques to other men in San Agustín, in 2000, when a water project was being carried out there. This initiative may have had some features of a peer-to-peer learning (Ellerman, 2006).

Some women in Agua Fría expressed their satisfaction for having visited other cantons and explained the use of the ecological stoves. However, their expressions suggest that their satisfaction came mainly from teaching and not from learning. They neither elaborated oral comparisons of different lifestyles nor told about valuable knowledge that their peers in such cantons had. In San Fernando, the social promoter was the channel between residents and project staff. Some of her decisions were not fully understood by people, even leaders, but they considered that 'she knew'.

In sum, leaders had more chances to gain intercultural knowledge. Non-leaders with high workload and low involvement in the projects (section 10.4.3) had restricted chances to learn beyond construction techniques. They reinforced their conceptions about external actors:

(i) Successes were mainly related, in people's minds, to the help of a well-meaning donor who designed everything well, but was sometimes unwary; and

(ii) Failures or problems during the projects were attributed to bad implementation by local bureaucrats (discredited water companies), contracted urban professionals (when regarded as not committed to their work) or the state at different levels (when regarded as inept, indolent or corrupt). Community organisations were more valued in Agua Fría and San Agustín and fewer problems attributed to them.

\section{Sensitivity to local culture promotes cultural understanding}

On some occasions, project staffs made efforts to understand the local culture. In San Agustín, the construction of the houses in the human settlements was meant to not disturb the privacy of households used to the rural life, so that, there was a small space between houses, despite the difficulties set by the (relatively small and sloped) land.

In Agua Fría, the executing NGO was national and relatively small, with some experience in the region. They were able to explain the utility of composting dry latrines and overcome a 
possible rejection to handling latrine wastes (human faeces) and using them as fertiliser (LD, 2003a). In San Fernando, the social promoter soon realised that people would not stop using tubs to store the water, instead of using the running water directly from the tap, because they were afraid of sudden water cut-offs. Hence, she taught people how to manipulate the stored water with vessels in order to avoid contaminating it.

In contrast, some professionals related to the Santa María project expressed harsh negative judgements about 'how those people were' and 'how used they were to receive everything because of their Sandinista past'. These generalisations, although explained by the difficult project context, signal stereotypes not useful to interact with others as equals. Martha Nussbaum (2006) points out that, in order to be a democratic citizen (of the world), one needs to develop 'narrative imagination':

The ability to think what it might be like to be in the shoes of a person different from oneself, to be an intelligent reader of that person's story, and to understand the emotions and wishes and desires that someone so placed might have (p. 390-391).

In order to develop critical thinking and imaginative learning, people need to be raised with enjoyable and autonomy supportive significant primary relations (an intermediate need in the THN) and educated in a special way. However, if selected project staff has at least empathy, cultural understanding and true commitment for improving the well-being and autonomy of beneficiaries, the latter will be in better position to learn from project staff things other than construction techniques or organisational practices (valuable as well). ${ }^{105}$

\subsubsection{Turning social resources into political resources}

As seen earlier, resources have meaning by the purpose assigned to them (section 2.3.2). This section presents some evidence on how people used their social resources to make claims, individually or in group. To the extent that those claims meant to challenge institutional or structural power, social resources turned into political resources.

\section{An individual case}

In Santa María, several people complained about mistreatments during the reconstruction project. A woman non-leader, Rosario, recounted that, shortly after the birth of her baby girl, she had difficulties to feed her because of the tight work schedules. She tells:

I was supported by people from Managua, by the female director of the health centre. I did not know what to do. I talked with them and denounced the case... in the media and even the director of [the NGO] came... Because of this, the work was carried out in a normal way: women would get special treatment if they had infants. Then, I would advise other people not to be silent. If they are being abused, they have to speak out (LIW).

Rosario used her connections in the health centre, still active because she had recently given birth to her child, to improve her situation. She learned with this individual action how to use formal legal structures to defend her claims and realised that she could make a difference in the situation of other people. Interestingly, Rosario did not turn to leaders for help

\footnotetext{
${ }^{105}$ It is amazing how much I could learn from the inhabitants of the four project sites in a short time. Admittedly, people in all project sites expressed that they felt more comfortable talking about their lives with me, a Peruvian woman, than with European foreigners that although generous could have preconceived ideas about them. Still, the possibilities for cultural exchange and cross-cultural learning in a two-year project are large.
} 
because they could not help her or they were already discredited. On another occasion, years later, she appealed to the mayor and even denounced in the media the apparent mismanagement of funds by the leaders, related to the issue of house ownership (Imhof, 2003). However, in this matter, Rosario has not been successful (section 6.3.4; Salinas Maldonado, 2008).

A group case

In San Agustín, CRDM built a complex network of relations inside and outside the municipality (public institutions, private NGOs, donors) with the support of the project chief who acted as a catalyst. Leaders learned new skills, personal and organisational; however, their symbolic power was based on their relations with outsiders instead of tangible resources. They 'became "empowered" not in themselves, but through relationships with outsiders' (Mosse, 2005, p. 19). After the project completion, leaders would need to find another partner. Hence, politicians, aware of the growing legitimacy of CRDM leaders, tried to co-opt the committee. The right-wing party offered the support of his party to Lucho (then president of CRDM) so that he could run as candidate for mayor. Even though this party had a political thinking opposite to his own, obvious to anyone in San Agustín, Lucho reflected on this. He justified that he could do it (as long as the CRDM general assembly approves) because they 'needed a municipality government that responds to the committee's vision'. He adds:

What is important here is the [development] process, neither the ideology nor the religion. We have fellows from the left-wing party and they say: 'I will have to close my eyes to vote for that flag'... The truth is that we need to take over the municipality government because it has worked wrongly.

Lucho explained that any party would recognise that CDRM was necessary because it had developed an effective structure. Moreover, there were many legal barriers for the formation of an independent political movement, so that:

Here we have to use the political parties, not the opposite... The local government is to represent the municipality, to protect the communities. Nowadays, the local power is in the hands of the community. I believe we have the capacity [to govern]. We already learned to represent ourselves, to manage and to express our needs. There were NGOs that had to leave because they tried to manipulate us, but could not. We said: 'Any NGO that wants to work with us has to do zero political campaigning'.

Lucho felt that, in order to progress, they needed to hold formal institutional power in addition to their symbolic power. For that power, they were willing to disregard their previous political commitments that had been so deeply rooted in their lives and caused armed conflicts. However, if successful, the power structures would have changed significantly: a committee composed by former combatants and cooperative agricultural leaders would have institutional power for the first time and displace traditional politicians.

It seems that the particular group dynamics during the project execution influenced a perception that CRDM was invulnerable to political pressure (see Cooke, 2001/2004), but such alliance was not necessary. Finally, Lucho did not run for mayor and the municipality elections of March 2006 were won by the left-wing party. Shortly, he was working in the municipality government as advisor of the mayor; he regained the presidency of CRDM. 
The CRDM leaders were able to reject the help from some NGOs with an agenda different from theirs. This is a signal of critical autonomy and group consciousness - besides, there were many offers from donors. In contrast, several years after the Casitas mudslide, leaders in Santa María, with power over non-leaders, were weak with respect to donors who could impose their goals. A woman non-leader in Santa María says about another project:

Who brings the funds is the one who gives opinions and decides what is going to be done. The guy [project coordinator] did everything that they wanted [the donors]. We were not aware. They do not allow one to decide, to develop one's own ideas. They say 'everything is already planned, framed. We know how we are going to prepare and do it here' (HIW).

This perception could be not exact, as non-leaders faced acute informational constrains (section 6.5.4). However, if it was accurate, it would signal the lack of options of people (since most donors left some time ago) and their interest to build relations with still willing donors to ask for help in crises. A patron-client relation emerged between the donors and the leaders, which reflects a reversed accountability from recipients of help to helpers (Mosse, 2005; Sogge, 2002).

Lucho's reflections reveal that he has developed critical autonomy and is aware of his own position and his group's position in society. Moreover, he seems to endorse the view that linkages between social and political movements are necessary, if people want to gain influence on policy formation processes in their structural contexts and with the actual power relations (Hickey, 2005; Friedmann, 1992). Leaders first would turn to political authorities to gain influence. If it failed, they would act politically by themselves; and, if that was not possible, they would need powerful partners (as the project chief was in San Agustín).

\subsubsection{Enhancing critical autonomy for critical participation}

Critical participation is a higher-order level of participation for which individuals and groups have developed critical consciousness and, hence, they behave with authentic motivation in matters that influence their lives and that of others in society in significant ways. Ideally, they do this with responsibility and recognising that others have needs equally valuable to theirs (i.e., they act in solidarity). As Giri (2000) points out, human development should be a responsibility and an 'object of both personal and social commitment' (p. 1004).

Most likely, critical participation is pursued in groups and by people who have satisfied or realised their potentials to an adequate level, that is, beyond a certain threshold. However, there are exceptional cases. Rosa, the brave woman in Santa María who lost her whole family during the mudslide, is a founding member of the self-help group (section 11.1.2). She participates with intrinsic motivation because it is important for the well-being of her community (the group promotes small income-generating activities), she enjoys being part of a group and she feels the commitment to teach with her example that 'life is always worthy to be lived'.

Critical participation cannot be assessed by looking at the number of public protests or membership associations. What qualifies critical participation is why people engage in those protests or groups. For instance, an individual sending letters to a minister, signing a constitutional reform proposal, or attending a school parents' meeting might be participating critically if he or she does that after having analysed relevant information and aiming at a positive change in his or her life and the lives of others. In this sense, it is unlikely that the 
seizure of a piece of land in Santa María was a sign of critical participation of non-leaders as they did not have access to relevant information to process and were driven by necessity.

This section discusses how participants could have learned or developed certain capacities to critical autonomy through their participation in the projects, and investigates how the structural contexts can support the critical participation of individuals.

\section{- Mutual learning toward critical autonomy during the projects}

Participation can enhance certain abilities that are crucial for critical autonomy. These are interpersonal, social, and political skills (Israel et al., 1994, cited in Eklund, 1999, p. 44) that can be used by individuals when they face crucial decisions, individually or in group. These are transferable skills learnt through collective action (Friedmann, 1992; Lyons et al., 2001; Osti, 2004) and have a positive influence on the resilience of people: they could organise themselves to better manage risks and recover from their manifestations (section 12.1.1).

The more these skills are enhanced, the less people will rely on external change agents and the more effectively they will negotiate (with government authorities, bureaucrats and donors) the goals and conditions of aid projects, based on their reflection on economic, political and cultural choices (Carmen, 1996, p. 87). During the projects, leaders had the chance to learn (or to revitalise) and to practice (or to learn by doing), to different extents, several transferable skills such as negotiation, conflict resolution and networking that were necessary for the project activities and are crucial to engage in active citizenship.

\section{Leaders learned from experience}

Leaders in Agua Fría received training on legal, administrative and organisational aspects related to the objective of forming a NGO, which was not approved by the mayor. This negative experience endured, more than the workshops, and taught them about the need to work with the formal institutions, not against or despite them (cf., Mosse, 2005, p. 111).

The emphasis on that type of training was lower in San Fernando. Leaders learned more from their personal relation with the social promoter than from courses. Indeed, knowledge is relational (Mosse, 2005, p. 79). Leaders learned to speak in public, to organise people, and to represent their locality in formal meetings. This was a great achievement, especially for women, who prior to the project, had lived almost entirely focused on their families. The vice-president of CASA, Liliana, recalls what happened in a very important meeting:

The mayor was invited, but he could not attend [the meeting] and he sent his representative, the deputy mayor.... He told me: 'I do not know anything about this'. I said: 'Do not worry, we, Juan and me, will cover you'. Then, we spoke. Whenever, they would ask us something, we answered. All the other mayors were there. Suddenly, one of them asked me: 'Mrs. Liliana, could you please tell us, how was the participation of the mayor?' I just said: 'Neither good nor bad because every time we invited him, he would send us a representative'.

As a result of the low involvement of the local government in the project execution, the CASA leaders were regarded as 'the representatives' of the community. This explains that some of them accepted the offer of the new mayor to participate in the new municipal committee.

The ASCA leaders in Santa María learned many things since the disaster because they directly managed several projects. They have successfully applied for funding from several 
donors and kept a close relationship with one foreign donor. There is a large gap between their skills and those of the leaders of the communal committee (CDC).

An 'action learning space' in San Agustín

The San Agustín case is special for three reasons. First, a local NGO worked in the municipality from 1999 to 2004 and developed a function of 'social intermediation' (Bennett et al., 1996, cited in Thorp et al., 2005, p. 912). It encouraged positive self-conceptions among residents (cf., Johnson, 2001) that motivated the formation of CRDM in 2001, and continued its advocacy work after the reconstruction was completed. Second, the inhabitants elaborated a participatory development plan. Third, this NGO also supported the creation of an intermunicipal sub-basin management committee. It mentored each of these municipalities by promoting deliberative participation and familiarising local people with state institutions.

FUNDAMUNI supported the continuous development of leaders' skills (e.g., courses on organisation and law), guided and monitored the process of the municipal development plan, facilitated the links between CRDM and the local government, joined the working group of the project at times and participated in the general assembly of CRDM as a nonvoting member.

On the other hand, the working group (main decision-maker) can be regarded as an 'action learning space' (Johnson, 2007, p. 282) for the mutual engagement, joint enterprise (common objective) and shared repertoire of members. First, learning was embedded in the organisational processes and the practice of weekly meetings was institutionalised. Second, other actors were invited to participate depending on the topic (e.g., religious, educative and health authorities) but their role was not considered legitimate for discussing the core issues (e.g., infrastructural decisions) and the group was not accountable to them. Third, the employees of the executing entities that worked in the project were committed to the project success, although they had different understandings of the project goals.

Non-leaders were taught, did not create knowledge

In some cases, non-leaders developed certain skills related to project activities such as bookkeeping, minute-taking and public speaking. If so, they enhanced their self-confidence and capacity to exercise voice (especially for women in water projects). However, only in the San Agustín case did the project intend to foster political literacy and the capacity to aspire of non-leaders (Hickey, 2005). The motto 'San Agustín for San Agustín' reflected the commitment of people, although not equally shared. However, a human rights course addressed to leaders and staff of the local government was interrupted due to political tension during the electoral process in 2003, and the targeting of leadership workshops was ineffective.

Nonetheless, it is not which courses are offered but how courses are offered that influences on critical skills (cf., Mosse, 2005, p. 79). For instance, some young women in San Fernando were able to list many educational activities during the project and to repeat almost exactly what they were taught during the project workshops; however, few really expressed that they were practicing those things. They did not internalise that knowledge. As Carmen (1996) points out, the creation of knowledge requires reflection and action. In these cases, knowledge was transmitted (and lost in some cases), not jointly created.

The situation was worse in Agua Fría: several leaders could not even recall the transmitted knowledge despite the fact that they had been like social promoters themselves. In Santa 
María, non-leaders did not recall having received any training or having had individual responsibilities in their construction work groups more than being assistants. Learning specific skills was a decision made by a few men while interacting with construction workers. In any case, creative knowledge could have been restricted by autonomy-controlling practices.

In this way, not much changed for non-leaders in terms of critical autonomy. Furthermore, they have not developed the capacity to watch over their leaders, in any of the localities studied. Next, some aspects about the role of multilevel structural contexts are analysed.

\section{- The role of the state in promoting critical participation}

In which ways can critical participation be promoted and sustained? In situations with economic and social unbalances and a political culture of inequality, the chances to cultivate critical autonomy among the poor are low because 'they are excluded not only economically, but also politically and socially. This limits their ability to exert pressure and to participate in political dialogues, and thus reinforces a cycle of inequality, lack of citizenship, and poverty' (Calderón \& Szmukler, 2004, p. 290).

Poor people need allies to help them in a process of gaining spaces to participate in those spheres. As Drèze and Sen (2002) point out 'the sharing of political power need not to be postponed until economic power is widely generated and equitable shared' (p. 9) especially because the poorest have low entitlements to bargain a better distribution of the economic progress. This is clear in Nicaragua and El Salvador: poor farmers are more and more excluded from the market-oriented policies and many have emigrated.

Policy makers can promote the critical participation of citizens by securing political freedoms, economic and social opportunities, transparency guarantees and protective security (Sen, 1999); implementing inclusive and progressive education and other social policies; and fostering the emergence of committed groups. At the same time, they should develop more transparent practices that make the state responsive to its citizens, at different levels.

Precisely, the main ally of poor people can be the state (Hickey, 2005) to overcome the control that economic or political elites exercise over the poorest in local contexts (Thorp et al., 2005; Abraham \& Platteau, 2004; Drèze \& Sen, 2002). Nonetheless, the inhabitants of the four localities have a negative perception of the state. They rely on themselves, on their physical strength and abilities, on client-patron practices, on family remittances (not many), or on generous donors.

In exceptional cases, an individual can make a difference in the lives of others for a shortterm (e.g., Rosario, the young mother in Santa María) but there is no certainty that the gains will be sustained. Some people engage in membership associations to defend their rights and formulate and claim others (Hickey \& Mohan, 2005). However, none of the community organisations is in position to make their claims a reality. Therefore, in order to promote human development, external agents (such as aid agencies) should focus on local organisations and on the state because empowerment takes place within the state structures (cf., Mohan, 2001/2004).

\section{- Groups and critical participation}

If not engaging in political action, how could membership social organisations change the rules of the game? Heyer et al. (2002, cited in Stewart, 2005, p. 189) classify groups in three 
types: efficiency groups, claim groups, and pro bono groups. The first groups aim to overcome market failures, the second aim to increase crucial entitlements of their members, and the third aim to provide benefits for more disadvantaged groups. Claim groups have the potential to transform the socio-structural contexts and so have efficiency groups because they improve the economic position of their members and, consequently, their entitlements and relational power.

Producer associations, credit groups, and management committees of common resources are examples of efficiency groups (Stewart, 2005). In the localities studied, only in Santa María were there a self-help group and a farmers' group supported by a church. A few had some backyard animals remaining from several projects, but were not collectively organised; these income-generating activities would not make a difference for the well-being of the majority. In Agua Fría, as seen earlier, the small project to raise tilapias in the reservoir failed.

None of the community organisations has been able to promote productive activities steadily. If they had secured some income-generating activities for their members, they could have not only supported their members' well-being but also ensured their sustainability as a group (Stewart, 2005). The projects studied did not promote sustainable productive activities (due to design or failure) even though people had on several occasions expressed that these were their main concern. Hence, these organisations were 'functional' for the implementation of the projects. Their long-term sustainability after the projects were completed is far from achieved (see Riddell et al., 1995, p. 71). This situation restricts the possibilities of the community organisations to advance as claim groups or even pro bono groups in defence of the poorest of each village.

How could groups promote the critical autonomy of their members? Community organisations could offer a space for public deliberation and mutual learning, in which every member is treated fairly and shares in the decision-making process. This requires a non-repressive solidarity among the members based on rational and spiritual grounds (Giri, 2000, p. 10145), which is result of critical thinking about one's situation in the social environment.

\section{- Democratic decentralisation and critical participation}

Decentralisation can support democracy and autonomy because it devolves the decisionmaking power and resources to the local governments, closer to local people and institutions. It can promote public deliberation and dialogue about the local needs and the strategies that would better address these needs. The governments of Nicaragua and El Salvador have delegated more responsibilities to the local governments and participation has been institutionalised through local open forums and participatory planning and budgeting.

\section{Critical participation when participation is institutionalised}

Democratic functioning is enhanced when local participation results from the authentic motivation of social actors and they can have some influence on decisions that affect their opportunities (Drydyk, 2006). In both countries, by law, each municipality must have a development committee integrated by representatives of each canton. This means that even the formation of CRDM was externally required - but the earthquakes accelerated the process. In Nicaragua, during 2004, the transfers from the central to local governments were conditioned to the existence of participatory annual and multi-annual plans (Appendix 1-A). This partly explains the urgency of the new mayor to integrate the CASA leaders in a new com- 
munal committee and to work with them in the definition of investment priorities. ADESCO in Agua Fría sends its representatives to the municipal committee but, until 2005, not one investment project had been financed by the local government in the canton. In Santa María, members of the community council sit in the municipal committee of Posoltega, also without tangible benefits or influencing decision-making at the municipal level.

For decentralisation to be effective requires that local elites do not co-opt the decisionmaking process to impose their own interests and that accountability is enhanced. The composition of participant groups could mirror the power unbalances in the locality and legitimise them. Hence, the role of organised groups to negotiate a space in institutional arrangements and demand better performance from the local government is crucial (Thorp et al., 2005). These groups may build alliances through multi-scaled strategies and networks (Hickey \& Mohan, 2005). These alliances can include the local government (cf., Schneider, 1999), that could have greater credibility than the central government and other public institutions (Calderón \& Szmukler, 2004). This could be the case for San Fernando (with the new mayor) and Santa María (with a mayor personally related to leaders).

However, local authorities might be neither accountable nor interested in listening to citizens' proposals and might thus be part of an economic elite group keeping the political power through opportunistic electoral strategies. As Andersson and Laerhoven (2006) assert, 'local strongmen cannot be expected to become facilitators of participatory decision making overnight' (p. 3). In the eyes of Agua Fría residents, the mayor behaves as a strongman.

Only in San Agustín was there broad-based participatory planning. Moreover, the project aimed at reducing the financial vulnerability of the local government; so as a first step, a diagnosis of its financial situation was elaborated. Although the activities did not occur as planned, at least the CRDM leaders knew about the actual financial constraints and needs. Besides, during the reconstruction period, the municipal government was relatively permissive to every initiative led by CRDM, but also weaker in terms of resources and relations. This situation could have favoured the empowerment of CRDM because there was no opposition (Birner \& Wittmer, 2000). In fact, a committee of this type could mature politically, if it focuses on strategies that would not raise opposition from formal power (Florisbelo \& Guijt, 2001/2004), as happened in this case.

\section{Critical participation when public institutions are not accountable}

The provision of water service illustrates the need for organisational reform combined with collective action that rests on critical participation.

Agua Fría residents regarded themselves as water suppliers (section 10.5.2); they could form a water users' association that could work with the water company and share in decisions related to the repairs of the water infrastructure, the control of consumption levels, and the maintenance of sanitation infrastructure by part of the households. In this way, they would compensate for the inefficiency of the provider to make the water service more sustainable and effective to promote autonomy. They could 'make and create' instead of simply 'consume' the services they receive (Lister, 1998, cited in Cornwall \& Gaventa, 2001, p. 6).

In San Fernando, the main problem was the high water tariffs. Consumers cannot negotiate the price, they can only argue about inaccuracies in consumption recording. Besides the 
problem in the definition of the subsidy (section 10.5.2), the main point is that there is only one provider and people cannot withdraw the relation (or exit) even if they consider it abusive. This situation could reflect two problems: (i) the lack of a strong regulator or (ii) the low access of people to formal institutions (e.g., the institute for consumer defence). If the CASA members or the municipal staff took the responsibility to negotiate the solution of the most common claims with the water company, they would still need to learn more about the project, the cost structure, and the water company, among other issues. Most probably, a NGO could sponsor the process in order to countervail the bargaining power of the water company, as the project staff could do.

During the fieldwork, both water companies were not accountable to people. Only maintenance operators or sales representatives were physically in the localities or nearby areas; they could not give any prompt solution to claims. Hence, time and financial resources would be necessary to present claims, to request physical inspections and to follow up the bureaucratic procedures. Low access to entitlements silences voice. Again, vulnerability restrains participation, even authentically-motivated participation that would enhance wellbeing and that would in turn reduce vulnerability. Institutional change is required and, at the same time, the actions of self-mobilised groups in selected topics and combining multiple strategies to enrol other actors and promote change when the conditions improve.

\subsection{Conclusions}

This chapter has analysed two topics that are crucial to individual autonomy: vulnerability and critical autonomy. Vulnerability is a constant in the lives of people of the four localities visited. The analysis of people's experiences of vulnerability (or experiences of individual autonomy) re-affirms the notion that people use social relations to improve their situation although with different motivations. Hence, collective action has been examined further. This chapter has also discussed some elements of critical autonomy and its manifestation: critical participation. The main ideas follow:

1. Vulnerability is a state of insecurity related to the low capacity of individuals to face risks without damaging loss in present and future well-being. An individual is vulnerable to loss in well-being from several risks. The vulnerability that matters is not only vulnerability to monetary poverty and not only vulnerability from natural disasters or economic crises. Vulnerability, like well-being, is multi-dimensional.

2. Resilience is the internal element of the concept of vulnerability; it refers to the capacity to manage risks and recover without damaging loss in well-being. It is directly related to autonomy. First, expansions in autonomy can support resilience through three channels: (i) individuals with more entitlements can have more means to develop management risks strategies, (ii) individuals with improved physical and intellectual skills can develop more creative and effective strategies, (iii) individuals in better emotional situation and with strong ties can recover more quickly after a risk is manifested. Second, empowerment increases resilience because the undertaken strategies are more effective in protecting well-being.

3. Poor people engage in collective action to promote their goals. However, there are limits to its effect on reducing vulnerability: low value reciprocity, unequal social structures, and covariant risks (section 12.1.2). On the other hand, if collective action dam- 
aged intra-group relations, individuals could lose the support of social relations and be more vulnerable; while, if there were power inequalities within the group, outputs could favour some more than others. Hence, individuals should negotiate or create the rules that facilitate decision-making, resource mobilisation and management, communication and coordination, and conflict resolution within community associations or selfhelp groups. External social actors can ease these processes (as in San Agustín), to be started and carried out by individuals themselves.

4. People use their social relations to make claims, individually or in group. To the extent that those claims are meant to challenge (or reproduce) institutional or structural power, social resources turn into political resources (section 12.2.2). Through the exercise of autonomy, people learn how to use institutions and how to (and whether they can) overcome their own limitations enrolling other people in their endeavours.

5. Individuals engage in critical participation when they develop their critical consciousness and behave with authentic motivation in matters that influence their lives and those of others in society in significant ways (section 12.2.3). In this process, they can realise their human potentials, enhance their self-confidence, creativity, and aspirations. The reasons for such actions qualify whether participation is critical or not.

6. Critical participation can enhance crucial transferable skills (interpersonal, social, and political skills) that have a positive influence on the resilience of people. Hence, they will negotiate the goals and conditions of an aid project, policy proposals and so on, in better terms of recognition. Critical autonomy is improved when exercised, so that, social intermediaries can foster those skills throughout a 'change' process and continue as mentors after the change has taken place.

7. In many cases, this kind of actions will receive attention from existing groups who will enact overt or covert strategies to undermine the influence of emerging groups. The Agua Fría case is an example. Then, the safest strategies for these groups would be: to build relations with other powerful actors, although with client-patron features in some cases; to focus on issues without so much opposition, waiting for better political circumstances; or to build multi-scaled strategies and networks.

8. Decentralisation can support democracy and autonomy if it devolves the decisionmaking power and resources to the local government closer to local people and institutions. It can promote public deliberation. However, in many cases, existing participatory arrangements are not enough to secure options for critical participation. Local elites could co-opt the process. Then, the action of community associations in alliance with other civil society organisations is crucial to demand responsiveness from the state and public institutions within the existing economic, political and social structures. 


\section{Conclusions}

The study describes and analyses the experiences of individual autonomy of the inhabitants of four localities of Nicaragua and El Salvador. It assesses the effects of infrastructure projects, carried out in those localities, on the autonomy of their inhabitants. Based on the findings from the within- and cross-case analysis, the study:

- Develops a conceptual model of individual autonomy;

- Proposes a framework to evaluate the impacts of projects on individual autonomy; and

- Uses and tests that framework in examination of the four projects.

Table 13-1 shows basic data of the projects studied. The projects had some common features: (i) every project included a self-construction component, that is, households had to build their own houses or small sanitation infrastructure, and (ii) the community organisations participated in the projects to different extents.

Table 13-1: Coordinates of the case studies

\begin{tabular}{|c|c|c|c|}
\hline & & \multicolumn{2}{|c|}{ Country } \\
\hline & & Nicaragua & El Salvador \\
\hline \multirow{2}{*}{ Sector } & Reconstruction & $\begin{array}{c}\text { Santa María } \\
\text { (tragedy caused by a mudslide) } \\
05 / 1999-10 / 2001\end{array}$ & $\begin{array}{c}\text { San Agustín } \\
\text { (disaster caused by earthquakes) } \\
10 / 2001-03 / 2005\end{array}$ \\
\hline & Water & $\begin{array}{c}\text { San Fernando } \\
\text { (deficit caused by Hurricane Mitch) } \\
09 / 2002-01 / 2005\end{array}$ & $\begin{array}{c}\text { Agua Fría } \\
\text { (structural deficit) } \\
10 / 2001-01 / 2004\end{array}$ \\
\hline
\end{tabular}

Reasons for the need of aid appear between parentheses.

The dates correspond to the execution periods in each project site.

Source: Table 1-1.

On the other hand, there were differences, even between projects in the same sector. The reconstruction projects responded to different needs. In Santa María, people faced a human tragedy that caused many deaths. In San Agustín, people only had material losses, so they were better able to work in the project. The water projects also differed in terms of the needs addressed and the potential impacts. People had previously accessed potable water in San Fernando, while it was the first time that all residents in Agua Fría could access it.

Regarding the execution, Santa María was the only project managed by a contracted NGO that was also responsible for other projects in the same site. Inter-institutional coordination and accountability were poor. In contrast, San Agustín counted on a committed project chief who physically stayed in the town and set up a partnership relation with the community association. There was local ownership since the formulation stage. Regarding the water projects, Agua Fría had very ambitious goals aiming at offering a comprehensive solution, but project staff faced institutional problems at the national and local level. In contrast, San Fernando had an exclusive sectoral focus and committees were formed to facilitate the achievement of project goals. 
In fact, the cases have unique characteristics in terms of location, institutional contexts and community dynamics, which make this study richer and more useful to understand different experiences of autonomy in processes of change, such as an aid project.

The research is designed as a collective case study, which included two study visits to the project sites in 2005. Data used in this study include project documents, public national reports, external statistics, stakeholders' interviews, focus group discussions (FGDs) and a questionnaire survey. More than 300 people were contacted during the fieldwork. The choice of mixed methods matches the conception of autonomy proposed that contains objective and subjective elements. The research approach is flexible to adapt the methods to the four cases, employing interpretive lenses.

This chapter presents the main aspects of the conceptual framework (section 13.1) and the analytical framework (section 13.2). It then summarises findings for the five specific research questions explored during the fieldwork (section 13.3). Some implications for policy design, development aid practice and development research are drawn (section 13.4).

\subsection{A conceptual model of individual autonomy}

Autonomy is intrinsically valuable for well-being and instrumentally valuable to promote human development. First, people value helping themselves in significant aspects of their lives and they do exercise autonomy, to different extents, even under constrained circumstances. Second, the more autonomous people are better able to choose the life they want to lead and to take action to achieve it with authentic motivation; they are more likely to expand the potentials or capabilities that they most value (Sen, 1985a; 1993, 1999, etc.).

There are two levels of autonomy: a basic and a critical level (section 2.3.3). Almost all human beings can have basic autonomy if they have adequate achievements in their capabilities so that they are healthy and well-educated, they feel physically, emotionally and economically secure, they engage in significant social relations, and so on.

Critical autonomy, a higher-order level of autonomy, develops when individuals exercise their critical thinking in interaction with others in society. Self-awareness and cultural understanding support critical autonomy because individuals with these capacities are better able to make judgements about their lives and their culture and to decide whether social change is necessary. Critical autonomy requires that instrumental freedoms - political freedoms, economic and social opportunities, transparency guarantees, and protective security (Sen, 1999) - are secured, that individuals have access to intercultural knowledge and that core capabilities are realised to an optimum level so that individuals can focus on their most valuable goals. Self-confidence and critical consciousness (section 12.2.1), developed in social relations, help people to initiate a transformative action.

Furthermore, critical autonomy is promoted by opening up spaces for public deliberation and mutual learning, in which individuals with unequal (social, economic and political) power can express their voice and influence decisions that affect their lives. This is the biggest challenge of democratic societies: to go beyond formal practices (e.g., general elections) and to promote critical participation and citizenship that can transform structural contexts.

The study proposes a model of autonomy for individuals in relations, because individuals experience autonomy (or not) in the context of their interactions with others. These interac- 
tions influence the formation of values, the internalisation of norms and practices and the development of capacities (physical, intellectual and emotional) necessary to have agency.

Autonomy is a combined capability (Nussbaum, 2000) because it depends on: (i) an internal element, which corresponds to agency or the capacity to make reasoned choices and act accordingly, and (ii) an external element, the environment (or the multilevel structural contexts) that provides or restricts opportunities for the exercise of autonomy.

At a conceptual level, autonomy is qualified effective agency. It is effective because individuals can take action to advance their goals, if they so decide, given that the influence of contexts is already taken into account - this is the idea of capability as possible reachable outcomes. It is qualified because autonomy concerns decisions on significant aspects of life, decisions which cohere with one's own values and personality and for which one is authentically motivated.

At a practical level, autonomy is analysed in terms of three determinants: agency, multilevel structural contexts and entitlements, which are to be studied individually and in interaction. Entitlements are negotiated in multilevel structural contexts and their meaning is given by the use that individuals make of resources, which is culturally influenced (section 2.3).

Autonomy is an individual feature, which implies inner endorsement. However, it is possible that people willingly lend priority to a group (e.g., family, neighbourhood committee, country, etc.) or that they commit themselves to a political or religious cause with which they identify so that their later actions are constrained for such engagement. They would have a feeling of being autonomous, unless external conditions are so controlling or restrictive that their locus of causality changes from internal to external. On the other hand, autonomy does not always imply action. Not acting can be result of a free choice made by individuals in rejection of external factors that could result in conditioned action.

Studying agency requires looking at objective and subjective factors. Objective factors related to competence (physical, intellectual and emotional capacities) and access to resources are commonly used; however, it is perceived agency that most influences individual behaviour. The internal processes of agency (temporal orientation and causality orientation) make a difference in regard to aspirations and intrinsic motivation that are necessary to promote, sustain and defend well-being by one's own efforts. They depend on personality and cultural context, but are influenced by the multilevel structural contexts and by events such as projects that are important to individuals.

\subsection{Aid projects and the expansion of individual autonomy}

The study's analytical framework examines whether projects have a positive influence on individual autonomy. This evaluation criterion called human autonomy effectiveness (section 3.3.1) goes beyond project outputs (and operational effectiveness) to focus on changes in people's lives. Individual autonomy can be promoted through (i) an improvement in the determinants of individual autonomy, (ii) the exercise of autonomy during the project cycle, or (iii) the achievement of goals for which participants became involved in the project.

This framework has a crucial difference with traditional evaluation methods: the focus is on individuals as agents of change, not on projects designed to produce change or even on change in people's behaviours. Then, it is necessary to identify the priority goals of individuals, 
their initial situation of individual autonomy, their involvement in meaningful or valuable processes during the project and the project outcomes in regard to such goals and previous situation. This entails three important consequences:

i) The intermediate elements to be monitored are not only project activities and processes but also practices (forms of interaction and practical strategies) and relations. Practices can have important unintended effects and can be classified into four types: selection and design, conditionality, coordination, and accountability (see chapters 6 to 9).

ii) While processes are more or less defined in project documents, practices are in continuous definition over time. They are better understood by looking at project contexts and inputs such as resources, quality and composition of the management, commitment of staff and technical soundness. These factors also explain the achievement of project outputs.

iii) Changes in the determinants of individual autonomy can be the result of the projects, the multilevel structural contexts or the goal-oriented action of intended beneficiaries in interaction with others. These interactions affect practices, change and the processes of change.

Looking at the changes in the determinants of autonomy, this study proposes an assessment matrix (section 4.3.1) to examine the project effects and their possible causes. This matrix identifies the expected effects of projects, based on their full logic (as partially explicit in the logical framework and project documents and implicit in practices and crucial processes), and their actual effects. Judgements behind this assessment, such as whether the assumptions held, the expected conditions (planned processes and intended material outputs) were achieved or new factors intervened, have to be explicit.

Looking at the exercise of autonomy, this study explored the level of involvement in the project or high-quality participation of aid recipients through an 'involvement index' (section 4.2.1). This index captures the extent to which (i) participants had access to relevant information, (ii) the context supported their self-confidence and their perceived agency (whether participants gave opinions and felt that they had applied their own skills) and (iii) they had opportunities and actually exercised decision-making. Conceptually, involvement is more than working hard only. The cases suggest that although all beneficiaries worked in self-construction activities, in general, the level of involvement was low among non-leaders.

\section{- A normative analytical framework}

This framework gives a central role to the explicit identification of goals and values. These must be revised over the project cycle because projects may influence the expectations, values and goals of local people as result of their interaction with other actors (value endogeneity). Awareness of this unintended influence by project formulators, implementers and evaluators is necessary so that they develop their understanding of local cultures and needs. Moreover, individual motivations for certain behaviours, including participation in projects, must be explored. All these aspects are more visible in the field so that a combination of data collection and analysis methods was used (Chapter 4).

The four cases indicate that people want to be involved in valuable processes, important to them, either directly or through leaders depending on their cultural features. Moreover, the higher the involvement, the lower the weight that people give to external causes of success or failure in achieving goals. In the case of complex projects, it is necessary to identify priority processes and to define needs for training or supervision with local people so that they can be better involved, taking into account their latent and current capacities. 


\section{- Involvement in the project and feeling autonomous}

The effects of projects on the feeling of individual autonomy vary across individuals depending on their degree of individual involvement in valued project processes and the achievement of the goals related to such processes (Table 13-2).

Table 13-2: Looking at values and goals to assess empowerment (possible cases)

\begin{tabular}{|l|l|l|}
\cline { 2 - 3 } \multicolumn{1}{c|}{} & Valued processes & Non-valued processes \\
\hline Goals are achieved & $\begin{array}{l}\text { Empowerment } \\
\text { (objective and subjective) }\end{array}$ & $\begin{array}{l}\text { Awareness of positive effects. } \\
\text { May lead to empowerment. }\end{array}$ \\
\hline Goals are not achieved & $\begin{array}{l}\text { Negative effect on autonomy } \\
\text { causality orientation. }\end{array}$ & $\begin{array}{l}\text { Lower but still negative effect on } \\
\text { autonomy causality orientation. }\end{array}$ \\
\hline
\end{tabular}

Source: Section 10.6.

When project participants take part in valued processes:

a. If they were successful in reaching goals, they can be empowered in objective and subjective terms; or

b. If they failed, they can feel strongly harmed in their autonomy causality orientation because they committed themselves to a failed initiative.

In contrast, when project participants take part in non-valued processes:

c. If the project was successful to reach that goal, they first would gain awareness of unexpected positive effects. If their values changed, they could feel empowered.

d. If the project failed, they could be (only) mildly harmed in subjective terms because they could reason that, as they knew in advance, the effort was not important in the first place.

Project participants have to be involved in examining the project effects, during the project life cycle, so that their goals and values are better integrated. In this way, they could engage with intrinsic motivation in crucial processes and the intended effects, if achieved, would be more valued and sustained.

\subsection{Findings for the five research questions}

This section reviews the five research questions introduced in Chapter 1, investigated in the empirical part of this dissertation.

\section{How important do local people think that individual autonomy is for development? ${ }^{106}$}

First, the inhabitants of the localities studied highlighted the intrinsic value of autonomy. They expressed concerns regarding their lifestyles, with a great deal of uncertainty (e.g., in the dry season) and inadequate fulfilment of intermediate needs. Many respondents had evident material lacks as they are income-poor and this adds to a feeling of vulnerability related to low resilience or constrained autonomy (section 12.1.1), which means that they cannot live as they value, that is, as farmers.

\footnotetext{
106 This is a sub-question of the first research question: How important is individual autonomy for promoting human development? Conceptually, this question was answered in Chapter 2 (see section 13.1). In the empirical part, the inhabitants of the four localities expressed their conceptions of life and community. Some of them, directly or indirectly, referred to autonomy.
} 
Autonomy was associated to self-reliance as the condition of having the means to live well (e.g., a job, a piece of land, or agricultural credit) and also to relations. Entitlements to material resources are necessary for a minimum experience of well-being. Depending on cultural features, participants gave more weight to self-reliance (e.g., in Santa María) or to social networks (e.g., in Agua Fría).

Second, in terms of the instrumental value of autonomy to promote human development, fieldwork participants referred to several determinants of autonomy needed to improve their lives. Regarding the exercise of autonomy, they considered that by acting in a group (not individually) they have more chances to improve their lives, if the goals pursued and the values held by the (organised) group cohere with their own.

With respect to entitlements, social and cultural resources define entitlements over material resources. People with formal leadership roles, higher social status and engagement with community leaders, political leaders or donors are more likely to advance their goals. With respect to agency, competence was a recurrent topic, in relation to both self-perception and how one thinks to be perceived by others (section 11.1.2). However, group efficacy was more relevant than self-efficacy. Communities were regarded as crucial to open up opportunities for development, although not equally effective in this role across cases.

With respect to structural contexts, residents had different perceptions of the national and local governments. The first were seen as incapable to secure intermediate needs; this belief reflects the local political cultures. The second were better perceived, regardless of the quality of the existing relation between political authorities and community leaders. Although, they felt unable to change their contexts by their own effort, relations with 'people bigger than oneself' formed through projects can be used with that aim. This view of relations as resources to advance their own goals was mostly expressed by leaders, with different degrees of projective temporal orientation (i.e., future oriented) and autonomy causality orientation (i.e., internally motivated). As consequence of better social contexts or the success of certain project processes, some non-leaders expressed renewed trust in their own capacities to improve their lives, so that 'what [one] thinks can happen'.

\section{How do individuals in communities experience autonomy in their lives?}

The daily interactions of the inhabitants of the four localities in their closer contexts depend on several factors. Their perceived agency depends on individual, relational and symbolic factors, such as social standing (section 11.1.2). Their individual achievements fuel selfconfidence and aspirations. However, their perceived agency is based on the actual reality that they live, their poor living conditions and sometimes exclusionary multilevel structural contexts.

Then, their individual experience of autonomy is mostly affected by actors, their strategies and institutions at the structural contexts. A micro-level context that is autonomy-supportive (which encourages the process of choice and does not pressure behaviour toward specific outcomes) can fuel self-confidence and perceived agency. However, restrictive upper-level contexts limit autonomy, for example, a national economy in crisis, not accessible basic social services or a state not accountable to its citizens. In the long term, those negative contexts could harm self-esteem, causing apathy or impersonal causality orientation that blocks new endeavours. These effects are more likely to happen when the local political culture has features of inequality and conflict (section 12.2.1) as in Nicaragua and El Salvador. 
With regard to the national contexts, most project participants perceived the state as distant or unresponsive to their needs so that they take refuge in closer relations. Some of them engage in local networks or invest in client-patron relations under unequal conditions in exchange for security, as they live in 'informal security regimes' (Gough \& Wood, 2006). They depend on agricultural activities and are adversely incorporated to export-oriented economies that leave them in a vulnerable situation. Consequently, they develop a combination of strategies to secure a living with the household as decision-making unit.

With regard to the local contexts, their perceived agency is influenced by their perceptions about the life opportunities available and the closer social contexts, which can be more or less inclusive (section 11.3.2). First, perceived life opportunities depend on the economic situation of households in the village, their linkages with outside towns, the common resources to which they have access or might have access in the future and general life conditions, such as the level of physical security. Women in San Fernando were the most optimistic about their opportunities, while people in Santa María were the most pessimistic. Second, the perception of closer social contexts is influenced by personal entitlements, social position, the quality of social capital, and community dynamics. The most favourable perception of the social context was in Agua Fría, followed by San Agustín.

In the local context, community organisations were valued because individuals considered that they could channel joint energies toward development initiatives. However, their potential to contribute to human development is unequal; it depends on the internal group dynamics, leadership styles and local power relations. Some organisations were stronger, in terms of their efficacy to reach goals stipulated by funders, but not effective to promote residents' autonomy (e.g., Santa María). Others were more autonomy-supportive but weaker due to the adverse political context (e.g., Agua Fría). Organisations were valued but not necessarily socially effective. Not every resident considered that their community expanded their life opportunities significantly (section 11.2.3). In the Agua Fría case, residents did perceive a positive role.

Then, how do people engage in communal activities even if their assessment is not so positive? They do with different motivations, more intrinsic in contexts of lower vulnerability (e.g., Agua Fría) and more extrinsic in contexts of lower need satisfaction (e.g., Santa María). Besides, previous socio-historical experiences play an important role. This is clearer in the cases of San Fernando, with long experience of socio-political exclusion since the contra guerrilla war, and San Agustín, where most non-leaders are still affected by the turmoil lived during the civil war and 'organisation' is being re-valued.

The propensity to engage in collective action with intrinsic motivation (section 12.1.2) depends on: (i) individual characteristics such as preferences, perceived vulnerability, motivations and values; (ii) potential benefits, in terms of individual and group goals; (iii) perceived risks, related to group efficacy, trust in leaders, relative power of opposition groups and group dynamics; and (iv) transaction costs. Residents engaged in collective action for different reasons and they evaluated differently the outcomes of their collective action.

\section{How can communities shape opportunities for autonomy and human development?}

Project participants understand community in terms of people, values, material resources, social relations and organisation. They consider that the more people, the stronger a community. These people have to share some core values that make living together pleasant and 
predictable. The nature of the intra-community relations is crucial for residents' self-respect, self-trust and self-esteem (section 12.1.2). In this respect, people feel more or less vulnerable to loss in social support, depending on their position in social structures and their relative entitlements. In order to reduce this feeling of insecurity, they require access to relevant information about community activities and to feel respected regardless of their appearance, gender, age, religion, economic situation, occupation and so on.

Community organisations have a relatively higher access to resources. Then, residents need support to negotiate rules or create new rules within these organisations so that they perform four basic functions (decision-making, resource mobilisation and management, communication and coordination, and conflict management) in a manner that is inclusive and autonomy-supportive. This help can come from social intermediaries (e.g., local NGOs) or leaders themselves if they are committed to promote the empowerment of non-leaders. Through a more active communal participation, non-leaders could enhance their critical consciousness and crucial transferable skills (interpersonal, social, and political skills) that have a positive influence on their autonomy and resilience when facing risks.

The whole process is possible when there is space for public deliberation and mutual learning, in which each member is treated fairly and shares in the decision-making process. This requires a non-repressive solidarity, which does not prevent conflict to surface. Among the cases studied, ASCA in Santa María is the most restrictive, with elite capture of project benefits over time. In contrast, CRDM in San Agustín has the potential to fuel critical autonomy because its membership base is broader and already a participatory municipal plan has been carried out - although a new elite group could emerge as result of the change in social and political relations (section 12.1.2).

There are limits to the effect that collective action could have on reducing vulnerability: low value reciprocity, unequal social structures, and covariant risks (section 12.1.2). The Agua Fría case tells much about these factors because although the levels of well-being inequality are lower than in the other cases (section 11.1.2); residents are affected by the impasse between the mayor and communal leaders. The San Agustín case illustrates the existence of covariant risks. Most likely, organised groups will have to build relations with other powerful actors (as already done with the sister cities agreement), to focus on issues without so much opposition and to build multi-scaled strategies and networks to develop linking social capital (section 11.2.2).

A desirable expansion of autonomy is one that, while assuring more opportunities by enhancing agency or expanding entitlements, does not contract the achievement of (or the capacity to achieve) other valuable priority goals (section 10.2.1). Then, community dynamics have to be evaluated and monitored. The more non-leaders are able to watch their (political and social) leaders themselves, the more their needs will be protected and realised.

\section{How might projects have affected the autonomy of non-leaders and leaders?}

This study looked at project effects on individual autonomy with respect to (i) changes in its determinants (chapters 6 to 9) and (ii) its exercise, either individually or in a group (sections 10.4.3 and 11.2.3). Surely, the exercise of autonomy has effects on some determinants of autonomy so that both analyses are interrelated. 


\section{- Analysing changes in the determinants of individual autonomy}

The changes in autonomy were explained not only by projects but also by structural contexts and individual characteristics (including the initial level of autonomy). Regarding the influences of projects, their outputs increased the resources within reach and had effects on actual agency (e.g., improved health, learnt skills) and on perceived agency. The micro-level context during the projects, whether controlling or autonomy-supportive, had varied effects on self-confidence and on causality orientation depending on the project operational effectiveness and the residents' involvement. Project practices were influenced by the intracommunity relations, but not necessarily the most experienced community organisations (e.g., in Agua Fría) were involved in the project.

Looking at non-leaders across localities, the degree of internalisation of work commitments differed in relation to the specific practices and interpersonal contexts. It directly affected the achievement of project outcomes and, indirectly, their individual autonomy. The specific project features determined varying impacts on the lives of non-leaders. These features correspond to the four kinds of practices explored in the case chapters and to sectoral differences (section 10.5). The process of definition and the clarity of entitlements set by the selection criteria were crucial. These two aspects are related to the spread of information within each locality, via informal or formal mechanisms. Indeed, the information problems during the project in Santa María have worsened, impairing the situation of the women non-leaders who are being more involved in groups to overcome this situation and to watch their formal leaders.

\section{- Analysing effects on the exercise of individual autonomy}

Leaders and non-leaders had different experiences. The quality of the participation of leaders varied across sites over the project cycle. The leaders of the four sites took part in the project execution as the projects included self-construction activities. However, the roles played in the water projects were less significant than those in the other projects. Only in San Agustín did the leaders have meaningful participation during the formulation stage. The leaders in Santa María had a relevant participation, but finally decisions were top-down.

These differences in involvement determined different impacts on perceived agency in terms of competence and causality orientation. There were important positive effects for the leaders in CRDM (in San Agustín) and ASCA (in Santa María), linked to their higher management experience during and after the reconstruction periods. However, the women leaders in San Fernando felt the largest expansion in perceived agency because, although they exercised low decision-making during the project, their positions allowed them to be part of the communal development committee later on - something hard to imagine for women whose lives had been centred on their families only.

With respect to the exercise of individual autonomy by non-leaders, there were three hypotheses (see Figure 13-1):

(i) The higher the workload in the project, the higher the chances to be involved in the project;

(ii) The higher the individual involvement in the project, the higher the expansion in individual autonomy because people would have made decisions during the project and continue making relevant decisions in their life; and 
(iii) As people can be more effective acting in group than individually, it was expected that community participation would increase or that opportunities for decision-making in relevant community issues would improve in relation to the situation prior to the projects.

Figure 13-1: Working hypotheses related to the exercise of autonomy

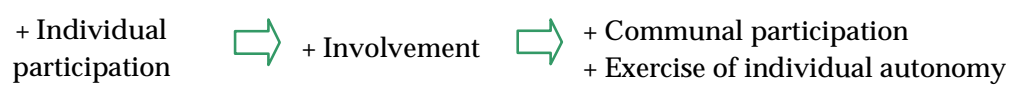

All participants worked a great deal, although (i) high workload did not necessarily produce a high involvement in the projects, (ii) their low levels of involvement were explained by little decision-making during the projects, and (iii) an improvement in perceived agency, for some, was related to an increased awareness of their own practical skills (section 10.4.3).

It seems that, in most cases, participation was instrumental to reach previously defined project objectives. However, the participants in Agua Fría and Santa María had a relatively higher involvement than those in the other sites, which is related to their tradition of organisation and collective action, that is, their internal contexts of agency (section 11.2.3). These contexts also influence the formation of preferences to engage in membership associations nowadays. Then, the projects did not influence the communal participation of most nonleaders (section 11.2.2). Although everyone worked hard during the projects, not all participated in associational life after the projects because they were not intrinsically motivated.

Moreover, given the low involvement of non-leaders, the projects had low effect on their chances to participate in community decisions. This study has not explored the exercise of autonomy in different significant personal issues. As a global evaluation, focus group participants reported improvements in individual decision-making, but lower in the reconstruction project sites.

It is worth noticing that none of the projects addressed gender issues. Women participated in the projects for (i) cultural reasons, because they work in home chores and collect water, or (ii) opportunistic reasons as it was easier to gather women (especially for female social promoters) when they were at home. Although their hard work during the project implementation was recognised by men (especially in the reconstruction cases), most probably their opportunities for decision-making in other community issues did not improve.

\section{In which communities are individuals more likely to experience an expansion of auton- omy? Why?}

Several factors determine the potential of projects to expand autonomy. Living in a certain type of locality does not solely determine this potential. For instance, San Fernando and San Agustín are municipal centres, but only the non-leaders in San Fernando reported high positive changes in perceived agency (section 11.3.2). The level of involvement in the projects (low in all cases) and the strength of the community organisations (higher in San Agustín and Santa María) did not explain higher expansions of autonomy, either.

While the inhabitants of the water project sites were less affected by disasters and wealthier in monetary terms than those of the reconstruction project sites, they did not necessarily experience higher improvements in individual autonomy. Looking at perceived agency, indeed, they reported high positive changes (section 11.3.1), but they gave different reasons for such improvements. The (female) participants in San Fernando were very optimistic about future 
opportunities to be opened up by the new leaders together with the local government through the communal development committee, but their actual living conditions were still difficult. Hence, the positive effect could be short-lived. For the inhabitants of Agua Fría, perceived agency was related to self-confidence as result of having equal access to water. However, in both cases, the awareness of personal skills was an important factor.

The living conditions in Agua Fría did not improve as much as they could have because of technical problems with the water system and adverse structural contexts such as the reorganisation of the public water company, which harmed the accountability of the project, and the physical insecurity in the canton that led to the failure of the small fish agriculture project. In this case, perceived agency was supported by project practices that shared relevant information, supported voice and fuelled the awareness of own skills. Nevertheless, this positive effect was overridden by the structural contexts.

In general, it seems that the command over social and political resources by the leaders was favourable for the individual autonomy of non-leaders to an extent that depends on the community dynamics and the kind of support from external actors. The management and political skills of the members of ASCA and CRDM have developed over time. However, their relations with other inhabitants in their respective villages are different. Truly, the political context was more difficult in the Santa María case (section 6.2.2 and 6.3.1), but leaders of each locality faced their respective contexts differently. The role of the project chief and FUNDAMUNI in San Agustín was crucial to facilitate the relation between the community organisation and the political authorities, while there was no visible social intermediary in the Santa María case. Hence, the San Agustín case had more chances to effectively expand individual autonomy. The leaders in Agua Fría, although they enjoy legitimacy in the eyes of their neighbours, do not have political influence. The leaders in San Fernando are only slowly gaining their position.

In sum, many factors have to be analysed to judge the potential to expand individual autonomy in each locality. A priori one specific community cannot be positively expected to have higher potential than others. Once a situational analysis is done, external actors have to support the local efforts to develop capacities and help project participants in their interactions with actors in multilevel structural contexts, where power imbalances are likely to be found. This is a fine-tuned engagement process (Bastiaensen et al., 2005) that must be done with caution to not override the autonomy causality orientation of individuals.

\subsection{Implications}

This research study has a practical-oriented fundamental nature. It has implications for policy design, development aid practice and development research, which are listed below.

\subsubsection{For policy design}

1) Public, private and foreign aided projects should back strategies designed to respond to local priorities defined in local development plans. This behaviour would resemble the goals of ownership and alignment of the Paris Declaration (2005) and be in line with decentralisation trends that devolve decision-making and resources to local governments. As Ellerman points out, aid agencies do not accomplish development; participants must be 'in the driver's seat' (section 3.2.4). 
2) Projects have to build on existing institutions, not to bypass the municipality government or create an organisation in competition with the political authorities, even if the new organisation was representative (e.g., the failed NGO in Agua Fría). A new organisation born because of a project and without formal institutional support would be short-lived and reinforce a feeling of continuous neediness.

3) On the contrary, projects should be led by management teams composed by representatives of the local government and the national counterpart (either the water company or a ministry), the community organisations and the aid agency or donor (a local professional). In this way, the project could have formal institutional support and be less sensitive to political shocks in the national contexts.

4) Likewise, political calendars have to be included in the planning of project activities because the redefinition of powers could translate into varying goals and practices. Alternative strategies to support the execution of projects and complementary actions have to be envisaged.

5) Insofar as governments of receiving countries lack technical expertise or institutional guarantees, the donor can maintain a watchdog role or even lead the project management team by selecting the project chief. This professional has at least to have the required technical expertise and assure that financial audit is contracted. Moreover, technical cooperation to line ministries or public water companies (as intended in San Fernando) would enhance the operational effectiveness of aid.

6) Donor coordination is crucial, especially in reconstruction projects. The lack or weakness of a national coordinating agency can produce delays in the allocation of emergency relief aid, ineffective targeting, uncertainty about the project outputs, and even deeper psychological insecurity for the affected people. Political factors aside, donor coordination has direct consequences on accountability because low coordination dilutes responsibility for outcomes so that beneficiaries do not find one actor to whom to turn in case of problems. National institutional arrangements are rarely known by the inhabitants of small villages and they feel powerless when projects do not deliver what was expected.

7) In post-emergency reconstruction, in rural areas, both the construction of houses and the rehabilitation of the agricultural land are needed to support the livelihood of households, according to their customs and values. More than resources, people need entitlements to a worthy house and land, in which they enjoy to live and to work and that they could use to get credits (section 10.5.1). Issues of land ownership have to be solved, which may require formal institutional changes (cf., Grunewald et al., 2001).

8) In the case of water projects, the definition of water tariffs is crucial for the actual entitlement to safe drinking water (section 10.5.2). Foreign aided projects that follow a demand-based approach could end up benefiting far fewer people than initially intended if the tariffs do not agree with the actual payment capacity of beneficiaries. Alternative pricing options in the case of income-poor localities should be evaluated while a profound sector reform is not implemented in both countries.

9) Frequently, the work of women in projects (assessed by counting the number of women mobilised for activities) is thought to reflect a change in gender relations. However, cultural change takes time and is not 'doable' by projects. Gender awareness should be 
supported with specific programmes framed in a state policy. When women take part in projects, their involvement in other community issues should be monitored to conclude about the sustainability of their entitlement to participation, apparently gained during the projects (as in the San Fernando case).

\subsubsection{For development aid practice}

10) Local governance has to be assessed. Each locality has its own established processes and institutional arrangements to define decision-making, power relations and ways to reach common goals. These are in constant redefinition, but some social practices endure. In regular situations (as opposed to tragic ones), aid projects should not disrupt the local networks that (have the potential to) support crucial entitlements for all. Empowerment is only possible when people can control certain resources to pursue their goals.

11) It is not accurate to assume that power is evenly spread out (e.g., in Santa María) or that 'people do not know' (e.g., specific processes in Agua Fría). On the contrary, project planners and implementers have to understand the living conditions of potential beneficiaries and their socio-historical experiences; this understanding will raise awareness of the motivations to participate in the project and help to identify stakeholders.

12) An integrated strategy is different from an 'integral' project. Complex projects that aim to solve multiple problems could be ineffective (e.g., Agua Fría and Santa María). Instead, projects should be part of an integrated strategy that involves different actors and institutions in a coordinated way, so that relevant stakeholders are engaged early and the project management team builds rapport between different government levels.

13) Integrated strategies build on local development plans. The more skilful and capable the local inhabitants, the most likely they will have such a plan. This brings two risks:

a. Localities with relatively less competent actors (more in need of aid) will be less likely to have a local development plan and to benefit from aid projects that follow an integrated strategy; and

b. Localities with relatively more competent actors could attract a multiplicity of donors willing to fund projects (given the expected higher returns) so that the local development plan is distorted.

14) These situations should be prevented. In the first case, aid agencies can have a catalyst role helping people realise their existing capacities and develop their own strategies. In the second case, aid agencies have to respect local partners and not override their intrinsic motivation and autonomy causality orientation.

15) Whether selection criteria are defined by external agents (e.g., water projects) or by project participants (e.g., reconstruction projects), it is necessary that these criteria are widely known throughout the project life and that reasons for changes or exceptions are agreed and communicated. Then, people would regulate their expectations and accept these criteria based on reflection and commitment, due to intrinsic or internalised extrinsic reasons, not because they feel lucky or grateful to a charitable entity.

16) The project chief, as coordinator of the management team, could act as social intermediary and actively monitor the project and community practices in structural contexts so 
that early danger signals (Bourne \& Walker, 2005) that could put at risk the project are timely addressed. Moreover, the project chief should be involved from the project formulation as to understand the relevance of the project for participants, become familiar with and in the local context, and develop autonomy-supportive practices, rather than only performing the formal stated activities.

17) The selection of the executing NGOs is crucial because their staffs validate project practices and imprint their culture on the project - with usually higher symbolic power than other actors. Next to having good technical qualifications, NGO staffs must know the region, local politics and idiosyncrasy (especially in countries with features of sharp inequality and social exclusion) and to have cultural understanding, empathy and true commitment to the well-being of participants. They should have characteristics both of insiders and outsiders (Crocker, 2004).

18) The agents of development are always local people, who require only assistance from external actors. Project staff should identify the goals and aspirations of participants, respect their change process, not impose values that are 'accepted' as result of conditionality, and encourage their internal efforts to exercise voice. In this way, the project could be an opportunity for helping people to promote their human development (e.g., in San Agustín) and not just a single point in their lives.

19) During the project cycle, staff can foster critical autonomy by promoting a culture of active learning and horizontal exchange of experiences (Ellerman, 2006) with complementary activities such as the planned human rights workshops in San Agustín. In this way, projects could support the self-confidence and aspirations of project participants.

20) The conceptual confusion between autonomy and independence (section 2.2.2) has led to make food aid conditional on work activities (cf., Harvey \& Lind, 2005) even in emergency contexts. This conditionality could apply to predictable events such as recurrent floods and be part of disaster prevention plans. Nevertheless, it is not acceptable when the degree of vulnerability of those affected is so high that their lives are unbearable; it would harm their basic autonomy even further.

21) In these emergency contexts, aid should not only ensure human survival, but also promote the resilience of the affected population (section 12.1.1), for which one needs:

a. To support the emotional status of the individuals affected and the reactivation of their aspirations because tragic events could trap them in apathy, lack of selfesteem or resentment, and hence, in long-term deprivation (e.g., Santa María);

b. To identify developing strategies carried out by individuals themselves to overcome their situation so that aid relief: (i) does not override but reinforce the strategies that work (e.g., San Agustín), (ii) does not constrain other valuable goals, and (iii) does not support those strategies that only favour minority groups; and

c. To explicitly include a long-term development objective (Hoddinot, 1999) that incorporates the revitalisation (or establishment) of economic activities in a way that agrees with local cultures and the socio-historical experiences of participants.

22) The application of so-called 'best practices' for projects, a notion already subject to several criticisms (White, 2005; Johnson, 2007), is also not a guarantee of success if success means expanding autonomy instead of only achieving quantitative pre-specified tar- 
gets. Hard indicators cannot capture the richness of people's lives and their changes (Hofmann et al., 2004) which can be better understood by looking at specific livelihoods (cf., Ashley \& Hussein, 2000) and contexts.

\subsubsection{For development research}

23) The potential benefits and costs of participation are realised in concrete situations: by specific people engaged in particular community dynamics and facing varying project practices. A fruitful exercise would be to identify the failure risks of participatory experiences in several cases and the possible trade-offs. For instance, there are risks for autonomy causality orientation of mobilising an organised community only to fulfil externally defined purposes, there are risks for operational effectiveness of delegating crucial decisions to a nascent organisation without representativeness and authority in the locality, and there are risks for critical autonomy of obliging people to work so much that they are not available for sharing in decisions relevant for the development of their community.

24) This study has focused on assessing change in individual autonomy understood as a combined capability. The analysis covered (i) the internal and external conditions that would support this capability (determinants), that is, not necessarily the achieved functioning, and (ii) how people could have exercised autonomy during the projects or the functioning of being involved in the project.

25) Even if involvement would have been high across projects (which was not the case), the involvement index per se would not be an indicator of empowerment, whose analysis requires a mixed method analysis. Moreover, there is insufficient evidence on the effectiveness of decisions during the project (if made) and their effects on other significant life domains.

26) The analysis has concluded about changes in the conditions, based on several data sources, and changes in the communal participation, based on self-reported data. This means that: (a) the improvements of the conditions for exercising individual autonomy (in whatever people considered valuable), in multilevel structural contexts, were considered as indicative of expansions in their capability, and (b) the actual exercise of autonomy or functioning was analysed in one specific life domain (society, in contrast to market and state) and at the micro-level of analysis (individuals in communities).

27) A next step for research would be to identify other core or significant life domains and then to observe the behaviours and self-reported attitudes (predispositions to act) of individuals in such areas. This implies to check which topics and with which effects people exercise autonomy in these domains. Some studies investigate decision-making in several domains, but without reference to projects (e.g., Ibrahim \& Alkire, 2007); while other studies do that for credit projects (Kabeer, 1999) where women are expected to improve their bargaining power within the household. No similar studies have been made in the case of infrastructure projects.

28) Because values change over time (value endogeneity), it would be necessary at least to follow two strategies: (i) to identify the core life domains prior to the project implementation and follow up the decision-making in such areas over time, and (ii) to identify those core areas over the project cycle in order to capture the change in values related to 
the project. Both strategies require the use of several data collection methods and mixed analysis methods. The best-case scenario would be to test the methodology over the lifespan of a project - not only at its completion, as in the cases here studied.

In sum, this dissertation takes the challenge to assess project aid with respect to what is important: the promotion of worthy human lives. It puts forward that projects should explicitly aim at expanding individual autonomy. Projects so focused would lead to more horizontal relations between aid recipients and funders toward the achievement of valuable goals, with greater chance of sustained positive effects on people's well-being. 


\section{References}

Abraham, A. \& Platteau, J. (2004). Participatory development: where culture creeps in. In Rao, V. \& Walton, M. (Eds.), Culture and public action (pp. 210-233). Stanford: Stanford University Press.

ACI Prensa (1998, November 6). Iglesia en Nicaragua distribuirá ayuda para evitar corrupción [Catholic Church will distribute aid to avoid corruption]. Association for Catholic Information, Catholic press agency in Latin America.

'A German man threatens' (2001). Alemán amenaza con echar a sobrevivientes del Casitas [A German man threatens to cast out survivors of Casitas]. (2001, September 7). El Nuevo Diario. Retrieved October 22, 2006, from http://archivo.elnuevodiario.com.ni/2001/septiembre/07-septiembre-2001/nacional/nacional14.html

Agua Fría health post (2005). Statistics of weekly reports, years 2001, 2002, and 2004.

Alexander, J.C. (1992). Recent sociological theory between agency and social structure. Schweizerische Zeitschrift für Soziologie / Revue suisse de sociologie, 18(1), 7-11.

(1993). More notes on the problem of agency: a reply. Schweizerische Zeitschrift für Soziologie / Revue suisse de sociologie, 19, 501-506.

Alexander, N. (2004). Judge and Jury: the World Bank's scorecard for borrowing governments. Maryland: Citizens' Network on Essential Services. Retrieved May 24, 2006 from http://www.servicesforall.org/html/otherpubs judge_jury_scorecard.pdf

Aliber, M (2001). Study of the incidence and nature of chronic poverty and development policy in South Africa: an overview. CPRC Working Paper 3, Institute for Development Policy and Management, University of Manchester.

Alkire, S. (2002). Valuing freedoms: Sen's capability approach and poverty reduction. Oxford: Oxford University Press.

(2004). Culture, poverty, and external intervention. In Rao, V. \& Walton, M. (Eds.), Culture and public action (pp. 185-209). Stanford: Stanford University Press.

(2005). Subjective quantitative studies of human agency. Social Indicators Research, 74, 217-260.

Allison, M.E. (2006). The transition from armed opposition to electoral opposition in Central America. Latin American Politics \& Society, 48 (4), 137-162.

Alsop, R. (Ed.) (2004). Power, rights, and poverty: concepts and connections. Washington, DC and London: World Bank and DFID.

Alsop, R., \& Heinsohn, N. (2005). Measuring empowerment in practice: structuring analysis and framing indicators. World Bank Policy Research Working Paper 3510. World Bank.

Alsop, R., Bertelsen, M., \& Holland, J. (2006). Empowerment in practice: from analysis to implementation. Directions in Development Series, Washington, DC: World Bank.

Altamirano, C. (2001, February 2). En El Tanque: "Construimos vida y esperanza" [In El Tanque: ‘We build life and hope']. La Prensa. Retrieved October 22, 2006, from http:/www.laprensa.com.ni/cgibin/print.pl?id=regionales-20010202-01

Alvarenga Jule, L. E. (2001). La situación económico-laboral de la maquila en El Salvador: Un análisis de género [The economic-labour situation of maquila in El Salvador: A gender analysis]. Serie Mujer y Desarrollo, 34. Santiago de Chile: ECLAC.

Álvarez Montalván, E. (2000). Cultura política nicaragüense [Nicaraguan political culture] (2nd ed.). Managua: HISPAMER.

Alwang, J., Siegel, P.B., \& Jørgensen, S.L. (2001). Vulnerability: a view from different disciplines. Social Protection Discussion Paper Series, 0115. Washington: Social Protection Unit, Human Development Network, WB.

AMSS [Municipal mayoralty of San Salvador] (2007). [Map of El Salvador]. Retrieved April 7, 2007, from http://www.amss.gob.sv/pages/municipios/municipios.htm

AMUNIC [Association of Municipalities of Nicaragua] (2006). [Map of Nicaragua]. Retrieved April 6, 2007, from www.amunic.org 
Anderson, J., \& Honnet, A. (2005). Autonomy, vulnerability, recognition, and justice. In Christman, J. \& Anderson, J. (Eds.), Autonomy and the challenges to liberalism: new essays (pp. 127-149). New York: Cambridge University Press.

Andersson, K. \& van Laerhoven, F. (2006). Institutional incentives for participatory municipal governance in Latin America. Comparative Political Studies, 20(10), 1-27.

Appadurai, A. (2004). The capacity to aspire: culture and the terms of recognition. In Rao, V. \& Walton, M. (Eds.), Culture and public action (pp. 59-84). Stanford: Stanford University Press.

Archer, M. S. (2002). Realism and the problem of agency. Journal of Critical Realism (incorporating Alethia), 5(1), 11-20.

Areas Calvo, W. (1998, November 26). Huracanes: no se pueden prevenir, pero sí minimizar sus daños [Hurricanes: they cannot be prevented but their damages can be minimised]. La Prensa. Retrieved June 23, 2007, from http://archivo.elnuevodiario.com.ni/1998/noviembre/26-noviembre-1998/opinion/opinion3.html

Arnstein, S. R. (1969). A ladder of citizen participation. Journal of American Planning Association, 35 (4), $216-224$.

Arnson, C. (Ed.) (2003). El Salvador's democratic transition ten years after the peace accord. Washington D.C.: Woodrow Wilson International Center for Scholars.

Ashley, C., \& Hussein, K. (2000). Developing methodologies for livelihood impact assessment: experience of the African wildlife foundation in East Africa. ODI Working Paper 129. London: Overseas Development Institute.

ASIPES [Salvadorian Association of Research and Economic and Social Promotion] (2002). La migración y su vinculación con las remesas familiares en El Salvador [Migration and its linkage with family remittances in El Salvador]. San Salvador: ASIPES.

Ausín Cantero, F.J. (2001a). Informe de misión: Proyecto NIC/009 Reconstrucción de Posoltega [Report of mission: Project NIC 009 Reconstruction Posoltega]. November 2001. Madrid: Desarrollo, Medio Ambiente y Salud (DMAS) Consultora S.A.

(2001b). Respuesta a los comentarios de la Sra. Risch en relación con el informe de la misión de clausura: Proyecto NIC 009 Reconstrucción Posoltega [Response to Mrs. Risch's comments with respect to the report of the mis-sion of closure: Project NIC/009 Reconstruction Posoltega]. December 2001. Madrid: DMAS Consultora S.A.

(2001c). Informe final de la misión para la realización del informe de clausura del proyecto NIC/009 Reconstrucción de Posoltega financiado por Lux-Development S.A. [Final report of the mission for the elaboration of the report of closure of the Project NIC/009 Reconstruction Posoltega, financed by LuxDevelopment S.A.] November 2001. Madrid: DMAS Consultora S.A.

Balmaceda Vivas, M. (2005). Informe general sobre encuesta de hogares, para medición del empleo, noviembre 2004 [Employment household survey report, November 2004]. Managua: INEC.

Bandura, A. (2000). Exercise of human agency through collective efficacy. Current Directions in Psychological Science, 9(3), 75-78.

Barahona, A. \& Balanzategui, J. (2005). Ejercicio de revisión del PIC - Nicaragua. Recomendaciones del estudio de revisión a la mitad de su período de ejecución (Informe Final) [Final report: Recommendations of the mid-term review of the ICP with Nicaragua]. Luxembourg: CAMIRE, Estadística y Analisis, S.L.

Barahona, T. \& Mendoza, R. (1999). El papel de los gobiernos municipales en la gestión de los recursos naturales. Chinandega: El manejo de una reserva natural en un mundo de agricultores [The role of municipal governments in natural resources management in Chinandega: The management of a natural reserve in a farmers' world]. Managua: Nitlapán-UCA, CIFOR, PROTIERRA-Inifom.

Barclay, L. (2000). Autonomy and the social self. In Mackenzie, C. \& Stoljar, N. (Eds.), Relational autonomy: feminist perspectives on autonomy, agency, and the social self (pp. 52-71). Oxford: Oxford University Press.

Bardhan, P. (1993). Analytics of the institutions of informal cooperation in rural development. World Development, 21(4), 633-639.

Bastiaensen, J., De Herdt, T. \& D'Exelle, B. (2005). Poverty reduction as a local institutional process. World Development, 33(6), 979-993.

Bastiaensen, J., D'Exelle, B. \& Famerée, C. (2006). Political arenas around access to land: a diagnosis of property rights practices in the Nicaraguan interior, Discussion Paper, 2006.08. Antwerp: Institute of Development Policy and Management. 
Baumann, P. (2000). Sustainable livelihoods and political capital: Arguments and evidence from decentralisation and natural resource management in India. ODI Working Paper 136. London: Overseas Development Institute (ODI).

BCN [Central Bank of Nicaragua] (2007). [Statistics]. Retrieved May 25, 2007, from http://www.bcn.gob.ni/ estadisticas/

BCR [Central Reserve Bank of El Salvador] (2006). Series Estadísticas [Statistical series]. Retrieved October 13, 2006, from http://www.bcr.gob.sv/estadisticas/series_estadisticas.html

Bell, S. (2000). Logical frameworks, Aristotle and soft systems: a note on the origins, values and uses of logical frameworks, in reply to Gasper. Public Administration and Development, 20, 29-31.

Belli, P., J. Anderson, H. Barnum, J. Dixon, \& Tan, T. (1997). Handbook on economic analysis of investment operations. World Bank, Operations Policy Department, Learning and Leadership Centre.

Bennett, L., Goldberg, M., \& Hunte, P. (1996). Ownership and sustainability: Lessons on group-based financial services from South Asia. Journal of International Development, 8(2).

Berlin, I (1969). Two concepts of liberty. In Berlin, Four essays on liberty (1969); excerpted in Miller, D. (Ed.) (1999), Liberty (pp. 33-57). Oxford: Oxford University Press.

Bernard, H.R. (1988). Research methods in cultural anthropology. Newbury Park: Sage Publications, Inc.

Bevan, P. \& Pankhurst, A. (2007). Power structures and agency in rural Ethiopia: development lessons from four community case studies. Paper prepared for the Empowerment Team in the WB poverty reduction group. Retrieved February 24, 2008, from http:/wwww.wed-ethiopia.org/docs WBPowerAgencyComplete .pdf

Biekart, K. (2003). The politics of civil society building: European private aid agencies and democratic transitions in Central America. Utrecht and Amsterdam: International Books and the Transnational Institute. (Original work published 1999).

Bierschenk, T., Chauveau, J.-P., \& Olivier de Sardan, J.-P. (2000). Courtiers en développement: les villages africains en quête de projets. Paris: Karthala.

Billson, J.M. (1991). The progressive verification method: toward a feminist methodology for studying women cross-culturally. Women's Studies International Forum, 14 (3), 201-215.

(2004). The power of focus groups: a training manual for social and policy research: Focus on international development. Barrington, RI: Skywood Press.

Birner, R. \& Wittmer, H. (2000, May). Converting social capital into political capital: How do local communities gain political influence? A theoretical approach and empirical evidence from Thailand and Colombia. Paper presented at the $8^{\text {th }}$ Conference of the International Association for the Study of Common Property on 'Constituting the commons: crafting sustainable commons in the New Millennium', Bloomington, Indiana, USA.

Bloomington-Posoltega Committee of Sister Cities, International (2004). Dreams and designs for clean water for Santa María. SCI Newsletter. Retrieved August 7, 2006, from http://www.bloomington.in.us/ scipos WinterNewsl_04_dir_water_art.html

Bolsa de Noticias (2000, May 10). Damnificados tendrán vivienda digna [Victims will have worthy house]. Retrieved October 16, 2006, from http:/Wwww.bolsadenoticias.com.ni/2000/bn/05/10/damMM0510.htm

Booth, D. (Ed.) (1994). Rethinking social development: theory, research and practice. Essex: Longman Scientific and Technical.

Booth, D. (1994). Rethinking social development: an overview. In Booth, D. (Ed.), Rethinking social development: theory, research and practice (pp. 3-41). Essex: Longman Scientific and Technical.

Booth, D. \& Fritz, V. (2008). Good governance, aid modalities and poverty reduction: from better theory to better practice, Final Synthesis Report, Research project (RP-05-GG) of the Advisory Board for Irish Aid.

Booth, J.A. \& Richard, P.B. (1998). Civil society, political capital, and democratization in Central America. The Journal of Politics, 60 (3), 780-800.

(2006). Revolution's legacy: Residual effects on Nicaraguan participation and attitudes in comparative context. Latin American Politics \& Society, 48 (2), 117-140.

Botchway, K. (2001). Paradox of empowerment: reflections on a case study from Northern Ghana. World Development, 29 (1), 135-153.

Bourne, L. \& Walker, D.H.T. (2005). Visualising and mapping stakeholder influence. Management Decision, 43 (5), 649-660. 
Brás, M. (1993). Chapter I - Historical setting. In Merrill, T. (Ed.), Nicaragua: a country study. Washington, D.C.: Federal Research Division, US Library of Congress.

Bratman, M.E. (2005). Planning agency, autonomous agency. In Taylor, J.S. (Ed.), Personal autonomy: new essays on personal autonomy and its role in contemporary moral philosophy (pp. 33-57). Cambridge: Cambridge University Press.

Braütigam, D. (2000). Aid dependence and governance. Expert Group on Development Issues (EGDI). Stockholm: Almqvist \& Wiksell International.

Brown, S.R. (2003, February). Empowerment as subjective operant. Paper presented at the WB workshop on 'Measuring Empowerment: Cross-Disciplinary Perspectives', Washington D.C.

Burchardt, T. (2004). Capabilities and disability: the capabilities framework and the social model of disability. Disability \& Society, 19(7), 735-751.

Burri, G. (2002a). [The San Agustín project] Quarterly report, February - June 2002, prepared by the project chief. (2002b). [The San Agustín project] Annual progress report, year 2002.

(2002c). Réponses et commentaires au message électronique reçu le 04 juillet [Responses and com-ments to email received on July 4]. Email to V. Stoz. July 4, 2002.

(2002d). Guide, commentaires et synthèse de la situation après sept mois de travail de terrain de FESPAD [Guide, commentaries and synthesis of the situation after seven months of field work of FESPAD]. Extract of the quarterly progress report, September 2002.

(2003a). [The San Agustin project] First quarterly report 2003.

(2003c). [The San Agustin project] Third quarterly report 2003.

(2003d). [The San Agustín project] Annual progress report, year 2003.

(2004c). [The San Agustín project] Third quarterly report 2004.

(2004d). [The San Agustín project] Annual progress report, year 2004.

Buss, S. (2002, winter). Personal autonomy. In Zalta, E.N. (Ed.), The Stanford Encyclopedia of Philosophy. Retrieved April 8, 2005 from http://plato.stanford.edu/archives/win2002/entries/personal-autonomy/. Last modified 25/09/2002

Cabrera, M. (2002, December). Living and surviving in a multiply wounded country. Revista Envío, 257. Retrieved August 4, 2008, from http://www.envio.org.ni/articulo/1629

Calderón, F. \& Szmukler, A. (2004). Political culture and development. In Rao, V. \& Walton, M. (Eds.), Culture and public action (pp. 281-306). Stanford: Stanford University Press.

Camfield, L. \& Ruta, D. (2007). 'Translation is not enough': using the Global Person Generated Index (GPGI) to assess individual quality of life in Bangladesh, Thailand, and Ethiopia. Quality of Life Research, 16, 10391051.

CAMIRE (2005). Rapport suite à misión de terrain - Evaluation du Projet SVD/016 Reconstruction San Agustín, San Salvador [Evaluation report]. Prepared by P. Canel and E. Sánchez. Luxembourg: CAMIRE, Estadística y Análisis, S.L. in collaboration with InSyDe Information, Systèmes et Développement, sàrl.

CARE (2000a). [The Santa María project], Monthly report January 2000.

(2000b). [The Santa María project], Monthly report, February 2000.

(2000c). [The Santa María project], Monthly report, March 2000.

(2000d). [The Santa María project], Monthly report, April 2000.

(2000h). [The Santa María project], Monthly report, August 2000.

(2001a). [The Santa María project], Quarterly report, November 2001 - January 2001.

(2001b). [The Santa María project], Quarterly report, February 2001 - April 2001.

(2003b). [The San Fernando project] Quarterly report, June - August 2003, by O. Toval Lezama.

(2003c). [The San Fernando project] Quarterly report, 4th quarter 2003.

(2004a). Resumen de Encuestas socioeconómicas de las localidades San Fernando, Tastaslí, El Jícaro, Somoto y Palacagüina, departamento Madriz y Nueva Segovia [Summary of the socioeconomic surveys of the localities San Fernando, Tastasli, El Jicaro, Somoto and Palacaguina]. February 2004. Managua: CARE.

(2004b). [The San Fernando project] Monthly report, January 2004.

(2004c). [The San Fernando project] Monthly report, October 2004. 
(2005b). Informe final de San Fernando [Final report of San Fernando]. Elaborated by L. Díaz Huete, social promoter.

(2005c). Informe final de actividades de monitoreo y seguimiento realizadas por el promotor itinerante [Final report of monitoring and follow-up activities of the itinerant promoter]. El Jícaro, Tastaslí, San Fernando, Palacagüina. Elaborated by M. Paguaga Rivera.

(2005e). [The San Fernando project] Monthly report, March 2005.

(2005f). [The San Fernando project] Quarterly report, February - April 2005.

Carmen, R. (1996). Autonomous development, humanizing the landscape: an excursion into radical thinking and practice. London and New Jersey: Zed Books Ltd.

(2000). Prima mangiare, poi filosofare. Journal of International Development, 12, 1019-1030.

Carney, D., Drinkwater, M., Rusinow T., Neefjes K., Wanmali S., \& Singh, N. (1999). Livelihood approaches compared. A brief comparison of the livelihoods approaches of the UK Department for International Development (DFID), CARE, Oxfam and the United Nations Development Programme (UNDP). London: DFID.

Carreño Collatupa, R. (1998). Evaluación del desastre y de peligros residuales en el volcán Casita: Identifica-ción y evaluación preliminar de peligros asociados a terrenos inestables en algunos puntos del norte y centro de Nicaragua [Evaluation of the disaster and of residual dangers in the volcano Casita: Identification and preliminary evaluation of dangers associated to unstable lands in some points of the North and Center of Nicaragua].

Carver (2002, autumn). Discourse analysis and the 'linguistic turn'. European Political Science (EPS), 2(1), 51-52.

Cassen, R. \& associates (1994). Does aid work? Oxford: Clarendon Press.

CENIDH [Nicaraguan Centre of Human Rights] (1998). Segundo informe sobre el huracán Mitch [Second report of CENIDH about hurricane Mitch]. Managua: The Nicaraguan Human Rights Centre (CENIDH). Retrieved October 21, 2006, from http://www.gvom.ch/mitch/e11.html

Cernea, M. (1997). The risks and reconstruction model for resettling displaced populations. World Development, 25(10), 1569-1587.

Chambers, R. (1995). Poverty and livelihoods: whose reality counts? Environment and Urbanization, 7(1), 173204.

(2004). Ideas for development: reflecting towards. IDS Working Paper 238. Brighton: Institute of Development Studies.

Chávez, B. \& Thomas, F. (1998, November 18). Clama por insepultos: Sacerdote pide implementos para enterrar [He clamors for unburied: Priest requests equipment to bury]. El Nuevo Diario. Retrieved June 30, 2006, from http://archivo.elnuevodiario.com.ni/1998/noviembre/18-noviembre-1998/nacional/nacional4.html

Chirkov, V., Kim, Y., Ryan, R.M., \& Kaplan, U. (2003). Differentiating autonomy from individualism and independence: a self-determination theory perspective on internalisation of cultural orientations and wellbeing. Journal of Personality and Social Psychology, 84(1), 97-110.

Christman, J. (Ed.) (1989). The inner citadel: essays on individual autonomy. New York: Oxford University Press.

Christman, J. (1998). Autonomy, independence, and poverty-related welfare policies. Public Affairs Quarterly, 12(4), 383-405.

Christman, J. (2003, fall). Autonomy in moral and political philosophy. In Zalta, E.N. (Ed.), The Stanford Encyclopedia of Philosophy. Retrieved April 8, 2005 from http://plato.stanford.edu/archives/fall2003/entries/ autonomy-moral/. Last modified on 27/08/2003

CIDAI (Research Centre of UCA Nicaragua) (1998). La tormenta tropical "Mitch" en Centroamérica: un balance preliminar [The tropical storm "Mitch" in Central America: a preli-minary balance]. Carta a las Iglesias, 413, 1-15 noviembre, 1998. San Salvador: Universidad Centroamericana “José Simeón Cañas". Retrieved October 3, 2006, from http://www.uca.edu.sv/publica/cartas/ci413.html

(2002, January 16). Editorial: very limited results. Proceso, 983. Retrieved April 17, 2007, from http://www.uca.edu.sv/publica/proceso/proci983.html

Chamorro, C.F. (1999, April). Promesas incumplidas en Posoltega [Unfulfilled promises in Posoltega]. Confidencial, 136. Retrieved October 3, 2006, from http://www.confidencial.com.ni/1999-136/html/body_tema _central_1.html

Clark, D.A. (2005.) Sen's capability approach and the many spaces of human well-being. Journal of Development Studies, 41(8), 1339-1368. 
Cleaver, F. (2004a). Institutions, agency and the limitations of participatory approaches to development. In Cooke, B. \& Kothari, U. (Eds.), Participation: the new tyranny? (pp. 36-55). London and New York: Zed Books.

(2004b). The social embeddedness of agency and decision-making. In Hickey, S. \& Mohan, G. (Eds.), Participation: from tyranny to transformation? Exploring new approaches to participation in development (pp. 271277). London and New York: Zed Books.

(2005). The inequality of social capital and the reproduction of chronic poverty. World Development, 33(6), 893-906.

(2007). Understanding agency in collective action. Journal of Human Development, 8(2), 223-244.

Clements, P. (1995). A poverty-oriented cost benefit approach to the analysis of development projects. World Development, 23(4), 577-592.

CODECA (2001). Resultados del diagnóstico rural participativo en el cantón de Agua Fría, municipio de San Alejo, La Unión [Results of the PRA in Agua Fría canton, municipality of San Alejo, La Unión].

(2002b). [The Agua Fría project] Quarterly technical report, February - April 2002.

(2003a). Informe final proyecto SVD/012 [Final report of project SVD/012]. From November 1, 2001 to October 31, 2003. La Unión: October 2003.

(2003b). Diagnóstico general de los cantones Agua Fría, Cercos de Piedra y Mogotillo [General diagnosis of cantons Agua Fría, Cercos de Piedra and Mogotillo]. Project SVD 012. November 2003.

(2003c). Database used for the ex-post diagnosis in the canton of Agua Fría. Provided by J.A Ruiz Sorto, August 2005.

(2003f). [The Agua Fría project] Quarterly technical report, May - July 2003.

Cohen G.A. (1993). Equality of what? On welfare, goods, and capabilities. In Nussbaum, M. \& Sen, A. (Eds.), The quality of life ( $p p$. 9-30). Oxford: Oxford University Press.

Collier, P. (2002). Making aid smart: institutional incentives facing donor organizations and their implications for aid effectiveness. Paper presented at the Forum Series of the Center for Institutional Reform and the Informal Sector [IRIS] on 'The role of institutions in promoting economic growth'. Retrieved on June 24, 2005, from http://www.iris.umd.edu/forum/f2-collier-keynote.pdf

Collier, P. \& Dollar, D. (2002). Aid allocation and poverty reduction. European Economic Review, 46, 1475-1500.

Comin, F. \& Carey, F. (2001, November). Social capital and the capability approach: are Putnam and Sen incompatible bedfellows? Paper presented at the 2001 EAEPE Conference, Siena.

COMURES (2006). [List of mayors and political parties], Association of municipality governments of El Salvador, Retrieved January 19, 2006, from http://www.comures.org.sv/html/agremiados/istado_2003.html

Conway, T. \& Maxwell, S. (1999a). Country programme evaluation: synthesis report from the workshop. In OECD, Evaluating Country Programmes, Vienna Workshop 1999, chapter 1, DAC Working Party on Aid Evaluation.

Cooke, B. \& Kothari, U. (Eds.) (2004). Participation: the new tyranny? London and New York: Zed Books (Original work published 2001).

Cooke, B. \& Kothari, U. (2004). The case for participation as tyranny. In Cooke, B. \& Kothari, U. (Eds.), Participation: the new tyranny? (pp. 1-15). London and New York: Zed Books.

Cooke, B. (2004). The social psychological limits of participation. In Cooke, B. \& Kothari, U. (Eds.), Participation: the new tyranny? (pp. 102-121). London and New York: Zed Books.

Copestake, J. (2007). Poverty and exclusion, resources and relationships: theorising the links between economic and social development. In Gough, I. \& McGregor, J.A. (Eds.), Wellbeing in developing countries: from theory to research (pp. 199-215). Cambridge: Cambridge University Press.

Cornwall, A. \& Gaventa, J. (2001). From users and choosers to makers and shapers: repositioning participation in social policy. IDS Working Paper 127. Brighton: Institute of Development Studies.

Cornwall, A. (2003). Whose voices? Whose choices? Reflections on gender and participatory development. World Development, 31 (8), 1325-1342.

Crawford, P. Swete Kelly, D., Mitchell, C. \& Bryce, P. (2005). Aristotle and Plato at it again? Philosophical divergence within international aid project design and monitoring \& evaluation [electronic paper]. Retrieved June 10, 2008, from http://www.aid-it.com.au/Portals $0 /$ Documents 070105 Aristotle $\% 20$ and $\% 20$ Plato\%20at\%20it\%20again.pdf 
CRDM (2001). Estatutos [Articles of association]. Official Diary, Vol. 353. San Salvador. Published on November $8,2001$.

(2004). [Summary table of the reconstruction works as of December 12, 2004]. Unpublished raw data.

Creswell, J. W. (1998). Qualitative inquiry and research design: choosing among five traditions. Thousand Oaks, CA; London: Sage Publications, Inc.

Crocker, D.A. (1995) Functioning and capability: the foundations of Sen's and Nussbaum's development ethic, Part 2. In Nussbaum, M. \& J. Glover, (Eds.), Women, culture and development: a study of human capabilities (pp. 153-198). Oxford: Clarendon Press.

(2004). Cross-cultural criticism and development ethics. Philosophy \& Public Policy Quarterly, 24(3), 2-8.

Cruz, J. M. (2003). The peace accords ten years later: A citizens' perspective. In Arnson, C. J. (Ed.), El Salvador's democratic transition ten years after the peace accord (pp. 13-36). Washington D.C.: Woodrow Wilson International Center for Scholars.

Cruz, R. (2000, June 12). Damnificados piden ayuda al Gobierno para concluir casas [Survivors request help to the government to conclude houses]. La Prensa. Retrieved October 1, 2006, from http:/wwww.laprensa.com.ni/cgi-bin/print.pl?id=regionales-20000612-06

Cruz Barreiro, I. (2006). Human development assessment through the human-scale development approach: integrating different perspectives in the contribution to a sustainable human development theory. Unpublished doctoral dissertation. Universidad Politècnica de Catalunya, Càtedra UNESCO de Sostenibilitat, Terrasa, Spain.

Cuéllar, N. \& de Larios, S. (2001). Acceso al agua potable en El Salvador: Tendencias, perspectivas y desafíos [Access to potable water in El Salvador: Trends, perspectives and challenges]. PRISMA 42.

Dalgaard, C., H. Hansen, \& Tarp, F. (2004). On the empirics of foreign aid and growth, The Economic Journal, $114,191-216$.

Dallas, S. (2005). Reedbeds for the treatment of greywater as an application of ecological sanitation in rural Costa Rica, Central America. Unpublished doctoral dissertation. Murdoch University, Perth, Western Australia.

Dalton, J.J. (2003, October 20). Violencia doméstica, origen de pandillas en El Salvador [Domestic violence, origin of gangs in El Salvador]. La Opinión Digital. Retrieved April 16, 2007, from http://www.laopinion.com/print.html?rkey=00031019193756862617

Damiani, S. (2003a). [The Agua Fría project] Annual progress report 2002, prepared by the project chief. (2003b). [The Agua Fría project] Quarterly report, July-September 2003.

Davies, R. \& Smith, W. (1998). The basic necessities survey: The experience of ActionAid Vietnam. Hanoi, Vietnam: ActionAid. Retrieved July 17, 2005, from http://www.mande.co.uk/docs/BasicNecessitiesSurvey AAV1998.pdf

Dávila, Y. (2005, December 11). Los del Mitch olvidados en el tiempo... [Those of the Match forgotten in the time...]. El Nuevo Diario. Retrieved October14, 2006, from http://www.elnuevodiario.com.ni/2005/12/11/ nacionales $/ 7777$

De Groot, J. P. (1993). Transformación agraria en Nicaragua en los años ochenta y perspectiva actual [Agrarian transformation in Nicaragua during the eighties and current perspectives]. In Linck T. (Ed.), Agricultures et paysanneries en Amérique Latine : mutations et recompositions (pp. 207-212). Paris: ORSTOM.

(1994). Reforma agraria in Nicaragua: una actualización [Agrarian reform in Nicaragua: an update]. In De Groot J.P. \& Spoor, M. (Eds.), Ajuste estructural y economía campesina: Nicaragua, El Salvador, Centroamérica (pp. 99-121). Managua: Escuela de Economía agrícola (ESECA-UNAM).

De Herdt, T. (2006, November). The circumstances of agency: a relational view on poverty. Paper presented at the international conference of the Institute of Development Policy and Management (IOB) on 'Challenging the poverty reduction paradigm', Antwerp.

De Jong, N. Bedi, A., Ponce, J., \& Vos, R. (2005). Budgeting for Education: Bolivia, Honduras and Nicaragua. Evaluation and monitoring of poverty reduction strategies - 2005. Prepared for the Swedish International Development Cooperation Agency (SIDA). The Hague: Institute of Social Studies (ISS).

De Neubourg, C. \& Weigand, C. (2000). Social policy as social risk management. Innovation: The European Journal of Social Sciences, 13(4), 401-412.

De Renzio, P. (2007). Aid effectiveness and absorptive capacity: Which way aid reform and accountability? Africa after the Africa Commission: What priorities for the German G8? Forum May 2nd, 2007. DFID, DSA, IDS, ODI. 
De Valk, P., Apthorpe, R. \& Guimarães, J. (2005). Local ownership, co-ownership and capacity building in aid projects: the findings of a comparative study, ISS Working Paper Series, 407. The Hague: Institute of Social Studies.

De Vries, P. (1992). Unruly clients: a study of how bureaucrats try and fail to transform gatekeepers, communists and preachers into ideal beneficiaries. Unpublished doctoral dissertation, Wageningen Agricultural University

Deci, E.L. \& Ryan, R.M. (1985). The general causality orientations scale: self-determination in personality. Journal in Research on Personality, 19, 109-134.

(1987). The support of autonomy and the control of behaviour. Journal of Personality and Social Psychology, 53(6), 1024-1037.

(2000). The "what" and "why" of goal pursuits: human needs and the self-determination of behaviour. Psychological Inquiry, 11(4), 227-268.

Deci, E.L., Koestner, R., \& Ryan, R.M. (2001, spring). Extrinsic rewards and intrinsic motivation in education: reconsidered once again. Review of Educational Research, 71(1), 1-27.

Deneulin, S. (2004). Human development, participation and gender. Lectures at the Universidad Centroamericana José Simeón Cañas, San Salvador. Retrieved November 7, 2004, from http:/fas.harvard.edu/ freedoms/ resources 589 CAtraining_Deneulin_english.pdf (2006a). The capability approach and the praxis of development. New York: Palgrave Macmillan. (2006b). Individual well-being, migration remittances and the common good. European Journal of Development Research, 18(1), 45-58.

Devereux, S. (2001). Sen's entitlement approach: critiques and counter-critiques. Oxford Development Studies, 29(3), 245-263.

Devine, J., Camfield, L. \& Gough, I. (2006). Autonomy or dependence - or both? Perspectives from Bangladesh. Journal of Happiness Studies, 9, 105-138.

Diener, E. \& Biswas-Diener, R. (2005). Psychological empowerment and subjective well-being. In: Narayan, D. (Ed.), Measuring empowerment: cross-disciplinary perspectives (pp. 125-140). Washington, D.C.: World Bank.

DIGESTYC [General Directorate of Statistic and Censuses of El Salvador] (2007). Household surveys reports, several years (1998-2005) and secondary data statistics. Retrieved April 22, 2007, from http://www.digestyc.gob.sv/

Dijkstra, G. (2005). The PRSP approach and the illusion of improved aid effectiveness: lessons from Bolivia, Honduras and Nicaragua. Development Policy Review, 23 (4), 443-461.

Dio, W.M. (2004). Volume 2: Country study Nicaragua. National monitoring of sustainable poverty reduction strategies / PRSPs. Eschborn: GTZ GmbH.

Dollar, D., \& Levin, V. (2004). The increasing selectivity of foreign aid, 1984-2002. World Bank Policy Research Working Paper 3299. World Bank.

Douglas, M. (2004). Traditional culture - Let's hear no more about it. In Rao, V. \& Walton, M. (Eds.), Culture and public action (pp. 85-109). Stanford: Stanford University Press.

Doyal, L., \& Gough, I. (1991). A theory of human need. London: Macmillan Press Ltd.

Drèze, J., \& Sen, A. (2002). India: development and participation. Oxford: Oxford University Press.

Drydyk, J. (2006, August). Empowerment and power: some conceptual analysis. Paper presented at the 2006 International Conference of the Human Development and Capability Association, contribution to panel 'Evaluating the World Bank's measuring empowerment', Groningen, Netherlands.

Duncan, L.E. (1999). Motivation for collective action: group consciousness as mediator of personality, life experiences, and women's right activism. Political Psychology, 20(3), 611-635.

Durham, W.H. (1979). Scarcity and survival in Central America: ecological origins of the soccer war. Stanford: Stanford University Press.

Dworkin, G. (1976). Autonomy and behavior control. The Hastings Center Report, 6(1), 23-28. (1988). The theory and practice of autonomy. Cambridge: Cambridge University Press.

Earl, S., Carden, F. \& Smutylo, T. (2002). Outcome Mapping: building learning and reflection into development programs. Ottawa: International Development Research Centre (IDRC).

Easterly, W. (2002). The cartel of good intentions: bureaucracy versus markets in foreign aid. Working Paper 4. Center for Global Development (CGD), Institute for International Economics. 
(2006a). The white man's burden: Why the West's efforts to aid the Rest have done so much ill and so little good. New York: Penguin Books.

(2006b). Can the West save the Rest? [Transcript prepared from a tape recorder]. Washington D.C.: Center for Global Development (CGD), March 23, 2006. Retrieved May 20, 2006 from http://www.cgdev.org/doc/ event\%20docs/transcript_Easterly.pdf

EC (European Commission) (2004). Project cycle management guidelines. Aid Delivery Methods (Vol. 1). Brussels: EuropeAid Cooperation Office.

ECLAC (Economic Commission for Latin American and the Caribbean) (1999). Nicaragua: assessment of the damage caused by Hurricane Mitch, 1998. Implications for economic and social development and for the environment.

(2001a). El Salvador: Evaluación del terremoto del martes 13 de febrero del 2001 (Addendum al documento de evaluación del terremoto del 13 de enero) [El Salvador: Evaluation of the earthquake of Tuesday 13 February 2001 (Addendum to the evaluation report of the earthquake of 13 January)], Mexico: ECLAC.

(2001b). La estructura agraria y el campesinado en El Salvador, Guatemala y Honduras [The agrarian structure and peasantry in El Salvador, Guatemala and Honduras].

(2005). Latin America: urban and rural population projections 1970-2025, Demographic Bulletin, year XXXVIII, No. 76, ECLAC, Latin American and Caribbean Demographic Centre (CELADE) - Population Division, Santiago, Chile.

(2007a). Cohesión social: inclusión y sentido de pertenencia en América Latina y el Caribe [Social cohesion: inclusion and sense of belonging in Latin American and the Caribbean]. Santiago de Chile: United Nations.

(2007b). Latin America and the Caribbean statistics: CEPALSTAT. Retrieved April 15, 2007, from http://websie.eclac.cl/sisgen/consultaintegrada.ASP

Eggers, H.W. (1998). Project cycle management revisited. The Courier, 169, 69-72.

Eisenhardt, K.M. (1989). Building theories from case study research. Academy of Management Review, 14(4), 532550.

Eklund, L. (1999). From citizen participation towards community empowerment: an analysis on health promotion from citizen perspective. Academic dissertation, Faculty of Medicine of the University of Tampere.

Ekstrom, L.W. (1993). A coherence theory of autonomy. Philosophy and Phenomenological Research, 53(3), 599-616.

El Diario de Hoy (2001, February 17). Luxemburgo reconstruirá San Agustín [Luxembourg will reconstruct San Agustin]. Retrieved September 7, 2006, from http://www.elsalvador.com/noticias/2001/2/17/NACIONAL/ nacio1.html

Ellerman, D. (2001). Helping people help themselves: towards a theory of autonomy-compatible help. Policy Research Working Paper 2693. Washington D.C.: World Bank.

(2004). Autonomy-respecting assistance: toward an alternative theory of development assistance. Review of Social Economy, LXII (2), June 2004.

(2006). Helping people help themselves: from the World Bank to an alternative philosophy of development assistance. Ann Harbor: The University of Michigan Press.

(2007). Helping self-help: the fundamental conundrum of development assistance., The Journal of SocioEconomics, 36, 561-577.

Emirbayer, M., \& Mische, A. (1995). What is agency? American Journal of Sociology, 103(4), 962-1023.

Enríquez, L.J. (2000). The varying impact of structural adjustment on Nicaragua's small farmers. European Review of Latin American and Caribbean Studies, 69, 47-68.

Envío Team (1983). ¿Pacificar o liberar a los campesinos? Reforma Agraria en El Salvador y Nicaragua [To pacify or to free peasants? Agrarian reform in El Salvador and Nicaragua]. Revista Envío, 26. Retrieved February 4, 2006, from http://www.envio.org.ni/articulo/88

(1987). Nicaragua. Los contras: Una derrota anunciada [The contras: an announced defeat]. Revista Envío, 68. February 1987. Retrieved June 18, 2007, from http://www.envio.org.ni/articulo/511

(1998). How Managua saw the passage of hurricane Mitch. Revista Envío, 209. Retrieved September 30, 2006, from http://www.envio.org.ni/articulo/1363

Escobar, I. (2007, January 26). Comunidad Linares Cabrotal aún resiente efectos de la guerra [Community Linares Cabrotal still resents war effects]. Diario CoLatino. Retrieved February 4, 2007, from http://www.diariocolatino.com/nacionales/detalles.asp?NewsID=15347 
Evans, P. (2002). Collective capabilities, culture and Amartya Sen's Development as Freedom. Studies in Comparative International Development, 37 (2), 54-60.

Everingham, M. (2001). Agricultural property rights and political change in Nicaragua, Latin American Politics $\mathcal{E}$ Society, 43 (3), 61-93.

Eyben, R. (2004). Linking power and poverty reduction. In Alsop, R. (Ed.), Power, rights, and poverty: concepts and connections (pp. 15-28). Washington, DC and London: World Bank and DFID.

Feinberg, J. (1989). Autonomy. In Christman, J. (Ed.), The inner citadel: essays on individual autonomy (pp. 27-53). New York: Oxford University Press.

FESPAD (2002a). [The San Agustín project] First report, January - June 2002. (2002b). [The San Agustín project] Second report, July - September 2002. (2002c). [The San Agustín project] Third report, October - December 2002. (2003a). [The San Agustín project] Fourth report, January - March 2003. (2003e). FESPAD 15 años 1988-2003 [15th Anniversary]. San Salvador: FESPAD. (2005a). [The San Agustín project] Positive and negative aspects of the project, unpublished raw data.

FISDL (Salvadoran social investment fund) (2003). Estrategia Nacional de Desarrollo Local: Avances del trabajo realizado por el FISDL en el marco de la ENDL período 1999-Agosto 2003 [National strategy of local development: Progress by FISDL in 1999-August 2003 period]. San Salvador: FISDL.

(2005). San Agustín en Usulután y Préizerdaul en Luxemburgo firman importante protocolo de hermanamiento [San Agustin in Usulutan and Preizerdaul in Luxembourg sign important sister cities agreement]. Retrieved February 4, 2007, from http://docu.fisdl.gob.sv/index2.php?option=com_content\&do_pdf=1\&id $=451$

FLACSO [Latin American Faculty of Social Sciences] (2005a). Mapa de pobreza: política social y focalización [Poverty map: social policy and targeting] (Vol. I). San Salvador: FISDL.

(2005b). Politica social y focalización: El mapa nacional de pobreza extrema [Social policy and targeting: the national extreme poverty map]. [Presentation], Retrieved February 21, 2007, from http://gateway.infocentros.org.sv/instituciones/flacso/archivos/0/archivo_19.pps

Florisbelo, G.C. \& Guijt, I. (2004). Participatory municipal development plans in Brazil: divergent partners constructing common futures. In Hickey, S. \& Mohan G. (Eds.), Participation: from tyranny to transformation? Exploring new approaches to participation in development (pp. 190-204), London and New York: Zed Books.

Frankfurt, H. (1989). Freedom of the will and the concept of a person. In Christman, J. (Ed.), The inner citadel: essays on individual autonomy (pp. 63-76). New York: Oxford University Press.

Friedmann, J. (1992). Empowerment: the politics of alternative development. Cambridge: Blackwell Publishers.

Fuentes, R. (2002, October 27). Capturan supuesta banda de "Juan Gallina" [The supposal band of "Juan, the hen" is captured]. El Diario de Hoy. Retrieved May 8, 2005, from http:/Www.elsalvador.com/noticias/ 2002/10/27/elpais/elpais3.html

Fuentes, R. (2003, January 14). PNC afirma tener pistas: “Uniformados” operan en sector de San Agustín [National police says to have hints: Uniformed people operate in sector of San Agustin]. El Diario de Hoy. Retrieved September 7, 2006, from http://www.elsalvador.com/noticias/2003/1/14/elpais/elpais9.html

FUNDAMUNI (1999). Diagnóstico rural participativo con enfoque de género (DRPEG) [PRA with gender approach]. Municipality of San Agustín, Department of Usulután. Project AGUA. Consortium CARE, FUNDAMUNI, Salva NATURA, SACDEL. Financed by USAID.

(2001). Estrategia para apoyar procesos de desarrollo local con participación de la población [Strategies to support processes of local development with participation of the population]. Project AGUA. Consortium CARE, FUNDAMUNI, Salva NATURA, SACDEL. Financed by USAID.

(2005). FUNDAMUNI en breve [Fundamuni at a glance]. San Salvador. Unpublished raw data.

FUNDASAL (2002c). [The San Agustin project] Third quarterly report 2002. (2002d). [The San Agustín project] Fourth quarterly report 2002.

(2003a). [The San Agustin project] First quarterly report 2003.

(2003b). [The San Agustín project] Second quarterly report 2003.

(2003c). [The San Agustín project] Third quarterly report 2003. 
(2005b). [The San Agustín project] Summary tables of beneficiaries by sex, by family situation, by household size and by occupation. Unpublished raw data.

(n.d). La promoción social en el desarrollo de procesos participativos [The social promotion in the development of participatory processes]. Retrieved May 10, 2005, from http:/wwww.fundasal.org.sv/paginas/ frame06.html

FUNDE [National Development Foundation] (2005). GPN global labor market database: El Salvador, 2005. Global Policy Network. Retrieved April 27, 2007, from http://gpn.org/data/elsalvador/el-salvador-data.pdf

García Peñate, O. (Coord.) (2005). El Salvador sociología general: realidad nacional de fin de siglo y principio del milenio [El Salvador General Sociology: National reality of end of century and beginning of millennium] (2nd ed.). San Salvador: Nuevo Enfoque (Original work published 2003).

Gasper, D. (1999). Problems in the logical framework approach and challenges for project cycle management. The Courier, 173, 75-77.

(2000a). Development as freedom: taking economics beyond commodities -the cautious boldness of Amartya Sen. Journal of International Development, 12, 989-1001.

(2000b). Evaluating the 'logical framework approach' towards learning-oriented development evaluation. Public Administration and Development, 20, 17-18.

(2000c). Anecdotes, situations, histories: varieties and uses of cases in thinking about ethics and development practice. Development and Change, 31, 1055-1083.

(2003). Nussbaum's capabilities approach in perspective: purposes, methods and sources for an ethics of human development. ISS Working Paper Series, 379. The Hague: Institute of Social Studies (ISS).

. (2004). The ethics of development. Edinburgh: Edinburgh University Press.

(2007). Conceptualising human needs and wellbeing. In Gough, I. \& McGregor, J.A. (Eds.), Wellbeing in developing countries: from theory to research (pp. 47-70). Cambridge: Cambridge University Press.

Gasper, D. \& Cameron, J. (2000). Introduction: Assessing and extending the work of Amartya Sen. Journal of International Development, 12, 985-988.

Gaventa, J. (2004). Towards participatory governance: assessing the transformative possibilities. In Hickey, S. \& Mohan, G. (Eds.), Participation: from tyranny to transformation? Exploring new approaches to participation in development (pp. 25-41). London and New York: Zed Books.

Giddens, A. (1984). The Constitution of Society. Outline of the Theory of Structuration. Cambridge: Polity.

Giri, A. K. (2000). Rethinking human well-being: a dialogue with Amartya Sen. Journal of International Development, 12, 1003-1018.

GOES (Government of El Salvador) (2001). El Salvador que queremos: Unidos por la reconstrucción [El Salvador that we want: united for the reconstruction]. Ministry of Foreign Affairs. Retrieved May 16, 2005, from http:/www.rree.gob.sv/sitio/sitio.nsf/23e5e39594c064ee852564ae004fa010/f52c88683d17602606256a16007e1 b18 \$FILEMAPA.DA\%C3\%91OS.pdf

GOL (Government of Luxembourg) (2004). About... development cooperation. Luxembourg: GOL, Information and press services.

(2008). National report of Luxembourg: Implementing the internationally agreed goals and commitments in regard to sustainable development. Retrieved July 14, 2008, from https:/wwww.mae.lu/images/biblio/ biblio-251-65_axzig_5956_5042_585.pdf

GOL \& GOES (2002). Programa indicativo de cooperación entre el gobierno del gran ducado de Luxemburgo y el gobierno de la república de El Salvador [Indicative cooperation programme between the government of the Grand Duchy of Luxembourg and the government of the Republic of El Salvador] 2003-2006.

Gómez Sabaini, J.C. \& Geffner, M. (2006). Nicaragua: el papel de los municipios como instrumento para el combate de la pobreza [Nicaragua: the role of municipality governments as tools to alleviate poverty]. Medio Ambiente y Desarrollo series, 131, Santiago de Chile: ECLAC.

GON (Government of Nicaragua) (1999). Nicaragua: Huracán Mitch. Daños, costos, acciones de rehabilitación del Gobierno y la Cooperación Internacional [Hurricane Mitch. Damages, costs, rehabilitation actions of government and international cooperation]. Report prepared for the meeting of the consultative group in Stockholm, Sweden. Retrieved November 12, 2006, from http://www.iadb.org/regions/re2/consultative_group/ plans/nicaragua_esp.htm 
(2001a). Mapa de pobreza extrema de Nicaragua: Censo 1995 - EMNV 1998 [Nicaragua's extreme poverty map].

Retrieved January 19, 2006 from http://www.inec.gob.ni/bibliovirtual/publicacion/mapapobreza2001.pdf

(2001b). Estrategia reforzada de crecimiento económico y reducción de pobreza [Strengthened growth and poverty reduction strategy]. Managua: Technical Secretary of the Presidency (SETEC).

(2005). National development plan. Managua: SETEC.

(2006a) Informe liquidación del Presupuesto General de la República 2005 [Liquidation of the general budget report] General Budget Directorate, Ministry of Finances and Public Credit, Managua.

(2006b) [Disbursements of external resources] System of Official Development Assistance for Nicaragua, Secretariat of Economic Relations and Cooperation, Ministry of Foreign Affairs.

GON \& GOL (2003). Programa indicativo de cooperación entre el gobierno del gran ducado de Luxemburgo y el gobierno de la república de Nicaragua [Indicative cooperation programme between the government of the Grand Duchy of Luxembourg and the government of the Republic of Nicaragua] 2003-2006.

González, J.L. (2003, October 28). Sobrevivientes del Casita construyendo vida y esperanza en El Tanque [Casita's survivors constructing life and hope in El Tanque]. La Prensa. Retrieved October 14, 2006, from http:/www-ni.laprensa.com.ni/archivo/2003/octubre/28/regionales/regionales-20031028-02.html

Gonzalez, S. (2001, January 18). San Agustín: El delirio de un pueblo devastado por la tragedia [San Agustín: The delirium of a town desolated by the tragedy]. La Prensa. Retrieved May 8, 2005, from http://archive.laprensa.com.sv/20010118/nacionales/nac41.asp

Gore, C. (1997). Irreducible social goods and the informational basis of Amartya Sen's capability approach. Journal of International Development, 9(2), 235-250.

Gosparini, P., Carter, R., Hubbard, M., Nickson, A., \& Ocón Núñez, L. (2006). Nicaragua country report, Joint Evaluation of General Budget Support 1994-2004: Burkina Faso, Malawi, Mozambique, Nicaragua, Rwanda, Uganda, Vietnam, International Development Department, University of Birmingham (IDD), under the auspices of the DAC Network on Development Evaluation, OECD.

Gough, I. (2003). Lists and thresholds: comparing the Doyal-Gough theory of human need with Nussbaum's capabilities approach. WeD Working Paper 01. Bath: ESRC Research Group on Wellbeing in Developing Countries.

(2004). Human well-being and social structures. Global Social Policy, 4(3), 289-311.

Gough, I. \& Wood, G. (2006). A comparative welfare regime approach to global social policy. World Development, 34(10), 1696-1712.

Gough, I. \& McGregor, J.A. (Eds.) (2007). Wellbeing in developing countries: from theory to research. Cambridge: Cambridge University Press.

Gough, I., McGregor, J.A. \& Camfield, L. (2007). Theorising wellbeing in international development. In Gough, I. \& McGregor, J.A., (Eds.), Wellbeing in developing countries: from theory to research (pp. 3-43). Cambridge: Cambridge University Press.

Goulet, D. (1983). Obstacles to world development: an ethical reflection. World Development, 11(7), 609-624. (1989). Participation in development: new avenues. World Development, 17(2), 165-178.

Grigsby, W. (2004). Nicaragua, 2004 Municipal elections: FSLN-Convergence Victory in Numbers. November 2004. Revista Envío, 280. Retrieved December 1, 2006, from http://www.envio.org.ni/articulo/2672

Grunewald, F., Pirotte, C. \& de Geoffroy, V. (2001). An experimental and inclusive approach to evaluation as a lesson-learning tool: Groupe URD's work on the post-hurricane Mitch emergency. In Wood, A., Apthorpe, R. \& Borton, J. (Eds.), Evaluating international humanitarian action: Reflections from practitioners (pp. 153-170). London: Alnap.

Guaraldo Choguill, M. B. (1996). A ladder of community participation for underdeveloped countries. Habitat International, 20 (3), 431-444.

Guba, E.G., \& Lincoln, Y.S. (1998). Competing paradigms in qualitative research. In Denzin N.K. \& Lincoln, Y.S. (Eds.), The landscape of qualitative research (pp. 195-220). Thousand Oaks, CA: Sage.

Guglielmi, G. (2004). [The San Fernando Project] Estudio de la encuesta socioeconómica de Agua y Saneamiento [Study of socioeconomic survey of Water and Sanitation]. Consultancy Report. Managua: CARE.

Guimarães, J. \& Avendaño, N. (2004). A strategy without an owner? The experience of the poverty reduction strategy in Nicaragua. Executive summary. Evaluation and Monitoring of Poverty Reduction Strategies (PRS) in Latin America - 2003. Prepared for SIDA. The Hague: ISS. 
Gutiérrez, R. (2007). DDHH - El Salvador: Amnistía pone barreras a la democracia [El Salvador: Amnesty blocks democracy]. Inter Press Service (IPS) News Agency. Retrieved April 15, 2007, from http://hpsnoticias. net/print.asp?idnews $=40454$

Hagen-Zanker, J. \& Muñiz Castillo, M. (2006). Exploring multi-dimensional wellbeing and remittances in El Salvador. MGSoG Working Paper, 2. Maastricht: Maastricht University.

Hailey, J. (2004). Beyond the formulaic: process and practice in South Asian NGOs. In Cooke, B. \& Kothari, U. (Eds.), Participation: the new tyranny? (pp. 88-101) London and New York: Zed Books.

Harvey, P. \& Lind, J. (2005). Dependency and humanitarian report: a critical analysis. HPG Research Report 19. London: Overseas Development Institute.

Hawthron, G. (Ed.) (1987). The standard of living: the Tanner lectures. Cambridge: Cambridge University Press.

Henríquez, A. (2006a, January 15). Los 20,000 km más letales [The 20,000 most lethal km]. La Prensa Gráfica. Retrieved April 25, 2007, from http:/Aaprensa.com.sv/enfoques/394579.asp

Henríquez, A. (2006b, December 4). Perla llega a El Salvador y amenaza con implicar a otros ex funcionarios [Perla arrives to El Salvador and threatens to implicate other former officials]. Elfaro.net. Retrieved January 12, 2006, from http://www.elfaro.net/secciones/Noticias/20061204/noticias1_20061204.asp\#

Hernández Ramos, N. (2000). Posoltega bebe agua contaminada [Posoltega drinks polluted water]. La Prensa. Retrieved [25/06/2006] from http://www-ni.laprensa.com.ni/archivo/2000/octubre/30/nacionales/nacionales20001030-06.html

Herrera, A.E. (2003). Francisco Flores, un memorial de corrupción al frente de la presidencia de El Salvador [Fernando Flores, a brief of corruption in front of the presidency of El Salvador]. Boletín Incidencia y Compromiso. Pastoral Social Cáritas Panamá. Retrieved January 12, 2007, from http:/wwww.caritaspanama.org/ incidencia/realidad_lc/fransisco_flores_memorial_corrupcion.htm

Herrera Hernández, Y.K., González Ortez, O.A., Ortez Herrera, P., Ruiz Abraham, B.R., \& Mejía Bautista, X. (2004). Proyecto de rehabilitación de agua potable en el municipio San Fernando [Project to rehabilitate the potable water service in San Fernando]. San Fernando, Nicaragua: Institute Padre José Carlos Jirón.

Hertvik, N. (2002). El Salvador: effecting change from within. UN Chronicle, 39 (3). Retrieved June 3, 2006, from http://www0.un.org/Pubs/chronicle/2002/1ssue3/0302p75_el_salvador.html

Heston, A., Summers, R. \& Aten, B. (2002). Penn World Table Version 6.1, Center for International Comparisons at the University of Pennsylvania (CICUP). Retrieved August 2, 2005, from http://pwt.econ.upenn.edu/php_site/pwt61_form.php

Heyer, J., Stewart, F. \& Thorp, R. (Eds.) (2002). Group behaviour and development: Is the market destroying cooperation? Oxford: Oxford University Press.

Hickey, S. (2005). Capturing the political? The role of political analysis in the multi-disciplining of development studies. GPRG Working Paper Series, 6, ESCR Global poverty research group (GPRG).

Hickey, S. \& Mohan, G. (Eds.) (2004). Participation: from tyranny to transformation? Exploring new approaches to participation in development. London and New York: Zed Books.

Hickey, S. \& Mohan, G. (2005). Relocating participation within a radical politics of development, Development and Change, 36(2), 237-262.

Hindess, B. (1986). Actors and social relations. In Wardell, M.L. \& Turner, S.P. (Eds.), Sociological theory in transition. (pp. 113-126). Boston, MA: Allen \& Unwin.

Hinrichsen, D., Robey, B., \& Upadhyay, U.D. (1998). Solutions for a water-short world. Population Reports, 26(1), Baltimore: Johns Hopkins School of Public Health, Population Information Program. Retrieved February 6, 2006, from http://www.infoforhealth.org/pr/m14edsum.shtml

Hirschman, A.O. (1967). Development projects observed. Washington, D.C.: The Brookings Institution (reissued 1995).

(1970). Exit, voice, and royalty: responses to decline in firms, organizations, and states. Cambridge, Massachusetts: Harvard University Press.

(1984). Getting ahead collectively: grassroots experiences in Latin America. Published as a supplement to World Development (Vol. 12). New York: Pergamon Press.

Hoddinott, J. (1999). The shift from development to emergency assistance and its impact on poverty and nutrition: a conceptual framework. Paper presented at the Conference of the IDB, Poverty and Inequality Advisory Unit of the Sustainable Development Department on Social Protection and Poverty, Washington D.C. 
Hofmann, C., L. Roberts, J. Shoham, \& Harvey P. (2004). Measuring the impact of humanitarian aid: a review of current practice. HPG Research Report $\mathrm{n}^{\circ} 17$. London: Overseas Development Institute.

Hodgson, G. (2006). What are institutions? Journal of Economic Issues, 40(1), 1-25.

Holland, J. \& Brook S. (2004, July). Measuring empowerment: country indicator. Draft paper for discussion, The World Bank's empowerment team.

Holzmann, R. \& Jørgensen, S. (2000). Social risk management: a new conceptual framework for social protection, and beyond. Social Protection Discussion Paper, 6, Washington: The World Bank.

Howard, J. (n. d.). Write ups on Estelí's participatory planning initiative. Excerpt from master thesis on the role of citizen participation in local governance. Retrieved April 6, 2007, from http:/wwww.ids.ac.uk/logolink/resources/downloads/PPcase_studies/Nicaragua-Esteli1.doc

Hsieh, H., \& Shannon, S.E. (2005, November). Three approaches to qualitative content analysis. Qualitative Health Research, 15(9), 1277-1288.

IACHR (The Inter-American Commission on Human Rights) (1994). Informe sobre la situación de los derechos humanos en El Salvador [Report on human rights in El Salvador]. Retrieved April 14, 2007, from http://www. cidh.org/countryrep /ElSalvador94sp/indice.htm

Ibrahim, S. \& Alkire, S. (2007, May). Agency and empowerment: a proposal for internationally comparable indicators. Paper prepared for the workshop on 'Missing directions of poverty data', Oxford, UK. Retrieved on June 4, 2007, from http:/łwww.ophi.org.uk/pubs/Ibrahim_Alkire_Empowerment_Final.pdf

IDA (International Development Association) (2004a). Country Policy and Institutional Assessments: 2004 Assessment Questionnaire, Operations Policy and Country Service, Retrieved May 24, 2006 from http://siteresources. worldbank.org/DA/Resources/CPIA2004questionnaire.pdf

(2004b). Summary of the performance-based allocation system for IDA14, Annex 1, Retrieved May 24, 2006 from http://siteresources.worldbank.org/DAResources/ANNEX1CPIA.pdf

IDB (Inter-American Development Bank) (1999). El Salvador national reconstruction Plan. Consultative Group meeting for the reconstruction and transformation of Central America. Retrieved April 17, 2007, from http://www.iadb.org/regions/re2/consultative_group/plans/elsalvador.htm

(2005). El Salvador: IDB country strategy with El Salvador.

IDS (Institute of Development Studies) (2005). Increased aid: minimising problems, maximising gains. IDS Policy Briefing, 25.

Imhof, V. (2003, December 28). Le dan casa pero sigue su angustia [She got a house but her anguish continues]. El Nuevo Diario. Retrieved October 22, 2006, from http://archivo.elnuevodiario.com.ni/2003/diciembre/28diciembre-2003/nacional/naciona19.info

Imhof, V. (2004, March 15). Continúa calvario de víctimas del Casitas [Calvary for victims of Casitas continues]. El Nuevo Diario. Retrieved October 22, 2005, from http://archivo.elnuevodiario.com.ni/2004/marzo/ 15-marzo-2004/nacional/nacional19.html

INEC (National Institute of Statistics and Censuses of Nicaragua) (2002a). III Censo nacional agropecuario CENAGRO [III National agricultural census]. Retrieved November 19, 2006, from http:/www.inec.gob.ni/ cenagro/portaltabulados.htm

(2002b). Perfil agropecuario de Nueva Segovia [Agricultural profile of Nueva Segovia]. Retrieved November 19, 2006, from http://www.inec.gob.ni/cenagro/perfiles $/ 05 \% 20$ Nueva\%20Segovia.pdf

(2003). Perfil comparativo de la pobreza en Nicaragua [Encuesta Nacional de Hogares sobre Medición de Nivel de Vida) 1993-1998-2001 [Comparative poverty profile in Nicaragua (Living Standards Measurement Survey)]. Managua: INEC.

(2006). Resumen Censal: Censo Nacional, 2005 [Summary report of 2005's national census]. VIII Censo de Población y IV de Vivienda. Managua: INEC. Retrieved November 26, 2006, from http:/www.inec.gob.ni/ censos2005/ResumenCensal/RESUMENCENSAL.zip

INEC \& MINSA (2002). Encuesta Nicaragüense de Demografía y Salud, ENDESA 2001 [Nicaraguan survey of demographics and health]. Managua: INEC, MINSA, USAID, SIDA, WB/FISE, IDB/PMSS, UNDP, UNPF

INIDE [National Institute of Information for Development] (2007). Perfil y características de los pobres en Nicaragua 2005. Encuesta de hogares sobre medición del nivel de vida [Profile and characteristics of the poor in Nicaragua 2005. Living conditions measurement survey]. Managua: INIDE, MECOVI programme. 
Innocenti, Z. de (2005) Situación de la violencia de género en El Salvador [Situation of gender violence in El Salvador], Antigua Guatemala: Salvadoran Institute for Woman's Development (ISDEMU).

Israel B., Checkoway B., Schultz A., \& Zimmerman M. (1994). Health education and community empowerment: Conceptualizing and measuring perceptions of individual, organizational, and community control. Health Education Quarterly, 21(2), 149-170.

ISTA [Salvadoran Institute of Agrarian Transformation] (2005). Reforma agraria y desarrollo rural en El Salvador [Agrarian reform and rural development in El Salvador]. Paper prepared for the International Conference 'A Vision for the Future' on Agrarian Reform and Rural Development, Porto Alegre, Brazil.

Jasek-Rysdahl, K. (2001). Applying Sen's capabilities framework to neighbourhoods: using local asset maps to deepen our understanding of well-being. Review of Social Economy, 59 (3), 313-329.

Johnson, C. (2001). Local democracy, democratic decentralisation and rural development: theories, challenges and options for policy. Development Policy Review, 19(4), 521-532.

Johnson, H. (2007). Communities of practice and international development. Progress in Development Studies, 7(4), 277-90.

Johnston, B.F. \& Kilby, P. (1975). Agricultural development and structural transformation. New York: Oxford University Press.

Johnston, R.J., Gregory, D., Pratt, G. \& Watts, M. (2000). The dictionary of human geography (4th ed.). Oxford: Blackwell Publishing Ltd.

Kabeer, N. (1999). The conditions and consequences of choice: reflections on the measurement of women's empowerment. UNRISD Discussion Paper 108. Geneva: United Nations Research Institute for Social Development.

(2000). The power to choose: Bangladeshi women and labour market decisions in London and Dhaka. London: Verso.

Karl, T.R. (1995). The hybrid regimes of Central America. Journal of Democracy, 6 (3), 72-86.

(2003). Comment: The nature of the political transition: advances and setbacks in democratic consolidation. In Arnson, C.J. (Ed.), El Salvador's democratic transition ten years after the peace accord (pp. 37-43). Washington D.C.: Woodrow Wilson International Center for Scholars.

Kandel, S. (2002). Migraciones, medio ambiente y pobreza rural en El Salvador [Migrations, environment and rural poverty in El Salvador]. San Salvador: Fundación Prisma.

Kelly, U. (2004). Confrontations with power: moving beyond 'the tyranny of safety'. In Hickey, S. \& Mohan G. (Eds.), Participation: from tyranny to transformation? Exploring new approaches to participation in development (pp. 205-218). London and New York: Zed Books.

Kelsall, T. \& Mercer, C. (2003). Empowering people? World Vision \& 'transformatory development in Tanzania. Review of African Political Economy, 96, 293-304.

Kerle, N., Wyck de Vries, B. (van), and Oppenheimer, C. (2003). New insight into the factors leading to the 1998 flank collapse and lahar disaster at Casita volcano, Nicaragua. Bull Volcanol, 65, 331-345. Retrieved [13/06/2006] from http:/www.geo.mtu.edu//hnlechne/volcanicpapers/KerleBV.pdf

King, A. (2004). Structure and agency. In King, A., The structure of social theory (chapter 1). London: Routledge. Retrieved November 8, 2005 from http://www.ex.ac.uk/ acking/Papers/AfterStructCh1.doc

Kleemeier, E. (2000). The impact of participation on sustainability: An analysis of the Malawi rural piped scheme program. World Development, 28 (5), 929-944.

Kothari, U. (2004). Power, knowledge and social control in participatory development, in Cooke, B. and Kothari, U. (Eds.) Participation: the new tyranny? (pp. 139-152) London and New York: Zed Books.

Kowalchuck, L. (2003). From competition to cooperation: threats, opportunities, and organizational survival in the Salvadorian Peasant movement. European Review of Latin American and Caribbean Studies, 74, 43-63.

Lara López, E. (2003, June). La contribución de la industria maquiladora al desarrollo económico de El Salvador [The contribution of maquila industry to El Salvador's economic development]. Paper presented at the $1^{\text {st }}$ international meeting about development and regional integration in South Mexico and Central America. Retrieved April 27, 2007, from http://is.ucr.ac.cr/pagWeb/publicaciones/tlc/integracion/mesa2/Edgar_Lara.pdf

Lathrop, G. (2004). Desarrollo económico local y alivio de la pobreza en Bolivia, Honduras y Nicaragua [Local economic development and poverty alleviation in Bolivia, Honduras and Nicaragua]. Evaluation and Moni- 
toring of Poverty Reduction Strategies - 2004. With collaboration of J.P. Pérez Sáenz, Y. Ceciliano, J. Aguilar, and J. Valdéz. Prepared for the SIDA. The Hague: FLACSO-Costa Rica and the ISS.

Latinobarómetro (2004). Informe resumen Latinobarómetro 2004: Una década de mediciones [Summary report Latinobarometro 2004: A decade of measurements]. Santiago de Chile: Corporación Latinobarómetro.

(2005). Informe Latinobarómetro 2005: 1995-2005. Diez años de opinión pública, 176.554 entrevistas, 10 mediciones en 18 países [Latinobarometro Report 2005: 1995-2005. Ten years of public opinión, 176.554 interviews, 10 measurements in 18 countries]. Santiago de Chile: Corporación Latinobarómetro.

LD (Lux Development S.A.) (1999a). NIC 009 Reconstrucción Posoltega [Reconstruction Posoltega]. Formulation report. Prepared by M. Riehl, and approved by F.A. Koos. May 1999. Luxembourg: LD.

(2001a). SVD/012 Agua y medio ambiente: San Alejo [Water and environment: San Alejo]. Formulation report. September 2001. Luxembourg: LD.

(2001b). El Salvador: misión de formulación (del 11 al 16 de septiembre) [El Salvador: formulation mission (from 11 to 16 September)]. Elaborated by M. Demare (consultant) and P. Rossignol.

(2001c). SVD/016 Reconstrucción San Agustín [Reconstruction San Agustin]. Formulation report. September 2001.

(2002a). NIC 012 Agua potable Nueva Segovia y Madriz [Drinking water Nueva Segovia and Madriz]. Formulation report. October 2002. Luxembourg: LD.

(2002b). SVD 008 y SVD 011 Agua potable San Agustín - El Tamarindo. Final Report. March 2002.

(2003a). Informe final de la misión de clausura, SVD/012 Agua y medio ambiente: San Alejo [Final report of the closure mision]. Prepared by S. Sandoz, S.H.E.R. Ingenieros Consultores S.A. December 2003.

(2003b). Proyecto agua y medio ambiente San Alejo [Project water and environment San Alejo]. [DVD]. Prepared by Pro Art El Salvador and supervised by S. Damiani and N. Levy. December 2, 2003.

(2004a). Análisis socio-económico de las encuestas con miras a definir la capacidad de pago de los beneficiarios del proyecto NIC/012 en relación con el costo del servicio de agua potable [Socioeconomic analysis of surveys to define the payment capacity of NIC 012's beneficiaries in regard to the cost of the drinking water service]. Memorandum addressed to ENACAL. Ocotal, Project NIC $/ 012$ staff (revised version August 10, 2004).

(2004b). Informe Final, SVD/012 Agua y Medio Ambiente: San Alejo [Final Report]. May 2004.

(2005a). Informe de evaluación de medio término, NIC 012 Agua potable Nueva Segovia y Madriz [Intermediate evaluation report, Drinking water Nueva Segovia and Madriz], prepared by D. Kopitopoulos (preliminary version, April 22, 2005).

(2005b). Informe de evaluación final, SVD/016 Reconstrucción San Agustín [Final evaluation report]. February 2005.

(2005c). Proyecto de Agua Galingagua. [DVD]. Responsible of production: M. Ruiz.

(2006). Informe de evaluación final, NIC 012 Agua potable Nueva Segovia y Madriz [Intermediate evaluation report, Drinking water Nueva Segovia and Madriz], prepared by Eng. D. Kopitopoulos, final version, October 30, 2006.

Le Grand, J. (1991). Equity and choice. London: HarperCollins.

(2003). Motivation, agency, and public policy. New York: Oxford University Press Inc.

Leeuw, F.L. (1999). Evaluating anti-corruption initiatives: underlying logic and mid-term impact of a World Bank program. Evaluation, 5 (2), 194-219

Lincoln, Y.S. \& Guba, E.G. (2002). Judging the quality of case study reports. In Huberman, A.M. \& Miles, M.B. (eds.), The qualitative researcher's companion (pp. 205-216). Thousand Oaks, CA: Sage Publications, Inc. (Original work published 1990).

Lister, R. (1998). Citizen in action: citizenship and community development in Northern Ireland Context. Community Development Journal, 33(3), 226-235.

Long, N. \& Long, A. (Eds.) (1992). The battlefields of knowledge: the interlocking of theory and practice in social research and development. London: Routledge.

Long, N. (1992a). Conclusion. In Long, N. \& Long, A. (Eds.), The battlefields of knowledge: the interlocking of theory and practice in social research and development (pp. 268-277). London: Routledge. (1992b). From paradigm lost to paradigm regained? In Long, N. \& Long, A. (Eds.), The battlefields of knowledge: the interlocking of theory and practice in social research and development (pp. 16-43). London: Routledge. 
(2001). Development sociology: actor perspectives. Routledge: London.

Long, N. \& van der Ploeg, J.D. (1994). Heterogeneity, actor and structure: towards a reconstitution of the concept of structure. In Booth, D. (Eds.), Rethinking social development: theory, research and practice (pp. 6289). Essex: Longman Scientific and Technical.

Lopez, E. (2006, January 20). San Agustín se recupera [San Agustin recovers]. El Diario de Hoy. Retrieved September 7, 2006, from http://www.elsalvador.com/DIARIOS/ORIENTE/2006/01/20/portada2.asp

Lorío, A. (2006, August 3). Protegen pinares segovianos [Segovian pines are protected]. La Prensa. Retrieved November 11, 2006, from http://aprensa.com.ni/archivo/2006/agosto/03/noticias/campoyagro/134778 _print.shtml

Lubell, M., Vedlitz, A., Zahran, S. \& Alston, L.T. (2006). Collective action, environmental activism, and air quality policy. Political Research Quarterly, 59(1), 149-160.

Lukes, S. \& Haglund, L. (n.d.) Power and luck. Retrieved March 6, 2008, from http://as.nyu.edu/docs/1O/244/ power.luck.pdf

Lyons, M., Smuts, C. \& Stephens, A. (2001). Participation, empowerment and sustainability: (how) do the links work? Urban Studies, 38(8), 1233-1251.

Lyubomirsky, S. (2001). Why are some people happier than others? The role of cognitive and motivational processes in well-being. American Psychologist, 56(3), 239-249.

MacCallum, G. (1967). Negative and positive freedom. The Philosophical Review, 76, 312-334; reprinted in Miller, (Ed.) (1999), Liberty (pp. 100-122). Oxford: Oxford University Press.

Mackenzie, C. \& Stoljar, N. (Eds.) (2000). Relational autonomy: feminist perspectives on autonomy, agency, and the social self. Oxford: Oxford University Press.

Malhotra, A., Schuler, S.R., \& Boender, C. (2002). Measuring women's empowerment as a variable in international development. Paper prepared for the World Bank workshop on 'Poverty and gender: new perspectives'.

Mangas, B., Cuadra, M., Zambrana Godoy, R., Quintana, M., Quirós, A., Bradshaw, S., \& Linneker, B. (2001). Enfoque y prioridades para una estrategia: resultado del proceso de consulta, debate y análisis [Approach and priorities for a strategy: results of the consultation process, debate and analysis]. Managua: Coordinadora Civil para la Emergencia y la Reconstrucción (CCER).

Manikutty, S. (1998). Community participation: lessons from experiences in five water and sanitation projects in India. Development Policy Review, 16, 373-404.

Marquez, C. M. (2000). El Salvador: power to the parents! The UNESCO courier, 3, 26-27. Retrieved February 15, 2007, from http://unesdoc.unesco.org/images/0011/001192/119217e.pdf

Marquez, N. (2005, May 31). Pasó el examen. Usulután: La Policía Rural trajo tranquilidad a los ciudadanos [It passed the exam. Usulután: the rural police brought tranquility to the citizens]. El Diario de Hoy. Retrieved September 7, 2006, from http://www.elsalvador.com/noticias/2005/05/31/nacional/nac5.asp

Martel, R. (2003, October). La construcción de ciudadanía en El Salvador de Posguerra [Construction of citizenship in postwar El Salvador]. Paper presented at the XI Latin American meeting of Faculties of Social Communication. Universidad de Rio Piedras, Puerto Rico.

Martí i Puig, S. (1997). Cuando la revolución llegó al campo: La política agraria sandinista, su debate y su impacto en las zonas rurales del interior [When the revolution arrived to the countryside: The Sandinista agrarian policy, its debate and its impact on rural areas]. Anuario de Estudios Centroamericanos, 23 (1-2), 71114.

(1998a). Why did the rearmed rearm? Revista Envío, 199. February 1998. Retrieved June 21, 2007, from http://www.envio.org.ni/articulo/1318

(1998b). La violencia política en Nicaragua: élites, bases sandinistas y contras en los 90 [Political violence in Nicaragua: elites, Sandinista bases and contras in the 90s]. Nueva Sociedad, 156, 32-43. July-August 1998.

Martínez, N. (2005, January 24). Los orígenes de la matanza indígena de 1932 [The origins of the indigenous slaughter of 1932]. Diario Colatino. Retrieved April 16, 2007, from http://www.diariocolatino.com/reportajes/ detalles.asp? NewsID=2

Martínez Peñate, O., (Ed.) (2005). El Salvador: sociología general (Realidad nacional de fin de siglo y principio del milenio) [El Salvador: general sociology (National reality at the end of century and beginning of the millennium]) (2nd- ed.). San Salvador: Editorial Nuevo Enfoque (Original work published 2003). 
Max-Neef, M.A., Elizalde, A. \& Hopenhayn, M. (1991). Human scale development: conception, application and further reflections. New York: The Apex Press.

Max-Neef, M. (1992). From the outside looking in: experiences in 'barefoot economics'. London and New Jersey: Zed Books Ltd.

Maxwell, J.A. (2002). Understanding and validity in qualitative research. In Huberman, A.M. and Miles, M.B. (Eds.), The Qualitative Researcher's Companion (pp. 37-64). Thousand Oaks, CA: Sage Publications, Inc. (Original work published 1992).

Mayoux, L. (2001). Tackling the down side: social capital, women's empowerment and micro-finance in Cameroon. Development and Change, 32(3), 421-450.

Mayring, P. (2000, June). Qualitative content analysis. Forum Qualitative Sozialforschung / Forum: Qualitative Social Research, 1(2). Retrieved August 21, 2006 from http:/qualitative-research.net/fqs/fqs-e/2-00inhalte.htm

McGillivray, M. (2003). Aid effectiveness and selectivity: integrating multiple objectives into aid allocations. Discussion Paper 2003/71, Helsinki: UNU WIDER.

McGregor, J.A. (2000). A poverty of agency: resource management amongst poor people in Bangladesh. Draft Paper presented at the Plenary Session of European Network of Bangladesh Studies, University of Bath.

McLeod, C. \& Sherwin S. (2000). Relational autonomy, self-trust, and health care for patients who are oppressed. In Mackenzie, C. \& N. Stoljar, (Eds.), Relational autonomy: feminist perspectives on autonomy, agency, and the social self (pp. 3-31). Oxford: Oxford University Press.

McMillan, D.W. \& Chavis, D.M. (1986). Sense of community: A definition and theory. Journal of Community Psychology, 14(1), 6-23.

Mead, G.H. (1932). The philosophy of the present. Chicago: University of Chicago Press.

MECD (Education Ministry of Nicaragua) (2004). Transformación Educativa, Programas de la Nueva Visión: Educación para La Vida [Educational transformation, new vision programmes: Education for life] [Presentation]. Managua: MECD and DFID.

Mehta, L. (2006). Water and human development: capabilities, entitlements and power. Human Development Report Office Occasional Paper 2006/8, Human Development Report 2006, UNDP.

Merrill, T. (Ed.) (1993). Nicaragua: a country study (3 $3^{\text {rd }}$ ed.). Washington, D.C.: Federal Research Division, US Library of Congress. Retrieved June 9, 2007, from http://cweb2.loc.gov/frd/cs/nitoc.html

MFA El Salvador (Ministry of Foreign Affairs) (n.d., a). San Agustin, Usulutan. Conociendo a los 32 municipios más pobres [Knowing the 32 poorest municipalities]. Retrieved February 21, 2007, from http://www.comunidades.gob.sv/website/comunidades/dlocal/32MUNIMASPOBRES/sanagustin.pdf (n.d., b). San Esteban Catarina, San Vicente. Conociendo a los 32 municipios más pobres [Knowing the 32 poorest municipalities]. Retrieved February 24, 2007, from http://www.comunidades.gob.sv/website/comunidades/dlocal/32MUNIMASPOBRES/sanestebancatarina. pdf

(n.d., c). Torola, Morazan. Conociendo a los 32 municipios más pobres [Knowing the 32 poorest municipalities]. Retrieved February 24, 2007, from http://www.comunidades.gob.sv/website/comunidades/dlocal/ 32MUNIMASPOBRES/torola.pdf (n.d., d). Potonico, Chalatenango. Conociendo a los 32 municipios más pobres [Knowing the 32 poorest municipalities]. Retrieved February 24, 2007, from http://www.comunidades.gob.sv/website/comunidades/dlocal/32MUNIMASPOBRES/potonico.pdf

MFAL (Ministry of Foreign Affairs of Luxembourg) (2003). La politique luxembourgeoise de coopération au développement. Mémorandum présenté au Comité d'Aide au Développement à l'occasion de l'examen des pairs le 18 mars 2003. [Luxembourg's policy of development cooperation. Memo presented to DAC] Luxembourg: MFAL.

(2006a). The Luxembourg development cooperation: strategies and principles. Retrieved June 22, 2008, from https:/www.mae.lu/mages /biblio/biblio-250-57_ipiuk_6359_472_8638.pdf

(2006b). La coopération luxembourgeoise au développement. Rapport Annuel 2005. [2005 annual report of Luxembourg's development cooperation], Luxembourg: MFAL, Development Cooperation Directorate.

(2007). La coopération luxembourgeoise au développement. Rapport Annuel 2006. [2006 annual report of Luxembourg's development cooperation]. Luxembourg: MFAL, Development Cooperation Directorate. 
MI (Medico International) (2002). "Wir sind Bauern und brauchen Land" ['We are farmers and need land']. Newsletter 1/2002. Retrieved October 1, 2006, from http://www.medico.de/rundschr/rs-1-02/rs102-nica.htm (2003) Der Kampf um Land reflektiert die Armutsgeschichte Nicaraguas [The fight for land reflects Nicaragua's poverty history]. Newsletter 4/2003. Retrieved October 1, 2006, from http://www.medicointernational.de/projekte/nicaragua/eltanque.asp

Midlarsky, M.I. \& Roberts, K. (1985). Class, state and revolution in Central America: Nicaragua and El Salvador compared. Journal of conflict resolution, 29 (2), 163-194.

MINSA (Ministry of Health of Nicaragua) (n.d.). Indicadores de morbilidad, 2004 and 2005. [Morbility indicators]. Retrieved November 5, 2006, from http://www.minsa.gob.ni/estadisticas/ind2006//mages/ind_ morbilidad.jpg

'Minutes' (2000). [The Santa María Project] Minutes of meeting held on November 22, 2000, by the mayor, the president of ASCA and the CARE social promoter.

Mohan, G. (2004). Beyond participation: strategies for deeper empowerment. In Cooke, B. \& Kothari, U. (Eds.), Participation: the new tyranny? (pp. 153-167). London and New York: Zed Books.

Molenaers, N. (2006). Vida asociativa y desarrollo local en dos pueblos nicaragüenses [Associative life and local development in two Nicaraguan towns]. Revista de la CEPAL, 90, 121-133.

Moore, A. (2004, summer) Hedonism. In Zalta, E.N. (Ed.), The Stanford Encyclopedia of Philosophy. Retrieved [08/03/2006] from http://plato.stanford.edu/archives/sum2004/entries/hedonism/. Last modified 20/04/2004

Moreno, R. (2005). El marco jurídico para la privatización del agua en El Salvador [Legal framework for water privatisation in El Salvador]. San Salvador, Brot für die Welt.

Moreno, S.F. (2001, November). Solidaridad in El Salvador [Solidarity in El Salvador]. Umbrales, 123. Retrieved May, 8, 2005, from http:/www.chasque.net/umbrales/rev123/pag28a29.htm

Moser, C.O.N. (1998). The asset vulnerability framework: reassessing urban poverty reduction strategies. World Development, 26(1), 1-19.

Mosse, D. (2004). Power relations and poverty reduction. In Alsop, R. (Ed.), Power, rights, and poverty: concepts and connections (pp. 51-67). Washington, DC and London: World Bank and DFID.

(2005). Cultivating development: an ethnography of aid policy and practice. London and Ann Arbor: Pluto Press

MSA (Municipality of San Agustín) (2001). Plan de acción para el desarrollo del municipio San Agustín. [Action plan for the development of the Municipality of San Agustín]. San Agustín. June 2001.

(2004b). Plan participativo de desarrollo con proyección estratégica, municipio de San Agustín, departamento de Usulután [Participatory strategic development plan, municipality of San Agustín, department of Usulután]. San Agustín. October 2004.

MSPAS (Ministry of Health of El Salvador) (2005). [Statistics for Agua Fría health post ('Casa de Salud'), years 1999 to 2005].

Muellbauer, J. (1987). Professor Sen on the standard of living. In Hawthron, G (Ed.), The standard of living: the Tanner lectures (pp. 39-58). Cambridge: Cambridge University Press.

Mumby, D.K. \& Putnam, L.L. (1992). The politics of emotion: a feminist reading of bounded rationality. Academy of Management Review, 17(3), 465-486.

Murray, K. (1997). El Salvador: peace on trial. An Oxfam Country Profile. Oxford: Oxfam (UK and Ireland).

Narayan, D., Petesch, P., \& Shah, M.K. (1999). Consultations with the poor: methodology guide for the 20 country study for the world development report 2000/01. Washington D.C.: World Bank.

Narayan, D. (2002). Empowerment and poverty reduction: a sourcebook. Washington D.C.: World Bank.

Narayan, D. (Ed.) (2005). Measuring empowerment: cross-disciplinary perspectives. Washington D.C.: World Bank.

Narayan, D., Chambers, R., Shah, M., \& Petesch, P. (2000). Voices of the poor: crying out for change. New York: Oxford University Press for the World Bank.

Navarro, K. (2001). La cultura del conflicto en Nicaragua [The culture of the conflict in Nicaragua]. Managua: Fondo Editorial CIRA.

Nelson, J. (1996). Feminism, objectivity and economics. London: Routledge.

Nicol, A. (2000) Adopting a sustainable livelihoods approach to water projects: implications for policy and practice. ODI Working Paper 133. London: Overseas Development Institute. 
Nitlápan-Envío team (1987). Central American peace accord. Revista Envío, 74. Retrieved June 18, 2007, from http://www.envio.org.ni/articulo/3209

(1999a). The long march against corruption. Revista Envío, 213. April 1999. Retrieved September 30, 2006, from http://www.envio.org.ni/articulo/2233

(1999b). After Stockholm and before the pact. Revista Envio, 215. June 1999. Retrieved September 30, 2006 from http://www.envio.org.ni/articulo/2248

North, L. (1981). Bitter grounds: roots of revolt in El Salvador. Ontario: Between the lines.

Nuijten, M. (1998). In the name of the land: organization, transnationalism, and the culture of the state in a Mexican ejido. Doctorate Thesis, Wageningen Agricultural University.

Núñez Salmerón, L. (2006, 2 June). AN hace tambalear apoyo FMI [National Assembly makes to stagger IMF's support]. La Prensa.com.ni, El Diario de los Nicaragüenses. Retrieved on June 2, 2006, from http://www.laprensa.com.ni/archivo/2006/junio/02/noticias/nacionales/121267.shtml

Nussbaum, M. (1995a). Human capabilities, female human beings. In Nussbaum, M. \& Glover, J. (Eds.), Women, culture and development: a study of human capabilities (pp. 61-104). Oxford: Clarendon Press.

(1995b). Emotions and women's capabilities. In Nussbaum, M. and Glover, J. (Eds.), Women, culture and development: a study of human capabilities (pp.360-395). Oxford: Clarendon Press.

(2000). Women and human development. Cambridge: Cambridge University Press.

(2003a). Capabilities as fundamental entitlements: Sen and social justice. Feminist Economics, 9(2-3), 33-59.

(2003b). Tragedy and human capabilities: a response to Vivian Walsh. Review of Political Economy, 15(3), 413-418.

(2006). Education and democratic citizenship: capabilities and quality education. Journal of Human Development, 7(3), 385-395.

Nussbaum, M. \& Glover, J. (Eds.) (1995). Women, culture and development: a study of human capabilities. Oxford: Clarendon Press.

OECD (Organisation for Economic Co-operation and Development) (1992). DAC principles for effective aid, Development Assistance Manual. Paris: OECD.

(2001). The well-being of nations: the role of human and social capital. Paris: OECD, Centre for Educational Research and Innovation.

(2002a). Glossary of key terms in evaluation and results based management. Paris: OECD, DAC.

(2003). DAC per review of Luxembourg. Paris: OECD, DAC.

(2005a). Harmonisation, alignment, results: progress report on aid effectiveness. Paper presented at the High level forum Joint Progress toward Enhanced Aid Effectiveness: Ownership, Harmonisation, Alignment, Results, and Mutual Accountability. Paris, 28 February - 2 March, 2005.

(2005b). Budget support, sector wide approaches and capacity development in public financial management. In OECD, Harmonising donor practices for effective aid delivery (Vol. 2), DAC Guidelines and Reference Series.

(2007). Towards better division of labour: concentration and fragmentation of aid. Paper presented at the Global Forum on Development - Policy Workshop on the Challenges of Scaling Up at Country Level: Predictable Aid Linked to Results.

(2008a). Development Cooperation Report 2007, Vol. 9, No 1. Paris: OECD.

(2008b). Development database on aid from DAC members: DAC online. Retrieved June 9, 2008, from http://www.oecd.org/document/33/0,2340,en_2649_34447_36661793_1_1_1_1,00.html

(2008c). Development database on aid activities: CRD online. Retrieved July 9, 2008, from http:/Www.oecd.org/document/0/0,2340,en_2649_34447_37679488_1_1_1_1,00.html

(2008d). Luxembourg Development Assistance Committee (DAC) per review. Paris: OECD.

Oka, T. (2003, March). Effectiveness and limitations of cost-benefit analysis in policy appraisal. Government Auditing Review, 10, 17-28.

Olmos Guevara, R. (2005). La Nación: aproximación a la problemática [The Nation: approaching the problem], in Martínez Peñate, O. (Coord.), El Salvador: general sociology (National reality at the end of century and beginning of the millennium) (pp. 133-144). San Salvador: Editorial Nuevo Enfoque. 
Orozco, M. (2002). Globalisation and migration: the impact of family remittances in Latin America. Latin American Politics and Society, 44(2), 41-66.

Osti, R. (2004). Forms of community participation and agencies' role for the implementation of water-induced disaster management: protecting and enhancing the poor. Disaster Prevention and Management, 13(1), 6-12.

Paige, J.M. (1996). Land reform and agrarian revolution in El Salvador: Comment on Seligson and Diskin. Latin American Research Review, 31 (2), 127-139.

PAHO (Pan American Health Organisation) (2007). [Disasters' records]. Disasters and humanitarian assistance. Retrieved May 9, 2007, from http://www.paho.org/spanish/dd/ped/disasterarchives.htm

Pantazis, C., Gordon, D., \& Townsend, P. (2000). Perceptions of the necessities of life: Scotland and England compared. 1999 PSE Survey Working Paper, 24. Bristol, UK: Poverty and Social Exclusion Survey of Britain.

Paris Declaration on Aid Effectiveness (2005). High level forum Joint progress toward enhanced aid effectiveness: Ownership, harmonisation, alignment, results, and mutual accountability, Paris: 28 February - 2 March, 2005. Retrieved May 22, 2006 from http://www.oecd.org/dataoecd/11/41/34428351.pdf

Patton, M.Q. (1987). How to use qualitative methods in evaluation (2nd ed.). Newbury Park, CA: Sage Publications, Inc.

Pawson, R. \& Tilley, N. (2000). Realistic evaluation. London, Thousand Oaks, New Delhi: Sage Publications.

Peter, F. (2003). Gender and the foundations of social choice: the role of situated agency. Feminist Economics 9(23), 13-32.

Platteau, J. (2004). Monitoring elite capture in community-driven development. Development and Change, 35 (2), 223-246.

Pléitez Chávez, R. (2006). Violencia y criminalidad, obstáculo para el desarrollo [Violence and criminality, obstacle for development]. Presentations 2006. Department of Economic and Social Studies (DEES), FUSADES. Retrieved April 25, 2007, from http:/www.fusades.com.sv/presentaciones/violencia/ violencia.pdf

Potoy Rosales, F. (1998, November 22). Posoltega resurge de las cenizas y el lodo: Buscan alternativas de siembra y de reconstrucción de viviendas [Posoltega resurges of the ashes and the mud: They look for alternatives to sow and to reconstruct houses]. La Prensa. Retrieved June 30, 2006, from http://www.disasterinfo.net/cepredenac/05_nove/a_prensa/1998/nov_98/posolte.htm

PRISMA (1996). La deuda del sector agropecuario: Implicaciones de la condonación parcial [Agricultural sector's debt: Implications of partial condonation]. San Salvador: PRISMA

ProNicaragua (2003). Nicaragua investment guide. ProNicaragua, Investment promotion agency.

Prowse, M. (2003). Towards a clearer understanding of 'vulnerability' in relation to chronic poverty. CPRC Working Paper 24.

Putnam, R.D. (1993). The prosperous community. The American Prospect, 4(13), March 21, 1993.

Queen Sofia Foundation (2001). Programa de construcción de Centros Comunitarios enmarcados en el desarrollo integral de la comunidad en Honduras, Nicaragua, Guatemala y El Salvador [Programme of construction of community centres in Honduras, Nicaragua, Guatemala and El Salvador]. Retrieved October 15, 2006, from http://www.fundacionreinasofia.es/areas/ficha_area.jsp?xml=/docs /20040209 /0035.xml\&anyo=1999

QUEST-Consult (2001). Central America hurricane Mitch, global plans 1998, 1999 and 2000. Rehabilitation sector. Prepared by Mr. B Schrikkema financed by the European Commission.

Quinn, J. (2000, October 1). Too many helping hands? The view from Posoltega, Nicaragua. Progressio: changing minds, changing lives. Retrieved August 7, 2006, from http:/wwww.ciir.org/Templates/Internal.asp? NodeID $=90152$

Quizilbash, M. (1996). Ethical development. World Development, 24(7), 1209-1221.

Raffer, K. \& Singer, H.W. (1996). The foreign aid business: economic assistance and development co-operation. Cheltenham: Edward Elgar Publishing Limited.

Ragin, C.C. (1997). Turning the tables: how case-oriented research challenges variable-oriented research. Comparative Social Research, 16, 27-42. Retrieved August 23, 2006 from poli.haifa.ac.il/ levi/res/pitfallt.rtf

Rakodi, C. (1999). A capital assets framework for analysing household livelihood strategies: implications for policy. Development Policy Review, 17, 315-342.

Rao, V. \& Walton, M. (Eds.). Culture and public action. Stanford: Stanford University Press.

Rappaport, J. (1985). The power of empowerment language. Social Policy, 16(2), 15-21. 
Raz, J. (1986). The morality of freedom. Oxford: Oxford University Press.

RDL (2006). El Salvador, desarrollo local y descentralización del Estado: Situación actual y desafíos [El Salvador, local development and State decentralisation: Current situation and challenges]. January 2003 - December 2005 Period. San Salvador: RDL (Red para el Desarrollo Local). Retrieved April 26, 2007, from http:/www.fundaungo.org.sv/novs/images/InforRDL.pdf

Reader, S. (2006). Does a basic needs approach need capabilities? The Journal of Political Philosophy, 14(3), 337350.

Regalia, F. (2000). An assessment of poverty and safety nets in Nicaragua. Retrieved May 14, 2006, from http://www.iadb.org/sds/doc/POVnicaraguaguidelines.pdf

Riddell, R.C. (1990). Judging success: evaluating NGO approaches to alleviating poverty in developing countries. Working paper 37. London, Overseas Development Institute (ODI). (2007). Does foreign aid really work? Oxford: Oxford University Press.

Riddell, R.C. \& Robinson, M. with de Coninck, J., Muir, A., \& White, S. (1995). Non-governmental organizations and rural poverty alleviation. London: Overseas Development Institute and Oxford: Clarendon Press.

Rivas, A. (2001). Familia, libertad y pobreza: un nuevo híbrido escolar. La experiencia de las escuelas autónomas en Nicaragua [Family, freedom and poverty: a new hybrid school. The experience of autonomous schools in Nicaragua]. Paris and Buenos Aires: International Institute for Educational Planning and UNESCO.

Robeyns, I. (2003). Sen's capability approach and gender inequality: selecting relevant capabilities. Feminist Economics 9(2-3), 61-92.

(2005). The capability approach: a theoretical survey. Journal of Human Development, 6(1), 93-114.

Rocha N., J.F. (2001). Un paso arriba y dos abajo: Los hogares agropecuarios en Nicaragua [One step up and two steps down: agricultural households in Nicaragua]. Managua: INEC.

Rocha, J.L. (1999a). Posoltega: where the earth burns. Revista Envío, 215. June 1999. Retrieved June 13, 2006, from http://www.envio.org.ni/articulo/2253 (1999b). Posoltega: Unresolved property problems and continuing vulnerability. Revista Envío, 216. July 1999. Retrieved September 30, 2006, from http://www.envio.org.ni/articulo/2258

(2007). Posoltega nine years after the tragedy, Revista Envío, 313. August 2007. Retrieved February 28, 2008, from http://www.envio.org.ni/articulo/3629

Roche, C. (2004). Impact assessment for developing agencies: learning to value change. Oxfam Development Guidelines. Oxford: Oxfam Publishing. (Original work published 1999).

Romero J.J. \& Ferrero G. (Eds.) (2004). Desarrollo rural en Nicaragua: del consenso en los principios a una propuesta para la acción [Rural development in Nicaragua: from consensus in the principles towards a proposal for action]. Bilbao: Editorial Desclée de Brouwer, S.A.

Romero Vargas, G. (2003). Historia de Nicaragua [History of Nicaragua]. Managua: HISPAMER.

Rosa, H. (2005). Transformación económica y medio ambiente en El Salvador: de las exportaciones agrícolas a la exportación de mano de obra [Economic and environmental change in El Salvador: from agriculture exports to labour exports]. In Blanco, H. Togeiro de Almeida, L. \& Gallagher, K. P. (Eds.) (2005), Globalización y Medio Ambiente: Lecciones desde las Américas [Globalisation and environment: Lessons from America] (pp. 93-110). Santiago de Chile: RIDES - GDAE.

Rossi, P.H., Lipsey, M.W., \& Freeman H.E. (2004). Evaluation: a systematic approach (7th ed.). Thousand Oaks, CA: Sage Publications.

Ruben, R. \& Lerman, Z. (2004). Why Nicaraguan peasants stay in agricultural production cooperatives. Discussion Paper 13.04. The Hebrew University of Jerusalem.

Rubio-Fabián, R. \& Valdez, P. (2004). Revisión intermedia del programa indicativo de cooperación entre los gobiernos de Luxemburgo y El Salvador: principales hallazgos y recomendaciones. [Mid-term review of the indicative cooperation programme between the governments of Luxembourg and El Salvador: main findings and recommendations]. Luxembourg: CAMIRE, Estadística y Analisis, S.L.

Ryan, R.M. \& Deci, E.L. (2000). Self-determination theory and the facilitation of intrinsic motivation, social development, and well-being. American Psychologist, 55(1), 68-78.

(2001). On happiness and human potentials: a review of research on hedonic and eudaimonic well-being. Annual review of Psychology, 52, 141-166. 
(2006). Self-regulation and the problem of human autonomy: Does psychology need choice, selfdetermination, and will? Journal of Personality, 74(6), 1557-1585.

Ryan, R.M. \& Sapp, A.R. (2007). Basic psychological needs: a self-determination theory perspective on the promotion of wellness across development and cultures. In Gough, I. \& McGregor, J.A. (Eds.), Wellbeing in developing countries: from theory to research. (pp. 71-92). Cambridge: Cambridge University Press.

Salinas Maldonado, C. (2008, January 26). Los olvidados del Casitas [The forgotten people of Casitas]. Gualinse's webblog. Retrieved May 5, 2008, from http://acomunidad.elpais.com/gualinse/2008/1/26/losolvidados-del-casita

San Alejo Culture House [Casa de la Cultura] (2004). The monograph of San Alejo [in Spanish]. Responsible: Prof. Jorge Mariano Flores. CONCULTURA [the National Council for the Culture and the Arts].

Sánchez Mondragón, M. (2000, October 29). La tribulación de Posoltega: El dolor aún no se disipa y la esperanza se ve lejana [The tribulation of Posoltega: the pain has not still vanished and the hope is distant]. El Nuevo Diario. Retrieved June 13, 2006, from http://archivo.elnuevodiario.com.ni/2000/octubre/29-octubre2000 /nacional/nacional17.html

Scanlon, T. (1993). Value, desire, and quality of life. In Nussbaum, M. \& Sen, A. (Eds.), The quality of life (pp. 185-200). Oxford: Oxford University Press.

Schneider, H. (1999). Participatory governance for poverty reduction. Journal of International Development, 11, 521-534.

Schneider, A. \& Zúñiga-Hamlin, R. (2005). A strategic approach to rights: lessons from clientelism in rural Peru. Development Policy Review, 23(5), 567-584.

SDT (n.d.). The theory. Self-determination theory: an approach to human motivation and personality. Retrieved on December 13, 2005, from http://www.psych.rochester.edu/SDT/theory.html

Segovia, A. (2002). Transformación estructural y reforma económica en El Salvador [Structural transformation and economic reform in El Salvador]. Guatemala: Democracia y Desarrollo, Consultores and F\&G Editores.

Sen, A. (1982). Poverty and famines: an essay on entitlement and deprivation. Oxford: Clarendon Press. (1985a). Commodities and capabilities, Amsterdam: Elsevier Science Publishers B.V. (1985b). Well-being, agency and freedom: the Dewey lectures 1984. The Journal of Philosophy, 82(4), 169221.

(1987a). The standard of living: lecture I, concepts and critiques. In Hawthron, G., (Ed.), The standard of living: the Tanner lectures (pp. 1-19). Cambridge: Cambridge University Press.

(1987b). The standard of living: lecture II, lives and capabilities. In Hawthron, G., (Ed.), The standard of living: the Tanner lectures (pp. 20-38). Cambridge: Cambridge University Press.

(1988). The concept of development. In Chenery, H. \& Srinivasan, T.N. (Eds.), Handbook of Development Economics (Vol. I, pp. 9-26). Amsterdam: North Holland.

(1993). Capability and well-being. In Nussbaum, M. \& Sen, A. (Eds.), The quality of life (pp. 30-53). Oxford: Oxford University Press.

(1996). Freedom, capabilities and public action: a response. Notizie di Politeia, 43/44, 107-125.

(1999). Development as freedom. New York: Anchor books.

(2002). India development and participation. Oxford: Oxford University Press.

(2003). Rationality and freedom. Cambridge, MA: Harvard University Press (Original work published 2002). (2004). Capabilities, lists, and public reason: continuing the conversation. Feminist Economics, 10(3), 77-80.

SIECA (Secretariat of Central American Integration) (2005). Centroamérica: Tarifas de servicios públicos y salarios mínimos vigentes al 2005 [Central America: public services tariffs and minimum wages effective at 2005]. Retrieved March 28, 2007, from http:/www.sieca.org.gt/Publico/CA_en_cifras/precios_tarifas_Nersion_2005/

Siegel, S. \& Castellan, N.J., Jr. (1988). Nonparametric statistics for the behavioral sciences (2nd edition). Singapore: McGraw-Hill Book Co.

Siegel, P.B. (2005). Using an asset-based approach to identify drivers of sustainable rural growth and poverty reduction in Central America: a conceptual framework. WB Policy Research Working Paper, 3475. Washington D.C.: World Bank. 
SIEMMES (System of statistical information on migrations of Central America and Mexico) (2007). [Migration statistics]. International Organisation for Migration (IOM) and Universidad Nacional de Costa RicaIDESPO (Instituto de Estudios Sociales de Población). Retrieved July 5, 2007, from http://63.178.140.43/

Smulovitz, C. \& Walton, M. (2002). Evaluating empowerment. Draft paper presented at the WB Workshop on Measuring Empowerment: Cross-Disciplinary Perspectives (February 2003), Washington, DC.

Sogge, D. (2002). Give and take: what's the matter with foreign aid? London and New York: Zed Books.

Spence, J. (2004). La guerra y la paz en América Central: una comparación de las transiciones hacia la democracia y la equidad social en Guatemala, El Salvador y Nicaragua [War and peace in Central America: A comparison of transitions toward democracy and social equity in Guatemala, El Salvador and Nicaragua]. Brookline: Hemisphere Initiatives.

Sprangers, M.A.G. \& Schwartz, C.E. (1999). Integrating response shift into health-related quality of life research: a theoretical model. Social Science \& Medicine, 48, 1507-1515.

Stewart, F. (2005) Groups and capabilities. Journal of Human Development, 6(2), 185-204.

Stoll, D. (2005). The Nicaraguan contras: were they indios? Latin American Politics \& Society, 47(3), 145-157.

Streeten, P. with Burki, S.J., Haq, M., Hicks, N., \& Stewart, F. (1981). First things first: meeting basic needs in developing countries. London: Oxford University Press.

Streeten, P. (1984). Basic needs: some unsettled questions, World Development, 12(9), 973-978.

Sullivan, F., Bell, J., Jackson, D., Moyers, R., McIntyre, D., and Vega, M. (2000). Nicaragua ARAP Agriculture Reconstruction Assistance Program: Agricultural recovery and reconstruction project assessment. Managua: Chemonics International, Inc. Retrieved September 17, 2006, from http:/pdf.usaid.gov/pdf_docs/ PDABX183.pdf

Swift, A. (2004). Political philosophy: a beginners' guide for students and politicians. Cambridge: Polity Press.

Tandia, C. T. (2004). What is on-site sanitation? A case study of latrines. Centre Régional pour l'Eau Potable et l'Assainissement à faible coût (CREPA). Burkina Faso. Retrieved November 18, 2006, from http://www.irc.nl/page/10371

Tartter, J.R. (1993). Chapter 5 - National security. In Merrill, T. (Ed.), Nicaragua: a country study. Washington, D.C.: Federal Research Division, US Library of Congress.

Taylor, C. (1979). What's wrong with negative liberty. In Alan Ryan, (Ed.), The idea of freedom (1979); excerpted in Miller, D. (Ed.) (1999), Liberty (pp. 141-162). Oxford: Oxford University Press.

Taylor, J.S. (1999.) The theory of autonomy. Humane Studies Review, 12(3). Retrieved April 8, 2005 from http://www.theihs.org /ibertyguide/hsr/hsr.php/33.html

(Ed.) (2005). Personal autonomy: new essays on personal autonomy and its role in contemporary moral philosophy. Cambridge: Cambridge University Press.

(2005). Introduction. In Taylor, J.S. (Ed.), Personal autonomy: new essays on personal autonomy and its role in contemporary moral philosophy (pp. 1-29). Cambridge: Cambridge University Press.

TCES (The Truth Commission for El Salvador) (1993). Summary. De la Locura a la Esperanza: La Guerra de los Doce Años en El Salvador: Informe de la Comisión de la Verdad para El Salvador [From madness to hope: the 12year war in El Salvador: Report of the Commission on Truth for El Salvador]. Commissioners: B. Betancur (chairman), R. Figueredo Planchart and T. Buergenthal. Retrieved April 14, 2007, from http:/www.usip.org/ library/tc/doc/reports/el_salvador/tc_es_03151993_toc.html

Tearfund (2002). El costo de sobrevivir [The cost of survival], Nuevos cimientos: fortaleciendo comunidades en tiempo de crisis [On solid grounds: strengthening communities in times of crisis], Video 6. (Available from Tearfund, 100 Church Road, Teddington, Middlesex, TW11 8QE, UK)

The Advocacy Project (1999, May 21). On the Record. Central America after Mitch: Your electronic link to civil society and the reconstruction of Central America, 8 (6). Retrieved June 13, 2006 from http://www.advocacynet.org/news_view/news_141.html

The White House (1999). Remarks by the President and President Alemán of Nicaragua in roundtable discussion with Las Casitas volcano mud slide survivors from hurricane Mitch. Auditorium, Cotton Research Center, Posoltega, Nicaragua. March 8, 1999. Retrieved October 3, 2006 from http://clinton3.nara.gov WH/New/centralam/ 19990310-90110.html

Thorp, R., Stewart, F. \& Heyer, A. (2005). When and how far is group formation a route out of chronic poverty? World Development, 33(6), 907-920. 
Tórrez A., J. (2001, August 12). Nuevo alud, ahora de críticas sobre casas [New avalanche, now of critics on houses]. El Nuevo Diario. Retrieved October 21, 2006, from http://archivo.elnuevodiario.com.ni/2001/agosto/12-agosto-2001/nacional/nacional2.html

Trolese, B. (1999). Bob Trolese's update on the hurricane relief efforts. March 18. Verbo Nicaragua. Retrieved June 13, 2006, from http://www.verbo.org/nicaragua/nica-old.htm

UN (United Nations) (2002). Report of the International Conference on Financing for Development, Monterrey, Mexico, 18-22 March, New York: UN.

(2005). 2005 World Summit Outcome. United Nations General Assembly, 15 September 2005.

(2007). The Millennium Development Goals Report 2007, UN.

UNDP (United Nations Development Programme) (1990). Human Development Report 1990, New York: Oxford University Press.

(2001). Human Development Report El Salvador 2001, San Salvador.

(2002). Informe de desarrollo humano en Nicaragua 2002: Las condiciones de la esperanza [Human development report in Nicaragua 2002: the conditions for hope] (1st ed.). Managua: UNDP.

(2003a). Millennium development goals: a compact among nations to end human poverty. Human Development Report 2003. New York-Oxford: Oxford University Press.

(2003b). Human development report El Salvador 2003. San Salvador.

(2004). Cultural liberty in today's diverse world. Human Development Report 2004, New York: Hoechstetter Printing Co.

(2005a). International cooperation at a crossroads: aid, trade and security in an unequal world. Human Development Report 2005. New York: Hoechstetter Printing Co.

(2005b). Una mirada al nuevo nosotros. el impacto de las migraciones [A glance at the new us: the impact of migrations]. Informe sobre Desarrollo Humano El Salvador (IDHES) 2005. San Salvador: UNDP.

(2005c). Informe 262: Indicadores municipales sobre desarrollo humano y objetivos de desarrollo del milenio [Report 262: Municipal indicators on human development and millennium development goals]. El Salvador: UNDP.

(2005d). UNDP role in a changing aid environment: direct budget support, SWAps, basket funds. Programme and Operational Guidelines. A UNDP Capacity Development Resource. New York: UNDP.

(2007a). Trayectorias hacia el cumplimiento de los ODM en el Salvador [Trajectories towards the achievement of the MDGs in El Salvador]. Cuadernos sobre Desarrollo Humano, 6. San Salvador: UNDP.

(2007b). Fighting climate change: human solidarity in a divided world. Human Development Report 2007/2008. New York: Palgrave Macmillan.

UNESCO (UN Educational, Scientific and Cultural Organisation) (2002). UNESCO Universal declaration on cultural diversity. Retrieved January 18, 2006, from http://www.unesco.org/education/_mld_2002/unversal_ decla.shtml

UN Millennium Project (2005). Investing in development: a practical plan to achieve the millennium development goals. New York: UNDP.

Uphoff, N. (2005). Analytical issues in measuring empowerment at the community and local levels. In Narayan, D. (Ed.), Measuring empowerment: cross-disciplinary perspectives (pp. 219-246). Washington D.C.: WB.

Urquilla, K. (2006, March 25). Ex gerente de Anda se entregaría a la justicia [Former manager of ANDA would surrender to the justice]. El Diario de Hoy. Retrieved January 12, 2007, from http:/www.elsalvador.com/ noticias /2006/03/25/nacional/nac8.asp

USAID (US Agency for International Development) (2001). Nuevas oportunidades económicas para productores en Posoltega [New economic opportunities for producers in Posoltega]. Programa de Reconstrucción Post-Huracán Mitch [Post-hurricane Mitch reconstruction programme] (Vol. 3, No. 20). Managua: USAID Nicaragua. Retrieved June 19, 2005 from http://nicaragua.usaid.gov/pdf/stories/2001/historia52.pdf (2005). Mission accomplished: the United States completes a $\$ 1$ billion hurricane relief and reconstruction program in Central America and the Caribbean. Washington: USAID. Retrieved September 17, 2006 from http:/hurricane.info.usaid.gov/updates/mitch_english.pdf

USAID (2006a). Increased access by rural households to clean water: 1998-2005. Close-out report. Antiguo Cuscatlán: USAID. Retrieved February 19, 2007, from http:/pdf.usaid.gov/pdf_docs/PDACI143.pdf 
(2006b) US overseas loans \& grants [Greenbook], Year 2004. Data retrieved May 28, 2006, from http://qesdb.usaid.gov/gbk/index.html, last modified [01/03/2006]

WB (The World Bank) (n.d.). Empowerment. Retrieved March 17, 2006 from http:/łwww.worldbank.org/ empowerment

(2001). World development report 2000/2001: Attacking poverty. Washington, DC: WB.

(2002). World Development Report 2003: Sustainable development in a dynamic world: transforming institutions, growth and quality of life. Washington, DC: WB

(2003). Community-driven development: a study methodology, Operations Evaluation Department [OED].

(2005). El Salvador poverty assessment, strengthening social policy. Report No. 29594-SV, Poverty Reduction and Economic Management and Human Development Sector Management Units, Latin America and the Caribbean Region.

(2007). Millennium development goals: confronting the challenges of gender equality and fragile states, Global Monitoring Report 2007. Washington DC: WB.

WFP (UN World Food Programme) (2002, October 4). Emergency Report n. 40. World Food Programme. Re$\begin{array}{llll}\text { trieved } \quad \text { May 2007, from } & \text { 30, }\end{array}$ http://www.wfp.org/newsroom/emergency_reports_new/emergencyreport.asp?Item=495\#558

White, H. (2005). Challenges in evaluating development effectiveness. IDS Working Paper 242. Sussex: IDS.

White, H.N. \& Dijkstra, A. G. (2003). Programme aid and development: beyond conditionality. London and New York: Routledge.

White, S. (1996). Depoliticising development: the uses and abuses of participation. Development in Practice, 6(1), 6-15.

White, S. \& Pettit, J. (2004). Participatory approaches and the measurement of human well-being. WIDER Research Paper 2004/57, UNU-WIDER.

White, S. \& Ellison, M. (2007). Wellbeing, livelihoods and resources in social practice. In Gough, I. \& McGregor, J.A. (Eds.). Wellbeing in developing countries: from theory to research (pp. 157-175). Cambridge: Cambridge University Press.

Williams, B. (1987). The standard of living: interests and capabilities. In Hawthron, G. (Ed.), The standard of living: the Tanner lectures (pp. 94-102). Cambridge: Cambridge University Press.

Wood, G. (2003). Staying secure, staying poor: the "Faustian bargain". World Development, 31(3), $455-471$. (2007). Using security to indicate wellbeing. In Gough, I \& McGregor J.A. (Eds.), Wellbeing in developing countries: from theory to research (pp. 109-132). Cambridge: Cambridge University Press.

Woolcock, M. (2001). The place of social capital in understanding social and economic outcomes. Retrieved February 25, 2008, from http:/wwww.oecd.org/dataoecd/5/13/1824913.pdf

Yin, R.K. (1981, March). The case study crisis: some answers. Administrative Science Quarterly, 26, 58-65. (2003). Case study research: design and methods (3 ${ }^{\text {rd }}$ ed.). Applied Social Research Method Series, Vol. 5. Thousand Oaks, CA; London: Sage Publications, Inc. 


\section{Appendix 1-A: Nicaragua, an introductory review}

I am from a simple town, like the John word, like the love that I give, like the love that I am given.

I am from a town born between rifles and songs that having suffered so much, it has so much to teach.

Extract from 'I am from a simple town', (L.E. Mejía Godoy, 1983)

Section 1 presents the political and historical background with a focus on the experiences of rural inhabitants in order to understand the meso-level context in which the individuals of Santa María and San Fernando live, their entitlements and opportunities. Section 2 develops a balance of economic, human development, and social situation. It also presents the mechanisms of participation at the community level in 2005.

\section{Section 1: Political and historical background of Nicaragua ${ }^{107}$}

The unique political culture and historical background of Nicaragua has marked the lives of its inhabitants. Since its independence from Spain, in 1821, Nicaragua has faced political turmoil, with military intervention or authoritarian rulers, during more than two thirds of its political existence (Alvarez Montalván, 2001; Navarro, 2001). The most tragic episode was the Somoza dynasty that lasted more than four decades. Four main characteristics delineate what Navarro (2001) calls 'the culture of the conflict', that Nicaragua had:

1. Extended periods of authoritarian regimes in which rulers concentrated all the political, military and economic power;

2. Armed conflicts as strategy to defeat such regimes;

3. Acute political polarisation (a two-party system led by caudillos) and clientelism; and

4. Active foreign involvement in national affairs solicited by rulers to overcome the lack of legitimacy of political leaders.

Table 1 shows important political events during the twentieth century and the armed conflicts that took place at different stages. By far, the guerrilla rising led by the Sandinista National Liberation Front (FSLN) during the 1970s was the most important. Its strong actions during 1978 and 1979 caused the end of the Somoza dynasty.

Table 1: Main political events and armed conflicts

\begin{tabular}{|c|c|c|c|}
\hline \multicolumn{2}{|c|}{ Main political events } & \multicolumn{2}{|c|}{ Armed conflicts } \\
\hline $1909-1932$ & US intervention in Nicaragua & 1927-1932 & Guerrilla led by Gen. Sandino \\
\hline 1937-1979 & Somoza dynasty & 1974-1979 & Guerrilla led by the FSLN ${ }^{(1)}$ \\
\hline $1979-1990$ & Sandinista government & $1981-1990$ & Contra-guerrilla backed by the US \\
\hline Since 1990 & Alternation of political power & 1991-1996 & Riots by re-contras and re-compas(2) \\
\hline
\end{tabular}

107 This section is primarily based on Merrill (Ed.) (1993, Navarro (2001), Alvarez Montalván (2000), and Romero Vargas (2003). 
Political polarisation characterised the relationship between political leaders since colonial times. First, it was the competition between two cities (León and Granada) related to liberal and conservative thoughts respectively, that evolved during years and caused the persecution and killings of opponents. Polarisation also explained the hostility between supporters of authoritarian regimes (not related to one specific political ideology) and other groups. In recent years, polarisation was manifested by the existence of two parties led by two caudillos: Liberal Constitutional Party (PLC) and Sandinista National Liberation Front (FSLN). These parties, however, through an agreement called 'the Pact' (2004-2005), united forces in the Congress and became majority to reject legislative proposals of the President and gain more power over the Judicial and Electoral branches.

In several occasions, foreigners were called to solve internal political disputes. Their interest was related to geopolitical reasons. The Somoza dynasty was close to the US government. During the 1980s, the contra guerrilla was supported by the US, while the Sandinista government was related to the URSS and Cuba. At the end of the Cold War, foreign interests for controlling the Central American region decreased. This helped to end the civil war; although, the peace process had deeper national and regional influences.

Below, the main events and armed conflicts presented in Table 1 are discussed. The phases of the Sandinista government and contra movement receive more attention because the inhabitants of Santa María and San Fernando participated in different bands: the first supported Sandinistas and formed their cooperatives legitimised by the agrarian reform, while the second were in favour of the contras.

\section{- The US intervention in Nicaragua and the guerrilla led by Gen. Sandino}

In 1909, US marines suppressed a rebellion in the Atlantic region and the US government forced the liberal president to resign. In 1912, a conservative president requested support from the US to fight against the liberals. US marines controlled the capital city and occupied the centre of economic activity in the Atlantic region (Bluefields).

Later, in a period of turmoil after a coup d'état, the president named by the Congress called again the US for support while the constitutional (liberal) president in exile was supported by Mexico. A peace agreement sponsored by the US was signed in 1927, but it was not accepted by Gen. Sandino who led a guerrilla war against the foreign occupation in the northwestern highlands. Taking advantage of the geography and local people's sympathies, Sandino's fight persisted despite the attacks of US marines supported by the National Guard and US air forces. After the 1932 elections, US troops left the country and a peace agreement was signed by the new government and the guerrilla. Nevertheless, in 1934, Gen. Sandino was killed by orders of Gen. A. Somoza G. who was some years later elected president.

\section{- The Somoza dynasty and its fall}

The Somoza dynasty lasted more than four decades (1937-1979). ${ }^{108}$ During most of this period, the clan kept the government by three means: (i) economic power via the direct ownership of productive resources (e.g., coffee plantations) and clientelism of elites that appreci-

\footnotetext{
108 The Somoza dynasty corresponds to the government of Anastasio Somoza García (1937-1956) and his two sons: Luis Somoza Debayle (1956-1967) and Anastasio Somoza Debayle (1967-1979). In the last two cases, some rulers close to the clan held the national government for brief periods.
} 
ated the political peace that the regime promoted (Alvarez Montalván, 2001); (ii) a corrupted National Guard that repressed opponents; and (iii) foreign support from the US.

The presence of the clan was felt everywhere, in the public and private sectors. The clan rulers used political pacts to perpetuate their 'dictatorship by negotiation' (ibid, p. 134) that gave shares of power to opponents and puppet presidents to control the country. The Somoza dynasty enjoyed US economic support, in return for backing its geopolitical objectives in the region, for example, allowing the Bay of Pigs invasion to start from Nicaragua (Raffer \& Singer, 1996).

The 1960s and 1970s were decades of strong repression in which the Somoza dynasty ruled overbearingly (Navarro, 2001). Political opponents were jailed, tortured and, in many occasions, killed. A guerrilla movement, the FSLN, founded in 1961 by a group of university students brought together peasants and labour activists to its cause of opposing the dictatorship. A broad opposition front emerged from political parties, businesspeople, academics, and social movements. Private entrepreneurs took distance of the regime after decades of tacit support.

In 1972, there was a terrible earthquake that almost destroyed the capital city and caused 10 thousand deaths. The misappropriation of aid funds by the government was a definite cause for the political fall of the Somoza dynasty. It was condemned by the international community, businesspeople and labour movements (Brás, 1993). In addition, the attitude of the US toward Nicaragua was changing as the new government of J. Carter (1977) aimed at promoting human rights, which were severely at risk under the Somoza regime. However, effective financing to Somoza was not interrupted (Biekart, 1999 /2003, p. 153).

There was international consensus that the dictator had to leave the country and a transition government junta was established in June 1979, in Costa Rica. After the resignation and escape of A. Somoza D., fuelled by the military successes of the Sandinistas, the junta took the power. The process had cost 50,000 deaths and 150,000 people in exile (Brás, 1993, 'the Sandinista revolution' section, II 4).

In sum, the Somoza dynasty was defeated by a guerrilla movement that enjoyed broad support from national and international actors. Nicaraguans were tired of decades of repression and the impossibility of a democratic change. Furthermore, Catholic groups ('popular church') inspired the trust of population in the left-wing guerrilla. In this respect, Alvarez Montalván (2001, p. 140) asserts: 'No other triumphant revolution has arrived to the power in Nicaragua with so much popular sympathy, and national and international expectation, as the Sandinista [revolution]'.

\section{- The Sandinista government}

The junta carried out a series of important reforms in order to reconstruct the economy and to improve the human rights situation. It renegotiated the foreign debt, obtained reconstruction aid funds, and initiated an extensive agrarian reform. It captured former National Guard members and took them to trial. In 1980, it started a successful literacy campaign that mobilised urban students across the country, increasing literacy rates over the years from $50 \%$ to $87 \%$ (Rivas, 2001, p. 14 ). 
The junta created some institutions to strengthen the military power of the revolution: a new national army (the Sandinista People's Army) and a Sandinista police. It also promoted mass organisations and neighbourhood groups (Sandinista defence committees) that were responsible for community improvement projects and, later, for distributing rationed goods (Brás, 1993). The National Union of Farmers and Ranchers (UNAG), created in 1981, is the largest peasant organisation in Central America.

In 1984 elections, the leader of FSLN D. Ortega was elected President and his party won majority in the Congress. Although the elections were considered legitimate by most international actors (Allison, 2006, p. 141), the US government continued its support to the contra guerrilla, implemented an economic embargo since 1985, and influenced the restriction of aid funds from multilateral organisations to Nicaragua (White \& Dijkstra, 2003).

There were important social changes in Nicaragua. A displacement of high social class by the low and very low middle class in important political positions took place and women's participation in popular movements was notable. The Sandinista government promoted popular participation in public policy and made great advances in health care, education, and popular democracy (Allison, 2006). However, the increased state intervention in the economy (e.g., nationalisation of banks, control of prices, and control of foreign trade) and anti-classist and anti-imperialistic discourses caused criticism from businesspeople and certain groups of the Catholic Church. The president became a caudillo with authoritarian features that centralised political power.

An acute economic crisis fuelled by the civil war and the restriction of aid funds caused the deterioration of living standards. People in rural areas were the most affected. Despite the redistribution of land, high inflation by the end of the 1980s made their credits unbearable.

\section{- The contra revolution}

In 1981, the inaugurated president R. Reagan changed the US foreign policy toward Nicaragua. It accused Nicaraguan government of providing arms to FMLN in El Salvador with the support of Cuba and the URSS. Concomitantly, the US financed a contra revolution army (called 'contra') with military bases in Honduras, led by former national guards (Brás, 1993). The contra became stronger toward 1983-1985, operating in bases located in Nicaraguan lands and with a defined organisational structure (Envío team, 1987). The number of members grew including peasants of the north highlands and inhabitants of the Atlantic region.

There were several reasons that explain the support of North-western peasants to the contra. The Sandinista message was against their cultural tradition of patron-client relationships (Stoll, 2005). Productive land owners were considered by poor peasants as successful farmers who accumulated lands thanks to their effort and whose legitimacy came from their responsibility toward the poorest farmers (e.g., providing access to pasture, seasonal work). They were like role-models for individual progress and social mobility (Bastiaensen et al., 2006; Martí i Puig, 1997): admired not envied. Therefore, there was no particular reason to take their lands, as the Sandinista government could do. The agrarian reform was perceived as illegitimate. Contra combatants developed a strong ideological-religious campaign that spread fear among peasants toward the Sandinista revolution (Envío team, 1987). The message of the contras was less complicated: that the Sandinistas wanted to take their liberty; children, due to forced military service; religion; and lands, due to its egalitarian discourse 
and regulations such as the forced selling of crops to the state (Envío team, 1987; Tartter, 1993; Spence, 2004).

Stoll (2005) hypothesises that peasants were scared of revenge from contra rebels, whose atrocities against opponents contrasted to the relatively higher respect that the Sandinistas had for their enemies. The contra attacked civilians and agriculture cooperatives (Spence, 2004). Being amid two fires, they would have chosen the most fearsome group to protect their physical security. Another possibility was to become refugees in Honduras.

By the start of 1985, three groups were fighting against the Sandinista regime: the contras in the North highlands, the inhabitants of the Atlantic region, and a former Sandinista commander in the South (Revista Envío, 1987; Brás, 1993). The native leader in the Atlantic region reached a 'political autonomy' agreement with Sandinistas, recognised in the new 1987 Constitution. The southern movement was defeated. The northern movement was significantly harmed by the military strategies of Sandinistas and the lack of military aid since 1987 (Alvarez Montalván, 2001, p. 168). However, this group remained active until the end of the Sandinista government; it did not disarm and continued receiving humanitarian aid from the US despite that, since 1986, peace negotiations were taking place.

The consequences of this contra war were tragic for the country. Resources initially targeted to social programmes had to be channelled to military expenses that reached as much as $50 \%$ of the government budget. The civil war caused the abandonment of agricultural lands and the displacement of people. The restriction of foreign funds and the outflows of national capitals retracted credit to productive sectors and global liquidity that fuelled stagflation and high unemployment rates. Total GDP, that had grown by $14 \%$ in $1979-1983$, fell by $20 \%$ in 1983-1990 (BCN, 2007) - although other events such as Hurricane Joan in 1988 and a severe drought in 1989 affected the economy (Brás, 1993). Furthermore, there were around 100 thousand deaths during the civil war (Navarro, 2001, p. 160).

\section{- The peace accords, government transfer and the resurgence of violence}

The Esquipulas II agreement (1987) signed by the presidents of Costa Rica, El Salvador, Guatemala, Honduras and Nicaragua, under the leadership of the Costa Rican president O. Arias, was focused on a negotiated cease-fire, national reconciliation (incl. amnesty), an end to military, logistical, financial, propagandistic aid by foreign governments to insurgent forces (Nitlápan-Envío team, 1987), and democratic reforms leading to the celebration of free elections. However, there was no demobilisation before the elections (Spence, 2004).

The winner of the 1990 elections in Nicaragua was the candidate of a political opposition coalition (V. Barrios de Chamorro). There was a 'peaceful transfer of power from governing to opposition forces... the first such transfer since the founding of the Republic' (Karl, 1995, p. 74). The new government reached a set of agreements with Sandinistas. The FSLN, despite their defeat, kept an important political position in the country.

The government downsized the army, put the intelligence service and police forces under civil tutelage, and protected individual guarantees. However, many violations to human rights during the civil war were unpunished (Alvarez Montalván, 2000, p. 145). The government promoted the reconciliation and focused on dismantling the army and allocating lands to demobilised army and contra fighters. But it did not fulfil its commitment to create 'development poles' and to provide demobilised people with basic services and resources 
for productive activities (Martí i Puig, 1998a). The number of people directly affected by the civil war and in need of reallocation exceeded all expectations: around 600,000 people including returned refugees from Costa Rica and Honduras, demobilised contra fighters and their families, demobilised Sandinista troops, and internally displaced people (Martí i Puig, 1998a; 1998b).

These people were not integrated to the social and economic life of the country and many former middle-range fighters became leaders of armed gangs (Navarro, 2001). During a considerable period, there were unstable areas due to looting of former combatants: gangs of former 'contras' became 're-contras', gangs of former Sandinista army soldiers became 're-compas' (re-fellows), and gangs composed by members of two groups were called 'revueltos' (the jumbled). Beyond their denominations, these people were doing the only thing they were used to do almost during a decade: to fight, due to the lack of real opportunities of progress in different ways (Martí i Puig, 1998a).

\section{- Agrarian reform}

An agrarian reform was implemented by the Sandinista government as response to the long-lasting problem of land destitution. With the introduction of coffee plantations (toward the mid-1800s), laws had been dictated to eliminate communal lands, to divide and to sell them. Workers who would not fulfil their contracts would be persecuted, jailed and returned to their patrons (Romero Vargas, 2003). Traditional diversified agricultural economy became export oriented and this change severely affected the life of peasants. There was an indigenous rebellion in Matagalpa (1881) that lasted up to 8 months and, after which, soldiers executed hundreds of native people (Navarro, 2001). Native people were forced to work in public works. In time, the only new rebellion fully supported by peasants was the one led by Gen. Sandino. In contrast, the Sandinista guerrilla against A. Somoza D. was an urban movement (Spence, 2004). The contra guerrilla had peasant support in the areas that formerly had supported Gen. Sandino.

Before the agrarian reform, land and trade of agricultural products were concentrated in the hands of the Somoza family and their allies, as were financial sector and industries. Hence, the reform started with the expropriation of such properties. Nevertheless, in the agriculture sector, the model was of a 'mixed economy' (White \& Dijkstra, 2003). Large landowners not related to Somoza continued working and also got state credit, but their surpluses would be controlled by the state via trade and banking sectors (De Groot, 1993).

De Groot (1993) explains that the reform had four stages. In the first stage (1979-80), these expropriated lands became state farms and cooperatives. In the second stage (1981-84), the emphasis was on production cooperatives and self-defence cooperatives (in areas with contra guerrilla presence). In the third stage (1985-87), the idea was to strengthen the workerpeasant strategic alliance and land was allocated to individual producers. In the last stage (1988-90), the emphasis was on securing the titles to the reformed sector.

The reform resulted in a lower concentration of land in private hands (see Table 2). However, land registration was poor: only $27 \%$ of reallocated lands received a property title and most of them were provisional (Bastiaensen et al., 2006, p. 20, citing De Groot, 1994). In addition, state farms were inefficient and cooperatives became fully dependent on state support with absence of long-term investment. The organisation capacity of peasants im- 
proved during these years, but patronage and clientelism have remained as characteristics of the rural social fabric.

Table 2: Agrarian reform (Land tenure as \% of total cultivable land)

\begin{tabular}{|lccc|}
\hline Type of land tenure & 1978 & 1988 & 1997 \\
\hline Private sector & $\mathbf{1 0 0} \%$ & $\mathbf{6 5 \%}$ & $\mathbf{7 0} \%$ \\
\hline -Larger than 350 ha. & $36 \%$ & $7 \%$ & $8 \%$ \\
-Between 140 and 350 ha. & $16 \%$ & $13 \%$ & $15 \%$ \\
-Between 35 and 140 ha. & $30 \%$ & $28 \%$ & $29 \%$ \\
-Smaller than 35 ha. & $18 \%$ & $17 \%$ & $18 \%$ \\
\hline Reformed sector & & $35 \%$ & $\mathbf{3 0} \%$ \\
\hline -Individual & & $9 \%$ & $19 \%$ \\
-Cooperative & $14 \%$ & $9 \%$ \\
-State farm & $12 \%$ & $2 \%$ \\
\hline -Worker enterprise & & \\
\hline
\end{tabular}

Source: Everingham (2001, Table 1, p. 70) based on INRA (1997).

During the 1990s, state farms were privatised and their holdings were allocated to individual owners. Many cooperative members parcelled-out their land for individual exploitation given that the incentives such as input subsidies and soft credits that existed during the Sandinista government were cut off. Uncertainty about land ownership and debts are other factors that explain the decision to stay or not in cooperatives (Ruben \& Lerman, 2004).

In addition, former owners sued the government and with the diplomatic pressure of the US, several got their lands back (or were compensated). Impoverished peasants sold out their lands to rich farmers that slowly re-initiated a land concentration process. According to the 2001 national agricultural census, farms larger than 350 ha represented 22\% of total arable land (INEC, 2002a).

\section{Section 2: Situational analysis}

Following the economic debacle caused by the Sandinista political plan and the contra war promoted by the US, the liberal governments during the 1990s implemented severe economic adjustment programmes and focused their efforts on reinserting Nicaragua into the international map. This section briefly describes these actions in the economic area and develops a situational analysis.

\section{a) Economic situation}

During the 1990s, the reforms introduced by the Sandinista government were abandoned. Furthermore, the intention was to undo many policies (Booth \& Richard, 2006). Foreign trade was liberalised, the public sector was downsized (especially the military), social expenditure was cut, the 351 state enterprises that represented 30\% of GDP (GON, 2001b) were privatised or closed (including commercial banks), electricity and telecommunications utilities were privatised, the pension system and public administration were reformed, among other measures. The focus was on stabilisation and economic adjustment programmes conditioned by IMF and WB (White and Dijkstra, 2003; see also Gosparini et al., 2006).

The growth strategy was export oriented. It favoured large farmers against small or medium farmers who had benefited of promotional credit during the Sandinista government (En- 
ríquez, 2000) and could not afford to switch from basic grain to export crop production. Trade liberalisation pushed prices of basic grains down which, further deteriorated the incomes of small farmers. In the worst cases, they had to sell part of their plots to pay off their debts.

Below, the focus is on three topics: economic structure, dependence on external resources, and financial vulnerability.

\section{Economic structure}

Agriculture has represented around $20 \%$ of total production during the last decade. It has kept an important influence on the economic activity in the last years as shown in Figure 1.

Figure 1: Economic growth and agriculture

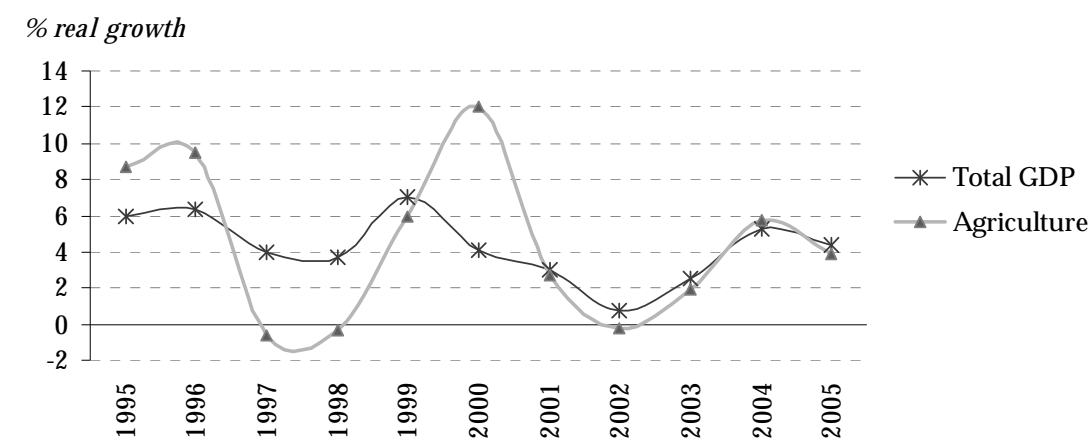

Source: BCN (2007).

Aggregate economic activity was affected by climatological events such as the El Niño phenomenon in 1997 and a severe drought in 2001/2002. Nevertheless, Hurricane Mitch that hit the country in 1998 did not affect global production so strongly. GDP grew by 7\% in 1999 led by reconstruction activities (construction increased over 35\%) and high investment rates in related industries (total investment grew from $29.8 \%$ to $35.5 \%$ of GDP in 1999) that pushed manufacturing and trade. The impact of Mitch was much larger in human terms: over 3,000 deaths and more than 150,000 families affected.

Coffee had been the main export crop of Nicaragua, but the decline in international prices decreased their export value. At the same time, the maquila industry (textile products mainly) took over its place as main export product fuelled by the promotion of export processing zones (free trade zones), formalised since 1991, and the special treatment given by the US to Central American products in the framework of the Caribbean Basin Initiative (CBI).

In 2005, maquila represented $46.8 \%$ of total exports and coffee exports accounted for $7.6 \%$ in contrast to $24.1 \%$ in 1995 . Cotton that was an important export product during the $1950 \mathrm{~s}$ and 1960s is not relevant anymore. Despite the expansion of maquilas, food exports are relevant.

Regarding employment, the informal sector represented about $63 \%$ of total employment in 2000-2004 (Balmaceda Vivas, 2005). It is higher in rural areas (around 72\%) because of the unequal access to land. Nearly $30 \%$ of the production units are smaller than $5 \mathrm{mz}$ (or $3.5 \mathrm{ha}$ ) and accounts for only $1 \%$ of total arable land (INEC, 2002a). Subsistence farmers have to 
work in alternative activities to make a living. Moreover, the participation of agriculture in total employment fell from about 40\% to 34\% between 1995 and 2005 (INEC, 2006).

\section{Dependence on external resources}

Nicaragua has faced large macro-economic deficits in the current account of the balance of payments and in the government accounts. Increasing oil prices affect the trade balance and also fiscal accounts as the government has subsidised energy prices.

The government has been unable to cover its fiscal deficit without external aid. Fiscal deficit grew due to reconstruction works after Hurricane Mitch and the 2001's banking crisis, which caused state intervention and the issuance of government bonds to avoid runoffs. In 2001 , fiscal deficit excluding grants reached its peak at $10 \%$ of GDP (BCN, 2007). In 2005, it was still high (4.5\% of GDP excluding grants and 1\% of GDP including grants), despite several tax reforms that increased tax revenues by four percentage points of GDP (ibid).

International aid increased significantly after Mitch (see Figure 2); it represented $19.1 \%$ of GDP in 1999 and remains at a high level (13.2\% of GDP in average in 2000-2005). Over the years, family remittances have increased to represent, in 2005, 12\% of GDP and surpass the aid flows for that year. Considering both items, the external financing of macroeconomic deficits has risen from 19.3\% to 23.8\% of GDP between 1995 and 2005 .

Figure 2: Main sources of external financing

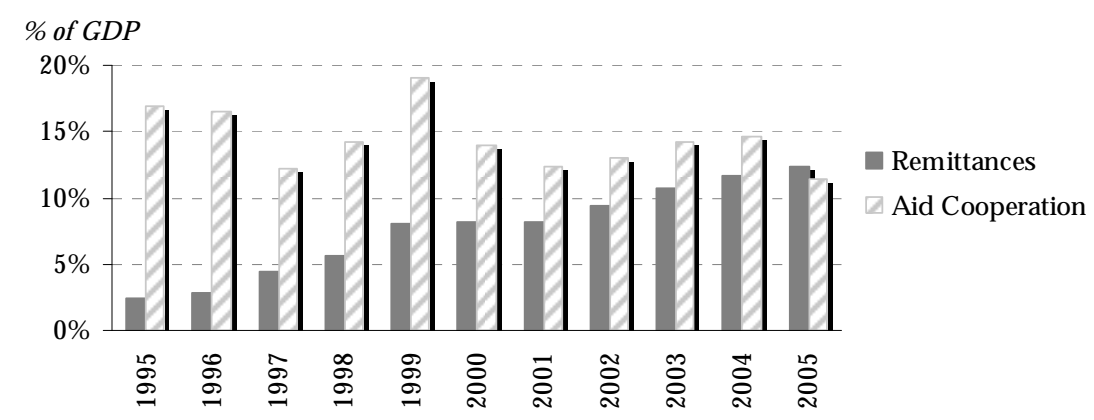

Source: BCN (2007) and GON (2006b).

\section{Financial vulnerability}

After following the commitments agreed in poverty reduction plans with multilateral institutions, in 2004, Nicaragua benefited of the Highly Indebted Poor Countries (HIPC) initiative and other debt relief schemes. More than $80 \%$ of its foreign public debt, in net present value, was forgiven (GON, 2005). However, fiscal deficits are recurrent so that foreign and domestic public debts added up to $136.2 \%$ of GDP in 2005 . Hence, changes in international interest rates affect the government's capacity to invest and to expand consumption.

In sum, Nicaragua is a poor country that has structural economic weaknesses and is very dependent on external resources. National strategies have privileged economic growth over other concerns and the means to grow has been to promote private investments and exports (GON, 2005) taking advantage of relative competitiveness (e.g., cheap labour cost, geographical location, trade preferences). An official message to potential investors was: 
Nicaragua's workforce... is known for its flexibility, high productivity, good work habits and a capacity to learn quickly when properly trained.... The availability of workers is abundant... [Employee] absenteeism [in free zones] is extremely low.... (ProNicaragua, 2003, 'People' section, II 1)

It clearly reflects that human development was not the priority. Although poverty reduction was an explicit objective, and the protection of vulnerable groups was in the 2001's national strategy, it would result from economic growth (cf., Guimarães \& Avendaño, 2004). This, in turn, would require the use of local human resources, well trained and flexible. The strategy 'does not emphasise the development of human capabilities but the investment in human capital in order to increase labour productivity' (Mangas et al., 2001, p. 24 [emphasis in original]).

\section{b) Human development situation}

Nicaragua is a country of medium human development. It has the $110^{\text {th }}$ place out of 177 countries ranked in terms of the human development index (UNDP, 2007b). ${ }^{109}$ Its index has grown from 0.610 in 1990 to 0.710 in 2005, but it is still lower than the average index $(0.803)$ of Latin American countries.

Poverty is acute. Poverty rate remains at about $48 \%$, but there are more poor people now than in 1998. As Table 3 shows, poverty incidence is much higher in rural than in urban areas: $70 \%$ versus $31 \%$ of the inhabitants are poor in rural and urban areas, respectively. Furthermore, poverty dynamics vary greatly between regions. Poverty declined in the Atlantic and Pacific but rose in Managua and the rural central highlands and Managua. Subsistence farmers belong to the segment of the poorest (Rocha, 2001) with large households (with high dependency ratios) and usually low access to basic services.

Table 3: Poverty rates in Nicaragua (\% of inhabitants)

\begin{tabular}{|l|cc|cc|cc|}
\hline & \multicolumn{2}{|c|}{$\mathbf{1 9 9 8}$} & \multicolumn{2}{c|}{$\mathbf{2 0 0 1}$} & \multicolumn{2}{c|}{$\mathbf{2 0 0 5}$} \\
& Extreme poor & Total poor & Extreme poor & Total poor & Extreme poor & Total poor \\
\hline Urban & 7.6 & 30.5 & 6.2 & 30.1 & 6.7 & 30.9 \\
Rural & 28.9 & 68.5 & 27.4 & 67.8 & 30.5 & 70.3 \\
\hline Total & $\mathbf{1 7 . 3}$ & $\mathbf{4 7 . 9}$ & $\mathbf{1 5 . 1}$ & $\mathbf{4 5 . 8}$ & $\mathbf{1 7 . 2}$ & $\mathbf{4 8 . 3}$ \\
\hline
\end{tabular}

Source: INEC (2003); INIDE (2007).

Consumption inequality is high, but it has decreased: the Gini coefficient fell from 0.49 in 1993 to 0.40 in 2005 (INIDE, 2007). The consumption of the richest $20 \%$ of households is 7.6 times the one of the poorest $20 \%$. About $45 \%$ of household consumption is food related. This proportion is higher among rural than urban households (56\% vs. $41 \%$ ) and among the poorest. Malnutrition is high and related to residence area and poverty levels.

Nowadays, only $14.5 \%$ of rural producers have access to credit. Nearly $48 \%$ of subsistence farmers do not have trade surpluses and, in many occasions, they sell their products in advance to patrons who pay half the market price (Romero \& Ferrero, 2004). In non-harvest season, many migrate to cut coffee and sugarcane in Costa Rica. The growth of agricultural production experienced in recent years has not produced an equal increase in real wages.

\footnotetext{
109 The human development index (HDI) measures three aspects: being able to lead a long and healthy life (measured by life expectancy), being well-educated (measured by adult literacy rate and gross enrolment ratio), and having a decent standard of living (measured by per capita GDP).
} 
Higher labour demand has been covered by unskilled labourers, which in several cases include children (Regalia, 2000).

Regarding education, Nicaraguans have low literacy levels (the progress made during the 1980s was lost due to public expenditure cuts). There has been an improvement in the last decade (Table 4), especially in the rural areas, but the rural-urban gap remains large. In addition, 'the net enrolment rates of the poor, indigenous people, and the inhabitants of rural areas are well below the national average' (De Jong et al., 2005, p. 22). In contrast, gender gap is almost inexistent. Women have more years of schooling than men (INEC, 2006).

Table 4: Literacy rates by gender and residence area, selected years

\begin{tabular}{|c|ccc|ccc|ccc|}
\hline & \multicolumn{3}{|c|}{ Total } & \multicolumn{3}{c|}{ Urban } & \multicolumn{3}{c|}{ Rural } \\
& Women & Men & Total & Women & Men & Total & Women & Men & Total \\
\hline 1995 & 75.5 & 75.2 & $\mathbf{7 5 . 4}$ & 86.8 & 88.7 & 87.7 & 59.1 & 58.9 & $\mathbf{5 9 . 9}$ \\
2005 & 79.7 & 79.3 & $\mathbf{7 9 . 5}$ & 88.3 & 89.7 & $\mathbf{8 8 . 9}$ & 66.7 & 66.2 & $\mathbf{6 6 . 4}$ \\
\hline
\end{tabular}

Note: Rate for people aged 10 years or older, based on national censuses.

Source: INEC (2006).

The situation in extreme poor households is the worst: almost one-third of children aged 712 in extreme poverty do not attend primary school (Gómez Sabaini and Geffner, 2006) and working children at that age work around 37 hours per week (Regalia, 2000).

On the other hand, housing conditions have improved in the last decade. However, the coverage of safe drinking water and electricity in rural areas is unsatisfactory. In 2005 , only $27 \%$ of rural households had access to drinking water and nearly $30 \%$ of rural households did not have any kind of sanitation (INEC, 2006).

\section{c) Social situation}

Based on the historical background described earlier and on Alvarez Montalván (2001) there are four basic elements of the Nicaraguan political culture that are reflected in the daily life experience of citizens:

(i) Impersonal causality orientation refers to identifying opportunities and decisions outside oneself. ${ }^{110}$ At the national political level, it refers to the tendency of looking for godfathers abroad to solve national matters that also reveals lack of solidarity and intolerance. At the individual level, it is related to the idea that the environment is uncertain, and as such, reality is unpredictable and hits strongly (UNDP, 2002).

(ii) Mistrust affects interpersonal communication and information sharing. It is explained by betrayal and lies, hidden motivations, and impunity of those who transgress the law. This explains the custom of 'playing clever on others' that lacks respect for the law and institutions and undermines the value of honesty, thus feeding feelings of insecurity, confusion and anarchy, besides mistrust (Navarro, 2001, p. 146-147).

(iii) Exclusion, exerted by politicians regarding their opponents, is also present in daily life as lack of access to economic opportunities (e.g., permanent job, credits), discrimination (e.g., gender, race), lack of representativeness and political power, and so forth (Mangas

\footnotetext{
110 Alvarez Montalván (2001) uses the word 'heteronomy' but it is not exactly the opposite of 'autonomy' as defined in the conceptual model of this study. It is closer to the concept of causality orientation that can be autonomy, controlling or impersonal.
} 
et al., 2001). Latinobarómetro (2004) finds that the main cause of discrimination in Latin American is 'being poor' and 55\% of Nicaraguan respondents agree.

(iv) Magic sense of the life is developed by the mixture of native mysticism and Catholic traditions that gives comfort. This would be evident in the treatment to the charismatic caudillo with attractive personality (e.g., Sandino), and in the hope that salvational events will improve everything at once (e.g., a new political Constitution, the trans-oceanic canal, the Central American union). Hence, most people relate success in life with good luck (UNDP, 2002). ${ }^{111}$

Alvarez Montalván (2001) affirms that these elements are complementary and form a holistic model that rejects pluralism, dissidence and competence. However, the experience of the Sandinista revolution may have had some positive effects. Martí i Puig (1998a) explains that at the micro-level, it introduced a new element: a mobilising and combative element that in some areas explained a process of 'reconciliation from below' among rural people who are not resigned to the exclusion, discrimination and abandonment. In addition, Booth and Richard (2006) find that, at the meso-level, it reinforced ideological polarisation, but it also turned Nicaraguans as supporters of democracy, not of authoritarianism (p. 132). At this respect, en effect, Latinobarómetro (2005) indicates that about $70 \%$ of Nicaraguans would 'under no circumstance support a military government', a percentage higher than the Latin American average (58\%).

A positive light is picked up by UNDP (2002) that identifies other factors of being Nicaraguan: people value to lead their lives and have a positive perception of their personal capacities and disposition to work (p. 25-27). However, the institutional framework is perceived as politicised and corrupt. ${ }^{112}$ It may block individual initiative and, in extreme cases, expel people out of the country (migration) or the society (i.e., delinquency and violence).

Migration has increased in the last years. Between 2000 and 2004, in average, around 90 thousand people emigrated while, in the first half of 2005, emigrants exceeded the 100 thousand (SIEMMES, 2007). Most migrants are aged 20-40 and have secondary education (42\% of those surveyed by INEC \& MINSA, 2002). There is an interesting pattern: the seasonal migrants come from the low social classes, while the permanent migrants (those who send periodic remittances and are more educated) come from the middle classes.

Violence is expressed in intra-family relationships and youth gangs. It has also reached the schools. MECD (2004) found, in a sample of 68 schools, that more than half of the respondents lived in violent circumstances, more than $40 \%$ were victims of psychological violent acts or robbery, and more than $20 \%$ were victims of physical violent acts.

With respect to social capital, at the end of the Sandinista regime, many mass organisations had become authoritarian, centralised and vertical so that after the electoral defeat and with the rampant economic crisis, there was a process of demobilisation. Then, 'Nicaraguans were overall less engaged in civil society than citizens in the other Central American countries' (Booth \& Richard, 2006, p. 118). Associational life is in many occasions restricted for the

\footnotetext{
111 The national survey of aspirations (PRANAFP, August 2001) indicates that $76.3 \%$ of Nicaraguans think that success is always or almost always by chance, while this percentage is higher $(80.9 \%)$ in rural areas (UNDP, 2002, p. 28).

112 Respondents to Latinobarómetro (2005) said in average that 77\% of public servants were corrupts.
} 
poorest and led by clientelism, instead of horizontal solidarity relationships (Molenaers, 2006). Hence, communal organisations are at risk of being co-opted by political parties.

\section{d) Mechanisms of participation at local level}

In 2001, the government included decentralisation in the national development plan as a tool to foster local economic development and to promote local participation. Since 2004, it has become a priority with the national policy of decentralisation and local development. A comprehensive institutional framework has been developed. For instance, there are budget transfers to municipal governments (Law 466) in order to provide basic services for the population (e.g., education, water provision) and improve the economic infrastructure. Next to this, local institutions such as committees of departmental development or committees of communal development are formed.

Transfers were first conditioned (not since 2005) by the existence of annual and multi-annual operative plans derived from local economic development plans elaborated by broad community discussion. To promote this, the central government has created deconcentrated coordinating entities at the departmental level with the support of a public municipal promotion institute.

However, the existence of policy documents and an institutional framework does not guarantee the success of such strategies if there are no clear priorities, coincidence between national and local goals, good enough planning and management capacity in municipalities, skilled human resources, and effective leadership of municipal government to attract the participation of productive sectors (Lathrop, 2004). ${ }^{113}$ The provision of public services and transparent use of public funds requires, in addition to the above, accountability (Dio, 2004) and that an equity objective is included in the distribution of funds among municipalities (Lathrop, 2004; Gómez Sabaini \& Geffner, 2006).

In several municipalities, committees are being formed to fulfil the requirement of local participation in budgets and strategic plans in order to receive the transfers. There are several detailed steps that municipal governments have to follow (e.g., balance of previous year's budget, physical and financial execution of investment plans) without distinction among municipalities. The participation of NGOs that are active in the municipalities is crucial to support this process, especially for the poorest municipalities, but these NGOs sometimes have their own agendas and conceptions about local development. This is a risk given the large presence of donors in Nicaragua.

In general, membership in development committees depends on relative affluence in terms of resources and relationships (that generate entitlements). Hence, the poorest at first might be excluded. For instance, Rocha (2001) finds, based on the 1998 national household survey, that rural households with subsistence economies (most likely in extreme poverty) hardly participate in agricultural organisations (only $7 \%$ ) or in related projects (4\%). Their opportunities are restricted to their individual actions and resources.

\footnotetext{
113 Indeed, since 1997, the reformed municipal law had included formal participation mechanisms as open forums ('cabildos abiertos'), free participation of citizens in meetings of the municipal councils, and the right of citizens to present policy proposals (Howard, n. d.). However, participation was not effective.
} 


\section{Appendix 1-B: El Salvador, an introductory review}

Salvadorian people have the sky as hat. So high their dignity is. They look for the time when the ground will flourish for those that fell, when happiness will arrive to wash the suffering... Go on Salvadorian that there is no little bird that stops flying after taking wing!

Extract from 'The blue hat' (A. Primera)

Section 1 presents the political and the historical background with a focus on the experiences of rural inhabitants regarding the 12-year civil war, its roots and consequences. Section 2 presents a balance of the recent economic, human development, and social situation of El Salvador. It also includes an assessment of mechanisms for local participation in place during 2005.

\section{Section 1: Political and historical background ${ }^{114}$}

El Salvador faced a bloody armed conflict during 1980-1992. The causes of the conflict persist, although with different patterns. Since the Spanish colonial times, Salvadorian society has been characterised by social and economic inequalities. During early years of the Republic, the rural population of El Salvador was excluded from the modernisation process chosen for the country by economic elites, supported by civilian dictatorial or military governments.

Land destitution is a root of conflict. In the 1880s, the legislative assembly abolished traditional communal lands (held by native people) and established that property titles would be given 'to anyone who would use [the land] for the cultivation of coffee and other export crops' (Murray, 1997, p. 9). Some years later, the productive land was in hands of a coffee oligarchy. Most peasants could not afford coffee cultivation that requires five years before the first harvest and, on the other hand, lacked the literacy skills to fulfil titling process requirements. In addition, laws were released against the 'laziness' of peasants, which implied that armed forces would patrol rural areas and detect those people who were not working and assign them to plantations (ECLAC, 2001b; Martínez, 2005; North, 1981). In sum, coffee oligarchy governed the lands and the cheap labour. This was a tragedy for the native people who were so attached to their land by cultural reasons. ${ }^{115}$ During the 1920s, high coffee prices fuelled the expansion of coffee plantations pushing native people to roles of wage workers or subsistence tenants of the least productive and most marginal lands. Later, during the 1930s' economic depression, peasants either received lower wages or were unemployed.

During this crisis situation, in 1932, native people, led by caciques or headmen of the villages, carried out an insurrection against land owners in Sonsonate, Ahuachapán and Santa Ana (western region of El Salvador). In parallel, urban workers and university students

\footnotetext{
114 This section is primarily based on North (1981), Arnson (Ed.) (2003), Murray (1997), Biekart (1999 2003), and Segovia (2002).

${ }^{115}$ Martínez (2005) explains that native people had a philosophy about the land and human goals: 'The best expression of their relationship with the land was the maize, the main purpose of sowing, so that indigenous people believed that human beings were created from the maize' (II 2).
} 
linked to the Salvadorian communist party (PCS) had coordinated actions in San Salvador in support of rural revolts but they were discovered, imprisoned and their leaders (incl. A. Farabundo Martí) assassinated. Several rebellions had taken place earlier in rural areas to regain access to lands, but the insurrection of 1932 was the largest one. It was brutally wiped out by the army causing the death of between 10,000 and 30,000 people in a short period known as La Matanza ('slaughter' or a killing of higher order than a massacre). This event is known as a sign of repression and despair.

After this event, native people realised that they could not defend their rights in any way as already, since the 1920s, any form of rural political organisation had been prohibited (North, 1981, p. 74). Furthermore, repression would be a tool of economic elites backed by army forces to control them. The National Guard acted as the private police of large landowners (North, 1981; TCES, 1993). Murray (1997) explains that this event also marked the mestización or the 'assimilation of indigenous people to the point of cultural uniformity' (p. 10) because they stopped wearing their traditional clothing and changed other aspects of their culture to avoid being targeted by the army (cf., North, 1981).

Since 1932, El Salvador had been governed by military rulers sometimes in partnership with civilians (notably, the National Conciliation Party or PCN, during the 1960s and 1970s). The process of land destitution continued and El Salvador's economy became more dependent on exports of coffee and, after the World War II, on exports of sugar and cotton that displaced subsistence crops, thus affecting the livelihoods of small farmers. Sugar and cotton production is capital-intensive and basically requires temporary workers only during harvest season. Hence, the expansion of these export crops brought lower employment opportunities for wage labourers. Meanwhile, urban areas, especially the capital city, did benefit from the export boom. Industrialisation during the 1950s and 1960s was fuelled by export profits, government policies to promote import substitution, and US foreign investment. Urban labour unions and civil organisations emerged but the military rulers kept leaders under close watch. Political parties were also founded (1960s) but in rural areas small farmers did not enjoy political freedom.

Opposition parties led by the Christian Democratic Party (PDC) became stronger and gained presence in the Congress and in municipal governments, especially in San Salvador. In 1969, over 130,000 Salvadorian refugees returned from Honduras; they were peasants that had left the country looking for land in the less populated Honduras and had been expelled after the 'football war'. The issue of agrarian reform was raised by opposition parties and organised groups of civil society, given the large number of landless farmers. ${ }^{116}$ In 1970, they gathered in a national agrarian reform forum convoked by the Congress.

But the military rulers closed the little political space opened (there were electoral frauds in 1972 and 1977) and persecuted the opposition political parties. Over the years, the Catholic Church (Jesuit priests and other groups) had worked in rural areas and organised peasant unions in line with its 'preferential option for the poor'.117 Then, priests together with rural

\footnotetext{
${ }^{116}$ Murray (1997, p. 11) citing Durham (1979) explains that 'between 1892 and 1971 the average amount of land available to poor rural households declined from 7.4 to 0.4 hectares' basically due to increasing concentration of land ownership. According to Revista Envío (1983), 40\% of rural population was landless in 1975.

117 The Catholic Church in Latin America was living a change process after the II Vatican Council (1962-1965) and the Latin American bishops' conference in Medellín, Colombia (1968). Over these years, the 'Theology of
} 
organisations were also persecuted with crude violence. The international condemnation to the regime increased. In 1979 there was a coup d'état led by young military officers that would break the long lived partnership between the military and coffee export oligarchy (Segovia, 2001).

Civilians from opposition parties were invited to form government juntas but several resigned because they had been used as a façade by military groups to gain credibility abroad while controlling the country at their wish with repression (North, 1981). However, a junta established in 1980, in which PDC politicians participated, started some structural reforms such as the agrarian reform (to address the land problem considered being the root of the conflict), the nationalisation of banks (to channel credits to the reformed agriculture sector) and the nationalisation of coffee and sugar export system (Segovia, 2002). These measures directly affected the interests of the agro-export elite but received temporary support by the army and the US government, afraid to spreading revolution in the region. The US gave military aid to the Salvadorian government despite the large-scaled violence.

Monsignor O. Romero became 'a national voice for the rights of the poor' (Murray, 1997, p. 13). He supported the legitimacy of peasants' demands, urged the armed forces to stop the violence and even asked the US government to stop its military assistance to Salvadorian government. He was assassinated in 1980 while celebrating a mass in San Salvador. This event symbolised the climax of the political violence. In January 1981, the Farabundo Martí National Liberation Front (FMLN) launched its 'final offensive'. It was its first military action that, although unsuccessful, showed its mobilisation capacity.

\section{- The civil war}

FMLN was founded in 1980 and was composed of five different guerrilla organisations developed during the 1970s. It had a political branch called the Democratic Revolutionary Front (FDR) that in turn grouped Marxist and social Christian political groups and associations of peasants, industrial workers, teachers, and university students (North, 1981).

It gained popular acceptance given their plurality and attitude toward rural population: guerrilla combatants would build roads and bridges in small towns or provide medical attention and literacy classes in exchange for food. This situation was opposite to the brutal violence applied by military groups against all popular organisations and rural population. For instance, there was a practice of 'cutting the guerrillas' lifeline' for which people who lived in areas under guerrilla influence were at death risk as automatically suspected of being guerrilla members or collaborators (TCES, 1993). Even more tragic is that soldiers of the national army were the same poor and excluded people forced to enrol and to attack their neighbours.

Around 75,000 people are estimated to have died and at least 5,500 to have disappeared during the 12-year conflict (Gutiérrez, 2007). Human right violations were widespread. The truth commission (TCES, 1993) registered more than 22,000 complaints from which, 85\% were attributed to state agents (security and military forces, civil defence units), $10 \%$ to

Liberation' was developed and later broadly spread along the region. Priests were promoting Christian base communities in rural areas. 
death squads (or right-wing paramilitary forces) and 5\% to FMLN. ${ }^{118}$ Over $75 \%$ of serious violent acts took place in the period 1980-1983. After that period, violence levels were less indiscriminate.

A junta (led by conservative PDC members) called for legislative and presidential elections between 1982 and 1985. The PDC candidate J.N. Duarte was elected President for the period 1984-1989. His opponent was the founder of the National Republican Alliance (ARENA) Major R. D'Aubuisson, a death squad leader (TCES, 1993); while the FDR could not participate. The PDC government implemented a strategy of 'crisis management' (Segovia, 2002, p. 21) that included periodic price adjustments and exchange rate and import controls, but it did not initiate any major reform. USAID continued its aid flows to El Salvador for geopolitical reasons. ${ }^{119}$ These funds financed the deficit in the balance of payments resulting from the export crisis fuelled by the war. The violence continued.

The liberal economic agenda promoted by ARENA was supported by the US and also gained the sympathy of right-wing groups. Meanwhile, PDC was losing support due to the spread of the war and unpopular economic measures. The ARENA candidate, A. Cristiani, was elected president for the period 1989-1993. He proposed peace negotiations with FMLN. Nevertheless, armed forces' violence continued so that FMLN organised a 'nationwide military offensive' (November, 1989) that showed that it was not defeated and furthermore, it convinced ARENA and the US government that the war would not have a military solution (Biekart, 1999/2003; Spence, 2004).

\section{- The peace accords}

Peace talks with the auspices of the United Nations started in May 1990 and finished in 1992 with the signature of the Chapultepec peace accords by the government and FMLN. This agreement or 'negotiated settlement' (Allison, 2006, p. 151) aimed to cease the fire via political negotiation, promote democratisation, guarantee respect for human rights, and reunify and reintegrate the society (Arnson, 2003). FMLN became a political party and participated in the 1994 presidential elections. It was the first time that a left-wing party could participate in elections. Nowadays, FMLN is the second largest political party in the country.

A truth commission was set up to investigate the serious acts of violence. A UN observers' mission remained in El Salvador until April 1995 to oversee the fulfilment of the peace accords (in especial, military demobilisation) and to watch the electoral processes of 1994 (Presidential election with runoff, legislative and municipal elections).

The role of military forces in internal security affairs was significantly reduced. This was very important because El Salvador's government, since 1931 until 1989, had functioned under military control or influence (civilians supported by military forces or juntas). This influence was strengthened during the civil war and, even worse, despite formal civilian ruling, military forces had enjoyed impunity to act.

\footnotetext{
118 Death squads were either military or civilian forces heavily armed that attacked targeted people to whom they abducted, tortured, and most times, disappeared or executed. They acted clandestinely and wore civilian clothes to hide their identities and affiliation.

119 US aid funds to military and economic assistance reached USD1,104.5 million and USD3,405.7, respectively, between 1980 and 1992 (USAID, 2006b).
} 
The constitution was amended. There were reforms to the judiciary system and to the electoral political system. New institutions were created (the procurator of human rights, the civil national police, the supreme electoral tribune, and national council of judicatory) and others had important changes (the supreme court of justice and the general fiscal office).

In March 1993, the Congress approved the law of general amnesty for political crimes committed during the war (IACHR, 1994). Former soldiers and guerrilla fighters benefited from land transfer programmes which aimed to accelerate their reintegration to social life. Lands that were in areas 'controlled' by the guerrilla were legalised.

\section{- The agrarian reform}

The agrarian reform had several stages. It was complemented with the land transfer programme (PTT), after the peace accords, and with the rural solidarity programme (PSR), an extension of the PTT.

The agrarian reform was initiated in 1980 by a junta because it was hoped that a civil war and the spread of revolution across the region could be avoided by solving the land issue. The reform was implemented by armed forces that took over the haciendas, watched the elections of cooperative representatives and, in many cases, killed the elected boards or kept control (also collecting money) of them under death threat (Revista Envío, 1983). Second, it was meant for permanent workers of the lands but many peasants were working as seasonal temporary workers. Third, lands were allocated to cooperatives formed by inexperienced farmers with external administrators. The training component was not provided as planned and many cooperatives were abandoned (ISTA, 2005).

The agrarian reform had three stages (see Table 1). The first stage allocated the larger number of hectares (around 15\% of cultivable land and 11\% of total territory) to 333 cooperatives but the third stage had the highest impact in terms of the number of individual beneficiaries (although the plots were much smaller). It had the motto 'land to the tiller', that is, it benefited the tenants in any modality such as sharecroppers, renters, or colonos (PRISMA, 1996).

Table 1: Agrarian reform and other land transfers in El Salvador

\begin{tabular}{|llccc|}
\hline Phase & \multicolumn{1}{c}{ Characteristics } & Properties affected & Hectares & Beneficiaries \\
\hline \multirow{3}{*}{ First } & (1) Agrarian Reform: & 5095 & 300,283 & 583,344 \\
Second & -Full-time workers, farms larger than 500 ha. & 480 & 227,543 & 317,085 \\
Third & -Full-time workers, farms larger than 245 ha. & 55 & 7,385 & 9,219 \\
& -All tenants, farms up to 7 ha. & 4,560 & 65,355 & 257,040 \\
& (2) Other land transfers & 3,548 & 110,868 & 352,886 \\
\hline \multicolumn{2}{l}{ Total (1)+(2) } & $\mathbf{8 , 6 4 3}$ & $\mathbf{4 1 1 , 1 5 1}$ & $\mathbf{9 3 6 , 2 3 0}$ \\
\hline
\end{tabular}

* There were several decrees related to the agrarian reform and also to the post-civil-war land transfers. Source: ISTA (2005, p. 5).

The PTT allocated around 104,400 hectares among 49,218 beneficiaries. From these, 68\% were former guerrilla fighters, $22 \%$ were army soldiers and $10 \%$ were civil organisations. Transfers took place in all departments of the country but at different intensities in relation to the incidence of violence during the civil war. The extreme cases were Usulután (where San Agustín is located), with 26\% of all hectares transferred, and La Unión (where Agua Fría is located), only with $2 \%$. The PSR distributed around 10,578 hectares of small plots to 35,483 former army combatants in extreme poverty. 
In global terms, the agrarian reform and post-civil war land transfers had redistributed about $20 \%$ of Salvadoran territory to $14 \%$ of households (ISTA, 2005). In many cases, it allocated the marginal lands in which no coffee was produced Moreover, the lands redistributed in the third stage were so small that only could be used for subsistence farming. ISTA (2005) reports that reformed lands produced 15\% of total coffee production in 1991, while they produced $33 \%$ of total maize production.

Paige (1996) studies the linkage between landlessness and conflict in Latin American countries and notices that in El Salvador case the peasant support toward the FLMN was not simply related to land destitution. In fact, 'the western coffee regions where the number of landless labourers is the greatest' (p. 132) and that suffered the matanza did not participate in the armed conflict. This means that there were other causes besides land destitution that explained the conflict: long lived exclusion and the actions of guerrillas about it.

In all cases, the owners of the lands were compensated, for instance, with long-term government bonds. New owners acquired long-term credits with the state to get their lands and many of them received loans to finance working capital. Later laws allowed parcelling-out the cooperatives lands among individuals. The cooperatives that had experienced problems during the conflict (especially those in the eastern region) and cumulated arrears, could apply for debt refinancing. In practice, some cooperatives sold part of their property to repay debts getting a discount and divided the remaining property among their members who kept smaller individual plots (Kowalchuck, 2003). Other cooperatives exist because its members have to repay the debt.

\section{Section 2: Situational analysis}

This section analyses the recent economic situation of El Salvador in relation to human development concerns. It includes some reflections about the social context in El Salvador, and mechanisms for local participation until 2005 (year of the fieldwork).

\section{a) Economic situation}

During the 1990s, the government introduced structural economic reforms such as the elimination of price controls and the introduction of a flexible exchange rate system, trade liberalisation (reduction in the import tariffs and creation of 15 free trade zones), financial liberalisation (unregulated interest rates and re-privatisation of financial institutions), pension system reform, tax reform (elimination of export tax, introduction of the value-added tax, elimination of direct taxes, etc.), and the privatisation of state enterprises of telecommunications and electricity, among others.

During the first half of the 1990s, El Salvador's economy expanded around 6\% per year (Figure 1) pushed by the expansion of maquila exports, that in turn increased employment, and by domestic consumption financed by family remittances and credit expansion (financial sector grew over $12 \%$ in this period). 
Figure 1: Long-term GDP growth, 1991-2005

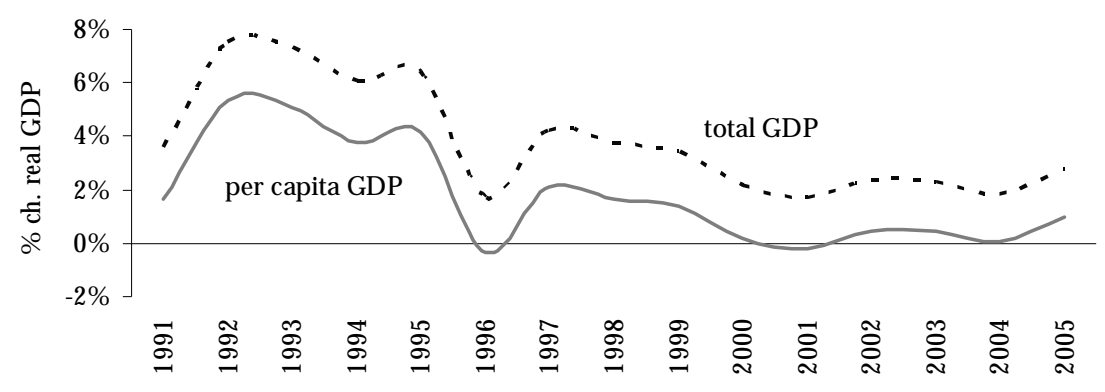

Source: BCR (2006).

During the second half of the 1990s, restrictive fiscal and monetary policies applied to control inflation had negative effects on private investment. The latter fell by $16.9 \%$ in 1996 , in real terms. In addition, remittances lost their dynamism. On the other hand, world economic slowdown and natural disasters (e.g., earthquakes in 2001 and hurricanes, in 1998 and 2005) have affected El Salvador's economic performance overall.

Negative impacts were exacerbated by structural problems such as low economic productivity (IDB, 2005) and aggregate gaps in fiscal accounts and balance of payments. In order to assure economic stability, thus reducing the risk of external vulnerability, the economy was dollarised as of January 2001 (the US dollar is legal tender as the Salvadorian colon is).

Three features of the Salvadorian economy are discussed below: economic structure; export base and growth strategy; and migration and remittances.

\section{Economic structure}

The participation and influence of agriculture in aggregate production has decreased. In 2005 , agriculture production accounted by $11.8 \%$ of GDP while this percentage had been $16.5 \%$ in 1991 and $19.0 \%$ in 1980 . Coffee only represented $1.5 \%$ of the total production in 2005. In later years, industry, trade and tourism and construction have been the leading sectors, to which private banking prefers to lend.

Regarding employment, global employment grew (by over 6\% in average between 1997 and 2005) fuelled by maquila sector and services. Maquila sector has increased female labour participation and actual employment, because around $80 \%$ of maquila workers are women (Segovia, 2002; Lara López, 2003). In contrast, employment in the agricultural sector fell (by $0.6 \%$ annually) and real wages in rural areas decreased (FUNDE, 2005). Agriculture provided 19.5\% of total employment in 2005 much lower than 34.3\% in 1997 (DIGESTYC, 2007). Migration from rural to urban areas increased due to the location of industries. Underemployment and unemployment together have risen in the last five years to represent $40 \%$ of total employment in 2005.

\section{Export base and growth strategy}

El Salvador has pursued an export oriented growth strategy aiming to increase the competitiveness of leading export products in international markets, for which it has signed free trade agreements. Over $60 \%$ of their exports are directed to the US and around $27 \%$ to Central American countries (BCR, 2006). 
Nowadays, El Salvador depends more on maquila products (mostly textile products) than on traditional export products such as coffee (the main export product until the 1980s), sugar or cotton. Figure 2 shows that maquila exports increased exponentially (in a period in which total exports went up by four times) to represent $53.6 \%$ of exports in 2005 , while coffee has lost importance, affected by low international prices.

Figure 2: Main export products, 1991-2005

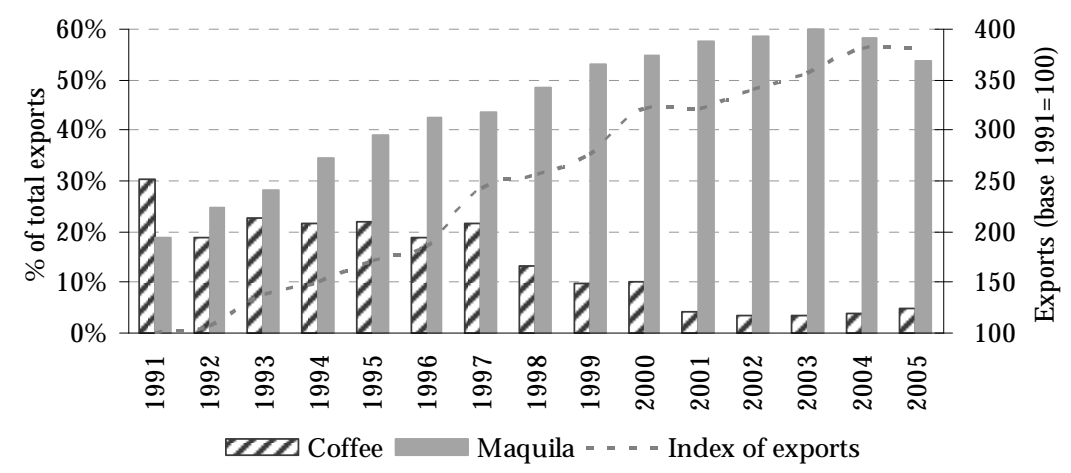

Source: BCR (2006).

While maquila exports in 2005 represented 10.7\% of GDP, net maquila exports (exports minus imports) accounted for only $2.4 \%$ of GDP. It seems that El Salvador has simply replaced its dependence from coffee to maquila with low added value that might be producing a modern labour exploitation structure. Its 'success' is based on low wages and precarious jobs (Alvarenga Jule, 2001; Lara López, 2003). However, its effect on other industries is low because its activities are simple and most non-labour inputs are imported. Moreover, there is no investment in research and development.

\section{Migration and remittances}

Family remittances are the main source of foreign resources for El Salvador. The government has implemented some measures to channel remittances via formal institutions, such as the temporary registration of emigrants in the US and the reduction of remittances transaction costs, in order to improve their impact on the economy. At the micro-level, remittances have changed the power relationships in rural economies because, while coffee producers have lost importance, remittance-receiving households have more opportunities to improve their lives (cf., Saravia, 2002). Besides, in rural areas, a process of urbanisation related to remittances is taking place (UNDP, 2005b).

International emigration continues (see Figure 3). The lack of economic opportunities and the linkages built by first-generation emigrants in the destination country, mainly the US, triggers emigration nowadays (ASIPES, 2002). Roughly one-fifth of households receive remittances (see Hagen-Zanker \& Muñiz Castillo, 2006). In 2005, remittances were over USD 2,800 million and represented $16.7 \%$ of GDP, a higher percentage than private investment (13.2\% of GDP). They are partially covering recurrent deficits in fiscal accounts (about $2.3 \%$ of GDP in the last decade) and in the current account of the balance of payments (over $4 \%$ of GDP in last three years). 
Figure 3: Remittances and net migration, 1991-2005
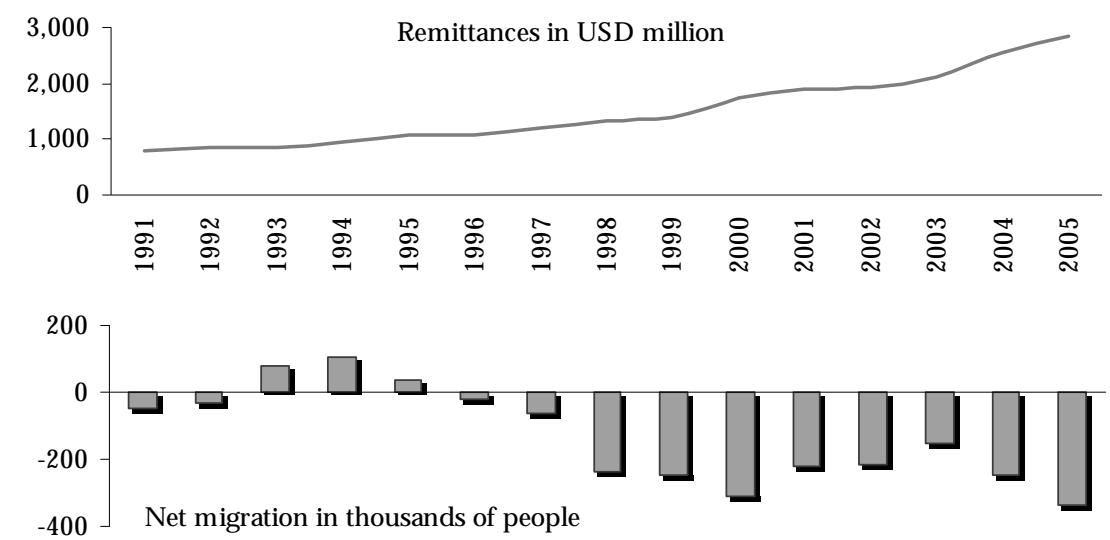

Note: Net migration is inflows minus outflows of Salvadorians as registered in borders.

Source: BCR (2006) and SIEMMES (2007).

In sum, El Salvador has passed from being a primary-good exporting country to a labour exporting country (Orozco, 2002), with workers in the US and in maquilas (cf., Rosa, 2005). This significant change at the macro level has micro-level implications because the living conditions of some people in rural households are improving after decades of impoverishment.

\section{b) Human development situation}

El Salvador is a country of medium human development (UNDP, 2007b). Most of its municipalities are in that range but there are disparities within the country (see Figure 4).

Figure 4: Municipalities classified by the HDI

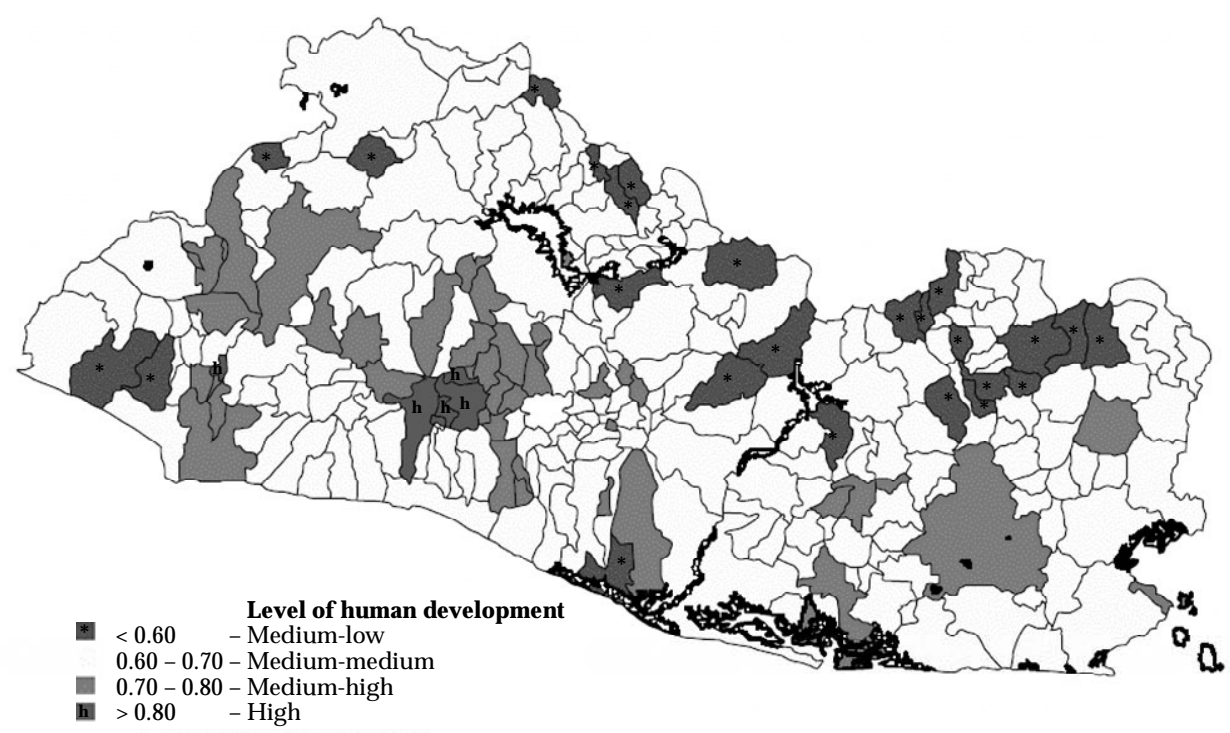

Source: UNDP (2005c). 
It is worth noticing that this index does not necessarily agree to the monetary poverty rate. For instance, the municipalities of San Agustín and San Alejo classified both in a mediummedium level, have different poverty rates so that San Agustín is classified as of severe extreme poverty while San Alejo appears as of low extreme poverty.

The rate of monetary poverty has decreased over the last 15 years (see Figure 5). However, the reduction in absolute terms could be lower than showed due to measurement problems (WB, 2005; UNDP, 2007a). Poverty is higher among rural households, for structural reasons related to socio-economic exclusion that has evolved due to low agriculture wages (cf., Segovia, 2002; IDB, 1999).

Figure 5: Poverty incidence in urban and rural areas, 1991-2005

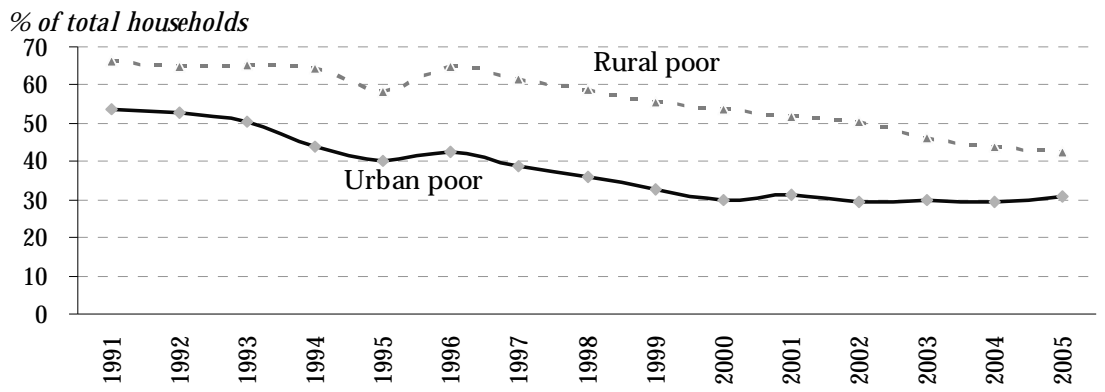

Source: DIGESTYC (2007).

In 2005 , poverty reached $42.4 \%$ of rural households and $30.9 \%$ of urban households. In rural areas, $16.9 \%$ of households were living in extreme poverty. The rural-urban gap seems to be narrowing as some households are migrating from agriculture to other activities. However, for those who depend on agriculture as main source of earnings, the reduction in poverty incidence was minimal (WB, 2005). Remittances have an important role in poverty alleviation but it is not necessarily the main driver. ${ }^{120}$ Although remittances basically sustain private consumption, they are also dedicated to education and health expenses (Kandel, 2002).

Income inequality is high. The Gini coefficient is 0.52 and the income of the richest $20 \%$ of households nearly 21 times the income of the poorest 20\% (ECLAC, 2007b; UNDP, 2007b). Furthermore, per capita income of the poor grew below the nationwide average and, especially since 2000 , the differences in income growth between the moderate poor and the extreme poor widened so that income inequality increased (WB, 2005, p. xiii).

WB (2005) found that 'education, ownership of land or other physical assets, and access to markets and basic services (via proximity to all-weather roads and transportation) were all key factors in households' ability (or not) to participate in recent economic progress' (ibid, p. xiv). Other factors such as having formal-sector salaried employment in non-agricultural enterprises and possibilities for income diversification were also important.

Regarding education, from 1991 onwards, the inhabitants of El Salvador have improved their education achievements significantly. First, net enrolment ratio in primary education grew

\footnotetext{
${ }^{120}$ UNDP (2003b, p. 14) finds that more than half the reduction in the extreme rural poverty - between 1992 and 2002 - was explained by the increase of remittances. In contrast, WB (2005, p. 26) calculates that only a $13 \%$ of the reduction of extreme rural poverty would be explained by remittances.
} 
from $78.0 \%$ to $88.4 \%$. Second, the percentage of children reaching fifth grade rose from $58.1 \%$ to $74.6 \%$ (in 2002). Third, youth literacy rate increased from $85.0 \%$ to $93.8 \%$ (UNDP, 2005c). Moreover, there is gender equity (ibid, p. 38) although rural-urban gaps remain. Children who enrol school in rural areas are less likely to complete their studies and the quality of education is still a challenge (WB, 2005).

Adult literacy rates are lower in rural than in urban areas (see Table 2). In 2005, almost 77\% of rural inhabitants and $90 \%$ of urban inhabitants were literate. However, a literacy rate of $85.1 \%$ is still below the regional average $(90.2 \%)$. Years of schooling were also lower in rural areas (3.8) than in urban areas (6.9).

Table 2: Literacy rates (\%) by gender and residence area, selected years

\begin{tabular}{|c|ccc|ccc|ccc|}
\hline & \multicolumn{3}{|c|}{ Total } & \multicolumn{3}{c|}{ Urban } & \multicolumn{3}{c|}{ Rural } \\
& Women & Men & Total & Women & Men & Total & Women & Men & Total \\
\hline 1999 & 79.6 & 84.5 & $\mathbf{8 1 . 9}$ & 85.3 & 91.9 & $\mathbf{8 9 . 3}$ & 67.7 & 74.2 & $\mathbf{7 0 . 9}$ \\
2002 & 81.7 & 85.9 & $\mathbf{8 3 . 4}$ & 87.5 & 93.0 & $\mathbf{9 0 . 0}$ & 71.0 & 75.6 & $\mathbf{7 3 . 2}$ \\
2005 & 82.5 & 88.2 & $\mathbf{8 5 . 1}$ & 87.6 & 93.6 & $\mathbf{9 0 . 3}$ & 74.1 & 80.0 & $\mathbf{7 6 . 9}$ \\
\hline
\end{tabular}

Note: Rate for people aged 10 years or older, based on household surveys.

Source: DIGESTYC (2007).

Regarding housing, the access to all primordial services has increased, especially with the reconstruction aid after the 2001's earthquakes. The changes during 1991 and 2004 are quite impressive in rural areas: the coverage of safe drinking water increased from $57 \%$ to $72 \%$, the coverage of sanitation went up from $59 \%$ to $84 \%$, and the access to electricity grew from $44 \%$ to $71 \%$ of total households (UNDP, 2005c). Currently, $85 \%$ of the total households have access to safe drinking water in El Salvador but only $57 \%$ have sustainable access to an improved water source (i.e., the household has a private connection in its piece of land).

\section{c) Social situation}

The expectations raised by the peace accords regarding social and economic integration were not fulfilled (Cruz, 2003; CIDAI, 2002). On the contrary, the structural adjustment and liberal policies implemented during the 1990s caused disillusion among the population about the feasibility of changes in economic structures. This disillusion, together with preexisting distrust, weaker family structures and the availability of guns, gave birth to new kinds of violence that manifest in delinquency, assaults and homicides. Criminal or social violence produces a feeling of insecurity and threatened physical integrity and survival (Cruz, 2003).

Levels of insecurity are high in El Salvador. The homicide rate in 2005 was the highest in Latin America: 54.7 homicides per 100,000 inhabitants, higher than Honduras's (40.7) and much higher than Colombia's (33.7). The rate was above 100 for groups aged $15-34$ and $80 \%$ of homicides were using firearms (Henríquez, 2006a; Pléitez Chávez, 2006). Insecurity has increased with street gangs (maras) that are more active in urban areas. These gangs develop among young people who feel marginalised and without economic and social opportunities (Hertvik, 2002) and those who witnessed or suffered intra-family violence (Dalton, 2003).

Social reintegration aimed with the peace process is still to be reached. Society is polarised and segmented (Arnson, 2003), while 'social sectors that during decades have been margin- 
alised in the government decision-making are still not taken into account' (Olmos Guevara (2003/2005, p. 137).

Political polarisation is deep as evidenced by the practices of the two main parties, ARENA and FMLN, and resembles their position during the conflict. ARENA has governed the country since 1989. In contrast, FMLN faced divisions among its five constitutive groups but keeps a second place in political preferences. PCN and PDC that existed since the 1960s and 1970s maintain presence in national politics. PCN has influence in rural areas. It got $20 \%$ of municipality councils for the period 2003-2006 (COMURES, 2006).

Considering previous factors (disillusion, insecurity, economic exclusion, and political polarisation), most people show low trust in institutions, low participation in political life and in organisations (excepting religious groups), a growing discontent with democracy, and collective frustration (Martel, 2003). Therefore, when communal participation occurs, this is not translated into increased political participation but does increase interpersonal trust (Booth \& Richard, 1998). There is a clear difference between interpersonal trust in small groups and trust in the government, public institutions or an idea of Salvadorian society.

Concerning ideas of democracy, Latinobarómetro (2004) found that Salvadorians among other Latin American preferred 'more order although some freedoms would be limited'. In addition, in its poll, only $43 \%$ of people surveyed reported that a military government could solve lesser things than a democratic one, while $78 \%$ of respondents said that 'a firm hand does not hurt'. Karl (2003) explains that unlike other countries, in El Salvador 'the higher the income and educational level, the more people prefer authoritarian rule' (p. 41). Authoritarian roots are embedded in the political culture of El Salvador.

\section{d) Mechanisms of participation at the local level}

There are several institutions engaged in local development. The economic and social development fund for municipalities (FODES) receives $7 \%$ of current government revenues and finances investment projects executed by municipal governments. In the poorest municipalities, this transfer makes most of their revenues. In 2004, FODES flows represented $0.8 \%$ of GDP. The funds were applied to roads, education, rural electrification projects and water infrastructure (RDL, 2006).

The social investment fund (FISDL) supports the formulation, execution and supervision of projects financed by FODES, at the communal and the municipal levels. It also collaborates for the strengthening of municipal governments' capacities in financial, administrative, and territorial matters (FISDL, 2003) and promotes participatory planning. UNDP (2001, p. 27) states that more than $60 \%$ of municipalities had some type of participatory plan in 2000 .

FISLD's resources come from national budget, donors, NGOs and emigrants. FISDL channels resources from Salvadorian emigrants via the 'United for Solidarity' programme. Project proposals (presented by emigrants with commitment of resources) compete for FISDL funds and, if selected, these projects are executed in coordination with local communities (with emigrants-FISDL mixed funds). FISDL uses the same competition mechanism to allocate funds from donors; in this case, communities have to commit funds as counterparties.

At the national level, there is a national commission for local development (CONADEL) integrated by line ministries, public institutions, municipal governments, and aid agencies. 
Its objective is 'revising the policies and mechanisms that secure the implementation of local development in the municipalities' (RDL, 2006, p. 64). It does not include the private sector.

At the local level, there are local development committees (CDL) or municipal development committees (CDM) that incorporate ADESCOS (local development associations that are legalised by municipal ordinance), women and youth groups, religious associations, and others. According to a public poll by FUNDE (UNDP, 2001), there was one CDL in 78\% out of 250 local governments (surveyed) in 2001 and 62\% of them had been formed in 1999 or 2000. Nevertheless, as many of them depend on external aid to function or on the political party in the municipal government, their mortality index is high (RDL; 2006, p. 82).

There are several social programmes managed by the central government with the participation of local communities in the rural areas. In the cases studied, long-dated decentralised education programmes have helped to develop organisation capacities in the communities.

\section{Box: The EDUCO programme in rural El Salvador}

EDUCO is a rural programme that relies on community participation. It was implemented after the peace accords in order to reopen the schools quickly, in rural areas that had suffered by civil war combats, and to improve the quality of education (Smulovitz \& Walton, 2002; Marquez, 2000). Community Education Associations (ACEs) make decisions regarding hiring (and firing) teachers, infrastructure improvements and operating budgets. They receive transfers form the central government to pay the teachers and are allowed to make deductions if a teacher is absent without a good reason. Teachers have annual contracts whose renewal depends on the performance evaluation by ACEs (Marquez, 2000). Although the academic performance of EDUCO students is not different from that of nonEDUCO rural students (Smulovitz \& Walton, 2002, p. 41), the effect of EDUCO was important to expand coverage and promote parental participation. The number of EDUCO students grew 3.7 times from 1993 to 2002 and, currently, 44\% of rural schools are under EDUCO programme (WB, 2005). Moreover, teachers meet frequently with parents to discuss about their children's needs and behaviours. 


\section{Appendix 2-A: List of persons interviewed}

\section{Santa María (Nicaragua)}

Inhabitants who participated in focus group discussions or questionnaire surveys:

Avelina Caballero, Adán Castellón, Adrián Canales Blandón, Albertina Mayorga, Alberto Morales, Anielca Martínez Ramírez, Antolín Esteban Díaz Caballero, Apolinar García, Cándida Juárez, Cándida Rosa Mondragón, Cándida Velásquez, Carlos Adán Camas, Carmen Reynaldo Gonzáles, Carmelo Gonzáles, Casimiro Canales, Celia Vargas Ramírez, Darling Martínez, Diana Mercedes Mejía, Diega Olivia Cortés Pantoja, Domingo Jesús Medina, Domitila Lucía Ruiz Machado, Elsa Sáenz Cortés, Ernestina Poveda, Esteban de Jesús Cruz Blandón, Estela Amador Vallejos, Evangelina Salmerón, Fausto Moreyra Ruiz, Félix Bayardo Martínez Canales, Félix Pedro Caballero, Félix Rodríguez, Francisca Medina, Francisco José Sánchez, Gilberto E. Poveda U., Henry García, Idalia Ramírez Vargas, Inés Verónica Vanega, Isa Lorena Martínez, Isidora Acosta, Jeremías Exequiel Poveda, José Benito Castillo Morales, Juan Acevedo Zeledón, Juan Carlos Lanza, Juan José Moreno, Juan Ramón Martínez, Julia Donaire, Junieth Chávez, Karla Ulloa, Ligia María Martínez, Lili Esperanza Sáenz Cortés, Liseth Sáenz Cortés, Lucía Petrona Morales, Luciano Rueda, Luis Alberto Liras Betanco, Manuel José Méndez, María Elena Escoto, María Estela Amador Vallejos, María Eugenia Vargas Ramírez, María Felícita Espinalez Obregón, María Isabel Membreño R., María Narvaez Castro, María Maribel Laguna R., Mariana Moreno, Maribel Miranda Poveda, Marina del Socorro García, Maritza Acevedo López, Martha Adilia Velásquez, Martha Petrona Flores, Marvin Rodríguez, Mauro Gómez Garache, Miguel Santos Canda Ruiz, Nelly Narciso Moraga, Nicolas Facundo García Poveda, Olivia Cortés Pantoja, Pablo Fidel Fichardo Espinoza, Pedro José Martinez Alvarado, Reynaldo Pineda Mercado, Roberto Fabio Tenorio Mayorga, Rodolfo Poveda, Rosa Chávez, Rosa Gloria Vargas Ramírez, Rosalba Ruiz, Roxana Díaz, Salomón Flores, Santana Pantaleón Rivas Gonzales, Santos Humberto Brand Acosta, Santos Marlene Centeno, Susana Ramírez Canales, Teófilo Cortés Gutiérrez, Vicente Cortés Guevara, Vicente Jesús Vanega Gonzáles, Virginia María López Calero, Wilber Fornus, William Alberto Castillo Morales

Other stakeholders contacted (including communal leaders in special focus group discussion):

Alonso Hurtado (president of ASCA), Avelina (member of ASCA), Benito Pérez (councilman of Posoltega), Carlos Alonso Tercero Huete (Mayor of Posoltega), Cecilia Manzano (CARE former social promoter), David Mayorga (member of ASCA), Edgar Maltez (member of CDC, crime prevention committee), Esperanza Morales (member of CDC, water committee), Eugenia Vargas Ramírez (block representative), Francisco José Sánchez (young leader), Gregorio Sánchez (coordinator of CDC), Inés Herrera (block representative), Ivania Castro (school parents association), José Telles (religious leader, Verbo), Karla Avendaño (member of CDC, water committee), Lucía Morales (member of ASCA), Marbelly Flores (health promoter), María Felícita Espinales Obregón (teacher), Petrona Gutiérrez (health promoter), Reynaldo Avendaño (block representative), Roberto Tenorio (political representative, FSLN), Verónica Espinoza (member of CDC, health committee), Vidal Tercero (legal adviser of NGO ASCA), Virginia María López Calero (school parents association), William Pineda (religious leader, free apostolic church) 


\section{San Fernando (Nicaragua)}

Inhabitants who participated in focus group discussions or questionnaire surveys:

Adelayda del Rosario Guillén Ortez, Andrés Avelino Herrera Ortez, Antonio Ortez Herrera, Arnoldo Aguilar Martínez, Arnulfo Ortez Ortez, Aura Lila Ortez O., Aura María Ortez O., Aurora del Carmen Gonzáles Aguilar, Cándida Beltrán O., Carolina Herrera Ortez, Concepción Herrera López, Dinora Ester Gonzáles, Dolores Vanega Mejía, Dominga Ernestina Ortez Herrera, Donaldo Cuadra Dávila, Edmundo Urbina Herrera, Elda Vílchez Soto, Elizabeth Abraham, Emilio Herrera Chavarría, Ermis Pozo Vásquez, Ernesto Herrera, Fátima del Rosario Zelaya, Flor de María Guerra Herrera, Florencio Bautista Muñoz, Genaro Herrera, Germán López, Geysell Mairena Herrera, Gloria María Merlo Ferrutino, Imelda Chavarría Rodríguez, Irma de Jesús Beltrán Beltrán, Isabel López Pérez, Javier Antonio Ramírez Jarquín, Jeaneth Urbina, Jessica Ortez Balladares, José Manuel Herrera, José René López Gutiérrez, José Rubén Herrera Ortez, Josefana Suárez, Juanita Ortez Ziles, Julio Damián Balladares Sánchez, Laura López Herrera, Lázaro Zelaya, Lucila Herrera, Luis Alfonso Palma Castellano, Luisa Emilia López, Lupita Urbina, Luz Amparo Matute, Mabel del Rosario Chavarría Ortez, Magdalena Zamora, María Auxiliadora Guillén Herrera, María de Jesús Mejía, María de los Angeles Zelaya, María Estela Herrera Vílchez, María Flor Martínez Vílchez, Marta Verónica Cárdenas, Martha Argentina Guadamuz Herrera, Mauro José Ortez Herrera, Mercedes López Pérez, Neris Antonio García, Néstor Ortez Quiñones, Oliver Josué Zelaya Pozo, Oneyda Herrera, Orfilia Ortez Sánchez, Pastora Maitell Hernández, Pedro Rafael Chavarría Rodríguez, Rafael Herrera, Ramón Abel Herrera Beltrán, Roger Isaías Bautista Velásquez, Rosa Evelia Hernández, Rosalpina Herrera Ortez, Ruth María Herrera Hernández, Sandra Maritza Rivera Mejía, Sebastián Vásquez Vallesillo, Telma Cornejo Abraham, Tomasa Sánchez Castellón, Vicente Ariel Herrera Soza, Yadira del Carmen Aguilar Cuadra, Yesenia Auxiliadora Barahona Ortez, Yesenia Barahona Ortez, Yesenia Hernández Alvarado, Yorling del Socorro López, Zayda Yadira Zelaya

Other stakeholders contacted (including leaders in special focus group discussion):

Alma Nidia Herrera Ortez (vice-coordinator of CASA), Arely Abraham D'tourniel (former local social promoter), Bernabé López Zamora (committee leader), Carmen Corea de Ponce (coordinator of CASA), Daisy Ponce (committee leader), Damaris Abraham (health promoter, CASA), Danilo de Jesús Centeno Sevilla (mayor of San Fernando), Elia Margot Aguilar Ponce (committee leader), Enrique Morales (health ministry), Hazell Francisca Beltrán Amador (committee leader), Hildebrando Hernández (planning director, Mun. San Fernando), Isabel Cristina Quiñónez (committee leader), Johanna del Carmen Herrera Ortez (committee leader), Jorge Centeno Sevilla (mayor of San Fernando), José Alberto Herrera Zamora (committee leader), José Rubén Herrera (committee leader, former coordinator of CASA), Juan Manuel Pérez (committee leader), Lisseth Díaz Huete (CARE social promoter), Lisseth Pérez (member of CASA), Marina Balladares (committee leader), Maryeli Vanesa Pérez Barahona (committee leader), Mauricio Paguagua Rivera (CARE temporary social promoter), Miguel Medina Iglesia (health ministry), Mirna Clotilde Herrera Ortez (vice-coordinator of CASA), Olivia Pozo (committee leader), Porfirio Herrera (CARE project manager), Róger Herrera (committee leader), Sandra del Carmen Sánchez Rodríguez (committee leader), Víctor Trejos (environment secretary, Mun. San Fernando), Wilmer Donaldo Ortez López (ENACAL, San Fernando) 


\section{Agua Fría (El Salvador)}

Inhabitants who participated in focus group discussions or questionnaire surveys:

Adela Torrez, Ana Mercedes Pacheco Castro, Ana Silvia Asencio, Andrea Medrano, Antonia Viatoro, Balbino Juárez, Blanca Aurora Gutiérrez, Carmen Fuentes Pavón, Celestina Torrez, Celia del Carmen Marchante, Celia Yolanda Serrano Fuentes, Domitila Pavón, Elifonso Mancilla, Emma Argentina Perla, Ester Lorenza Pacheco, Eusebia Conde, Felipe Castañeda, Felipe Viera, Fernando Asencio Fuentes, Florentín Fuentes, Gertrudes Hernández Torres, Gloria del Carmen Gonzáles Juárez, Guadalupe Medina, Héctor Fuentes, Ignacia Asencio, Ignacio Viera López, Jorge Humberto Calis, José Alexandro Romero, José Antonio Medrano, José Antonio Montesinos, José Armando Guevara Fuentes, José Dolores Treminio, José Magdaleno Portillo Romero, José Santos Asencio, Juan Andrés Ríos, Juan Antonio Colindre, Juan Antonio Medina, Juan Clímaco Tremiño Viera, Julián Guevara, Leonardo Juárez Asencio, Leonidas Vega Viera, Lorenza Bendrice Ventura vda.de Flores, Luis Alonso Gonzáles, Margarita Viera Gutiérrez, María Angélica Contreras, María de la Paz Medina B., María Inés Asencio de Ortiz, María Josefa Zelaya Ochoa, María Olimpia Hernández, María Rosario Flores, Mario Romero, Martina Asencio Cuevas, Mayra Noemí Parada de Viera, Mayra Olinda Lemus Castillo, Mercedes Viera, Napoleón Romero, Nelson Antonio Meléndez Alfaro, Nora Celina Corea Torres, Pastora Ortiz Medina, Pedro Angel Colindre, Pedro Ramos Pavón, Polinaria Ortiz Romero, René Escobar, Rogelio Gonzáles, Román Asencio, Rosa María Herrera, Rufina Fuentes, Samuel Gonzáles, Sonia Noemí Flores, Vilma Noemí Hernández Ramos

Other stakeholders contacted (including leaders in special focus group discussion):

Adonys Fermán (councilman, San Alejo municipality), Alejandro Ortiz Medina (member of ADES$\mathrm{CO})$, Ana Betty Morales, Andrés Alonso Gómez Vigil (mayor of San Alejo), Arnoldo Romero (member of ADESCO), Benjamín Samayoa (physician assistant, health post), Blanca de Santos (health ministry, La Unión), Catalina Romero de Grande, Cruz Imalda Coreas de Ascencio (health promoter, Agua Fría), Fausto Ríos (leader, Trinchera), Gloria Haydée Romero de Torres (school director), Gregorio Viera Gutiérrez (leader, Piedra Gorda), Hernán Campos (ANDA employee), Iris Iveth Guardado Rodríguez (doctor, health post Agua Fría), Isabel Romero de Ortiz, José Agustino Pavón (member of ADESCO), José de la Paz Meléndez (member of ADESCO), José del Carmen Asencio (member of ADESCO), José Dimas Conde (member of ADESCO), Juan Arnulfo Ruiz Sorto (coordinator, CODECA), Juan Flores Velásquez (ANDA employee), Juan Manuel Cruz (ANDA employee), Manuela de Jesús Juárez (member of ADESCO, Agua Fría), Marcia Emeldy Ríos Hernández (local promoter, Trinchera), Marcos Antonio Torres (vice-president of ADESCO), Miriam Consuelo Flores Pacheco (teacher, Piedra Gorda), Oscar Alberto Benavides (health ministry, La Unión), Pedro Marchante (member of ADESCO), Roberto Carlos Arias (leader, Mogotillo), Samuel Guevara (ANDA employee), Víctor Manuel Grande (president of ADESCO, Agua Fría), Zulma Yolanda Vásquez (secretary, health post) 


\section{San Agustín (El Salvador)}

Inhabitants who participated in focus group discussions or questionnaire surveys:

Ana Patricia Rivera, Antonio Aguilero, Blanca Estela Solano, Catalina Osorio, Cayetano Rodríguez, Clara del Carmen Rodríguez, Doroteo Rodríguez, Francisco Luna, Francisco Rivera Portillo, Guadalupe Cruz Iglesias, Héctor Antonio Rodríguez, Idalia Marisol Romero, Jesús Aguilar Sánchez, José Amilcar Mendoza, José Horacio Alvarado, Juan Antonio Amaya, Juan Francisco Márquez, Juana de Jesús Zelaya Rodríguez, Juana Mejía Flores, Lorenzo de Jesús Rodríguez, Luis Alonso Marroquín Sorto, Luz Calero, Luz Isabel Roque, Manuel Ángel Asencio, Marco Rodas, María Araceli Mejía, María Celsa Jiménez, María de la Cruz Alemán, María Evangelina Mena, María Jesús Morales, María Marta Granados, María Telma Montano, María Teresa Campos, María Victoria Ruiz, Martha Jovel Barahona, Mayra del Carmen de Aguilar, Mercedes de Jesús Granadeño, Nicolasa Cruz de Alvarado, Rina Margarita Alvarado Cruz, Santos Mauricio González, Víctor Manuel Hernández Serpas, Vilma Mavel Argueta, Yolanda de Jesús Benites

Other stakeholders contacted (including leaders in special focus group discussion):

Alberto Alejo (mayor of San Francisco Javier, neighbouring municipality), Anita Avila (president of CRDM), Blanca Estela Pozo Ramírez (member of CRDM), César Portillo Baquedano (governor of Usulután), Doroteo de Jesús Pozo (member of CRDM), Elizabeth Samayoa (former secretary of the project), Father César Ochoa Asencio (Catholic parish), Father Nico Vatres (Catholic parish), Freddy Revelo (councilman), Ignacio Carranza (mayor of San Agustín), José Alfredo Mejía (member of CRDM), José Antonio Rodríguez (former president of CRDM), José Gilberto Calero (member of CRDM), José Mario Goches (member of CRDM), José Salvador Olivera Solís (member of CRDM), Juana del Carmen Morales (promoter of culture house), Luis Alonso Alemán (member of CRDM), María Magdalena Solano (member of CRDM), María Sebastiana de Paz García (secretary, health centre), Mario Alfredo López Ramírez (regional director of ANDA), Mario Goches (leader), Mario Octavio Flores (construction dpt., FUNDASAL), Maureen Madeline Zavala (director of the health centre), Napoleón Hernández (FUNDASAL social promoter), Nubia (lawyer, FESPAD), Numas Francisco Cruz (director of culture house), René Alfaro (doctor of the health centre), Ricardo Melara (promoter, FUNDAMUNI), Saúl Fernández (secretary, government of Usulután), Vidal Sibrián (coordinator, FESPAD) 


\section{Lux-Development S.A.}

Project NIC/012, Ocotal, Nicaragua:

Eduardo Acuña Bibarén (chief of project), Jean-Louis Augeras (technical assistant), Chiara Trombetta (professional in training).

Project SVD/016, San Agustín, El Salvador:

Georges Burri (chief of project).

Regional office, Nicaragua:

Sara Briones (coordinator, regional office), Marc Riehl (regional director)

Headquarters:

Nathalie Davila-Levy (manager of operations, former regional director), Alice Risch (manager of quality and evaluation), Pascal Rossignol (director of studies and evaluation, former regional director), Raymond Weber (general director of LD)

\section{Government officials, bilateral cooperation}

Nicaragua: Ministry of Foreign Affairs, Secretary of Economic Relations and Cooperation

Lucrecia García Cortez (Bilateral cooperation: Central and Eastern Europe, director; Benelux region, former officer)

El Salvador: Ministry of Foreign Affairs, Direction of External Cooperation

Tirso Sermeño (director) and Guillermo Antonio Iglesias (officer)

Luxembourg: Ministry of Foreign Affairs, Development and Humanitarian Aid

René Lauer (bilateral cooperation with Latin America, officer) 


\section{Appendix 2-B: Project fact sheets}

The reconstruction project in Santa María

\begin{tabular}{|llll|}
\hline Basic information & & \\
\hline Country: & Nicaragua & Type of settlement: & Colony ('comunidad') \\
Department: & Chinandega & Urban /rural: & Rural \\
Municipality: & Posoltega & Households: & 350 (registered) \\
\hline
\end{tabular}

\begin{tabular}{|llll|}
\hline Official data & & & \\
\hline Counterpart: & Municipal government & Type of contribution: & Grant \\
Management & CARE Nicaragua & Contribution of Luxembourg: & EUR1,698,071 \\
Executing NGO: & - CARE Nicaragua (houses) & Starting date: & May 1999 \\
& - Eng. Julián Pérez (school and & Ending date: & October 2001 \\
& community centre) & & \\
\hline
\end{tabular}

\begin{tabular}{|lll|}
\hline Logical Framework \\
\hline Overall Goal: & $\begin{array}{l}\text { To contribute to the economic and social rehabilitation of } 350 \text { households (of Posoltega) } \\
\text { victims of the hurricane Mitch }\end{array}$ \\
\hline Outcomes: & $\begin{array}{l}\text { 1) That } 350 \text { households again have a } \\
\text { roof }\end{array}$ & $\begin{array}{l}\text { 2) That } 350 \text { households restart their economic } \\
\text { activities }\end{array}$ \\
\hline Outputs: & $2.1 \quad \begin{array}{l}\text { One community centre constructed and } \\
\text { functioning }\end{array}$ \\
& 1.1550 households relocated & $\begin{array}{l}\text { One school constructed and functioning } \\
\text { Peasant families restart their productive } \\
\text { activities }\end{array}$ \\
& $2.4 \begin{array}{l}\text { Household members manage the psycho- } \\
\text { logical sequels of hurricane Mitch }\end{array}$ \\
\hline
\end{tabular}




\begin{tabular}{|c|c|c|}
\hline \multicolumn{3}{|l|}{ Important dates } \\
\hline Date & Event related to & Detail \\
\hline August 1998 & Antecedent & End of first stage of water project in Casitas \\
\hline $30 / 10 / 1998$ & Antecedent & Tragedy of Casitas \\
\hline November 1998 & Project & Visits of identification (Luxembourg) \\
\hline 09/12/1998 & Antecedent & Lands in Casitas are expropriated \\
\hline $28 / 12 / 1998$ & Antecedent & Survivors take over El Tanque \\
\hline $13 / 01 / 1999$ & Project & Financing is approved by MFA, Luxembourg \\
\hline $08 / 03 / 1999$ & Antecedent & US Pres. Clinton visits Posoltega \\
\hline April 1999 & Project & Donors buy finca Santa Maria \\
\hline May 1999 & Project & Project formulated by LD was approved \\
\hline June 1999 & Context & Agriculture activities start (financed by emergency funds - CARE) \\
\hline September 1999 & Context & ASCA is legally registered as NGO \\
\hline October 1999 & Context & Agriculture project starts (financed by USAID) \\
\hline $27 / 10 / 1999$ & Project & Construction of houses starts \\
\hline April 2000 & Project & Problems with social promoter (LD visits the site) \\
\hline $18 / 04 / 2000$ & Project & Construction of school starts \\
\hline May 2000 & Project & First 120 houses are allocated (by drawing) \\
\hline $14 / 08 / 2000$ & Project & LD and CARE decide to include humid areas \\
\hline August 2000 & Project & All 350 houses are assigned \\
\hline $05 / 09 / 2000$ & Project & 30 families live in their houses (they already had latrine) \\
\hline September 2000 & Project & Construction of houses ends \\
\hline November 2000 & Context & Water project ends \\
\hline $15 / 12 / 2000$ & Project & Construction of school and community centre end \\
\hline $05 / 01 / 2001$ & Project & 314 houses were given (with keys) to their new tenants \\
\hline February 2001 & Project & Classes start in the new school \\
\hline $19 / 03 / 2001$ & Project & The mayor and LD decide to prepare new census (empty houses) \\
\hline $27 / 04 / 2001$ & Project & Verification commission starts (ASCA is replaced by CCD) \\
\hline $17 / 08 / 2001$ & Project & New census is accepted by all parties \\
\hline Aug.-Oct. 2001 & Project & Humid areas are constructed \\
\hline September 2001 & Context & Representatives of CCD are selected \\
\hline November 2001 & Project & Closure mission \\
\hline $12 / 03 / 2002$ & Context & Visit of Ambassador Jean Feyder (MFA) \\
\hline
\end{tabular}

\begin{tabular}{|c|c|c|}
\hline \multicolumn{3}{|c|}{ Other projects after the disaster } \\
\hline & Production & Services \\
\hline 1999 & Upbringing of cows (10) & \\
\hline 2000 & Machines of sewing (4) & Electric installations in houses; Memorial Park \\
\hline 2001 & $\begin{array}{l}\text { Planting bananas on common land ( } 20 \mathrm{mz} .) \\
\text { Pigs ( } 20 \text { families) and chickens ( } 30 \text { families) } \\
\text { Machines of sewing (5) }\end{array}$ & Infants' park \\
\hline 2002 & $\begin{array}{l}\text { Pigs and chickens (100 families) } \\
\text { Livestock, with artisan well (16 families) } \\
\text { Truck, tractor }\end{array}$ & $\begin{array}{l}\text { Installation of public electricity } \\
\text { Health centre; dinning room for children } \\
\text { First-aid kit (with subsidised drugs) }\end{array}$ \\
\hline 2003 & Personal computers (courses) & Child care programme PAININ (government) \\
\hline 2004 & Upbringing of peliguey* $(10)$ with revolving fund & Sport court \\
\hline 2005 & & $\begin{array}{l}\text { Attention in health centre (staff }+ \text { drugs) } \\
\text { Breakfast in the school }\end{array}$ \\
\hline
\end{tabular}

* A mix-breed of a goat and a sheep

Note: This list is not exhaustive and may have some errors. It is based on a group interview with key informants (July 8, 2006) and a FGD with leaders (July 15, 2006). 


\section{The water project in Agua Fría}

\begin{tabular}{|c|c|c|c|}
\hline \multicolumn{4}{|c|}{ Basic information } \\
\hline Country: & El Salvador & Type of settlement: & Canton (three sites) \\
\hline Department: & La Unión & Urban /rural: & $\begin{array}{l}\text { Urban (canton quarters) and } \\
\text { rural (two villages) }\end{array}$ \\
\hline Municipality: & San Alejo & Households: & $424(*)$ \\
\hline
\end{tabular}

(*) Number of houses occupied and unoccupied: 641

\begin{tabular}{|llll|}
\hline Official data & & & \\
\hline Counterpart: & ANDA & Type of contribution: & Grant \\
Management & LD & Contribution of Luxembourg: & EUR4,200,000 $\left(^{*}\right)$ \\
Executing entities: & -Water: private constructor and & Starting date: & October 2001 \\
& $\begin{array}{l}\text { supervisor } \\
\text {-Sanitation works and promo- }\end{array}$ & Ending date: & January 2004 \\
& tion activities: CODECA & & \\
\hline
\end{tabular}

$\left({ }^{*}\right)$ This is the total budget of the project which covers three cantons (thirteen sites).

\begin{tabular}{|l|l|}
\hline Logical Framework \\
\hline Overall Goal: & To contribute to the improvement of the health and living conditions of the inhabitants \\
\hline Outcome: & $\begin{array}{l}\text { To provide a stable access to drinking water service and to improve the environmental } \\
\text { conditions }\end{array}$ \\
\hline Outputs: & $\begin{array}{l}\text { 1. A drinking water network is created and put into operation. } \\
\text { 2. At least } 90 \% \text { of households have means to dispose of and purify residual water }{ }^{(1)} \text {. } \\
\text { 3. Around } 80 \% \text { of households have a latrine adapted to local conditions (2). } \\
\text { 4. The population is sensitised to the issue "water and environment" and hence, the com- } \\
\text { munal organisation is strengthened. } \\
\text { 5. Activities of conservation of natural resources and activities of sensitization to improve } \\
\text { the agriculture sector are carried out. }\end{array}$ \\
Assumptions: & $\begin{array}{l}\text { For output } 1: \\
\text {-The water sector reform does not affect the methodology and results of the project. } \\
\text {-Lands are legal property of ANDA. } \\
\text {-ANDA trains water operators and takes care of the network maintenance. }\end{array}$ \\
\hline $\begin{array}{l}\text { For output 2: } \\
\text {-The special circumstances of certain families do not put obstacles to the achievement of } \\
\text { results. }\end{array}$
\end{tabular}

(1) This target was introduced in the formulation report "based on previous experience".

(2) The formulation report indicated a number fixed of latrines that was almost $80 \%$ of connection targets. 


\begin{tabular}{|c|c|c|}
\hline \multicolumn{3}{|l|}{ Important dates } \\
\hline Date & Event related to & Detail \\
\hline April 2000 & Min. F.A. & Identification mission \\
\hline July 2000 & Min. F.A. & Formulation mission \\
\hline End 2000 & ANDA & Report about water sources \\
\hline Beginning 2000 & ANDA & New technical studies (only 1 water source) \\
\hline Jun.-Oct.2001 & Min. F.A. & Formulation report \\
\hline $11 / 10 / 2001$ & LD & Approval to start the project \\
\hline November 2001 & Project & Project presented to population, workshops, population census \\
\hline $11 / 03 / 2002$ & Project & Construction of water infrastructure started \\
\hline Jan.-Oct.2002 & Project & 'Soak away' pits are constructed \\
\hline Jun.-Aug.2002 & Project & Reforestation works \\
\hline Jan.2002-Apr.2003 & Project & Latrines and ecological wood stoves are installed \\
\hline September 2002 & Project & Mission M. Foreign Affairs (Luxembourg) \\
\hline $27 / 09 / 2002$ & Project & CARE report on baseline indicators \\
\hline October 2002 & Project & CODELUM (in Cercos de Piedra and Mongotillo) is dismissed \\
\hline March 2003 & Context & Municipal elections \\
\hline Feb.-May.2003 & Project & Reservoir is built \\
\hline Apr.-Jun.2003 & Project & Final Balance of the canton \\
\hline $22 / 05 / 2003$ & Project & Construction of water infrastructure finished \\
\hline June 2003 & Project & Formal inauguration of the project \\
\hline $05 / 11 / 2003$ & Project & Visit of the Duke of Luxembourg with other authorities \\
\hline $10-15 / 11 / 2003$ & Project & Evaluation mission (with participatory workshops) \\
\hline April 2004 & Project & Project is closed \\
\hline
\end{tabular}

\begin{tabular}{|c|c|c|c|c|}
\hline \multicolumn{5}{|c|}{ All sites covered by the project } \\
\hline Municipality: & San Alejo & & Villages: & \\
\hline \multirow[t]{3}{*}{ Sites: } & - Agua Fría & - Canton & $\begin{array}{l}\text { - Trinchera, Agua Fría y Piedra } \\
\text { Gorda }\end{array}$ & - 424 households \\
\hline & - Cercos de Piedra & - Canton & $\begin{array}{l}\text { - Monte Verde, La Maltez, Cercos } \\
\text { de Piedra }\end{array}$ & - 202 households \\
\hline & - Mogotillo & - Canton & $\begin{array}{l}\text { - El Alto, Los Ranchos, La Colo- } \\
\text { nia, La Pandura, El Limón, Mogo- } \\
\text { tillo, La Escoba }\end{array}$ & - 211 households \\
\hline
\end{tabular}

Note: The actual number of houses connected to the water system was different (higher). Some empty houses were connected while other households living in the cantons did not want to be connected. Total number of resident households $=837$. Total number of houses connected $=913$ 


\section{The water project in San Fernando}

\begin{tabular}{|llll|}
\hline Basic information & & \\
\hline Country: & Nicaragua & Type of settlement: & Municipal centre \\
Department: & Nueva Segovia & Urban /rural: & Urban \\
Municipality: & San Fernando & Households: & 421 \\
\hline
\end{tabular}

\begin{tabular}{|c|c|c|c|}
\hline \multicolumn{4}{|l|}{ Official data } \\
\hline Counterpart: & ENACAL & Type of contribution: & Grant \\
\hline Management & LD & Contribution of Luxembourg: & EUR5,975,000 (1) \\
\hline \multirow[t]{2}{*}{ Executing entities: } & $\begin{array}{l}\text {-Water: private constructor and } \\
\text { supervisor }\end{array}$ & Starting date: & April 2003 \\
\hline & $\begin{array}{l}\text {-Sanitation works and promo- } \\
\text { tion activities: CARE Nicara- } \\
\text { gua }\end{array}$ & Ending date: & June $2005^{(2)}$ \\
\hline
\end{tabular}

(1) This is the total budget of the project which covers five sites.

(2) The activities of the whole project ended in October 2006 because it was extended to another site (Somoto).

\begin{tabular}{|c|c|}
\hline \multicolumn{2}{|c|}{ Logical Framework } \\
\hline Overall Goal: & To contribute to the improvement of the health and living conditions of the inhabitants \\
\hline Outcome: & To improve the drinking water service and the conditions of sanitation and environment \\
\hline Outputs: & $\begin{array}{l}\text { 1. A drinking water service that is permanent and of good quality. } \\
\left.\text { 2. At least } 80 \% \text { of households have means to dispose of residual water } *^{*}\right) \text {. } \\
\text { 3. Each house has a latrine or a toilet with septic tank. } \\
\text { 4. It triggered off a process for protecting the water resource through activities of reforesta- } \\
\text { tion in micro-basins and management of solid wastes. } \\
\text { 5. The communal organisation is strengthened and the population is sensitised to the issue } \\
\text { "water, health, and environment". }\end{array}$ \\
\hline \multirow[t]{6}{*}{ Assumptions: } & $\begin{array}{l}\text { For outcome: } \\
\text {-Users have capacity to pay for the service and acquire an adequate 'payment culture' } \\
\text {-Reforms in the water sector do not affect the operations of small aqueducts. } \\
\text {-Communities aim at developing by common effort based on a strong community organisa- } \\
\text { tion. }\end{array}$ \\
\hline & $\begin{array}{l}\text { For output 1: } \\
\text {-External factors will not put at risk the water sources. } \\
\text {-Users are satisfied with the new service and feel it as a "benefit". }\end{array}$ \\
\hline & $\begin{array}{l}\text { For output 2: } \\
\text {-Inhabitants will change their hygiene habits. }\end{array}$ \\
\hline & $\begin{array}{l}\text { For output } 3: \\
\text {-There is interest on the composting latrine. }\end{array}$ \\
\hline & $\begin{array}{l}\text { For output } 4 \text { : } \\
\text {-The project will achieve that beneficiaries change their habits regarding the disposal and } \\
\text { elimination of garbage. }\end{array}$ \\
\hline & $\begin{array}{l}\text { For output 5: } \\
\text {-The partisan mentality does not put at risk the achievement of the result. }\end{array}$ \\
\hline
\end{tabular}

$\left({ }^{*}\right)$ The target of $70 \%$ appears in the logical framework, but in the content of the formulation report, the target is $80 \%$ and it is followed by an estimate of units to be built. 


\begin{tabular}{|c|c|c|}
\hline \multicolumn{3}{|l|}{ Important dates } \\
\hline Date & Event related to & Detail \\
\hline August 2000 & Project & Pre-feasibility study (SHER) \\
\hline November 2000 & Project & $1^{\text {st }}$. Formulation report \\
\hline January 2001 & Context & New municipal government (Mayor P.J. Ortez Beltrán, PLC) \\
\hline \multirow[t]{2}{*}{ July 2001} & Project & CARE is chosen for promotion activities \\
\hline & Project & $2^{\text {nd }}$. Formulation report \\
\hline January 2002 & Context & New national government (Pres. Bolaños, PLC) \\
\hline March 2002 & Project & Mission M. Foreign Affairs (Luxembourg) and LD \\
\hline October 2002 & Project & $3^{\text {rd }}$. Formulation report is approved \\
\hline Feb.-Apr.2003 & Project & Topographical and geotechnical studies \\
\hline $29 / 04 / 2003$ & Project & Presentation of the project to the inhabitants of San Fernando \\
\hline May 2003 & Project & Initial socio-economic survey (census) \\
\hline May.Jun.2003 & Project & CASA is constituted \\
\hline $22 / 07 / 2003$ & Project & Office of CARE starts operations \\
\hline \multirow[t]{2}{*}{ September 2003} & Project & Sowing of 8,000 plants \\
\hline & & Change of one social promoter in San Fernando \\
\hline October 2003 & Project & Sowing of 2,000 plants \\
\hline November 2003 & Project & Change of CARE project manager \\
\hline $04 / 12 / 2003$ & Project & Diagnosis regarding solid wastes (external consultant) \\
\hline December 2003 & Project & CARE report on census \\
\hline $13 / 01 / 2004$ & Project & Start of infrastructure works (D'Guerrero) \\
\hline \multirow[t]{3}{*}{ March 2004} & Project & Report on census (external consultant) \\
\hline & Project & All neighbourhood committees are in operation \\
\hline & Visit & Visit of LD project manager - Mr. D'Elia \\
\hline Nov.2003-Mar.2004 & Project & Studies of the controlled tipping (external consultant) \\
\hline May 2004 & Project & Socio-economic diagnosis concluded (CARE) \\
\hline July 2004 & Project & LAMSA stops its work. ENACAL and the PIU do the supervision. \\
\hline August 2004 & Project & Inhabitants have piped water in their houses \\
\hline $29 / 09 / 2004$ & Project & Technical and commercial diagnosis of 5 local offices of ENACAL \\
\hline October 2004 & Project & Change of CARE project manager \\
\hline Oct.-Nov.2004 & Project & Water treatment plant is installed \\
\hline October 2004 & Project & "Carnival of garbage" \\
\hline \multirow[t]{2}{*}{ November 2004} & Project & Workshop of participatory evaluation (CARE) \\
\hline & Visit & Visit of LD project manager - Ms. Stoz \\
\hline $15 / 12 / 2004$ & Project & The pumping system and treatment plant are in full operation \\
\hline January 2005 & Context & New municipal government (Mayor D. Centeno Sevilla, FSLN) \\
\hline $31 / 01 / 2005$ & Project & Office of CARE is closed \\
\hline March 2005 & Project & Training to the operators of treatment plant \\
\hline April 2005 & Project & LD formal evaluation \\
\hline Feb.-May.2005 & Project & Itinerant social promoter (in several sites) \\
\hline
\end{tabular}

\begin{tabular}{|lllll|}
\hline All sites covered by the project & & & \\
\hline Department: & Nueva Segovia & & \\
Sites: & - San Fernando & - Municipal head & - Urban site & - 421 households \\
& - El Jícaro & - Municipal head & - Urban site & $-1,098$ households \\
& - Tastaslí & - Canton (of Jalapa) & - Rural site & - 415 households \\
\hline Department: & Madriz & & & \\
Sites: & - Palacagüina & - Municipal head & - Urban site & $-1,254$ households \\
& - Somoto & - Departmental head & - Urban site & - 959 households \\
\hline
\end{tabular}

Note: The number of households in each site comes from Guglielmi (2004). The final number of households covered by the project in Somoto is higher because the project was extended. 
The reconstruction project in San Agustín

\begin{tabular}{|c|c|c|c|}
\hline \multicolumn{4}{|c|}{ Basic information } \\
\hline Country: & El Salvador & Type of settlement: & $\begin{array}{l}\text { Municipality centre + two can- } \\
\text { tons }\end{array}$ \\
\hline Department: & Usulután & Urban /rural: & $\begin{array}{l}\text { Urban (municipality centre) and } \\
\text { rural (two cantons) }\end{array}$ \\
\hline Municipality: & San Agustín & Households: & 438 \\
\hline
\end{tabular}

\begin{tabular}{|llll|}
\hline Official data & & & \\
\hline Counterpart: & Municipality government, & Type of contribution: & Grant \\
& CRDM & Contribution of Luxembourg: & EUR3,660,000 \\
Management & LD & $\begin{array}{l}\text { November 2001 } \\
\text { Executing entities: }\end{array}$ & $\begin{array}{l}\text {-Private construction company. } \\
\text { FUNDASAL }\end{array}$ \\
& $\begin{array}{l}\text { Starting date: } \\
\text {-Legalisation of property titles: }\end{array}$ & Ending date: & March 2005 \\
& FESPAD & \\
\hline
\end{tabular}

\begin{tabular}{|c|c|}
\hline \multicolumn{2}{|c|}{ Logical Framework } \\
\hline Overall Goal: & $\begin{array}{l}\text { To contribute to the reduction of the vulnerability of the population of the municipality of } \\
\text { San Agustin. }\end{array}$ \\
\hline Outcome: & $\begin{array}{l}\text { To rehabilitate and/or to build the basic family and social infrastructure, propitiating the } \\
\text { integral, sustainable and participatory, development. }\end{array}$ \\
\hline Outputs: & $\begin{array}{l}\text { 1. } 438 \text { households have a housing solution of approximately } 50 \mathrm{~m}^{2} \text { in a term of } 24 \text { month. } \\
\text { 2. All properties have been legalised and registered. } \\
\text { 3. Several buildings, facilities and services of the socio-economic sector have been built, } \\
\text { rehabilitated and/or equipped. } \\
\text { 4. The labour, organisation and management capacities of the actors and beneficiaries are } \\
\text { improved } \\
\text { 5. The municipality government has an integral plan of municipal development }\left(^{*}\right) \text {. }\end{array}$ \\
\hline \multirow[t]{5}{*}{ Assumptions: } & $\begin{array}{l}\text { For outcome: } \\
\text { Adequate macro-economic policies; there is coordination in the national reconstruction } \\
\text { process; natural phenomena are not reiterative; there is no conflict on land property; prop- } \\
\text { erty titles are legalised. }\end{array}$ \\
\hline & $\begin{array}{l}\text { For output 1: } \\
\text { Construction materials are available; the price of materials fluctuates around }+/-5 \% \text {; con- } \\
\text { struction activities take place during dry season (summer); construction enterprises and } \\
\text { NGOs have the capacity to absorb the demand of professionals and skilled labour; the } \\
\text { beneficiaries are trained in construction techniques. }\end{array}$ \\
\hline & $\begin{array}{l}\text { For output } 2 \text { : } \\
\text { The departmental tribunal, landowners and beneficiaries have good disposition when } \\
\text { accessing information and collecting data. }\end{array}$ \\
\hline & $\begin{array}{l}\text { For output 3: } \\
\text { The mayor's office is committed; it provides lots for building social infrastructure. }\end{array}$ \\
\hline & $\begin{array}{l}\text { For output 4: } \\
\text { The communal associations are willing to be trained; the political leaders and communal } \\
\text { associations are willing to participate in the reconstruction process; the beneficiaries are } \\
\text { willing to organise themselves; the local authorities are willing to let the associations nego- }\end{array}$ \\
\hline
\end{tabular}


tiate and manage projects freely.

For output 5:

There is a legal framework and regional and national prevention plans; efforts and actions in the region are coordinated; the issue is priority to inhabitants.

$\left(^{*}\right)$ In the formulation report this output was: 'the municipality has a plan of environmental protection and disasters prevention'.

\begin{tabular}{|c|c|c|}
\hline \multicolumn{3}{|l|}{ Important dates } \\
\hline Date & Event related to & Detail \\
\hline $13 / 01 \& 13 / 02 / 2001$ & Context & Earthquakes \\
\hline $16 / 02 / 2001$ & MFA & Delegation of Min. F.A. of Luxembourg offers support \\
\hline $18 / 02 / 2001$ & Project & The chief of project arrives \\
\hline $24 / 02 / 2001$ & Context & CRDM is constituted \\
\hline April 2001 & Project & Formulation mission (participatory methods) \\
\hline 11-16 Sep. 2001 & Project & Formulation mission, closure \\
\hline January 2002 & Project & Socio-economic survey by FUNDASAL \\
\hline $04 / 02 / 2002$ & Project & Construction of first five houses start (models) \\
\hline $24 / 02 / 2002$ & Project & Ceremony of "first stone" \\
\hline $09 / 04 / 2002$ & Project & Construction with directed mutual help starts in the urban centre \\
\hline Apr.2002 - Jan.2005 & Project & Construction of houses \\
\hline \multirow[t]{2}{*}{ April 2002} & MFA & Visit \\
\hline & Context & $\begin{array}{l}\text { National assembly approves that international cooperation projects } \\
\text { are included in regime of decree } 800 \text { (to speed up registration) }\end{array}$ \\
\hline $02 / 05 / 2002$ & Project & First meeting of the consultative committee \\
\hline \multirow[t]{2}{*}{ September 2002} & MFA & Visit \\
\hline & Project & Field coordinator of FESPAD is changed \\
\hline January 2003 & Project & Training to all local bricklayers finishes \\
\hline Jan.2003 - Jan.2004 & Project & Training to ADESCO members: 136 participants \\
\hline \multirow[t]{3}{*}{ March 2003} & Project & Specialised consultant joins FESPAD (for registration) \\
\hline & Context & Municipal elections \\
\hline & Project & Workshop of consensus building (institutions) \\
\hline $26 / 04 / 2003$ & Project & Workshop to discuss special cases \\
\hline May 2003 & Project & First designs of communal infrastructure \\
\hline May.2003- Jan.2004 & Project & Training to new leaders: 184 participants \\
\hline $01 / 07 / 2003$ & Project & The resident engineer of FUNDASAL is changed \\
\hline $01 / 08 / 2003$ & Project & Definitive list of beneficiaries \\
\hline September 2003 & Project & Works in main square in execution \\
\hline October 2003 & Project & Agreement with the National Centre of Registration (CNR) \\
\hline End-October 2003 & Project & Works in multi-purpose communal centre start \\
\hline November 2003 & MFA & Visit of the Duke of Luxembourg with companions \\
\hline February 2004 & MFA & Visit \\
\hline April 2004 & Project & Municipal development plan: 2 seminars \\
\hline June 2004 & Context & Presidential elections \\
\hline September 2004 & MFA & Visit \\
\hline December 2004 & Context & Sister cities agreement with Préizerdaul \\
\hline $18 / 04 / 2005$ & Project & Inauguration of communal infrastructure \\
\hline June 2005 & Project & Farewell to chief of project \\
\hline
\end{tabular}




\section{Appendix 2-C: Focus group discussion protocols}

\section{Leader participants}

\section{Preamble}

Thank you very much for your presence.

My name is Mirtha Muñiz. I am Peruvian, economist. With me, here is Miss Yamileth Escobar, a Nicaraguan sociologist. We are analysing the effects of the project financed by Luxembourg in your community.

\section{Introduction}

(Yamileth)

Game: We will play with this ball game...

Once you receive this ball, you will say your name, family situation (if you are accompanied, with children, for example), your title and preferred colour. Next, you will throw the ball to someone else (someone who is not sitting next to you) and then, you continue...

\section{Explanation of the Activities}

(Mirtha)

The objective of this meeting is to learn your opinion about the context that can influence the long-term results of the project.

We will tape this conversation in order to not lose any detail of what you have to tell us.

Therefore, please speak out and clear, without interrupting other people or talking with others apart from the whole group. Let's all participate!

\section{Part I: The Project and its impacts}

(Mirtha)

1. From your point of view, what were the objectives of the project financed by Luxembourg?

2. What activities were included in the project? How was this undertaken?

[Briefly, only what they can recall]

3. What were the main positive effects of the project?

4. What were the main negative effects of the project?

Check effects in these areas: health (first-aid kit with cross), housing and physical security (house), environment (tree), education and knowledge (book), emotional and spiritual status (church), economic security (money), social relations (two hands that are tightened), gender balance (a woman and a man), other?

5. Now, we will order the positive effects according to their importance. Please, give a number from 1 to 3 to the three most important effects of the project, number 1 means that the effect is the most important (first place).

Let's discuss your opinions 
Example

\begin{tabular}{|l|c|c|c|c|}
\hline Area & 1 & 2 & 3 & Place \\
\hline Health & $\mathrm{XX}$ & $\mathrm{XXX}$ & $\mathrm{X}$ & 3 \\
\hline Housing & $\mathrm{XXXX}$ & $\mathrm{X}$ & & 1 \\
\hline Etc. & $\mathrm{X}$ & $\mathrm{XXXX}$ & $\mathrm{X}$ & 2 \\
\hline
\end{tabular}

\section{Part II: Project Context}

\section{(Yamileth)}

6. Now, let's do a timeline and indicate the most important events that happened to this community since year [just before starting the project or before the disaster, depending on the case] until now.

(It is possible to include activities to have the 'complete' story?)

Example

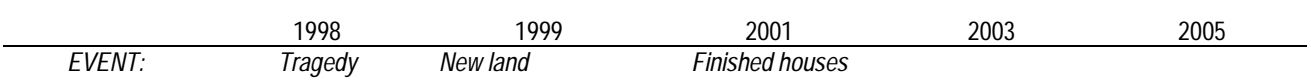

\section{Part III: Community}

\section{(Yamileth)}

7. When do you think that a community is strong? When it has what?

[Check if they include the following elements:

- Information is available and can be analysed

- $\quad$ There is solidarity and trust among its members

- $\quad$ There is more authority and control over community assets (i.e. donations)

- There is good organisation

- $\quad$ Leaders do the things community members need

- $\quad$ There is accountability

8. What has to improve so that your community will become stronger?

9. Do you think that the project has contributed to strengthen your community? If this is the case, please, give us examples.

[Show the flipchart paper with the important changes in Part I to compare]

\section{Closure}

10. What advice would you give to people who are starting a similar project in their community?

11. Any other comment?

Thank you very much for your collaboration! 


\section{Non-leader participants}

\section{Preamble}

Welcome! Thank you very much for your presence. As you were previously informed, we are carrying out a study regarding some projects financed by Luxembourg. In this community [name] the works during the project were... [Describe briefly]

My name is Mirtha Muñiz. I am Peruvian, economist, and researcher at Maastricht University, Maastricht Graduate School of Governance.

With me, here is Mr. /Mrs. [name] whom you already know. He / she will ask you some questions like I will. With me, here is also Miss Yamileth Escobar, sociologist, who is collaborating to my study and during the session, she will take care of logistic details.

Our meeting will last two hours and fifteen minutes at most; we will have a break in the middle.

After the meeting, we will agree on some schedules to hold individual interviews and fill out a questionnaire with you.

Again, we thank your voluntary participation and we hope you will be with us in the other activities that will finish with the individual interview.

This will be an informal talk. We are interested in listening to your experience and opinions because each of you has an experience a little different from the others. There are no good or bad answers, but only different points of view. We are interested in comments, both positive and negative, in order to evaluate the different effects that the project had on your lives. We have prepared some questions but if you feel at any point that there are topics important for you about which you would like to talk, they, of course, be welcome.

\section{Introduction}

\section{(Person A/B)}

Let's start with a game with this ball. My name is [name], I am [civil status], I have [number] children and I like the colour [colour]. Now, I throw the ball to someone who is not sat next to me. This person says his or her name, family situation, if he or she has children and of which ages, and which colour he or she likes the most. This person throws the ball to another person and this person introduces him or herself. We continue like that until the last person has presented him or herself.

\section{Explanation of the Activities}

(Mirtha)

Very good! Now let's define some ground rules:

- We will audio record the meeting in order to not lose any of your comments. Later, I will write out the content of the recorded conversations. These notes will be in my personal files. I will not use your real names in the reports when I refer to the comments here expressed.

- $\quad$ Because we are recording in tapes, please, speak out and clear. Only one person can talk at the same time.

- You cannot have small talks in low voice with your neighbours otherwise we will not able to understand the whole conversation. Always talk to the whole group, please.

- $\quad$ Let's all participate!

The project and its general impacts

(Person A/B)

1. Reconstruction Projects: Please, tell us what it was like in this town before the disaster, in year [year]: what activities did you use to do? 
Water projects: Please, tell us how you used to get drinking water before the project in year [year]. Did you buy it? Did you get it from somewhere?

2. Tell us, what was happening in the community during the project's lifetime?
a) At the beginning...
b) During....
c) At the end....

(Person A/B)

3. How did you participate in the project? Please, explain what you personally did and how you felt during the project. [Mention the period so they will remember well]

4. What new things did every one of you learn during the project?

[Make a list, writing or drawing]

(Person A/B)

5. What important changes happened in your community as a result of the project? Please, give us examples.

[Make a list with drawings]

[Check if there are impacts in the following areas: life-health, housing and physical security, environment, knowledge, friendship (social relations), emotional-mental status, spiritual, economic security]

For water projects: How do you use the drinking water now? (To wash, to take a bath, to cook)

\section{Elements for expansion in elements associated to autonomy ${ }^{121}$}

(Mirtha)

I am handing out some sheets of paper to each of you. When we finish the exercise, please, leave them on the table because they will help me with my research. Do not write your names on the sheets.

6. We are interested in whether you personally received sufficient information about the project?

Look at this picture- please circle the number that best fits the amount of information you needed. A " 0 " means that you received no information. A " 1 " means that you received very little-and a " 10 " means that you received all the information you needed. What fits your situation best? You can choose any number between 0 and 10 .

\begin{tabular}{lllllllllll}
\hline 0 & 1 & 2 & 3 & 4 & 5 & 6 & 7 & 8 & 9 & 10
\end{tabular}

[Vertical scale in the sheets provided]

[With illiterate people, it is necessary to explain very well the numbers with the small circles that grow in quantity as numbers from 0 to 10. Tick an example in the flipchart paper]

Let's discuss your opinions...

7. Now, please, tell us what was the situation in terms of access to information regarding your community's activities, before the project and now? Please, tick your option in the second sheet.

[On the same sheet, they have both lines. Also, explain with example so they understand well. It is important because the other questions are similar.]

Let's discuss your opinions with the group...

${ }^{121}$ The last section presents some sheets used during the scoring exercise. 
[The idea is that they explain the reasons of their change or not change, with examples)

Can we conclude with a possible change of direction within the community's access to information (if it went up, down or stayed)?

(Person A/B)

8. Now, let's talk of self-confidence to express one's ideas to others and defend them.

In the next sheet, indicate your level of self-confidence before the project and now.

[Discussion with the group, the same as in previous questions]

(Person A/B)

9. On the next sheet, please, indicate the number that corresponds to the value (quantity and importance) of the opportunities that people in your community had before the project and now.

[Discussion with the group, the same as in previous questions]

(Person A/B)

10. On the last sheet, indicate the number that represents the times you have taken important decisions in your daily life freely, which means, decisions which you have carefully analysed. Again, please circle the number before the project and now.

[Discussion with the group, the same as in previous questions]

Now, we will have a break. You can have some snacks and drinks.

We will continue in 5 minutes...

------ Break -----

Please, let's continue our talk.

\section{Community empowerment}

(Person A/B)

11. When do you think that a community is strong? When it has what?

[Write in the flipchart paper or draw]

[Check at the end if they include the following elements:

- Information is available and can be analysed

- $\quad$ There is solidarity and trust among its members

- $\quad$ There is more authority and control over community assets (i.e. donations)

- $\quad$ There is good organisation

- $\quad$ Leaders do the things community members need

- $\quad$ There is accountability]

(Person A/B)

12. What has to improve so that [name] will be a stronger community?

(Person A/B)

13. Do you think that the project has contributed to strengthen [name]? If this is the case, please, give us examples.

[Show the flipchart paper with the important changes to compare] 
Closure

(Person A/B)

14. What advice would you give to people who are starting a similar project in their community?

[Use the flipchart sheet: writing or drawing]

(Person A/B)

15. Are there any other important topics that we should have discussed? We still have a few minutes left...

Thank you very much for your time and collaboration!

Your comments are very important for this research.

Note: Person A / B refers to Mirtha or the local co-moderator, depending on the skills of the co-moderator. In each project, there was a specific allocation of questions, which were rehearsed previously.

Anonymous sheets for the scoring exercise

Question 6:

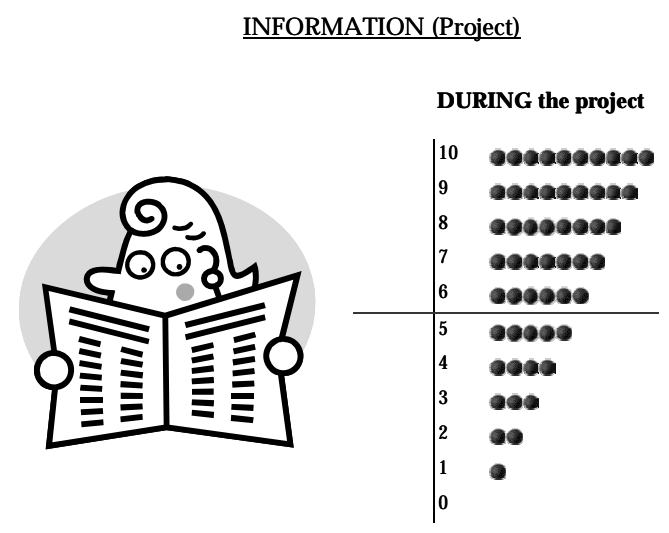

Question 7:

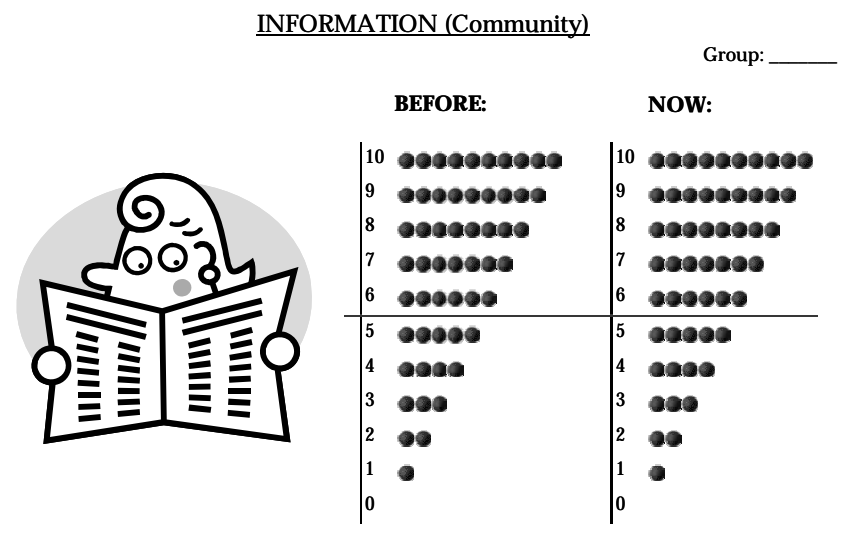


Question 8:

\section{SELF-CONFIDENCE}

BEFORE:

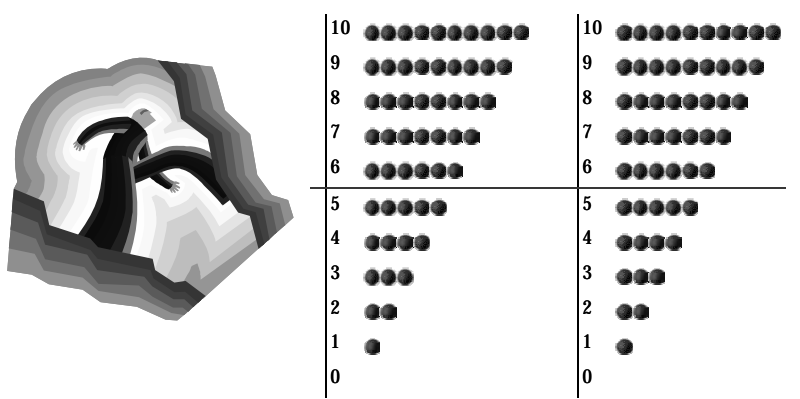

Question 9:

OPPORTUNITIES

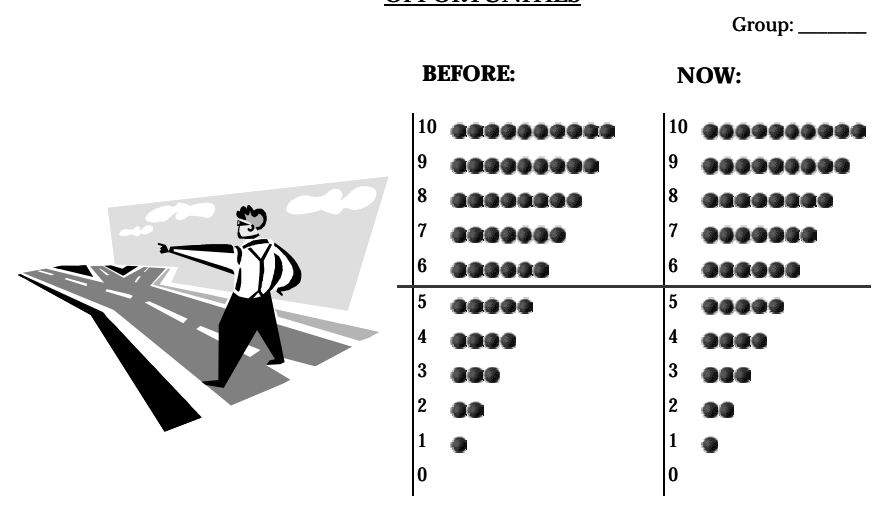

Question 10:

DECISION-MAKING WITH RESPONSIBILITY

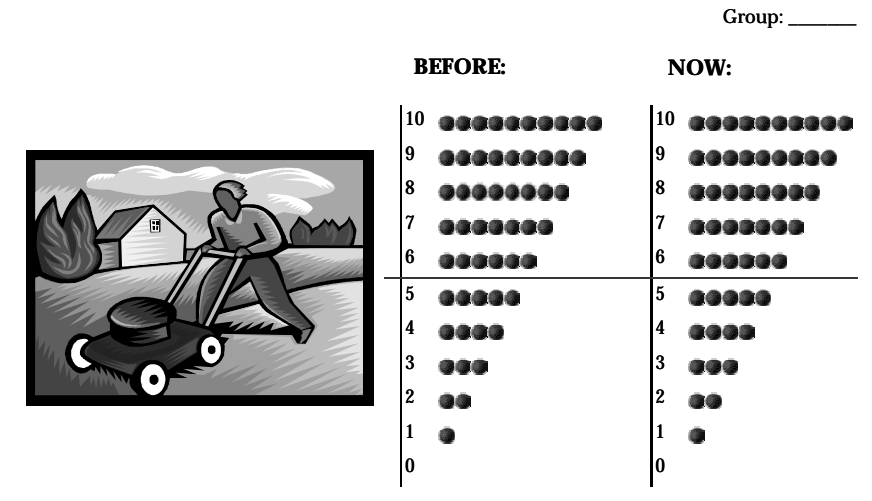




\section{Appendix 2-D: Characteristics of FGD participants}

Number of leader FGD participants (1 group per community)

\begin{tabular}{|lccccc|}
\hline & Santa María & San Fernando & Agua Fría & San Agustín & Total \\
Women & 8 & 10 & 1 & 3 & 22 \\
Men & 5 & 4 & 11 & 7 & 27 \\
Total & 13 & 14 & 12 & 10 & 49 \\
\hline
\end{tabular}

Number of non-leader FGD participants (4 groups per community)

\begin{tabular}{|lccccc|}
\hline & Santa María & San Fernando & Agua Fría & San Agustín & Total \\
Women & 25 & 26 & 29 & 20 & 100 \\
Men* & 16 & 6 & 23 & 9 & 54 \\
Total & 41 & 32 & 52 & 29 & 154 \\
\hline
\end{tabular}

${ }^{*}$ Only 1 FGD with men in San Fernando

Percentage of literate participants

\begin{tabular}{|lccccc|}
\hline & Santa María & San Fernando & Agua Fría & San Agustín & Total \\
Women & 64.0 & 65.4 & 44.8 & 40.0 & 54.0 \\
Men & 56.3 & 83.3 & 56.5 & 66.7 & 61.1 \\
Total & 61.0 & 68.8 & 50.0 & 48.3 & 56.5 \\
\hline
\end{tabular}

Age distribution of FGD participants (\%)

Women

\begin{tabular}{|lccccc|}
\hline & Santa María & San Fernando & Agua Fría & San Agustín & Total \\
\hline $15-29$ yrs. & 32.0 & 26.9 & 13.8 & 15.0 & 22.0 \\
$30-44$ yrs. & 32.0 & 53.8 & 31.0 & 45.0 & 40.0 \\
$45-59$ yrs. & 20.0 & 11.5 & 24.1 & 25.0 & 20.0 \\
60 yrs. + & 16.0 & 7.7 & 31.0 & 15.0 & 18.0 \\
All ages & 100.0 & 100.0 & 100.0 & 100.0 & 100.0 \\
\hline Men & \multicolumn{7}{r}{} & & & \\
\hline & Santa María & San Fernando & Agua Fría & San Agustín & Total \\
$15-29$ yrs. & 25.0 & 50.0 & 13.0 & 22.2 & 22.2 \\
$30-44$ yrs. & 37.5 & 16.7 & 17.4 & 55.6 & 29.6 \\
$45-59$ yrs. & 25.0 & 33.3 & 56.5 & 11.1 & 37.0 \\
60 yrs. + & 12.5 & 0.0 & 13.0 & 11.1 & 11.1 \\
All ages & 100.0 & 100.0 & 100.0 & 100.0 & 100.0 \\
\hline
\end{tabular}




\section{Appendix 2-E: Survey questionnaire}

The objective of this survey is to analyse the effect that the [water/reconstrucion] project financed by Luxembourg had on you and your community. Thank you very much for your collaboration!

\section{GENERAL INFORMATION}

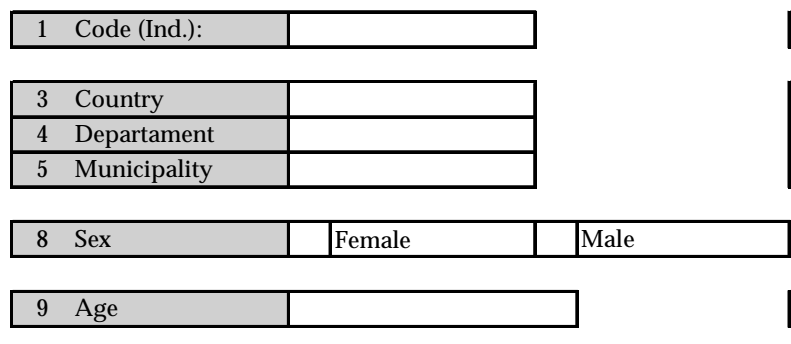

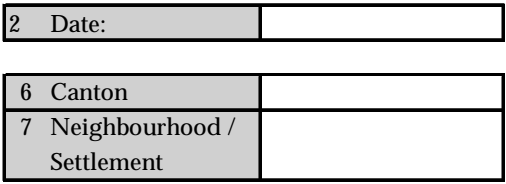

(If he or she remembers)

\begin{tabular}{|l|l}
\hline 10 Birth date & \\
\hline
\end{tabular}

\begin{tabular}{|c|c|c|c|c|}
\hline 11 Family situation & Single & Married /n-union & Widow(er) & Divorced /Separ. \\
\hline
\end{tabular}

\begin{tabular}{|l|l|l|l|l|}
\hline $12 a$ Do you know how to read and to write? & & Yes & & No \\
\hline
\end{tabular}

\begin{tabular}{|ll|}
\hline 12 Highest attained educational level & \\
\hline Kindergarten & $\square$ Primary \\
\hline Incomplete primary & $\square$ Secondary \\
\hline
\end{tabular}

\begin{tabular}{|l|l|l|}
\hline 13 Relation with household head? & \\
\hline
\end{tabular}

Data of household head

\begin{tabular}{|c|c|c|c|}
\hline 14 Sex & Female & Male & \\
\hline & & & (If he or she \\
\hline 15 Age & & & 16 Birth date \\
\hline
\end{tabular}

Day / Mon. / Year

\begin{tabular}{|l|l|l|l|}
\hline 17a Do you know how to read and how to write? & Yes & & No \\
\hline
\end{tabular}

\begin{tabular}{|lll|}
\hline 17 Highest attained educational level & \\
\hline & Kindergarten \\
Incomplete primary & $\square$ Primary & $\square$ Tertiary \\
\hline Incondary & $\square$ Incomplete secondary \\
\hline
\end{tabular}

\begin{tabular}{|ll|l|}
\hline 18 & Num. members in household (total) & \\
\hline 19 & Num. children (younger than 12 years) & \\
\hline
\end{tabular}

\section{SOCIO-ECONOMIC INFORMATION}

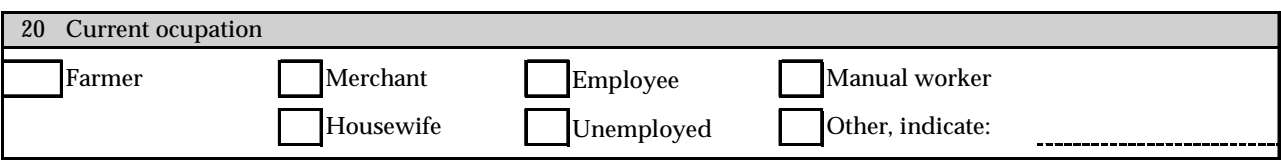




\begin{tabular}{|l|l|l|l|}
\hline 21 & Have you travelled abroad during the last 5 years? \\
\hline & Yes & No Country: \\
\hline
\end{tabular}

\begin{tabular}{|c|c|c|c|}
\hline Farmer & Merchant & Employee & Manual worker \\
\hline & Housewife & Unemployed & Other, indicate \\
\hline
\end{tabular}

\begin{tabular}{|l|l|l|l|l|l|l|l|l|}
\hline 23 & The monthly expenditure of your household is between: \\
\hline & 0 - USD37 & USD38 - USD92 & USD93 - USD230 & & USD230 - USD500 & > USD500 \\
\hline
\end{tabular}

\begin{tabular}{|l|l|l|}
\hline $24 \quad$ Does your household receive remittances? \\
\hline & Yes & No \\
\hline
\end{tabular}

\section{Only for water projects:}

\section{RELATIVE MULTIDIMENSIONAL WELLBEING}

A Which of the elements shown in the cards do you think are necessary for everyone (that no one should lack them)?

$\begin{array}{lllll}\square \text { Figure 1 } & \square \text { Figure 6 } & \square \text { Figure 11 } & \square \text { Figure 16 } & \square \text { Figure 21 } \\ \square \text { Figure 2 } & \square \text { Figure 7 } & \square \text { Figure 12 } & \square \text { Figure 22 } \\ \square \text { Figure 3 } & \square \text { Figure 8 } & \square \text { Figure 13 } & \square \text { Figure 18 } \\ \square \text { Figure 4 } & \square \text { Figure 9 } & \square \text { Figure 14 } & \square \text { Figure 19 } & \square \text { Figure 24 } \\ \square \text { Figure 5 } & \square \text { Figure 10 } & \square \text { Figure 15 } & \square \text { Figure 20 } & \square \text { Figure 25 }\end{array}$

B Please, order the elements chosen above from the most to the least important.

\begin{tabular}{|c|c|c|c|c|}
\hline Figure 1 & Figure 6 & Figure 11 & Figure 16 & Figure 21 \\
\hline Figure 2 & Figure 7 & |Figure 12 & ]Figure 17 & |Figure 22 \\
\hline Figure 3 & Figure 8 & Figure 13 & Figure 18 & Figure 23 \\
\hline Figure 4 & Figure 9 & Figure 14 & Figure 19 & |Figure 24 \\
\hline Figure 5 & Figure 10 & Figure 15 & Figure 20 & Figure 25 \\
\hline
\end{tabular}

C Which of these elements do you have?

\begin{tabular}{|c|c|c|c|c|}
\hline Figure 1 & |Figure 6 & |Figure 11 & Figure 16 & |Figure 21 \\
\hline Figure 2 & Figure 7 & |Figure 12 & Figure 17 & |Figure 22 \\
\hline Figure 3 & Figure 8 & |Figure 13 & Figure 18 & |Figure 23 \\
\hline Figure 4 & Figure 9 & Figure 14 & Figure 19 & |Figure 24 \\
\hline Figure 5 & Figure 10 & Figure 15 & Figure 20 & Figure 25 \\
\hline
\end{tabular}

\section{PROJECT FORMULATION}

\begin{tabular}{|c|c|c|c|c|}
\hline \multicolumn{3}{|c|}{25 Did you know about the project before it started? } & Yes & No \\
\hline \multicolumn{5}{|c|}{26 If yes, how did you get that information? } \\
\hline Com. Assembly & Workshops & Friends Relatives & Oth & \\
\hline
\end{tabular}




\begin{tabular}{|c|c|c|c|}
\hline 27 & Were you informed about the project during its implementation? & Sí & No \\
\hline 28 & \multirow{2}{*}{\multicolumn{3}{|c|}{$\begin{array}{l}\text { How did you get this information? } \\
\text { a) I received it through: }\end{array}$}} \\
\hline & & & \\
\hline & City hall & Community & Other, indicate: \\
\hline & \multicolumn{3}{|l|}{ b) No I did not receive it and had to ask for it } \\
\hline 29 & Was this information important for you? & Yes & No \\
\hline 30 & Was this information received timely? & Yes & No \\
\hline 31 & Was this information understandable? & Jyes & No \\
\hline
\end{tabular}

\begin{tabular}{|ll|l|l|}
\hline 32 & Did you express your opinions about the project? & Yes & No \\
\hline 33 & Were your opinions taken into account? \\
34 & If the answer to question 33 is no, why?
\end{tabular}

\begin{tabular}{|l|l|l|}
\hline 35 & Did you participate in the project activities? \\
\hline & & \\
& & \\
& &
\end{tabular}

\begin{tabular}{|ll|l|l|}
\hline 36 & Did you use your practical skills during the project? & & Yes \\
\hline 37 & If yes, how did you use them? \\
38 & If no, why did not you use them?
\end{tabular}

\begin{tabular}{|l|l|}
\hline 39 Did you participate in the following activities? \\
\hline House construction \\
\hline Works in lavatories, baths, drains, soak-away pits \\
\hline Agriculture activities \\
\hline Other, indicate:
\end{tabular}

For water projects:

\begin{tabular}{|c|c|c|c|c|}
\hline \multicolumn{3}{|c|}{40 Did you receive some kind of training? } & Yes & No \\
\hline \multicolumn{5}{|c|}{$42 \mathrm{w}$ Was this training useful? } \\
\hline Soak-away pit & No & A little & Fairly & Very \\
\hline Latrines & No & A little & JFairly & Very \\
\hline Health and water & No & A little & Fairly & Very \\
\hline Environment & No & A little & JFairly & Very \\
\hline Solid wastes & No & A little & JFairly & Very \\
\hline Other & No & A little & Fairly & Very \\
\hline
\end{tabular}


For reconstruction projects:

\begin{tabular}{|l|l|l|l|l}
40 Did you receive some kind of training? & & Yes & & No
\end{tabular}

41 Of what kind?

42 Was this training suitable for the role you had during project implementation?

$\square$ No $\square$ Rarely $\square$ Sometimes $\square$ Usually

43 Is or will be this training useful for you in the future?

$\square$ No $\square$ Unlikely $\square$ Likely $\square$ Most likely

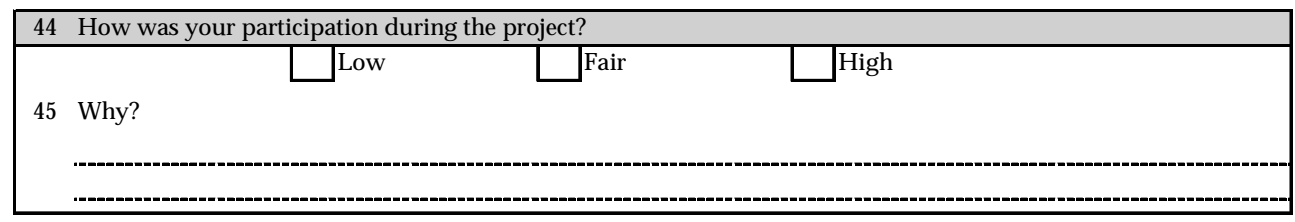

\section{PROJECT EVALUATION}

\begin{tabular}{|l|l|l|l|l}
\hline 46 Were you informed about the results of the project? & & Yes & No
\end{tabular}

47 Was the project monitored or followed-up during its implementation?

\begin{tabular}{|l|l|l|l|l|l|l|}
\hline & No & Yes, good & & Yes, bad & Does not know \\
\hline
\end{tabular}

\begin{tabular}{|lll|l|l|}
\hline 48 & Do you collaborate for maintaining common infrastructure? & & Yes & No \\
\hline 49 & Why? & How? & - & - \\
50 & & - & & \\
\end{tabular}

For water projects:

51 You consider that the quality of water is:

$\bigsqcup$ Bad $\bigsqcup$ Good $\quad \square$ Very good

For reconstruction projects:

52 How much satisfied are you with the quality of your house?

\begin{tabular}{|l|l|l|l|l|l|l|l|}
\hline & Not satisfied & A little satisfied & & Fairly satisfied & & Very satisfied \\
\hline
\end{tabular}

\begin{tabular}{|ll|l|l|l|}
\hline 53 & From your point of view, was the project successful? & & Yes & No \\
\hline 54 & Why? &
\end{tabular}

\section{YOU AND YOUR COMMUNITY}

\begin{tabular}{|l|l|l|l|l|}
\hline 55 & Which organisations exist in your community? & \\
\hline & Committees /development associations & RGOs & Religious assoc. \\
& $\square$ Parents associat. \\
& $\square$ Other, indicate:
\end{tabular}

\begin{tabular}{|l|l|l|}
\hline 56 & Do you participate in some of the previous organisations or programmes promoted by them? \\
\hline \multicolumn{2}{|c|}{ Yes } & If yes, how? \\
\hline
\end{tabular}


Questions about social relations

57 Most people in your community are willing to help you if you need it.

$$
\square \text { Yes } \square \text { No }
$$

58 In this community, you have to be alert or someone could take advantage of you.

$\square$ Yes $\square$ No

59 In this community, there is greater cooperation among smaller groups than whole community.

$$
\square \text { Yes } \square \text { No }
$$

60 As a result of the project, is your community better organised?

61 Do you feel that the leaders respond more effectively to your needs now than they did seven years ago?

\begin{tabular}{|l|l|l|l|}
\hline & Yes & & No \\
\hline
\end{tabular}

62 How frequently do you feel that your community expands your opportunities?

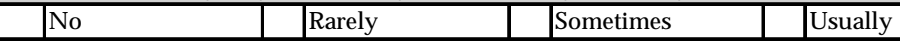

Questions about decision making

63 How much control do you feel that you have over your daily life's decisions? (that you take them freely)

No $\square$ Little $\square$ Fair $\square$ Nearly full

64 How much control do you feel that you have over family decisions?

$\square$ No $\square$ Little $\square$ Fair $\square$ Nearly full

65 How much control do you feel that you have over decisions that affect the development of your community?

$\square$ No $\square$ Little $\square$ Fair $\square$ Nearly full

\section{THANK YOU VERY MUCH!}

\section{General comments:}

\begin{tabular}{|c|c|c|c|}
\hline 1 & Having a sense of inner peace & 14 & Feeling secure \\
\hline 2 & Having adequate housing & 15 & Having electricity \\
\hline 3 & Having a family & 16 & Being healthy \\
\hline 4 & Having access to safe drinking water & 17 & Having livestock \\
\hline 5 & Being well fed & 18 & Being able to express care for others \\
\hline 6 & Being literate & 19 & Having support during childbearing period \\
\hline 7 & Having a job & 20 & Having a land to cultivate \\
\hline 8 & Having a bike & 21 & Enjoying recreational activities \\
\hline 9 & Having telephone & 22 & Being free to speak one's mind \\
\hline 10 & Having access to public transportation & 23 & Having friends \\
\hline 11 & Having access to credit when needed & 24 & Being part of a group or association \\
\hline 12 & Having television & 25 & Being able to travel \\
\hline 13 & Being well dressed & & \\
\hline
\end{tabular}

\section{Description of the figures (cards) used in questions A, B, and C}

Note 1: The Purchasing Power Parity (PPP) index was used to homogenise the thresholds of income considered in the questionnaires for Nicaraguan and Salvadorian project sites. Source: Estimations in Penn World Tables (Heston, Summers E Aten, 2002) and the PPP for GNI calculated by the World Bank (n.d., e) - ICP, International Comparison Program.

The thresholds for Nicaraguan survey were $C \$ 400, C \$ 1,000$ and $C \$ 2,500$. It had only four brackets instead of the five of Salvadorian survey because respondents had higher consumptions levels in Salvadoran sites than in Nicaraguan sites.

Note 2: Questions 55 to 65 were based on WB (2003, Annex I, p. 85). 


\section{Summary statistics}

\begin{tabular}{|c|c|c|c|c|c|c|}
\hline Variable & Description & Obs & Mean & Std. Dev. & Min & Max \\
\hline \multicolumn{7}{|c|}{ Identification codes } \\
\hline id & Individual code & 231 & 116 & 66.83 & 1 & 231 \\
\hline project & $\begin{array}{l}\text { 1=Santa María, 2=San Agustín, 3=Agua } \\
\text { Fría, 4=San Agustín }\end{array}$ & 231 & 2.10 & 1.07 & 1 & 4 \\
\hline sector & $1=$ reconstruction, $2=$ water & 231 & 1.48 & 0.50 & 1 & 2 \\
\hline country & 1=Nicaragua, 2=El Salvador & 231 & 1.31 & 0.46 & 1 & 2 \\
\hline \multicolumn{7}{|c|}{ Respondent characteristics } \\
\hline $\operatorname{sex}$ & Dummy variable. 1 if male & 231 & 0.40 & 0.49 & 0 & 1 \\
\hline age & Age in years & 231 & 42.70 & 16.06 & 14 & 87 \\
\hline age_range & $\begin{array}{l}1=15-29 \text { yrs., } 2=30-44 \text { yrs., } 3=45-59 \text { yrs., } \\
4=60+\text { yrs. }\end{array}$ & 231 & 2.38 & 1.04 & 1 & 4 \\
\hline famsituation & $\begin{array}{l}1=\text { single, } 2=\text { married, } 3=\text { divorced, } \\
4=\text { widowed }\end{array}$ & 231 & 2 & 0.80 & 1 & 4 \\
\hline Married & Dummy variable. 1 if married & 231 & 0.67 & 0.47 & 0 & 1 \\
\hline Literate & Dummy variable. 1 if literate & 231 & 0.64 & 0.48 & 0 & 1 \\
\hline Lite_sex & $\begin{array}{l}\text { 1=illiterate woman, 2=illiterate man, } \\
\text { 3=literate woman, } 4=\text { =literate man }\end{array}$ & 231 & 2.68 & 1.02 & 1 & 4 \\
\hline \multicolumn{7}{|c|}{ Household characteristics } \\
\hline Members & Number of household members & 231 & 4.66 & 2.23 & 1 & 14 \\
\hline Children & Number of children in household & 231 & 1.49 & 1.42 & 0 & 8 \\
\hline If_children & Dummy variable. 1 if children & 231 & 0.71 & 0.45 & 0 & 1 \\
\hline Depratio & $\begin{array}{l}\text { Children dependency ratio (children / } \\
\text { no children) }\end{array}$ & 231 & 0.59 & 0.63 & 0 & 3 \\
\hline \multicolumn{7}{|c|}{ Individual indicators of involvement in the project } \\
\hline Information & Did you receive relevant information? & 231 & 1.52 & 0.84 & 0 & 3 \\
\hline Opinions & $\begin{array}{l}\text { Did you give your opinions to your } \\
\text { community? }\end{array}$ & 231 & 1.05 & 0.81 & 0 & 3 \\
\hline Awareness & $\begin{array}{l}\text { Did you use your abilities or practical } \\
\text { knowledge? }\end{array}$ & 231 & 1.36 & 0.90 & 0 & 3 \\
\hline Opportunities & $\begin{array}{l}\text { Did you have opportunity to make } \\
\text { decisions? }\end{array}$ & 231 & 1.02 & 0.93 & 0 & 3 \\
\hline Decisions & $\begin{array}{l}\text { How frequently did you make deci- } \\
\text { sions? }\end{array}$ & 231 & 1.08 & 0.99 & 0 & 3 \\
\hline \multicolumn{7}{|c|}{ Involvement in the project } \\
\hline Involvement & $\begin{array}{l}\text { Involvement index (simple average of } \\
\text { above var.) }\end{array}$ & 231 & 1.20 & 0.65 & 0 & 3 \\
\hline High_involved & $\begin{array}{l}\text { Dummy variable. } 1 \text { if the respondent } \\
\text { has a involvement index }>1.5\end{array}$ & 231 & 0.32 & 0.47 & 0 & 1 \\
\hline Index 1 & $\begin{array}{l}\text { Aggregated index: } \\
\text { Information } \cup(\text { Opinions } \cap \text { Awareness ) }\end{array}$ & 231 & 1.60 & 0.81 & 0 & 3 \\
\hline Index 2 & $\begin{array}{l}\text { Aggregated index: } \\
\text { Opportunities } \cap \text { Decision-making }\end{array}$ & 231 & 0.88 & 0.83 & 0 & 3 \\
\hline
\end{tabular}


Involvement in the project: Distribution of responses (\%) by project

\begin{tabular}{|c|c|c|c|c|c|c|}
\hline & & Santa María & San Fernando & Agua Fría & San Agustín & Total \\
\hline \multirow[t]{5}{*}{ Information } & No & 7.1 & 17.1 & 14.3 & 2.8 & 10.8 \\
\hline & Little & 45.2 & 35.5 & 20.0 & 50.0 & 39.0 \\
\hline & Fair & 38.1 & 30.3 & 54.3 & 38.9 & 38.1 \\
\hline & Much & 9.5 & 17.1 & 11.4 & 8.3 & 12.1 \\
\hline & Total & 100.0 & 100.0 & 100.0 & 100.0 & 100.0 \\
\hline \multirow[t]{5}{*}{ Opinions } & No & 25.0 & 32.9 & 17.1 & 25.0 & 26.4 \\
\hline & Rarely & 51.2 & 43.4 & 42.9 & 44.4 & 46.3 \\
\hline & Sometimes & 19.1 & 18.4 & 40.0 & 27.8 & 23.4 \\
\hline & Usually & 4.8 & 5.3 & 0.0 & 2.8 & 3.9 \\
\hline & Total & 100.0 & 100.0 & 100.0 & 100.0 & 100.0 \\
\hline \multirow[t]{5}{*}{ Awareness } & No & 16.7 & 22.4 & 22.9 & 11.1 & 18.6 \\
\hline & Rarely & 34.5 & 42.1 & 25.7 & 44.4 & 37.2 \\
\hline & Sometimes & 38.1 & 25.0 & 45.7 & 33.3 & 34.2 \\
\hline & Usually & 10.7 & 10.5 & 5.7 & 11.1 & 10.0 \\
\hline & Total & 100.0 & 100.0 & 100.0 & 100.0 & 100.0 \\
\hline \multirow[t]{5}{*}{ Opportunities } & $\mathrm{No}$ & 33.3 & 38.2 & 37.1 & 41.7 & 36.8 \\
\hline & Rarely & 26.2 & 34.2 & 22.9 & 33.3 & 29.4 \\
\hline & Sometimes & 32.1 & 25.0 & 34.3 & 22.2 & 28.6 \\
\hline & Usually & 8.3 & 2.6 & 5.7 & 2.8 & 5.2 \\
\hline & Total & 100.0 & 100.0 & 100.0 & 100.0 & 100.0 \\
\hline \multirow[t]{5}{*}{ Decisions } & $\mathrm{No}$ & 32.1 & 36.8 & 37.1 & 41.7 & 35.9 \\
\hline & Rarely & 27.4 & 34.2 & 20.0 & 33.3 & 29.4 \\
\hline & Sometimes & 31.0 & 25.0 & 22.9 & 16.7 & 25.5 \\
\hline & Usually & 9.5 & 4.0 & 20.0 & 8.3 & 9.1 \\
\hline & Total & 100.0 & 100.0 & 100.0 & 100.0 & 100.0 \\
\hline
\end{tabular}

Involvement in the project: Distribution of indexes (\%) by project

\begin{tabular}{|lllccccc|}
\hline & & & Santa María & San Fernando & Agua Fría & San Agustín & Total \\
\hline Index 1 & 0 & No & 6.0 & 11.8 & 11.4 & 0.0 & 7.8 \\
& 1 & Rarely & 42.9 & 36.8 & 17.1 & 44.4 & 37.2 \\
& 2 & Sometimes & 40.5 & 32.9 & 60.0 & 47.2 & 42.0 \\
& 3 & Usually & 10.7 & 18.4 & 11.4 & 8.3 & 13.0 \\
& & Total & 100.0 & 100.0 & 100.0 & 100.0 & 100.0 \\
\hline Index 2 & 0 & No & 33.3 & 44.7 & 37.1 & 41.7 & 39.0 \\
& 1 & Rarely & 38.1 & 36.8 & 28.6 & 38.9 & 36.4 \\
& 2 & Sometimes & 27.4 & 15.8 & 31.4 & 16.7 & 22.5 \\
& 3 & Usually & 1.2 & 2.6 & 2.9 & 2.8 & 2.2 \\
& & Total & 100.0 & 100.0 & 100.0 & 100.0 & 100.0 \\
\hline
\end{tabular}




\section{Appendix 2-G: D escription of dataset 2}

\section{Summary statistics}

\begin{tabular}{|c|c|c|c|c|c|c|c|}
\hline Variable & Q & Description & Obs & Mean & Std. Dev. & Min & $\operatorname{Max}$ \\
\hline \multicolumn{8}{|l|}{ Identification } \\
\hline Country & 3 & 1=Nicaragua, 2=El Salvador & 172 & 1.54 & 0.50 & 1 & 2 \\
\hline Sector & & $1=$ reconstruction, $2=$ water & 172 & 1.53 & 0.50 & 1 & 2 \\
\hline Project & & $\begin{array}{l}\text { 1=Santa María, 2=San Fernando, 3=Agua Fría, } \\
\text { 4=San Agustín }\end{array}$ & 172 & 2.52 & 1.09 & 1 & 4 \\
\hline \multicolumn{8}{|l|}{ Respondent variables } \\
\hline Sex & 8 & $0=$ female, $1=$ male & 172 & 0.37 & 0.48 & 0 & 1 \\
\hline Age & 9 & Age in years & 172 & 42.80 & 14.87 & 15 & 87 \\
\hline Family_situation & 11 & $\begin{array}{l}1=\text { single, } 2=\text { married or in-union, } 3=\text { widow }(\mathrm{er}), \\
4=\text { divorced or separated }\end{array}$ & 172 & 1.86 & 0.61 & 1 & 4 \\
\hline Literate & $12 \mathrm{a}$ & $0=$ no, $1=$ yes & 172 & 0.64 & 0.48 & 0 & 1 \\
\hline Educationlevel & 12 & $\begin{array}{l}\text { 1=kindergarten, } 2=\text { incomplete primary, } \\
3=\text { primary, } 4=\text { secondary, } 5=\text { incomplete secon- } \\
\text { dary, } 6=\text { tertiary, } 7=\text { other }\end{array}$ & 112 & 2.92 & 1.10 & 1 & 5 \\
\hline Occupation1 & 20 & $\begin{array}{l}\text { Current occupation of respondent. } 1=\text { farmer, } \\
2=\text { merchant, } 3=\text { employee, } 4=\text { manual worker, } \\
5=\text { housewife, } 6=\text { unemployed, } 7=\text { other }\end{array}$ & 172 & 3.81 & 2.02 & 1 & 7 \\
\hline Travel & 21 & $0=$ no, $1=$ yes & 172 & 0.22 & 0.42 & 0 & 1 \\
\hline Relation_hh & 13 & $\begin{array}{l}1=\text { head, } 2=\text { spouse } / \text { partner, } 3=\text { child, } \\
6=\text { grandchild, } 7=\text { other relative, } 8=\text { relative }\end{array}$ & 172 & 1.68 & 1.14 & 1 & 8 \\
\hline \multicolumn{8}{|c|}{ Head of household variables } \\
\hline Sex_hh & 14 & $0=$ female, $1=$ male & 172 & 0.72 & 0.45 & 0 & 1 \\
\hline Age_hh & 15 & Age in years & 165 & 46.67 & 16.09 & 21 & 99 \\
\hline Literate_hh & $17 \mathrm{a}$ & $0=$ no, $1=$ yes & 167 & 0.65 & 0.48 & 0 & 1 \\
\hline Educationlevel_hh & 17 & $\begin{array}{l}\text { 1=kindergarten, } 2=\text { incomplete primary, } \\
3=\text { primary, } 4=\text { secondary, } 5=\text { incomplete secon- } \\
\text { dary, } 6=\text { tertiary, } 7=\text { other }\end{array}$ & 107 & 2.73 & 1.10 & 1 & 6 \\
\hline Occupation1_hh & 22 & $\begin{array}{l}\text { Current occupation of household head. } \\
1=\text { farmer, } 2=\text { merchant, } 3=\text { employee, } 4=\text { manual } \\
\text { worker, } 5=\text { housewife, } 6=\text { unemployed, } 7=\text { other }\end{array}$ & 172 & 2.74 & 2.19 & 1 & 7 \\
\hline \multicolumn{8}{|l|}{ Household variables } \\
\hline Members & 18 & Number of household members & 172 & 4.97 & 2.37 & 1 & 15 \\
\hline Children & 19 & Number of members younger than 12 years & 172 & 1.49 & 1.39 & 0 & 5 \\
\hline Expenditure & 23 & $\begin{array}{l}\text { Self-reported monthly expenditure in brackets: } \\
1=\text { lower than } \$ 37,2=\text { between } \$ 38 \text { and } 92 \text {, } \\
3=\text { between } \$ 93 \text { and } \$ 230,4=\text { higher than } 500\end{array}$ & 172 & 2.15 & 0.97 & 1 & 4 \\
\hline Remittances & 24 & $\begin{array}{l}\text { Household regularly receiving remittances: } \\
0=\text { no, } 1=\text { yes }\end{array}$ & 172 & 0.23 & 0.42 & 0 & 1 \\
\hline \multicolumn{8}{|c|}{ Variables on information } \\
\hline Info_start & 25 & $\begin{array}{l}\text { Had information before the project started? } \\
0=\text { no, } 1=\text { yes }\end{array}$ & 171 & 0.90 & 0.30 & 0 & 1 \\
\hline Info_during & 27 & Had information during the project? $0=$ no, $1=$ yes & 172 & 0.97 & 0.18 & 0 & 1 \\
\hline How_info & $28 \mathrm{a}$ & How? $0=$ given, $1=$ had to ask & 166 & 1.02 & 0.15 & 1 & 2 \\
\hline Important_info & 29 & $0=$ no, $1=$ yes & 163 & 1.00 & 0.00 & 1 & 1 \\
\hline Timely_info & 30 & $0=$ no, $1=$ yes & 164 & 0.97 & 0.17 & 0 & 1 \\
\hline Understandable_info & 31 & $0=$ no, $1=$ yes & 165 & 0.80 & 0.40 & 0 & 1 \\
\hline Info_end & 46 & Informed about the results? $0=$ no, $1=$ yes & 167 & 0.81 & 0.39 & 0 & 1 \\
\hline
\end{tabular}




\begin{tabular}{|c|c|c|c|c|c|c|c|}
\hline \multicolumn{8}{|c|}{ Variables on self-confidence } \\
\hline Opinions & 32 & $0=$ no, $1=$ yes & 171 & 0.61 & 0.49 & 0 & 1 \\
\hline Respect & 33 & $0=$ no, $1=$ yes & 100 & 0.94 & 0.24 & 0 & 1 \\
\hline \multicolumn{8}{|c|}{ Participation during the project } \\
\hline Participation & 35 & $0=$ no, $1=$ yes & 170 & 0.85 & 0.36 & 0 & 1 \\
\hline Why_notparticipation & $35 a$ & $\begin{array}{l}1=\text { relative, } 2=\text { paid worker, } 3=\text { other, } 4=\text { relative \& } \\
\text { paid worker }\end{array}$ & 21 & 1.86 & 1.06 & 1 & 4 \\
\hline House_act & 39 & Participated in house construction? $0=$ no, $1=$ yes & 168 & 0.40 & 0.49 & 0 & 1 \\
\hline Latrines_act & 39 & Participated in latrine construction? $0=$ no, $1=$ yes & 169 & 0.46 & 0.50 & 0 & 1 \\
\hline Innerwater_act & 39 & Participated in water-related works? $0=$ no, $1=$ yes & 169 & 0.75 & 0.44 & 0 & 1 \\
\hline Communalworks_act & 39 & Participated in communal works? $0=$ no, $1=$ yes & 169 & 0.26 & 0.44 & 0 & 1 \\
\hline Agriculture_act & 39 & $\begin{array}{l}\text { Participated in agricultural activities? } 0=\text { no, } \\
1=\text { yes }\end{array}$ & 169 & 0.31 & 0.46 & 0 & 1 \\
\hline Education_act & 39 & $\begin{array}{l}\text { Participated in educational campaigns? } 0=\text { no, } \\
1=\text { yes }\end{array}$ & 169 & 0.02 & 0.13 & 0 & 1 \\
\hline Other_act & 39 & Participated in other activities? $0=$ no, $1=$ yes & 169 & 1.24 & 2.68 & 0 & 7 \\
\hline \multicolumn{8}{|l|}{ Awareness and learning } \\
\hline Awareness & 36 & Used practical skills? $0=$ no, $1=$ yes & 140 & 0.76 & 0.43 & 0 & 1 \\
\hline Training & 40 & $0=$ no, $1=$ yes & 169 & 0.46 & 0.50 & 0 & 1 \\
\hline Useful_training & 42 & $\begin{array}{l}\text { Suitable for activities during the project? } 0=\text { no, } \\
1=\text { a little, } 2=\text { fairly, } 3=\text { very }\end{array}$ & 10 & 1.80 & 0.42 & 1 & 2 \\
\hline Futuruseful_training & 43 & $\begin{array}{l}\text { Useful for you in the future? } 0=\text { no, } 1=\text { unlikely, } \\
2=\text { likely, } 3=\text { most likely }\end{array}$ & 10 & 1.60 & 1.07 & 0 & 3 \\
\hline Soakawaypit_train & $42 w$ & $0=$ no, $1=\mathrm{a}$ little, $2=$ fairly, $3=$ very & 40 & 2.13 & 0.69 & 0 & 3 \\
\hline Latrines_train & $42 w$ & $0=$ no, $1=$ a little, $2=$ fairly, $3=$ very & 54 & 1.74 & 0.91 & 0 & 3 \\
\hline Healthwater_train & $42 w$ & $0=$ no, $1=$ a little, $2=$ fairly, $3=$ very & 44 & 1.95 & 0.68 & 0 & 3 \\
\hline Environment_train & $42 w$ & $0=$ no, $1=\mathrm{a}$ little, $2=$ fairly, $3=$ very & 45 & 1.80 & 0.66 & 0 & 3 \\
\hline Solidwastes_train & $42 w$ & $0=$ no, $1=\mathrm{a}$ little, $2=$ fairly, $3=$ very & 24 & 2.08 & 0.83 & 0 & 3 \\
\hline Other_train & $42 w$ & $0=$ no, $1=\mathrm{a}$ little, $2=$ fairly, $3=$ very & 15 & 2.40 & 0.91 & 0 & 3 \\
\hline \multicolumn{8}{|l|}{ Evaluation } \\
\hline Overall_part & 44 & $\begin{array}{l}\text { How was your participation? } 1=\text { low, } 2=\text { fair, } \\
3=\text { high }\end{array}$ & 168 & 2.05 & 0.79 & 1 & 3 \\
\hline Supervision & 47 & $\begin{array}{l}\text { 1=no, 2=yes \& good, 3=no \& bad, } 4=\text { does not } \\
\text { know }\end{array}$ & 170 & 2.15 & 0.51 & 1 & 4 \\
\hline Water_quality & 51 & $0=$ bad, $1=$ good, $2=$ very good & 91 & 1.29 & 0.50 & 0 & 2 \\
\hline House_satisfaction & 52 & $\begin{array}{l}\text { How much satisfied with the quality of the } \\
\text { house? } 1=\text { not, } 2=\text { a little, } 3=\text { fairly, } 4=\text { very }\end{array}$ & 81 & 2.54 & 0.67 & 1 & 3 \\
\hline Project_success & 53 & $0=$ no, $1=$ yes & 170 & 0.96 & 0.20 & 0 & 1 \\
\hline \multicolumn{8}{|l|}{ Sense of community } \\
\hline Comunal_works & 48 & $\begin{array}{l}\text { Collaborate in maintenance of communal } \\
\text { works? } 0=\text { no, } 1=\text { yes }\end{array}$ & 81 & 0.80 & 0.40 & 0 & 1 \\
\hline Develop_assoc & 55 & $0=$ no, $1=$ yes & 170 & 0.75 & 0.44 & 0 & 1 \\
\hline NGO & 55 & $0=$ no, $1=$ yes & 170 & 0.26 & 0.44 & 0 & 1 \\
\hline Clubs & 55 & $0=$ no, $1=$ yes & 170 & 0.05 & 0.21 & 0 & 1 \\
\hline Religious & 55 & $0=$ no, $1=$ yes & 170 & 0.32 & 0.47 & 0 & 1 \\
\hline Parents_assoc & 55 & $0=$ no, $1=$ yes & 170 & 0.20 & 0.40 & 0 & 1 \\
\hline Other & 55 & $0=$ no, $1=$ yes & 170 & 0.16 & 0.37 & 0 & 1 \\
\hline Part_networks & 56 & $0=$ no, $1=$ yes & 148 & 0.41 & 0.49 & 0 & 1 \\
\hline \multicolumn{8}{|l|}{ Community variables } \\
\hline Solidarity & 57 & $0=$ no, $1=$ yes & 171 & 0.74 & 0.44 & 0 & 1 \\
\hline Trust & 58 & $0=$ no, $1=$ yes & 172 & 0.90 & 0.31 & 0 & 1 \\
\hline Group_competence & 59 & $0=$ no, $1=$ yes & 170 & 0.78 & 0.42 & 0 & 1 \\
\hline Community_organisation & 60 & $0=$ no, $1=$ yes & 171 & 0.87 & 0.34 & 0 & 1 \\
\hline Leaders_empowerment & 61 & $0=$ no, $1=$ yes & 163 & 0.72 & 0.45 & 0 & 1 \\
\hline Perceived_opportunities & 62 & $0=$ no, $1=$ rarely, $2=$ sometimes, $3=$ usually & 168 & 1.26 & 0.91 & 0 & 3 \\
\hline
\end{tabular}




\begin{tabular}{|c|c|c|c|c|c|c|c|}
\hline \multicolumn{8}{|l|}{ Decision-making } \\
\hline Self_control & 63 & $0=$ no control, $1=$ little, $2=$ fair, $3=$ nearly full & 172 & 1.47 & 0.88 & 0 & 3 \\
\hline Family_control & 64 & $0=$ no control, $1=$ little, $2=$ fair, $3=$ nearly full & 172 & 1.36 & 0.84 & 0 & 3 \\
\hline Community_control & 65 & $0=$ no control, $1=$ little, $2=$ fair, $3=$ nearly full & 171 & 0.70 & 0.82 & 0 & 3 \\
\hline
\end{tabular}

\section{Responses to some open-ended questions}

\section{Question 26 \& 28b: Main channel of information}

\begin{tabular}{|l|ccc|ccc|}
\hline \multirow{4}{*}{ Question 26 \& 28b: Main channel of information } \\
\cline { 2 - 7 } Municipal government & \multicolumn{2}{|c|}{ Before the project started (Q 26) } & \multicolumn{3}{c|}{ During the project (Q 28b) } \\
\cline { 2 - 7 } NGO & Freq. & Percent & Cum. & Freq. & Percent & Cum. \\
\cline { 2 - 7 } Community & 4 & 2.6 & 2.6 & 4 & 2.5 & 2.5 \\
Donor & 23 & 15.1 & 17.8 & 60 & 38.2 & 40.8 \\
Friends/relatives & 96 & 63.2 & 80.9 & 81 & 51.6 & 92.4 \\
Other & 4 & 2.6 & 83.6 & 2 & 1.3 & 93.6 \\
\hline All channels & 18 & 11.8 & 95.4 & 7 & 4.5 & 98.1 \\
\hline
\end{tabular}

\begin{tabular}{|lrrr|}
\hline Question 33 - Why did not you express your opinions during the project? & & \\
\hline & Freq. & Percent & Cum. \\
Personality & 31 & 48.4 & 48.4 \\
Not opportunity & 17 & 26.6 & 75.0 \\
Not present & 8 & 12.5 & 87.5 \\
Men know better & 3 & 4.7 & 92.2 \\
Sick & 2 & 3.1 & 95.3 \\
Agreed & 2 & 3.1 & 98.4 \\
Other reason & 1 & 1.6 & 100.0 \\
\hline Total & 64 & 100.0 & \\
\hline
\end{tabular}

\begin{tabular}{|lccc|}
\hline Question 37 - How did you use your practical skills during the project? & & & \\
\hline & Freq. & Percent & Cum. \\
Organisation & 9 & 8.6 & 8.6 \\
Teaching others & 4 & 3.8 & 12.4 \\
Applied previous experience & 5 & 4.8 & 17.1 \\
Reforestation & 13 & 12.4 & 29.5 \\
Cooking, roads, cleaning & 15 & 14.3 & 43.8 \\
Bricklayer, welder & 7 & 6.7 & 50.5 \\
Construction assistant & 51 & 48.6 & 99.0 \\
Other & 1 & 1.0 & 100.0 \\
\hline Total & 105 & 100.0 & \\
\hline
\end{tabular}

\begin{tabular}{|lccc|}
\hline Question 41 - What kind of training did you receive? (Reconstruction projects only) & & & Cum. \\
& Freq. & Percent & 53.9 \\
Construction assistant & 7 & 53.9 & 69.2 \\
Bricklayer & 2 & 15.4 & 84.6 \\
Leadership & 2 & 15.4 & 92.3 \\
Social relationships & 1 & 7.7 & 100.0 \\
Painting & 1 & 7.7 & \\
\hline Total & 13 & 100 & \\
\hline
\end{tabular}




\begin{tabular}{|c|c|c|c|c|c|c|c|c|}
\hline \multicolumn{9}{|c|}{ Question 45 - Why was your participation: low, fair or high? } \\
\hline & Low & $\%$ & Fair & $\%$ & High & $\%$ & Total & $\%$ \\
\hline Worked in everything & 1 & 2.2 & 2 & 3.2 & 17 & 32.1 & 20 & 12.5 \\
\hline Participated until the end (to finish) & & & 2 & 3.2 & 2 & 3.8 & 4 & 2.5 \\
\hline Harder in human settlements & & & & & 2 & 3.8 & 2 & 1.3 \\
\hline For the well-being of the community & 1 & 2.2 & 8 & 12.9 & 10 & 18.9 & 19 & 11.9 \\
\hline Learned & & & 6 & 9.7 & 1 & 1.9 & 7 & 4.4 \\
\hline Was group coordinator & & & 1 & 1.6 & 1 & 1.9 & 2 & 1.3 \\
\hline Fulfilled commitment & 1 & 2.2 & 23 & 37.1 & 12 & 22.6 & 36 & 22.5 \\
\hline Attended meetings & 2 & 4.4 & 10 & 16.1 & 7 & 13.2 & 19 & 11.9 \\
\hline Did not attend meetings & 5 & 11.1 & 3 & 4.8 & & & 8 & 5.0 \\
\hline Others participated on his or her behalf & 18 & 40.0 & 2 & 3.2 & 1 & 1.9 & 21 & 13.1 \\
\hline Did not collaborate enough for his or her community & 6 & 13.3 & & & & & 6 & 3.8 \\
\hline Busy with work & 6 & 13.3 & 1 & 1.6 & & & 7 & 4.4 \\
\hline Not present & 1 & 2.2 & & & & & 1 & 0.6 \\
\hline Donated land & & & 1 & 1.6 & & & 1 & 0.6 \\
\hline Other reasons & 4 & 8.9 & 3 & 4.8 & & & 7 & 4.4 \\
\hline Total & 45 & 100.0 & 62 & 100.0 & 53 & 100.0 & 160 & 100.0 \\
\hline
\end{tabular}

\begin{tabular}{|c|c|c|c|c|c|c|c|c|c|c|}
\hline \multicolumn{11}{|c|}{ For those with high participation: } \\
\hline & $\begin{array}{l}\text { Santa } \\
\text { María }\end{array}$ & $\%$ & $\begin{array}{c}\text { San } \\
\text { Fernando }\end{array}$ & $\%$ & Agua Fría & $\%$ & $\begin{array}{c}\text { San } \\
\text { Agustín }\end{array}$ & $\%$ & Total & $\%$ \\
\hline $\begin{array}{l}\text { Worked in every- } \\
\text { thing }\end{array}$ & 1 & 7.1 & 7 & 53.8 & 4 & 40.0 & 5 & 31.3 & 17 & 32.1 \\
\hline $\begin{array}{l}\text { Participated until the } \\
\text { end (to finish) }\end{array}$ & 1 & 7.1 & & & & & 1 & 6.3 & 2 & 3.8 \\
\hline $\begin{array}{l}\text { Harder in human } \\
\text { settlements }\end{array}$ & & & & & & & 2 & 12.5 & 2 & 3.8 \\
\hline $\begin{array}{l}\text { For the well-being of } \\
\text { community }\end{array}$ & 6 & 42.9 & 1 & 7.7 & & & 3 & 18.8 & 10 & 18.9 \\
\hline Learned & 1 & 7.1 & & & & & & & 1 & 1.9 \\
\hline $\begin{array}{l}\text { Was group coordina- } \\
\text { tor }\end{array}$ & & & & & & & 1 & 6.3 & 1 & 1.9 \\
\hline $\begin{array}{l}\text { Fulfilled commit- } \\
\text { ment }\end{array}$ & 5 & 35.7 & 2 & 15.4 & 3 & 30.0 & 2 & 12.5 & 12 & 22.6 \\
\hline Attended meetings & & & 3 & 23.1 & 3 & 30.0 & 1 & 6.3 & 7 & 13.2 \\
\hline $\begin{array}{l}\text { Others participated } \\
\text { on his or her behalf }\end{array}$ & & & & & & & 1 & 6.3 & 1 & 1.9 \\
\hline Total & 14 & 100.0 & 13 & 100.0 & 10 & 100.0 & 16 & 100.0 & 53 & 100.0 \\
\hline
\end{tabular}

\section{Multidimensional well-being (for water projects only)}

Question A: Elements necessary for everyone

\begin{tabular}{|c|c|c|c|c|c|c|c|}
\hline \multirow[t]{2}{*}{ Variable } & \multirow[t]{2}{*}{ Item } & \multicolumn{2}{|c|}{ San Fernando } & \multicolumn{2}{|c|}{ Agua Fría } & \multicolumn{2}{|c|}{ Total } \\
\hline & & Necessary & $\%$ & Necessary & $\%$ & Necessary & $\%$ \\
\hline Inner_peace & 1 & 30 & 81.1 & 44 & 86.3 & 74 & 84.1 \\
\hline Housing & 2 & 29 & 78.4 & 46 & 90.2 & 75 & 85.2 \\
\hline Family & 3 & 24 & 64.9 & 40 & 76.9 & 64 & 71.9 \\
\hline Water & 4 & 31 & 83.8 & 46 & 90.2 & 77 & 87.5 \\
\hline Well-fed & 5 & 30 & 81.1 & 43 & 84.3 & 73 & 83.0 \\
\hline Being_literate & 6 & 26 & 70.3 & 37 & 72.6 & 63 & 71.6 \\
\hline Job & 7 & 31 & 83.8 & 42 & 80.8 & 73 & 82.0 \\
\hline Bike & 8 & 6 & 16.2 & 6 & 11.8 & 12 & 13.6 \\
\hline Telephone & 9 & 11 & 29.7 & 29 & 56.9 & 40 & 45.5 \\
\hline
\end{tabular}




\begin{tabular}{|ll|cc|cc|cc|} 
Public_transport & 10 & 11 & 29.7 & 29 & 56.9 & 40 & 45.5 \\
Credit & 11 & 21 & 56.8 & 29 & 56.9 & 50 & 56.8 \\
TV & 12 & 7 & 18.9 & 14 & 27.5 & 21 & 23.9 \\
Well-dressed & 13 & 13 & 35.1 & 18 & 35.3 & 31 & 35.2 \\
Secure & 14 & 20 & 54.1 & 32 & 62.8 & 52 & 59.1 \\
Electricity & 15 & 26 & 70.3 & 38 & 74.5 & 64 & 72.7 \\
Healthy & 16 & 29 & 78.4 & 38 & 74.5 & 67 & 76.1 \\
Livestock & 17 & 13 & 35.1 & 18 & 35.3 & 31 & 35.2 \\
Care & 18 & 23 & 62.2 & 39 & 76.5 & 62 & 70.5 \\
Childbearing & 19 & 25 & 67.6 & 34 & 66.7 & 59 & 67.1 \\
Land & 20 & 30 & 81.1 & 40 & 78.4 & 70 & 79.6 \\
Recreation & 21 & 9 & 24.3 & 13 & 25.5 & 22 & 25.0 \\
Freedom_speech & 22 & 23 & 62.2 & 33 & 64.7 & 56 & 63.6 \\
Friends & 23 & 22 & 59.5 & 38 & 74.5 & 60 & 68.2 \\
Group & 24 & 18 & 48.7 & 29 & 56.9 & 47 & 53.4 \\
Trip & 25 & 5 & 13.5 & 10 & 19.6 & 15 & 17.1 \\
\hline Total & & 37 & 100.0 & 51 & 100.0 & 88 & 100.0 \\
\hline
\end{tabular}

Question B: Rankings of priority

\begin{tabular}{|c|c|c|c|c|c|c|c|c|c|}
\hline Item & Variable & $\begin{array}{c}\text { San } \\
\text { Fernando }\end{array}$ & $\begin{array}{l}\text { Agua } \\
\text { Fría }\end{array}$ & Total & Item & Variable & $\begin{array}{c}\text { San } \\
\text { Fernando }\end{array}$ & $\begin{array}{l}\text { Agua } \\
\text { Fría }\end{array}$ & Total \\
\hline 1 & Inner_peace & 1 & 2 & 1 & 14 & Secure & 14 & 16 & 16 \\
\hline 2 & Housing & 5 & 1 & 2 & 15 & Electricity & 9 & 10 & 10 \\
\hline 3 & Family & 7 & 5 & 7 & 16 & Healthy & 4 & 7 & 6 \\
\hline 4 & Water & 6 & 4 & 4 & 17 & Livestock & 18 & 20 & 21 \\
\hline 5 & Well-fed & 3 & 3 & 3 & 18 & Care & 13 & 11 & 11 \\
\hline 6 & Being_literate & 10 & 9 & 9 & 19 & Childbearing & 15 & 13 & 14 \\
\hline 7 & Job & 2 & 6 & 5 & 20 & Land & 8 & 8 & 8 \\
\hline 8 & Bike & 22 & 24 & 24 & 21 & Recreation & 24 & 23 & 22 \\
\hline 9 & Telephone & 20 & 14 & 17 & 22 & Freedom_speech & 11 & 15 & 12 \\
\hline 10 & Public_transport & 21 & 17 & 18 & 23 & Friends & 16 & 12 & 13 \\
\hline 11 & Credit & 12 & 18 & 15 & 24 & Group & 17 & 21 & 19 \\
\hline 12 & TV & 25 & 22 & 23 & 25 & Trip & 23 & 25 & 25 \\
\hline 13 & Well-dressed & 19 & 19 & 20 & & & & & \\
\hline
\end{tabular}

Question C: Achievements or the important items that the respondent 'has'

(Data for 'own' index, see chapter 4)

\begin{tabular}{|lcccc|}
\hline & \multicolumn{2}{c}{ San Fernando } & \multicolumn{2}{c|}{ Agua Fría } \\
Index range & $\mathrm{N}$ & $\%$ & $\mathrm{n}$ & 0.0 \\
\hline $0.0-0.1$ & 2 & 5.6 & & 0.0 \\
$0.11-0.2$ & 3 & 8.3 & & 0.0 \\
$0.21-0.3$ & 3 & 8.3 & 1 & 1.9 \\
$0.31-0.4$ & 1 & 2.8 & 3 & 5.8 \\
$0.41-0.5$ & 6 & 16.7 & 3 & 5.8 \\
$0.51-0.6$ & 8 & 22.2 & 5 & 9.6 \\
$0.61-0.7$ & 0 & 0.0 & 17 & 32.7 \\
$0.71-0.8$ & 6 & 16.7 & 15 & 28.8 \\
$0.81-0.9$ & 3 & 8.3 & 8 & 15.4 \\
$0.91-1.0$ & 4 & 11.1 & 52 & 100.0 \\
\hline Total & 36 & 100.0 & \\
\hline
\end{tabular}




\section{Appendix 3-A: Abbreviations}

\begin{tabular}{|c|c|c|}
\hline ADD & Acute Diarrhoeal Diseases & \\
\hline ADESCO & Asociación de Desarrollo Comunitario [Community Development Association] & El Salvador \\
\hline AMDES & $\begin{array}{l}\text { Asociación de Mujeres en Desarrollo [Association of Women for Develop- } \\
\text { ment] }\end{array}$ & Nicaragua \\
\hline AMUNSE & $\begin{array}{l}\text { Asociación de Municipios de Nueva Segovia [Association of municipalities of } \\
\text { Nueva Segovia] }\end{array}$ & Nicaragua \\
\hline ANDA & $\begin{array}{l}\text { Administración Nacional de Acueductos y Alcantarillados [Public water com- } \\
\text { pany of El Salvador] }\end{array}$ & El Salvador \\
\hline ARENA & Alianza Republicana Nacionalista [Nationalist Republican Alliance] & El Salvador \\
\hline ASCA & $\begin{array}{l}\text { Asociación de Sobrevivientes del Casitas (Survivors' Association in Santa } \\
\text { Maria) }\end{array}$ & Nicaragua \\
\hline $\mathrm{BCN}$ & Banco Central de Nicaragua [Central Bank of Nicaragua] & Nicaragua \\
\hline BCR & Banco Central de Reserva de El Salvador [Central Re & El Salvador \\
\hline BNA & Basic Needs Approach & \\
\hline CA & Capability Approach & \\
\hline CARE & Cooperative for Assistance and Relief Everywhere, Inc. & \\
\hline CASA & $\begin{array}{l}\text { Comité "Agua, Salud y Ambiente" [“Water, Health and Environment" com- } \\
\text { mittee] }\end{array}$ & Nicaragua \\
\hline CBA & Cost-Benefit Analysis & \\
\hline CDC & Comité de Desarrollo Comunal [Committee of Communal Development] & Nicaragua \\
\hline $\begin{array}{l}\text { CENDEPE- } \\
\text { SCA }\end{array}$ & $\begin{array}{l}\text { Centro de Desarrollo de la Pesca y Acuicultura [Centre for the Development of } \\
\text { Fishing and Aquaculture] }\end{array}$ & El Salvador \\
\hline CODECA & $\begin{array}{l}\text { Asociación Coordinadora de Comunidades para el Desarrollo del Cacahuatique } \\
\text { (Development Association of Cacahuatique, NGO working in Agua Fria) }\end{array}$ & El Salvador \\
\hline CNOR & $\begin{array}{l}\text { Coordinadora Nacional de Oficiales Retirados [National Coordinator of Retired } \\
\text { Officers] }\end{array}$ & Nicaragua \\
\hline CPIA & Country Policy and Institutional Assessment & \\
\hline CRDM & $\begin{array}{l}\text { Comité de Reconstrucción para el Desarrollo del Municipio de San Agustín } \\
\text { [Committee of Reconstruction for the Development of the municipality of } \\
\text { San Agustín] }\end{array}$ & El Salvador \\
\hline DAC & Development Assistance Committee & \\
\hline DIGESTYC & $\begin{array}{l}\text { Dirección General de Estadísticas y Censos [General Direction of Statistic and } \\
\text { Censuses, El Salvador] }\end{array}$ & El Salvador \\
\hline ECLAC & Economic Commission for Latin American and the Caribbean & \\
\hline ENACAL & $\begin{array}{l}\text { Empresa Nicaragüense de Acueductos y Alcantarillados [Public water company } \\
\text { of Nicaragua] }\end{array}$ & Nicaragua \\
\hline FISE & $\begin{array}{l}\text { Fondo de Inversión Social de Emergencia [Emergency Social Investment Fund, } \\
\text { Nicaragua] }\end{array}$ & Nicaragua \\
\hline FGD & Focus group discussion & \\
\hline FLACSO & $\begin{array}{l}\text { Facultad Latinoamericana de Ciencias Sociales [Latin American Faculty of } \\
\text { Social Sciences] }\end{array}$ & \\
\hline FMLN & $\begin{array}{l}\text { Frente "Farabundo Martí" para la Liberación Nacional [Farabundo Marti } \\
\text { National Liberation Front] }\end{array}$ & El Salvador \\
\hline FESPAD & $\begin{array}{l}\text { Fundación de Estudio para la Aplicación del Derecho (Foundation of studies for } \\
\text { law application) }\end{array}$ & El Salvador \\
\hline FISDL & Fondo de Inversión Social para el Desarrollo Local (Social investment fund) & El Salvador \\
\hline FODES & $\begin{array}{l}\text { Fondo para el Desarrollo Económico y Social de los Municipios [Economic and } \\
\text { social development fund for municipalities] }\end{array}$ & El Salvador \\
\hline
\end{tabular}


FSLN

Frente Sandinista de Liberación Nacional [Sandinista National Liberation

Nicaragua Front]

FUNDA- Fundación de Apoyo a Municipios de El Salvador [Foundation of Support to El Salvador MUNI Municipalities of El Salvador]

FUNDASAL Fundación Salvadoreña de Desarrollo y Vivienda Mínima [Salvadoran Founda- El Salvador tion of Development and Minimum Housing]

FUNDEMUNI Fundación de Desarrollo Municipal de Ocotal [Foundation of municipal devel- Nicaragua opment of Ocotal]

GOES Government of El Salvador

GON Government of Nicaragua

HIM High-involvement man (non-leader participant in a FGD)

HIW High-involvement woman (non-leader participant in a FGD)

ICP Indicative Cooperation Programme

IDA International Development Association

INEC Instituto Nacional de Estadísticas y Censos [National Institute of Statistics and Nicaragua Censuses]

IOM International Organisation for Migration

LD Lux-Development S.A.

LFA Logical Framework Approach

LIM Low-involvement man (non-leader participant in a FGD)

LIW Low-involvement woman (non-leader participant in a FGD)

MDG Millennium Development Goal

MFA Ministry of Foreign Affairs

MFAL Ministry of Foreign Affairs of Luxembourg Luxem-

MSA Municipality of San Agustin $\quad$ El Salvado

ODA Official Development Assistance

OECD Organisation for Economic Co-operation and Development

PCN Partido de Conciliación Nacional [National Conciliation Party] El Salvador

PDC Partido Democrático Cristiano [Christian Democratic Party] El Salvador

PIU Project Implementation Unit

PLC Partido Liberal Constitucionalista [Liberal Constitutional Party] Nicaragua

PLOC Perceived Locus of Causality

PRA Participatory Rural Appraisal

PRSP Poverty Reduction Strategy Paper

RQ Research Question

RWDS Residual Water Disposal System

SDT Self-Determination Theory

SDC Swiss Agency for Development and Cooperation

SWAp Sector-Wide Approach

THN Theory of Human Need

THSD Theory of Human Scale Development

UCA Universidad Centroamericana "José Simeón Cañas" El Salvador

UCA Universidad Centroamericana Nicaragua

UNDP United Nations Development Programme

USAID US Agency for International Development

VIP Ventilated improved pit (latrines)

WFP World Food Programme 


\section{Appendix 3-B: Glossary}

$\begin{array}{ll}\text { Agency } & \begin{array}{l}\text { The internal capability of social actors to make reasoned choices and act accord- } \\ \text { ingly. }\end{array} \\ \text { Artesian well } & \begin{array}{l}\text { Well made by drilling into the earth until the instrument reaches water, which, } \\ \text { from internal pressure, flows spontaneously like a fountain. }\end{array} \\ \text { Attitude } & \begin{array}{l}\text { Predisposition to act in a positive or negative way in regard to an object based on } \\ \text { beliefs, emotions or circumstances. }\end{array}\end{array}$
Attribution Assigning a causal relationship between an observable change and an aid project or programme.
Autonomy The combined capability of social actors to make choices in significant matters and act authentically motivated, in coherence with their values and personality, by applying their agency in structural contexts that may promote or restrict purposive action.

Autonomy- A context that is not coercive (i.e., individuals do not act due to external demands) supportive context but motivating and promotes the sharing of information and the process of choice.

$\begin{array}{ll}\begin{array}{l}\text { Bahareque } \\
\text { Beneficio }\end{array} & \begin{array}{l}\text { Construction modality that includes walls of cane and mud } \\
\text { Processing plants where coffee is dried and the beans are separated from the coffee } \\
\text { cherries. }\end{array} \\
\text { Canton } & \begin{array}{l}\text { A small territorial unit in which the municipalities are divided. A canton has a } \\
\text { distinguished urban centre and can include several villages ('caserios'). }\end{array} \\
\text { Capabilities } & \begin{array}{l}\text { Potential functionings that a person can achieve. Available life conditions from } \\
\text { which a person chooses. }\end{array} \\
\text { Case study data- } & \begin{array}{l}\text { All major information used to analyse a case study. It includes fieldwork material, } \\
\text { public and project documentation, tabular material, archival and process records, } \\
\text { and physical artefacts. }\end{array}\end{array}$

Caudillo A charismatic leader who leads the crowds and gains support for his or her political programme.

Causality orienta- Personal orientation that influences how each person understands the origin or tion cause of his or her behaviour, or who initiates or regulates it.
Clientelism A social and political system which depends upon relationships of patronage, favouritism, and self-interested exchange (OED, 2003).
Colonato Economic system by which farmers live and work independently in a piece of land that belongs to a patron to whom they give part of their crops or a payment.

Commodatum The gratuitous loan of a thing to be returned after a specified period, or after the purpose of the loan has been served, or in any event after the lapse of a reasonable time or on request, in the same form an state as when lent, save for necessary wear and tear (OED, 1989).

Composting la- $\quad$ Latrines that ensure the recovery of waste by separating urine and faeces in view of trines their re-use of the fertilization of soil for agricultural purposes (Tandia, 2004)

Communal partici- Membership participation in a communal organisation or association of any type pation (economic, religious, social, sportive, etc.)

Community em- The expansion of the capacity of an organised group of people, living in a common powerment geographical location, to take effective collective action that allows significant positive change in the lives of its members. It requires and supports the expansion 
of individuals' autonomy and thus it is fuelled by democratic participation.

Contra Contra revolution guerrillas also called National Resistance (RN), financed by the US that challenged the Sandinista government in Nicaragua from 1984 to 1990.

Controlled tipping Method of disposal of solid wastes by burial in successive layers in earth exclu(sanitary landfill) sively reserved for this purpose.

Controlling con- Contexts that direct people toward specific behaviours or outcomes by using open texts coercion or external motivation via punishments, rewards, deadlines and so on.

Critical autonomy The capacity to adopt personal projects, develop relationships, accept commitments, compare cultural rules, reflect upon them, and participate in changing them or move to another culture (Doyal \& Gough, 1991).

Dataset 1 Data from the recruitment survey previous to the focus group discussions. The questionnaire included socio-demographic questions and screening questions to assess the level of involvement of respondents in the project.

Dataset 2 Data from the survey administered after the focus group discussions. The questionnaire had 65 questions regarding demographics, socio-economic situation; project formulation, implementation (information, participation, awareness), and evaluation; and community dynamics (social capital, organisation, decisionmaking).

Demonstration A project is said to have demonstration effects when its experience affects the effects formulation or implementation of other projects. These effects are positive when the project is successful and provides evidence that its design and activities caused this success so that lessons are applied for the formulation of new projects.

Ecofogones or eco- Ecological wood stoves with enclosed fireboxes and chimneys that reduce the wood stoves amount of firewood needed for cooking in comparison to traditional wood stoves.

Effectiveness The quality of bringing about an intended effect.

Empowerment Expansion of autonomy, evidenced in the degree of effectiveness of authentically motivated actions.

Entitlements Resources to which a person has access because he or she owns or can use them.

Eye /emergence Place where spring water surfaces.

Finca Strictly it refers to a large farm, however, some people in El Salvador mean by with 'finca' a farm of different sizes.

Functionings What people actually do (behaviour) or their actual state of being.

Grease trap Construction for separating fatty material from wastewater before disposal in a soak-away pit or infiltration field

Greywater Wastewater from kitchens, lavatories and bathrooms.

Human develop- Human development refers to (i) a sustainable improvement in well-being or a ment positive change in the actual lives that people lead - that include objective and subjective aspects, and (ii) the expansion of valuable human potentials (capabilities) that secure a life with dignity for everyone in interaction with others.

Human autonomy An evaluation criterion that examines whether individual autonomy (instrumental effectiveness to human development) has been expanded, without contracting other valuable capabilities.

Humid areas Bathroom, lavatory and residual water disposal system.

Infiltration Infiltration trenches are a series of excavation located over porous soils and backtrenches filled with stone to form a subsurface reservoir to hold storm water and allow it to infiltrate the soil. Infiltration trenches require smaller superficies than soak-away pits do. 
Involvement index Index that measures high-quality participation of individuals during the project. It is the single aggregate of scores reported by project participants in five variables: information, opinions, awareness, opportunities, and decisions.

Involvement index Index that describes the contextual support to self-confidence during the project. It 1 is a result of a combination of information, opinions and awareness.

Involvement index Index that describes the exercise of decision-making during the project. It aggre2 gates the variables opportunities and decisions.

Junta Administrative committee or council that governs a country in absence of proper constitutional branches and following a period of democratic disruption. Also called government's junta.

Landfill A method for solid waste disposal that consists of burying the solid materials.

Leader A person who has formal or informal influence on many of the inhabitants of the locality. Representatives of communal organisations, priests, school teachers, the doctor of a village, or few old people or successful migrants may be leaders.

Locus of causality Perception that a person has of the origin of his or her behaviour.

Locus of control Expectation that a person has of his or her competence in influencing the outcomes of his or her own behaviour.

Maquila Offshore assembly industries. In the case of Nicaragua and El Salvador, most of them produce textile and apparel products for the US.

Manzana

A measure of area equivalent to 0.705 hectares (abbreviation: mz.)

Mestizo

A person of mixed Spanish and Native American ancestry.

Milpa

A small cultivated field primarily dedicated to subsistence crops (maize, frijol).

Multilevel struc-

The external contexts at the micro, meso or macro-level in which individuals negotural contexts tiate their roles, meaning systems and entitlements. These contexts include all kinds of economic, political and social networks, and institutions as systems of rules (laws, regulations, norms and customs) that frame possible behaviours and organisations.

Municipality Political and administrative unit ('municipio') in which the departments are divided. It is composed of several cantons. It has at least one urban centre where the local government is based. The mayor is the highest form of authority.

Official develop- Grants and concessional loans to developing countries in order to promote ecoment assistance nomic development and welfare.

On-site sanitation System of sanitation where the means of collection, storage and treatment (where it exists) are contained within the plot occupied by the settlement and its immediate surroundings (Tandia, 2004).

Operational effec- Effectiveness related to operational goals such as the adequate operation and sustiveness tainability of a water infrastructure and the resistance of social infrastructure.

Pit latrine $\quad$ Latrine with a pit for collection and decomposition of excreta and from which liquid infiltrates into the surrounding soil.

Practices Conventional and repetitive ways of doing things.

Practices are also forms of interaction, procedures, practical strategies, and types of discourse and cultural categories (Long \& Van Der Ploeg, 1994)

Private water House plumbing connection

connection

Processes Systemic series of activities leading to a defined goal.

Project fact sheet Summary sheet that contains basic information about the project sites, official project data (i.e., financial information, organisation chart, and logical framework), 
a timeline with key activities, and other relevant information. Reedbed $\quad$ A sub-surface flow wetlands sanitation system that allows re-using the' grey water'
to plant non-food crops; also called 'biofiltro' (Dallas, 2005).

Residual water System that allows disposing of residual water (or grey water) by infiltrating it into disposal system the soil. It consists of two elements: a grease trap, and a 'soak-away' pit, infiltration trenches or reedbed.

Resilience The capacity of a population to recover (how easily and rapidly) after facing a hazard (e.g., an earthquake or hurricane).

Soak-away pit Hole filled with stones, used for infiltration of wastewater.

Stakeholder Someone who is affected by a project and has an interest or capacity to influence its outcome.

Subsidiarity Principle that states that decisions should be made as low down as possible depending on local capacities.

Technical sound- The suitability of the technical solution and its correct implementation.

ness

Temporal Orienta- Tendency to focus either on the past, future or present to analyse the course of an tion action.

Urban population The living in a group of urban localities i.e., municipal centres and localities with 1,000 or more inhabitants which have such characteristics as officially defined streets, electricity, commercial and industrial establishments, among others (ECLAC, 2005).

Vulnerability State of being exposed to suffering an undesirable outcome. It depends not only on the probability of occurrence of risky events but also on individual characteristics that define the capacity to deal with the risk and recover without damaging loss in well-being (resilience).

Waterborne dis- 'Dirty-water' diseases or those caused by water contaminated by human, animal, or eases chemical wastes. They include cholera, typhoid, shigella, polio, meningitis, and hepatitis A and E. Diarrhoeal disease is the major one (Hinrichsen et al., 1998).

Water micro-metre Device to measure the volume of water used by a household in cubic metres. 


\section{Summary}

Human development is a process during which people experience higher levels of well-being or have more opportunities to lead their own lives. From this perspective, human beings are seen as agents of their own development, not as passive recipients of the help from others (Sen, 1999). Individual autonomy, the main topic of this study, is regarded as instrumental to promote human development because more autonomous people can better promote and defend their gains in well-being and expand their human potentials. In this study, the main question is: How can foreign aided projects support the individual autonomy of final aid recipients?

The foreign aid industry has faced changes in terms of amounts of aid, number and type of actors, and the manner of how aid is being delivered. Most importantly, its goals have broadened to explicitly include the promotion of well-being through a set of agreed millennium development goals. Then, foreign aid increasingly aims at expanding the access to basic services and social infrastructure. Effectiveness remains a core issue, but new questions arise: How is aid effective and for what?

Project evaluation usually focuses on intended and tangible project outputs because a linear causal logic (logical framework) specifies that the achievement of such outputs leads to positive outcomes or development goals. This practice runs the risk of distracting us from the most relevant: the project effects on people's lives. Tangible outputs are only means to be used by people to promote their goals. This study proposes an evaluation criterion called 'human autonomy effectiveness' for which the expansion of individual autonomy is considered a priority goal.

Discrete projects take place in specific national and local contexts that imprint their character. However, they are influenced by the international context with its policies and practices. This dissertation pays attention to multilevel contexts and to the interactions among social actors at the local level. Moreover, the focus is on human beings, final aid recipients who live in specific communities, not on 'the project'.

The empirical analysis is based on four bilateral projects supported by the Luxembourg aid agency (LD) in Nicaragua and El Salvador, in the sectors of water and reconstruction, and executed between 1999 and 2005.

This study achieves three main objectives:

1. It develops a conceptual model of autonomy, informed by approaches in the human development paradigm and multidisciplinary studies, and enriched by the experiences of individuals in the four localities studied.

2. It proposes an analytical framework to evaluate the effects of projects on individual autonomy, which explicitly looks at practices (ways how things are done), goals, motivations and values of intended beneficiaries, project staff and other stakeholders. In this way, it aims at contributing to the design, implementation and evaluation of aid projects that promote autonomy.

3. It uses and tests that framework in examination of the four projects. 
This dissertation is composed of thirteen chapters: one general introduction (chapter 1), three parts containing eleven chapters, and conclusions (chapter 13). Part I (chapter 2 to 4) presents the conceptual foundations of this study and the methods used. Part II (chapter 5 to 9) describes and analyses each case individually. Part III (chapter 10 to 12) presents a comparative analysis, further develops the analytical framework and discusses the findings.

Chapter 1 provides an overview of the research study; it introduces the research questions and the case studies. This study responds to two kinds of questions.

Regarding the conceptual model, the questions are:

- How important is individual autonomy for promoting human development, and how important do inhabitants of the four localities think individual autonomy is for development?

- How do individuals in communities experience autonomy in their lives?

- How can communities shape opportunities for autonomy and human development?

Regarding the project effects on individual autonomy, the questions are:

- How might projects have affected the autonomy of non-leaders and leaders?

- In which communities are individuals more likely to experience an expansion of autonomy? Why?

Part I includes three chapters. Chapter 2 develops the conceptual model of individual autonomy that leads this study, makes the model suitable for project assessment, and discusses the linkages between individual autonomy and human development.

The chapter defines individual autonomy as a combined capability (Nussbaum, 2000) because it includes an internal and an external element. The internal element is called agency or the capacity to make reasoned choices and act accordingly. The external element is the context that provides or restricts opportunities for the exercise of autonomy. Moreover, autonomy refers to decisions on significant aspects of life, which cohere with one's own values and personality and for which one is authentically motivated. To make this concept operational, the model distinguishes between three determining factors of autonomy: agency, entitlements (or accessible resources) and multilevel structural contexts (social relations and institutions at different levels), on which the projects can have varied influences.

Chapter 3 explores the structural practices of international aid and discusses their possible linkages with the functioning of specific projects. It specifies four kinds of practices: selection and design decisions, conditionality, coordination and accountability, which can be analysed at a macro and micro level. Then, it develops a method to identify the full project logic: (i) the logic explicit in logical frameworks and project documents, and (ii) the logic implicit in practices and crucial processes. Finally, it raises some working hypotheses on the effects of projects on individual autonomy, based on the conceptual model.

Chapter 4 explains the design of the empirical work and its data collection and analysis methods. The research is designed as a collective case study, which included two study visits to the project sites in 2005. Data used in this study include project documents, public national reports, external statistics, stakeholders' interviews, focus group discussions (FGDs) and a questionnaire survey. The research approach is flexible to adapt the methods to the four cases. 
Part II focuses on each case independently. Chapter 5 introduces the cases, discusses special features of the countries that influence the local contexts and presents the general policies and practices of Luxembourg aid.

Chapters 6 to 9 analyse the cases individually, from two perspectives: the inhabitants of each project site and the projects. First, each chapter presents some antecedents of the individuals in each site and analyses in detail their lived and perceived experiences of autonomy, in relation to their conceptions of autonomy, community and participation in society. Second, each chapter identifies the main features, contexts and practices of the projects, relevant for the fieldwork participants. Then, it analyses the project effects on individual autonomy through an assessment matrix, which contrasts the hypothesised effects, based on the full project logic, with the actual effects.

Santa María is the first reconstruction project carried out by LD. The intended beneficiaries were survivors of a mudslide caused by Hurricane Mitch (1998) in Nicaragua. The mudslide destroyed their old towns and killed many of their relatives and friends. The trauma and difficult living and work conditions were constant during the project. An NGO managed this project and also two other projects in the same town, funded by other donors. Despite several problems, the project achieved its operational outputs in terms of housing and social infrastructure. Given the weak local institutional capacity in the country, at that moment, this can be called a project 'without an owner', a situation that over time led to elite capture.

Agua Fría is a water project in a rural canton of El Salvador. In this sector and country, LD has had presence since 1993. The project had ambitious goals that covered aspects beyond the construction of water infrastructure, such as the strengthening of community organisation and the promotion of sustainable agricultural practices. The project documents explicitly included self-construction activities as local contribution. Certain project practices could have supported autonomy, but the contexts harmed this potential. Governance issues in the national and local contexts affected the project operational effectiveness.

San Fernando is a water project that benefited an urban centre in Northern Nicaragua. The project had two main components: the rehabilitation of the water system that had been badly damaged by Hurricane Mitch, and technical support to the public water company. Community organisation was fostered in order to secure the project objectives related to the sanitation infrastructure and hygiene habits. The work of women in committees, selfconstruction activities, and project workshops stressed traditional gender roles. However, some women felt more autonomous when they participated in the municipal development committee. Contexts were favourable to the project.

San Agustin is the second reconstruction project. It covered a municipality marked by the Salvadorian civil war and almost destroyed by two earthquakes in 2001. It is the most complex project and the largest in terms of budget for one specific locality. Three entities worked in different components: the construction of homes and social infrastructure, the legalisation of property titles, and the elaboration of the municipal development plan. The project supported the management capacities of the community organisation, which worked together with the project chief, sharing in decisions during the project. However, the strengthening of this organisation did not necessarily lead to community empowerment.

Part III groups three chapters. Chapter 10 contains the analytical framework of project effects on individual autonomy and presents the cross-case analysis. The framework looks at 
changes in the three determinants of autonomy, the exercise of autonomy during the project, and the achievement of individual goals. The analysis underlines that: (i) multilevel structural contexts can affect the change and processes of change, (ii) participation as hard work only, is different from involvement in a project, and (iii) individual goals should not constrain other valuable capabilities. Hence, the framework's emphasis is on practices and relations, not only on activities and expected outputs.

This framework is normative because it gives a central role to the explicit identification of goals and values. If autonomy is related to significant matters and individuals value differently certain project processes, the exercise of autonomy has to be analysed with respect to such processes. In fact, involvement is higher when people are intrinsically motivated, not when they are externally induced to work. On the one hand, the feeling of being autonomous varies depending on the value attached to certain processes and the degree of involvement. On the other hand, project contexts can make an initially internalised commitment feel like an external imposition, depending on the community dynamics.

Chapter 11 explores the factors that characterise the experiences of individual autonomy in dynamic terms (during a process of change) and how communities can shape opportunities for autonomy and human development. First, perceived agency is not detached from the lived reality of individuals, which means that gains in self-confidence require real foundations to be sustainable. The effectiveness of individual autonomous decisions depends on individual entitlements and group support.

Second, different leadership styles and local power structures influence the potential of community organisations to contribute to human development. Communal participation can be an expression of (i) genuine motivation, thus reflecting the value that individuals attach to their communities, (ii) urgent necessities, which oblige people to engage in networks even under unequal conditions, or (iii) mistrust of leaders, leading people to watch them from close or to challenge their power by joining efforts with others. The cases suggest that strong community associations, with management experience and dynamism, can improve the operational effectiveness of a project, if they are functional counterparts. However, they are not necessarily positive for the autonomy of non-leaders.

Chapter 12 returns to two fundamental topics in promotion of human development: the reduction of vulnerability and the enhancement of critical autonomy (Doyal \& Gough, 1991). First, reducing vulnerability implies that the falls in well-being as consequence of the occurrence of risks are minimised and that individuals are able to recover promptly after these events. The chapter analyses the relation between risks, vulnerability and individual autonomy at the micro-level. Then, it focuses on how collective action can overcome individual vulnerabilities and promote the common goals of a group.

Second, critical autonomy (a higher-order level of autonomy) develops when individuals exercise their critical thinking in interaction with others in society. Self-awareness and cultural understanding support critical autonomy because individuals with these capacities are better able to make judgements about their lives and their culture and decide whether social change is necessary. Then, the chapter discusses (i) how residents of the four localities could have expanded their critical autonomy, (ii) how some of them made use of political resources, and (iii) how people can organise themselves to engage in critical participation, with the support of others. 
The concluding Chapter 13 summarises the main aspects of the conceptual model and the proposed analytical framework. It also presents findings for the specific research questions explored. Finally, it discusses implications for policy design, development aid practice and development research.

In sum, this dissertation takes the challenge to assess project aid with respect to what is important: the promotion of worthy human lives. It puts forward that projects should explicitly aim at expanding individual autonomy. Projects so focused would lead to more horizontal relations between aid recipients and funders toward the achievement of valuable goals, with greater chance of sustained positive effects on people's well-being. 


\section{Samenvatting}

Menselijke ontwikkeling is een process waarin mensen een hoger niveau van welzijn ervaren of meer mogelijkheden hebben om hun leven te leiden. Vanuit dit perspectief worden mensen als grondleggers van hun eigen ontwikkeling gezien, niet als passieve ontvangers van de hulp van anderen (Sen, 1999). Individuele autonomie, het hoofdonderwerp van dit onderzoek, wordt als een vereiste gezien om menselijke ontwikkeling te bevorderen. Immers, mensen die meer autonoom zijn, zullen beter in staat zijn hun welzijn te vergroten en te verdedigen en hun capaciteiten te vergroten. In dit onderzoek is de centrale vraag: "Hoe kunnen ontwikkelingshulpprojecten de individuele autonomie van de uiteindelijke hulpontvangers bevorderen?"

De internationale ontwikkelingshulp heeft veranderingen ondergaan betreffende de hoeveelheid hulp, aantallen en type actoren en de manier van helpen. De belangrijkste verandering is dat de doelstellingen van hulporganisaties zijn verbreed door heel specifiek het bevorderen van welzijn op te nemen middels een afgesproken reeks van milleniumontwikkelingsdoelstellingen. Hierbinnen richten de hulporganisaties zich meer op het uitbreiden van de toegang tot basisdiensten en de sociale infrastructuur. Effectiviteit blijft centraal, samen met nieuwe vragen als: "Op welke manier is hulp effectief en waarvoor?"

Projectevaluaties richten zich gewoonlijk op bedoelde en tastbare projectproducten omdat een liniaire, causale logica (logisch raamwerk) specificeert dat het behalen van zulke producten tot positieve resultaten of ontwikkelingsdoelstellingen leidt. Deze methode heeft het nadeel dat het afleidt van waar het werkelijk om gaat, namelijk, het effecten dat projecten hebben op de levens van mensen. Tastbare producten zijn alleen maar middelen die door mensen gebruikt kunnen worden om hun doelstellingen te bereiken. Dit onderzoek stelt de zogenaamde 'effectiviteit van menselijke autonomie' voor als evaluatiecriterium, waarin het vergroten van individuele autonomie de belangrijkste doelstelling is.

Onafhankelijke projecten vinden plaats binnen specifieke nationale en lokale contexten die hun specifieke karakter achterlaten. Echter, ze worden beïnvloed door de internationale context met haar beleid en de werking hiervan. Deze dissertatie geeft aandacht aan contexten op meerdere niveau en aan de interactie tussen sociale actoren op lokaal niveau. Belangrijk hierbij is dat de focus op mensen, de uiteindelijke hulpontvangers in specifieke gemeenschappen, ligt niet op projecten.

De empirische analyse is gebasseerd op vier bilaterale projecten in de water -en wederopbouwsector, geleid door het Luxemburgse hulpagentschap (LD) in Nicaragua en El Salvador, uitgevoerd tussen 1999 en 2005.

Dit onderzoek bereikt 3 hoofddoelstellingen:

1. Het ontwikkelt een conceptueel autonomiemodel, verfijnd door benaderingen binnen het menselijke ontwikkelingsmodel en multidisciplinaire studies. Daarnaast is het model verrijkt door het inbrengen van de ervaringen van de individuen binnen de vier bestudeerde gemeenschappen. 
2. Het stelt een analytisch raamwerk voor om de effecten van projecten op de individuele autonomie te evalueren; dit model kijkt expliciet naar de praktijken (hoe zaken worden geregeld), de doelstellingen, de drijfveren en de belangen van de beoogde ontvangers, de projectmedewerkers en andere 'stakeholders'. Op deze manier probeert het raamwerk bij te dragen aan de opzet, de implementatie en de evaluatie van hulpprojecten die autonomie bevorderen.

3. Het gebruikt en test dit raamwerk bij de onderzoeken van de vier projecten.

Deze dissertatie bestaat uit dertien hoofdstukken: een algemene introductie (hoofdstuk 1), drie onderdelen die elf hoofdstukken bevatten en conclusies (hoofdstuk 13). Deel I ( hoofdstuk $2 \mathrm{t} / \mathrm{m} \mathrm{4}$ ) presenteert de conceptuele basis en de methodes die gebruikt worden. Deel II (hoofdstuk $5 \mathrm{t} / \mathrm{m}$ 9) beschrijft en analyseert iedere individuele casus. Deel III (hoofdstuk $10 \mathrm{t} / \mathrm{m} \mathrm{12)}$ presenteert een vergelijkende analyse die het analytisch raamwerk verder uitwerkt. Daarnaast worden de bevindingen besproken.

Hoofdstuk 1 geeft een overzicht van deze onderzoeksstudie; het introduceert de onderzoeksvragen en de te onderzoeken casussen. Dit onderzoek beantwoordt twee soorten vragen:

Ten eerste, de vragen betreffende het conceptuele model:

- Hoe belangrijk is individuele autonomie for het bevorderen van menselijke ontwikkeling, en hoe belangrijk vinden de inwoners van de vier projecten dat autonomie is voor ontwikkeling?

- Hoe ervaren individuen binnen een gemeenschap autonomie in hun leven?

- Hoe kunnen gemeenschappen mogelijkheden creeëren voor autonomie en menselijke ontwikkeling?

Ten tweede, de vragen aangaande de effecten van de projecten op individuele autonomie:

- Hoe zouden de projecten de autonomie van leiders en niet-leiders beïnvloed kunnen hebben?

- In welke gemeenschappen zullen individuen naar alle waarschijnlijk een toename van autonomie ervaren en waarom?

Deel I omvat 3 hoofdstukken. Hoofdstuk 2 ontwikkelt een conceptueel autonomiemodel dat de grondslag is van dit onderzoek definieert. Het maakt het model gebruiksvriendelijk voor project evaluaties en de verbanden bestudeert tussen individuele autonomie en menselijke ontwikkeling.

Dit hoofdstuk omschrijft individuele autonomie als een gecombineerd 'capability' (Nussbaum, 2000) dat zowel een innerlijk element als ook een extern element bevat. Het innerlijke element wordt ook wel agency, of de mogelijkheid om weloverwogen keuzes te maken en hiernaar te handelen, genoemd. Het externe element omvat de context die mogelijkheden voor het uitoefenen van autonomie schept of beperkt. Nog belangrijker, autonomie verwijst naar beslissingen in die betrekking hebben op belangrijke aspecten van het leven, die corresponderen met iemand's eigen waarden en persoonlijkheid en voor welke iemand oprecht gemotiveerd is. Om het model werkbaar te maken, wordt er in het model onderscheid gemaakt tussen bepalende factoren voor autonomie, op welke de projecten verschillende invloeden kunnen hebben: 'agency', 'entitlements' (of toegankelijke middelen), en structurele contexten (de sociale relaties en instellingen) op meerdere niveau. 
Hoofdstuk 3 onderzoekt de structurele praktijken van international hulp en behandelt hun mogelijke samenhang met het functioneren van specifieke projecten. Er worden vier soorten praktijken omschreven die zowel op macro als op micro niveau getoetst kunnen worden: selectie -en ontwerpbeslissingen, de voorwaarden, coördinatie en verantwoordelijkheid. Hiernaast wordt er een methode ontwikkeld om een integrale projectlogica te identicificeren: (i) de expliciete logica binnen een logisch raamwerk en binnen projectdocumenten en (ii) de impliciete logica in praktijken en cruciale processen. Tenslotte worden er beproevingshypotheses uitgezet betreffende de effecten van projecten op individuele autonomie, gebaseerd op het conceptuele model.

Hoofdstuk 4 verduidelijkt de opzet van de empirische analyse en de hierbij horende dataverzamling en onderzoeksmethoden. Het onderzoek is opgezet als een collectieve casus analyse dat twee studie- bezoeken in 2005 naar de projectplaatsen bevat. Data die in dit onderzoek gebruikt worden betreffen: projectdocumenten, publieke nationale rapportages, externe datagevens, interviews met 'stakeholders', focusgroepdiscussies (FDG's) en een onderzoek d.m.v. vragenlijsten. De onderzoeksbenadering is flexibel in de zin dat deze aanpasbaar is aan de vier casussen.

Deel II concentreert zich op iedere, individuele, casus. Hoofdstuk 5 geeft een inleiding op de casussen, het behandelt de unieke kenmerken van de landen die van invloed kunnen zijn op de lokale context en presenteert de algemene strategie en toepassingen van de Luxemburgse hulp.

De hoofdstukken 6 tot en met 9 analyseren de individuele casussen vanuit twee perspectieven: de inwoners van ieder project en de projecten zelf. Ten eerste, presenteert ieder hoofdstuk enkele antecedenten van de inwoners van elke lokaliteit en analyseert ieder hoofdstuk in detail hun beleefde en ondervonden ervaringen van autonomie met betrekking tot hun visie op autonomie, gemeenschap en sociale deelname. Ten tweede, identificeert ieder hoofdstuk de hoofdzaken, de contexten en de praktijken die relevant zijn voor de veldwerkdeelnemers. Daarnaast worden in deze hoofdstukken de effecten, die de projecten op individuele autonomie hebben, door middel van een beoordelingsmatrix geanalyseerd. Deze beoordelingsmatrix gaat uit van de algehele projectlogica en de feitelijke effecten, in tegenstelling tot de aangenomen effecten.

Santa Maria is het eerste wederopbouwproject dat uitgevoerd is door LD. De betreffende begunstigden waren overlevenden van de modderstroom van de Casitas vulkaan. Deze modderstroom werd veroorzaakt door de orkaan Mitch (1998) in Nicaragua. De modderstroom verwoestte oude steden en doodde vele bekenden en vrienden. Hun trauma en de moeilijke werk en leefomstandigheden waren constant aanwezig gedurende het project. Een NGO leidde dit project en twee andere projecten in dezelfde stad, gefinancierd door andere donoren. Ondanks verschillende problemen behaalde het project de operationele doelstellingen of producten betreffende behuizing en sociale infrastructuur. Daar de lokale institutionale capaciteit zwak was, kan men dit project een project 'zonder eigenaar' noemen, een situatie die uiteindelijk zorgde voor een elite overname.

Agua Fria is een waterproject in een plattelandsgemeenschap in El Salvador. In deze sector is de LD aanwezig sinds 1993. Het project had ambitieuze doelstellingen die verder gingen dan de constructie van een waterinfrastructuur, zoals bijvoorbeeld het verbeteren van de gemeenschapsorganisatie en het vergroten van duurzame landbouw. De projectdocumenten 
omvatten expliciet zelfwederopbouw als lokale bijdrage. Sommige van deze projectpraktijken zouden autonomie hebben kunnen versterken, maar de context belemmerde deze optie. Het project werd bedreigd door beleidsproblemen in nationale- en lokale context dat zijn weerslag had op de operationele effectiviteit.

San Fernando is een waterproject waarvan een stedelijk centrum in Nicaragua profijt had. Het project had twee belangrijke bestanddelen: de wederopbouw van het watersyteem, dat zwaar bescfhadigd was door de orkaan Mitch, en de technische ondersteuning van de publieke watermaatschappij. De gemeenschapsorganisatie werd in stand gehouden om de projectdoelstellingen, die gerelateerd waren aan sanitatieinfrastructuur en hygiënegewoontes, veilig te stellen. Het werk van vrouwen in comittees, wederopbouwactiviteiten en alle projectworkshops, benadrukte traditonele rolpatronen. Echter, sommige vrouwen voelden zich autonomer toen zij deelnamen aan de gemeentelijke ontwikkelingscommittee. Structurele contexten op meerdere niveau waren gunstig voor het project.

San Agustin is het tweede wederopbouwproject. Het betrof een gemeenschap aangetast door de burgeroorlog en een gebied dat bijna geheel verwoest is door twee aardbevingen in 2001 . Het is het meest complexe en grootste project, gelet op het budget voor één specifieke lokatie. Drie eenheden werkten aan verschillende onderdelen: het bouwen van huizen en een sociale infrastructuur, het legaliseren van eigendommen en de uitbreiding van een gemeentelijk ontwikkelingsplan. Het project ondersteunde de managementcapaciteiten van de gemeenschapsorganisatie, die met de projectleider, de besluitvorming deelde tijdens het project. Desondanks leidde het versterken van deze gemeenschapsorganisatie niet noodzakelijkerwijze tot het sterker worden van de gemeenschap.

Deel III omvat drie hoofdstukken. Hoofdstuk 10 bevat het analytische raamwerk van de projecteffecten op individuele autonomie en presenteert een cross-case analyse. Het raamwerk kijkt naar veranderingen in de drie determinanten voor autonomie, de uitoefening van autonomie gedurende het project, en het bereiken van individuele doelen. De analyse bekrachtigt dat (i) structurele contexten op meerdere niveau kunnen tot verandering leiden alsook het process van verandering beïnvloeden, (ii) deelname door hard werken alleen is anders dan betrokkenheid aan een project, en (iii) individuele doelstellingen zouden andere waardevolle capabiliteiten niet in de weg moeten staan. Dientengevolge ligt de nadruk van het raamwerk op praktijken en relaties, niet alleen op activiteiten en de verwachte producten.

De raamwerk is normatief omdat het een centrale plaats geeft aan de expliciete benoeming van doelstellingen en waarden. Als autonomie gerelateerd is aan belangrijke zaken en als individuen bepaalde projectprocessen verschillend waarderen, dan moet het uitoefenen van autonomie bestudeerd worden met in acht name van deze processen. Sterker nog, betrokkenheid is groter wanneer mensen intrinsiek gemotiveerd raken, niet wanneer zij door externen aan het werk worden gezet. Aan de ene kant, variërt het gevoel van autonoom zijn afhankelijk van de waarde die gehecht wordt aan bepaalde processen en de mate van betrokkenheid. Aan de andere kant, kan een bepaald project een aanvankelijk innerlijke verplichting laten aanvoelen alsof het van buitenaf is opgelegd, afhankelijk van de groepsdynamica.

Hoofstuk 11 verkent de factoren die de ervaringen van individuele autonomie binnen de dynamische terminologie (gedurende een veranderingsprocess) karakteriseren, alsook hoe 
gemeenschappen mogelijkheden voor autonomie en menselijke ontwikkeling kunnen scheppen. Ten eerste, is de beleving van 'agency' is niet gescheiden van de daadwerkelijk geleefde realiteit van individuen. Dit betekent dat voor het doen toenemen van zelfvertrouwen een concreet fundament nodig is om bestendig te zijn. De effectiviteit van individuele autonome besluiten hangt af van persoonlijke 'entitlements' en groepsondersteuning.

Ten tweede, vervolgens beïnvloeden verschillende manieren van leiderschap en lokale machtsverhoudingen de capaciteit die gemeenschaporganisaties hebben om bij te kunnen dragen aan menselijke ontwikkeling. Gemeenschapsdeelname kan een uiting zijn van (i) oprechte motivatie, gebasseerd op de waarde die individuen aan hun gemeenschap toedichten, (ii) een dringende noodzakelijkheid, die mensen verplicht om in netwerken te participeren, zelfs in ongelijke omstandigheden en (iii) een wantrouwen jegens de leiding dat er toe kan leiden dat mensen deze in de gaten houden of hun macht trotseren door zich aan te sluiten bij andere partijen. De casussen suggereren dat de aanwezigheid van sterke gemeenschapsverenigingen met managementervaring en een zekere vorm van dynamiek, de operationele effectiviteit van het project kunnen verbeteren als ze functioneel samenwerkende partijen zijn. Desondanks zijn ze niet noodzakelijkerwijs positief voor de autonomie van niet-leiders.

Hoofdstuk 12 keert terug naar de fundamentele onderwerpen over het versterken van menselijke ontwikkeling: het terugdringen van kwetsbaarheid en de versterking van kritische autonomie (Doyal \& Gough, 1991). Ten eerste, het terugdringen van kwetsbaarheid houdt in dat dalingen in het welzijn (als gevolg van het voorval van risico's) geminimaliseerd worden en dat individuelen in staat zijn snel te herstellen in zulke omstandigheden. Het hoofdstuk analyseert de relatie tussen risico's, vatbaarheid en individuele autonomie op micro niveau. Daarna richt het hoofdstuk zich op hoe gemeenschappelijk handelen, individuele kwetsbaarheid kan overwinnen en de algemene doelstellingen van een groep kan verbeteren.

Ten tweede, kritische autonomie (hoger niveau van autonomiteit) ontwikkelt zich wanneer individuen hun kritisch denken in interactie met anderen binnen de maatschappij kunnen uitoefenen. Zelfbewustzijn en cultureel inzicht ondersteunen kritische autonomie omdat individuen met deze capaciteiten betere beslissingen over hun leven en hun cultuur kunnen maken en tevens ook kunnen beslissen of sociale verandering noodzakelijk is. Daarnaast wordt in het hoofdstuk besproken (i) hoe inwoners van de vier lokaties hun kritische autonomie hadden kunnen vergroten (ii) hoe sommige van hen gebruik hebben gemaakt van politieke middelen en (iii) hoe mensen zichzelf kunnen organiseren om deel te nemen in kritische participatie met hulp van anderen.

Het concluderende hoofdstuk 13 vat de hoofdpunten van het conceptuele model en het voorgestelde analytische raamwerk samen. Ook worden de bevindingen van de specifieke onderzoeksvragen verkend. Tenslotte worden de gevolgen voor het opstellen van beleidsplannen, ontwikkelingshulp en ontwikkelingsonderzoek besproken.

Samengevat, gaat deze dissertatie de uitdaging aan om projecthulp te beoordelen op grond van wat belangrijk is: de verbetering van het waardig kunnen leven van mensen. De dissertatie laat zien dat projecten zich expliciet moeten richten op het vergroten van individuele autonomie. Wanneer projecten op deze manier worden gevormd, zullen er meer 
gelijkwaardige relaties ontstaan tussen hulpontvangers en hulpgevers. Deze gelijkwaardige relatie is noodzakelijk voor het bereiken van waardevolle doelstellingen die duurzame, positieve effecten hebben op het welzijn van mensen. 


\section{Resumen}

El desarrollo humano es un proceso a través del cual las personas experimentan mayores niveles de bienestar o tienen más oportunidades de conducir sus propias vidas. Bajo esta perspectiva, los seres humanos son agentes de su propio desarrollo, no recipientes pasivos de la ayuda de otros (Sen, 1999). La autonomía individual, el tema principal de este estudio, es considerado instrumental para promover el desarrollo humano porque cuanto más autónomas, las personas pueden promover y defender mejor sus ganancias en bienestar y expandir sus potenciales humanos. En este estudio, la pregunta clave es: ¿Cómo pueden los proyectos de ayuda extranjera apoyar la autonomía individual de los recipientes finales de ayuda?

Han ocurrido importantes cambios en la industria de la ayuda extranjera en términos de los montos de ayuda, número y tipo de actores, y modalidades de ayuda. Lo más importante es que sus objetivos se han ampliado para incluir explícitamente la promoción del bienestar, a través de un conjunto de objetivos de desarrollo del milenio ampliamente aceptados. De este modo, la ayuda extranjera busca expandir el acceso a servicios básicos e infraestructura social. La efectividad sigue siendo un tema crucial, pero nuevas preguntas surgen: ¿Cómo es la ayuda efectiva y para qué?

Generalmente, los proyectos son evaluados en función de sus resultados planeados tangibles dado que una lógica causal lineal (marco lógico) especifica que el logro de dichos resultados conduce a efectos positivos u objetivos de desarrollo. Esta práctica lleva el riesgo de distraernos de lo más importante: los efectos de los proyectos en la vida de las personas. Los resultados tangibles son sólo medios a ser usados por las personas para promover sus objetivos. Esta tesis doctoral propone un criterio de evaluación llamado "eficacia de autonomía", por el cual, la expansión de autonomía individual es un objetivo prioritario.

Los proyectos se ejecutan en contextos nacionales y locales específicos que les imprimen su carácter; mas, ellos también reciben influencia del contexto internacional, con sus políticas y prácticas. Este estudio presta atención a los contextos a varios niveles y a las interacciones entre los actores sociales al nivel local. Además, el punto central son los seres humanos, los recipientes finales de ayuda que viven en comunidades específicas, no "el proyecto".

El análisis se basa en cuatro proyectos bilaterales, administrados por la agencia de cooperación para el desarrollo de Luxemburgo (LD) en Nicaragua y El Salvador, en los sectores de agua y reconstrucción, y ejecutados entre 1999 y 2005.

Este estudio alcanza tres objetivos principales:

1. Desarrolla un modelo conceptual de autonomía, basado en enfoques relacionados al paradigma del desarrollo humano y estudios multidisciplinarios, y enriquecido por las experiencias de los habitantes de las cuatro localidades estudiadas;

2. Propone un marco analítico para evaluar los efectos de los proyectos en la autonomía individual, el cual explícitamente analiza las prácticas (modos de hacer las cosas), objetivos, motivaciones y valores de los beneficiarios, personal del proyecto y otros grupos 
de interés. Así, se espera contribuir al diseño, implementación y evaluación de proyectos de ayuda que promuevan la autonomía; y

3. Utiliza y pone a prueba este marco analítico en el análisis de los cuatro proyectos.

Esta tesis doctoral está compuesta de trece capítulos: una introducción general (capítulo 1), tres partes que contienen once capítulos y conclusiones (capítulo 13). La parte I (capítulo 2 al 4) presenta los fundamentos conceptuales de este estudio y los métodos usados. La parte II (capítulo 5 al 9) describe y analiza cada caso individualmente. La parte III (capítulo 10 al 12) presenta un análisis comparativo, desarrolla a profundidad el marco analítico y discute los hallazgos.

El capítulo 1 proporciona una visión general del estudio; introduce las preguntas de investigación y los casos. Este estudio responde a dos tipos de preguntas.

Con respecto del modelo conceptual:

- ¿ ¿Cuán importante es la autonomía individual para promover el desarrollo humano? ¿Cuán importante los habitantes de las cuatro localidades piensan que es la autonomía para el desarrollo?

- ¿Cómo los individuos en las comunidades experimentan autonomía en sus vidas?

- ¿Cómo pueden las comunidades moldear las oportunidades para autonomía y desarrollo humano?

Con respecto de los efectos de los proyectos en la autonomía individual:

- ¿Cómo podrían los proyectos haber afectado la autonomía de no-líderes y líderes?

- ¿En qué comunidades las personas más probablemente experimentaron una expansión de autonomía? ¿Por qué?

La parte I incluye tres capítulos. El capítulo 2 desarrolla el modelo conceptual que guía este estudio, lo hace aplicable para el análisis de proyectos y discute los vínculos entre autonomía individual y desarrollo humano.

El capítulo define la autonomía individual como una "capability" combinada (Nussbaum, 2000) porque incluye un elemento interno y otro externo. El elemento interno se llama agencia o la capacidad de hacer elecciones razonadas y actuar en consecuencia. El elemento externo es el contexto que proporciona o restringe las oportunidades para ejercer autonomía. Además, la autonomía se refiere a decisiones en aspectos de vida significativos, que guardan coherencia con los valores propios de uno y su personalidad y hacia las cuales uno está auténticamente motivado. Para aplicar este concepto, el modelo distingue tres factores determinantes de autonomía: agencia, "entitlements" (o recursos accesibles) y contextos estructurales multinivel (relaciones sociales e instituciones a diferentes niveles), sobre los cuales los proyectos tienen variadas influencias.

El capítulo 3 explora las prácticas estructuradas de la ayuda internacional y discute sus posibles vínculos con el funcionamiento de proyectos específicos. Especifica cuatro tipos de prácticas: decisiones de selección y diseño, condicionalidad, coordinación y responsabilidad ("accountability"), que pueden ser analizadas al nivel macro y micro. Además, desarrolla un método para identificar la lógica completa de un proyecto: (i) la lógica explícita en el marco lógico y documentos del proyecto y (ii) la lógica implícita en las prácticas y procesos crucia- 
les. Finalmente, formula algunas hipótesis sobre los efectos de los proyectos en la autonomía individual basadas en el modelo conceptual.

El capítulo 4 explica el diseño del trabajo empírico y sus métodos para la recolección de datos y para el análisis. La investigación está diseñada como un estudio colectivo de casos. Incluyó dos visitas de estudio a las localidades de los proyectos en el 2005. Los datos utilizados incluyen los documentos de los proyectos, reportes nacionales y estadísticas publicadas, entrevistas a grupos de interés ("stakeholders"), discusiones de grupos focales y una encuesta. El enfoque de investigación es flexible para adaptar los métodos a los cuatro casos.

La parte II se concentra en cada caso independientemente. El capítulo 5 presenta los casos, discute las características especiales de los países que podrían influir en los contextos locales y describe las políticas y prácticas generales de la ayuda de Luxemburgo.

Los capítulos 6 al 9 analizan los casos individualmente, bajo dos perspectivas: los habitantes de cada localidad y los proyectos. Primero, cada capítulo presenta algunos antecedentes de los habitantes de la localidad y analiza en detalle sus experiencias de autonomía, percibidas y vividas, con respecto de sus concepciones de autonomía, comunidad y participación social. Segundo, cada capítulo identifica las principales características, contextos y prácticas de los proyectos, que son relevantes para los participantes del estudio de campo. Luego, analiza los efectos del proyecto en la autonomía individual a través de una matriz de valoración que compara los efectos hipotéticos, basados en la lógica completa del proyecto, con los efectos reales.

Santa María fue el primer proyecto de reconstrucción ejecutado por LD. Los beneficiarios fueron sobrevivientes de un deslave causado por el huracán Mitch (1998) en Nicaragua El deslave destruyó sus pueblos y mató a muchos de sus familiares y amigos. El trauma y las difíciles condiciones de vida y trabajo fueron constantes durante el proyecto. Una ONG administró éste y otros dos proyectos en la misma localidad, financiados por distintos donantes. A pesar de varios problemas, el proyecto alcanzó sus objetivos operacionales en términos del número de viviendas e infraestructura social. Dada la débil capacidad institucional en el país, en ese momento, este proyecto puede ser considerado "sin dueño". Esta situación condujo, a través del tiempo, a la captura de beneficios por parte de una elite.

En Agua Fría, un cantón rural de El Salvador, se llevó a cabo un proyecto de agua. En este país y sector, LD tenía experiencia desde 1993. El proyecto tuvo objetivos ambiciosos que cubrían aspectos más allá de la construcción del sistema de agua, tales como el fortalecimiento de la organización comunal y la promoción de prácticas agrícolas sostenibles. Los documentos del proyecto explícitamente incluían las actividades de auto-construcción como contribución local. Algunas prácticas pudieron haber apoya la autonomía, pero los contextos dañaron esta oportunidad. Problemas de gobernabilidad en el contexto nacional y local afectaron la eficacia operacional del proyecto.

El proyecto de agua de San Fernando benefició un centro urbano en el norte de Nicaragua. El proyecto tuvo dos componentes principales: la rehabilitación del sistema de agua potable que había sido muy dañado por el huracán Mitch y el apoyo técnico a la compañía pública de agua. Se promovió la organización comunal para asegurar los objetivos del proyecto relacionados a hábitos de higiene e infraestructura de saneamiento. El trabajo de las mujeres en los comités, actividades de auto-construcción y todos los talleres del proyecto reforzaron los roles de género tradicionales. Sin embargo, algunas mujeres se sintieron más autónomas 
porque llegaron a ser miembros del comité de desarrollo municipal. Los contextos estructurales a varios niveles fueron favorables al proyecto.

El proyecto en San Agustín es el segundo proyecto de reconstrucción. San Agustín era un municipio marcado por la guerra civil de los ochenta, en El Salvador, y fue casi destruido por dos terremotos en el 2001. Éste es el proyecto más complejo y más grande en términos de presupuesto para una sola localidad. Tres entidades trabajaron en sus diferentes componentes: la construcción de casas e infraestructura social, la legalización de la propiedad y la elaboración del plan de desarrollo municipal. El proyecto apoyó las capacidades de gestión de la asociación comunal existente; sus líderes y el jefe de proyecto trabajaron juntos y tomaron decisiones. Sin embargo, el fortalecimiento de esta asociación comunal no necesariamente significó el empowerment de la comunidad.

La parte III agrupa tres capítulos. El capítulo 10 presenta el marco analítico para evaluar los efectos de los proyectos en autonomía individual. El marco analítico examina los cambios en los tres determinantes de autonomía, el ejercicio de autonomía durante los proyectos, y el logro de objetivos individuales. El análisis subraya que: (i) los contextos estructurales a múltiples niveles pueden afectar el cambio y los procesos de cambio, (ii) participación definida como sólo trabajo duro no es igual a involucramiento en el proyecto, y (iii) los objetivos individuales no deberían restringir otras capabilidades valiosas. Así, el énfasis de este marco analítico está en las prácticas y relaciones, no sólo en las actividades y los resultados esperados de los proyectos.

El marco analítico es normativo porque da un rol central a la identificación explícita de objetivos y valores. Si autonomía está relacionada a asuntos significativos y las personas valoran de manera distinta ciertos procesos de los proyectos, el ejercicio de autonomía debe ser analizada con respecto de tales procesos. De hecho, el involucramiento es mayor cuando las personas están intrínsicamente motivadas, no cuando son inducidas externamente a trabajar. Por un lado, el sentimiento de ser autónomo varía dependiendo del valor adscrito a ciertos procesos y el grado del involucramiento. Por otro lado, los contextos específicos de los proyectos pueden hacer que un compromiso inicialmente interiorizado se sienta después como una imposición externa, dependiendo de la dinámica de la comunidad.

El capítulo 11 explora los factores que caracterizan las experiencias de autonomía individual en términos dinámicos (durante un proceso de cambio) y cómo las comunidades pueden moldear las oportunidades para autonomía y desarrollo humano. En primer lugar, la agencia percibida no está separada de la realidad vivida por las personas, lo que significa que las mejoras en confianza en uno mismo requieren fundamentos reales para ser sostenibles. La eficacia de las decisiones autónomas depende del acceso individual a recursos (entitlements) y del apoyo de un grupo.

En segundo lugar, los estilos de liderazgo y las estructuras de poder locales influyen en el potencial de las organizaciones comunales para contribuir al desarrollo humano. La participación comunal puede ser una expresión de (i) motivación genuina, reflejando así el valor que las personas adscriben a sus comunidades, (ii) necesidades urgentes, que obligan a las personas a integrarse a redes, aún en condiciones de desigualdad, o (iii) desconfianza en los líderes, que lleva a las personas a vigilarlos de cerca o desafiar su poder uniéndose a otros. Los casos sugieren que asociaciones comunales fuertes, con experiencia de gestión y dinamismo, pueden mejorar la eficacia operacional del proyecto, si son contrapartes funcionales. 
Sin embargo, estas asociaciones no son necesariamente positivas para la autonomía de nolíderes.

El capítulo 12 retoma dos temas fundamentales en la promoción de desarrollo humano: la reducción de la vulnerabilidad y la mejora de la autonomía crítica (Doyal \& Gough, 1991). En primer lugar, reducir vulnerabilidad conlleva que caídas en bienestar como consecuencia de la ocurrencia de riesgos sean minimizadas y que las personas sean capaces de recuperarse prontamente después de estos eventos. El capítulo analiza la relación entre riesgos, vulnerabilidad y autonomía individual al nivel local. Luego, se centra en cómo la acción colectiva puede ayudar a superar vulnerabilidades individuales y a promover los objetivos comunes de un grupo.

En segundo lugar, la autonomía crítica (una autonomía de orden superior) se desarrolla cuando las personas ejercen su pensamiento crítico en interacción con otros en la sociedad. La conciencia de uno mismo y el entendimiento cultural favorecen la autonomía crítica porque personas con estas capacidades están en mejor posición de hacer juicios acerca de sus vidas y su cultura y de decidir si un cambio social es necesario. Así, este capítulo discute (i) cómo los residentes de las cuatro localidades podrían haber mejorado su autonomía crítica, (ii) cómo algunos de ellos hicieron uso de recursos políticos, y (iii) cómo las personas pueden organizarse para participar críticamente, con el apoyo de otros.

El capítulo 13 (conclusiones) resume los principales aspectos del modelo conceptual y el marco analítico propuesto. Además, presenta los hallazgos respecto de cada pregunta de investigación explorada. Finalmente, discute las repercusiones para el diseño de política, la práctica de ayuda para el desarrollo y la investigación.

En suma, esta tesis doctoral acepta el reto de examinar los proyectos de ayuda con respecto de lo que es realmente importante: la promoción de vidas humanas dignas. Propone que los proyectos deberían buscar de manera explícita una mejora en la autonomía individual. Proyectos así enfocados llevarían a relaciones más horizontales entre los recipientes y los proveedores de ayuda hacia el logro de objetivos valiosos, con efectos positivos sostenibles en el bienestar de las personas. 


\section{Curriculum Vitae}

Mirtha Rosaura Muñiz Castillo was born in Lima, Peru, on 1 September 1972. She studied in Universidad del Pacifico, in Lima (1989-1993) and graduated as an economist with second honours (class 1993-II). Her bachelor thesis was about the urban informal sector in Lima. In 1996, she obtained her Licentiate title in Economics, with a thesis on private housing credit.

During almost seven years, between 1994 and 2004, she occupied several positions in the largest private bank of Peru, Banco de Credito, and was involved in the core businesses: intermediation, credit management, financial investments, and fund management. In her last position, as a senior research analyst, she advised on financial investment decisions and macro-economic policies.

She studied a MBA in Pontificia Universidad Catolica de Chile (1998-1999), including a fourmonth exchange study period in New York University. To pursue her MBA studies, she was awarded a full scholarship by the Inter-American Development Bank and the Government of Japan. Later, she obtained her MSc in Social Protection Financing from Maastricht University (2002-2003) with a thesis on the public pension expenditure of Peru.

Mirtha Muñiz worked as a PhD researcher since April 2004 at Maastricht University (since October 2005, at the Maastricht Graduate School of Governance). Her research work was mainly carried out in Maastricht, but finalised in Lima. Her fieldwork in Nicaragua and El Salvador took place in two periods, between January-February and June-September of 2005. Between 8 May and 7 July, 2006, she was a visiting researcher at the ESRC Research Group on Well-being in Developing Countries (WeD) at the University of Bath (the UK).

Her studies were funded by a grant from Maastricht University and a research scholarship from the Ministry of Culture, Research and Superior Education of Luxembourg (2004-2006). Her fieldwork was partially funded by a travel grant from the Ministry of Ministry of Foreign Affairs, Direction of Development and Humanitarian Aid, of Luxembourg.

Between August 2007 and January 2008, she worked as a technical officer in the Social Security Department of the International Labour Office, in Geneva (Switzerland), elaborating the social budget model of Zambia in the framework of the 'ILO global campaign for social security and coverage for all as a means to combat poverty in Africa and Asia'. Her assignment included a mission to Lusaka (Zambia).

She is a member of the Human Development and Capability Association, the Netherlands Association of Latin American and Caribbean Studies, the Society for Latin American Studies, the Latin American and Caribbean Economic Association, and the Colegio de Economistas de Lima. 

Previous Titles in the Maastricht Graduate School of Governance Dissertation Series:

3 Christiane Arndt, 2009

Governance Indicators

2 Britta Augsburg, 2009

Microfinance - Greater Good or Lesser Evil?

1 Geranda Notten, 2008

Measuring and Managing Poverty Risks

www.maastrichtuniversity.nl/governance 